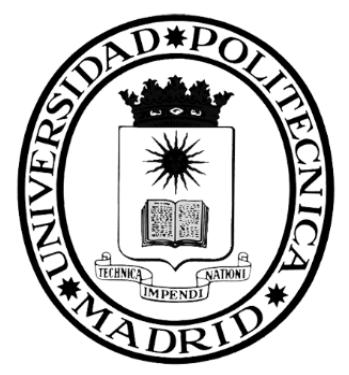

\title{
Floating Structures as a Means of Safeguarding Coastal Urbanizations Sovereignty Against the Rising Seas: A Floating Community for Egypt
}

\author{
Doctoral Thesis
}

Ahmed Ashraf Mohamed ElShihy,

Architectural Engineer, and Master's in Advanced Architecture and City Planning 

INTERDEPARTAMENTAL

ESCUELA TÉCNICA SUPERIOR DE ARQUITECTURA DE MADRID

\title{
Floating Structures as a Means of Safeguarding Coastal Urbanizations Sovereignty Against the Rising Seas: A Floating Community for Egypt
}

\author{
Author: \\ Ahmed Ashraf Mohamed ElShihy, \\ Architectural Engineer, and Master's in Advanced Architecture and City Planning
}

Thesis Director:

José María Ezquiaga Domínguez,

Ph.D. Architect 



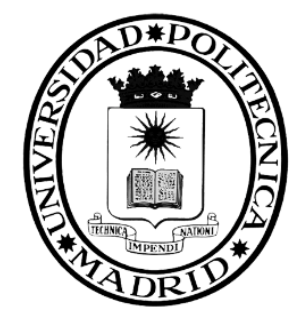

Tribunal nombrado por el Magnifico y Excelentísimo Sr. Rector de la Universidad Politécnica de Madrid el día. de. de 2019.

Presidente D.

Vocal D.

Vocal D.

Vocal D.

Secretario D.

Realizado el acto de defensa y lectura de la tesis el día....................... de......................de 2019 en la Escuela Técnica Superior de Arquitectura de Madrid.

Calificación:

EI PRESIDENTE

LOS VOCALES

\section{EI SECRETARIO}





\section{ACKNOWLEDGEMENTS}

I would like to thank my director and tutor, Prof. Dr. José María Ezquiaga Domínguez for your guiding and support throughout this thesis. You have set a great example of excellence as a researcher, mentor and tutor.

I would like to give a special thanks to my family for the love and support they have provided me. In particular, I would like to thank and dedicate this Ph.D. thesis to my father and role model Prof. Dr. Ashraf Mohamed El Shihy, Minister of Higher Education and Minister of Scientific Research of Egypt, and my mother Prof. Dr. Eman Ahmed Aly Ismail. I would also like to thank my sister Dr. Dina El Shihy, my brother Youssef El Shihy, and my aunts Prof. Dr. Rasha Ahmed Aly Ismail and Prof. Dr. Heba Ahmed Aly Ismail. Also, I would like to thank Dr. Mohamed AbdelKader.

Finally, I would like to thank and dedicate this thesis to my grandfather, Prof. Dr. Ahmed Aly Ismail and my grandmother Hemmat El Hendawy. It was you who originally generated my love for geography, history, culture and nature that is reflected in my passion to architecture, urbanism, city and heritage. Even though it has been years since you both have passed away, I still remember your lessons and learn from it everyday. 


\section{TABLE OF CONTENTS}

ACKNOWLEDGEMENTS ....................................................................................

TABLE OF CONTENTS .................................................................................................

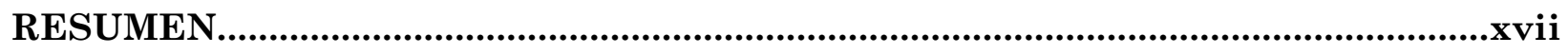

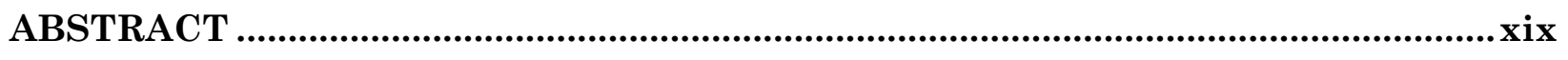

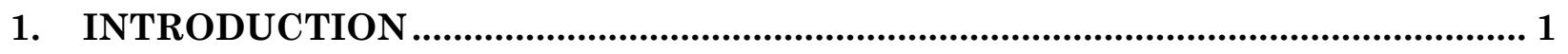

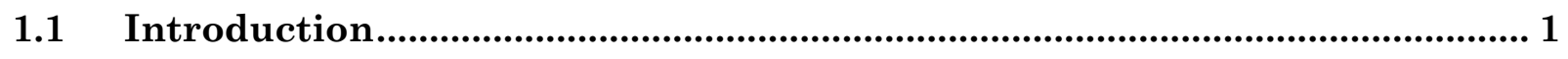

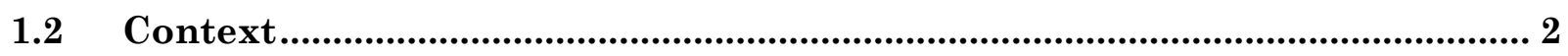

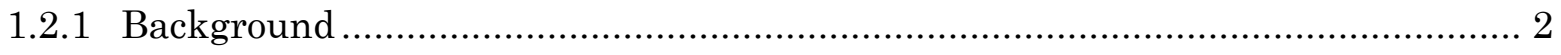

1.2 .2 Previous Studies ...................................................................................... 3

1.3 Motivation and Scope of the Research .......................................................... 4

1.3 .1 Research Gaps........................................................................................ 5

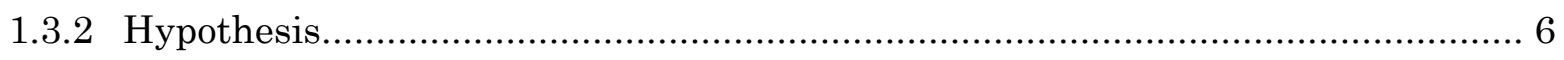

1.3.3 Significance of the Research Topic ........................................................ 7

1.4 Analytical Research Framework ............................................................. 8

1.4.1 Objectives and Research Questions..................................................... 8

1.4.2 Limitations and Constraints .................................................................. 10

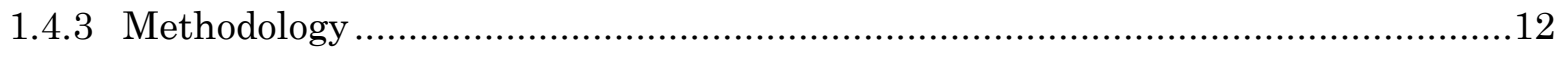

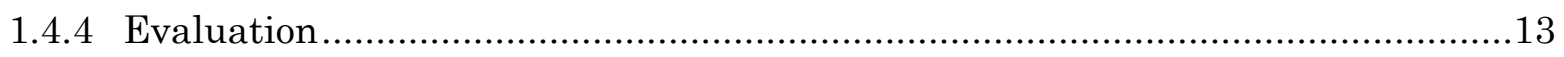

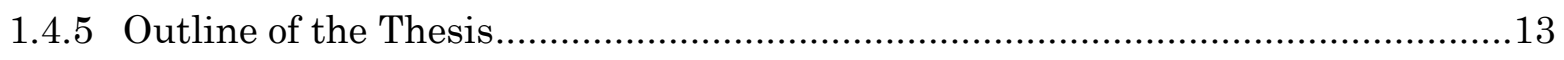

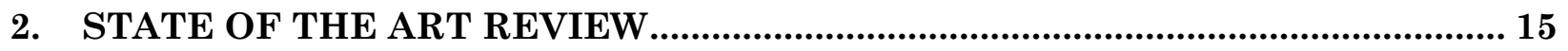


2.1 Introduction............................................................................................ 15

2.2 History of SLR Impacts on the Nile Delta................................................ 16

2.2.1 Population, Expansion, and Land-shortage in the Nile Delta ...........................17

2.3 SLR Impacts on the Most Vulnerable Mega-deltas ...................................... 18

2.3.1 Long-term SLR Impacts on the Most Vulnerable Regions ...............................22

2.4 SLR Impacts on Egypt and Adaptation Approaches ................................... 24

2.4.1 Egypt's Plans Against SLR Impacts.................................................26

2.4.2 Adaptation Approaches Executed Against SLR Impacts in the Nile Delta of Egypt 27

2.4.3 Most Common Adaptation Approaches Against SLR ....................................28

2.4.4 Floating Structures as a Solution for Tackling SLR Impacts.............................30

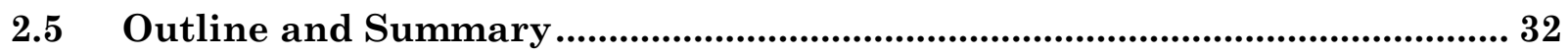

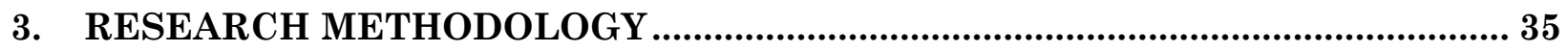

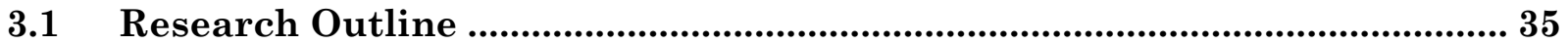

$3.2 \quad$ Data and Methods ...................................................................................... 37

3.3 Design Methodology and Guidelines for Case Study ................................. 45

3.3.1 Research Methodology for Sustainability .....................................................4

3.4 Constraints, Limitations, and Assumptions ............................................ 48

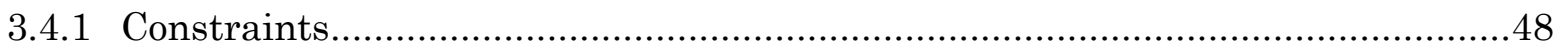

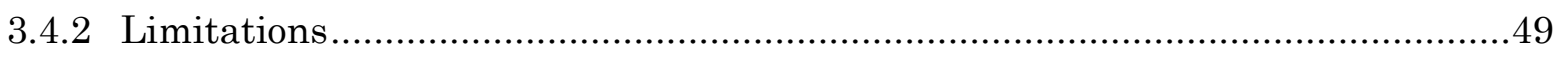

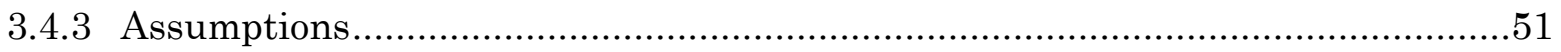

3.4.4 Alternative Solutions for VLFS ........................................................... 52

3.5 Analytical Framework and Interpretation............................................... 52

4. ANALYSIS ON SOLUTIONS TO SLR IMPACTS AND FLOATING COMMUNITY

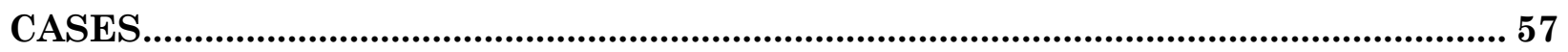

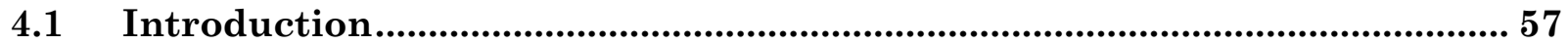

4.2 Evaluation on Adaptation Approaches and Mitigation Solutions Against

SLR Impacts ......................................................................................................5 59

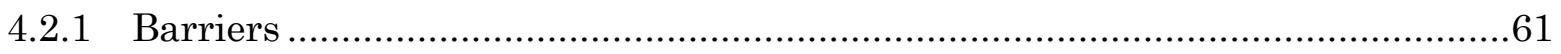

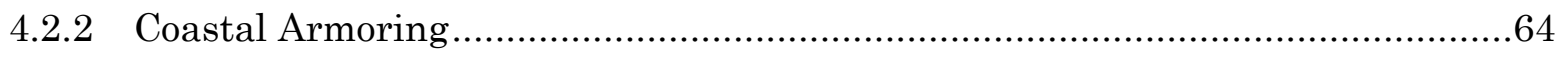

4.2.3 Elevated Development .....................................................................67

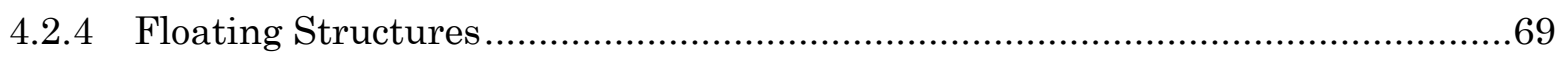

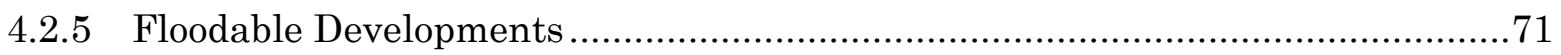

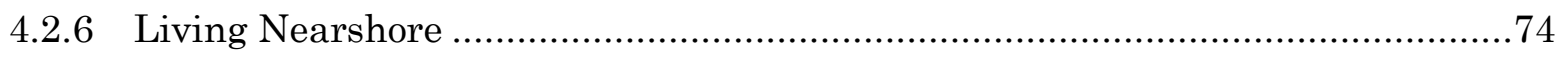

4.2.7 Managed Retreat .................................................................................. 76

4.2.8 Findings and Further Solutions to SLR Impacts .......................................78

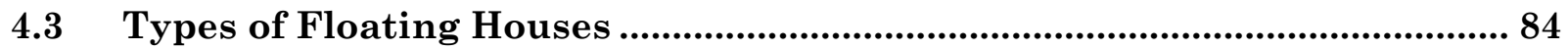




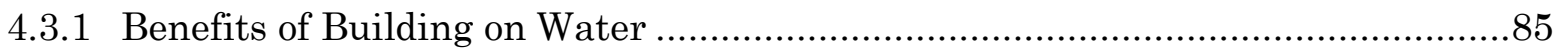

4.3.2 Basic Types of Floating Houses .......................................................................86

4.4 Comparative Analysis on in-Depth Case Studies ........................................ 88

4.4.1 Uros Islands, pre-Incan Floating Community in Lake Titicaca, Peru and Bolivia 89

4.4.2 The Ha Long Floating Fishing Communities, Vietnam..................................93

4.4.3 The Floating Market Community in Bangkok .................................................95

4.4.4 Harvest City, a Recovery Concept Proposal for Haiti........................................97

4.4.5 Floating Houses in IJburg, Amsterdam, The Netherlands ...............................102

4.4.6 The Lily-pad Floating City Concept ........................................................... 105

4.4.7 The Jacques Rougerie Foundation ............................................................ 109

4.5 The Seasteading Institute ........................................................................ 114

4.5.1 Green Float, the Botanical City Concept .............................................. 114

4.5.2 The Floating Island Project, French Polynesia ..........................................116

4.6 Conclusions ........................................................................................... 120

5. APPLICATIONS, ANALYSIS, DEVELOPMENT, AND DESIGN APPROACHES

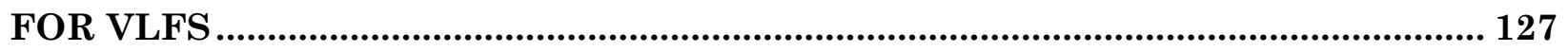

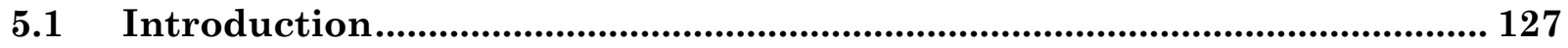

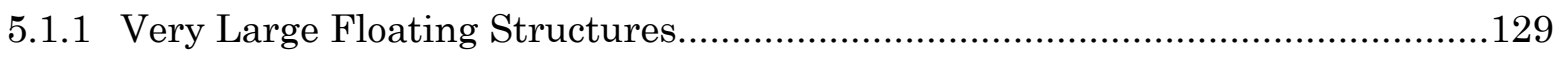

5.2 Applications of VLFS ............................................................................ 130

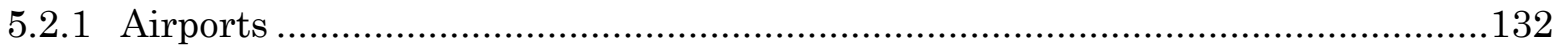

5.2.2 Mobile Offshore Base .............................................................................. 133

5.2.3 Offshore Port Facilities .............................................................................. 134

5.2.4 Offshore Storage and Waste Disposal Facilities .............................................134

5.2.5 Energy Islands and Food Production ......................................................... 134

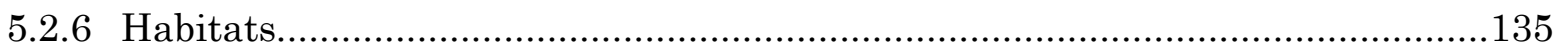

5.3 Concluded Advantages of VLFS........................................................ 135

5.4 Analysis on Structure and Design of VLFS ......................................... 136

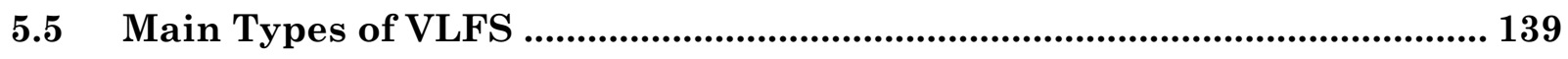

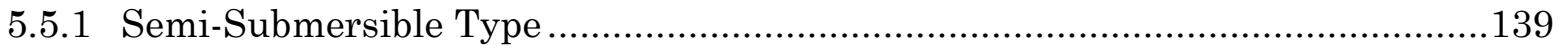

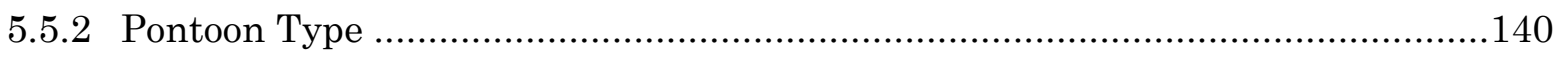

$5.6 \quad$ VLFS Developments .............................................................................. 141

5.6.1 MOB and Mega-Floats .......................................................................... 141

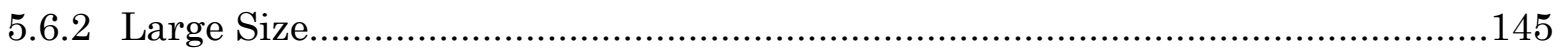

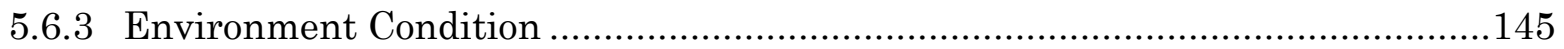

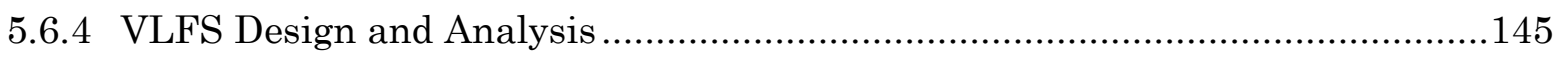

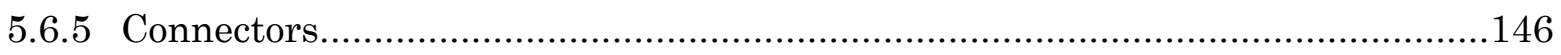

5.6.6 Connection at Sea ............................................................................... 147 


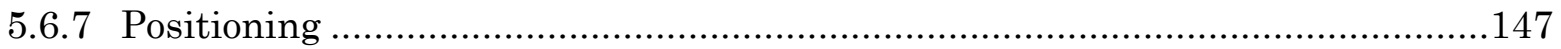

5.6.8 Design Life and Other Unique Criteria ...................................................... 147

5.7 The Environment .................................................................................... 148

5.7.1 Measurements Supporting Environmental Compliance..................................148

5.7.2 Design Environment .................................................................................. 149

4.7.3 Buoyancy, Waves, Current and Wind .......................................................150

5.8 Design Considerations for the Floating Body ........................................ 152

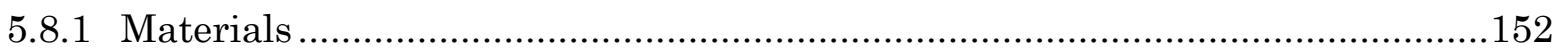

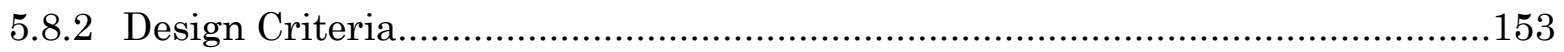

5.8.3 Corrosion Protection ............................................................................... 156

5.9 Design Considerations for Mooring Systems .......................................... 158

5.10 Design Considerations for Breakwaters ............................................... 159

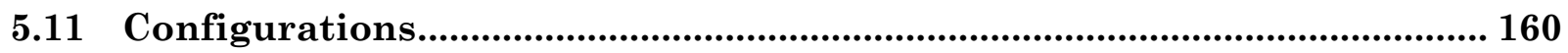

5.11 .1 Design Loads ................................................................................... 160

5.12 Hydro-elastic response ..................................................................... 161

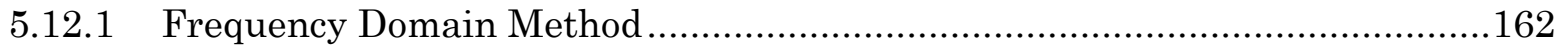

5.12.2 Time Domain Method .................................................................................. 163

5.12.3 Mitigation of Hydro-elastic Response ...................................................... 164

5.13 Structural integrity (Functionality and Safety Criteria) ......................... 166

5.14 Drift Forces for Mooring System Design ................................................ 167

5.15 Development of VLFS Technology ........................................................ 168

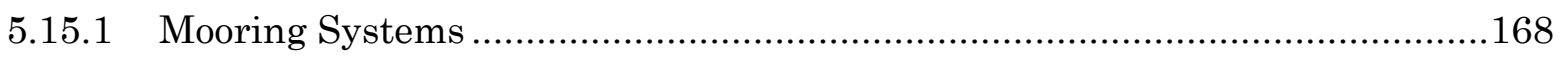

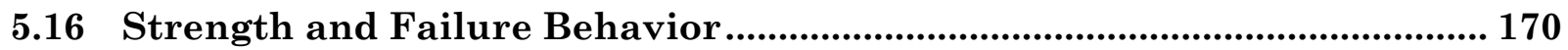

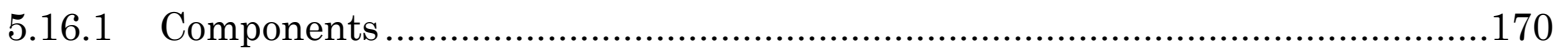

5.16.2 Load Types and Combinations.................................................................. 174

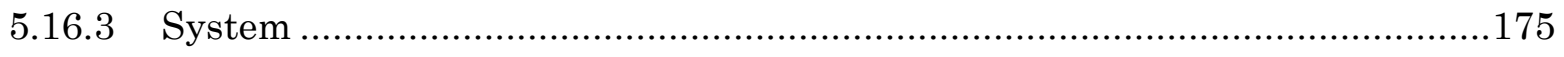

5.17 Difference Between Conventional Ship, Offshore Structures, and VLFS 177

5.18 Design of VLFS .......................................................................................... 178

5.18.1 Design Methodology for Any Floating City Project ..................................178

5.18.2 Comparative Analysis for Different Approaches and Methods for Floating Cities 179

5.18.3 Local Conditions Criteria that Should be Considered...................................193

5.18.4 Design Procedure .................................................................................. 198

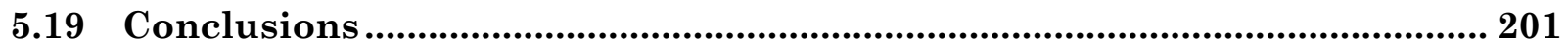

6. CASE STUDY ANALYSIS: THE NILE DELTA, EGYPT ................................... 205 
6.1 Introduction........................................................................................... 205

6.2 History "Then and Now" ...................................................................... 206

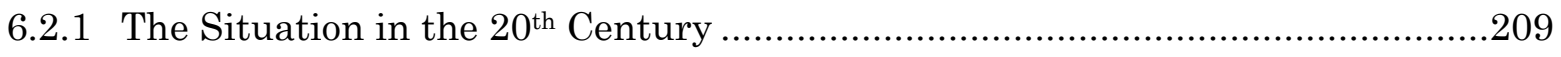

6.2.2 Dangers Facing the Nile Delta .................................................................209

6.3 Site Analysis........................................................................................ 210

6.3.1 Concluded Climate Change Impacts on Egypt...........................................213

6.4 Time Series Analysis and Ranking for the Nile Delta ............................... 214

6.4.1 SLR Impacts on the Nile Delta's Coastline Area ...........................................215

6.5 Risk Assessment on the Nile Delta's Coastline Against SLR Impacts...... 222

6.5.1 Coastal Management Approaches .................................................................222

6.5.2 Vulnerability Ranking .........................................................................225

6.5.3 Risk Assessment ......................................................................227

6.5.4 Possible Location in the Nile Delta's Coastline for a Floating Community Project 229

6.6 Egypt's Energy Consumption and Production ........................................ 239

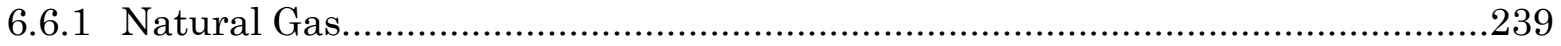

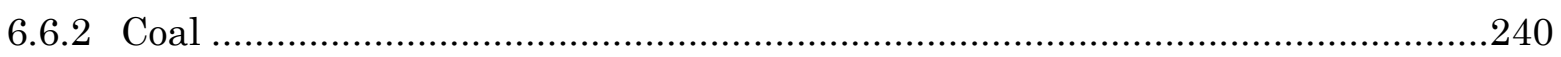

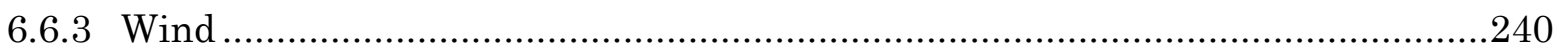

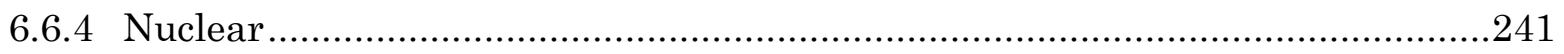

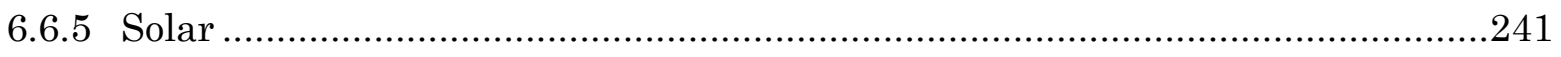

6.6.6 The Use of Renewable Energy Sources in Egypt ......................................242

6.6.7 Intended Nationally Determined Contributions (INDC) within the Framework of the Paris Climate Agreement............................................................................24

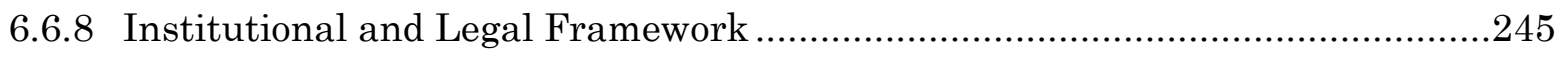

6.6.9 Ocean Energy Production ...............................................................................245

6.6.10 Multi-fuel Cell Technology ...................................................................248

6.7 Floating Building System Design Background......................................... 249

6.7.1 Floating Building Design, Layout, Superstructure and Orientation ...............249

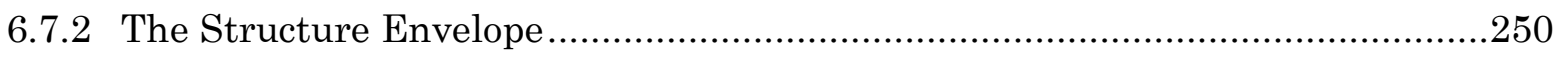

6.7.3 The Flotation System............................................................................251

6.7.4 Natural Ventilation and Controlling Air Quality Internally .........................252

6.8 Air Purification System Based on Hydroponic Plants............................... 254

6.9 Natural Lighting ................................................................................... 254

6.10 Water Collection, Purification and Recycling .......................................... 256

8.3 Floating Building Vegetation and Marine Ecosystem ............................... 259

6.12 Wave Attenuators and Walkways ............................................................... 261

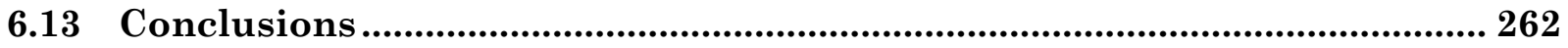


7. CASE STUDY DESIGN: FLOATING COMMUNITY CONCEPT PROPOSAL FOR

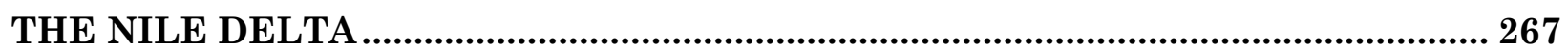

7.1 Introduction........................................................................................................... 267

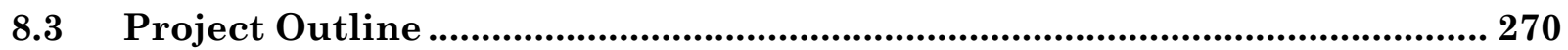

8.3 Initial Structural Design Proposal...................................................................... 272

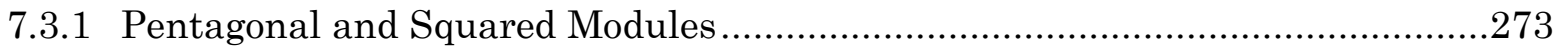

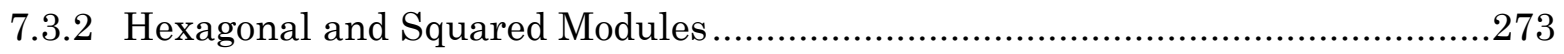

7.4 Project Characteristics.................................................................................. 274

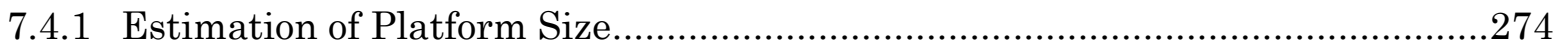

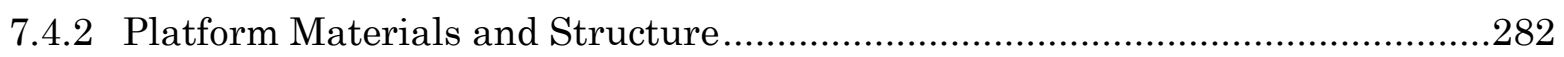

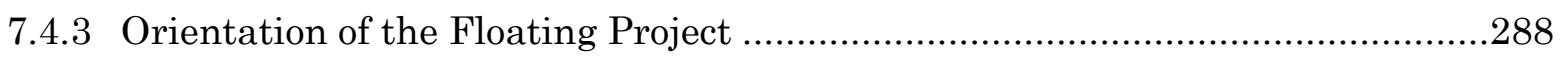

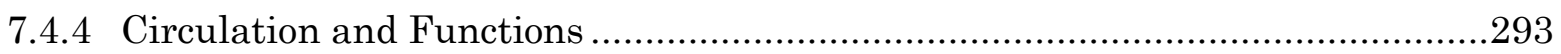

7.5 Preliminary Members Formation................................................................. 297

7.5.1 Floating Modules Layout and Space Distribution ........................................299

7.6 Sustainability ........................................................................................................ 303

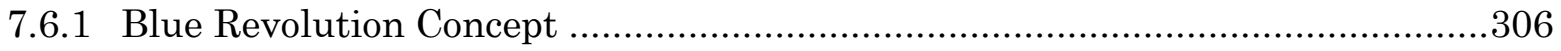

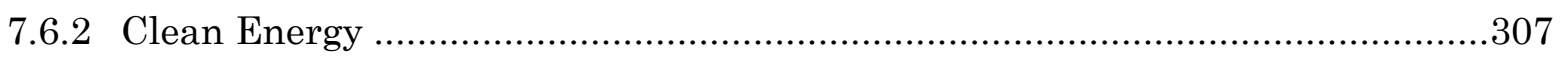

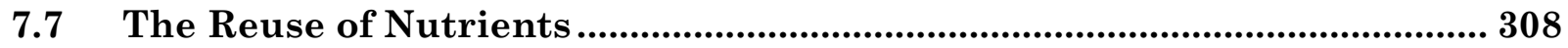

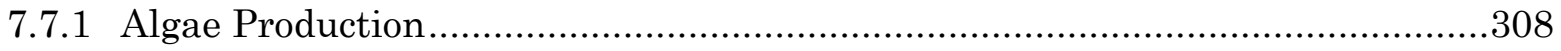

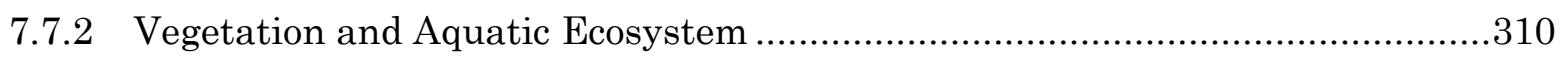

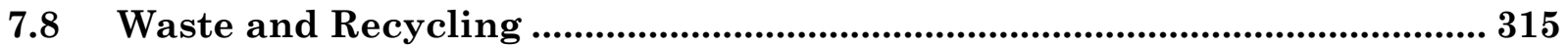

7.9 Sustainable Water System................................................................................ 316

7.10 Mobility ..................................................................................................................... 318

7.10.1 Marina, Wave Attenuating Paths, Floating Wetlands, Building Forms and Patios 318

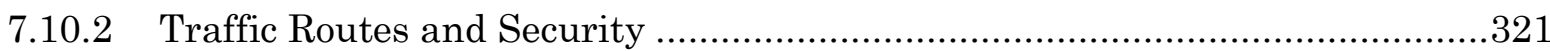

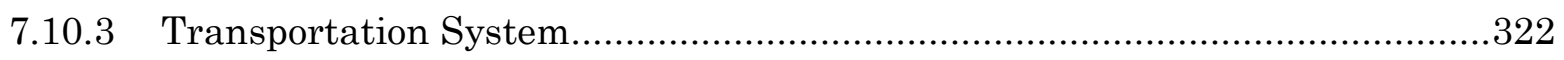

7.11 Cost Evaluation and Practicability ................................................................. 322

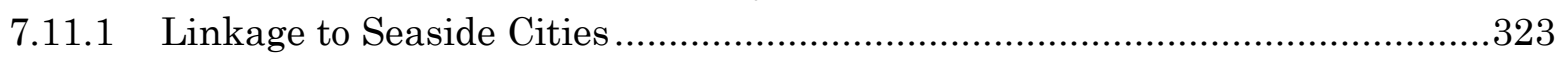

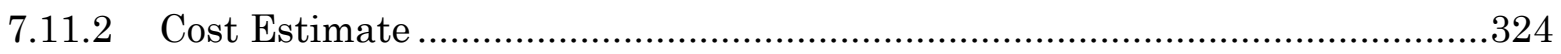

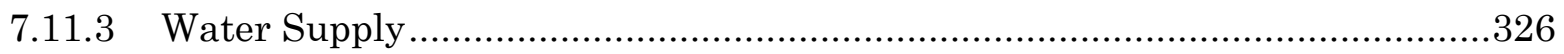

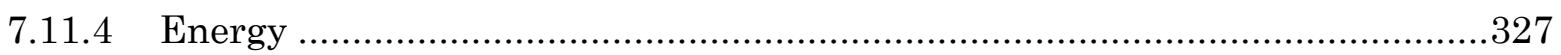

7.12 Growth Strategy................................................................................................ 327

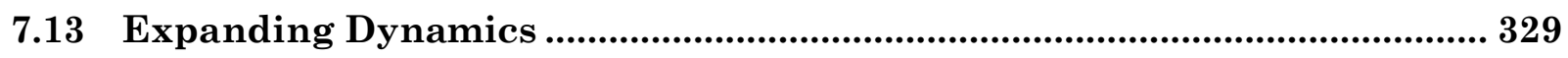

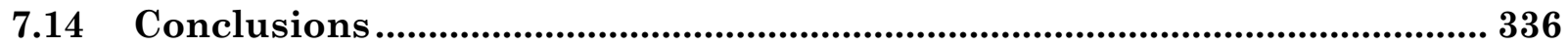

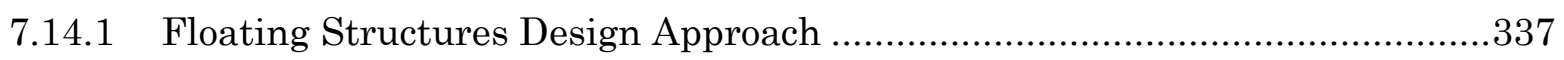

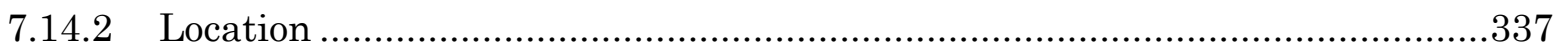




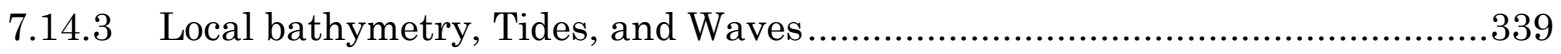

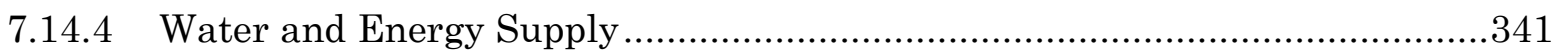

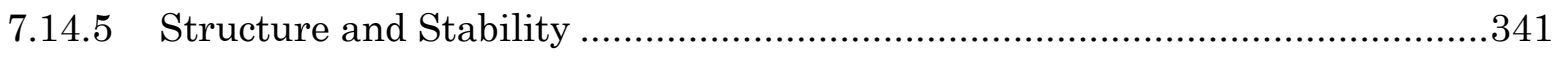

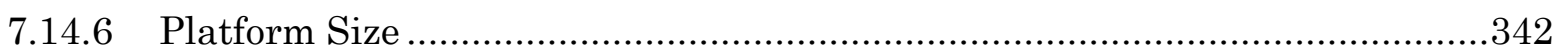

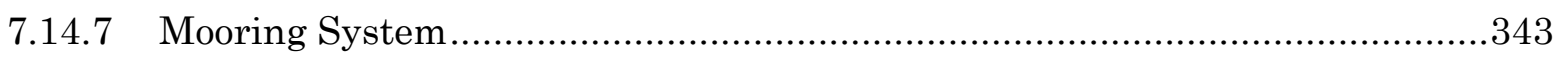

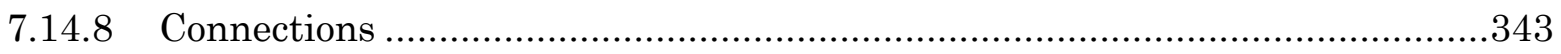

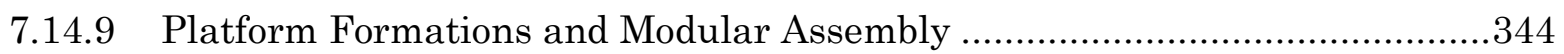

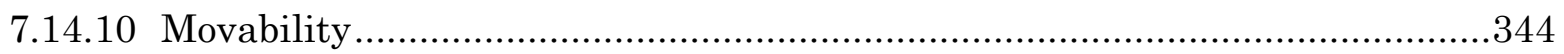

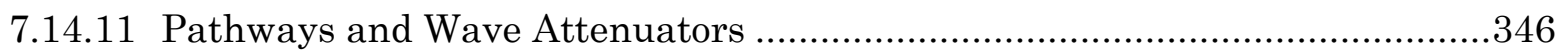

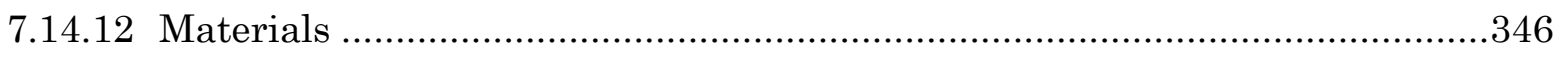

7.14.13 Expanding Dynamics and Growth Strategy ...........................................347

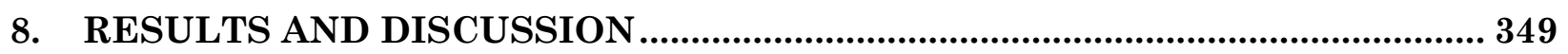

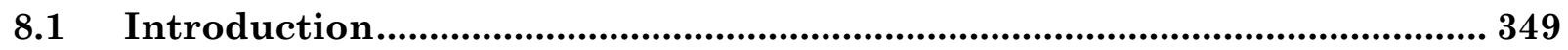

8.2 Methods and Materials ............................................................................... 350

8.3 Results and Impacts ................................................................................... 353

8.3.1 Chapter 4: Analysis on Solutions to SLR Impacts and Floating Community Cases 355

8.3.2 Chapter 5: Applications, Analysis, Development, and Design Approaches for VLFS 363

8.3.3 Chapter 6: Case Study Analysis: The Nile Delta, Egypt 372

8.3.4 Chapter 7: Case Study Design: Floating Community Concept Proposal for the Nile Delta 378

8.4 Architectural Design Guidelines for Building on Water in the Nile Delta's Coastline............................................................................................................. 392

8.5 Relation to Similar Studies.................................................................. 395

8.6 Alternative Explanations ................................................................... 397

9. CONCLUSIONS, IMPLICATIONS, AND FUTURE RESEARCH....................... 399

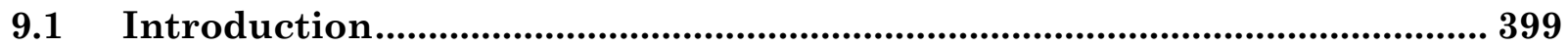

9.2 Empirical and Analytical Findings ........................................................ 402

9.3 Theoretical Implications .................................................................. 410

9.4 Practical Implications ................................................................... 411

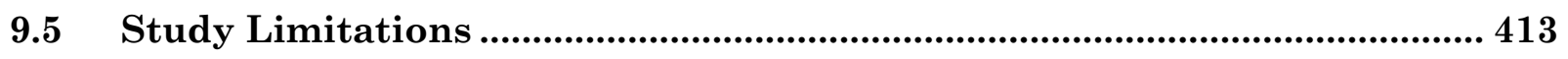

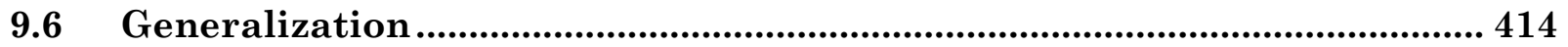

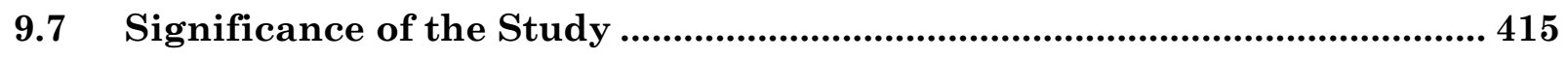

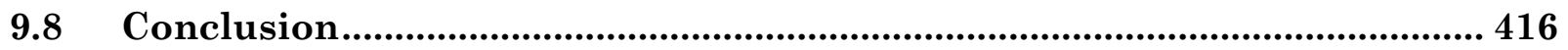

$9.9 \quad$ Recommendation for Future Research ................................................... 417 


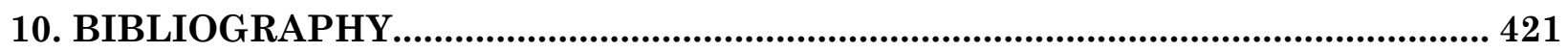

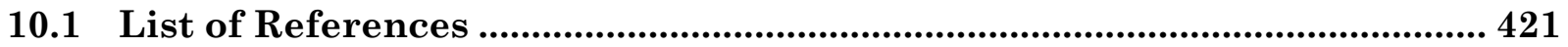

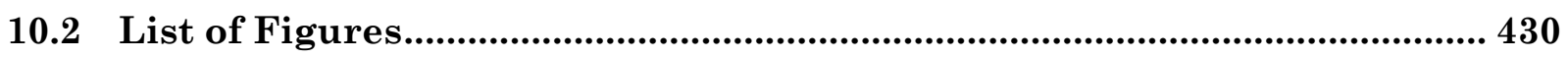

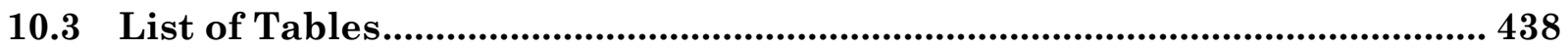

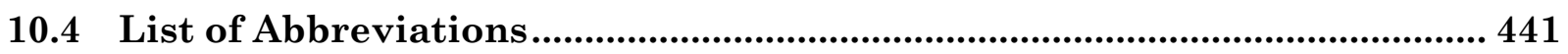

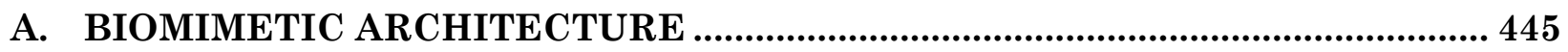

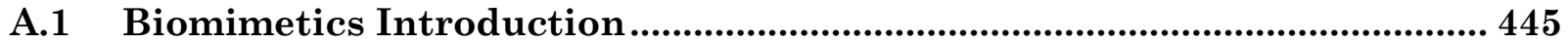

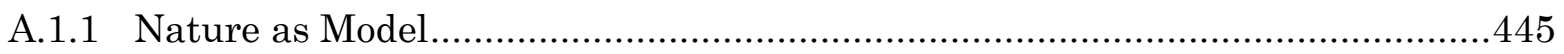

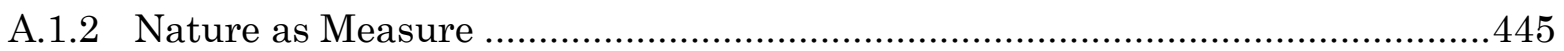

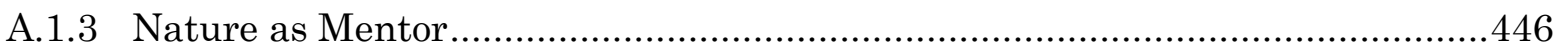

A.2 Biomimetic Approach .................................................................................... 446

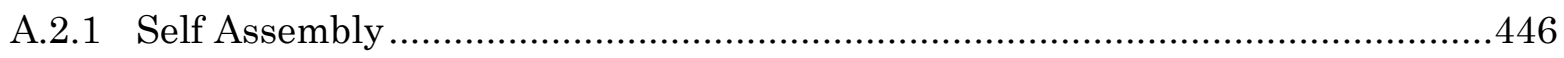

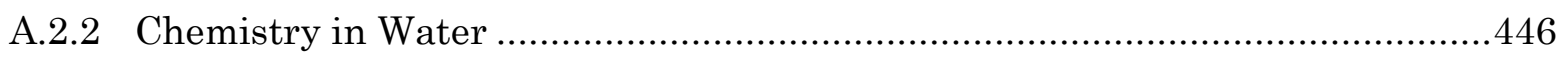

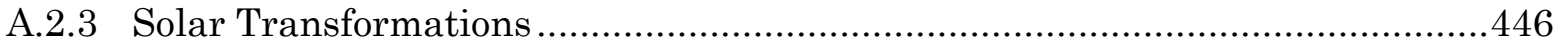

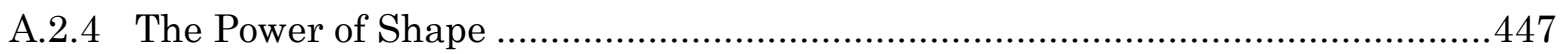

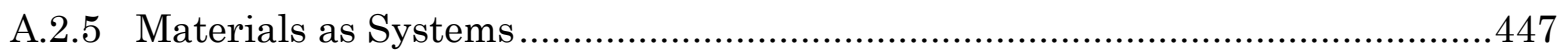

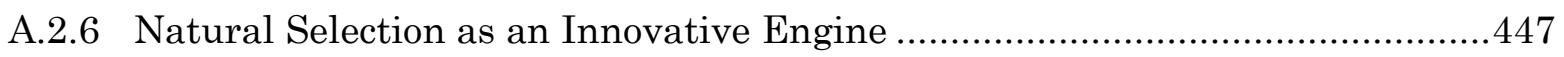

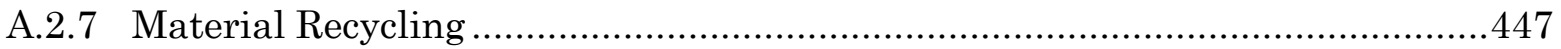

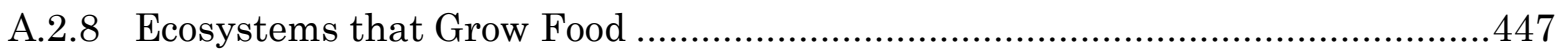

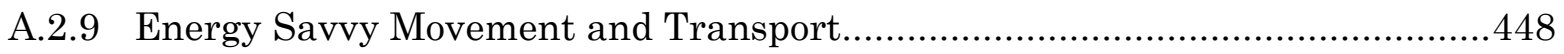

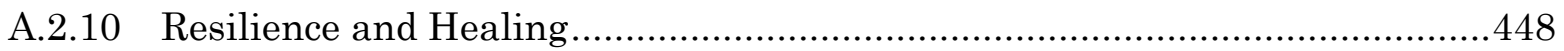

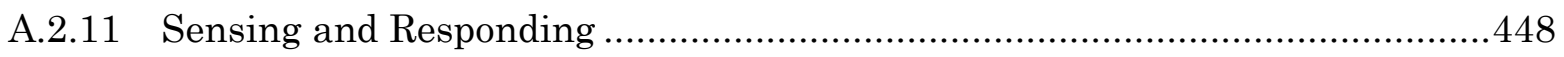

A.2.12 Life Creates Conditions Conducive to Life …….........................................448

A.3 Biomimetic Solutions Concerning Designing Disciplines............................ 448

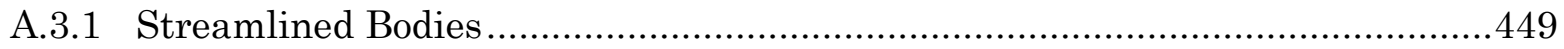

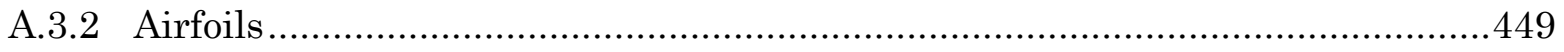

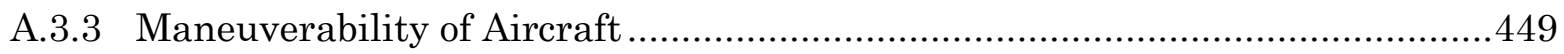

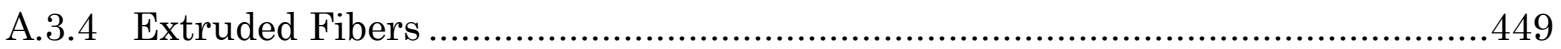

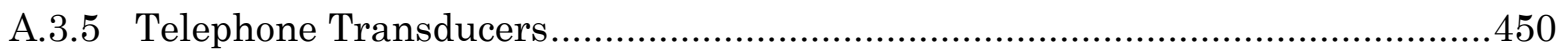

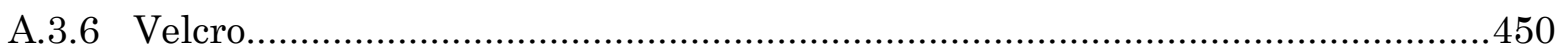

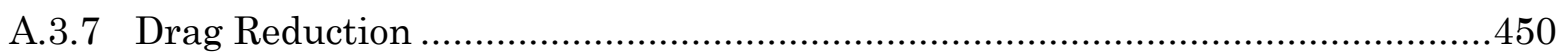

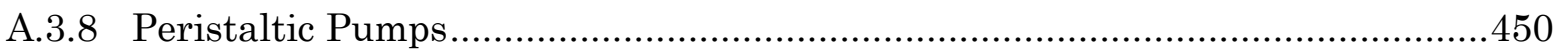

A.4 Further Biomimetic Solutions .......................................................................... 450

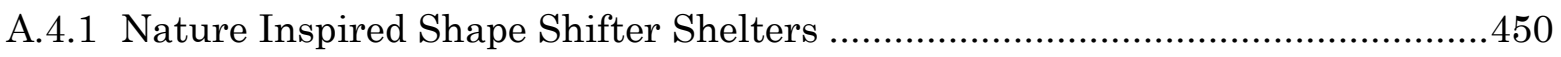

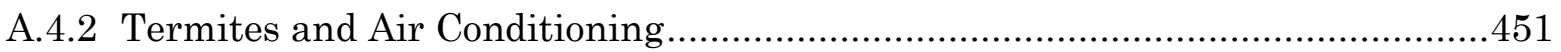

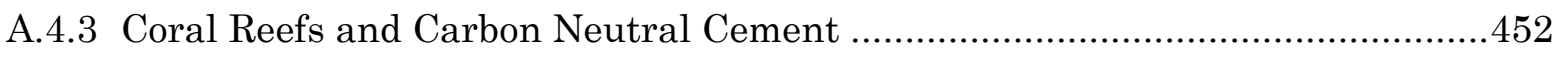

A.4.4 Floating Jellyfish Lodge and Polluted Rivers .................................................453

B. EXTENSION TO THE FLOATING PROPOSAL FOR ABU-QIR ........................... 455 
B.1 Floating Modules Layout and Space Distribution .................................... 455

B.2 Housing and Expanding Dynamics ....................................................... 458

B.3 Model and Mobility ............................................................................ 460 


\section{ESTRUCTURAS FLOTANTES COMO MEDIO DE SALVAGUARDAR LA SOBERANÍA DE LAS URBANIZACIONES COSTERAS CONTRA LOS MARES CRECIENTES: UNA COMUNIDAD FLOTANTE PARA EGIPTO}

\section{RESUMEN}

El tema de esta tesis es evaluar los impactos del aumento del nivel del mar (SLR) en las costas de Egipto y proponer estructuras flotantes (VLFS) como un medio para enfrentarlos. Este estudio ofrece dos hipótesis: en última instancia, las líneas costeras del Delta del Nilo se sumergirán mientras las aproximaciones de recuperación de tierras llevadas a cabo solo ofrecen soluciones a corto plazo; y que las VLFS ofrecen la solución óptima para salvaguardar la soberanía costera de Egipto al abordar los problemas de hundimiento del terreno. Por tanto, esta tesis está motivada por tres preguntas de investigación: ¿cuáles son los lugares más vulnerables en las costas del delta? ¿son las VLFS la mejor solución para el SLR en estas áreas? y ¿cómo implementarlas en dichos emplazamientos? Estudios previos concluyen que las VLFS desarrolladas durante las últimas décadas son la solución más sostenible, preferible a los planteamientos de recuperación de tierras, que se presentan como un método sostenible y rentable. Hasta la fecha, ninguna investigación sistemática de VLFS ha sido seriamente considerada en Egipto con respecto a abordar los impactos del SLR, ya que el gobierno aún se apoya en soluciones de recuperación de tierras. Si el gobierno aplica el método recomendado derivado de los resultados de esta tesis, salvaguardará la soberanía costera de Egipto a largo plazo. Se guiará a las autoridades sobre qué se debe hacer para sostener eficientemente las urbanizaciones costeras. El estudio ayudará a poner de manifiesto los impactos críticos del SLR y ofrece VLFS como una solución sostenible a largo plazo, que las investigaciones egipcias parecen ignorar. Por lo tanto, se explora un nuevo enfoque para adaptarse al SLR en Egipto.

Para ilustrar esta aproximación, las líneas costeras del Delta del Nilo se toman como un caso de estudio para mostrar cómo las VLFS podrían presentar la solución ideal para esta región. El estudio realiza ocho investigaciones utilizando datos actualizados. El primer estudio de esta tesis trata del análisis de series temporales del SLR y de la clasificación de las áreas afectadas del delta. El segundo, realiza una evaluación cualitativa sobre los impactos del SLR en diez casos de estudio, así como presenta evaluación de soluciones de la adaptación practicada en cada uno de ellos. El tercero se centra en el análisis de sitio del área 
más afectada de los diez casos de estudio. El cuarto estudio refleja la matriz de diseño para evaluar las soluciones de adaptación y mitigación. El quinto realiza un profundo análisis comparativo de ocho casos de estudio sobre las VLFS. El sexto presenta un análisis comparativo de diferentes estrategias y métodos sobre las ciudades flotantes. El séptimo presenta un análisis de contenido para llegar a una fórmula de ampliación y expansión dinámica de las ciudades flotantes. Por último, el octavo estudio establece pautas de diseño arquitectónico y propuesta de modelo de VLFS para Egipto.

Los hallazgos muestran que los impactos de los tradicionales enfoques de recuperación de tierras en las costas egipcias son más complejos que lo pensado anteriormente y sugieren que fueron tolerados con el tiempo, cuando las VLFS no estaban tecnológicamente avanzadas como en la actualidad.

Estos hallazgos apoyan los argumentos clave de que los métodos tradicionales no son una solución práctica a largo plazo por sus diversos inconvenientes. Los análisis evidencian que Abu-Qir es la zona más vulnerable al SLR. Aunque las VLFS han demostrado no ser la solución óptima en todos los casos con respecto a la rentabilidad y la idoneidad del sitio, tras analizar el emplazamiento se presentan como la mejor solución para la bahía de Abu-Qir debido a muchas razones. El concepto per se no debería ser observado como una demostración concreta de un futuro módulo de comunidad flotante, sino como una referencia para futuros desarrollos de áreas costeras en sustitución de los costosos métodos de recuperación de tierras.

\section{Palabras clave:}

El aumento del nivel del mar; cambio climático; soluciones de adaptación y mitigación; arquitectura biomimética; islas artificiales; las estructuras flotantes y mega-flotantes; sistema de amarre; Alejandría; la bahía de Abu-Qir; el delta del Nilo, Egipto. 


\title{
FLOATING STRUCTURES AS A MEANS OF SAFEGUARDING COASTAL URBANIZATIONS SOVEREIGNTY AGAINST THE RISING SEAS: \\ A FLOATING COMMUNITY FOR EGYPT
}

\begin{abstract}
The issue of this dissertation is to assess sea level rise (SLR) impacts on Egypt's coasts and to propose floating structures as a means to tackle them. This study offers two hypotheses: the Nile Delta's coastlines will eventually be submerged where land reclamation approaches practiced only offer short-term solutions; and that floating structures offer the optimum solution for safeguarding Egypt's coastal sovereignty when addressing land subsidence problems. Therefore, this thesis is motivated by three research questions: What are the most vulnerable sites to SLR impacts in the Nile Delta's coastline? What are the adaptation approaches and mitigation solutions practiced in theses sites and can floating structures offer a better solution against SLR for these sites? How to implement floating structures in the Nile Delta's most vulnerable coastline sites to SLR? Previous studies indicate that floating structures developed through the last decades concluding that it's the most sustainable solution, preferring it to land reclamation approaches where it may present a sustainable and cost-effective method. To date, no systematic floating structures investigation has been seriously considered in the Nile Delta regarding tackling SLR impacts as the government still rely on land reclamation solutions. If the government applies the recommended method derived from the outcomes of this thesis, it will safeguard Egypt's coastal sovereignty for the long-term. The study will help to uncover critical impacts of SLR on costal urbanizations and offers floating structures as a sustainable long-term adaptation solution that Egyptian researches seem to disregard. Therefore, a new approach on adapting to the rising seas concerning Egypt's Nile Delta is explored.

To illustrate such approach, the Nile delta is used as a case study to show how floating structures could present the ideal solution for such low-lying region. To answer the research questions, the study conducts eight researches using up-to-date data. The first study conducts time series analysis and ranking of impacted areas from SLR on the Nile Delta. The second study conducts a qualitative assessment on SLR impacts for ten case studies and evaluates adaptation solutions practiced in each case. The third study conducts site analysis on the most impacted area identified. The fourth study conducts evaluation design matrix of
\end{abstract}


adaptation and mitigation solutions. The fifth study conducts comparative analysis on eight in depth floating community case studies. The sixth study conducts comparative analysis of different approaches and methods to set guidelines for building on water. The seventh study conducts content analysis to set expanding dynamics guidelines of floating cities. Finally, the eighth study sets architectural design guidelines and floating community concept model for the Nile Delta.

The findings show that the impacts of traditional adaptation approaches on Egypt's coastlines are more complex than previously thought and suggest that they were tolerated over time when floating structures were not technologically advanced as nowadays.

Findings provide support for the key arguments that traditional adaptation and mitigation methods are not a long-term solution. Analysis demonstrate Abu-Qir Bay to be the most vulnerable area to SLR. Although floating structures have demonstrated not to be the optimum solution in every case regarding cost effectiveness and site suitability, however upon site analysis, it presents itself to be the best solution for Abu-Qir bay for many reasons. The concept per say should not be observed as a precise demonstration for a future floating community module, but a reference for future projects rather than costly land reclamation methods.

\section{Keywords:}

Sea level rise; climate change; adaptation approaches and mitigation solutions; biomimetic architecture; artificial islands; very large floating structures and mega-floats; mooring system; Alexandria; Abu-Qir Bay; the Nile Delta, Egypt. 
"Dedicated to my beloved parents \& family"

For their love, endless support, encouragement \& sacrifices... 
xxii 


\section{Chapter 1}

\section{INTRODUCTION}

\subsection{Introduction}

The primary purpose of this thesis is to determine the impacts of sea level rise (SLR) on Nile Delta coastline and to propose floating structures as a means to tackle them. Research and speculation on SLR impacts on coastal areas, small islands and low-lying areas in the world have been growing at a rapid rate. In recent years, the study of adaptation and mitigation solutions regarding tackling the rising seas challenges has dramatically increased. Over the past few decades, studies on very large floating structures (VLFS) has been attracting architects, urban and city planners, and civil engineers as it has emerged as an effective solution for tackling the SLR challenges. This aim of this thesis is to investigate if floating structures is currently the best solution for safeguarding Egypt's coastal sovereignty and how could such solution be implemented for the Nile Delta's coastline. 


\subsection{Context}

\subsubsection{Background}

Climate change phenomenon is a challenge for centuries to come. SLR is caused by three main influences: thermal expansion, melting glaciers and polar ice caps, and ice loss from Greenland and West Antarctica. Such S`LR leads to floods, increasing coastal erosion, vicious natural catastrophes, such phenomenon is anticipated to profoundly restructure our existing geography. Low-lying urbanised coastal areas may even be permanently submerged in the near future. The Global Mean Sea Level (GMSL) has increased from 10 to $20 \mathrm{~cm}$ only in the 20th century (National Oceanic and Atmospheric Administration (NOAA), 2017). SLR challenges the state sovereignty through several social, economic, and legal implications as it's speculated that the world will have over a hundred million climate refugees by 2050 (IPCC, 2014).

The rising seas will disturb a lot of coastal areas around the world, either urban or agricultural, would possibly be flooded. Buildings and infrastructures in coastal regions will be affected by SLR caused by climate change all around the world. For instance, in Africa, it is believed that climate change creates a significant harm to the day-to-day economic development, mainly for the water-resources sectors and agriculture, and that the affect will not be only at a regional level but also at local, and domestic levels. In Asia, climate change has significantly pressurized agriculture production, life, urban settlements, and health. In Australia, the climate change impact has endangered wildlife, agriculture and the water

supply. In Europe, warmer conditions have led to a rise in disastrous fires, submerging of islands, season floods and droughts. Finally, in the Americas, climate change will form more 
and more natural catastrophes, droughts, floods, and demolition of coastline areas. Also, the low-lying coastal areas and small urbanised islands may face the threat of extinction due to the SLR and the increased natural disasters and global warming following natural catastrophes.

The Nile delta is one of the lowest lying coastal areas in the world. Due to the ascending terrain from Ethiopia until the Nile delta, the Nile river carries the fertile water of freshwater and silt which benefits agricultural soil, descending from their sources according to the terrain of the earth. Over time, the delta has formed from the continuous flow of silt, which is deposited in large quantities in the delta and inside the Mediterranean waters, therefore adding land to the Nile delta from the sea. Unfortunately, after the construction of the High Dam in 1970 the balance between Nile and the sea have changed. According to the results of studies in 1975, when the silt was cut of in the Nile River after the obstacle of the High Dam, the sea overtook the Nile Delta over time, parts of which were strongly eroded by the impact of continuous waves, leading to a decline in the level of the Delta corresponding to sea level. Such land submergence isn't a first in Egypt as Heracleion (Greek), also known as Thonis in Ancient Egyptian, like Atlantis, was an ancient Egyptian city that has disappeared in the second century BC under the Mediterranean Sea (Fabre \& Goddio, 2013). The Nile Delta and sea front cities most probably may face a similar fate.

\subsubsection{Previous Studies}

Recent studies conducted by the Intergovernmental Panel on Climate Change (IPCC, 2014) concerning mega-deltas have shown that the Nile Delta in Egypt, the GangesBrahmaputra Delta in Bangladesh and India, and the Mekong Delta in Vietnam are the most vulnerable mega-deltas due to their low-lying coastlines. The probable one-meter SLR is 
anticipated may impact around 6.1 million inhabitants of the Nile Delta, while a 1.5 meters SLR may submerge an area around $22,000 \mathrm{~km}^{2}$ in the Ganges-Brahmaputra Delta, impacting up to 17 million residents (FitzGerald, Fenster, Argow, \& Buynevich, 2008).

Most researchers in the field agree that people still build nearshores in the Egyptian delta. There is now a considerable body of research which suggests that people risk a lot when using the old-fashioned land reclamation when extending the shorelines into the sea. The rising seas and between several social, economic and legal restrictions of state sovereignty. Some approaches, like Artificial Islands and Structures (AIS) and floating structures, for undertaking SLR challenges and preserving regional territories from disappearing sinking lands as stated by Tsaltas, Bourtzis, \& Rodotheatos (2010). Floating communities as human habitats and for safeguarding marine borders sovereignty for sinking lands and islands is some of the greatest notable concepts. As stated by Suzuki et al. (2006), the demand on floating structures applications like floating piers, floating hotels, floating fuel storage facilities, floating stadiums, floating bridges, floating airports, and as well as floating cities have generated wide-ranging research studies since the last decades. The developments in floating structures has advanced noticeably through the last decades and now we have several innovative approaches planned to decrease the hydro-elastic motion, advance the mooring system and structural integrity of the VLFS.

\subsection{Motivation and Scope of the Research}

There are four main driving reasons in this thesis for protecting coastal cities against SLR. The first is historical where the city of Thonis-Heracleion as well as other unknown underwater areas hold more submerged world heritage historical monuments, properties and sites of Pharaonic, Greek, Roman, and Christian as listed by the UNESCO can not be 
replaced. The second is to safeguard Egypt's marine borderlines sovereignty. The third is ecological where that endangers the marine and coral life habitat. The fourth is people risking their own lives when building in such sites risking the scenario of Thonis-Heracleion to reoccur again.

\subsubsection{Research Gaps}

The approaches practiced by the Egyptian Shore Protection Authority (ESPA): Architects, urban \& city planners in Egypt rely heavily on land reclamation to decrease the pressure on heavily busy zones in the Nile Delta's region where the costs are being submerged gradually due to SLR (Frihy \& El-Sayed, 2013).

Land Reclamation Methods: Wang (2017) have stated that by implementing fill materials from the seabed, mountains, deep subsurface excavations, and construction wreckages, a respected area from the sea could be reclaimed. Although its an unexpansive solution, however, it's only short-term, its are unsustainable to coral reefs, and not cost-effective in areas with large depth.

Proposed Approach: other natural phenomena's other than SLR exist like soil erosion and delta appearances, which modifies shorelines, thus, highlighting the issue of movable borderlines is essential to define a countries sea borders (Tsaltas et al., 2010). Future SLR problems to coastlines must be undertaken over an official adaptation. Such as the disposition of VLFS as a future approach not just hypothetically (Wang \& Tay, 2011). Although the research on VLFS technology has substantially advanced providing distinct features in settings and environments which are preferred for their applications advantages, 
there has been based on relatively small case study samples. While the Nile Delta is one of the most affected spots by the rising seas in the world, Egypt has yet to consider such solution.

Research gaps: not just locally, but there is an absence of global authorised context regarding the application and usage of VLFS. Locally, there is negligence in protecting underwater world heritage monuments. Locally, any adaptation solutions executed to safeguard coastal borders neglect the marine ecosystem factor. Therefore, this thesis defines the architect and urban planner roles through the establishment of architectural design guidelines and expanding dynamics formula to serve as a context for future implementation and usage of VLFS as well as proposing a floating city proposal.

\subsubsection{Hypothesis}

Would an analysis of artificial islands and floating structures bear out the claims that they are optimum solution for undertaking the rising seas challenges over old fashioned and traditional land reclamation solutions? What requires clarification is whether site analysis of Nile Delta's coastlines would show if artificial islands and floating structures are the best solution for the Nile Delta over land reclamation solutions or not.

This study offers two hypotheses: the Nile Delta's coastlines will eventually be submerged where land reclamation approaches practiced only offer short-term solutions; and that floating structures offer the optimum solution for safeguarding Egypt's coastal sovereignty when addressing land subsidence problems. 


\subsubsection{Significance of the Research Topic}

This thesis well deserves careful analysis on SLR impacts, adaptation approaches, and sustaining the coastal developments of the Nile Delta as it highlights the most vulnerable locations and both adaptation and mitigation approaches practiced. The findings of this thesis introduce floating community model and architectural design guidelines for floating structures to demonstrate the benefits of VLFS as the optimum adaptation solution for tackling SLR impacts in some of the most vulnerable areas in the Nile Delta coastline and to offer a future floating structures design reference for Egypt. The more the SLR, the greater the risk on vulnerable and low-lying coastal areas around the world. Therefore, old fashioned and traditional land reclamation solutions practiced by the ESPA should be abolished and replaced by floating structures wherever possible. The distinct sustainable and flexibility features of floating buildings in settings and environments makes them preferred for their various applications and advantages. If the government applies the recommended method derived from the outcomes of this research, it will safeguard Egypt's coastal sovereignty for the long-term wherever implementation is possible. Herein this thesis, authorities are guided on what should be done to efficiently design and sustain costal urbanizations in the Nile Delta's most vulnerable locations. The study uncovers critical impacts of SLR on costal urbanizations of the Nile Delta and offers VLFS as a sustainable long-term adaptation solution that Egyptian researches seem to disregard. Therefore, a new approach on adapting to SLR concerning Egypt's Nile Delta is explored. 


\subsection{Analytical Research Framework}

\subsubsection{Objectives and Research Questions}

The aim of this study is to analyze the Nile Delta's coastlines to explore the most vulnerable sites. Furthermore, this dissertation highlights the probable uses of floating structures for tackling the SLR challenges, to emphasize the absence of global authorised context regarding their implementation and usage, and to discuss that floating structures as the optimum solution for Egypt's North Coast. Finally, this thesis attempts to create a floating community concept proposal for the Nile Delta.

The aim of this dissertation is set out to explore SLR impacts on the Nile Delta's coastlines. Furthermore, this dissertation highlights the probable uses of floating structures for tackling the SLR challenges, to emphasize the absence of global authorised context regarding their implementation and usage. This study is designed to assess two hypotheses: The Nile Delta's coastlines will eventually be submerged where land reclamation approaches practiced only offer short-term solutions; and that floating structures offer the optimum solution for safeguarding Egypt's coastal sovereignty when addressing land subsidence problems. The objectives of this thesis research have been:

The general theoretical literature on this subject and specifically in the context of Egypt is inconclusive on several vital questions. Therefore, this study sought to answer these three questions:

1. What are the most vulnerable sites to SLR impacts in the Nile Delta's coastline? 
2. What are the adaptation approaches and mitigation solutions practiced in theses sites and can floating structures offer a better solution against SLR for these sites?

3. How to implement floating structures in the Nile Delta's most vulnerable coastline sites to SLR impacts?

The initial aim of this dissertation is set out to explore SLR impacts on the Nile Delta's coastlines, furthermore, this dissertation highlights the probable uses of VLFS for tackling the SLR challenges, to emphasize the absence of global an authorised context regarding their implementation and usage. The objectives of this thesis research have been:

- To identify the impacts of SLR on the Nile delta region in terms of people affected, land subsidence on the infrastructure, and land submergence area.

- To identify the most vulnerable sites to SLR in the Nile Delta.

- To identify adaptation approaches practiced and main topographic characteristics that influence flood levels and permanent inundation of lowlands by SLR impacts in most vulnerable sites to SLR and their evaluation in respect to Egypt's most vulnerable regions identified.

- To assess the most vulnerable area identified to evaluate SLR impacts on people, buildings, and infrastructure in the most vulnerable site.

- To identify the most sustainable and cost-effective solution against SLR impacts.

- To analyze and study different floating community cases in respect to Egypt's most vulnerable regions to set design approaches and strategies.

- To develop an architectural systematic design guidelines approach for developing floating communities for Egypt and the Nile Delta coastline to function as a future 
reference for architects and urban planners in Egypt when designing and planning coastal developments.

- To identify the optimum materials and sustainability approaches, mooring system, and project feasibility.

- To set an expanding dynamics design guidelines approach for developing floating communities for Egypt's coastlines to function as a future reference for architects and urban planners to be considered in Egypt when designing and planning coastal developments.

- To offer a floating community concept proposal for the Nile Delta's most vulnerable area identified to function as a future reference for architects and urban planners in Egypt when designing and planning coastal developments.

\subsubsection{Limitations and Constraints}

The central idea of this thesis is about resilience. This thesis studies in detail the problems of climate change and mitigation strategies, which is to say carbon emission reduction. However, this thesis is part of the response to climate change, which is adaptation, which is resilience. The challenges brought by SLR are extremely complex, not complicated, and certainly not moderate. However, technological and engineering solutions tend to transform complex problems into complicated ones, and complicated issues into moderate ones. In response, this thesis is in an intermediate territory between the urban scale and the architectural and technological proposal.

Therefore, this thesis demonstrates an evaluative perspective on SLR impacts on Egypt and proposes floating structures as a means to tackle such phenomenon. However, the issue 
SLR and adaptation approaches are rather broad and wide-ranging. As a result of such methodology, some limitations and constraints were established to bound the research. This thesis mainly covers to how safeguard underwater world heritage and historical sites and properties, safeguarding marine borders and habitats. Secondary, it touches but does not cover issues such as the infrastructure and people. Also, this thesis won't cover all of Egypt's coastline, but only the Nile Delta's most impacted area to SLR identified.

Further different adaptation solutions alternatives are analyzed such as: building seawalls, raising roads, building storm-water pumps, upgrading sewage systems, using beaches as barriers, creating natural infrastructure, slowing land sink-age, managed retreat, elevating houses, and VLFS. Despite of analyzing all these solutions to SLR, some issues were not covered. This thesis has covered only these solutions regarding their pros and cons, site suitability, design limitations, maintenance, feasibility, environmental impact, costeffectiveness, and their efficiency on the long-term. Therefore, such solutions should be analyzed separately on a wider scale to conclude a more accurate assessment. Where VLFS where chosen to its sustainability features, cost-effectiveness, and its capabilities in safeguarding the marine borders and habitat.

Furthermore, it is noted that the hypotheses in this thesis are limited to the Nile Delta's coastline and not in all low-lying areas in Egypt or around the world, as well as that floating structures are limited to the assessment regarding the most vulnerable areas identified in the Nile Delta. Therefore, the results of this thesis should not be generalized on any low-lying regions around the world, nevertheless, in an area with similar local conditions, site properties, and local bathymetry, VLFS may offer an attractive cost-effective and long-term solution like in the case in this thesis. 


\subsubsection{Methodology}

The data on Egypt regarding the SLR discussion will be including but not limited to the reports from the Intergovernmental Panel on Climate Change (IPCC, 2014; IPCC, 2007), the Arab Environment Climate Change Report by Tolba \& Saab (2009), and Atlas of Africa Energy Resources (UNEP, 2017). My approach is characterised by the assumption that solutions like traditional land reclamation methods that are executed in vulnerable areas in Egypt are not practical long-term solutions as well as having various disadvantages. This study analyzes and extends the idea that VLFS are more sustainable preferring it to old fashioned land reclamation solutions as it offers a cost-effective solution where there is a big water depth and preserve the nearshore maritime ecosystem. I have based my case study on the Nile delta to show how VLFS could be the ideal solution for such low-lying region. Upon architectural, structural and site analysis, a floating community concept proposal for the Nile Delta is created where Cradle to Cradle Building Charter by McDonough \& Braungart (2010) has defined the guidelines for sustainable environmental design.

To answer the research questions, the study conducts eight researches using up-to-date data. The first study conducts time series analysis and ranking of impacted areas from SLR on the Nile Delta. The second study conducts a qualitative assessment on SLR impacts for ten case studies and evaluates adaptation solutions practiced in each case. The third study conducts site analysis on the most impacted area identified. The fourth study conducts evaluation design matrix of adaptation and mitigation solutions. The fifth study conducts comparative analysis on eight in depth floating community case studies. The sixth study conducts comparative analysis of different approaches and methods to set guidelines for building on water. The seventh study conducts content analysis to set expanding dynamics 
guidelines of floating cities. Finally, the eighth study sets architectural design guidelines and floating community concept proposal model for the Nile Delta.

\subsubsection{Evaluation}

There is some evidence to suggest that old fashioned and traditional land reclamation solutions on the Nile Delta coastline is more complex than previously thought and suggest that they were tolerated and moderated over time when technological advancements of floating structures were not as developed as in the recent decades. The indication proposes that VLFS are more sustainable preferring it to old fashioned and traditional land reclamation solutions should be widely applicable in Egypt's shorelines for their advantages such as preserving Egypt's rich nearshore marine ecosystem. While there is some evidence to recommend floating structures as a cost-effective solution for sinking lands, however this only applies where there's a big water depth, therefore this is likely to limit their use to certain sites. This study offers a new proposal for tackling SLR impacts on the Nile Delta's coastlines as it presents a floating community proposal for such site.

\subsubsection{Outline of the Thesis}

The remaining chapters are structured as follows. Chapter 2 contextualises the research in the related literature about SLR impacts and adaptation and mitigation solutions executed in vulnerable areas while focussing on Egypt. Chapter 3 is an account of the research methodology on SLR and floating structures, as well as offering the design methodology where Cradle to Cradle Building Charter has defined the guidelines for sustainable environmental design. Chapter 4 conducts evaluation design matrix of adaptation and mitigation solutions, then conducts comparative analysis on eight in depth floating 
community case studies. Chapter 5 reviews floating structures where their definition, research studies, advancement applications, advantages, analysis and design for the last five decades are investigated, then conducts comparative analysis for different approaches and methods for floating cities. Chapter 6 conducts time series analysis and ranking for the Nile Delta, then conducts a qualitative assessment on SLR impacts for ten case studies and adaptation solutions practiced in each case, then it conducts site analysis, time series analysis and ranking of impacted sectors in Alexandria. Chapter 7 conducts content analysis for expanding dynamics of floating cities, then sets architectural design guidelines and floating community concept proposal model for the Nile Delta. 


\section{Chapter 2}

\section{STATE OF THE ART REVIEW}

\subsection{Introduction}

SLR challenges will disturb a lot of coastal areas around the world, either urban or agricultural, would possibly be flooded. Mega-deltas such as the Nile Delta in Egypt, the Ganges-Brahmaputra Delta in Bangladesh and India, and the Mekong Delta in Vietnam are some of the lowest lying coastal areas in the world (as shown in Figure 2.1). The rise of sea level in parallel with these countries rise in population and coastal cities developments urges the need for a solution for a long-term solution such low-lying lands. This literature review discusses the historical background of SLR impacts on the Nile Delta, the impacts of SLR on vulnerable coastal areas, defines the main problems impacts of SLR on the long-term, discusses general and specific adaptation solutions executed, and reviews VLFS as possible attractive solution for tackling SLR impacts. 


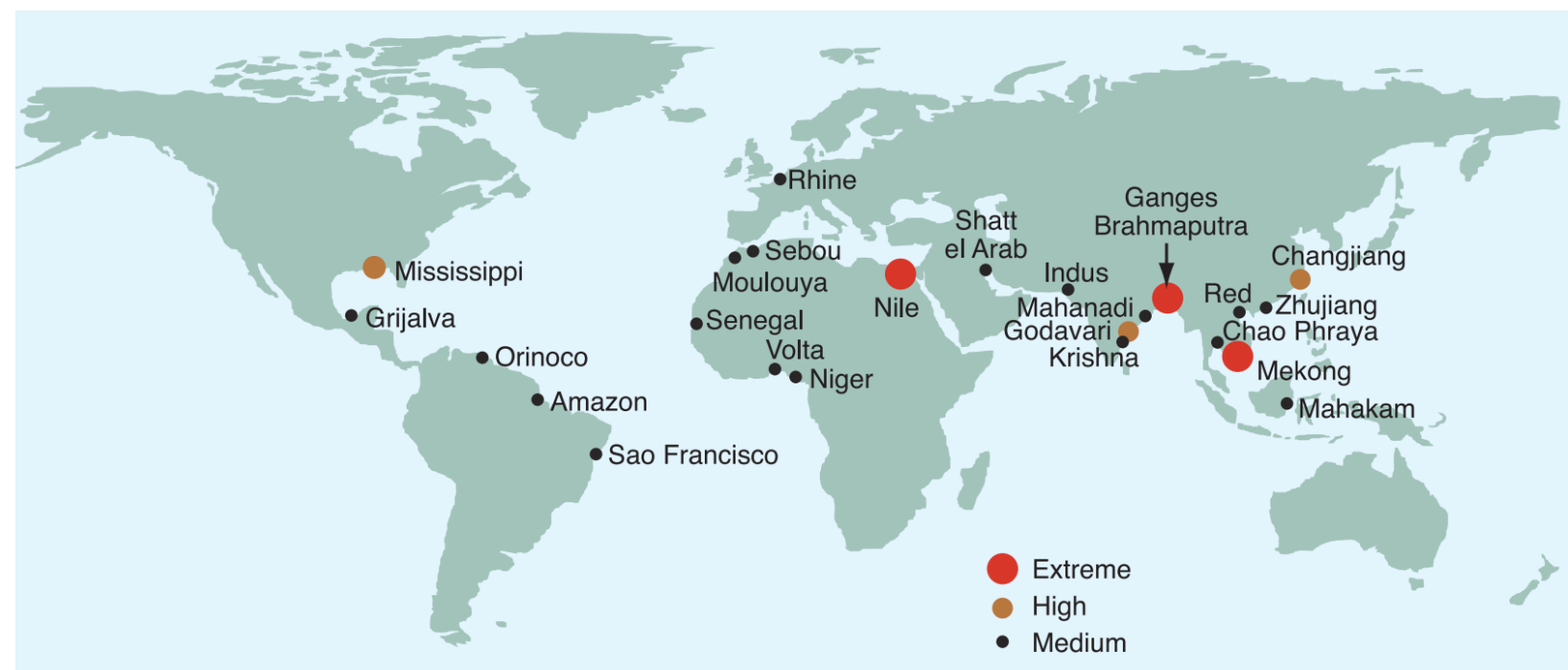

1 Figure 2.1: Relative vulnerability of shore deltas in 2050 as the anticipated population distribution and sea-level rates by present percentages (extreme is one million or over, high is from 50,000 up to one million, and medium is from 5,000 to 50,000). Reproduced from IPCC (2007).

\subsection{History of SLR Impacts on the Nile Delta}

Due to the ascending terrain from Ethiopia until the Nile delta, the Nile river carries the fertile water of freshwater and silt which benefits agricultural soil, descending from their sources according to the terrain of the earth. Over time, the delta has formed from the continuous flow of silt, which is deposited in large quantities in the delta and inside the Mediterranean waters, therefore adding land to the Nile delta from the sea. Unfortunately, after the construction of the High Dam in 1970 the balance between Nile and the sea has changed. According to the results of studies in 1975, when the silt was cut of in the Nile River after the obstacle of the High Dam, the sea overtook the Nile Delta over time, parts of which were strongly eroded by the impact of continuous waves, leading to a decline in the level of the Delta corresponding to sea level (Hereher, 2010). Such land submergence isn't a first in Egypt as Heracleion (Greek), also known as Thonis in Egyptian, like Atlantis, was an ancient 
Egyptian city on the Nile Delta that has disappeared in the second century BC under the Mediterranean Sea (Fabre \& Goddio, 2013). The Nile Delta coastal cities may probably face a similar fate.

\subsubsection{Population, Expansion, and Land-shortage in the Nile Delta}

In the Arab Environment Climate Change Report, Tolba \& Saab (2009) state that the urban demographics of the Nile Delta and valley didn't basically change since the past, nevertheless the $19^{\text {th }}$ century began with about 4 million people and now it's about 70 million. Despite the efforts since the $19^{\text {th }}$ century to expand the agricultural area into the desert and to enhance irrigation, nonetheless the available agricultural are per head has been constantly shrinking. Therefore, the Nile Delta is one of the highest population densities on Earth. In the past century, the urban ratio has increased from $20 \%$ to almost $50 \%$ Tolba \& Saab (2009). The report indicates that such growth was followed by great developments in both urban and rural settlements, which as a result has led into huge losses in agricultural areas due to building over it. Although building over agricultural lands is prohibited by law and the authorities demolish such constructions, nevertheless if the inhabitants of the Nile Delta can't construct horizontally then they'll construct vertically by increasing floors of the existing houses. Such act continuously adds loads to an already vulnerable low-lying region.

Several studies conducted by the Intergovernmental Panel on Climate Change (IPCC, 2007, 2014) concerning mega-deltas have shown that the Nile Delta in Egypt is one of the three most vulnerable mega-deltas around the world due to their low-lying coastlines besides the Ganges-Brahmaputra Delta in Bangladesh and India, and the Mekong Delta in Vietnam. The probable one-meter SLR is anticipated to impact around 6.1 million inhabitants of the 
Nile Delta, while 1.5.m SLR may submerge an area around $22,000 \mathrm{~km}^{2}$ in the Ganges-

Brahmaputra Delta, impacting up to 17 million residents (FitzGerald et al., 2008).

The Arab Environment Climate Change Report by Tolba \& Saab (Tolba \& Saab, 2009) state that about $94 \%$ of Egypt's area (over one million $\mathrm{km}^{2}$ ) is desert. With a population approaching a hundred million, most Egyptians only inhabit the Nile valley and the delta which make less than 6\% of Egypt's area. The delta is currently withdrawing because of the accelerating erosion lengthways its shoreline. The construction of the High Dam between 1960 to 1970 has blocked great quantity of sediments in Lake Nasser which accounts as the greatest issue for erosion in the Delta.

\subsection{SLR Impacts on the Most Vulnerable Mega-deltas}

\begin{tabular}{|c|c|c|c|c|c|c|c|}
\hline $\begin{array}{l}\text { Coastal } \\
\text { socio- } \\
\text { economic } \\
\text { sector } \\
\end{array}$ & $\begin{array}{l}\text { Temperat } \\
\text { ure rise } \\
\text { (air and } \\
\text { seawater) }\end{array}$ & $\begin{array}{l}\text { Extreme } \\
\text { events } \\
\text { (storms, } \\
\text { waves) } \\
\end{array}$ & $\begin{array}{l}\text { Floods } \\
\text { (sea } \\
\text { level, } \\
\text { runoff) }\end{array}$ & $\begin{array}{l}\text { Rising } \\
\text { water tables } \\
\text { (sea level) }\end{array}$ & $\begin{array}{l}\text { Erosion (sea } \\
\text { level, } \\
\text { storms, } \\
\text { waves) }\end{array}$ & $\begin{array}{l}\text { Salt water } \\
\text { intrusion } \\
\text { (sea level, } \\
\text { runoff) }\end{array}$ & $\begin{array}{l}\text { Biological } \\
\text { effects (all } \\
\text { climate } \\
\text { drivers) }\end{array}$ \\
\hline $\begin{array}{l}\text { Freshwater } \\
\text { resources }\end{array}$ & strong & strong & strong & strong & $\begin{array}{l}\text { insignificant } \\
\text { or unknown }\end{array}$ & strong & weak \\
\hline $\begin{array}{l}\text { Agriculture } \\
\text { and forestry }\end{array}$ & strong & strong & strong & strong & $\begin{array}{l}\text { insignificant } \\
\text { or unknown }\end{array}$ & strong & weak \\
\hline $\begin{array}{l}\text { Fisheries } \\
\text { and } \\
\text { aquaculture }\end{array}$ & strong & strong & weak & $\begin{array}{l}\text { insignificant } \\
\text { or unknown }\end{array}$ & weak & strong & strong \\
\hline Health & strong & strong & strong & weak & $\begin{array}{l}\text { insignificant } \\
\text { or unknown }\end{array}$ & strong & strong \\
\hline $\begin{array}{l}\text { Recreation } \\
\text { and tourism }\end{array}$ & strong & strong & weak & $\begin{array}{l}\text { insignificant } \\
\text { or unknown }\end{array}$ & strong & $\begin{array}{l}\text { insignificant } \\
\text { or unknown }\end{array}$ & strong \\
\hline Biodiversity & strong & strong & strong & strong & strong & strong & strong \\
\hline $\begin{array}{l}\text { Settlements } \\
\& \\
\text { infrastructu } \\
\text { re }\end{array}$ & strong & strong & strong & strong & strong & strong & $\begin{array}{l}\text { insignificant } \\
\text { or unknown }\end{array}$ \\
\hline
\end{tabular}

1 Table 2.1: Associated climate change effects on the socio-economic areas in coastal regions (Meehl et al., 2007). 
Abdrabo, Hassaan, \& Selmy (2014) states that they are commonly known for being extremely defenceless to the SLR effects like runoffs. The report describes them to be highly impacted by the load stress made by the residents' land-use alterations of the catchments and delta plain. Almost all deltas are currently experiencing natural collapsing which outcomes in comparatively higher sea-level rise percentages than the worldwide usual. Numerous areas are affected by water extraction and diversion factors, also the decreasing silt delivery caused by dam constructions. Delta plains, especially in Asia, are densely inhabited and frequently affected by either external impacts such as floods and the lack of silt, or external sea impacts such as storm tides and erosion. Climate change effects on the socio-economic areas in coastal regions and their level of disturbance are shown in Table 2.1 whereas the approximations of continents' vulnerabilities to SLR and baseline socioeconomics are shown in Table 2.2.

\begin{tabular}{|l|l|l|l|l|l|l|l|l|l|}
\hline Region & \multicolumn{3}{|l|}{ Land Area (km3) } & \multicolumn{3}{l}{ Population (millions) } & \multicolumn{2}{l}{ GDP } \\
billions)
\end{tabular}

2 Table 2.2: Revealing approximations of continents' vulnerabilities to SLR and baseline socio-economics. Market Exchange Rates (MER) (Anthoff, Nicholls, Tol, \& Vafeidis, 2006). 
Ericson, Vörösmarty, Dingman, Ward, \& Meybeck (2006) have predicted that there are around 300 million inhabitants of 40 deltas worldwide, counting all big mega-deltas. They approximate that a density of about 500 people $/ \mathrm{km}^{2}$ makes the Ganges-Brahmaputra delta as the most populated mega-delta, while the densest is the Nile delta. Most of such deltas and mega-deltas are related to urban areas expansions. Ericson et al., (2006) have used a comprehensive modelling method to estimate the actual sea-level rise percentage under the current circumstances, building the approximations on the silt trapped or stream rerouting on a worldwide dam data, and altering the approximations of the natural land dropping to integrate the human-made impact. Such study has exposed that most of the inhabitants of the 40 deltas are at danger from floods and erosion, mostly due to the reduced silt transported by the stream, and secondly due to the sea-level rise. Approximations via a digital topography model and the worldwide inhabitants' distribution statistics exposes that over 1 million people would be impacted by the year 2050 in three major mega-deltas which are the Nile delta in Egypt, the Ganges-Brahmaputra delta in Bangladesh, and the Mekong delta in Vietnam delta.

IPCC (2007) states that over 50,000 inhabitants are anticipated to be affected per delta in the other nine deltas, and over 5,000 inhabitants are anticipated to be affected per delta in the other 12 deltas. Such general modelling method concludes that $75 \%$ of the people impacted live in Asian deltas and mega-deltas, and high population of the rest live in African deltas and mega-deltas. Such influences could be worsened by faster sea-level rise and greater human loads and activities. Woodroffe, Nicholls, Saito, Chen, \& Goodbred (2006). The topography of the Asian mega-deltas is intricate due to the geomorphological evolution of the deltas, and residents' distribution demonstrates a high spatial variability, indicating the high density and the development of some of the world's biggest megacities 
Sánchez-Arcilla, Jiménez, \& Valdemoro (1998) and Woodroffe et al. (2006) state that numerous inhabitants in the mentioned deltas and others depend on the submerging from either floods or storm tides, and thus it is essential to advance in more approaches to measure the deltas' vulnerabilities

\begin{tabular}{|l|l|l|l|}
\hline SLR (SLR) Scenario & $\begin{array}{l}\text { Land submergence } \\
\text { estimated (square } \\
\text { kilometers) }\end{array}$ & $\begin{array}{l}\text { Percentage of Nile } \\
\text { Delta land to be } \\
\text { submerged }\end{array}$ & $\begin{array}{l}\text { Expected number of } \\
\text { people to be affected }\end{array}$ \\
\hline $0.5 \mathrm{~m}$ SLR & $1800 \mathrm{~km}^{2}$ & $7.5 \%$ & 4 million \\
\hline $1.0 \mathrm{~m}$ SLR & $4500 \mathrm{~km}^{2}$ & $18.9 \%$ & 6.1 million \\
\hline $1.5 \mathrm{~m} \mathrm{SLR}$ & $5700 \mathrm{~km}^{2}$ & $23.9 \%$ & 8 million \\
\hline
\end{tabular}

3 Table 2.3: Predicted land loss and people affected in the Nile delta Caused by SLR (SLR) scenarios (Eldeberky, 2011).

Organización de las Naciones Unidas (2005) states that Egypt is the most vulnerable African nation to SLR. The water in 2000 was assessed around $70 \mathrm{~km} 3$ where that the demand is already lower than the existing resources A main challenge is closing the growing gap between the available water with growing demand for water for numerous economical areas. Eldeberky (2011) suggests that the water use percentage has already reached its maximum 100\% in Egypt, and climate change impacts would only worsen the situation.

\begin{tabular}{|l|l|l|}
\hline Region & Protection Costs $\left(10^{9} \mathrm{US} \$\right)$ & Number of People Displaced $\left(10^{6}\right)$ \\
\hline Africa & 92 & 2.74 \\
\hline OECD Europe & 136 & 0.22 \\
\hline World & 955 & 8.61 \\
\hline
\end{tabular}

4 Table 2.4: The best coastal management costs and number of people to be displaced considering a $1 \mathrm{~m}$ SLR scenario in the $20^{\text {th }}$ century (Tol, 2002).

The data gathered for Africa, Organisation for Economic Co-operation and Development (OECD) Europe, and the world (as shown in Table 2.4), demonstrates the most ideal and cost- 
efficient coastal safety costs and the number of relocated residents for a SLR of one meter in the $20^{\text {th }}$ century (Tol, 2002).

Abdrabo, Hassaan, \& Selmy (2014) state that agriculture already use around $85 \%$ of Egypt's water supply yearly and has a crucial part in the country's economy, which forms around 20\% of Egypt's GDP. Conway (2005) states that over 70\% of the cultivated area rely on low-efficiency water systems, where that outcomes in a lot of water losses, less land production, waterlogging as well as salinity challenges. Furthermore, they state that such unsustainable farming techniques and inappropriate water management impact the quality of water supply. The decrease in such irrigation water quality impacts negatively on the agricultural soils and harvests.

\subsubsection{Long-term SLR Impacts on the Most Vulnerable Regions}

Meehl et al. (2005) conclude that the timespan of the ocean warming is a lot longer than the rise of temperature on the ocean's surface, therefore sea-level rise caused by the thermal expansion is projected to stay at a substantial amount for centuries, even if the temperature stabilises. He describes the deglaciation process of insignificant land-based glaciers, as well as Greenland and the West Antarctic ice sheets, could cause great further SLR, with permanent melting of Greenland would cause a worldwide temperature to rise between 1.1 to $3.8^{\circ} \mathrm{C}$ over the current average and if such scenario occurs then it would probably occur by 2100. Over 10 meters of sea-level rise is probable, even though that such rise would occur over long periods like centuries or more, and such scenario is referred to "the commitment to sea-level rise”. He describes that sea-level rise ratios are indefinite and anticipated to be around $>0.6$ to $0.7 \mathrm{~m}$ per century with a low possibility/high damage level. 
The projections for 2030 are clearly hypothetical as such projections are founded on the past data changes (as shown in Table 2.5). As every area's level of development relates to its per capita income, therefore the economic performance from 2000 to 2030 should impact the level of which area the populations would keep inhabiting or expanding (IPCC, 2007).

\begin{tabular}{|c|c|c|c|c|c|c|c|c|c|c|c|c|c|}
\hline \multirow[b]{2}{*}{ Year } & \multicolumn{4}{|c|}{ Percentage urban } & \multicolumn{4}{|c|}{$\begin{array}{l}\text { Percent of the world's } \\
\text { urban population living in } \\
\text { the region }\end{array}$} & \multicolumn{5}{|c|}{$\begin{array}{l}\text { Percent of urban population in } \\
\text { different size-class of urban } \\
\text { centre, } 2000\end{array}$} \\
\hline & 1950 & 1975 & 2000 & 2030 & 1950 & 1975 & 2000 & 2030 & $\begin{array}{l}\text { Under } \\
0.5 \mathrm{~m}\end{array}$ & $\begin{array}{l}0.5- \\
1 \mathrm{~m}\end{array}$ & $\begin{array}{l}1-5 \\
\mathrm{~m}\end{array}$ & $\begin{array}{l}5- \\
10 \\
m\end{array}$ & $\begin{array}{l}10 \\
\mathrm{~m}+\end{array}$ \\
\hline $\begin{array}{l}\text { Northern } \\
\text { America }\end{array}$ & 63.9 & 73.9 & 79.1 & 86.7 & 15.0 & 11.9 & 8.8 & 7.1 & 37.4 & 11.0 & 34.3 & 5.4 & 11.9 \\
\hline $\begin{array}{l}\text { Latin } \\
\text { America } \\
\text { and the } \\
\text { Caribbean }\end{array}$ & 42.0 & 61.2 & 75.4 & 84,3 & 9.6 & 13.0 & 13.9 & 12.4 & 49.8 & 9.0 & 21.7 & 4.9 & 14.7 \\
\hline Oceania & 62.0 & 71.5 & 70.5 & 73.8 & 1.1 & 1.0 & 0.8 & 0.6 & 41.9 & 0 & 58.1 & 0 & 0 \\
\hline Europe & 50.5 & 67.9 & 71.7 & 78.3 & 37.8 & 29.2 & 18.4 & 11.1 & 67.8 & 9.8 & 15.1 & 5.4 & 1.9 \\
\hline Asia & 16.8 & 24.0 & 37.1 & 54.1 & 32.0 & 37.9 & 47.9 & 53.7 & 49.0 & 10.0 & 22.6 & 8.8 & 9.7 \\
\hline Africa & 14.7 & 25.4 & 36.2 & 50.7 & 4.5 & 7.0 & 10.3 & 15.1 & 60.2 & 9.6 & 22.1 & 4.6 & 3.5 \\
\hline World & 29.0 & 37.2 & 46.8 & 59.9 & 100 & 100 & 100 & 100 & 52.6 & 9.8 & 22.4 & 6.8 & 8.4 \\
\hline
\end{tabular}

5 Table 2.5: Urban percentages considering different SLR scenarios (IPCC, 2007).

Nicholls et al. (2006) state that the possible exposure to such changes, according to the current socioeconomic situations, will be substantial on a global level; therefore, there is a contradiction between the long-term sea-level rise and the current human growth system in coastal cities. Anthoff et al. (2006) propose that protection should be the most efficient approach in developed regions, even in a $2 \mathrm{~m} /$ century scenario. Nevertheless, Nicholls \& Tol (2006) state that sea-level rise won't stop at 2100 which increases the possible effects as well as having numerous possible limitations in adapting to such changes that are insufficiently understood. Such scenario increases the long-term implications of either protecting the 
coastline or retreating from it when choosing the coastline adjusting strategies, and the best method to shore spatial development.

\begin{tabular}{|l|l|l|l|l|l|l|}
\hline Region & $\begin{array}{l}\text { Coral reef } \\
\text { area }(\mathrm{km} 2)\end{array}$ & $\begin{array}{l}\text { Destroyed } \\
\text { reefs (\%) }\end{array}$ & $\begin{array}{l}\text { Reefs } \\
\text { recovered } \\
\text { since 1998 } \\
(\%)\end{array}$ & $\begin{array}{l}\text { Reefs at } \\
\text { critical } \\
\text { stage (\%) }\end{array}$ & $\begin{array}{l}\text { Reefs at } \\
\text { threatened } \\
\text { stage (\%) }\end{array}$ & $\begin{array}{l}\text { Reefs at } \\
\text { low or no } \\
\text { threat } \\
\text { level (\%) }\end{array}$ \\
\hline Red Sea & 17,640 & 4 & 2 & 2 & 10 & 84 \\
\hline The Gulfs & 3,800 & 65 & 2 & 15 & 15 & 5 \\
\hline South Asia & 19,210 & 45 & 13 & 10 & 25 & 20 \\
\hline S-E Asia & 91,700 & 38 & 8 & 28 & 29 & 5 \\
\hline E \& N Asia & 5,400 & 14 & 3 & 23 & 12 & 1 \\
\hline Total & 137,750 & 34.4 & 7.6 & 21.6 & 25.0 & 51 \\
\hline Asia & $(48.4 \%)$ & - & - & - & - & 19.0 \\
\hline
\end{tabular}

6 Table 2.6: Coral reefs conditions in important areas of Asia in 2004 (Wilkinson, 2008).

The IPCC report (2014) shows the affected coral reefs conditions in important areas of Asia (as shown in Table 2.6), demonstrates that the destroyed reefs have a possibility about $90 \%$ of corals would not recover anytime soon. It predicts that the damaged reefs have a possibility about $50 \%$ to $90 \%$ of corals loss and/or probably would be destroyed in about 10 to 20 years, whereas the threatened reefs have a possibility about $20 \%$ to $50 \%$ of corals loss or and/or probably would be destroyed in about 20 to 40 years.

\subsection{SLR Impacts on Egypt and Adaptation Approaches}

Each coastal community in every country is trying hard to tackle SLR impacts and searching for the most advanced and practical approaches. Nevertheless, what works for one area might not work for the other. Selecting the best approach will be subject to issues such as the climate, funds, natural resources, and regulations. Since every approach may need time to design and implement, it's significant for such areas and inhabitants to be practical. 
Comprehending the impacts of the rising seas and floods might pose today and the next decades will offer such seaside areas the time to prepare and explore methods to shield their possessions, economies, houses, and quality of life.

Recent studies conducted by the Intergovernmental Panel on Climate Change (IPCC, 2007b, 2014) concerning mega-deltas have shown that the Nile Delta in Egypt is one of the three most vulnerable mega-deltas around the world due to their low-lying coastlines besides the Ganges-Brahmaputra Delta in Bangladesh and India, and the Mekong Delta in Vietnam. The probable one-meter SLR is anticipated to impact around 6.1 million inhabitants of the Nile Delta, while 1.5.m SLR may submerge an area around $22,000 \mathrm{~km}^{2}$ in the GangesBrahmaputra Delta, impacting up to 17 million residents (FitzGerald, Fenster, Argow, \& Buynevich, 2008; DSDG, 2017).

The Arab Environment Climate Change Report by Tolba \& Saab (2009) state that about 94\% of Egypt's area (over one million $\mathrm{km}^{2}$ ) is desert. With a population approaching a hundred million, most Egyptians only inhabit the Nile valley and the delta which make less than 6\% of Egypt's area (Saab \& Sadik, 2018; UNFCCC, 2007; United Nations Framework Convention Change Climate, 2016). The delta is currently withdrawing because of the accelerating erosion lengthways its shoreline. The construction of the High Dam between 1960 to 1970 has blocked great quantity of sediments in Lake Nasser which accounts as the greatest issue for erosion in the Delta (Saab, 2017; UNEP, 2017; United Nations Development Programme, 2014).

Submerged coastlines are vital, specially to islands and low-lying areas like the Abu Qir in the Nile Delta's region (Frihy \& El-Sayed, 2013; IDSC, 2011), as it may lead to real sovereignty losses, because of the of sea borders movements. Also, as for risky areas, these 
losses in land areas may lead into some countries' disappearances in case of island countries.

The stages of SLR and Consequences (Tsaltas et al., 2010):

- $\quad$ Stage 1: SLR.

- Stage 2: Land loss.

- Stage 3: Maritime boundaries movement.

- Stage 4: Potential economic and/or sovereignty loss.

Countries will have to spend a lot of money to tackle this problem, to guarantee minimizing the possible economic and land loss (NOAA, 2010; 2017). As that no country could obstruct any of the first two stages, they will have to delay the process form reaching the third stage (Tsaltas et al., 2010). Therefore, urban planning and development for any new and existing coastal settlements in any country, specially in Egypt's Mediterranean coastline, can not be designed for or carried out without incorporating climate change and SLR studies and analysis.

\subsubsection{Egypt's Plans Against SLR Impacts}

IPCC (2007) discusses the Egyptian government next goals via the National Improvement Plan:

- Enhancing water sanitation network in both cities and countryside regions.

- Managing wastewater

- Enhancing the usage of water resources by refining irrigation proficiency and recycling drainage-water for agricultural purposes. 
Nevertheless, with such global warming impacts, several significant threats are obvious.

- Sea-level rise may have a great effect on the Nile Delta and its inhabitants and other seaside regions (Conway, 2005).

- Higher temperature would probably decrease main crops production and increase their water necessities, consequently less crop water-use productivity (UNFCCC, 2007).

- There might be an overall increase in the irrigation demand (Attaher, Medany, \& El-Gindy, 2010).

- A large degree of ambiguity of the Nile stream is probable.

- According to SRES scenarios, Egypt would probably experience higher water stress, with an anticipated decrease in rainfall with an expected population of 151 million by 2050. Therefore, increasing water stress in every aspect.

- The constant development of irrigated zones would decrease the Egypt's' ability in dealing with the future flow instability (Conway, 2005).

\subsubsection{Adaptation Approaches Executed Against SLR Impacts in the Nile Delta of Egypt}

Tolba \& Saab (2009) and DSDG (2017) suggest that Egypt rely heavily on traditional land reclamation solutions especially in the Nile Delta's region where low-lying lands are being submerged gradually by SLR impacts. Architects, urban and city planners shift to land reclamation solutions to decrease the pressure on the current heavily busy zones and underground areas. Wang \& Tay (2011) and Wang (2017) state that by implementing fill 
materials from the seabed, mountains, as well as deep subsurface excavations, and construction wreckages, architects and urban planners are capable to make rather an enormous and respected area from the sea. Wang, Watanabe, \& Utsunomiya (2008) and Wang (2017) state that although land reclamation solutions can offer an unexpansive one, however, they only serve as temporary solutions, as they are unsustainable to coral reefs, and not cost-effective in areas with large depth.

\subsubsection{Most Common Adaptation Approaches Against SLR}

Building seawalls (dykes) serve as large dams, gateway which controls tidal movements in and out of bays. They are constructed on the seashore to reduce floods from currents and storms. Seawalls are implemented in the Maeslant Barrier, Thames Barrier, Venice MOSE, Treasure Island Master Plan, New Orleans (post-Katrina), Marin County, and Bay Arc. They are usually constructed from 1.5 to 2 meters above sea level (IPCC, 2014). However, in order to decrease floods, old seawalls require restoring and elevating as sea levels rise. Raising such dykes by would cost around $\$ 200$ per meter. New dykes often cost $\$ 2000$ to $\$ 6,700$ per linear meter (IPCC, 2007).

Raising roads acts like a linear shield, it is similar to levees or dykes, which fasten the coastline to stay in its location. It is mostly practiced in United States, the Netherlands, and Japan. Raising roads over the sea level could decrease tidal floods. To be certain that such higher roads won't transport flood waters to buildings lower levels, authorities usually implement storm-water pumps to prevent such extra water (National Oceanic and Atmospheric Administration (NOAA), 2010). 
Water won't drain out effectively as the seas rise, therefore building storm-water pumps can offer a solution. Pumps could accelerate the process of removing water from the roads by vacuuming up such water and discharging it back to the ocean (IPCC, 2014).

Floods could disturb sewage systems and danger septic tanks. Since saline water is destructive, it could break septic tanks which makes a stinking smell and creates health risks. Cities need to improve sewage systems in order to prevent storm water from infiltrating pipes, enhance septic tanks, or change them with new sewer lines as practiced in Florida (IPCC, 2007).

Shores and dunes could act as a natural barrier which decreases the effects of storm surges. The larger the coast, the more water it will prevent from reaching houses and streets. Cities use land implementation solution by adding sand to make beaches larger or to guard them from erosion (IPCC, 2014). Implementing such sort of natural infrastructure could shield from floods while preserving beaches for the public to enjoy. However, land reclamation solutions have proven to be destroy the marine ecosystem as stated by Wang \& Tay (2011).

Littoral areas can upgrade and build natural infrastructure which could act as a barrier from storms and coastal floods. Such natural structures functions like barrier islands, coral reefs, mangroves, and salt marshes could be merged with the built infrastructure, like dykes or breakwaters, to prevent storm surges. Such approach could be cost-effective and could enhance the natural environment for the city if the seabed wasn't too deep (National Oceanic and Atmospheric Administration (NOAA), 2017).

In areas such as Hampton Roads, land sinking happens due to pumping groundwater for usage that the land is trying in to fill such unfilled space. Cities could decrease such land 
subsidence by preventing more groundwater pumping and introducing pilot plans to stop such land subsidence (IPCC, 2014).

In many littoral areas, coastlines get damaged by storms, rising seas, erosion, and land subsidence. Despite that cities are executing several approaches to adapt to such impacts, some people are still considering relocating or managed retreat like in California, North Carolina, New Jersey, Texas and South Carolina (Parris et al., 2012). Although such possibility might not be the best solution for all littoral settlements fronting such SLR impacts, it appears to be the optimum approach to ensure their inhabitants safety.

\subsubsection{Floating Structures as a Solution for Tackling SLR Impacts}

Distinguished researchers (Caron, 2009, 2014; Kwiatkowska \& Soons, 1990; Soons, 1990) propose that future SLR impacts must be undertaken over an official adaptation. As stated by Suzuki et al. (2006), the demand on different architectural and urban planning floating applications like floating piers, floating hotels, floating fuel storage facilities, floating stadiums, floating bridges, floating airports, as well as floating cities have generated wideranging research studies throughout the last decades. Floating structures has advanced noticeably through the last decades and now we have several innovative approaches planned to increase the stability, advance the mooring systems, and structural integrity of floating structures (C.M. Wang, 2017). As Tsaltas et al. (2010) state that floating structures do not work in every case, but it could still be a practical answer in some cases for conservation of fragile ecosystems, protecting in and offshore strategic economic activities, safeguarding borders and habitats. 


\subsubsection{Advantages of VLFS}

As stated by Wang \& Tay (2011), all those Mega Floating structures have more benefits over the old and traditional land reclamation solution in terms of space creation in the following aspects:

- They're cost effective where the water depth is considerably big.

Although it is not the case in Egypt, but the price of imported sand for the usage of land reclamation in some areas has increased remarkably and a time could arrive where sand might not be even obtainable from neighbouring countries.

- Ecological friendly where they neither harm the maritime eco-system, nor do they siltup deep ports or disturb the tides and sea waves.

- They are simple and fast to assemble.

Different elements and components could be manufactured at different dockyards and then transported to the location to be assembled and thus sea-area could be exploited quickly.

- They could be easily disassembled or totally withdrawn if the sea space is required in the future as well as being able of expanding as they acquire modular forms.

- The facilities and the structure of the VLFS are protected to avoid harmful seismic shocks where their bases are fundamentally isolated.

- They do not suffer from a settlement gap because of the reclaimed soil consolidation.

- They have constant situations in consideration to the water surface and therefore enabling small ships and vessels to come along to be used as docks and ports. 
- Their position in seaside waters offer an attractive form in the water, making them an appropriate fit for future developments related to leisure, activities and water sport events.

\subsection{Outline and Summary}

In this chapter, the SLR challenges that the mega-deltas were covered. This chapter targets the Nile Delta and discusses the SLR scenarios, land submergence areas, number of people affected, associated climate change effects on the socio-economic areas in coastal regions, impacts on coral reefs in vulnerable areas, types of coastal management options and their costs.

The chapter demonstrates the impacts of SLR on Egypt's coastlines, future SLR impacts, adaptation solutions executed, and offering floating structures as a means to tackle them. Thus far, no systematic VLFS research has been considered in Egypt regarding undertaking the rising seas effects in the Nile Delta as the government still rely on old fashioned and traditional land reclamation solutions.

This chapter proposes that artificial islands and floating structures may currently be ideal solutions to protect the underwater world heritage historical monuments, properties and sites of Pharaonic, Greek, Roman, and Christian as listed by the UNESCO can not be replaced, as well as for safeguarding Egypt's coastal sovereignty. This study is designed to asses two hypotheses: the Nile Delta's coastlines will eventually be submerged where land reclamation approaches practiced only offer short-term solutions; and that floating structures offer the optimum solution for safeguarding Egypt's coastal sovereignty when addressing land subsidence problems. Former studies show that VLFS developed through the last decades concluding that it's the most sustainable solution, favouring it to old fashioned and 
traditional land reclamation solutions as it may offer a cost-effective possibility where there is a big water depth as well as not disturbing the nearshore marine ecosystem. However, no studies have dealt with VLFS as a solution for the Nile Delta's coastlines, and since VLFS do not look like working in every case, therefore, analyzing Egypt's coastlines for reaching the most vulnerable and suitable sites is crucial for advancing our understandings on VLFS.

To conclude, this study aims to analyze the Nile Delta's coastlines to find out the most vulnerable sites, proposing that VLFS is the optimum solution for Egypt's Nile Delta. Therefore, this thesis develops our understanding of VLFS for tackling the rising seas challenges in Egypt and proposes architectural design guidelines and concept proposal for a floating community model for the Nile Delta. 


\section{Chapter 3}

\section{RESEARCH METHODOLOGY}

\subsection{Research Outline}

The subject of this thesis is to analyze the impacts of SLR on Egypt's coasts and to suggest floating structures to challenge such issue. Recently, adaptation approaches and mitigation solutions regarding undertaking SLR impacts on coastal areas, small islands and low-lying areas have significantly improved. The argument is that old fashioned and traditional land reclamation solutions are not a practical on the long-term solution for their many disadvantages. In recent decades, VLFS has become appealing to architects, urban and city planners, and civil engineers as it has developed to be an effective approach against SLR impacts. Researches show that they're more sustainable as it offers a cost-effective solution where there is a big water depth and preserve the nearshore maritime ecosystem as they don't disturb sea currents or silt-up deep harbours. To date, no systematic floating structures investigation has been considered in Egypt regarding tackling SLR impacts in the Nile Delta as the government still rely on old fashioned and traditional land reclamation solutions. This study analyzes the Nile Delta's coasts to spot the most vulnerable sites, advances our 
understanding of floating structures for undertaking the rising seas challenges to explore if artificial islands and floating structures may present the optimum solution to Egypt's vulnerable coastal areas like Abu-Qir Bay to protect the underwater world heritage historical monuments, properties and sites of Pharaonic, Greek, Roman, and Christian as listed by the UNESCO can not be replaced, as well as for the preservation of Egypt's coastal sovereignty and how could it be applied for the Nile Delta coasts. Since the main driving cause for the thesis is to a provide a new approach on how to sustain the pressure of the rising seas on the coastal settlements, this thesis proposes a floating community concept proposal for the Nile Delta and hopes to promote for further advancements to be done to raise awareness from the local authorities and investors since until now there is no systematic floating structures investigation has been considered in Egypt regarding tackling SLR impacts in the Nile Delta as the government still rely on old fashioned and traditional land reclamation solutions. Therefore, this study advances our understanding of floating structures for undertaking the rising seas challenges.

This investigation is set to test the assumption that old fashioned solutions like traditional land reclamation methods that are executed in vulnerable areas in Egypt are not a practical long-term solution as well as having various disadvantages. This study analyzes and extends the idea that VLFS are more sustainable solution preferring it to old fashioned and traditional land reclamation solutions as it offers a sustainable and flexible solution. Case studies on the Nile delta are created to show how VLFS could be the ideal solution for such low-lying region. Upon structural and Site analysis, a floating community concept proposal for the Nile Delta is created where Cradle to Cradle Building Charter has defined the guidelines for sustainable environmental design. 


\subsection{Data and Methods}

This thesis has composed theoretical contributions and reliable secondary data regarding the impacts of SLR on low-lying coastal areas in the world like the Nile Delta. Using local, national, and international data to explore the impacts of SLR on Egypt's coasts and to propose floating structures to tackle them. Nowadays, several studies have focussed on floating structures when addressing land subsidence problems, specifically in small islands and low-lying areas around the world like the Nile Delta. To provide a valuable long-term sustainable solution for tackling SLR impacts on the Nile Delta, therefore state-of-the-art solutions should be practically considered. Such system should be sustainable, cost-effective, movable, adaptable, and feasible.

The empirical part of this thesis was conducted in the summer of 2018. This thesis was conducted in Egypt at Abu-Qir Bay as such SLR challenges could not be solved without site analysis because not every solution could be applied in any site. Therefore, the first step is to define the most vulnerable areas in Egypt. The data gathered from but not limited to the Intergovernmental Panel on Climate Change (ICPP, 2014; Ipcc, 2007), Tolba \& Saab (2009), and UNFCCC (2007) have provided the necessary data on Egypt as a whole about SLR challenges like land subsidence to create scenarios for land submergence areas, number of people affected, different coastal management solutions implemented. The information gathered from but not limited to Tolba \& Saab (2009) and ICPP (2014) have provided the necessary information about the adaptation approaches and mitigation solutions practiced in Egypt.

Omar \& Moussa (2016) discusses Egypt's water ambitious plans, while Atlas of Africa Energy Resources (UNEP, 2017) has significantly shaped the data on Egypt's energy 
resources, production and consumption. Andrisano et al. (2018) have helped achieving the required sustainable goals. Gebremichael et al. (2018) has helped identifying land deformation regions and sea encroachment coastal regions in the Nile Delta of Egypt.

Once the most vulnerable areas in the Nile Delta's coastline and approaches practiced has been identified and analyzed in each aspect, VLFS is analyzed as the optimum solution for such site. Wang \& Tay (2011), and (Wang et al., 2008) have stated their preference of floating structures over old land reclamation solutions. The thesis reviews findings of various types of floating structures projects where it analyzes and analyzes their features. The data gathered from but not limited to Suzuki et al. (2006), Wang et al. (2008), Clauss, Lehmann, \& Östergaard (1992), Moan (2004), Wang \& Tay (2011) were vital for defining the best location in the Nile Delta for creating a realistic VLFS concept as much as possible.

Including but not limited to Suzuki et al. (2006) was crucial for understanding VLFS's applications, developments, environment, design, structural integrity, strengths, and failure behaviour. Including but not limited to Wang et al. (2008) helped analyzing VLFS's advantages, types, design, and breakwaters. Including but not limited to Clauss et al. (1992) and Moan (2004) were essential for concluding VLFS's analysis. Including but not limited to Wang \& Tay (2011) which was vital for defining VLFS's developments, connectors, hydroelastic response, and mooring systems.

Having analyzed floating structures and site analysis, an attempt will be made to create a floating community concept proposal for the Nile Delta. Suzuki et al. (2006) have provided the required amount of information regarding load displacements, design, and the optimum size for floating structures. The guidelines and principles for achieving a sustainable floating community concept for Egypt is based on McDonough \& Braungart (2010). However, the criteria selected for the concept were influenced by Dal Bo Zanon, Roeffen, Czapiewska, de 
Graaf-Van Dinther, \& Mooij (2017). Andrisano et al. (2018) have contributed in achieving the sustainable objectives for the floating community concept proposal via their strategy for multidisciplinary methods and technological tools for the sustainable development and their employment for smart and sustainable cities.

The guidelines methodology for the concept development took place in four main steps that are based on the framework set by Sääskilahti et al. (2005), where they led the path for developing a sustainable floating concept:

- Determining the changing features that influence the concept (Subject, timescale, possible operator(open), as well as determining the motives for the concept).

- Creating the Scenario (The C2C Building Charter as a scenario and frame for the concept project).

- Determining the project needs (Based on the study conclusions and reviews).

- Creating the concept (Define the outline of the project based on all the inputs).

Upon setting the sustainable concept proposal development standards, the floating structures standards were adopted from the British Columbia Float Home Standard (2015), while the archetypal structural design outline adapted from Suzuki et al. (2006) is set to create more precise architectural design guidelines, strategies, and floating community proposal for the Nile Delta's coastline most vulnerable area. Throughout the design background study phase of the thesis, different driving forces affected the design where global, local, environmental, social, technical and biotechnological advances inputs have shaped the missing pieces for the concept proposal. To answer the research questions and test the hypotheses, the study conducted four researches using state-of-the-art data on SLR, 
adaptation approaches, mitigation solutions, and VLFS research as shown in Tables 3.1, 3.2,

\section{$3.3,3.4,3.5,3.6,3.7$, and 3.8 .}

\begin{tabular}{|c|c|c|c|c|}
\hline $\begin{array}{l}\text { Researchable } \\
\text { questions/objectives }\end{array}$ & $\begin{array}{l}\text { Information } \\
\text { required }\end{array}$ & $\begin{array}{l}\text { Scope } \\
\text { methodology }\end{array}$ & Limitations & $\begin{array}{l}\text { Probable output of } \\
\text { this evaluation }\end{array}$ \\
\hline $\begin{array}{l}\text { What are the most } \\
\text { vulnerable sites to } \\
\text { SLR impacts in the } \\
\text { Nile Delta's } \\
\text { coastline? } \\
\text { To identify the } \\
\text { impacts of SLR on } \\
\text { the Nile delta } \\
\text { region in terms of } \\
\text { people affected, } \\
\text { land subsidence on } \\
\text { the infrastructure, } \\
\text { and land } \\
\text { submergence area. } \\
\text { To test hypothesis I. }\end{array}$ & 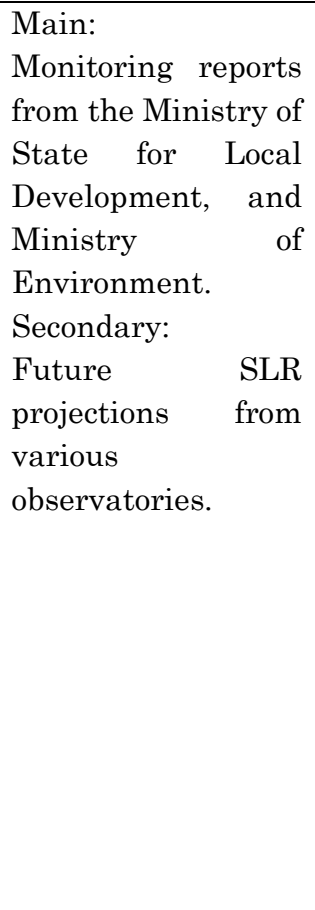 & $\begin{array}{l}\text { Time } \\
\text { Analysis and } \\
\text { Ranking: } \\
\text { Such analysis is a } \\
\text { compilation of } \\
\text { examinations of } \\
\text { precise data items } \\
\text { acquired through } \\
\text { frequent } \\
\text { measurements over } \\
\text { periods of time. } \\
\text { Such analysis is } \\
\text { aimed to update } \\
\text { SLR data on the } \\
\text { Nile Delta. } \\
\text { V\&A assessment: } \\
\text { V\&A assessors at a } \\
\text { spatial and } \\
\text { temporal scale to } \\
\text { create SLR } \\
\text { scenarios. }\end{array}$ & $\begin{array}{l}\text { Probable data value } \\
\text { and reliability } \\
\text { concerns. } \\
\text { Uncertainties and } \\
\text { assumptions } \\
\text { Lack of consistency } \\
\text { on the information } \\
\text { level with the } \\
\text { possible challenges } \\
\text { caused by climate } \\
\text { change and SLR } \\
\text { impacts zones. } \\
\text { Lack of a local long- } \\
\text { term SLR scenarios. }\end{array}$ & $\begin{array}{l}\text { Identify } \\
\text { impacts on the Nile } \\
\text { Delta. } \\
\text { Identify probable } \\
\text { risks, also } \\
\text { properties } \\
\text { resources that are } \\
\text { vulnerable to such } \\
\text { risks. }\end{array}$ \\
\hline
\end{tabular}

7 Table 3.1: The framework for the first study in the research methodology process.

\begin{tabular}{|c|c|c|c|c|}
\hline $\begin{array}{l}\text { Researchable } \\
\text { questions/objectives }\end{array}$ & $\begin{array}{l}\text { Information } \\
\text { required }\end{array}$ & $\begin{array}{l}\text { Scope } \\
\text { methodology }\end{array}$ & as & $\begin{array}{l}\text { Probable output of } \\
\text { this evaluation }\end{array}$ \\
\hline $\begin{array}{l}\text { To identify the most } \\
\text { vulnerable sites to } \\
\text { SLR in the Nile } \\
\text { Delta. } \\
\text { To identify } \\
\text { adaptation } \\
\text { approaches } \\
\text { practiced and main } \\
\text { topographic } \\
\text { characteristics that } \\
\text { influence flood } \\
\text { levels and } \\
\text { permanent } \\
\text { inundation of } \\
\text { lowlands by SLR } \\
\text { impacts in most } \\
\text { vulnerable sites to } \\
\text { SLR and their }\end{array}$ & $\begin{array}{l}\text { Main: } \\
\text { Geological plans } \\
\text { from the Egyptian } \\
\text { Ministry } \\
\text { Planning } \\
\text { Monitoring and } \\
\text { Administrative } \\
\text { reform } \\
\text { Monitoring reports } \\
\text { from Ministry of } \\
\text { State for Local } \\
\text { Development, and } \\
\text { Ministry of } \\
\text { Environment. } \\
\text { Secondary: } \\
\text { Studies on SLR } \\
\text { impacts and } \\
\text { adaptation }\end{array}$ & $\begin{array}{l}\text { Vulnerability } \\
\text { assessment and } \\
\text { ranking: } \\
\text { Such analysis is } \\
\text { concerned with the } \\
\text { probabilities of } \\
\text { decreasing the } \\
\text { negative impacts } \\
\text { and of refining the } \\
\text { capability. } \\
\text { Using geological } \\
\text { plans to create cross } \\
\text { sections of } \\
\text { vulnerable areas to } \\
\text { help assessing the } \\
\text { vulnerability levels } \\
\text { of each site. }\end{array}$ & $\begin{array}{l}\text { Lack of local data } \\
\text { that lead to } \\
\text { uncertainties and } \\
\text { assumptions. } \\
\text { Difficulties to } \\
\text { measure potential } \\
\text { loss and occurrence } \\
\text { probability. }\end{array}$ & $\begin{array}{l}\text { Assessment on } \\
\text { vulnerable areas } \\
\text { and ranking. } \\
\text { Evaluation } \\
\text { present and future } \\
\text { risk to identify } \\
\text { major risks. } \\
\text { Evaluation } \\
\text { adaptation } \\
\text { solutions } \\
\text { mitigation } \\
\text { strategies practiced. } \\
\text { Assessment on the } \\
\text { value } \\
\text { effectiveness } \\
\begin{array}{l}\text { coastal of } \\
\text { management }\end{array}\end{array}$ \\
\hline
\end{tabular}




\begin{tabular}{|l|l|l|l|l|}
\hline evaluation in & solutions practiced & Such assessment & & measures already \\
respect to Egypt's & such as the IPPC, & would pave the way & & implemented. \\
most vulnerable & NOAA, UNEP, & for a successful & & \\
regions identified. & UNFCCC, AFED & V\&A assessment. & & \\
& reports, and others. & & & \\
\hline
\end{tabular}

8 Table 3.2: The framework for the second study in the research methodology process.

\begin{tabular}{|c|c|c|c|c|}
\hline $\begin{array}{l}\text { Researchable } \\
\text { questions/objectives }\end{array}$ & $\begin{array}{l}\text { Information } \\
\text { required }\end{array}$ & $\begin{array}{ll}\text { Scope } & \text { and } \\
\text { methodology } & \end{array}$ & Limitations & $\begin{array}{l}\text { Probable output of } \\
\text { this evaluation }\end{array}$ \\
\hline $\begin{array}{l}\text { To assess the most } \\
\text { vulnerable area } \\
\text { identified } \\
\text { evaluate } \\
\text { impacts on people, } \\
\text { buildings, and } \\
\text { infrastructure in } \\
\text { the most vulnerable } \\
\text { site. }\end{array}$ & $\begin{array}{l}\text { Main: } \\
\text { Tidal gauges data } \\
\text { from Alexandria } \\
\text { governorate and } \\
\text { Ministry of } \\
\text { Environment. } \\
\text { Demographic and } \\
\text { other data from } \\
\text { Egyptian Ministry } \\
\text { of Housing, } \\
\text { Utilities and Urban } \\
\text { Communities, } \\
\text { Ministry of State } \\
\text { for Local } \\
\text { Development, and } \\
\text { Ministry of } \\
\text { Agriculture and } \\
\text { Land Reclamation. } \\
\text { Secondary: } \\
\text { Studies on SLR } \\
\text { impacts and } \\
\text { adaptation } \\
\text { solutions practiced } \\
\text { such as the UNEP, } \\
\text { UNFCCC, AFED, } \\
\text { IEASM reports. }\end{array}$ & $\begin{array}{l}\text { Site analysis: } \\
\text { Time Series } \\
\text { Analysis and } \\
\text { Ranking: } \\
\text { Such analysis is a } \\
\text { compilation of } \\
\text { examinations of } \\
\text { precise data items } \\
\text { acquired through } \\
\text { frequent } \\
\text { measurements over } \\
\text { periods of time to } \\
\text { improve the } \\
\text { capability to coping } \\
\text { with future } \\
\text { situations. } \\
\text { V\&A assessment: } \\
\text { V\&A assessors at a } \\
\text { spatial and } \\
\text { temporal scale to } \\
\text { create SLR } \\
\text { scenarios. } \\
\text { Analysis of existing } \\
\text { and practiced } \\
\text { sustainability } \\
\text { approaches \& self } \\
\text { sufficiency in terms } \\
\text { of water, } \\
\text { ventilation, waste } \\
\text { flow, and } \\
\text { electricity. }\end{array}$ & $\begin{array}{l}\text { Lack of local data } \\
\text { that lead to } \\
\text { uncertainties and } \\
\text { assumptions. } \\
\text { Difficulties to } \\
\text { measure potential } \\
\text { loss and occurrence } \\
\text { probability. }\end{array}$ & $\begin{array}{l}\text { Identify SLR } \\
\text { impacts on } \\
\text { Alexandria by the } \\
\text { sequence of } \\
\text { observations. } \\
\text { Projecting } \\
\text { (estimating SLR } \\
\text { impacts on } \\
\text { Alexandria by the } \\
\text { sequence of } \\
\text { observations). } \\
\text { Rank different } \\
\text { sectors affected like } \\
\text { people, land, } \\
\text { buildings, and } \\
\text { infrastructure. } \\
\text { Propose adaptation } \\
\text { approaches. }\end{array}$ \\
\hline
\end{tabular}

9 Table 3.3: The framework for the third study in the research methodology process.

\begin{tabular}{|c|c|c|c|c|}
\hline $\begin{array}{l}\text { Researchable } \\
\text { questions/objectives }\end{array}$ & $\begin{array}{l}\text { Information } \\
\text { required }\end{array}$ & $\begin{array}{ll}\text { Scope } & \text { and } \\
\text { methodology } & \end{array}$ & Limitations & $\begin{array}{l}\text { Probable output of } \\
\text { this evaluation }\end{array}$ \\
\hline $\begin{array}{l}\text { To identify the most } \\
\text { sustainable and } \\
\text { cost-effective } \\
\text { solution against } \\
\text { SLR impacts. }\end{array}$ & $\begin{array}{l}\text { Main: } \\
\text { Reports from the } \\
\text { Egyptian Ministry } \\
\text { of Planning } \\
\text { Monitoring and } \\
\text { Administrative } \\
\text { reform; Ministry of } \\
\text { State for Local }\end{array}$ & $\begin{array}{l}\text { Evaluation design } \\
\text { matrix: } \\
\text { Evaluation of the } \\
\text { performance of ten } \\
\text { selected types of } \\
\text { adaptation and } \\
\text { mitigation solution }\end{array}$ & $\begin{array}{l}\text { No local guides for } \\
\text { some analyzed } \\
\text { adaptation and } \\
\text { mitigation } \\
\text { solutions. } \\
\text { Uncertainties and } \\
\text { assumptions. }\end{array}$ & $\begin{array}{lr}\text { Ranking of } & \text { the } \\
\text { efficiency } & \text { of } \\
\text { adaptation } & \\
\text { approaches } & \text { and } \\
\text { mitigation solutions } \\
\text { against } & \text { SLR } \\
\text { impacts. } & \end{array}$ \\
\hline
\end{tabular}




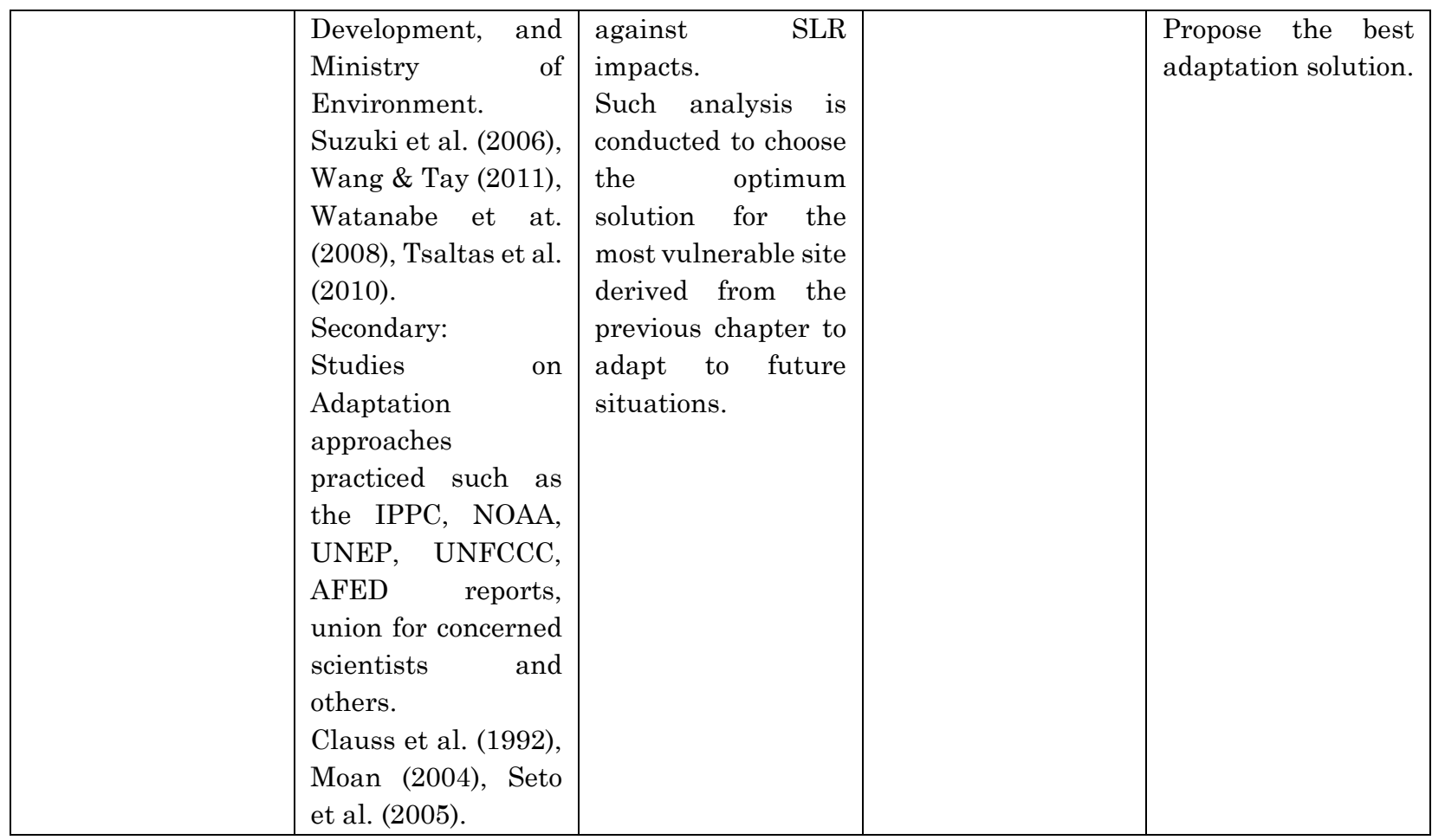

10 Table 3.4: The framework for the fourth study in the research methodology process.

\begin{tabular}{|c|c|c|c|c|}
\hline $\begin{array}{l}\text { Researchable } \\
\text { questions/objectives }\end{array}$ & $\begin{array}{l}\text { Information } \\
\text { required }\end{array}$ & $\begin{array}{ll}\text { Scope } & \text { and } \\
\text { methodology } & \end{array}$ & Limitations & $\begin{array}{l}\text { Probable output of } \\
\text { this evaluation }\end{array}$ \\
\hline $\begin{array}{l}\text { Analyze different } \\
\text { floating community } \\
\text { cases in respect to } \\
\text { Egypt's most } \\
\text { vulnerable regions. }\end{array}$ & $\begin{array}{l}\text { Main: } \\
\text { British Columbia } \\
\text { Float Home } \\
\text { Standard (2015). } \\
\text { Suzuki et al. (2006), } \\
\text { Wang \& Tay (2011), } \\
\text { Watanabe et at. } \\
\text { (2008), Tsaltas et al. } \\
\text { (2010). } \\
\text { Secondary: } \\
\text { Ministry of State for } \\
\text { Local Development. } \\
\text { Clauss et al. (1992), } \\
\text { Moan (2004), Seto } \\
\text { et al. (2005), } \\
\text { (United Nations } \\
\text { Framework } \\
\text { Convention Change } \\
\text { Climate, 2016). }\end{array}$ & $\begin{array}{l}\text { Comparative } \\
\text { analysis: } \\
\text { In depth eight case } \\
\text { studies on eight } \\
\text { different real and } \\
\text { conceptual cases of } \\
\text { floating community } \\
\text { with similar } \\
\text { characteristics to } \\
\text { Egypt. } \\
\text { Such analysis is } \\
\text { concerned with the } \\
\text { problems addressed } \\
\text { and methods } \\
\text { followed of each } \\
\text { floating community } \\
\text { case to conclude the } \\
\text { design objectives } \\
\text { when designing } \\
\text { floating cities } \\
\begin{array}{l}\text { against SLR } \\
\text { impacts to adapt to } \\
\text { future situations. }\end{array}\end{array}$ & $\begin{array}{l}\text { No local guides for } \\
\text { VLFS. } \\
\text { Absence of global } \\
\text { authorised context } \\
\text { regarding their } \\
\text { implementation } \\
\text { and usage. }\end{array}$ & $\begin{array}{l}\text { Identify design } \\
\text { approaches and } \\
\text { methods followed } \\
\text { against SLR. } \\
\text { Ranking of design } \\
\text { approaches and } \\
\text { methods followed } \\
\text { against SLR. } \\
\text { Propose the most } \\
\text { important } \\
\text { approaches } \\
\text { strategies. }\end{array}$ \\
\hline
\end{tabular}

11 Table 3.5: The framework for the fifth study in the research methodology process. 


\begin{tabular}{|c|c|c|c|c|}
\hline $\begin{array}{l}\text { Researchable } \\
\text { questions/objectives }\end{array}$ & $\begin{array}{l}\text { Information } \\
\text { required }\end{array}$ & $\begin{array}{ll}\text { Scope } & \text { and } \\
\text { methodology } & \\
\end{array}$ & Limitations & $\begin{array}{l}\text { Probable output of } \\
\text { this evaluation }\end{array}$ \\
\hline 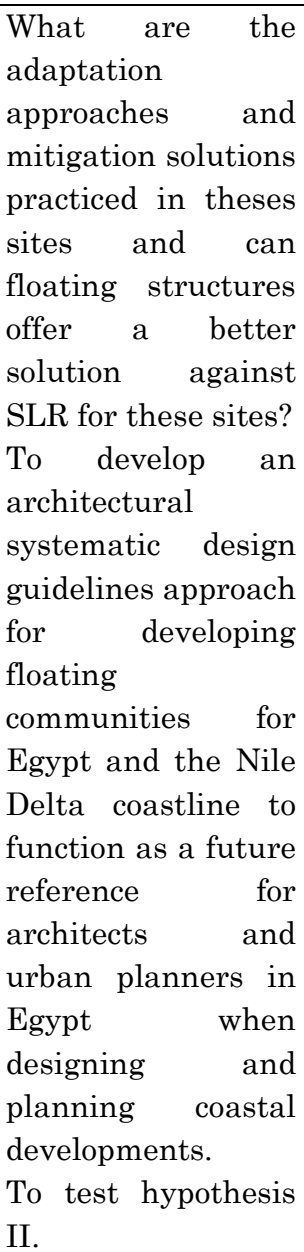 & $\begin{array}{l}\text { Main: } \\
\text { Program and } \\
\text { archetypal } \\
\text { structural design } \\
\text { outline for } \\
\text { designing VLFS. } \\
\text { Strategies and } \\
\text { methods on data } \\
\text { regarding mobility, } \\
\text { dynamic geography, } \\
\text { expanding and } \\
\text { development, } \\
\text { survivability/ } \\
\text { durability, security, } \\
\text { and water life for } \\
\text { building on water. } \\
\text { Suzuki et al. (2006), } \\
\text { Wang \& Tay (2011), } \\
\text { Watanabe et at. } \\
\text { (2008), Tsaltas et al. } \\
\text { (2010). } \\
\text { Secondary: } \\
\text { Czapiewska, Dal Bo } \\
\text { Roeffen, Draaf } \\
\text { Zanon, \& De Grat } \\
\text { (2013). }\end{array}$ & $\begin{array}{l}\text { Comparative } \\
\text { analysis for } \\
\text { different } \\
\text { approaches and } \\
\text { methods for floating } \\
\text { cities: } \\
\text { Such analysis is } \\
\text { concerned with } \\
\text { approaches and } \\
\text { methods followed } \\
\text { when designing } \\
\text { floating structures } \\
\text { in respect to Egypt's } \\
\text { criteria and } \\
\text { characteristics of } \\
\text { the Nile Delta. } \\
\text { It is aimed is to } \\
\text { define guidelines for } \\
\text { building on water to } \\
\text { cope with future } \\
\text { situations }\end{array}$ & $\begin{array}{l}\text { Some uncertainties } \\
\text { and assumptions. } \\
\text { The results should } \\
\text { not be generalized } \\
\text { in any low-lying } \\
\text { coastal area } \\
\text { impacted by SLR in } \\
\text { Egypt or anywhere. }\end{array}$ & $\begin{array}{l}\text { Identify different } \\
\text { types for each } \\
\text { approach. } \\
\text { Assess each } \\
\text { objective. } \\
\text { Ranking objectives } \\
\text { for the most } \\
\text { vulnerable sites. } \\
\text { Compare sites for } \\
\text { optimum types } \\
\text { ranking. } \\
\text { Propose design } \\
\text { types for each } \\
\text { design objective for } \\
\text { the Nile Delta. } \\
\text { To generate } \\
\text { architectural } \\
\text { design guidelines } \\
\text { for Egypt }\end{array}$ \\
\hline
\end{tabular}

12 Table 3.6: The framework for the sixth study in the research methodology process.

\begin{tabular}{|c|c|c|c|c|}
\hline $\begin{array}{l}\text { Researchable } \\
\text { questions/objectives }\end{array}$ & $\begin{array}{l}\text { Information } \\
\text { required }\end{array}$ & $\begin{array}{ll}\text { Scope } & \text { and } \\
\text { methodology } & \end{array}$ & Limitations & $\begin{array}{l}\text { Probable output of } \\
\text { this evaluation }\end{array}$ \\
\hline $\begin{array}{l}\text { To set an expanding } \\
\text { dynamics design } \\
\text { guidelines approach } \\
\text { for developing } \\
\text { floating } \\
\text { communities for } \\
\text { Egypt's coastlines to } \\
\text { function as a future } \\
\text { reference for } \\
\text { architects and } \\
\text { urban planners to } \\
\text { be considered in } \\
\text { Egypt when } \\
\text { designing and }\end{array}$ & $\begin{array}{l}\text { Main: } \\
\text { Laws, regulations } \\
\text { and requirements } \\
\text { for building on } \\
\text { water in Egypt from } \\
\text { database of } \\
\text { Ministry of State for } \\
\text { Local Development. } \\
\text { British Columbia } \\
\text { Float Home } \\
\text { Standard (2015). } \\
\text { Czapiewska et al. } \\
\text { (2013). }\end{array}$ & $\begin{array}{l}\text { Content analysis for } \\
\text { expanding } \\
\text { dynamics of floating } \\
\text { cities: } \\
\text { Such analysis is } \\
\text { concerned with the } \\
\text { expanding } \\
\text { dynamics that are } \\
\text { various stages when } \\
\text { designing floating } \\
\text { structures in } \\
\text { respect to Egypt's } \\
\text { criteria and } \\
\text { characteristics of } \\
\text { the Nile Delta. }\end{array}$ & $\begin{array}{l}\text { Some uncertainties } \\
\text { and assumptions. } \\
\text { The results should } \\
\text { not be generalized } \\
\text { in to a bigger region } \\
\text { or other cities. } \\
\text {. }\end{array}$ & $\begin{array}{l}\text { Identify different } \\
\text { types for level } \\
\text { required. } \\
\text { Assess each level. } \\
\text { Ranking types for } \\
\text { the most vulnerable } \\
\text { sites. } \\
\text { Compare levels for } \\
\text { optimum types } \\
\text { ranking. } \\
\text { Propose design } \\
\text { types for each } \\
\text { expanding dynamic } \\
\text { level for the Nile } \\
\text { Delta. }\end{array}$ \\
\hline
\end{tabular}




\begin{tabular}{|l|l|l|l|l|}
\hline $\begin{array}{l}\text { planning coastal } \\
\text { developments. }\end{array}$ & $\begin{array}{l}\text { It is aimed to add to } \\
\text { the guidelines for } \\
\text { building on water to } \\
\text { cope with future } \\
\text { situations. }\end{array}$ & & \\
& & & \\
\hline
\end{tabular}

13 Table 3.7: The framework for the seventh study in the research methodology process.

\begin{tabular}{|c|c|c|c|c|}
\hline $\begin{array}{l}\text { Researchable } \\
\text { questions/objectives }\end{array}$ & $\begin{array}{l}\text { Information } \\
\text { required }\end{array}$ & $\begin{array}{ll}\text { Scope } & \text { and } \\
\text { methodology } & \\
\end{array}$ & Limitations & $\begin{array}{l}\text { Probable output of } \\
\text { this evaluation }\end{array}$ \\
\hline $\begin{array}{l}\text { How to implement } \\
\text { floating structures } \\
\text { in the Nile Delta's } \\
\text { most vulnerable } \\
\text { coastline sites to } \\
\text { SLR impacts? } \\
\text { To offer a floating } \\
\text { community concept } \\
\text { proposal for the Nile } \\
\text { Delta's most } \\
\text { vulnerable area } \\
\text { identified. } \\
\text { To identify the } \\
\text { optimum materials } \\
\text { and sustainability } \\
\text { approaches, and } \\
\text { project feasibility. }\end{array}$ & $\begin{array}{l}\text { Building on water } \\
\text { codes and } \\
\text { regulations. } \\
\text { British Columbia } \\
\text { Float Home } \\
\text { Standard (2015). } \\
\text { Egyptian Ministry } \\
\text { of Housing, Utilities } \\
\text { and Urban } \\
\text { Communities. } \\
\text { Design methods and } \\
\text { strategies and } \\
\text { Expanding } \\
\text { dynamics } \\
\text { approaches. } \\
\text { Previous empirical } \\
\text { and analytical } \\
\text { chapters. } \\
\text { Structural } \\
\text { framework } \\
\text { VLFS. } \\
\text { Suzuki et al. (2006). } \\
\text { Watanabe et at. } \\
\text { (2008). } \\
\text { Sustainability } \\
\text { guidelines. } \\
\text { Cradle to Cradle } \\
\text { Building Charter by } \\
\text { McDonough } \\
\text { Braungart (2010). } \\
\text { Database } \\
\text { Ministry of State for } \\
\text { Local Development. } \\
\text { Database } \\
\text { Ministry } \\
\text { Environment. }\end{array}$ & $\begin{array}{l}\text { Application of the } \\
\text { findings of the } \\
\text { previous three } \\
\text { empirical and } \\
\text { analytical chapters } \\
\text { of site analysis, } \\
\text { adaptation } \\
\text { approaches, } \\
\text { mitigation } \\
\text { solutions, and } \\
\text { floating structures. } \\
\text { It is aimed to define } \\
\text { a floating } \\
\text { community model } \\
\text { for Abu-Qir Bay. }\end{array}$ & $\begin{array}{l}\text { Uncertainties and } \\
\text { assumptions. } \\
\text { The results should } \\
\text { not be generalized } \\
\text { in any low-lying } \\
\text { coastal area } \\
\text { impacted by SLR in } \\
\text { Egypt or anywhere. } \\
\text { No local guides for } \\
\text { VLFS. } \\
\text { Absence of global } \\
\text { authorised context } \\
\text { regarding their } \\
\text { implementation } \\
\text { and usage. }\end{array}$ & $\begin{array}{l}\text { Building on water } \\
\text { approaches and } \\
\text { regulations to serve } \\
\text { as a framework for } \\
\text { future references. } \\
\text { A genuine, } \\
\text { practical, } \\
\text { sustainable, and } \\
\text { self-efficient } \\
\text { floating community } \\
\text { concept proposal for } \\
\text { Egypt. }\end{array}$ \\
\hline
\end{tabular}

14 Table 3.8: The framework for the eighth study in the research methodology process. 


\subsection{Design Methodology and Guidelines for Case Study}

Throughout the background study phase of the thesis, different driving forces affected the project design where global, local, environmental, social, technical and biotechnological advances inputs have shaped the missing pieces for the concept proposal. Different scenarios were used here the thesis focusses on generating one scenario perception with advanced features on environmental innovations as well as for the entire system (Sääskilahti et al., 2005). As the C2C Building Charter embraces fundamentals as one kind of scenario approach method therefore, one scenario with several options rather than several scenarios was done. Cradle to Cradle (C2C) environmental design principles as well as the C2C Building Charter and theories were initially made by McDonough \& Braungart (2010). C2C Building Charter was specifically established for the built environment and fits visionary conceptual projects, as it has strong guiding philosophies that cover all built environment areas in principal level. In this thesis, the focal point is the $\mathrm{C} 2 \mathrm{C}$ Building Charter ideology and the following four guiding philosophies.

According to the "C2C Building Charter" (McDonough \& Braungart, 2010), the guiding principles are:

- "Incorporate materials that are technical and biological nutrients that can become safely reusable.

- Measurably use renewable energy. Examples of renewable energy include solar thermal, ground based and air-based heat exchange, wind, biomass, hydro and, photo-voltaic.

- Actively and measurably support biodiversity according to well established biological tools for measuring species diversity. 
- Anticipate evolution and change, incorporating strategies and approaches that enhance the ability for the building to adapt to a variety of uses over time.

(McDonough \& Braungart, 2010)”

McDonough \& Braungart (2010) put various features in the C2C Building Charter which has the guiding principles in the future floating community concept proposal. In general, the C2C Building Charter leads to the see the greater image of systems, products and methods rather than focusing on one thing only each time. They spotlight the valuable thinking and eco-effectiveness and refining each building system quality, products and methods. C2C Building Charter also inspire to brainstorm materials options rather than energy sources difficulties and leads to design building systems and developments according to their intended and proposed use (McDonough \& Braungart, 2010).

McDonough \& Braungart (2010) propose in many ways to imitate from nature and get inspired by it and its natural cycles. C2C ideology inspire for inventive answers in the recyclable technical and biological materials fields. C2C philosophies inspire to use materials, biological biotechnology mimicking the nature in its systems and cycles as biomimicry encourages and substituting outdated technologies with biotechnology solutions (Cohen \& Vogel, 2010; Visser \& Benyus, 2013). C2C philosophy could be an ideal mean to answer for the environmental challenges that we face in the built environment. The design method supports well the future floating concept design placed to the Nile Delta as the officials are aware and green concerned as demonstrated in future environmental strategies due to its limited resources. The $\mathrm{C} 2 \mathrm{C}$ Building Charter explains that the goal of architects should be to minimalize the negative impact on the environment by trying to decrease the environmental impact (McDonough \& Braungart, 2010). 


\subsubsection{Research Methodology for Sustainability}

- "Use building materials whose contents are measurably defined in Cradle to Cradle terms of chemical contents, effects on air, soil and water, and effects on human health from manufacturing through use and recovery in biological or technical pathways.

- Integrate topsoil production and carbon re-use into structures and landscapes to produce more biomass and soil than before development. Topsoil is defined here as the upper layer of soil, used for growing biomass. Topsoil is a main repository for carbon and for CO2 capture and storage. (Example: green roofs).

- Integrate renewable energy into buildings and area plans so they produce more energy than they use.

- Integrate healthy air production into buildings and area plans so they produce more healthy air than they use.

- Integrate measurable recycling of water and biological nutrients in buildings, landscaping, and spatial plans.

- Support measurable increases in species diversity (Flora and Fauna) according to accepted biological methods, so the area contains more diversity than before development of the building or site.

- Social Fairness: define, quantify and practice social responsibility criteria. Adopt and make publicly available statements regarding social performance goals and demonstrate it will be obtaining a third-party social accreditation.

(McDonough \& Braungart, 2010)” 


\subsection{Constraints, Limitations, and Assumptions}

The thesis evaluates SLR impacts on Egypt and proposes floating structures as a possible long-term, sustainable, and cost-effective adaptation approach. The empirical and analytical findings reported here must measured in the light of some constraints, limitations, and assumptions were set for such approach where such findings must be interpreted with caution and several limitations should be borne in mind.

\subsubsection{Constraints}

This thesis demonstrates an evaluative perspective on SLR impacts on Egypt and proposes floating structures as a means to tackle such phenomenon. As a result of such methodology, some constraints were established to bound the research such as:

- This thesis had several driving forces that have bounded the research with some constraints such as safeguarding historical sites and properties, marine borders, the ecosystem, and the infrastructure and people. Historical: the city of ThonisHeracleion and other unknown underwater submerged priceless world heritage monuments, properties and sites of Pharaonic, Greek, Roman, and Christian as listed by the UNESCO. Borders: To safeguard Egypt's marine borderlines sovereignty. Ecosystem: To protect marine and coral life habitat. People: To safeguard people from building nearshore and risk future Thonis-Heracleion scenario.

- The scenarios that have shaped the most vulnerable areas were only conducted on the lowest lying regions to sea level and the efficiency of the adaptation approaches being practiced in such sites. 
- The research on floating structures and floating communities case studies were bounded by the constraints of the architectural and urbanist roles and not on the levels of geology, civil engineering, marine engineering.

- Designing and employing the mooring system and pathways were investigated to some degree as both superstructures and the mooring systems are proposed. However, such matter is another subject isn't my area of expertise.

- Another challenging matter was the multidisciplinary materials required for the project and the quantity of such materials are not as familiar to someone with my academic background as an industrial engineer who is mostly specialized on exterior vessel design.

- The floating conapt proposal and the architectural design guidelines concluded were also bounded by the constraints of the architectural and urbanist roles. Nevertheless, the practical features of the floating community concept proposal were debated and approved in each level by specialists who had more knowledge in certain technical features of the design.

\subsubsection{Limitations}

The driving reason for attempting to generate architectural design guidelines for floating structures against SLR impacts for the Nile Delta. As a result of this methodology, some limitations that were faced such as:

- Lack of some local data on long-term SLR scenarios, uncertainties and assumptions regarding SLR impacts to measure potential loss and probability of occurrence. Therefore, to obtain the required, practical, and comprehensive results, and to answer 
the first research question and to test the first hypothesis, several observatories were utilized and compared to provide a more precise assessment on SLR scenarios on SLR impacts on the Nile Delta. Furthermore, the methodology for the qualitative risk assessment was adopted from the IDSC (2011), where such method has proven its efficiency over time and would provide the required conclusions in this thesis.

- Since there is no systematic floating structures investigation that has been considered in Egypt regarding tackling SLR impacts in the Nile Delta coastline since the government still rely on old fashioned land reclamation solutions, therefore several local guides on VLFS were not found. Therefore, to obtain the required, practical, and comprehensive results, and to answer the second research question and to test the second hypothesis, basic structural principles regarding floating structure design were adapted from Suzuki et al. (2006) where such strategy and framework has proven previously its quality and would provide the required approach in this thesis.

- Generally, there is an absence of global authorised context regarding their implementation and usage. Therefore, to obtain the required, practical, and comprehensive results, and to answer the second research question and to test the second hypothesis, basic design principles regarding floatation devices were adapted from the British Columbia Building Code Interpretation Committee (2015), where such codes and regulations have proven its efficiency and would provide the required guidelines in this thesis. 


\subsubsection{Assumptions}

As a result of the methodology followed, some assumptions were set to guide the research such as:

- The first assumption is that SLR scenarios are developed to determine the areas and sectors that will be impacted by SLR impacts for future countermeasures.

- The second assumption is that comparative and content analysis on adaptation approaches through the parameters: cost, durability, construction time, life-span, and environmental impact, would determine the most optimum solution. The assumption also gives each of the five parameters equally $20 \%$ each to form an overall evaluation out of $100 \%$.

- The third assumption is that exploratory analysis on VLFS and analysis on cases studies on floating communities would define the required measures, strategies, and systems for building on water in re Nile Delta.

- The fourth assumption is that comparative and content analysis on floating structures design approaches and strategies through the parameters: practicality, feasibility and cost, repositioning, low maintained costs, and minimum design limitations would determine the most ideal methods in each design strategy for the Nile Delta. The assumption also gives each of the five parameters equally $20 \%$ each to form an overall evaluation out of $100 \%$. 


\subsubsection{Alternative Solutions for VLFS}

Further different adaptation solutions alternatives were analyzed such as: building seawalls, raising roads, building storm-water pumps, upgrading sewage systems, using beaches as barriers, creating natural infrastructure, slowing land sink-age, managed retreat, elevating houses, and VLFS. Such solutions were briefly analyzed in this thesis; however, future research should address each of these solutions separately in a wider scale to conclude their pros and cons, site suitability, design limitations, maintenance, feasibility, environmental impact, cost-effectiveness, and their efficiency on the long-term.

\subsection{Analytical Framework and Interpretation}

To answer the research questions and test the hypotheses, the thesis has conducted eight studies through four study phases using state-of-the-art data on SLR, adaptation approaches, mitigation solutions, and VLFS research (see Tables 3.1, 3.2, 3.3, 3.4, 3.5, 3.6, 3.7, and 3.8.).

The first study conducts time series analysis and ranking of impacted areas from SLR on the Nile Delta. The second study conducts a qualitative assessment on SLR impacts for ten case studies and evaluates adaptation solutions practiced in each case. The third study conducts site analysis on the most impacted area identified. The fourth study conducts evaluation design matrix of adaptation and mitigation solutions. The fifth study conducts comparative analysis on eight in depth floating community case studies. The sixth study conducts comparative analysis of different approaches and methods to set guidelines for building on water. The seventh study conducts content analysis to set expanding dynamics guidelines of floating cities. Finally, the eighth study sets architectural design guidelines and floating community concept proposal model for the Nile Delta. 


\section{Phase I}

This phase conducts site analysis to explore the most vulnerable sites in the Nile Delta and investigates coastal management approaches practiced as their properties will provide the required knowledge for selecting the best adaptation approach and/or mitigation solution for the most vulnerable area.

- Time series analysis and ranking for the Nile Delta: Such analysis is a compilation of examinations of precise data items acquired through frequent measurements over periods of time to improve the capability to coping with future situations.

- Qualitative assessment on SLR impacts for ten case studies: Such analysis is concerned with the probabilities of decreasing the negative impacts and of refining the capability to coping with future situations. Qualitative risk analysis helps identifying probable risks, also properties and resources that are vulnerable to such risks. Qualitative analysis demonstrates both the value and effectiveness of coastal management measures already implemented.

- Site and time series analysis and ranking of impacted sectors in Alexandria: Such analysis is concerned with the probabilities of decreasing the negative impacts and of refining the capability to coping with future situations.

\section{Phase II}

- Evaluation design matrix of adaptation approaches and mitigation solutions: Such evaluation is concerned with the evaluation performance of each adaptation approach and mitigation solution against SLR impacts to choose the optimum solution for the most vulnerable site derived from the previous chapter to adapt to future situations. 
- Comparative analysis on eight in depth case studies: Such analysis is concerned with the problems addressed and methods followed of each floating community case to conclude the design objectives and strategies when designing floating cities against SLR impacts to adapt to future situations.

\section{Phase III}

This phase conducts analysis on artificial islands and floating structures to test the hypothesis if it may offer the optimum solution regarding the Nile Delta's most vulnerable coastal regions to SLR.

- Comparative analysis for different approaches and methods for floating cities: Such analysis is concerned with approaches and methods followed when designing floating structures in respect to Egypt's criteria and characteristics of the Nile Delta to offer guidelines for building on water to cope with future situations. The aim is to generate architectural design guidelines for Egypt.

- Content analysis and comparative analysis for expanding dynamics of floating cities: Such analysis is concerned with the expanding dynamics that are various stages when designing floating structures in respect to Egypt's criteria and characteristics of the Nile Delta to add to the guidelines for building on water to cope with future situations. The aim is to generate expanding dynamics strategies and guidelines for building on water in respect to the Nile Delta.

\section{Phase IV}

- This phase applies the conclusions of the previous three empirical and analytical chapters of site analysis, adaptation approaches, mitigation solutions, and VLFS to 
define a floating community model for Abu-Qir Bay and architectural design guidelines for Egypt.

- Concept development and guidelines on floating structures: Such analysis is concerned with approaches and methods followed when designing floating structures in respect to Egypt's criteria and characteristics of the Nile Delta to offer guidelines for building on water to cope with future situations. The aim is to conclude generate a genuine, practical, sustainable, and self-efficient floating community concept proposal for Egypt.

- The concept proposal per say should not be observed as a precise demonstration for a future floating community module, but somewhat a blend of probable factors to guide the future seaside area developments in which floating community projects on other regions could be well-thought-out rather than the costly land recuperation methods.
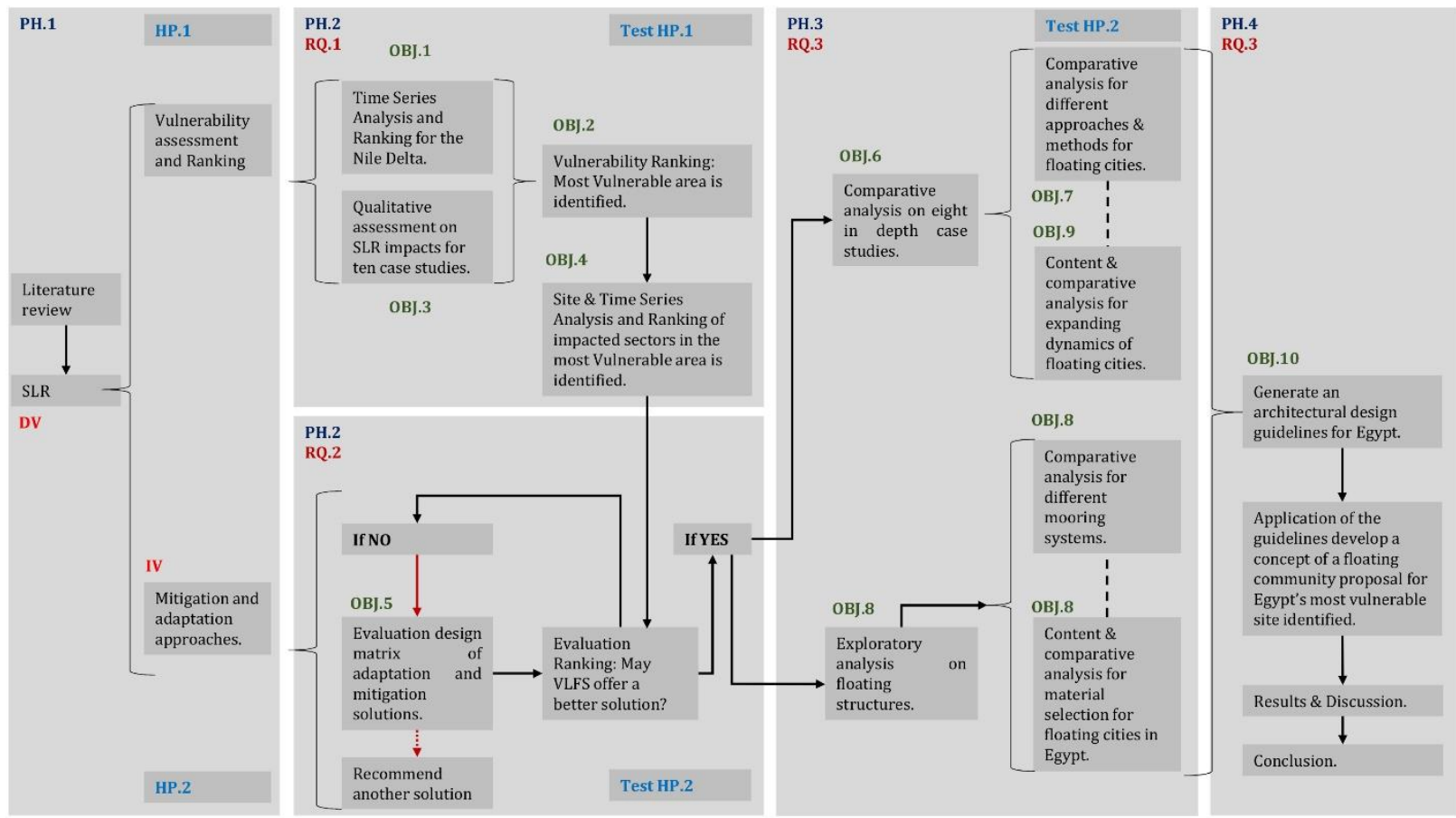

2 Figure 3.1: Analytical framework of the research methodology. 


\section{Chapter 4}

\section{ANALYSIS ON SOLUTIONS TO SLR}

\section{IMPACTS AND FLOATING COMMUNITY}

\section{CASES}

\subsection{Introduction}

This chapter initially conducts an evaluation design matrix of adaptation and mitigation solutions: such evaluation is concerned with the evaluation performance of each adaptation approach and mitigation solution against SLR impacts to choose the optimum solution for the most vulnerable site to adapt to future situations. Secondly, this chapter conducts comparative analysis on eight in depth case studies: such analysis is concerned with the problems addressed and methods followed of each floating community case to conclude the design objectives and strategies when designing floating cities against SLR impacts to adapt to future situations. 
Initially, this chapter conducts an evaluation design matrix which included ten different adaptation solutions analyzed which are: building seawalls, raising roads, building stormwater pumps, upgrading sewage systems, using beaches as barriers, creating natural infrastructure, slowing land sink-age, managed retreat, elevating houses, and VLFS. Solutions are analyzed through seven variables in detail which are: descriptions, costs, durability, constructing time, lifespans, their environmental impacts, and their overall evaluations which are set to explore the best possible solution against SLR.

Secondly, this chapter conducts comparative analysis on eight in depth case studies is established where such analysis is concerned with the problems addressed and methods followed of each floating community case to conclude the design objectives and strategies when designing floating cities against SLR impacts to adapt to future situations. Evaluation of features included eight real and conceptual floating community cases with similar site characteristics and/or objectives with the Nile Delta which are: the Uros people, the Ha-long community, Bangkok fishing markets, Harvest city, the floating houses of Ijburg, the Lilypad, the Humanitarian Harbour of the Ocean, and the floating island project of the Seasteading institute. Such cases are analyzed through twelve axis which are: facilities, markets, expandable, local food production, mobility, wave attenuators, business, agricultural, modifiable layouts, modularity, and self-sufficiency. This chapter shows the selected cases of floating community which exist all around the world that proved success on a community level. These examples are set to explore the criteria and preferences from their differences and similarities features. 


\subsection{Evaluation on Adaptation Approaches and Mitigation}

\section{Solutions Against SLR Impacts}

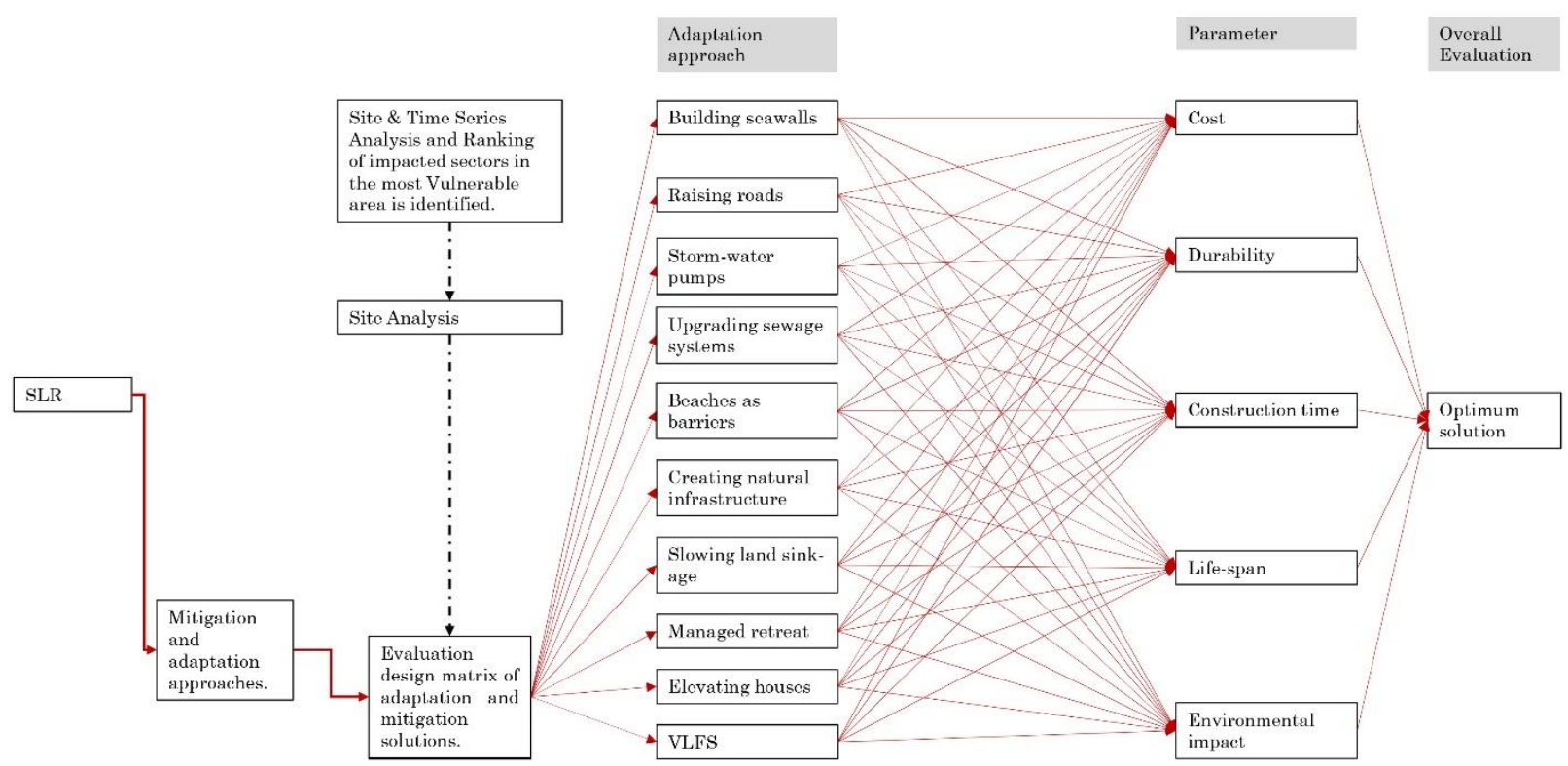

3 Figure 4.1: Analytical framework for evaluating adaptation approaches and mitigation solutions against SLR.

Water as an environment is rich in marine ecosystems, creatures as well as trade routes. Lovely scenery coastlines for leisure, activities and living. As they play a significant part in our environments affect climate, therefore we must preserve this dynamic environment (National Oceanic and Atmospheric Administration (NOAA), 2010), also to Egypt's vulnerable coastal areas like Abu-Qir Bay to protect the underwater world heritage historical monuments, properties and sites of Pharaonic, Greek, Roman, and Christian as listed by the UNESCO can not be replaced. Water is not only important, but it is the essential and crucial matter for existing and is in every single living organism. Oceans covers $71 \%$ of the surface of Earth as well as containing $97 \%$ of the Earth's water as stated by NOAA (National Oceanic 
and Atmospheric Administration (NOAA), 2017). Because of the vast water surface, Earth holds great opportunities accompanied with challenges to create floating communities.

Most of earth's population live nearby coastal cities which puts us in bigger danger more than ever (National Oceanic and Atmospheric Administration (NOAA), 2017). Several seaside areas around the world were stroke by the possible challenges since all the alarming researches considering climate change have predictive negative future scenarios full of natural catastrophes. The sooner we accept such facts the better as that time is not in our favor. As soon we have reached the point where it is not a war and that water is not our enemy, the sooner we can start embracing water by integrating it into our cities and making stronger and more efficient structures and infrastructure which can survive against SLR challenges. Thus, the implementation of water with the city is essential as it may be our only option to face the natural disasters that will come because of global warming.

Since the dawn of time, Mother Nature has never stopped growing, evolving, improving and perfecting its already efficient systems as the Earth is a planet which is a living organism, which develops, grows and adapts to what is happening. We live everyday surrounded by its biological systems, presenting us an unlimited source of knowledge. Architects have always been inspired and encouraged by nature long ago before the term biomimicry was introduced. It was not before a long time after where scientific and technological development, and post-modern architecture, where humankind once again found itself inspired by nature's models and its time-tested methods, they progressively combine both sustainable solutions to our energy and environment encountered problems.

“Those who are inspired by a model other than Nature, a mistress above all masters, are labouring in vain.” - Leonardo Da Vinci 
Biomimicry is a field where all biology, engineering and sustainability combine and intersect. Nature's methods and solutions have been tested through time, and energy effective and inspiring us to innovate and as a result pushes the boundaries of new technology. Biomimicry offers a whole new world of that once was just some impossibilities. It imitates nature's concepts and recreates them, as an alternative of just relying on nature in harvesting and using its goods. Each animal and plant, as well as each bacteria and fungus present us with whole genomes of a time-tested sustainable inspiration that not only could be used in terms of architecture and construction, but they can also offer us solutions in manufacturing methods, transportation, infrastructure in sustainable city development (Tavsan, Tavsan, \& Sonmez, 2015). (For more information about biomimicry, refer to Annex A). The approach is to offer Egypt's coastlines a sustainable inspired by nature solution against SLR by applying biomimicry architecture approaches in the process.

\subsubsection{Barriers}

It acts as a big dam, gateway, or a set of locks which controls waves and tidal flows inside and outside of San-Francisco Bay (Tam, 2009). Such approach might be implemented at the Golden-Gate Bridge, or in smaller, important areas of the bay which are already bounded (Tam, 2009). Such blockade might be static and permit regulated flow over a gateway for water transfer, tidal control and navigation (IPCC, 2007). Furthermore, it can be provisionally installed only to prevent or deflect strong floods in storm surge situations (IPCC, 2014). 


\section{Examples}

- Maeslant Barrier (Maeslantkering): a group of horizontal, revolving gateways in the Rhine River at the Port of Rotterdam area in Netherlands, it's anticipated to be locked approximately every decade to prevent surges above than 3m (Tam, 2009).

- Thames Barrier: a set of river gateways which was constructed in the 1970 s to shield the exposed London in areas from storm surges impacts. In 1990, such barrier was locked once or twice annually, although being locked around 14 times in 2003 alone. It's anticipated to be functional only for additional 50 years due to the SLR impacts (Tam, 2009).

- Venice M.O.S.E: around 80 portable barriers in the lagoon area of Venice in Italy, which would lie on the seabed, nevertheless they would expand in high tides. It's anticipated to be fully executed in 2022 , and to work around a hundred times annually (Tam, 2009).

- Bay Arc: a concept of a massive net which folds underwater of the Golden-Gate and elevated to avoid main storm surges from impacting the bay (Tam, 2009).

\section{Advantages}

- Barriers may efficiently shield a great area of land should it be implemented appropriately. One technological approach, predominantly if it's in the Golden Gate, guards a vast region of land from submerging (National Oceanic and Atmospheric Administration (NOAA), 2010). 
- Barriers shelter people as well, and consequently haven't any social justice problems which could trail more disorganized or land-based approaches where several places may get sheltered or people may have to relocate (IPCC, 2007).

\section{Disadvantages}

- Building barriers require high-costs. The Maeslant Barrier (Maeslantkering) was valued at $\$ 4$ billion, while the Three Gorges Dam in China is valued at $\$ 25$ billion when finished. In 2007, the San Francisco Bay Conservation and Development Commission (BCDC) has investigated the concept of building tidal dams, or waterway blockages, at the Golden-Gate (Tam, 2009). The BCDC states that it's probable that a Golden-Gate blockage could cost double or even triple alike projects in China (Tam, 2009). Furthermore, such approach could be a very expensive shielding approach for the bay than constructing embankments and rebuilding infrastructure. Barriers damage the ecosystem and destroys coral reefs (IPCC, 2007).

- The investigations carried out by the BCDC have also concluded that barriers could impact the waters' salinity, silt, swamps, environment and threatened species (Tam, 2009). It may impact silt as well, probably creating shallower areas in bays, as well as increasing coastal erosion (Tam, 2009).

\section{Unknowns}

Barriers does not seem to be working in every situation. Barriers which holds back the seas' storm surges will probably not function well on the other side, which might outcome in producing upstream submerging in the clean water branches of bays and harbors (National Oceanic and Atmospheric Administration (NOAA), 2017). 


\subsubsection{Coastal Armoring}

Linear fortification, like levees and dykes, which keeps the coastline in its existing location (IPCC, 2014). Currently, linear shielding is most broadly practiced approach for shielding both urbanizations and swamplands in bays and lengthways the shoreline. Diverse methods are implemented which is a subject to each coastline (IPCC, 2014). The most common method is mounting concrete dykes and embankments which shield the coastline from sturdy wave activities (Tolba \& Saab, 2009). Earthen embankments may safeguard lowlands which usually occurs from river floods where it may come in several shapes. They could even be elevated with sand-bags in emergency situations. Another practiced method for shielding defenceless coastlines is shore nourishment, which is implemented by adding sand to sustain eroding coastlines, as well as constructing or expanding sand-dunes (IPCC, 2007). Further coastline fortification approaches consist of offshore seawalls which is constructed in parallel to the coastline to decrease waves, and breakwaters, which act as vertical wall of rocks or interlocking concrete models lengthways the coastline to avoid erosion (United Nations Development Programme, 2014).

\section{Examples}

- San Francisco's Embarcadero which is a seawall that was completed in the 1920s and took over 50 years to construct (Tam, 2009). Coastlines are static in location by both an enormous seawall, as well as sand-dunes and shore nourishment. Levees are implemented all round this Delta to safeguard both urbanized and agricultural nearshore areas (UNEP, 2017)

- The Netherlands, one-third of the country lies some meters under sea level, therefore littoral management safeguard most of the Netherlands (Tam, 2009). It's also 
advancing in new types of levees and new methods for implementing them. For instance, a "smart levee" is implanted within a sequence of networked sensors that could forecast breaches over a day earlier (Tam, 2009). The Netherlands practice installing doubled-dikes as well, where an internal levee as well as a higher exterior one which are positioned numerous hundred meters aside in order to form a space for gathering flood-waters where no buildings are permitted to be construct in such areas (IPCC, 2014).

- Japan is seriously developing in "super levees," where they include mounting up the drylands side of a tall levee in order to be up to 30 times wider than its Hight (Tam, 2009). Such type is impenetrable, seismically stable, and could handle various forms of functions above them (IPCC, 2007).

- Emergency levees, although still being experimental, however, they contain foldable flood-walls which may be automatically elevated or lowered. The Dutch dam flood defence solution is allegedly portable and expandable by two individuals at the ratio of $1 \mathrm{~min}$ per $1 \mathrm{~m}$. It's an interlocking foldable method of floodproofing steel barrier and could be kept at location to be used or brought from outside. The United States Army is investigating new approaches of high absorbing polymers which could quickly absorb great quantities of water and installed as a method of adding water alternative levee (Union of Concerned Scientists, 2015).

\section{Advantages}

- Armoring is the earliest flood defence system. It's known, foreseeable and could be used in joint with further approaches to shield the existing developments from SLR impacts. It could work against either storm surges or SLR impacts (IPCC, 2007). 
- It could be planned to support new urbanizations like residential projects with superlevees or shield the vulnerable environments like sand dunes (IPCC, 2014).

\section{Disadvantages}

- It's a temporary approach (IPCC, 2014).

- All littoral armoring could be constructed only to shield from a specific storm size or SLR (Frihy \& El-Sayed, 2013; IDSC, 2011; Tam, 2009).

- It needs an expensive maintenance yearly and steady monitoring to guarantee that it stays functioning (IPCC, 2007).

- A bizarrely great storm occurrence could result in structural failure such as in New Orleans throughout Hurricane Katrina, even if such levees were well maintained (Tam, 2009).

- Inconsistently, it raises vulnerability. Rigid coastline shielding is not as efficient as the natural coastlines at dispelling the energy coming from either waves or tides (IPCC, 2007).

- Therefore, armored coastlines seem to be more exposed to erosion impacts as well as raising erosion of neighbouring coasts (IPCC, 2007).

- Structural flood defence system could raise the residents' vulnerability by offering people an untrue sense of safety and supporting expansions in such parts that are exposed to flooding (IPCC, 2014). 


\subsubsection{Elevated Development}

Elevating lands or existing buildings and shielding them with littoral armoring. Most of the current coastlines were created by land reclamation, a method which is practiced by land owners and cities like in the Gold Rush (Tam, 2009). Even though over 300 square meters of land was reclaimed in the such bay, it was stopped practically after introducing the BCDC in 1965. Such reclaimed land was raised hardly over sea level, however, maps of projected SLR in 2100 seems like the maps of the Bay in 1849 (Tam, 2009).

While additional filling for new expansions to be supported by new levees won't be popular probably, refilling is an approach which is being practiced in the Netherlands to develop and raise lands for urbanizations (IPCC, 2007). Possibilities could probably be limited to elevating the current filled lands and shielding them with armoring. Elevation could be practiced as well to shield infrastructure like airports, roads, and railways (IPCC, 2014).

\section{Examples}

- Treasure Island Master Plan, where it could lift the structure cushion for the island's planned area and focus expansion there (Tam, 2009). Such strategy is anticipated to shield buildings with levees and wide setbacks.

- Following hurricane Katrina, elevated houses in New Orleans essentially need new or reformed houses in levee-protected zones to be elevated either one meter above grade, or to the base of the flood elevation that is recognized by the Federal Emergency Management Agency (whichever is greater) (Tam, 2009). 
- Boardwalks and pole houses. Several footpath sort areas in Marin County, are constructed on poles above tidal salt swamplands of a probable tidal ratio, are some sort of elevated developments (Tam, 2009).

\section{Advantages}

Such approach permits buildings to be constructed nearby the intruding coastlines or in an exposed region, with little risk of flooding (IPCC, 2007). Even though it's possibly only cost-efficient for new constructions, it could offer a decent solution for modifying specific lowlands infrastructure, like airports (IPCC, 2014).

\section{Disadvantages}

- It's a temporary approach (IPCC, 2014).

- Except on poles right above water, it changes the features of coastlines and will require safety such as in lowlands (IPCC, 2007).

- Its benefits is that it isn't vulnerable by SLR impacts for a long time (IPCC, 2014).

\section{Unknowns}

It's unknown if higher areas or constructions could sustain the needs of large densities or transportation in new developments (Tam, 2009). If most of the area's high-dense districts and transit are neighbouring the shoreline, therefore, new developments raised in such regions, mainly if built close to the existing crowded or dense areas to supply the formation of innovative transit (such as in Treasure Island) might be a great approach to support expansions without deteriorating sprawl (Tam, 2009). Nevertheless, if low-density expansion is permitted to advance lengthways the coastline, it might raise global warming releases, and might not guarantee expensive safety approaches in the future. 


\subsubsection{Floating Structures}

Constructions which float on water surface, or might be floated infrequently throughout

floods, making them mostly safe from the varying currents (Tsaltas et al., 2010). Floating houses could either be moored to the coast or anchored to seabed. Floating structures varies from ships where they are fixed rather than having propulsion equipment (Suzuki et al., 2006). SLR impacts have encouraged projects for floating structures to new levels of advancements than just some single-family floating houses, like the offshore airport in the Netherlands' North Sea, also the offshore floating hotels or restaurants of Dubai. Infrastructure like electricity, water and wastewater have to be provided to floating houses via elastic piping (Wang \& Tay, 2011).

\section{Examples}

- Floating houses in Sausalito, since the initial modern floating communities were founded in the 1960s. Floating houses are common in some seaside metropolises with rather some threatened waterfronts such as Redwood City, Seattle, and Amsterdam (Tam, 2009).

- Floating infrastructure. A floating greenhouse was initially constructed as an architype in the Netherlands, and either floating or pontoon platform bridges were constructed in numerous areas in Washington state (Tam, 2009).

- Floating house architype for New Orleans. An innovative house planned for New Orleans which will mainly lie on an engineered base, nevertheless in disastrous floods it may float as high as four meters, attached to poles (Tam, 2009). 


\section{Advantages}

- Floating structures handles the ambiguity of high waves and tides, and earthquakes (Wang et al., 2008).

- Floating structures may work despite the doubt regarding the timing and SLR situations. equipment (Suzuki et al., 2006).

- Floating structures are extremely resilient to seismic movements (Wang \& Tay, 2011).

\section{Disadvantages}

- Mostly, floating structures function just in protected waters (Wang et al., 2008).

- Floating structures may not function as required in areas subjected to wind and wave activities from storms, like about all shorelines (Suzuki et al., 2006).

\section{Unknowns}

Such adaptation approach has not been implemented in high-density metropolises. Floating structures is starting to appear as a SLR strategy for bigger metropolises and islands (Suzuki et al., 2006). From an engineering standpoint, several constructions could be erected to float, nevertheless they could not be modified to do so (Wang et al., 2008). Since they haven't been installed wherever as an archetypal for high-density metropolises, floating structures might end up (like badly designed elevated development) enabling expansions in coastal areas which aren't near to services or infrastructure (Suzuki et al., 2006). 


\subsubsection{Floodable Developments}

Structures which are planned to endure floods and/or recollect storm-water. There are two concepts for floodable developments. The initial one is to plan both infrastructures and buildings to prevent damages by infrequent or periodic storm surges and floods. This might be an alternative approach if coastline armoring has failed (Tam, 2009). The second one is to make retention zones for storm surges or heavy precipitation (Tam, 2009). In Egypt, water should be collected, to be discharged later, or to be used in the wastewater system, as floodwaters retreat (Tolba \& Saab, 2009). Floodable development is a great system of LowImpact Development (LID) which is a set of tools for efficiently recycling floodwaters to create green areas and environments whereas decreasing the pressure on the city's wastewater treatment systems (Tam, 2009). New floodable developments built to endure SLR could be planned to handle storm-water, both saline and clean water over LID approaches (Tam, 2009).

\section{Examples}

- LID approaches are usually practiced in Seattle and Portland. They consist of swales or contoured ground, rain gardens, vegetations, swamplands, green rooftops, and porous pavements (Tam, 2009). They consist of great containers to store water for future usage. Floodable developments are being developed with concepts like landscape-scale overflow parks, floodable roads (probably channeled by impermanent flood-walls) and water plazas as flood-waters enter to create an attractive distinctive in dry-public areas (Tam, 2009). 
- In Rotterdam, Netherlands, a big underground vehicle parking garage is being constructed which is planned to collect water instead of vehicles throughout strong floods (Tam, 2009).

- In the UK, the concept of a "blue village" has been planned for several cities with increasing flood challenges and increasing populations. Such concept is a essential regeneration zone which develops an expandable water area, comprehensive with swimming and boating services, in flood situations (Tam, 2009).

\section{Advantages}

- Floodable developments might take such efficient toolbox to a new level. It can be considered as a set of tools (counting LID) which might be chosen according to the work at a specific location. Nevertheless, unlike LID, floodable developments' tools remain provisional (Tam, 2009).

- Various tools could be better for clean or saline water (or a blend) and several could be better in cities rather than agricultural or countryside regions (Tolba \& Saab, 2009).

\section{Disadvantages}

- Floodable developments may be dangerous. Storm-water, mainly at the offshore end of the basin, is frequently contaminated with metals and carbon-based substances, apart from deposits and bacteria. Great amounts of storm-water lie on the surface, or in underground storing facilities, may outcome in health threats throughout flood or create pollution (Tam, 2009). 
- This would be a certain issue in regions with joint sewer systems, like in San Francisco, as wastewater and road-runoff are directed to the same treatment system (Tam, 2009). Correspondingly, wastewater treatment systems which usually treat the threats of joint sewer runoffs before discharging them into waters don't function very good with saline water mixed in (Tam, 2009). If floodable development approaches are planned to collect and discharge black water, new treatment approaches would be required for the discharged water to reach the required water quality (Tam, 2009).

- All of emergency tools, public widespread and management may be essentials to avoid people from exploiting or getting stuck in flooding regions.

\section{Unknowns}

- Floodable developments are still experimental. It's unknown if constructions and infrastructure could be planned or retrofitted to support seasonal floods in feasible means.

- It's not obvious precisely how much is the capacity that such new floodable developments tools could hold.

- Some of such highly-engineered approaches, like the underground water-holding vehicle parking garage, would not appear to be more valuable than coastal armoring or investing in underlying structures of the current sewage systems. 


\subsubsection{Living Nearshore}

Marshlands are the basic characteristic of coastlines. They take in floods, slow down erosions and provide ecosystems. Living nearshores or swamplands are vital for the wellbeing of bays (United Nations Development Programme, 2014). They shield coastlines from floods and corrosion by absorbing wave activities and slowing-down water-flow (IPCC, 2014). Marshes have numerous forms, reliant on the features of their nearby watercourses (Tolba \& Saab, 2009). The Nile Delta area hosts a lot of swamplands which consist of tidal basins, swamps, sludge, and even some stone coasts (IPCC, 2014).

Tidal swamps are the basic characteristic of Bays coastlines, nevertheless, they're losing around five percent of their amount by filling, coastal armoring and land reclamation methods (IPCC, 2007). A technical valuation made a decade ago concluded that a healthy bay needs a minimum of 100,000 acres of tidal swamplands (Tam, 2009).

\section{Examples}

Even though minor areas of swamplands dot the San Francisco Bay coastline in each region, great tracts occur in the almost all northern and southern regions (Tam, 2009). The Northern Bay swamplands consist of the Richardson Bay and Sonoma marshlands, the San Pablo Bay National Wildlife Refuge and the Suisun Marsh (Tam, 2009). Key swamplands and upgrading plans in the South and East Bay consist of the Don Edwards Wildlife Refuge in Redwood City and the South Bay Salt Pond revival development, the main tidal marshland renovation plan on the western coastline (Tam, 2009). 


\section{Advantages}

Living nearshore helps the public. Swamplands disperse toxins off water, capture carbon, offer leisure open areas, and make serious environment for fish, nature and numerous species which live in tidal mud and are the base of marine food chains (Tolba \& Saab, 2009).

\section{Disadvantages}

Living nearshore only functions with area and time. Swamplands are commonly denser than linear armoring approaches like levees, therefore they require further lands (IPCC, 2007). They need running, supervision and time to be function (IPCC, 2007).

\section{Unknowns}

- Living s are usually adaptive to SLR, but only if two conditions are met. Initially, for adaptive nearshore living, space is essential to migrate/relocate backwards. Secondly, is that they require being appropriately provided with sediments to be able to resist such SLR intrusions. As a result of the various dams and altered hydrology in the Nile and its Delta, it's a vital matter for restoration accomplishment in the Nile Delta.

- Swamplands may never be return to their historical records, partially due to the pricetags of such relocations from residential lands at coastlines. Simultaneously, preserving a barrier or setbacks where marshlands could shape and migrate within developed areas and current's coastlines may look as a very cost-efficient flood defence approach.

- Significant issues for the Nile Delta would define how much submerging new tidal swamplands may decrease, recovering them in suitable areas, and leading upgrading at a higher degree than without the pending dangers of SLR. 


\subsubsection{Managed Retreat}

Managed retreat is a strategic relocation of vulnerable zones coast-by. Managed retreat is an approach which securely prevents settlement from the intruding SLR, permitting the water to invade coasts unobstructed (IPCC, 2014). It includes deserting, demolishing or relocating standing buildings and infrastructure either to other areas or higher levels. It consists of prohibiting new expansions in zones which would probably be submerged (IPCC, 2007). It's used when littoral armoring and other approaches become either extremely costly or are ineffective (Tam, 2009). The relocating from the coastlines includes pilot projects to prompt actions like either demolishing constructions or deserting attempts to control coastline erosion. Such pilot projects could be joined with repurchase plans to reimburse property owners for their losses, as well as firm construction codes which permit only specific sorts of relocatable or floodable constructions.

\section{Examples}

- Building setback codes and regulations in most littoral regions permit expansion only within a specific gap from water. California has assigned such management to local littoral plans in corporation with the California Coastal Commission (CCC) (Tam, 2009). In the past, California has established the limit using measurements for a 100year storm. Certainly, several older constructions don't follow such present setback codes (IPCC, 2007).

- Investing in plans for North Carolina and New Jersey permit states to obtain storm vulnerable or littoral barrier properties (Tam, 2009). Coastlines of California in Ventura and Pacifica have implemented less serious relocation strategies (Tam, 2009). 
- Relocation is getting with bigger constructions. In 1999, the famous Cape Hatteras lighthouse was relocated 1,000 meters to land from the corroding coastlines in the external banks of North Carolina (Tam, 2009).

- Erosion regulator (rolling) systems in Texas and South Carolina differ landward after the tide levels increases. Such rolling systems helps sustaining private properties and expansions, with limitations just on armoring and route access (Tam, 2009).

\section{Advantages}

- Managed retreat decreases enhance the well-being, by displacing buildings and infrastructure to secure locations before a disastrous floods and storm surges (United Nations Development Programme, 2014).

- Managed retreat frequently is less costly than other existing armoring approaches, particularly when structural calculations could only be provisional. It could be planned to permit the upgrading of flood-buffering swamplands and natural coastline ecosystem, that affords safety (IPCC, 2007).

- Managed retreat may possibly be costly for zones which are substantially advanced, and it may outcome in losses in the worth of littoral properties and infrastructure if such setback lines are to be changed (IPCC, 2014). It's an approach which is considered as a last option for numerous extremely developed littoral regions which have no possible available areas for structures to be repositioned (IPCC, 2014).

\section{Disadvantages}

- Such approach is a radical marsh. It includes great deal of lawful and equity matters, since not each property owner is prepared to sell (Tam, 2009). 
- In numerous regions, coastline urbanizations are lack the adaptive capability to move.

- Managed retreats could need costs past such repositioning or property prices if location clear-out (like to eliminate toxics) is required after the demolition phase (Tam, 2009).

\subsubsection{Findings and Further Solutions to SLR Impacts}

Building seawalls (dykes) serve as large dams, gateway which controls tidal movements in and out of bays. They are constructed on the seashore to reduce floods from currents and storms. Seawalls are implemented in the Maeslant Barrier, Thames Barrier, Venice MOSE, Treasure Island Master Plan, New Orleans (post-Katrina), Marin County, and Bay Arc. They are usually constructed from 1.5 to 2 meters above sea level (IPCC, 2014). However, in order to decrease floods, old seawalls require restoring and elevating as sea levels rise. Raising such dykes would cost around $\$ 200$ per meter. New dykes often cost $\$ 2000$ to $\$ 6,700$ per linear meter (IPCC, 2007).

Raising roads is acts like a linear shield, similar to levees or dykes, which fasten the coastline to stay in its location. It is mostly practiced in United States, the Netherlands, and Japan. Raising roads over the sea level could decrease tidal floods. To be certain that such higher roads won't transport flood waters to buildings lower levels, authorities usually implement storm-water pumps to prevent such extra water (National Oceanic and Atmospheric Administration (NOAA), 2010).

Water won't drain out effectively as the seas rise, therefore building storm-water pumps can offer a solution. Pumps could accelerate the process of removing water from the roads by vacuuming up such water and discharging it back to the Mediterranean. 
Floods could disturb sewage systems and danger septic tanks. Since saline water is destructive, it could break septic tanks which makes a stinking smell and creates health risks. Cities need to improve sewage systems in order to prevent storm water from infiltrating pipes, enhance septic tanks, or change them with new sewer lines as practiced in Florida (IPCC, 2007).

Shores and dunes could act as a natural barrier which decreases the effects of storm surges. The larger the coast, the more water it will prevent from reaching houses and streets. Cities use land recuperation solution by adding sand to make beaches larger or to guard them from erosion (IPCC, 2014). Implementing such sort of natural infrastructure could shield from floods while preserving beaches for the public to enjoy. However, land reclamation solutions have proven to be destroy the marine ecosystem as stated by Wang \& Tay (2011).

Littoral areas can upgrade and build natural infrastructure which could act as a barrier from storms and coastal floods. Such natural structures functions like barrier islands, coral reefs, mangroves, and salt marshes could be merged with the built infrastructure, like dykes or breakwaters, to prevent storm surges. Such approach could be cost-effective and could enhance the natural environment for the city if the seabed wasn't too deep (National Oceanic and Atmospheric Administration (NOAA), 2017).

In areas such as Hampton Roads, land sinking happens due to pumping groundwater for usage that the land is trying in to fill such unfilled space. Cities could decrease such land subsidence by preventing more groundwater pumping and introducing pilot plans to stop such land subsidence (IPCC, 2014).

In many littoral areas, coastlines get damaged by storms, rising seas, erosion, and land subsidence. Despite that cities are executing several approaches to adapt to such impacts, 
some people are still considering relocating or managed retreat like in California, North Carolina, New Jersey, Texas and South Carolina (National Oceanic and Atmospheric Administration (NOAA), 2010). Although such possibility might not be the best solution for all littoral settlements fronting such SLR impacts, it appears to be the optimum approach to ensure their inhabitants' safety.

The evaluation on different solutions analyzed such as building seawalls, raising roads, building storm-water pumps, upgrading sewage systems, using beaches as barriers, creating natural infrastructure, slowing land sink-age, managed retreat, elevating houses, and VLFS demonstrate that floating structures are the optimum overall solution. Adaptation approaches and mitigation solutions analyzed in detail through five axes which are: costs, durability, constructing time, lifespans, their environmental impacts, and their overall evaluations which conclude that floating structures could offer the best possible solution against SLR as shown in Tables $4.1 \& 4.2$. However, such approach does not appear to be working in every case as it has some special requirements, therefore analyzing similar cases with similar site characteristics is essential to test the hypothesis if such solution may fit and offer similar outcomes to the most vulnerable areas on the Nile Delta's coastlines. 


\begin{tabular}{|c|c|c|c|c|}
\hline Approach & Archetype & Characteristics & Advantages & Disadvantages \\
\hline $\begin{array}{l}\text { Building } \\
\text { seawalls }\end{array}$ & & $\begin{array}{l}\text { They are built } \\
\text { on the coast. } \\
\text { They decrease } \\
\text { flooding from } \\
\text { both tides and } \\
\text { storms. }\end{array}$ & $\begin{array}{l}\text { Tolerable } \\
\text { construction } \\
\text { time. } \\
\text { Tolerable } \\
\text { durability. } \\
\text { Walls could be } \\
\text { raised. }\end{array}$ & $\begin{array}{l}\text { Expensive. } \\
\text { Short lifespan. } \\
\text { Negative } \\
\text { environmental } \\
\text { impact on } \\
\text { marine } \\
\text { environment. }\end{array}$ \\
\hline Raising roads & . & $\begin{array}{l}\text { Elevating roads } \\
\text { above sea level } \\
\text { may help drain } \\
\text { water and } \\
\text { decrease tidal } \\
\text { floods. }\end{array}$ & $\begin{array}{l}\text { High } \\
\text { durability. } \\
\text { Tolerable } \\
\text { lifespan. } \\
\text { Tolerable } \\
\text { environmental } \\
\text { impact. }\end{array}$ & $\begin{array}{l}\text { Expensive. } \\
\text { Construction } \\
\text { time might } \\
\text { vary. }\end{array}$ \\
\hline $\begin{array}{l}\text { Building } \\
\text { storm-water } \\
\text { pumps }\end{array}$ & 百 & $\begin{array}{l}\text { Pumps could } \\
\text { speed up the } \\
\text { course of } \\
\text { removing water } \\
\text { from the roads } \\
\text { by vacuuming } \\
\text { up flood waters } \\
\text { and discharging } \\
\text { it back into the } \\
\text { sea/ocean. }\end{array}$ & $\begin{array}{l}\text { High } \\
\text { durability. } \\
\text { Long lifespan } \\
\text { if maintained. } \\
\text { Tolerable } \\
\text { environmental } \\
\text { impact. }\end{array}$ & $\begin{array}{l}\text { Very } \\
\text { expensive. } \\
\text { Long } \\
\text { construction } \\
\text { time. }\end{array}$ \\
\hline $\begin{array}{l}\text { Upgrading } \\
\text { sewage } \\
\text { systems }\end{array}$ & & $\begin{array}{l}\text { Whereas } \\
\text { saltwater is } \\
\text { corrosive, it } \\
\text { could disturb } \\
\text { tanks and push } \\
\text { sewage to spew } \\
\text { out, which } \\
\text { outcomes in a } \\
\text { smelly problem } \\
\text { and other } \\
\text { possible health } \\
\text { hazards. }\end{array}$ & $\begin{array}{l}\text { Tolerable } \\
\text { durability. } \\
\text { Long lifespan. } \\
\text { Tolerable } \\
\text { environmental } \\
\text { impact. }\end{array}$ & $\begin{array}{l}\text { Expensive. } \\
\text { Long } \\
\text { construction } \\
\text { time. } \\
\text { Needs regular } \\
\text { maintenance. }\end{array}$ \\
\hline $\begin{array}{l}\text { Using beaches } \\
\text { as barriers }\end{array}$ & & $\begin{array}{l}\text { Beaches and } \\
\text { dunes could } \\
\text { function as a } \\
\text { natural wall } \\
\text { that decreases } \\
\text { the effect of } \\
\text { storm surges } \\
\text { plus shielding } \\
\text { them from } \\
\text { erosion. }\end{array}$ & $\begin{array}{l}\text { Tolerable } \\
\text { durability. } \\
\text { Fast } \\
\text { construction } \\
\text { time. } \\
\text { If maintained, } \\
\text { could live long. }\end{array}$ & $\begin{array}{l}\text { Expensive. } \\
\text { Short lifespan } \\
\text { (but could be } \\
\text { maintained by } \\
\text { adding sand } \\
\text { frequently). } \\
\text { Negative } \\
\text { environmental } \\
\text { impact on } \\
\text { marine } \\
\text { environment. }\end{array}$ \\
\hline
\end{tabular}




\begin{tabular}{|c|c|c|c|c|}
\hline $\begin{array}{l}\text { Creating } \\
\text { natural } \\
\text { infrastructure }\end{array}$ & till & $\begin{array}{l}\text { Natural } \\
\text { structures like } \\
\text { barrier islands, } \\
\text { oyster, coral } \\
\text { reefs, } \\
\text { mangroves, } \\
\text { seagrass, and } \\
\text { salt marshes } \\
\text { could be united } \\
\text { with built } \\
\text { infrastructure, } \\
\text { to function as } \\
\text { seawalls, to } \\
\text { shield from } \\
\text { storm surges. }\end{array}$ & $\begin{array}{l}\text { High } \\
\text { durability. } \\
\text { Good } \\
\text { environmental } \\
\text { impact. } \\
\text { If maintained, } \\
\text { could live long. }\end{array}$ & $\begin{array}{l}\text { Average to } \\
\text { high costs. } \\
\text { Average to } \\
\text { long } \\
\text { construction } \\
\text { time. } \\
\text { Moderate } \\
\text { lifespan if not } \\
\text { maintained. }\end{array}$ \\
\hline $\begin{array}{l}\text { Slowing land } \\
\text { sink-age }\end{array}$ & & $\begin{array}{l}\text { Towns could } \\
\text { decrease land } \\
\text { sink-age by } \\
\text { preventing } \\
\text { additional } \\
\text { groundwater } \\
\text { pumping plus } \\
\text { introducing } \\
\text { pilot schemes to } \\
\text { reverse such } \\
\text { land sink-age. }\end{array}$ & $\begin{array}{l}\text { Good lifespan. } \\
\text { Good } \\
\text { environmental } \\
\text { impact. }\end{array}$ & $\begin{array}{l}\text { Expensive. } \\
\text { Long } \\
\text { construction } \\
\text { time. } \\
\text { Needs regular } \\
\text { maintenance. }\end{array}$ \\
\hline $\begin{array}{l}\text { Managed } \\
\text { retreat }\end{array}$ & & Relocation. & Safety. & $\begin{array}{l}\text { Expensive. } \\
\text { Hard work. }\end{array}$ \\
\hline $\begin{array}{l}\text { Elevating } \\
\text { houses }\end{array}$ & & $\begin{array}{l}\text { Elevating } \\
\text { houses over } \\
\text { flood levels by } \\
\text { using two } \\
\text { meters high } \\
\text { wooden stands } \\
\text { or concrete } \\
\text { blocks. }\end{array}$ & $\begin{array}{l}\text { Tolerable } \\
\text { lifespan. } \\
\text { Tolerable } \\
\text { durability. }\end{array}$ & $\begin{array}{l}\text { Moderate } \\
\text { environmental } \\
\text { impact. } \\
\text { Could be } \\
\text { expensive. } \\
\text { Could take } \\
\text { long. }\end{array}$ \\
\hline VLFS & $\Delta$ & $\begin{array}{l}\text { Artificial } \\
\text { floating islands. }\end{array}$ & $\begin{array}{l}\text { Moderate cost. } \\
\text { High } \\
\text { durability. } \\
\text { Moderate } \\
\text { construction } \\
\text { time. } \\
\text { Moderate } \\
\text { lifespan. } \\
\text { Good } \\
\text { environmental } \\
\text { impact. }\end{array}$ & $\begin{array}{l}\text { Poor } \\
\text { maintenance } \\
\text { expertise. }\end{array}$ \\
\hline
\end{tabular}

15 Table 4.1: Analyzed adaptation approaches practiced against SLR around the world. 


\begin{tabular}{|c|c|c|c|c|c|c|c|c|c|c|c|c|c|c|c|c|c|c|}
\hline 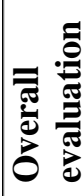 & 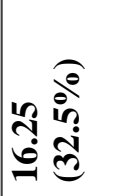 & & 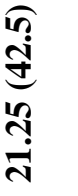 & 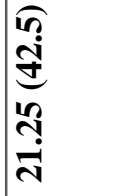 & & 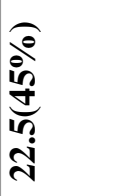 & & 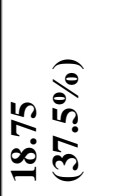 & & 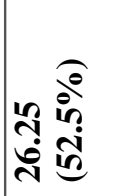 & & 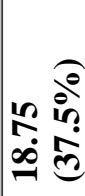 & & $\mid \begin{array}{l}0 \\
i \\
i n \\
i n \\
i\end{array}$ & & 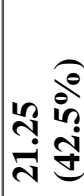 & & 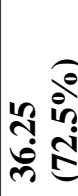 \\
\hline 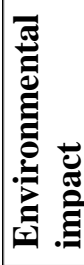 & D & 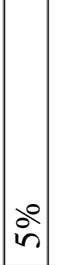 & 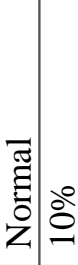 & $\begin{array}{l}\overline{\widetilde{g}} \\
\text { हี } \\
\text { Z }\end{array}$ & $\stackrel{0}{0}$ & 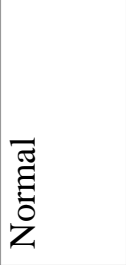 & $\begin{array}{l}0 \\
0 \\
0\end{array}$ & ص్జ & 齐 & ن & $\begin{array}{l}0 \\
\stackrel{2}{n}\end{array}$ & రి & $\begin{array}{l}0 \\
\end{array}$ & & & $\begin{array}{l}\overline{\widetilde{J}} \\
\text { हี } \\
\text { Zे }\end{array}$ & : & $\begin{array}{ll}z & \\
8 \\
0 \\
0 \\
0 \\
0 \\
> & 0\end{array}$ \\
\hline 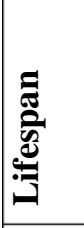 & 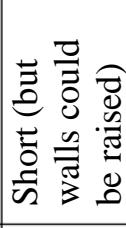 & 吕 & 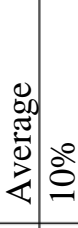 & 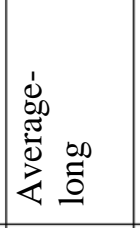 & $\begin{array}{c}0 \\
\\
\\
-\end{array}$ & 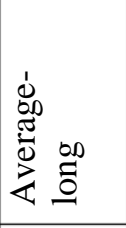 & 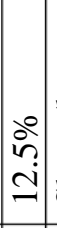 & 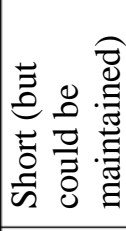 & : & 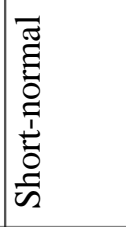 & $\begin{array}{l}0 \\
n \\
n \\
r\end{array}$ & 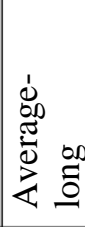 & $\mid \begin{array}{l}0 \\
\vdots \\
i \\
\end{array}$ & , & & 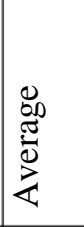 & @̊ & 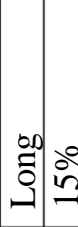 \\
\hline 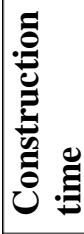 & 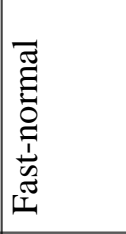 & $\begin{array}{c} \\
0 \\
0 \\
n \\
\vdots \\
-1\end{array}$ & 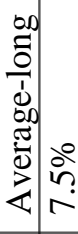 & 占 & $\begin{array}{l}0 \\
i n\end{array}$ & 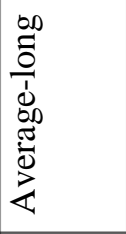 & 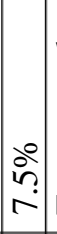 & 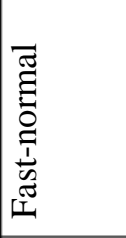 & $\begin{array}{l} \\
0 \\
n \\
i \\
i\end{array}$ & 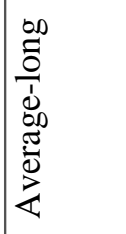 & $\begin{array}{l}0 \\
\\
r\end{array}$ & $\begin{array}{l}00 \\
\tilde{0} \\
.1 \\
\end{array}$ & $\begin{array}{l}0 \\
i n\end{array}$ & ' & & 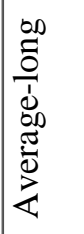 & $\begin{array}{l}0 \\
\\
r\end{array}$ & 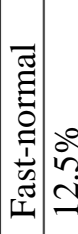 \\
\hline 莗 & 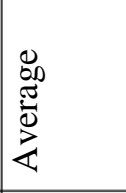 & $\stackrel{\circ}{\circ}$ & $\begin{array}{ll} & 50 \\
i 0 & 0\end{array}$ & $\begin{array}{l}50 \\
.000 \\
.7\end{array}$ & \begin{tabular}{l}
0 \\
\hdashline \\
-
\end{tabular} & 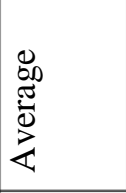 & @̊ & 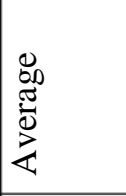 & 各 & $\begin{array}{l}50 \\
.000 \\
.7\end{array}$ & $\begin{array}{l}0 \\
\stackrel{0}{2}\end{array}$ & 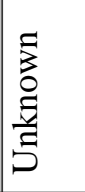 & ' & ' & 1 & 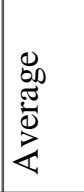 & : & 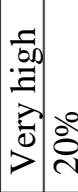 \\
\hline $\overrightarrow{\tilde{y}}$ & 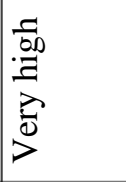 & 8 & 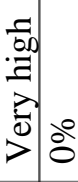 & 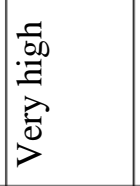 & $8^{0}$ & $\begin{array}{l}50 \\
.00 \\
1\end{array}$ & $\mid$ & 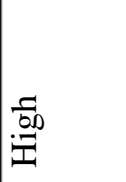 & @̊ & 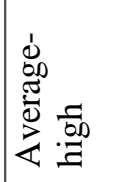 & $\begin{array}{l}\stackrel{0}{2} \\
\sim \\
r\end{array}$ & .00 & $\therefore$ & 票 & 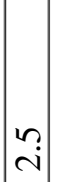 & 票 & in & 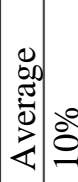 \\
\hline$\sum_{i}^{2}$ & 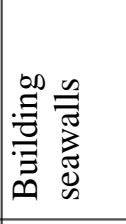 & 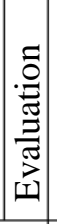 & 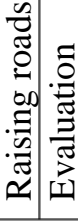 & 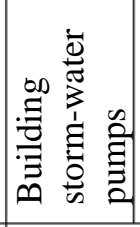 & 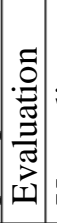 & 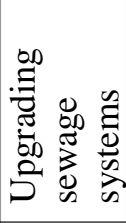 & 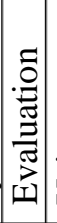 & 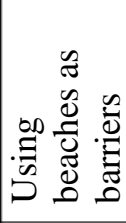 & 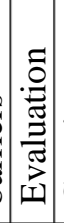 & 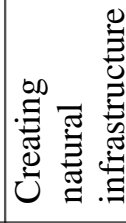 & 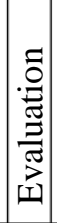 & 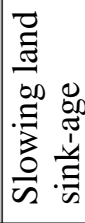 & 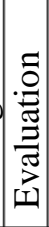 & 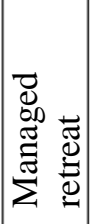 & 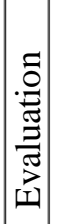 & 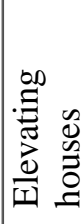 & 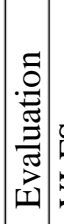 & 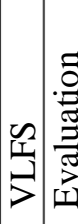 \\
\hline \# & - & & $N$ & $m$ & & $\nabla$ & & in & & 6 & & $r$ & & $\infty$ & & $a$ & & 은 \\
\hline
\end{tabular}

16 Table 4.2: Evaluation design matrix for different types and characteristics of adaptation approaches and mitigation solutions to SLR impacts.

Cost: Very High (0) High (5) Moderate (10) Low (15) Very low (20). Durability, Construction time, lifespan, Environmental impact: Very High (20) High (15) Moderate (10) Low (5) Very low (0). Main references: AFED reposts: Saab (2017), Tolba \& Saab (2009), Saab \&Sadik 
(2018); EEA (2013), Eldeberky (2011, 2015), Frihy \& El-Sayed (2013), IDSC (2011, 2013), IPCC (2007; 2014), NOAA (2010, 20,12, 2015), Tam (2009), UCS (2014, 2015).

\subsection{Types of Floating Houses}

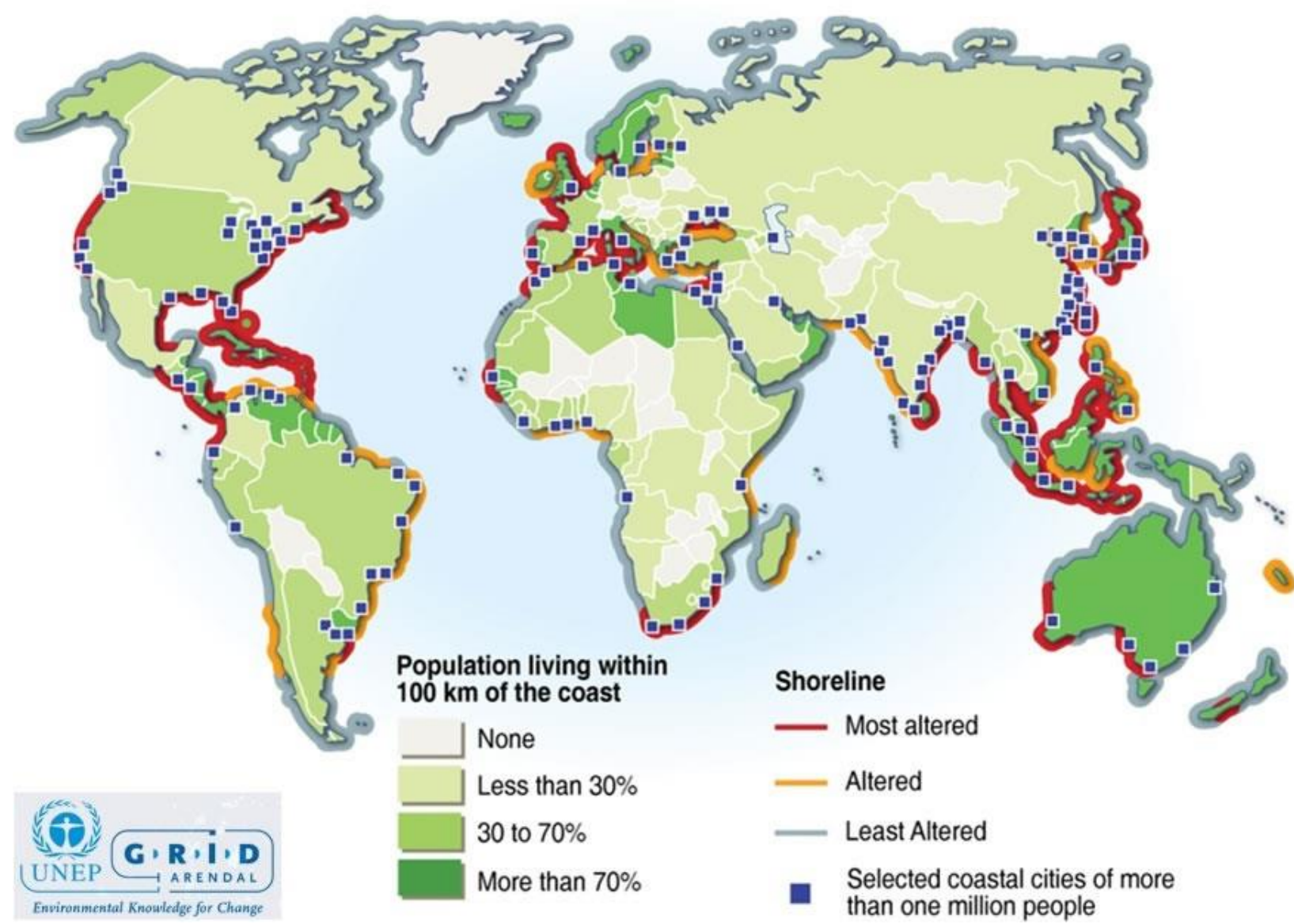

4 Figure 4.2: Coastal population and shoreline degradation (Rekacewicz, Ahlenius, \& UNEP/GRID-Arendal, 2006).

As the figure above shows the global urban settlements are concentrated nearby water resources. In cases, human settlements have developed by forming a sort of a floating habitat on water surfaces like lakes, rivers, coastlines where habitually with small connection to the coast. Floating communities occurred since the beginning of human kind history, for example the "Uros Island" pre-Incan settlement where they lived 3,700 years ago (Radding \& Orlove, 
2008). Countries that suffer from tsunami and floods where they have struggling living situations and floating housing communities benefit in similar conditions.

Modern time countries with the most floating building developments happens in the Netherlands, Japan, England, USA, Canada, Thailand, United Arab Emirates, South Korea, China, Philippines, Cambodia and Vietnam (Suzuki et al., 2006). These floating developments have advanced greatly from a primitive floating building level to an advanced futuristic city scale with a fully floating urban utopia.

The most important factor is the quality of water beneath the buildings is good. Which depends on the amount of oxygen, how sand goes beneath the foundation's platform as well as the water motion which is impacted by the wind. The biggest advantage in building on water is that the building and its floating foundations needs a very low level of conservation and maintenance if done correctly. Through incorporating features done in floating structures, waterproof houses, apartments, etc. it will allow us to construct normally on the structure of the polders, consequently conserving the environment natural landscape undamaged. Investing in floating structures results in less worrying about the rising seas as that floating structures will make the buildings move up and down with the sea and oceans waves affected by the wind (Ambica \& Venkatraman, 2016).

\subsubsection{Benefits of Building on Water}

Floating houses is a great possible solution for mega cities density problems. For example, metropolises as London, Tokyo and Hong Kong, where they all have in common some features like the large water surface as well as the population to land density and they all can benefit from implementing floating structure rather than in land expansions. It can as well be a 
possible answer for the coastal cities that are susceptible to natural disasters and tsunami.

Near coast building must withstand and endure natural disasters as floods would be very damaging. Although, these floating structures are infrastructures that are separated from the city's infrastructure which requires such floating structures to be self efficient, as that the electrical grid networks could be somehow unsafe for floating structures (Ambica \& Venkatraman, 2016).

\subsubsection{Basic Types of Floating Houses}

There are some floating houses design methods as well as there will be more in the future, as that the floating structures methods are just beginning to catch the interest of architects all around the world.

\subsubsection{House Barges}

The easiest way to build a floating house is House Barges. House Barges are not a difficult method to build a floating house. They are simple houses that are designed and planned to share the similar methods and principles that makes a boat float. Although House Barges is inspired by floating boats, they do not have the ability to move, but rather they only float. House Barges are firstly manufactured and assembled on land. Moreover, they get placed on a flat platform that is considered both another floor and a supporting structure that acts like a bond between the house and the floating structure. The floating structure is made up with a series of connected hollow air containers allowing them to float together as one piece, thus allowing some sort of a plain platform area to place the house on top of it and once they get attached together, they stable the house to float on water like a boat does (Stopp \& Strangfeld, 2010; Tennessee Valley Authority, 2016). 
This floating outline shape depends on the built surface area and the structure weight of the house. Occasionally, they have columns and rows some parallel to one another and some placed in opposing pairs. It is more like two small boats placed parallel to one another with a board-like platform which works as a base for a house. Stabilizing the house is always very important aspect as that a house on the seashore and another on a lake shore have different stabilizing means and that is a result of the water and wind movements. These houses are a great way to go eco-friendly as they are self-sufficient in terms of generating electricity and clean water. Clean water can be generated by a filtration method after pumping the water from the sea or the lake under the structure (Tennessee Valley Authority, 2016). The waste is not thrown into the sea, but stored into containers (Stopp \& Strangfeld, 2010).

\subsubsection{Houses on Pilotis}

Another method is a house on pilotis, while it might not be literally floating, but they are considered as floating houses because sometimes they are in contact with the sea. Unlike fully floating houses, they keep in stable in site therefore they do not require any stabilizing methods that can protect them from tilting to the sides or drifting away, although they face other sorts of challenges. They need to be very well insulated to avoid humidity as they are in direct contact to the water (Ambica \& Venkatraman, 2016).

In the case of the pilotis are made from wood, then they must be carefully and systematically coated and treated to the humidity, fungi and other decomposing related problems. This prevents humidity from affecting the walls and the floors, as well as preventing from decomposing and any possible collapse to the structure. In the case of the pilotis are made from steel, at that moment they must be frequently treated to face water decomposition, for example using waterproof paint and sealers where they act like a layer or 
a cluster that protects the structure from decaying. Also, floors should be properly insulated to prevent any kind of water infiltration (Ambica \& Venkatraman, 2016).

\subsubsection{Houses on Flotation Billets}

Yet, not all fixed floating houses are not just placed on top of floating platforms. Nevertheless, they are situated on a huge concrete structure where that it's full of expanded polystyrene, which is referred as floatation billets. These floatation billets functions as enormous sea buoys making the structure steady as well as decreasing the dangerous natural threats, also keeping down the humidity infiltrations (Feyen, Shannon, \& Neville, 2008).

\subsection{Comparative Analysis on in-Depth Case Studies}

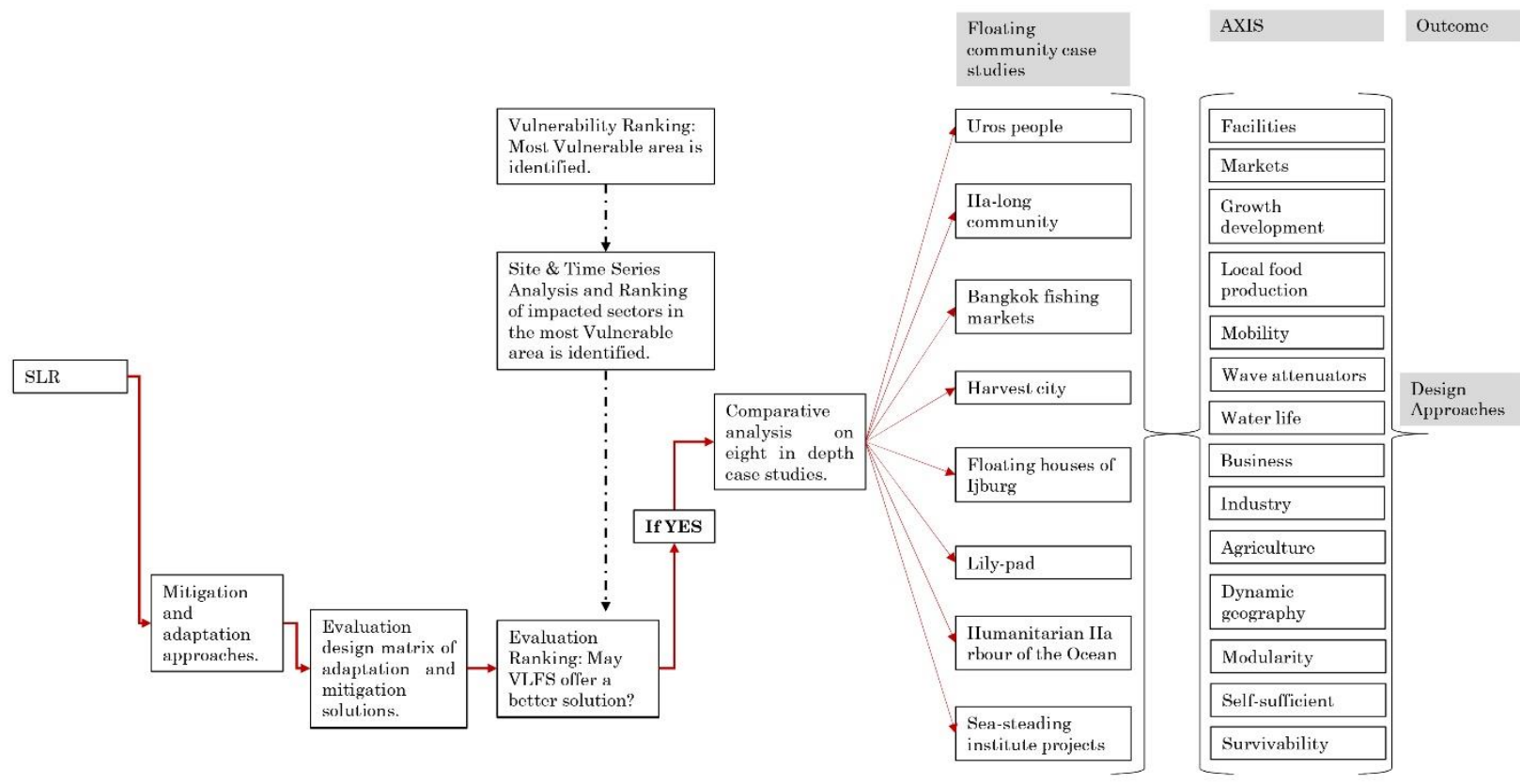

5 Figure 4.3: Analytical framework for floating community case studies.

Community living has many advantages than when compared to sole isolated floating house. In a project in a scale like a community, a dense building should be designed because 
sharing resources is a must at various levels and may as well mean sharing facilities and expenses for the community's greater good. This allows the opportunity for each community in each building to share investment strategies and plans in technology and sustainability.

\subsubsection{Uros Islands, pre-Incan Floating Community in Lake Titicaca, Peru and Bolivia}

The Uros floating settlements is a great example of old yet existing tribes who managed to make their living by creating floating islands made from reed. This characteristic floating community was founded as a close society for surviving. "Kotsuñas" which means the people of the water, is how the Uros people call themselves. They had to settle on these artificial floating islands on "Lake Titicaca" after their population grew and covered the land (Kent, 2008). Although these artificial floating islands were not by the land like nowadays. The Uros populations of Peru and Bolivia goes back to 3,700 BC (Radding \& Orlove, 2008). They survived until today and that's due to adapting to some of nowadays habits as well as opening some of their artificial floating islands for tourism. Nowadays, they live by fishing in addition to selling tourists' their handcrafts (Levieil \& Orlove, 2004). The inspiring quality of the Uros is that their inventive and sustainable usage of nature and its resources which also became the inspiration for floating communities' developments (Kent, 2008). The Uros people focused on the Totora reeds that grow near lake shores. Positioning their artificial islands was determined by placing them where the Totora reeds availability as well as water depth (Kent, 2008). These artificial islands are constructed from sheets of knitted Totora reeds. They also use these totora reeds for constructing their boats, as well as for food, herb tea element, arts and crafts. For daily use, they use boats constructed from reeds for fishing and gathering materials (Levieil \& Orlove, 2004). 
The Uros people frequently positioned their artificial islands adjacent to the shore. Their islands' mooring system is constructed on anchors that are connected to the base of the lake. Each platform has several blocks for houses (Kent, 2008). They maintained their artificial islands by adding a fresh new layer of dry reeds on the blocks each couple of months until it is nearly two meters high. They also made compost places to these artificial islands. Also, they used biodegradable materials compose to unite the reed sheets for degrading back to the waterbed (Radding \& Orlove, 2008). The Uros people share basic common services together like schools and public islands. They are also connected to the world as they are opened to use present technology like solar panels, television and radios. Also, they raise domesticated animals for food (Levieil \& Orlove, 2004). The Uros people is an outstanding example of an artificial floating land by existing regularly in equilibrium with their near shore ecosystem. Their simple and different lifestyle became an eco-tourism attraction therefore, giving them the sufficient income, they require in order to preserve their daily lifestyle (Kent, 2008).

\section{Conclusion and Influence:}

- The Uros people have an organised and simple routine which is focussed on their society's artificial islands and the rely on Totora reed in their daily life. They are organized and work together to preserve their daily life routine and their artificial islands. Future floating communities need to learn from this where every person should contribute in the community to preserve their daily life routine and adapt in order to survive. The Uros had to have mutual goals and determination to advance and sustain the community, artificial islands, respect for the environment, fishing, tourism, arts and crafts. 
- The Uros people offer early education as they have some primary school facilities. Therefore, future floating communities may likewise facilitate this early education and better understanding of the surrounding environment and the ecosystem.

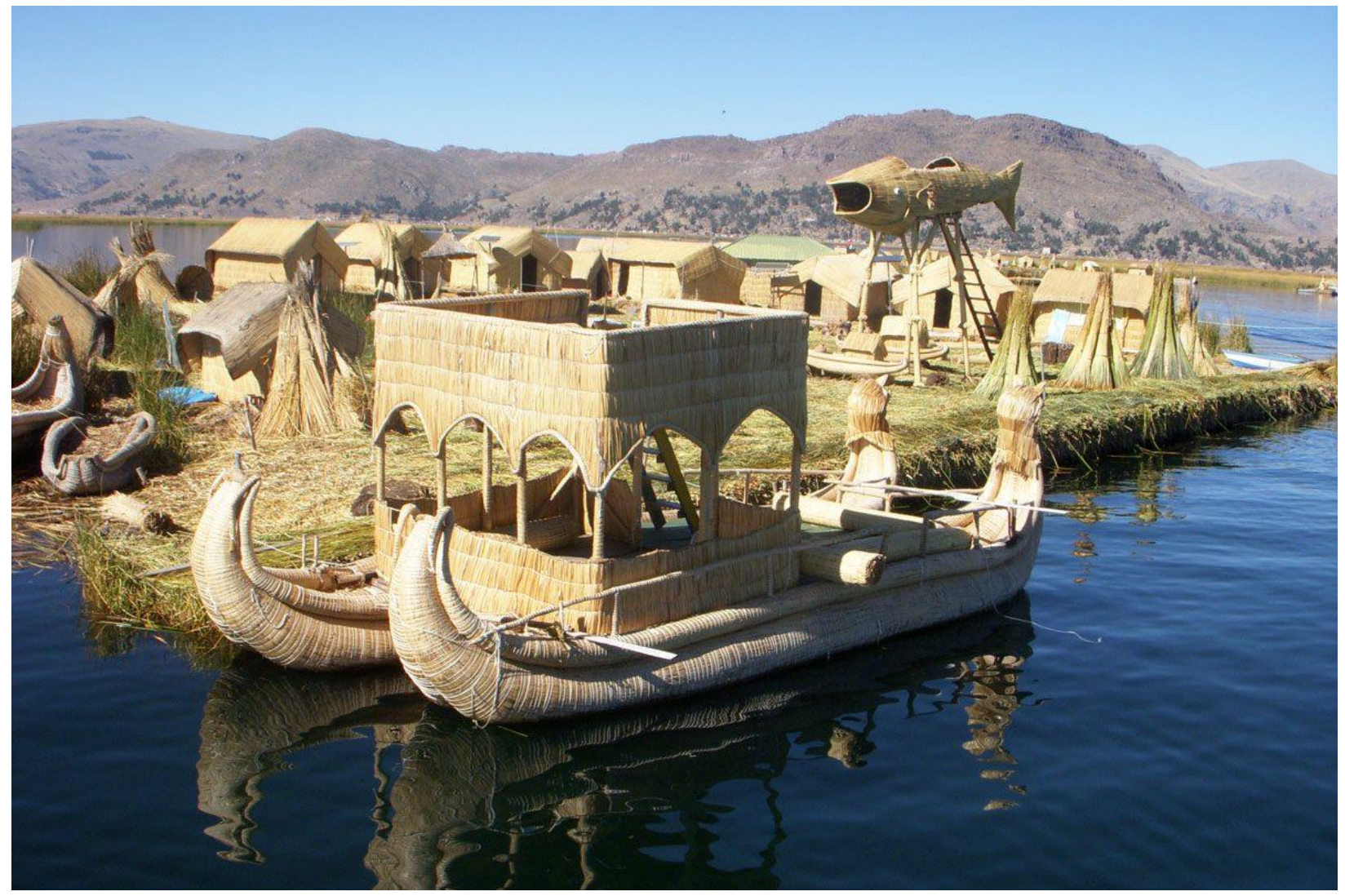

6 Figure 4.4: The extensive rely on totora reed ("13 Fascinating Facts", n.d.).

- The inventive usage of Totora as the completely ecological core building material and the composting value of the rotten Totora contributes a lot in the composting of the organic waste is very ecology friendly. The composting gasification outcome of Totora reed helps the islands by giving them more floating capacity. Nevertheless, the released biogases such as methane and carbon dioxide are bad for the environment. Future artificial islands biogas outcome from local bio waste 
may perhaps be harnessed such as in aerobic digestion process as an energy power source for the habitants. This is one of the Cradle to Cradle biological material cycle philosophies and from waste to food principles (McDonough \& Braungart, 2010).

- Uros people food production approaches could be useful in future artificial islands. This may result that the people of the future floating communities somehow be independent in food supply, decreasing cost expenditures and keeping a fresh food supply.

- Time and technology allow people to connect with the world. Modern technology could be a daily instrument for the development of the floating community. The community should manage to make an equilibrium when using these technologies, as that the excessive technology use could lead in to undesirable quantities of unrecyclable technical materials of waste which conflicts with the $\mathrm{C} 2 \mathrm{C}$ material recycling principles.

- The Uros used to construct their island platform, housing, boats, arts and crafts with one material. Using a biological rapid growing sustainable material that grows just next to the site location may be a great method for future floating developments.

- Reed can be used as a tea herb and for welfare. Medicinal plants and the welfare of the community should be respected in any future floating community. 


\subsubsection{The Ha Long Floating Fishing Communities, Vietnam}

Sometimes the reason why the community exist in an area like this is the source of living. The Ha Long Bay in Vietnam has 1600 people located in four fishing villages. Villages like Cua Van, Ba Hang Cong Tau and Vong Vieng in the Hung Thang community. The fishing families work in fishing and maritime aquaculture. The houses of these floating townships are light weight and constructed on floating platforms which are made from plastic containers linked to wooden frames (Wattanacharoensil \& Sakdiyakorn, 2016).

The floating houses contain todays kit's like furniture, radio and television. The fishers save fish in underwater hutches before being transported to be sold to the shops in the market places. The neighbouring islands have very sharp slopes for building houses. Therefore, the community is merely dependent on fishing making it a delicate lifestyle. Yet, these floating villages have the option to change their location when desirable. The floating fishing villagers form very close relations and as a result they take good care of one other (Wattanacharoensil \& Sakdiyakorn, 2016).

The main problem is in present time for the Ha Long fishing people are mostly ecological due to the bad hygiene, the waste and by-products that gets released in the water such as industrial runoff, absence of toilets and unaware tourists. Global warming has lately been responsible in increasing strong storms resulting in killing the fish and damaging properties in the zone (Wattanacharoensil \& Sakdiyakorn, 2016). Such issues question the future of such sort of communities and push us to solve the ecological solutions of such artificial islands. One more issue is fresh water supply that is collected from rain and occasionally is transported from seashore (Wattanacharoensil \& Sakdiyakorn, 2016). 


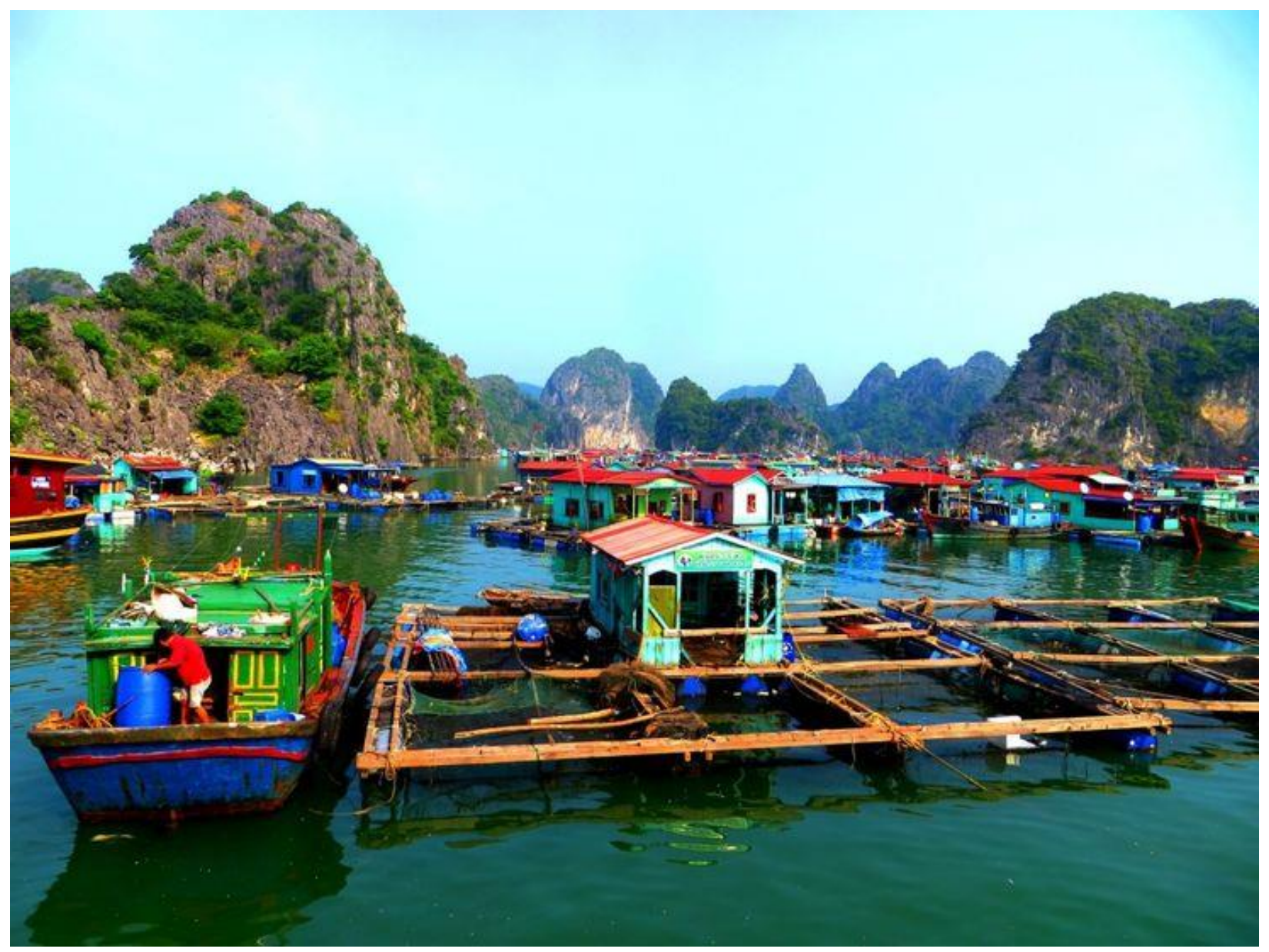

7 Figure 4.5: The Ha Long fishing society (Stroud, 2013).

The Ha long floating villages is a perfect example for a floating community that have environmental problems that disturb their way of living and as a result threaten their very being in the area.

Conclusion and Influence:

- Where the wellbeing problems such as bad hygienic and the absence of suitable clean water source is not resolved then the effects to the welfare of the community is at great risk. 
- Where environmental problems such as waste discharge, industrial by-products, toilets black and grey water, and unconscious tourists are not resolved then the aquatic ecosystem is in big risk. Therefore, this must not be the situation in similar communities as that water must be highly respected in such floating communities.

- Maritime aquaculture is a great possible potential for huge scale developments as floating communities, but first the environmental matters of similar scales must be resolved correctly. This possibly will be a good potential for producing food locally.

\subsubsection{The Floating Market Community in Bangkok}

Thailand has a history of active Floating Markets. Most of Thailand's communities were founded around river banks while people used small boats for navigating and crossing them. (Wattanacharoensil \& Sakdiyakorn, 2016).

Although this example is not literally a floating habitat, but still has an influential feature in floating communities' developments where it holds features which may affect the existence of floating communities such as water traffic, fish market, grocery, flower, herb, arts and crafts and various other local products. Activities established connected to maritime life is very important particularly in seaside areas like the Nile Delta. A similar activity may function for locals as shopping, services and trading as well as a tourist attraction.

\section{Conclusion and Influence:}

- The floating market is a significant public, cultural and market approaches which is an appropriate fit for floating community where activities take places such as selling and production goods as vegetables and fish. 


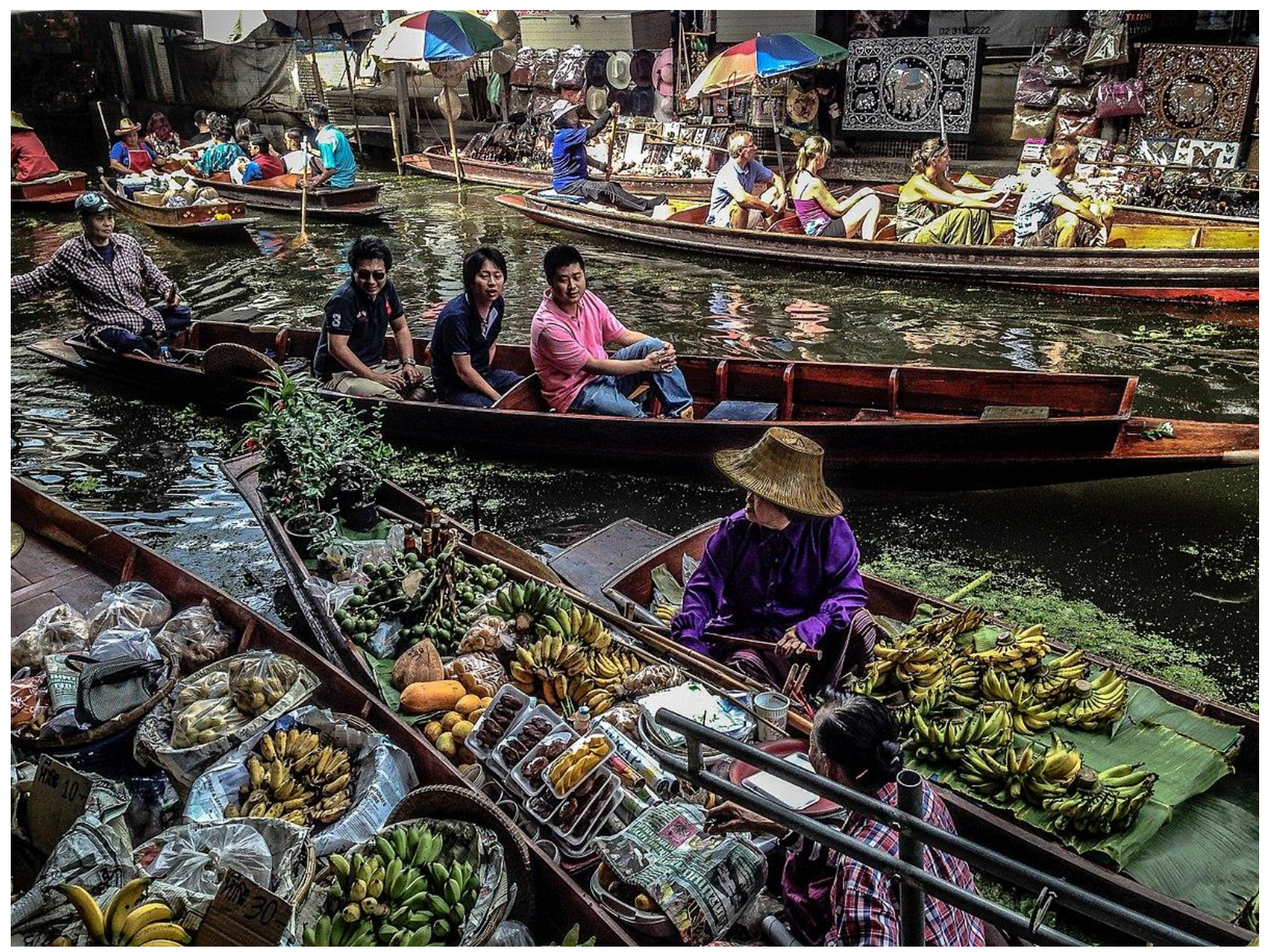

8 Figure 4.6: Floating markets in Bangkok, Thailand (“Explore Bangkok”, n.d.).

- The mobility feature is of great importance here as connecting to the coast where it is a sustainable human power-driven paddling activity by using small boats is heathy and environmentally friendly way of transportation in such rivers and floating markets.

- The formation of recreational activities such as floating commercial and markets as well as water related activities may be achieved by creating attractive floating developments which are planned to offer a platform of similar scale. Future floating urban developments may have to establish some sort of a waterway network that offers routes to connect community buildings creating a river-like 
effects. The distances between shore and the floating community areas where floating markets might exist is also important to notice. Although, there may not be enough market when it comes to covering long distances.

All the above criteria were taken into consideration and have dramatically influenced the architectural design guidelines and the outline of the actual proposal for the Nile Delta. The establishment of floating markets may income the floating community and encourage new businesses and activities around the floating markets.

\subsubsection{Harvest City, a Recovery Concept Proposal for Haiti}

The Harvest City is a floating city concept which was designed by Schopfer Associates LLC as a solution to the catastrophic earthquake that happened in 2010 in the Republic of Haiti (Lomholt, 2010). Although the concept has not thus far been executed, but the features it withstands was an inspiration for the future concept development for the Nile Delta. The whole concept involves on two main values. The first value was the design which was founded on the archology which highlights the environmentally sustainable and functional urban platforms (Smith, 2013). This is a step further towards achieving the philosophies of C2C Building Charter where both achieve the Architectural and environmental features required for the built environment.

The philosophy the Harvest City concept demonstrates was founded on the Charter City economic model that was intended for struggling countries. The Charter City may be an initial idea towards a similar city scale for future floating urban developments presented by Paul Romer (Romer, 2015). As stated by Romer Charter, cities share two fundamental principles; the first is that people have be allowed to decide to move in, secondly is the 
equality to guarantee that everybody will have a stake commercially and socially as a citizen (Romer, 2015).

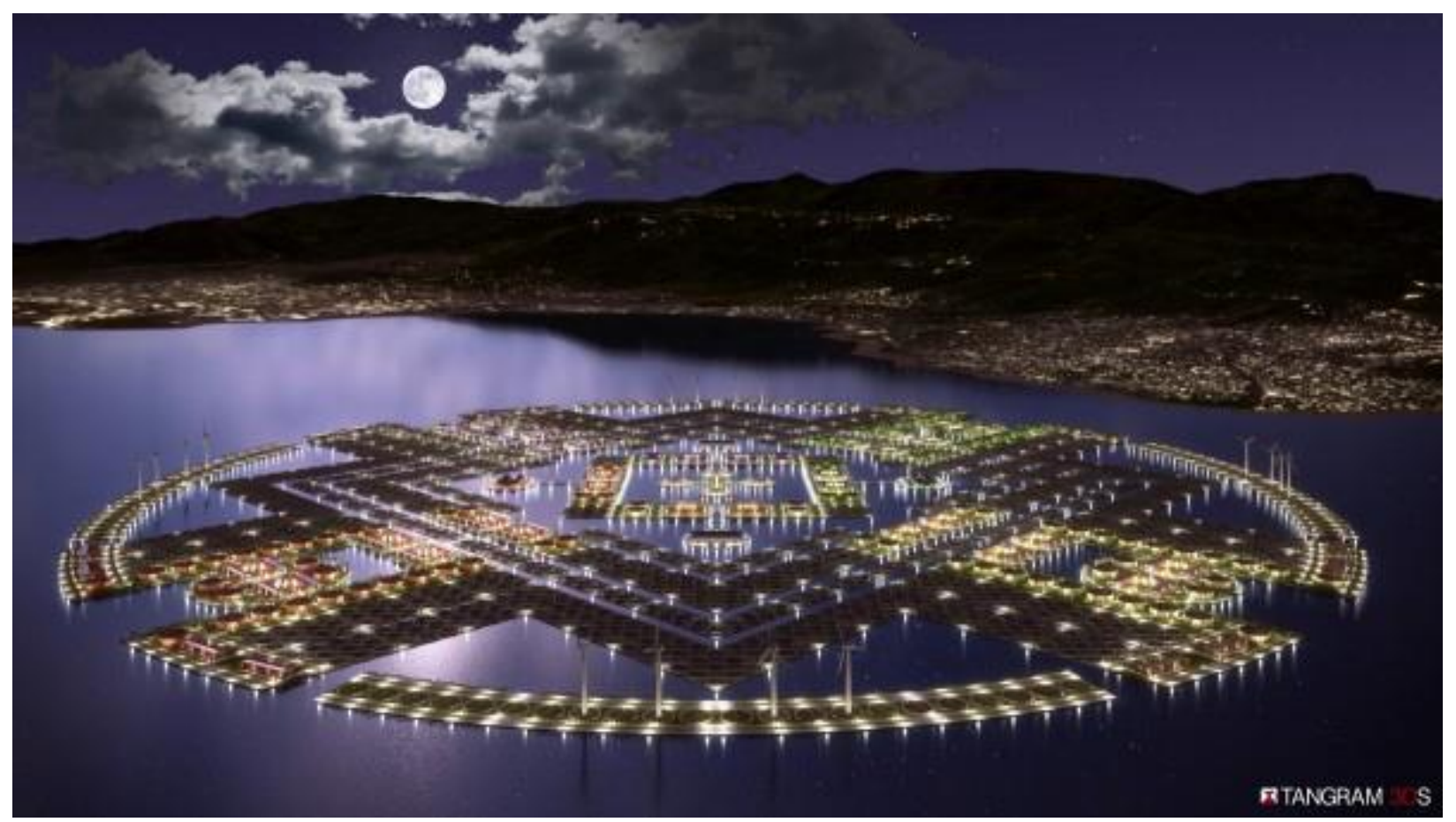

9 Figure 4.7: Harvest City ("Harvest City / Tangram 3DS", 2010).

Harvest City plan offers an agricultural area which will take place in two thirds of the project space while the other one third will be light industrial where the city is aimed to have an economic capability joined program (Lomholt, 2010). Although the economical model program was tempting, but also it required the support and collaboration from local authorities, investors and businesses to have a mutual goal. The Harvest City, Schopfer Associates has indicated that the drivers were relocating the people from the damaged areas and establishing fresh stable zones. Reforming the agricultural and fishing abilities and as a result making an economic development (Lomholt, 2010). The Harvest City was designed to accommodate 30,000 inhabitants. Schopfer architects planned to design the city to be 
practical and easily built with a simple yet advanced design. The city's diameter is around $3.2 \mathrm{~km}$ with connections to floating modules (Lomholt, 2010). The outline of the entire community was split into four community regions which have four levels high. The external border of the community had four floating crop arcs which create one full circle of crop as well as other harvesting areas with canals (Lomholt, 2010).

The Harvest City was designed so the middle harbour area would host essential buildings such as schools, administrative, public activities and markets (Lomholt, 2010). The district of the housing buildings had tilted walls of four levels floors high, with white concrete walls as well as floors system which offered high insulation (Lomholt, 2010). Insulation is vital for decreasing the interior temperature. The Harvest City concept had mostly 45 square meters studio apartments. Where $10 \%$ of the total apartments holds one or two-bedrooms apartments. The aim was to host 1,500 inhabitants in 560 apartment units (Lomholt, 2010). This was rather an appropriate fit for a small society scale development. The apartments had minimal features where it integrated a pre-fabricated kitchen and two separating walls. The Harvest City concept had a water harvesting which was handled by inclined roofs which focussed the water to fill containers to begin a process to get clean water via drinkable desalination technology which is planned for each apartment (Lomholt, 2010). The bamboo usage was an ecological solution which is fast crowing material that has great resilience where it could be used in various areas in construction.

The bamboo integrated in the design was for big passive shades. It was implemented over the cross vented window which resulted in improving the air-cooling potential. The dormitory bathrooms are used for both men and women separately in every floor which as a result centralizes the sewage and the grey water collection (Lomholt, 2010). 
The entire Harvest City's city concept was planned so the boundary can be protected by the wave attenuators therefore avoiding probable hurricanes and storms from making any harm. In this city scale project of development, a suitable assembly fit to the seabed is needed and here cable connection is implemented to preserve the floating city fixed and secured. Low draft dead mass and low-profile buildings plans were created for more protection capabilities (Lomholt, 2010). In this concept, recycling concrete wreckage caused by earthquake and other natural disasters would be a breakwater filler material which was taken as a sustainable solution (Lomholt, 2010).

This feature act jointly with the $\mathrm{C} 2 \mathrm{C}$ Building Charter as that recycling and materials usage opportunities whether recycled or as an alternative were pointed out (McDonough \& Braungart, 2010). The main material used in both the design as well as the floating platforms is concrete for the hulls. Most of floating structures projects use maritime concrete as well as similar reinforced concrete in the design. The architects reveal that the long lifespan of the concrete hulls ranges from 60 to 100 years as well as having low technology in fabrication and assembly on site (Lomholt, 2010). Lastly, the architects offer a safe waste release, as that waste processing is held as a decentralized solution where it has a sequence of compacted treatment plants by low energy consumption (Lomholt, 2010).

\section{Conclusion and Influence:}

- The philosophy named Arcology (Smith, 2013) as well as C2C Building Charter goes to the same path where architecture and ecology meet. C2C Building Charter aims to have sustainable as well as reformative features in the concept proposal.

- The Charter City philosophy proposed to construct floating communities as two third of the project would function as an agricultural zone and the other one third 
would function as a light industrial city as a fundamental program of economic power. This philosophy may be integrated in future community concept projects like planning possible platforms to host small businesses and agricultural or the possibility of creating a community farming activity to combine the small businesses to help the habitat, habitants and visitors.

- Bamboo usage as a light material with valuable sustainability feature has been taken into consideration as it is a famous used material in the Nile Delta's cities.

- The tilt wall strategy proved its effectiveness as an exterior shading system. Such feature has been taken into consideration where it combines effectiveness as well as low technology.

- The city's border wave attenuator held important issues by both blocking damaging waves or tsunamis while permitting the light boats traffic system to continue doing their work normally inside the floating city. Such factor with a circular shaped has encouraged the capabilities of the wave attenuator as a floating community proposal.

- The boat-use for moving inhabitants and goods is herein considered. Such way of transportation is considered for a sustainable mobility feature in the proposal.

- Rainwater collecting, and greywater sanitization are implemented for the community. Such a useful feature is implemented in the design as the Nile Delta's high average rainfall in the winter. 


\subsubsection{Floating Houses in IJburg, Amsterdam, The Netherlands}

In Ijburg, floating houses designed by Marlies Rohmer Architects (Witsen, 2012) are some of the best examples of present developments in modern floating houses making a 75 -floating housing community. Although, floating houses are not new to the Netherlands, it was only lately where such floating houses have been considered as a real solution there (Witsen, 2012). In their area, the floating houses form a segmental yet different architecture to Ijburg, Amsterdam.

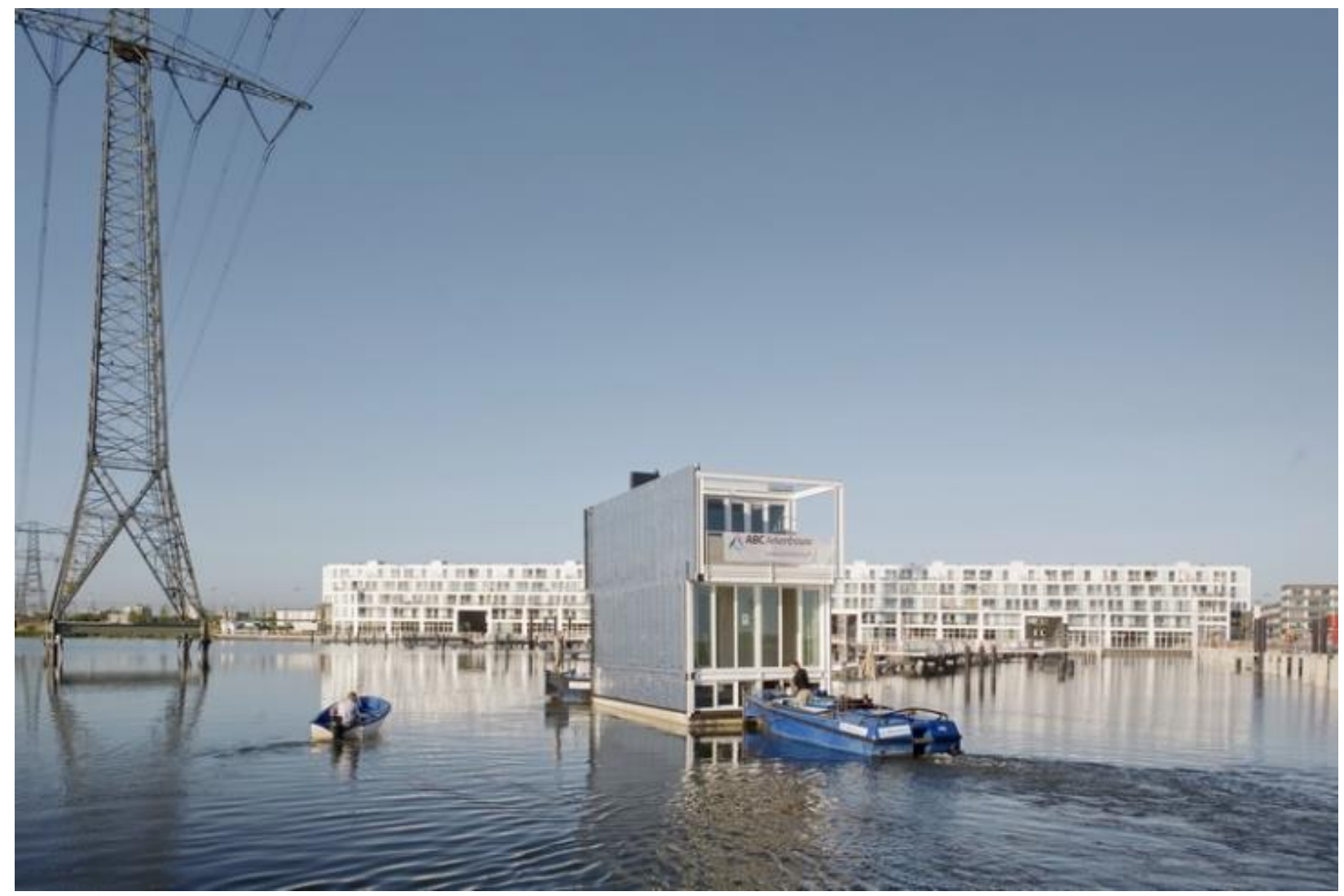

10 Figure 4.8: A floating module house being transported to site location (Architectenbureau Marlies Rohmer, 2011).

The IJburg floating houses are either rental and owned (Witsen, 2012). Rohmer Architects consider that the two driving forces that impact the development and the interest for living 
nearby the waters. Initially, the SLR plus more rainfall. Secondly, the scarcity of buildable land. The IJburg area has constructed whole floating communities which integrates piers and canals too (Witsen, 2012). Rohmer architects have designed their floor plans to achieve three layout levels which have several layout options (Witsen, 2012). Such design characteristics helps the building in adapting for the changed requirements through time such as in the C2C Building Charter (McDonough \& Braungart, 2010). The architects' plans suggest that in the underwater first floor area which has the bedrooms as privacy in needed. The following level is higher from the ground as the sea level is where the floor offers privacy from the boats traffic. It also offers a patio and a dock for the boat. The upper level has two balconies letting light in as well as offering comfort and socializing spaces (Witsen, 2012). The architect's suggests that building on water required considering the special nature of both water and the environment that surrounds it (Witsen, 2012). Such significant feature should be in every floating community development. Their concept highlighted the opportunities to incorporate the surrounding environment to take place in people's daily lives. For instance, their design gives the possibility to feed the swans from each kitchen window as well as ice-skating around their houses (Witsen, 2012).

\section{Conclusion and Influence:}

- The typical modular building process with sizable difference influenced the future floating design particularly after each apartment scale design is viewed. The floor sizes and interior spaces must involve characteristics permitting flexibility of present spaces such as the possibility of the mobile wall system to permit modifiable layouts in all floors. Such features are as the C2C Building Charter idea of altering to the changeable requirements throughout time. 


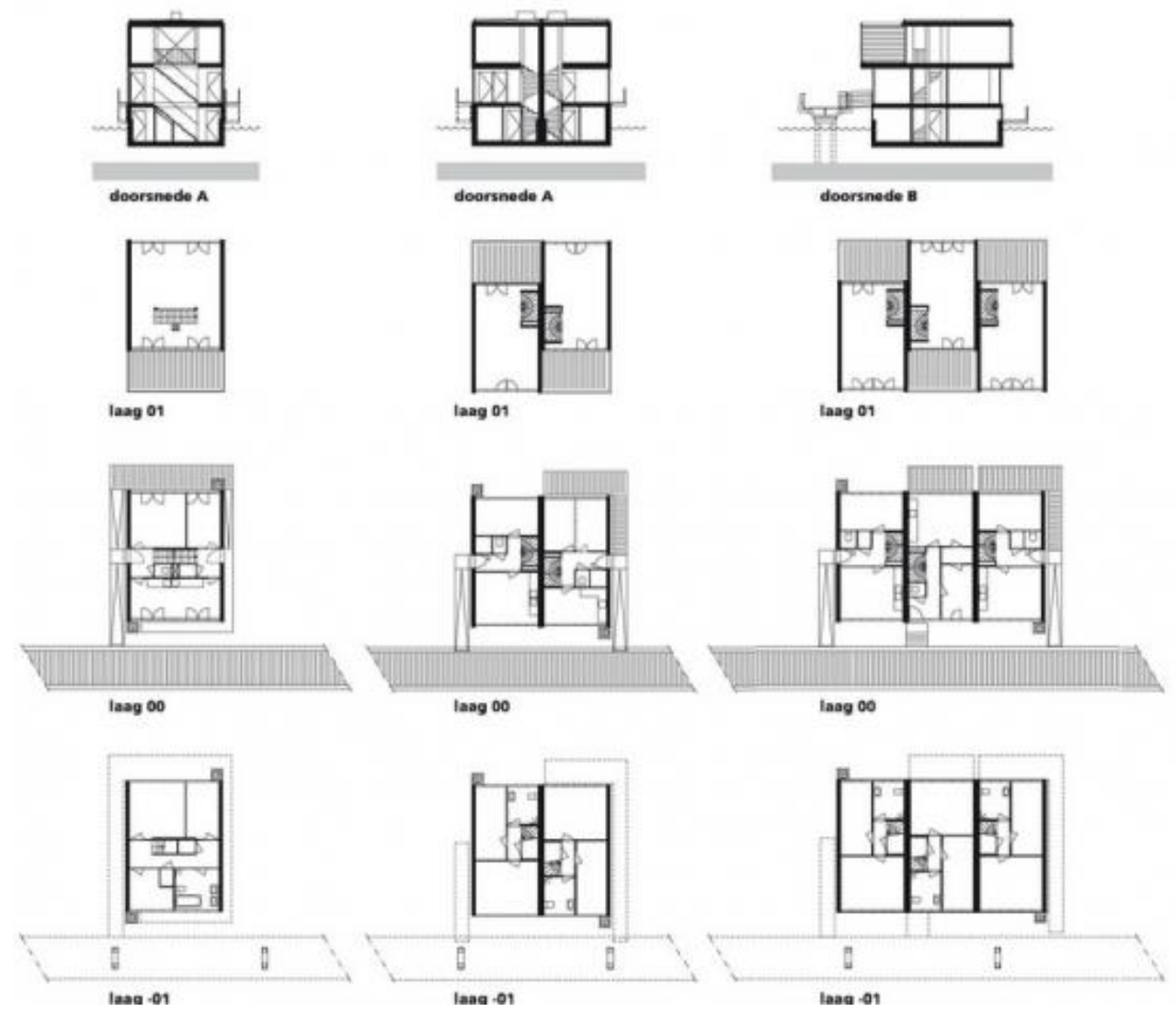

11 Figure 4.9: Varieties of apartment sizes from similar modular units (Architectenbureau Marlies Rohmer, 2011).

- The floating building components involved prefabricated parts that was assembled in site and such feature has been taken into consideration for the proposal for its efficiency and pre-fabrication potentials.

- The houses were water-transported to the site after being constructed on a shipyard (Witsen, 2012). This might work even in larger buildings that may contain modular construction design like in the floating community proposal.

- Such life on water idea has functioned as motivation such in Ijburg. Such features of on water life must be improved and enriched by integrating recreational areas and connecting nature with the buildings. 


\subsubsection{The Lily-pad Floating City Concept}

Architect Vincent Callebaut has planned a probable replacement for the rising seas refugees in the shape of a "Lily-pad" design. It is designed to be an entirely self-sufficient floating community which could house up to 50,000 inhabitants (Vincent Callebaut Architectures, 2017).

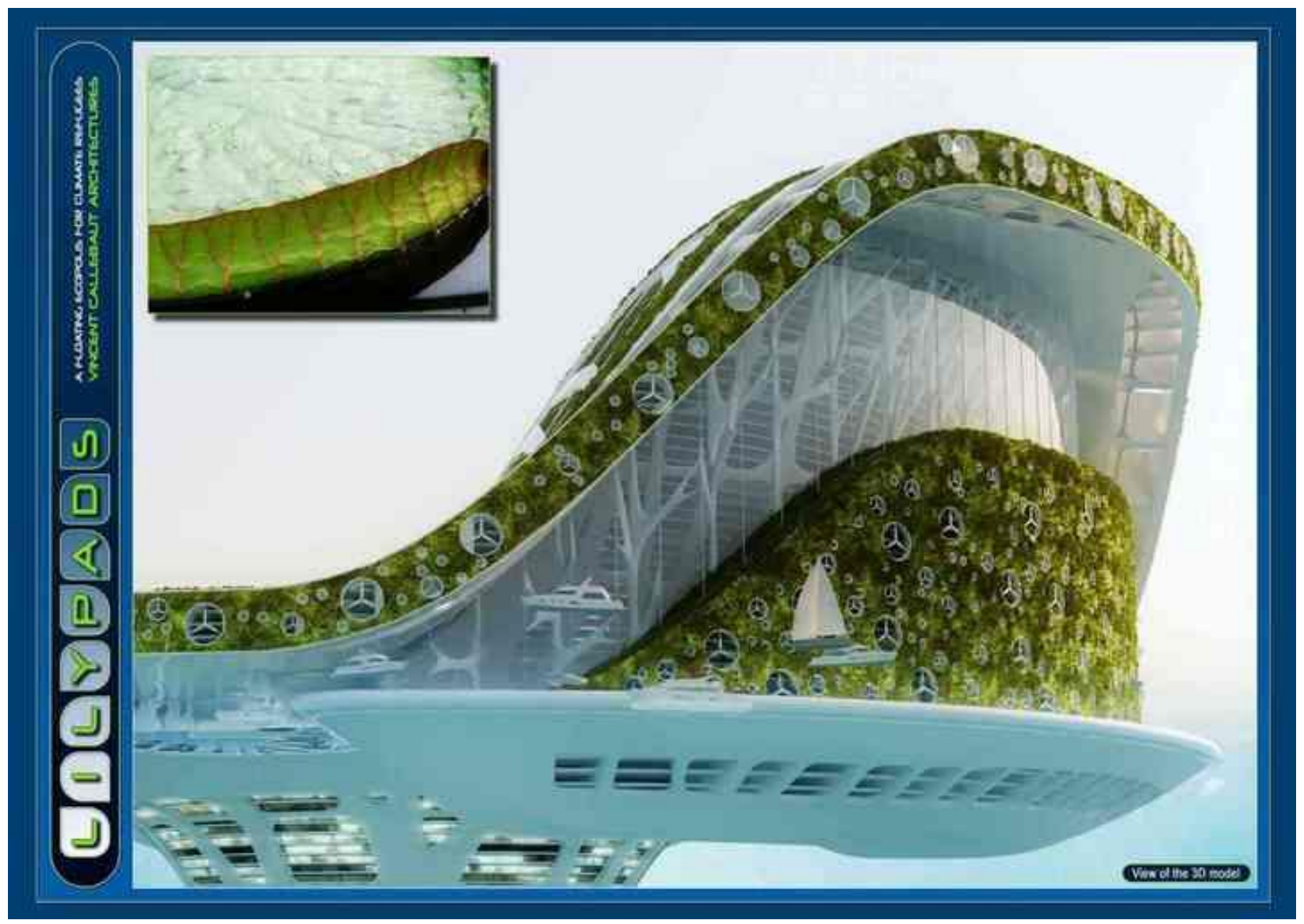

12 Figure 4.10: The design of the Lily-pad concept showing the concept influences ("Vincent Callebaut Architectures," 2017).

Through an outline that is highly influenced by the grooved shape of the leaf of the Victoria Amazonica lilies flowering plant multiplicated 250 times. The dual layers of the 
floating Eco-polis will be created out from polyester fibers shielded by a coating sheet of titanium dioxide ( $\mathrm{TiO} 2)$, just like the anatase that reacts with the ultraviolet rays and as a result it absorbs the atmospheric pollution through the photocatalytic effect which is similar to the method of the air-cleansing concrete and pavement stone tiles (Vincent Callebaut Architectures, 2017).

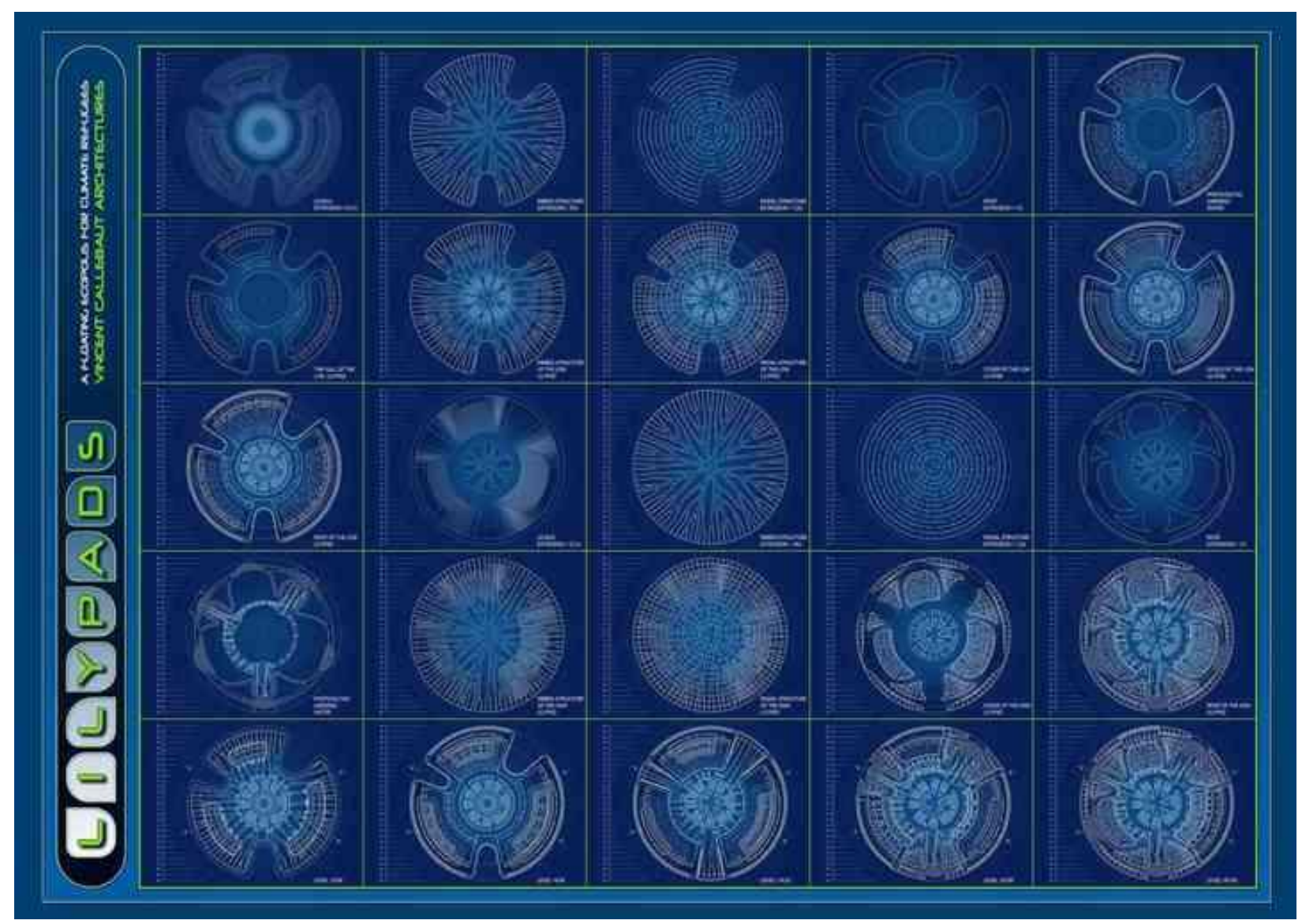

13 Figure 4.11: Different layers forming the Lily-pad project ("Vincent Callebaut Architectures," 2017).

A complete self-sufficient objective, the Lily-pad addresses the four focal challenges as stated by the Organization for Economic Cooperation and Development (OECD) in March 2008. The challenges are environment, biodiversity, water and wellbeing. The project has 
reached a positive equilibrium with zero $\mathrm{CO} 2$ emissions through implementing all the renewable energy sources such as solar energy, thermal and photovoltaic energies, wind energy, hydraulic energy, tidal power station, osmotic energies, and Phyto-purification, biomass, therefore creating further energy than the energy it consumes. The Lily-pads can be situated nearby a land or free positioned in order to follow the sea streams wherever they might come from.

“True biotope entirely recyclable, this floating Eco-polis tends thus towards the positive eco-accountancy of the building in the oceanic ecosystems by producing and softening itself the oxygen and the electricity, by recycling the $\mathrm{CO} 2$ and the waste, by purifying and softening biologically the used waters and by integrating ecological niches, aquaculture fields and biotic corridors on and under its body to meet its own food needs." (Vincent Callebaut Architectures, 2017).

Three harbours as well as three elevations border the core where there is an artificial lagoon which lies entirely under water level in order to act as the stabilizer for the floating structure. The three harbours and elevations could be devoted to work, shopping as well as entertainment. Whereas the suspended gardens and the aquaculture farms are situated under water level, then they could be used for producing food as well as biomass (Vincent Callebaut Architectures, 2017).

\section{Conclusion and Influence:}

The Lily-pad design embraces aspects that are worth considering for the floating community proposal for the Nile Delta.

- The design of the Lily-pad contains aspects such as the curving arc formed cave like shading elements that cools down the air as well as the seabed. Such characteristic 
might be useful in the design as that natural ventilation is the best desirable method to resolve the building cooling and lower the consumption of energy. Yet, such design could have an appealing worth simultaneously.

- The usage of diverse green roofs was influential and might contain recreational as well as farming activities. This might be useful by making greenery for any floating community project specifically in the roof floor.

- The feature of welfare recreational activities as well as spas were influential for the welfare of the people in the future floating community having optimistic consequences such as advancing and encouraging the healthy lifestyle.

- The main features of the Lily-pad design have been the wellness-center, the resort and a possible hotel-based trades. Even though if the floating building does not have a client as driver, such setting might be handy as the probable operator in the project to influence on the design criterion.

- Although the Lily-pad design project is projected to offer a habitat to the rising seas refugees immigrants, on the other hand it appears like such people are most probably the last people that could afford such luxuries residence where it could probably be an extremely expensive investment of real estate. That's why such aspect was deeply measured when designing the floating city proposal for the Nile Delta to create an affordable project not only for the higher-class refugees, but also to the middle-class and lower-class refugees.

- The integration of the topsoil as well as the re-usage of carbon is implemented in the Lily-pad concept. 


\subsubsection{The Jacques Rougerie Foundation}

In less than twenty years, 2,5 billion people will be living near shorelines. Currently, there are seven billion populate the earth, and by 2030 the population will rise to nine billion people. Such rise in population needs to be managed well for living spaces especially the shorelines. Whereas currently over 60 percent of the Earth's inhabitants are living within just $100 \mathrm{~km}$ from the shorelines, where such percentage is projected to increase to 75 percent by 2030 , which represents up to than 6 billion people. Where it is predicted that the sea level will rise to $70 \mathrm{~cm}$ by the year 2070 therefore, making it an important issue to be addressed. The world has already started witnessing the climate refugees' problem (Fondation Jacques Rougerie, n.d.).

Jacques Rougerie Foundation aims to offer new generations with the required knowledge so they can create a better future for the living atmosphere. The values and standards that Earth stands for were taken into consideration. Also, to increase people's awareness, support and action for shaping a new relation between humankind and the natural environment. To globally encourage and inspire the architecture and technological innovation, also to inspire for new designs which are related to the arenas of the sea and space, considering to the principles of sustainable development (Fondation Jacques Rougerie, n.d.).

The water and space that will define the destiny of our next civilisations where that exploring water and space are the two main journeys of humankind. They will most probably establish our future. Where the water surface dominates earth occupying three quarters of our planet's surface, the water has a marvellous potential to qualify us to encounter our challenges in the next decades. Numerous findings are essential for the future of civilization are yet to be discovered deep underwater such as pharmacological solutions, energy, food, 
and other. Therefore, little has been discovered of the space which environs us, such sixth continent soon will cause an increase to significant innovations (Fondation Jacques Rougerie, n.d.).

The foundation encourages the imagination and innovation for the future as acting fast. Challenged with such scenario, Jacques Rougerie wanted to form a suitable outline for the advance of new talents such as architects, engineers, and designers who are motivated to create and shape the environments and lives of the future, improving the sea and space potentials with respect to such God-given creations. Since 2011, the worldwide competition in architecture via the foundation has permitted anonymous architects to achieve the distinguishability as well as the credibility on the global platform (Fondation Jacques Rougerie, n.d.).

The competition submissions by different architects, designers, and engineers which is held by the Jacques Rougerie Foundation has had a great influence in shaping the thesis in terms of the design and architecture. The next part will cover some of the inspirations designwise example and then the concept design model for the Egyptian Nile Delta.

\subsubsection{H2O - Humanitarian Harbour of the Ocean}

The H2O - Humanitarian harbour of the ocean is a concept done by Zhicheng Weng and Zichengin Cui in 2016 (Zicheng, 2016). The project was a Special Mention in the "Architecture and SLR" category in the 2016 issue of the International Competition in Architecture of the Jacques Rougerie Foundation. The concept project has addressed issues such as atmosphere, ecosystem, environment, floating, futuristic, green, growing, house, and infrastructure development. 


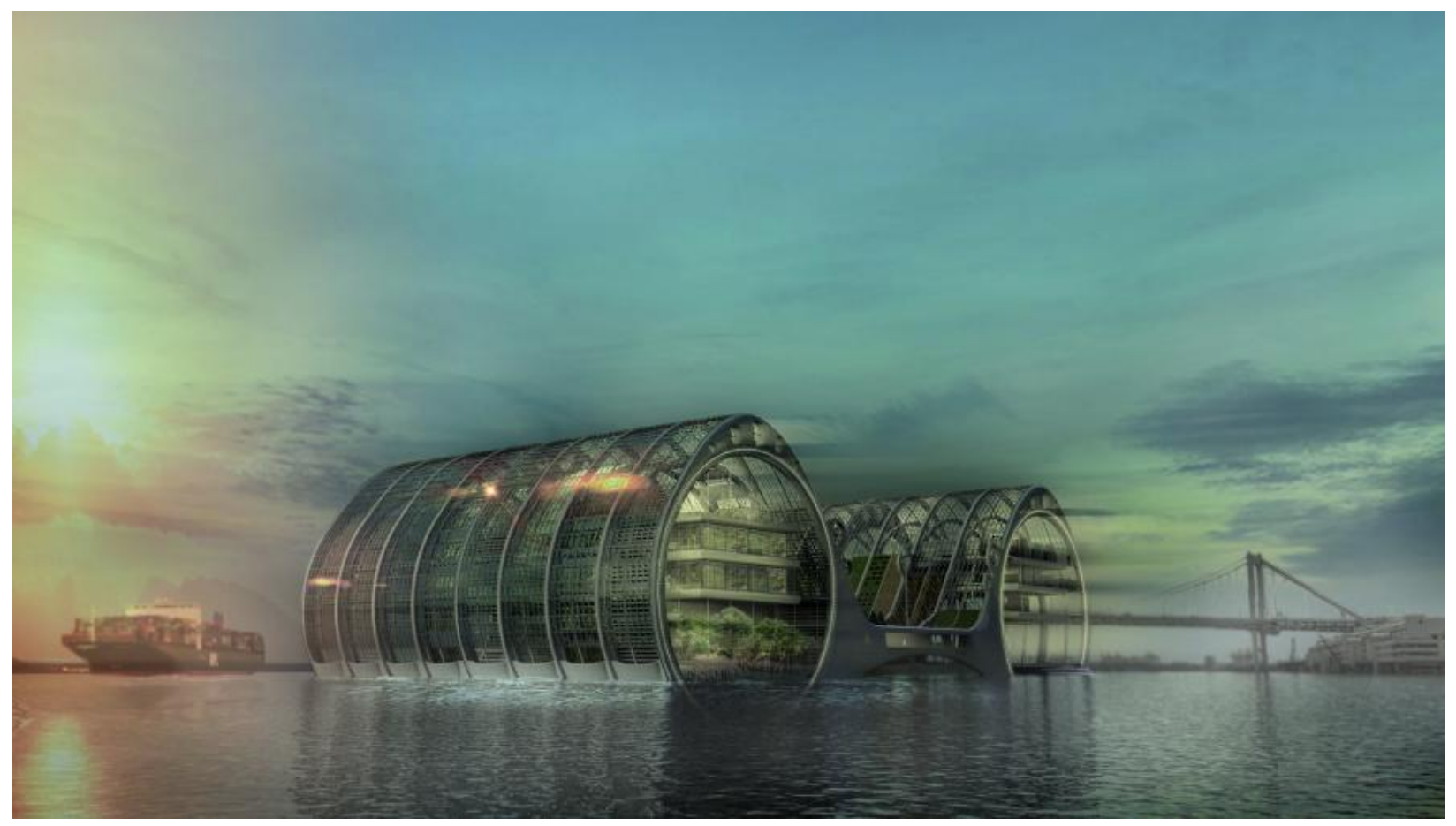

14 Figure 4.12: The Humanitarian Harbour of the Ocean concept "H2O” (Zicheng, 2016).

Such development addressed the belief that the SLR is a phenomenon that will continue rising throughout the next centuries. Creating floods, increasing coastal erosion, vicious natural catastrophes. Humankind will face incredible challenges in the global landscape scale due to it as such rising waters are anticipated to restructure profoundly our existing geography. Undeniably, a lot of coastal areas around the world, either urban or agricultural, would possibly be flooded, which is already threatening millions of people. The unavoidable truth is the significant amount of people which has basically already started to show signs of mass relocating. It is predictable that there will be up to a total of 250 million climate refugees by the year 2050 (Zicheng, 2016).

The project is projected to host up to 250 million inhabitants in 33 years, such community will be forced to move leaving their homes due to the shocking natural catastrophes that is getting more and more common (Zicheng, 2016). 


\section{Conclusion and Influence:}

The $\mathrm{H} 2 \mathrm{O}$ design embraces aspects that are worth considering for the floating community proposal for the Nile Delta.

- The molecule was named Humanitarian Harbour of the Ocean (H2O). It has the desire to find a residence to give such people the possible habitat to live in. Also, it is also a VLFS floating farm which should offer resources for its population. In this plan, the three architects have implemented the worlds most advanced agricultural techniques, which is aeroponics, aquaponics, or even entomoculture (insect farming), in order to create a self-sustaining eco-system that is named "high-tech permaculture" (Zicheng, 2016).

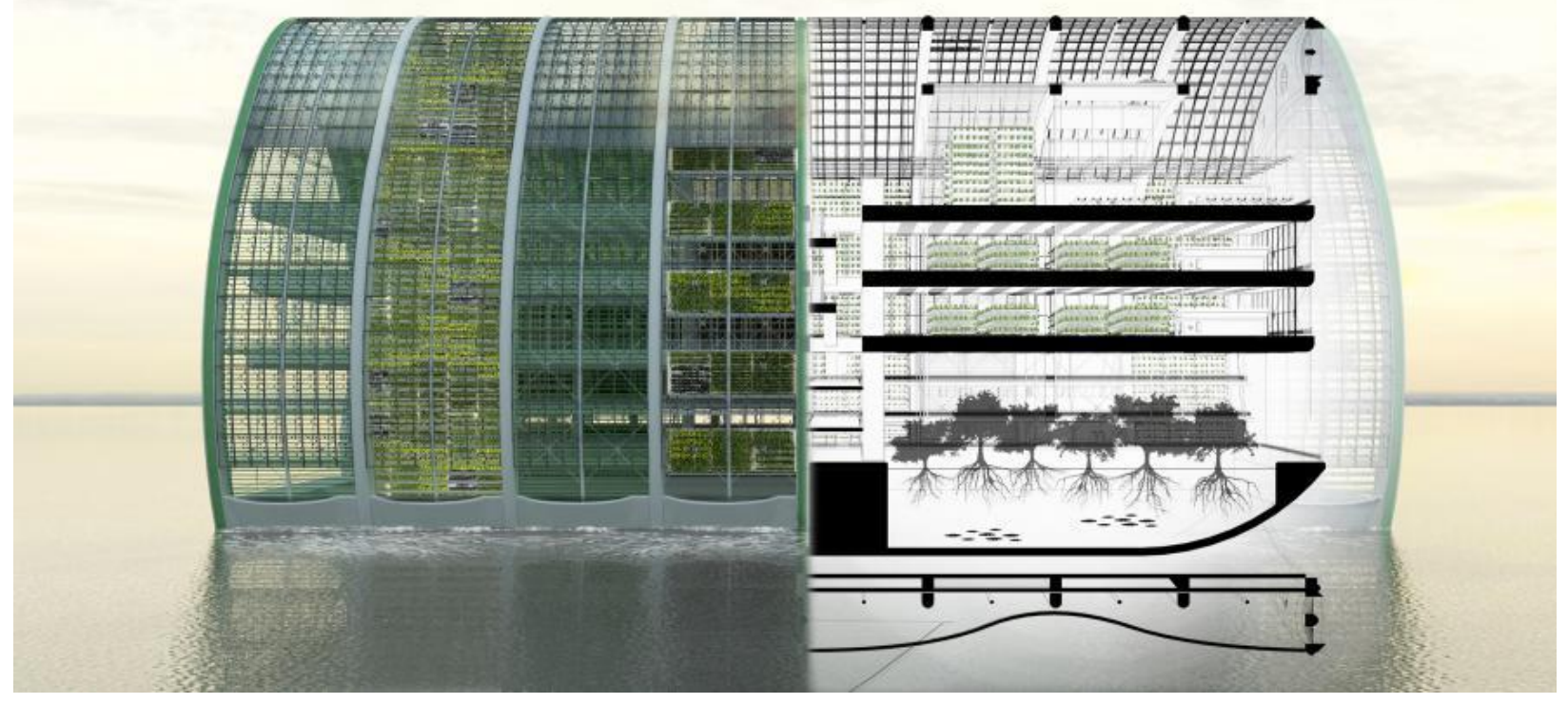

15 Figure 4.13: Section Elevation of the H2O concept (Zicheng, 2016). 
- Confronted with such a disturbing vision, H2O is a caring floating farm VLFS project which reacts to such a challenging call. An emergency habitat project which can accommodate around 500 climate refugees in a total of 250 dwellings.

- It is safe to say that it is comparable to a community or a small neighborhood, such a floating building platform is in general a concentrated farm which purposes to reach food and energy independence.

- Via all the furthermost advanced agricultural methods like aeroponics, aquaponics, or the entomoculture, the $\mathrm{H} 2 \mathrm{O}$ farm proposes a self-sustaining ecosystem which is named "high-tech permaculture".

- The H2O concept is of a modular structure which is able of adapt to the constant phases of the rising waters. For the moment, the $\mathrm{H} 2 \mathrm{O}$ module is planned to be positioned neighbouring a town which is directly endangered by a possible natural tragedy but could also be used as aa urban farm presenting some local products to cities that lack farmable lands.

By the year 2100, the union of numerous H2O modules could produce a floating urban development, while in the same time linking and shielding cities endangered by erosion. When thinking in the long term, by 2050 a bigger circular grouping of $\mathrm{H} 2 \mathrm{O}$ modules could form an actual floating city rather than a small separated community, resulting in independency from the real coastline lands. Therefore, H2O could reach the goal "live at sea" by presenting a pioneering idea and a productive archipelago (Zicheng, 2016). 


\subsection{The Seasteading Institute}

Present floating community developments have seen huge advancements globally in the past few years. That can be seen by the number of big scale developments that was demonstrated recently on the media. It is likely that the future would hold much more of such developments.

Architects, corporations and authorities are finding new ways to advance in floating city scale developments specifically in inhabited seaside areas as floating developments may offer better prices when comparing to the traditional land reclamation high land prices. The municipal matters, principles, standards and sustainability features for floating buildings are yet under development in many may countries around the world.

\subsubsection{Green Float, the Botanical City Concept}

The Seasteading Institute (TSI) and some corporations such as DeltaSync and Shimizu Corporation have multidisciplinary design studies developments and are pointing out new questions when developing concepts for floating city scale. DeltaSync and Shimizy Company have researched cities which have modular building modules. Shimizu Corporation developed the "Green Float" project offering modular floating city scale to accommodate 40,000 inhabitants (Shimizu Corporation, 2010). The DeltaSync company has developed the 'Blue revolution' project where it plans for spaces for food production and other developments Czapiewska et al. (2013). 


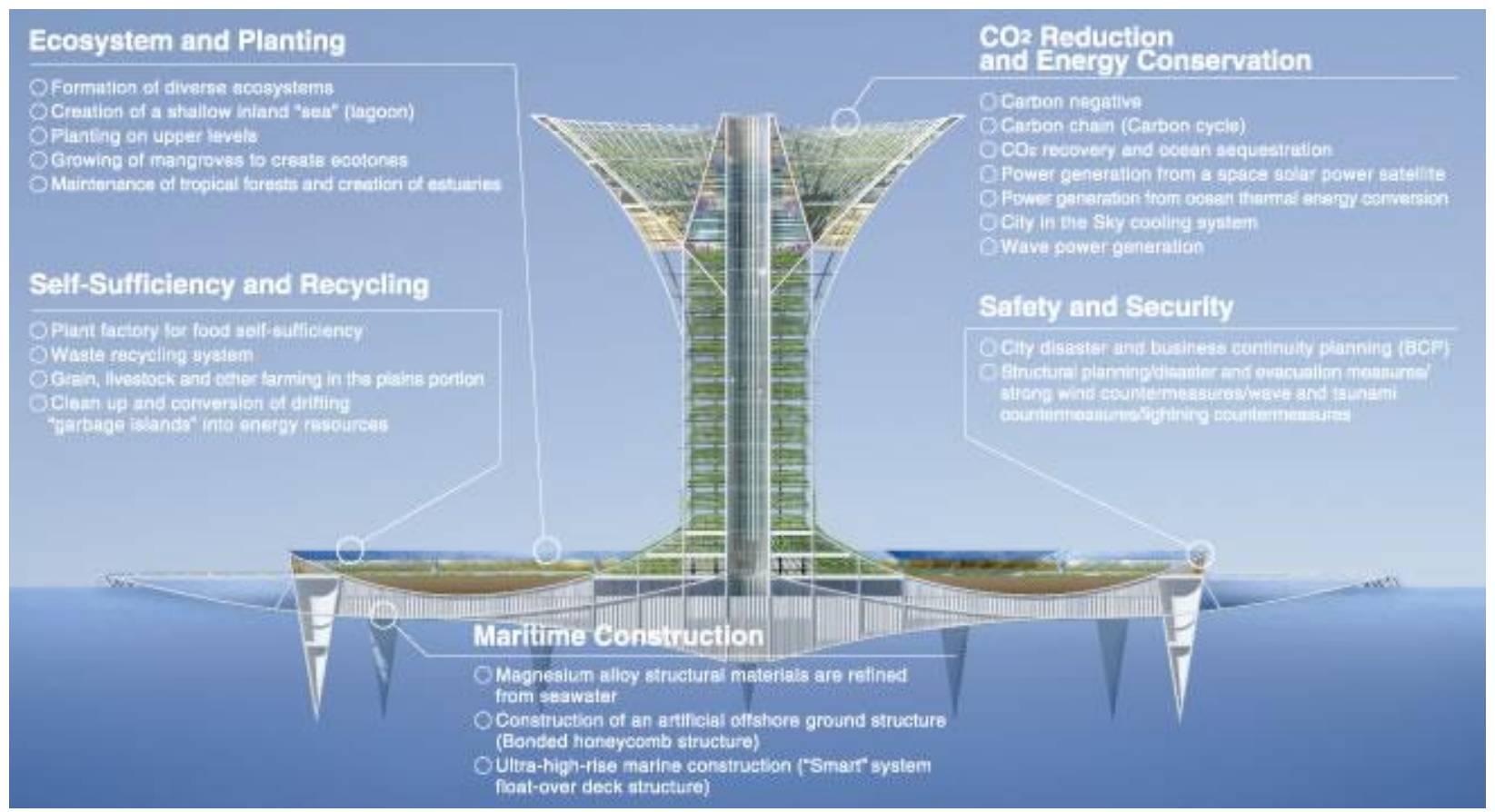

16 Figure 4.14: The Botanical City system demonstrating its sustainable features (Shimizu Corporation, 2010).

After catastrophic earthquakes like the one that happened in Haiti in 2010, some architects such as Schopfer Associates LLC decided to create an entire floating community project such as the "Harvest City" project.
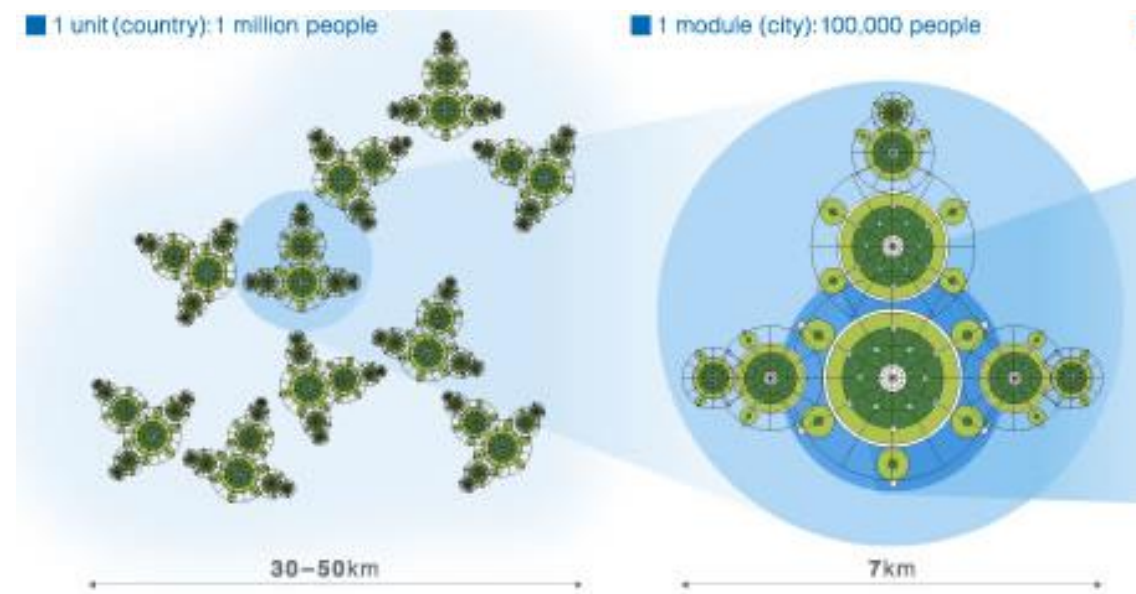

1 cell (district): 10,000-50,000 people

17 Figure 4.15: The Botanical City Modules (Shimizu Corporation, 2010). 


\subsubsection{The Floating Island Project, French Polynesia}

DeltaSync has finalized its initial design in December 2013. The idea is a community which is planned on two modular platforms, one is squared module while the other is a pentagonal one. The square module dimensions are 50 by 50 meters each side, where the pentagonal module dimensions are 50 meters each side. Both squares and pentagons could be linked and organised in several ways forming tree branches-like constructions. Squares are assessed to value around $\$ 15$ million each. Where that is equivalent to $\$ 4,230$ per square meters of gross space. Nevertheless, whereas 20 percent of every platform is made for either open or green spaces, the assessment anticipates the usable space to value around $\$ 5,425$ square meters Czapiewska et al. (2013).

The reinforced concrete is preferred as the building material of for its value as well as its strength and resilience. The concrete constructions could be connected into the durable hollow boxes, also known as "caissons". The units would sustain three level buildings. The project plan to host hotels, offices, residential housing, as well as terraced housing. Such project is founded on eleven units, that would host up to between 225 to 300 permanent inhabitants when joint, with a further fifty hotel bedrooms. The overall project is expected to cost around $\$ 167$ million Czapiewska et al. (2013).

In the Gulf of Fonseca, neighbouring three Central American countries, was selected as a case study for the appropriateness for the project for protected waters. Such site was selected as it was founded roughly on the standards and measures that the Seasteading Institute used for choosing the host countries. Criterion like the closeness to metropolises and already existing infrastructure, and the appropriate climate, far from any hurricanes. In such a location, the DeltaSync suggests that all the platforms may perhaps be totally solar-powered, 
and that such idea could even be more economical than using diesel engines, as well as after counting the battery storing expenses and also its distribution through a micro-grid Czapiewska et al. (2013).

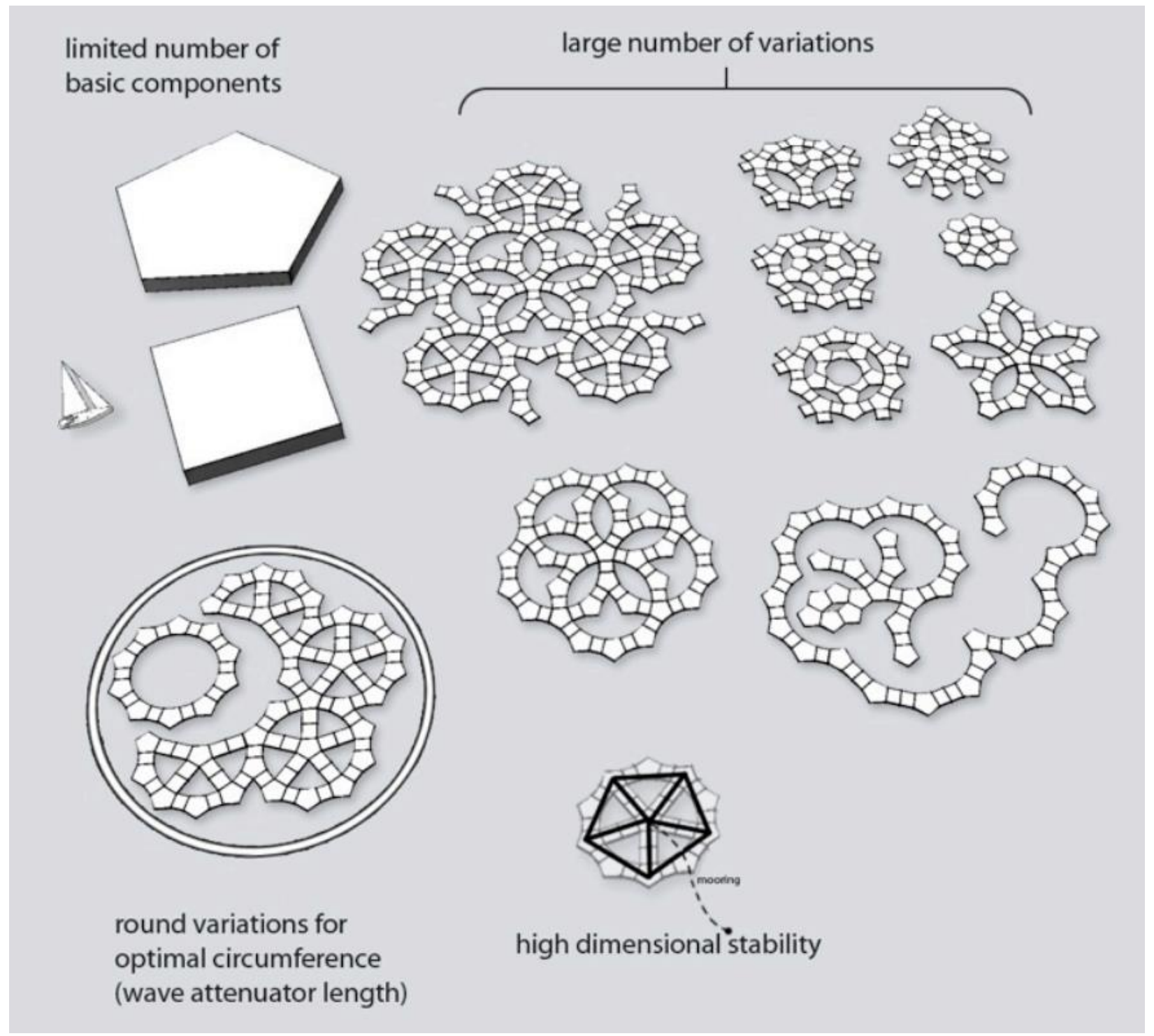

18 Figure 4.16: The outline system of project (Czapiewska et al., 2013). 


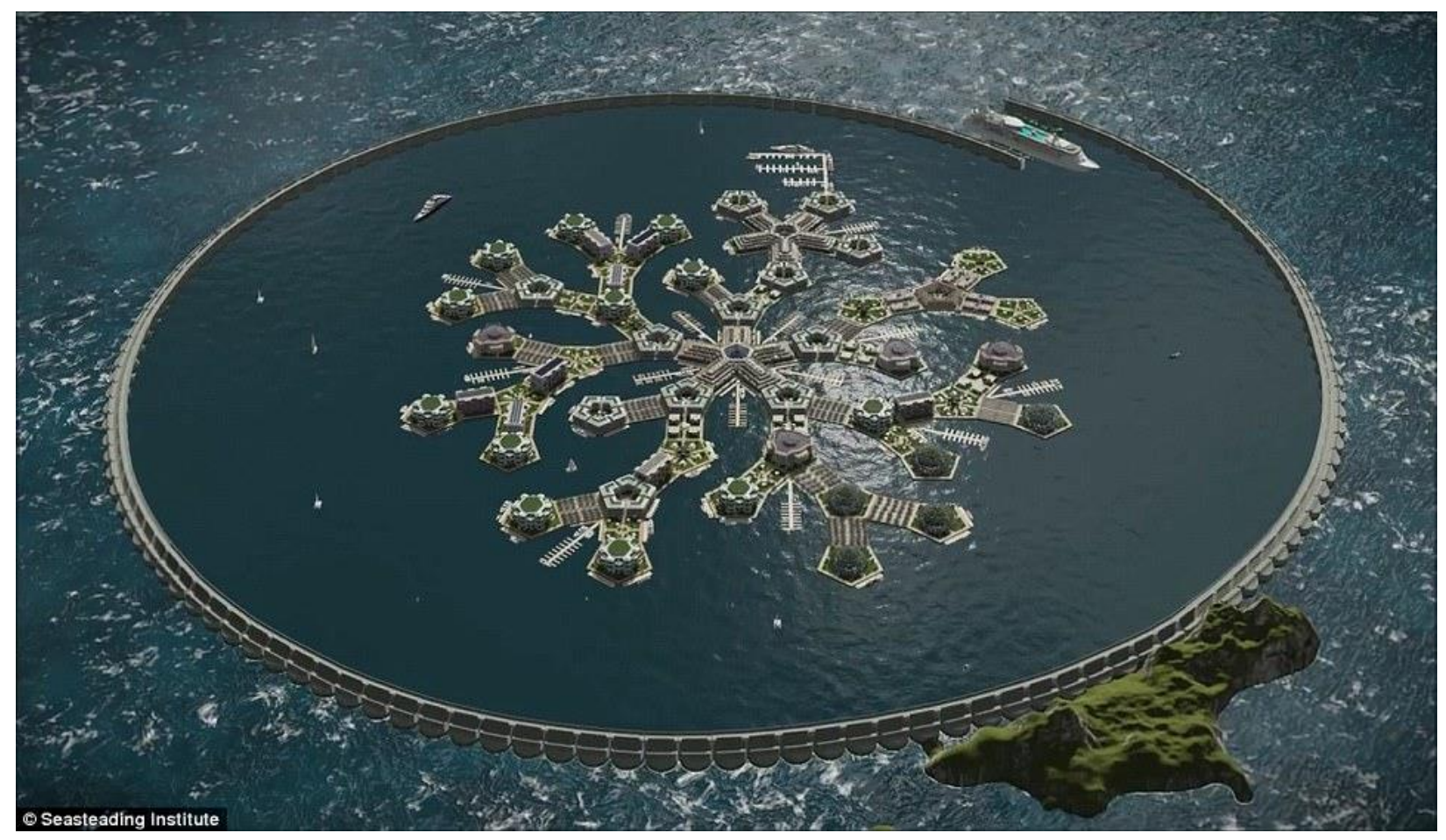

19 Figure 4.17: The initial plan for the long-term Seasteading community (Czapiewska et al., 2013).

Such project evaluates a mountable system with a breakwater that could as well ultimately border the community offering it to situate in the open waters. The dependability and flexibility of the units separately is vital in order to ensure the self-sufficiency of the community. In an occurrence where the hosting country is no longer in agreement with either party, therefore the platforms are capable of disconnecting from the moorings and move to another site. Both the modularity as well as the mobility aspects could allow an active geography and encourage its inhabitants to reposition the formations as the inhabitants' number increase. Although extensive engineering studies are yet to be done, the initial investigation proposes that the concrete platforms of $50 \times 50$ meters proportions create the equilibrium between price, portability, and constancy when confronting the waves of the demonstrative area Czapiewska et al. (2013). 


\section{Conclusion and Influence:}

- A marketplace for an inhabited seastead like currently existing examples.

- A real project could be constructed to compete with the market's value.

- It is expected that the Seasteading Institute could possibly reach an agreement with a host country which may acknowledge the floating community its political independence if it expands to an agreed certain level.

In conclusion, it is possible to place a floating community in calm protected waters of the hosting country to decrease the expenses of the structure rather than when compared to building employed in open waters. A seaside country could be interested in contributing to host such projects in their regional waters and permit a possible future political independence and in return they can benefit from an economic, social, and other aids. The Seasteading institute offers a lot of information regarding their procedures and developments opened to the public. Possible inhabitants from sixty-seven countries with different income levels has delivered a general idea on what purpose the floating community with its own political selfgovernment is required, and the desires for a floating community with the possibility of future political self-rule is curiously rising. 


\subsection{Conclusions}

Analysis included ten different adaptation solutions analyzed which are: building seawalls, raising roads, building storm-water pumps, upgrading sewage systems, using beaches as barriers, creating natural infrastructure, slowing land sink-age, managed retreat, elevating houses, and VLFS. Adaptation approaches and mitigation solutions were analyzed through seven variables in detail which are: descriptions, costs, durability, constructing time, lifespans, their environmental impacts, and their overall evaluations has identified floating structures as the best possible solution against SLR impacts.

The idea of biomimicry or technology inspired by nature is getting famous worldwide. Nature's methods and procedures are not only inspiring innovation in architecture and construction, but also in infrastructure, transportation, manufacturing methods, and sustainability approaches. Imitating nature's complicated processes as materials began to evolve is just the beginning. The time-tested proved, sustainable ideas and methods to learn and get inspired from mother nature is unlimited. Investing time and energy to learn and advance in them, will enable us to advance greatly in architecture, engineering and construction (Tavsan et al., 2015).

To re-sum up the main features of floating structures:

- It moves up and down with water, therefore making it sustainable as it its working with nature not against it, as well as being mobile so its location may change from one part to another making them very practical, for example in natural disasters areas as they could move from one point to the other to help climate refugees. 
- The best solution on the market against for the rising seas problems as it is the most cost-effective, faster in construction and much more sustainable when compared to land reclamation and artificial islands solutions.

- A floating community would help the region dying corals by lowering the temperature reaching them.

- Eco-system friendly as that land reclamation and artificial islands as they destroy the maritime eco-system, for example destroying the coral life.

To re-sum up the main floating structures advantages over building in soft soil areas are:

- They are cheaper to build therefore cost-effective.

- They are faster to built, as they can take only four months to build a floating house, where for a bigger project like in this thesis the time-span changes.

- If a land-based building is in a soft soil, therefore the pile system would be great.

- If a land-based building is in a soft soil, therefore they require a lot of effort and complexity.

- If a land-based building is in a soft soil, therefore in ten years these houses could most probably go off balance.

The Uros people inspired the project through their education offering as they have some primary school facilities. Therefore, the project stressed on early education and better understanding of the surrounding environment and the ecosystem. Also, using natural materials herbals and welfare. Medicinal plants and the welfare of the community should be respected in any future floating community proposal. 
The Ha long community inspired the project as their maritime aquaculture is a great possible potential for huge scale developments as floating communities, but first the environmental matters of similar scales must be resolved correctly. This is considered for local food production.

The mobility feature in the Bangkok fishing markets is a great inspiration as they are connected to the coast where it is a sustainable human power-driven paddling activity by using small boats is heathy and environmentally friendly way of transportation in such rivers and floating markets. The formation of recreational activities such as floating commercial and markets as well as water related activities may be achieved by creating attractive floating developments which are planned to offer a platform of similar scale.

Harvest city inspired planning possible platforms to host small businesses and agricultural or the possibility of creating a community farming activity to combine the small businesses to help the habitat, habitants and visitors. The city's border wave attenuator held important issues by both blocking damaging waves or tsunamis while permitting the light boats traffic system to continue doing their work normally inside the floating city. Such factor with a circular shaped has encouraged the capabilities of the wave attenuator as a potential feature in the project. The boat-use for moving inhabitants and goods was herein considered. Such way of transportation has been considered for a sustainable mobility feature in the proposal for the Nile Delta's.

The floating houses of Ijburg had a typical modular building process with sizable difference influenced the future floating design particularly after each apartment scale design is viewed. The floor sizes and interior spaces must involve characteristics permitting flexibility of present spaces such as the possibility of the mobile wall system to permit modifiable layouts in all floors. The floating building components involved prefabricated 
parts that was assembled in site and such feature has been taken into consideration as a must for the proposal for its efficiency and pre-fabrication potentials. The houses were watertransported to the site after being constructed on a shipyard. This might work even in larger buildings that may contain modular construction design like in the floating building project. Such approach has been taken into consideration when planning the proposal for the Nile Delta's most vulnerable region.

The Lily-pad inspired the project as the three harbours as well as three elevations border the core where there is an artificial lagoon which lies entirely under water level in order to act as the stabilizer for the floating structure. Also, gardens and the aquaculture farms are situated under water level, then they could be used for producing food as well as biomass.

The Humanitarian Harbour of the Ocean long-term thought inspired the project as it could form an actual floating city rather than a small separated community, resulting in independency from the real coastline lands.

Floating island project of thee Seasteading institute inspired the project by its dependability and flexibility of the units separately is vital in order to ensure the selfsufficiency of the community as well as the modular platforms that could be connected to expand to a small city-scale community.

Evaluation of features included eight real and conceptual floating community cases which are: the Uros people, the Ha-long community, Bangkok fishing markets, Harvest city, the floating houses of Ijburg, the Lily-pad, the Humanitarian Harbour of the Ocean, and the floating island project of thee Seasteading institute. in terms of: facilities, natural materials, growth development, local food production, mobility, markets, wave attenuator/water life, agriculture, business, dynamic geography, modular design, and self-sufficient/survivability. 
Such evaluation concludes that the most significant design approaches for floating communities in order are: movability, dynamic geography, seakeeping, water experience, growth development, and mooring system. These examples have identified the criteria and preferences from their differences and similarities features. (see Table 4.3).

\begin{tabular}{|c|c|c|c|c|c|c|c|c|c|c|c|c|c|}
\hline Project & $\begin{array}{l}\text { Facilitie } \\
\text { s } \\
\text { (school/ } \\
\text { hospital } \\
\text { ) }\end{array}$ & $\begin{array}{l}\text { Natu } \\
\text { ral } \\
\text { Mate } \\
\text { rials }\end{array}$ & $\begin{array}{l}\text { Growt } \\
\mathrm{h} \\
\text { develo } \\
\text { pment }\end{array}$ & $\begin{array}{l}\text { Local } \\
\text { food } \\
\text { prod } \\
\text { uctio } \\
\mathrm{n}\end{array}$ & $\begin{array}{l}\text { Mob } \\
\text { ility }\end{array}$ & $\begin{array}{l}\text { Mar } \\
\text { kets }\end{array}$ & $\begin{array}{l}\text { Wave } \\
\text { atten } \\
\text { uator/ } \\
\text { Wate } \\
r \text { life }\end{array}$ & $\begin{array}{l}\text { Agric } \\
\text { ultur } \\
\text { e }\end{array}$ & $\begin{array}{l}\text { Busi } \\
\text { ness/ } \\
\text { Indu } \\
\text { stry }\end{array}$ & $\begin{array}{l}\text { Dyna } \\
\text { mic } \\
\text { geogr } \\
\text { aphy }\end{array}$ & $\begin{array}{l}\text { Mod } \\
\text { ular } \\
\text { desi } \\
\text { gn }\end{array}$ & $\begin{array}{l}\text { Self- } \\
\text { suffici } \\
\text { ent/ } \\
\text { Surviv } \\
\text { ability }\end{array}$ & $\begin{array}{l}\text { To } \\
\text { tal }\end{array}$ \\
\hline Uros people & ++ & $\begin{array}{l}+++ \\
+ \\
\end{array}$ & ++++ & ++ & +++ & + & + & + & - & +++ & - & ++++ & 10 \\
\hline $\begin{array}{l}\text { Ha-long } \\
\text { community }\end{array}$ & - & +++ & ++ & ++++ & $\begin{array}{l}+++ \\
+\end{array}$ & ++ & + & - & - & +++ & + & ++++ & 9 \\
\hline $\begin{array}{l}\text { Bangkok } \\
\text { fishing } \\
\text { markets }\end{array}$ & - & - & - & ++++ & ++ & $\begin{array}{l}+++ \\
+\end{array}$ & - & - & - & - & - & ++ & 4 \\
\hline Harvest city & + & + & +++ & - & - & - & ++ & + & ++ & + & +++ & +++ & 9 \\
\hline Ijburg & - & - & ++++ & + & $\begin{array}{l}+++ \\
+\end{array}$ & - & + & - & - & ++++ & $\begin{array}{l}\text { +++ } \\
+\end{array}$ & - & 6 \\
\hline Lily-pad & - & - & ++ & - & $\begin{array}{l}+++ \\
+\end{array}$ & - & - & + & - & - & ++ & +++ & 5 \\
\hline $\begin{array}{l}\text { Humanitari } \\
\text { an Harbour } \\
\text { of the Ocean }\end{array}$ & + & - & ++++ & ++++ & $\begin{array}{l}+++ \\
+\end{array}$ & +++ & + & ++++ & + & +++ & +++ & ++++ & 11 \\
\hline $\begin{array}{l}\text { Seasteading } \\
\text { institute }\end{array}$ & ++++ & - & ++++ & ++ & $\begin{array}{l}+++ \\
+ \\
\end{array}$ & ++ & ++ & ++ & ++ & +++ & $\begin{array}{l}+++ \\
+ \\
\end{array}$ & +++ & 11 \\
\hline Total & 4 & 3 & 7 & 6 & 7 & 5 & 6 & 5 & 3 & 6 & 6 & 7 & \\
\hline
\end{tabular}

17 Table 4.3: Evaluation of features of the selected floating community case studies. ${ }^{1}$

Adaptation approaches analysed in terms of cost, durability, construction time, lifespan, environmental impact suggest VLFS as the most efficient solution. In order of efficiency: VLFS, creating natural infrastructure, upgrading sewage systems, elevating houses, raising

1 Very High (++++) High (+++) Moderate (++) Low (+) Not addressed (-) where each "+" accounts for $25 \%$ stress of each feature.

Method adopted from (IDSC, 2011) and Frihy \& El-Sayed (2013). 
roads, building storm-water pumps, slowing land sink-age, building seawalls, using beaches as barriers, and managed retreat.

Upon analyzing discusses real and conceptual inspiring cases on floating structures with similar characteristics to the sites and climate of the Nile Delta in this chapter, accordingly, next chapter analyzes all aspects concerning VLFS will be covered and analyzes the design strategies concluded in this chapter. 


\section{Chapter 5}

\section{APPLICATIONS, ANALYSIS, \\ DEVELOPMENT, AND DESIGN \\ APPROACHES FOR VLFS}

\subsection{Introduction}

Upon analyzing adaptation approaches, mitigation solutions, and real and conceptual cases with similar characteristics to the sites and conditions of the Nile Delta in the previous chapter. This chapter sought to answer this research question: What are the adaptation approaches and mitigation solutions practiced in theses sites and can floating structures offer a better solution against SLR for these sites?

Initially, this chapter also conducts exploratory analysis to investigate floating structures structural system and if it may offer a more sustainable and long-term solution than both adaptation approaches and mitigation solutions practiced in Egypt. Therefore, it analyzes 
floating structures by investigating their applications, advantages, analysis, technological advancement, environment, and design considerations for floating body, mooring systems, and breakwaters, structural integrity, drift forces, strength and failure, and design. These analyses would provide the required data and information on VLFS for Egypt's Nile Delta.

Secondly, this chapter initially conducts comparative analysis for different approaches, methods, and strategies to for architectural design guidelines for building on water: such analysis is concerned with approaches and methods followed when designing floating structures in respect to Egypt's criteria and characteristics of the Nile Delta to offer guidelines for building on water to cope with future situations. Such evaluation analyses: movability, dynamic geography, seakeeping, water experience, growth development, and mooring system.

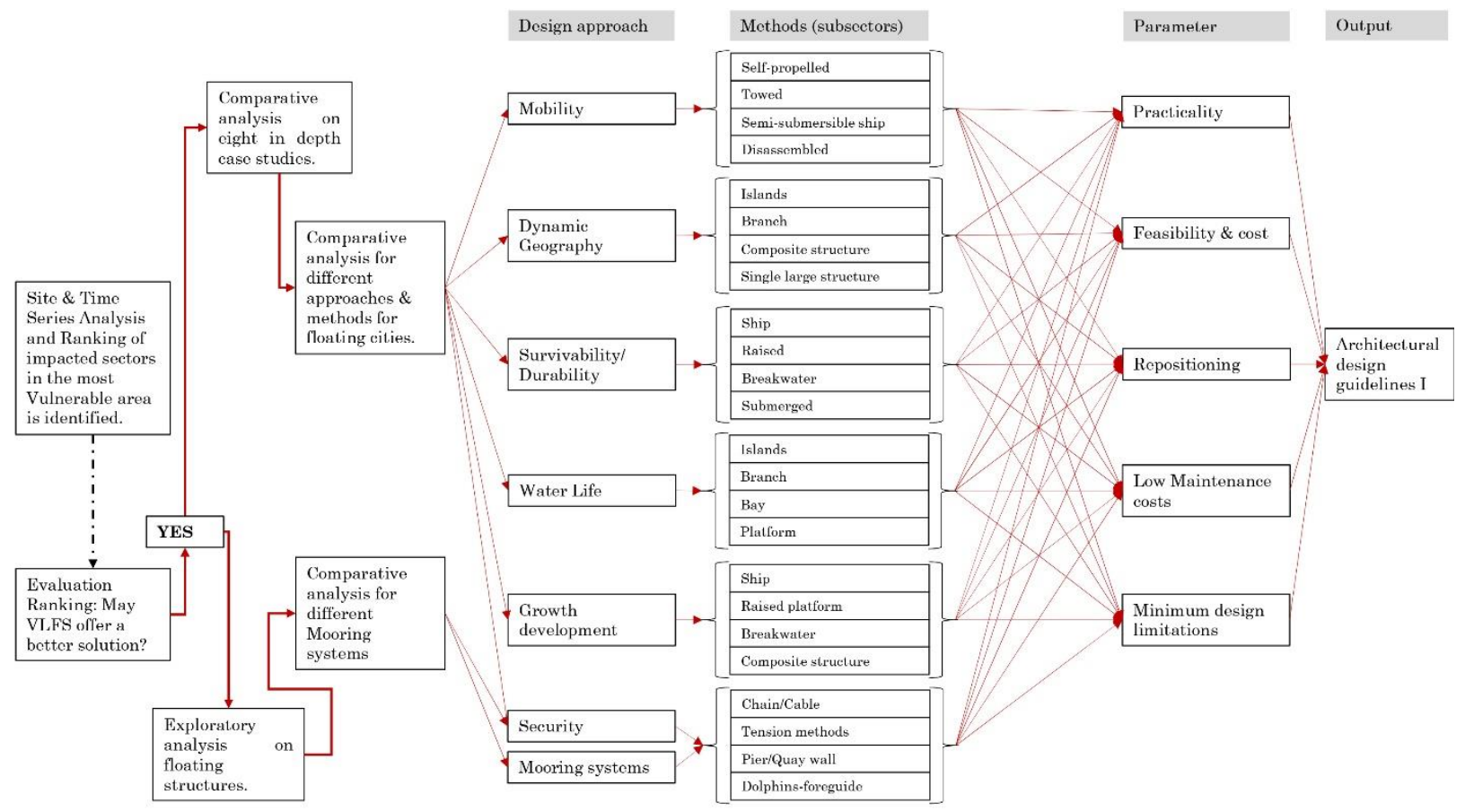

20 Figure 5.1: Analytical framework for different approaches \& methods for floating cities, and mooring systems. 


\subsubsection{Very Large Floating Structures}

As the rise of sea level goes parallel with the Nile Delta's growing population and coastal cities developments, the need for a solution is a must due to the low-lying lands of the Egyptian Nile Delta. City planners and engineers shift to land reclamation solutions in order to decrease the pressure on the current heavily busy zones and underground areas. By implementing fill materials from the seabed, mountains, as well as deep subsurface excavations, and construction wreckages, engineers are capable to make rather an enormous and respected area from the sea. Countries like as the Netherlands, Singapore and Japan, have extremely stretched their land above the sea by a series of extensive land reclamation projects (Suzuki et al., 2006). Possibly the first big scale and orderly land reclamation project was created by Kiyomori Taira off Kobe's seaside waters in the twelfth Century. Nevertheless, these land reclamation projects have their limitations and restraints. It's an appropriate solution where the water depth is shallow with a maximum of less than 20 meters (Wang et al., 2008). In a situation that the water depth is more than the allowed, consequently the seabed would be very soft and as a result, land reclamation solutions are no longer neither be cost effective nor even reasonable. Furthermore, land reclamation solutions usually ruin the aquatic environment, it also could possibly create some sorts of disorders for the toxic sediments. When confronted with such natural situations and environmental challenges, then VLFS could propose a very attractive substitute solution for creating land areas from the sea (Wang et al., 2008).

Distinguished researchers (Caron, 2009, 2014; Kwiatkowska \& Soons, 1990; Soons, 1990)

propose that future SLR problems to coastlines must be undertaken over an official adaptation (namely fixed baselines or outer limits). Some are permitted as recognized 
adaptation could be through the disposition of Artificially Island and Structures (AIS) as a future approach not just hypothetically (Tsaltas et al., 2010). Also, AIS ways don't look like working with every case, but it still could be a practical answer in some cases like in conservation of fragile ecosystems, protecting strategic economic in and offshore actions, safeguarding borders and habitats like in the situations in which the submerged area was highly important and unacceptable (Tsaltas et al., 2010). Other natural phenomena's other than SLR exist like soil erosion, delta appearances, annually melted ice from the oceans, may make modifications to the shorelines, therefore highlighting the issue of portable or movable borderlines as serious to define a country sea border. AIS can as well help as resolutions to similar situations under similar conditions (Caron, 2009).

VLFS (VLFS), also referred in Japan as Mega floating structures (MFS) are simply an artificial man-made island-like platform that acts as a floating land in the water. VLFS give the impression of huge platforms resting on the water surface. They could be roughly characterised into two types, semisubmersible and pontoon (Wang et al., 2008). The VLFS semisubmersible one has an elevated platform above the sea level and that occurs due to the column tubes and it's a very suitable fit in the case of deploying it in high sea levels areas with big and unexpected waves. On the other hand, the VLFS pontoon one has a platform in which rests on sea surface and is designed in order to be deployed in calm waters like bays, inlets, lagoons, lakes or harbours (Suzuki et al., 2006).

\subsection{Applications of VLFS}

The first remembered project of VLFS after the industrial revolution has begun is the Floating Island which was explained by the 19th century French novelist Jules Verne, who is considered as one of the founders of the science fiction. The primary real VLFS proposal 
was the Armstrong Sea-drome (Wang et al., 2008). It was originally planned the sea drome to allow the airline courses crossways with the world's oceans as a midway platform for the ocean crossing airplanes to rest and refuel (Suzuki et al., 2006). Its solidity was proved by tank tests, as well as some several other similar platforms were proposed until the death of Armstrong in 1955 (Wang et al., 2008). Nevertheless, the interest for constructing these floating airfields was diminished by Charles Lindbergh astonishing non-stop flight from New York to Paris in 1927. During the World War II, the United States Navy Civil Engineering Corps used the idea of the VLFS floating airfield to build a floating pontoon air jet platform deck of a $(552 \mathrm{~m} \times 83 \mathrm{~m} \times 1.5 \mathrm{~m}$ with a draft of $0.5 \mathrm{~m})$ for the UK (Suzuki et al., 2006). The United States navy as well planned a mobile offshore bases (MOB) before the pre-cold war era for military operations where direct land stations couldn't be offered (Suzuki et al., 2006). The VLFS technology was revived and advanced greatly in the 1970s by the Japan in order to make the fully floating Kansai International Airport and a floating city like the Okinawa International Ocean Exhibition “Aquapolis”. Even though the Kansai International Airport didn't exactly implement the floating airport proposal, the research study and progress practice has prepared the naval architects and the Japanese engineers in 1995 to construct the "Mega-Float" platform in Tokyo Bay as a test to floating runways. The Mega Float project offers an admirable life size structure to comprehend the hydro-elastic behavior of the VLFS, the mooring systems, the connector system, the anticorrosion system and its outcomes on waves, currents, water purity and marine eco-system (Wang \& Tay, 2011).

The approach in exploiting the space in which the seas offer for each country, for drives other than for just shipping or as a resource extraction, has improved a lot as seaside population concentrations have enlarged. It was not until the 1950s where the possible where the adequate shipbuilding technology development was obtained, the only method where 
such water space would be used in a big scale was done via land reclamation. Such exploitation is limited as it is a subject to the low areas of the inland ledge. In 1950s, the architects were attracted to the concept of floating cities and a concept was then established in at the Okinawa International Ocean Exhibition in 1975 that had a semi-submersible part of the city. In a parallel style, a floating airport was also planned for the new Kansai International Airport in 1973. Ever since the 1970s, the VLFS technology has been developing constantly, whereas altering to each culture requirements have lead to in many diverse applications of this technology has being measured to adapt to each different situation and context (Wang et al., 2008).

\subsubsection{Airports}

The initial suggestion to practice the VLFS as for airplanes for taking off and landing was in the 1920s to allow the aircraft courses across the world's oceans to happen. Such projects were studied in a serious manner by the army for military applications in the US in the 1940s and a demo development was constructed and tested effectively in 1943 (Suzuki et al., 2006).

Where huge developments in technology have taken place, in 1973 a floating airport project was planned in Japan for the new Kansai International Airport. Even though the original stage was not constructed as a floating structure, the interest in the floating structure remained high. Probably, that's why such part of VLFS study has received the so much consideration, because of the big part to the hard work of the Technological Research Association of Mega-Float (TRAM) took place in Japan from 1995 until 2001 (Suzuki et al., 2006). Such association has investigated the essential design and structure requirements for the floating airport to be comprehended where mathematical analysis methods were 
established together with an experimental programme which have led to the structure of a 1,000 meters technology demonstrator (Suzuki et al., 2006).

Even though the governing authority as well as the environmental influence of these floating structures were measured in depth as well shaping the design plans and form, the floating airport still has not been approved for building, still the interest remains solid as demonstrated by suggestions for the expansion in the Haneda International Airport in Japan (Suzuki et al., 2006).

\subsubsection{Mobile Offshore Base}

The post-Cold War period, the world has witnessed a smaller-scale struggles could be seen in diverse areas worldwide, and as a result the significance of strategic sealift was therefore increased. An implemented solution is the mobile offshore base (MOB), a very large floating structure containing numerous components that are put into location and then assembled together to create a solid single base. Such huge fixed-wing aircraft base together with the sea-vessels could support possible coastal conflict situations from a protected location without depending on having political backups from other states (Suzuki et al., 2006). The United States Navy have supported a considerable amount of extensive studies concerning during the 1990s in order to advance the design practices that are appropriate for such projects. Such progress has focused on providing the right numerical approaches and on directing experimental testing. A comparable idea could be envisioned as a mobile emergency rescue base to function as a haven globally in incidents of natural disasters. A fixed Sea Base Facility (SBF) was as well measured as a substitute to land reclamation for repositioning of the United States Marine Corps Station Futenma offshore Okinawa, Japan (Wang et al., 2008). 


\subsubsection{Offshore Port Facilities}

The floating airport is an interesting proposal for areas that the appropriate land near an urban settlement is not enough, therefore the offshore port facilities are considered. Suggestions have been shaped for some offshore container terminals to service the great sea vessels and to offer the direct surroundings with feeder container vessels. It could be valuable as well to position the termini for possibly dangerous vessels, like the liquified natural gas carriers (LNGC), offshore (Suzuki et al., 2006).

\subsubsection{Offshore Storage and Waste Disposal Facilities}

The possibility of a very large floating structure as a storage facility is already established in Japan as two of Japan's ten national oil supply centres are made up of floating units, built in 1988 and 1996. In progressively compacted inhabited coastal areas, the capability to place any sort of storage facilities, as well as waste processing and treatment plants is preferably if it's located out of sight as it has an unpleasant scenery and this facility could as well include power generation capability (Suzuki et al., 2006).

\subsubsection{Energy Islands and Food Production}

In an attempt to purely producing energy out from waste disposal, offshore facilities could be measured for their capability of integrating a variety of sustainable energy technologies. Reliant on the weather this structure could contain some, if not all, of wind turbines, wave power generators, tidal current turbines as well as ocean thermal energy conversion units. (Suzuki et al., 2006). These structures could as well be a useful host to environmental investigating activities and food production by aquaculture and maritime biomass 
vegetation. Numerous applications of such VLFS technology are being investigated in South Korea as well as being expressed by plans to integrate wind and current turbine plant in the Yellow Sea throughout five years, as well as the already planned installations which came from all of Japan, France, United Kingdom and USA (Wang et al., 2008).

\subsubsection{Habitats}

The innovative idea of a very large floating structure possibly started for habitat, it is maybe somehow weird as more proposals for the offshore floating cities have not been established throughout the last period, even though that there are present plans for some offshore sports facilities as well as some theme parks in Japan and South Korea. Nevertheless, with such growing pressure on seaside regions from the rising populations and the danger of ecological change, it is probable that these ideas could develop advantaging from the already used technology and offering a better foundation for future research (Suzuki et al., 2006).

\subsection{Concluded Advantages of VLFS}

All those Mega Floating structures have more benefits over the old and traditional land reclamation solution in terms of space creation in the following aspects:

- They're cost effective where the water depth is considerably big.

Although it is not the case in Egypt, but the price of imported sand for the usage of land reclamation in some areas has increased remarkably and a time could arrive where sand might not be even obtainable from neighbouring countries. 
- Ecological friendly where they neither harm the maritime eco-system, nor do they siltup deep ports or disturb the tides and sea waves.

- They are simple and fast to assemble.

Different elements and components could be manufactured at different dockyards and then transported to the location to be assembled and thus sea-area could be exploited quickly.

- They could be easily disassembled or totally withdrawn if the sea space is required in the future as well as being able of expanding as they acquire modular forms.

- The facilities and the structure of the VLFS are protected to avoid harmful seismic shocks where their bases are fundamentally isolated.

- They do not suffer from a settlement gap because of the reclaimed soil consolidation.

- They have constant situations in consideration to the water surface and therefore enabling small ships and vessels to come along to be used as docks and ports.

- Its nearshore position offers an attractive form in water, making them an appropriate fit for future developments related to leisure, activities and water sport events.

\subsection{Analysis on Structure and Design of VLFS}

When analyzing and planning VLFS, some distinct features require being addressed when compared to normal land structures. According to Clauss et al. (1992) and Moan (2004):

- In contrast to land-based structures with their connected foundations poured in location, VLFS are frequently built on shore such as dockyards building locations distant from the deep-water installation areas and without and comprehensive 
preparation of the foundation. Respectively, every module needs to be able to float separately where they will be floated to location for assembling on the water site.

- The floating structure scale as well as its mooring system are subject to its purpose and correspondingly on the environmental conditions regarding the waves, current and wind. The project could be subjugated either by the peak loading caused by permanent and inconstant loads or by fatigue strength caused by cyclic wave loading. Furthermore, it is vital to anticipate probable unplanned events like ship collisions and be sure that the general safety is not vulnerable by any probable progressive problems brought by these unplanned for damages.

- Owing to the corrosive situation of the sea environment, floating structures in general require good corrosion defence system.

- Probable degradation caused by such corrosion or growing fatigue cracks needs the appropriate system for review, monitoring, maintenance and reparation throughout its lifespan usage.

- Horizontal forces since that the waves are in general a few times larger than the (nonseismic) horizontal loads of normal land structures and the result of these loads rely on how the structure is linked to the seabed. There is difference between a rigid inflexible, and flexible compliant connection. Where the rigid connection effectively prevents the horizontal movements, the flexible compliant mooring permit maximum horizontal movements of a floating structure of the direction of the wave amplitude.

- In framed, tower-like structures that are piled to the seafloor, the horizontal forces from waves make a lot of strong bends and create overbalance moments as the wave forces act by the water surface. In such situation, the structure and the pile system 
require carrying practically almost all the vertical loads because to self-weight and payload in addition to the tidal waves, wind and wind current loads.

- In VLFS, the stationary vertical self-weight and payloads are supported by buoyancy. If the case of a VLFS which has a compliant mooring system, containing for example of catenary chain mooring lines, consequently the horizontal wave movements forces gets balanced by the inertia forces. Furthermore, if the horizontal dimensions of the floating structure are bigger than the wave length, as a result the horizontal forces will be decreased as the wave forces on various structural parts will probably have different phase (direction and size). At that moment, the forces in the mooring system will be small in relation to the entire wave forces. Then the most important purpose of the mooring system is to avoid drifting off due to the steady waves and wind forces in addition to probable steady and slow drifting wave forces.

- The tension-leg system is attained when an extremely pretension mooring system is practiced. An added buoyancy is therefore essential to provide such pretension. If such mooring system contains vertical lines, the system will still horizontally compliant nevertheless is rather rigid vertically. Correspondingly, the mooring forces will increase because of the high pretension as well as the vertical wave loading. In a scenario where the mooring system creates an angle, consequently the horizontal rigidity and the forces rise. Nevertheless, the foremost disadvantage of such system is the complexity when planning this system where the looseness of protected mooring lines is dodged. A probable loose may be trailed by an unexpected rise in tension leads to a probable failure. In such situation, these systems were never executed in any offshore structures. 


\subsection{Main Types of VLFS}

There are essentially two categories of VLFS (VLFSs), which are the semi-submersibletype and the pontoon-type.

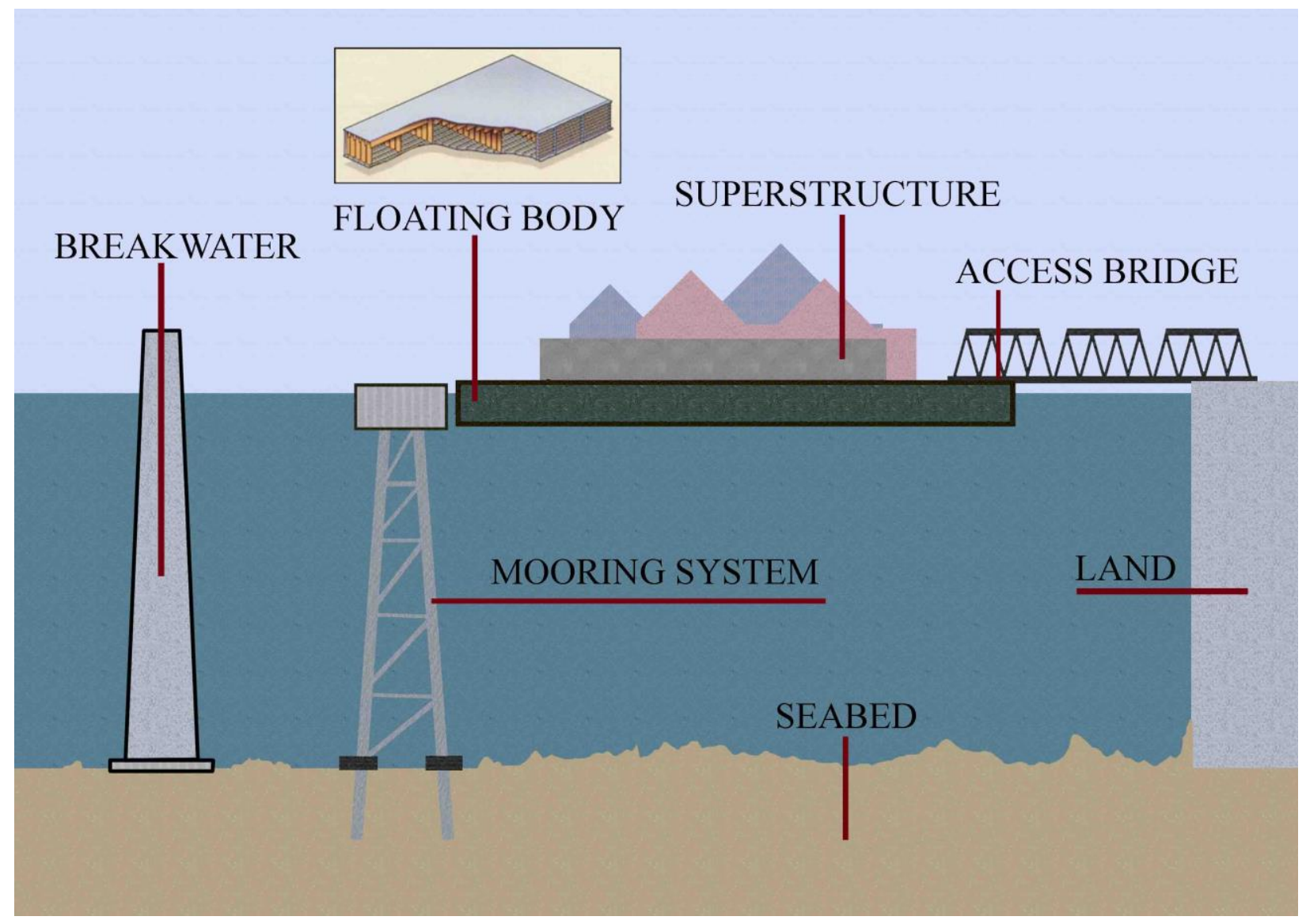

21 Figure 5.2: Components of Mega Floating Structure System (own illustration). Created with data from Wang et al. (2008).

\subsubsection{Semi-Submersible Type}

Semi-submersible type floating structures are elevated overhead the sea level via column tubes or stabilizer structural components to decrease the tidal and waves impact on the floating building and at the same time sustaining a constant buoyancy force. Therefore, they 
can decrease the wave made movements and as a result, appropriately installed in areas such as high-seas that have big waves. In the case of the floating oil drilling platforms which are made for drilling and producing oil and gas are perfect cases of the semi-submersible-type VLFSs. Once such semi-submersibles are connected to the seabed via vertical tethers with extremely high pretension like an extra buoyancy for the structure, they are called tensionleg platforms. On the other hand, pontoon-type floating structures float on water like a massive plain plate (Wang et al., 2008).

\subsubsection{Pontoon Type}

On the other hand, the Pontoon type floating structures are an appropriate fit only in calm waters, frequently in a bay or a lagoon and adjacent to the coastlines. Large pontoontype floating structures are called Mega-Floats by the Japanese engineers. A general guideline code is that Mega-Floats are floating structures are referred to floating structures that at least one of its sides have length more than 60 meters (Wang et al., 2008).

As shown in Figure 5.2, Mega Float system consists of:

I. The very large pontoon floating structure.

II. Mooring facility to make the floating structure in stay in position.

III. An access bridge or floating passageway to reach the floating structure from the coast.

IV. The breakwater (it is frequently required if wave heights reaches more than 4 meters) to decrease the wave forces which is affecting the floating structure.

(Wang et al., 2008). 


\subsection{VLFS Developments}

The forms of the VLFS might have more organic and uninformed geometries like the irregular design of the floating island in the Han river as a replacement for of the conservative four-sided form VLFS. Several scientists in the subject have also taken in their consideration that the VLFS of diverse forms which can possibly decrease the hydro-elastic responses. For instance, Chien Ming Wang, Riyansyah, \& Choo, (2009) have studied VLFS with diverse edge forms and has reached the conclusion that a jagged edge could lead to decreasing the spread of a possible deformation that could occur in the VLFS. With the need to decrease the hydro-elastic response, VLFS with moonpools and diverse difficulties are planned, and they can be very efficient in decreasing the hydro-elastic response of the VLFS where the wave length is not that great. On the other hand, Wang et al. (2008) have presented the pioneering gill cells in very large floating container terminal aiming to offer an efficient solution for decreasing the great difference of rebounds in the VLFS in a situation of an irregular static loading (Wang \& Tay, 2011).

\subsubsection{MOB and Mega-Floats}

The United States investigation concerning VLFS was mostly for military purposes. The US Navy Civil Engineering Corps have built a floating pontoon flight platform in the early 1940's to be used by Great Britain. It was built by many hinged arrays of pontoons, dimensions of $552 \mathrm{~m} \times 83 \mathrm{~m} \times 1.5 \mathrm{~m}$ with a $0.5 \mathrm{~m}$ draft and was installed in protected water. Nevertheless, as head winds were described being up to 40 knots assisted such determination. Therefore, it was finally considered very risky and dangerous. In the 60's and 70's there was an attempt mostly in the United States Navy laboratories as well as universities to plan ideas for the mobile offshore based structures as well as offshore harbours 
and cities. Nevertheless, constructability required proving, the material was mainly concrete for the semi-submersible type designs. A strong army concentration was for sea-based structures in the 1980's to compensate for overseas stations. Correspondingly, between the late 1980's and early 1990's, the United States National Science Foundation has supported some research studies for the VLFS and as a result, the terminology of "VLFS" was set as well as taking a huge leap in the field studies (Wang et al., 2008).

Maritime Platform Technology Program of the Defense Advanced Research Projects Agency (DARPA) has been implemented for three years from 1993 to 1996 with around US\$40 million Budget (Suzuki et al., 2006). MOB Science and Technology Program of the Office for Nuclear Regulation (ONR) then came next, with a US\$35M to US\$40M budget and has been implemented from 1997 to 2000 (Suzuki et al., 2006). Most MOB projects involve three to five semi-submersible units or a sole base unit interconnected on each end via several interlocking formations. Such units are planned to transfer, connect and disconnect, and to function in open waters. When constructed for the C-17 transportation abilities, in such case the planes runways span around 1800 meters long (Suzuki et al., 2006).

The idea of VLFS for economical purposes was developing in Japan in the Pacific Ocean. Shipbuilding development had caught the attention by the Japanese architects in the late 1950 's, and there was motivation in architecture and urban design to use the ocean space as well as to increase people's occupancy across the water surface (Lamas-Pardo, Iglesias, \& Carral, 2015). Aqua-polis, was a big semisubmersible VLFS type, represented a component of a floating city idea, and was built for the Okinawa International Ocean Exhibition that took place in 1975 (Suzuki et al., 2006).

The Technological Research Association of Mega-Float (TRAM) has instituted in 1995 and directed studies on the Mega-Float till 2001. The Mega-Float is the pontoon category of the 
VLFS, that contains both of mooring and access systems (Suzuki et al., 2009). It is envisioned for positioning in protected waters. The essential strategies and building technology were advanced with a budget of $\$ 172$ million (Suzuki, Yoshida, Iijima, \& Kobayashi, 2009). The In-Situ trials were directed to present soundness of the technology with the first phase demos a platform which had dimensions of $300 \mathrm{~m} \times 60 \mathrm{~m} \times 2 \mathrm{~m}$, while the second phase demos a platform that had dimensions of $1000 \mathrm{~m} \times 60$ to $120 \mathrm{~m} \times 3 \mathrm{~m}$. Aircrafts taking-off and landings were effectively established in the second phase experimentation where the activities of this Association were proceeded by establishing the Shipbuilding Research Center of Japan which encouraged a new floating runway for the Haneda International Airport. The Shipbuilders' Association of Japan developed such project (Sato \& Inoue, 2003).

\section{Concluded Progress of VLFS in the US and Japan}

Milestones in the progress of the VLFS are shown below. Even though both the MOB and Mega-Float agendas were individualistically originated and accomplished, but the essential science and technology aims were correspondingly planned and involved parallel investigation purposes. This is principally correct considering the operational requirements, the progressive analysis and the design procedures. Mega-Float interests has made an additional significance and pressure on the construction as well as the environmental effects fundamentally due to having mounted the trials and experimentational platforms. A considerable amount of the technological progress which concluded in the advanced analysis and design practices, some of which can be referred to in the classification paper made for MOB (Suzuki et al., 2009). 


\begin{tabular}{|c|c|}
\hline & In the United States \\
\hline 1924-1955 & Armstrong Seadrome and Related Concepts \\
\hline 1942-1944 & US Navy Civil Engineering Corps Flight Deck - Project SOCK \\
\hline 1963 & C-130 Landing and Takeoff Demonstrations on USS Forrestal \\
\hline 1960's-1970's & Navy Laboratory/University Research \\
\hline 1989-1996 & NSF Sponsored Research \\
\hline 1991 & First International Workshop of VLFS - University of Hawaii \\
\hline 1993-1996 & DARPA Maritime Platform Technology Program \\
\hline \multirow[t]{2}{*}{$1997-2000$} & ONR Mobile Offshore Base Science \& Technology Program \\
\hline & In Japan \\
\hline 1950’s & Floating City concepts in architecture and urban design \\
\hline 1960's & Puppet drama "Hykkori Hyoutan Jima" \\
\hline $1973-1974$ & $\begin{array}{l}\text { Proposal of Floating Airport for Kansai International Airport } \\
\text { Phase } 1 \text { construction, semisubmersible type floating structure }\end{array}$ \\
\hline 1975 & Okinawa International Ocean Exhibition - Aquapolis \\
\hline 1988 & Kamigoto Oil Stockpile $390 \mathrm{~m}$ x $97 \mathrm{~m}$ x $27.6 \mathrm{~m}$ x 5 Units \\
\hline 1994 & $\begin{array}{l}\text { Proposal of Floating Runway for Kansai International Airport } \\
\text { Phase } 2 \text { construction, pontoon type floating structure }\end{array}$ \\
\hline 1995 & Technological Research Association of Mega-Float. \\
\hline $1995-1996$ & TRAM Phase1 Experiment 300m x 60m x $2 \mathrm{~m}$. \\
\hline 1996 & Shirashima Oil Stockpile $397 \mathrm{~m}$ x $82 \mathrm{~m}$ x $25.1 \mathrm{~m}$ x 8 Units \\
\hline $1997-2001$ & $\begin{array}{l}\text { TRAM Phase } 2 \text { Experiment } 1000 \mathrm{~m} \times 60-120 \mathrm{~m} \times 3 \mathrm{~m} \\
\text { Landing \& Takeoff Experiments. }\end{array}$ \\
\hline $2001-2005$ & $\begin{array}{l}\text { R\&D by Shipbuilding Research Center. Proposed Haneda } \\
\text { International Airport Runway; Pontoon/Semisub Combination Hull }\end{array}$ \\
\hline
\end{tabular}

18 Table 5.1: Milestones VLFS projects. Reproduced from Suzuki et al. (2006).

The VLFS project like the MOB and Mega-Float are special water structures which is principally due to the unparalleled dimensions and dislocations where they measure around $10^{3}$ to $10^{4}$ meters as well as weighting around $10^{6}$ to $10^{7}$ tons, correspondingly. Such ideals are at least double the weight of present floating structures. That creates difficult challenges for engineers as they trail from such standards. Unlike ships and vessels, that has progressed due to the growth of practice and by such development in analysis technology, the VLFS is an unmatched floating structure not only in the matters of either scale or dislocation, but also in the budget and design life, since it comes from $\$ 5 \mathrm{~B}$ to $\$ 15 \mathrm{~B}$ and comes with a lifespan 
between 50 to 100 years, correspondingly (Suzuki et al., 2009). The next considerations describe the additional uniqueness of the VLFS.

\subsubsection{Large Size}

The VLFS is a record for being big and flexible floating structure. Therefore, the hydroelastic response turns out to be dominant and has motivated the required study and advancement in the worldwide systematic systems for VLFS. The subject of the global failure levels are key matters. The evolutionary experimental development kind is not tolerable due to the great socio-economic difficulties. It as well follows that the VLFS technology could be opposed to risk (Wang \& Tay, 2011).

\subsubsection{Environment Condition}

The Physical environmental situations where the VLFS should function might not be just considered partially uniform in matters when consistency of environmental settings like wind, wave and current have to be considered (Wang et al., 2008). Spatial consistency of waves is a key matter in the MOB plan development and must be effectively studied. The typical approaches for defining the environmental situations were in fact inadequate for planning the Mega-Float or MOB for the Nile Delta's coastline.

\subsubsection{VLFS Design and Analysis}

For global analysis initiatives, a vessel is usually taken as a rigid structure and its reaction to wave loading is assessed by answering to a rigid body hydrodynamics problem (Lamas-Pardo et al., 2015). The VLFS is taken as a flexible building in which the contact 
between elastic response as well as the fluid response is taken into consideration. As soon as the exterior loading is determined, the interior force impacts are assessed in an identical way like a structure of a vessel. Nevertheless, precision mostly depends on modeling the interior flexible and inertia forces in the local level. Many study tools with different stages of modeling and complications have been established for the hydro-elastic analysis for the MOB projects and Mega-Float projects and associated studies (Suzuki et al., 2009). The Innovative design procedure is wanted in the incident of danger doubt and risk caused by the VLFS. It is consequently sensible to follow a probabilistic and risk-based design method. Such method is implemented in the safety standards of the MOB as well as the safety standards of the MegaFloats (Suzuki et al., 2006; Wang et al., 2008).

\subsubsection{Connectors}

VLFS is frequently built in component units because of its enormous size. The component units are built in dockyards, and at that moment they get assembled on location in the sea site either via fusing or via rigid connectors. Lately, Wang et al. (2009) has suggested the practice of hinge or semi-rigid connectors as an alternative as they have found that the nonrigid connectors turned out to be more efficient in decreasing the hydro-elastic response as when related to the rigid connectors. There have been numerous connector plans suggested, for example an analysis paper by has given a varied range of such connector schemes. Nevertheless, there is yet work to be done on improving the robust as well as a cost-effective connector system for VLFS units (Wang et al., 2009). 


\subsubsection{Connection at Sea}

The VLFS is brought together and constructed by connecting the base components either by flexible or rigid connections. The Mega-Float was built from several pontoon base components which are welded together in spacious protected waters. Controlling the thermal distortion and the placement of the components are vital subjects in the construction (Wang et al., 2009). In contrast to permanently connecting base units with Mega-Float, base unit modules of MOB are connected to allow the assembly and disassembly at the sea site. Strength and fatigue of the intermodular connectors are key issues in the design of MOB (Suzuki et al., 2009).

\subsubsection{Positioning}

Station keeping of MOB is established by Dynamic Positioning System (DPS), on the other hand placing the Mega-Float is established by the dolphin moorings. The consistency of the station keeping functional is vital to the efficiency of the MOB, as well as for avoiding drifting, this is one of the most significant global failure levels for the Mega-Floats. The capacity of the mooring as well as the breakwater of the Mega-float are plan trade-offs, and dependability considering the seismic properties should be investigated in detail (Wu, Zhou, \& Cui, 2016).

\subsubsection{Design Life and Other Unique Criteria}

The design measures tail the VLFS functionality. The VLFS lifespan is usually 50 years and 100 years for the MOB and Mega-Float, correspondingly. Such measures are significantly more than those of the conventional vessels and the offshore projects. For 
instance, the fatigue design measures counting the corrosion-fatigue are considerably more difficult. Comparative rotation of the hinges in intermodular connectors in the case of the MOB flight deck is restricted to only some degrees, nevertheless or else it relies on the module lengths as well as its functioning sea state. Once active as an airfield, the Mega-Float's runway should be corresponding with and follow the same codes of the land-based runways. One of the hardest criteria's is that the minimum arc radius of for such runway is 30,000 meters as described (Sato \& Inoue, 2003). Unusual criteria are not only specified for the structural design, but also for review and maintenance, while still considering that the regular dry reducing in terms of maintenance and reparation is usually not probable (Suzuki et al., 2009).

\subsection{The Environment}

The unparalleled scale and outline of the VLFS, like the Mega-Float or the MOB, are distinct from any ship that was ever constructed, where is no experience on which to ground the prediction of risk on. Such challenge has formed the necessity for an enhanced understanding to the water environments, and the progress of an innovative environmental plan criteria. Study, examination, calculation, evaluation, and modeling of the marine environment situation have been directed (Suzuki et al., 2009).

\subsubsection{Measurements Supporting Environmental Compliance}

To the environmental parameters to be studied in order to evaluate the environmental effects of the VLFS, numerous types of information should be calculated like the pattern of the current flow, the water quality, as well as the bottom material and environmental cycle information both before and after the setting up in order to understand the behaviour of the 
environmental. The model involves two parts, first the hydrodynamic model and secondly is the marine ecosystem. Tidal flows, water temperature, as well as the density and salinity of the water are assessed and measured in the bay with and/or without the Mega-Float via the hydrodynamic model. An aquatic ecosystem model involving nutrients, phytoplankton, zooplankton and other organic substances have been already developed. Sato \& Inoue (2003) have planned the In-Situ experiment and the calculation scheme outline for a 1000 meters Mega-Float structure in Tokyo Bay where winds, waves, and other calculation outcomes were as well shortly addressed. Constant monitoring of water's temperature, salinity, liquified oxygen and chlorophyll-a profiles, and so on were directed at various static places underneath and surrounding a floating structure (Suzuki et al., 2006). Upon observation, it has been concluded that the perpendicular heat transfers directly through the Mega-Float model in Tokyo bay as archives on temperature, humidity and heat fluctuation on the pontoon-type mega-floats structure models were directed in both seasons of summer and winter (Suzuki et al., 2006).

\subsubsection{Design Environment}

Specification and Typhoon Database Supporting Structural MOB is envisioned for a comprehensive process in the open waters where the Mega-Float is mostly intended for a location detailed procedure in the case of protected waters. Nevertheless, the physical environmental requirements which have advanced for the MOB are now appropriate to any VLFS that is proposed for open waters (Suzuki et al., 2006). It consists of the environmental specifications as well as the environmental impacts highlighting the wave consistency as: 


\subsubsection{Physical Environmental Specification}

An accurate met-ocean requirement for all of winds, waves, and currents was advanced for the presence in the MOB Preliminary Design Guide. The description set involves two information groups. The initial one is the complete description briefing all the given theoretical and calculations material concerning phenomena's like winds gusting, waves spatial distribution, joint circulations of constraints like the substantial wave intervals and altitudes, and the interior wave and soliton representations. The initial group is a collaborative information list of joints, waves, currents hind-cast descriptors at 23 locations, and should be over 6 hours/24 km intermissions, for 20 years (Sato \& Inoue, 2003). The second one includes two illustrative hind-cast lists of the course details of winds, waves, and currents: a list for each of the long and the short term within the big storms. The second is hind-cast statistics which is for 25 big Northwest pacific storms simulated by a finer 1 hour/1 mile moving network (Ohmatsu, 2005).

\subsubsection{Buoyancy, Waves, Current and Wind}

The buoyancy is constantly calculated with the addition of hydrostatic pressure. The precise weight of the seawater is considered to be $10.09 \mathrm{kN} / \mathrm{m} 3$ or $1.03 \mathrm{t} / \mathrm{m} 3$ (Suzuki et al., 2006). When designing very large pontoon floating structures, the alteration in the water level caused by the tides, as well as tsunamis and storms surges would possibly control the design loads in the case is the floating structure is planned with a static vertical situation comparative to the seafloor/seabed. Where the activity of the buoyancy is subject to the tide as well as the water level, therefore it is required that the worst possible scenario should be measured (Wang et al., 2009). 
The water surface waves could be caused by either winds, tidal bore, earthquakes or landslides occurrences. The concentration is the oscillatory wind-produced water surface waves. The waves developed in a certain area could undergo even after the winds stop and spread to other areas; as swell with decaying intensity and gradually altering form. The longperiod swell collect energy, have faster velocity, and could manage winds and currents simply, outcoming in larger and longer crested waves (Wang et al., 2008).

The water surface waves which are caused by winds involve a great number of wavelets of various heights, phases and directions are very superimposed on one another. Even though the usual waves are not likely to be found in actual seas, nevertheless they still can closely model some swell situations. They correspondingly deliver the fundamental features in the unusual waves and are frequently used to estimate the wave situations and environment when setting the design. Consistent waves are considered with the waves periods as well as their heights (Wang et al., 2009).

\subsubsection{Wave Coherence Measurement}

The spatial consistency of waves crests and troughs dimensions at scales up to $2 \mathrm{~km}$ was studied by Suzuki et al. (2006). This data is essential for precise mathematical simulations of the hydro-elastic understanding for the extremely long platforms. The supported researches had another two matching pushes but a "quick-look" research was the most approaching one. It has the measured waves consistency upon straight analysis of the data offered (Wang \& Tay, 2011). The significance pressure was on the basic data using sensible yet realistic standards and analysis methods. A significant development was the Scanning Radar Altimeter (SRA) information done by NASA of immediate surface dimensions in seven 
of eight octants in Hurricane Bonnie wave area. It founds the initial dimension of the whole illustrative wave field in situations of tropical storms.

\subsection{Design Considerations for the Floating Body}

When designing a proposal of the floating structure it is essential achieve the operating conditions, strength as well as the required serviceability necessities, the required safety approaches, the durability, as well as being visually pleasing to offer a beautiful scenery that add to the environment and most importantly being cost efficient. A proper service lifespan is required to be set which depends on the function and the importance of the floating structure and the return period of the natural loads applied. The service lifespan is usually anticipated to be from 50 to 100 years with rather a low-cost maintenance (Wang et al., 2008).

\subsubsection{Materials}

The materials used for the floating structure body could be either steel, or concrete or steel-concrete composite and in relation associated features should be respected. Where water-tightness of the concrete is essential in order to dodge or limit the possible occurrence of corrosions of the reinforcement, therefore, either watertight concrete or offshore concrete ought to be implemented. High-performance concrete which incorporates fly ash and silica fume is the most appropriate for the floating structures. The occurrence of creep and shrinkage are measured just where the pontoons in the structure are dry, and consequently are not to be considered when the pontoon are launched in its water site. Steel that is used in VLFS should satisfy the proper standards and specifications in the Technological Standard and Commentary of Port and Harbour Facilities 1999 (Wang et al., 2008). 


\subsubsection{Design Criteria}

The appropriate performance of the offshore structures is safeguarded when planning them in terms to the serviceability and safety requirements for a lifespan that exceeds 100 years old. The serviceability standards are presented to safeguard that the structure fulfils the required purposes and can only be stated by the client. The usual serviceability necessities rely on the motions as well as the structural deformations. The motion features may not only consist of dislocations, velocities and accelerations. It is recognized that the standards concerning the third order time derivative of the movement are being measured when designing the floating bridges (Wu et al., 2016).

The safety standards are executed to dodge the worst-case scenarios Situations like possible fatalities, as well as probable environmental disasters, and property damages. Reliant on the standards controlling administration, distinct acceptance standards for such moments are recognised. In cases like property damages, it is considered through the economical aspects. Nevertheless, in cases such as fatalities or pollution, therefore they clearly have economical consequences. Whereas the fatalities due to structural failure could be connected to a bigger structural catastrophe, on the other hand, a smaller damage could be an outcome of property damages that could be rather costly to repair like for instance, a case of an underwater structure (Wang et al., 2008). A vital strategic matter concerning the safety of the people in emergency situations is in evacuation and rescue (Suzuki et al., 2006). An efficient safety means is in this construction and assembly phases that a safe zone should be provided where the people can shelter to a case of a structural failure for a sufficient amount of time until a safe escape way is to be provided (Ohmatsu, 2005). 
Generally, the worldwide failure levels of the floating structures consist of capsizing, sinking, general structural failure and drift-offs. A comprehensive risk analysis method requires to be considered in order to recognize every probable accident situation and their probability to occur. Nevertheless, the general stability of the VLFS is measured in relations of toppling periods just by wind, and up-righting periods which are caused by the hydrostatics of the inclined body. Though, because of these large scales of the VLFS in terms of the horizontal lengths, stability of the intact mega-floating structures does not cause any problems. Even damages to some of the sections does not appear to enforce any stability problem. Sinking may be due a situation as an extreme flooding or as a structural failure. Consequently, creating global failure situations of the main large structure and mooring system, thus having such failure modes (Suzuki et al., 2006).

The current safety criteria for the floating structures are stated by the limit states are briefly explained in Table 5.2. (Wang et al., 2008).

\begin{tabular}{|l|l|l|}
\hline Limit states & Description & Remarks \\
\hline Ultimate (ULS) & $\begin{array}{l}\text {-Overall "rigid body" stability } \\
\text {-Ultimate strength of } \\
\text { structure, } \\
\text {-Ultimate strength of mooring } \\
\text { system }\end{array}$ & $\begin{array}{l}\text { (Not relevant for VLFS) } \\
\text { Component design check }\end{array}$ \\
\hline Fatigue (FLS) & $\begin{array}{l}\text {-Failure of joint - normally } \\
\text { welded joints in hull and } \\
\text { mooring system }\end{array}$ & $\begin{array}{l}\text { Component design check } \\
\text { depending on residual system } \\
\text { strength after fatigue failure }\end{array}$ \\
\hline Accidental collapse (ALS) & $\begin{array}{l}\text {-Ultimate capacity (1) Capacity } \\
\text { to resist "rigid body" instability } \\
\text { or total structural failure) of } \\
\text { damaged structure (due to } \\
\text { fabrication defects or } \\
\text { accidental loads) or operational } \\
\text { error. }\end{array}$ & \\
\hline
\end{tabular}

19 Table 5.2: Safety Criteria (e.g. ISO 19900 1994, Moan 2004). Reproduced from Wang et al. (2008). 
Such ULS and FLS standards for the floating structural components have been constantly developing for the related failure levels reliant on the geometry as well as the loading situations. The applicable criteria track matching standards which are recognized for ships and vessels specifically for the offshore structures, that are founded on first standards. Nevertheless, the understood safety level is intended to be cautiously measured in assessment of the possible situations of failure. The safety levels defined by the ULS and FLS necessities are defined by the classification of distinctive standards of loads and strength as well as the safety aspects in the ULS standards and the safety boundaries in the FLS. The fatigue lifetime of the floating structure is assessed by relating the longstanding cyclic loading in each structural component to the resistance of that component to the fatigue damage (Wang et al., 2008).

The Accidental Collapse Limit State (ALS) standards are derived by the design idea which is that the unavoidable minor damages expected, must not cause any unfortunate outcomes (Tsaltas et al., 2010). Whereas the drive of this standard is to avoid the progressive expansion of any failure, the standard was originally defined as Progressive Limit State criterion (Tsaltas et al., 2010).

It is obligatory that the floating structure as well as the mooring system to be aimed to endure the numerous damage circumstances. Working with such requirements for the floating structure project could be in some situations be established by changing the damaged components, and therefore achieving a conservative ULS design check, founded on a global linear analysis and the component design checks via the ultimate strength formulations. Nevertheless, theses approaches can be extremely conservative and therefore, more precise nonlinear analysis procedures must be applied (Suzuki et al., 2006). 


\subsubsection{Corrosion Protection}

The corrosion protection approaches consist of coatings, cathodic protection, corrosion allowance and corrosion monitoring. Overprotection that could cause hydrogen embrittlement ought to be dodged. In zones where the maritime creatures exist, antifouling coatings could be measured to decrease any further maritime progress (Wang et al., 2008).

It is essential to protect the steel from corrosion rust problems via corrosion protection system values. Attention must be considered concerning only under the mean low water level (MLWL) whereas serious local corrosion happens. In these areas, cathodic shielding approach is usually applied when coating means are applied for areas lower than the depth of 1 meter under the low water level (LWL). The coating approaches consist of painting, titanium-clad lining, stainless steel lining, thermal spraying with zinc, aluminium and aluminium alloy (Wang et al., 2008).

\begin{tabular}{|l|l|l|}
\hline & Corrosive Environment & Corrosion Rate (mm/year) \\
\hline Offshore side & Above HWL & 0.3 \\
\cline { 2 - 3 } & HWL to -1 m below LWL & $0.1-0.3$ \\
\cline { 2 - 3 } & 1 m below LWL to seabed & $0.1-0.2$ \\
\cline { 2 - 3 } & Mud layer beneath seabed & 0.03 \\
\hline Onshore side & Air & 0.1 \\
\cline { 2 - 3 } & Earth above water level & 0.03 \\
\cline { 2 - 3 } & Earth above water level & 0.02 \\
\hline
\end{tabular}

20 Table 5.3: Levels of Corrosion. Reproduced from Wang et al. (2008).

The typical standards of the rate of corrosion occurrences and of the distribution of corrosion are based on the depth of water and the seabed. The splash area is the furthermost severe concerning corrosive region as well as its higher limit zone is set based on the installation of the floating structure. The ebb and flow zone relate to the subsequent most 
severe region, nevertheless such area does not occur for floating structures where they adapt to the varying water level. Superior consideration must be put for the region directly under LWL. Regarding the seawater zone, such region becomes milder but on the other hand, the maritime progress as well current could occasionally quicken such corrosion. The region of the soil layer under the seabed zone is even milder, even though it relies on the salt concentration and the level of pollution (Wang et al., 2008).

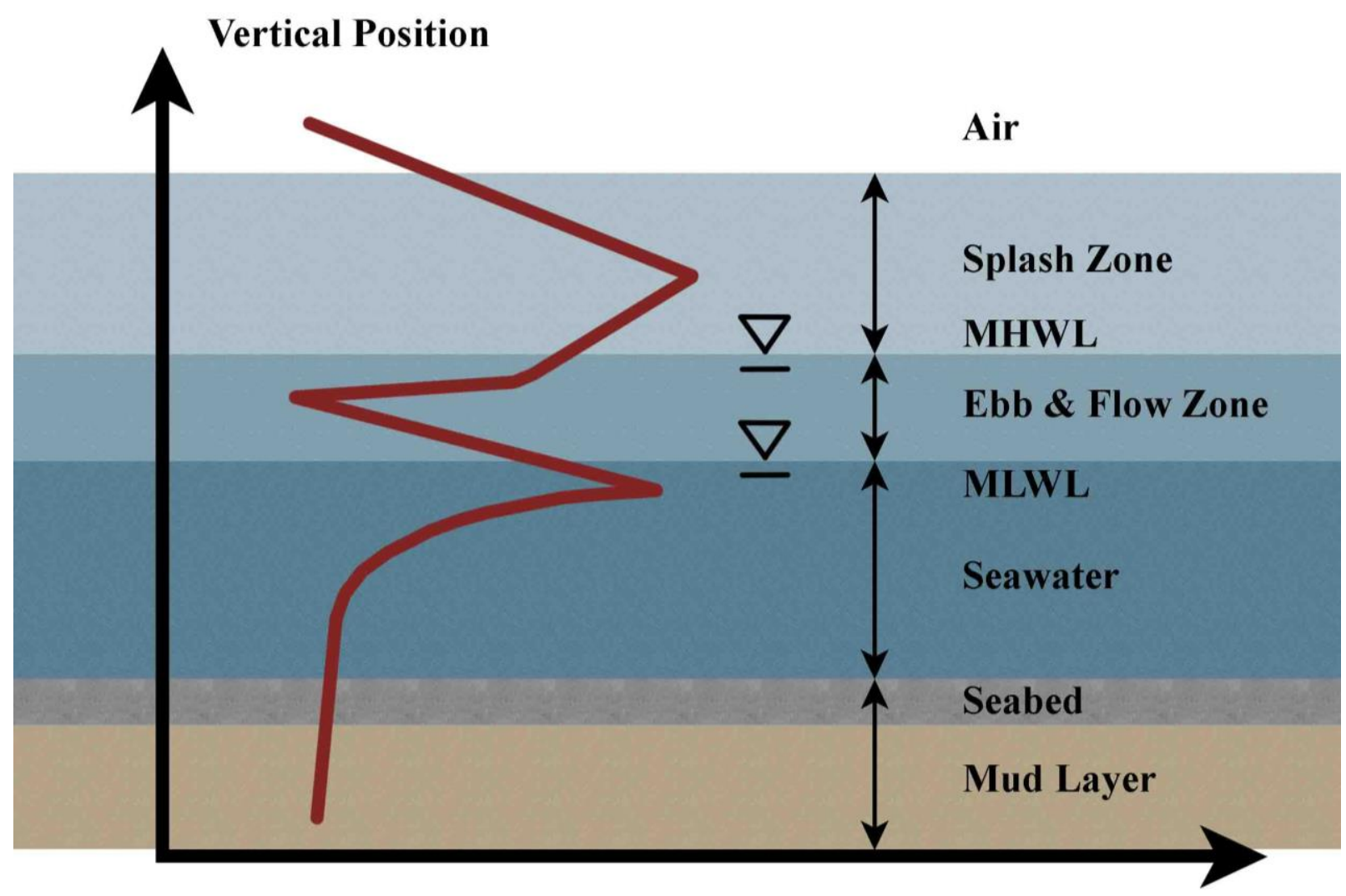

Corrosion Rate

22 Figure 5.3: Corrosion rate distribution rate of steel in the air, water and seabed (own illustration). Created with data from Wang et al. (2008). 


\subsection{Design Considerations for Mooring Systems}

It is essential that the mooring system is cautiously planned so it guarantees that the very large floating structure is preserved in location in order, so the facilities mounted on the floating structure could be dependably operated and to avoid the floating structure from drifting by the risky sea circumstances and storms. A freely drifting VLFS could not only lead to a damage to the adjacent facilities, but also human casualties if it collides with vessels and ships (Suzuki et al., 2006).

The design process concerning the mooring system could embrace the following steps: initially choosing the mooring system type, the shock absorbing material, the quantity and layout of devices in order to meet the environmental situations as well as the operational settings and necessities. The design outline of the mooring dolphin system for instance is like that the horizontal dislocation of the floating structure should be sufficiently controlled as well as that the mooring forces are properly distributed around (Suzuki et al., 2006). The performance of the floating structure with such numerous loading situations must be studied. The outline and amount of the devices are precisely adjusted in order that any possible occurrence of dislocations of floating structure as well as the mooring forces do not surpass the permissible limits and standards. Lastly, methods like the dolphin system and the guide frames are calculated by applying the design load according to the measured mooring forces (Wang et al., 2008).

The materials which are used for the mooring system should be chosen considering the situation, purpose, location, environment, durability as well as the economy. Such criteria will be minorly considered in the future floating structure concept proposal for Egypt and further calculation and details will not be discussed in detail. 


\subsection{Design Considerations for Breakwaters}

For decreasing the wave size which impacts the VLFS, breakwaters are built close. A global general unspoken rule is to integrate a breakwater only if the substantial wave height is higher than 4 meters Ohmatsu (2005). Breakwaters are generally of a gravity-type (or bottom-mounted). Even though the conventional bottom-mounted breakwaters deliver the greatest wave-breaking behaviour, nevertheless they prevent the water stream around the VLFS and therefore they stop the ecological friendly quality. Furthermore, the building budgets for such breakwaters could be rather high in a situation where the seabed depth is deep. In assessment to decrease the expenses, also sustaining the environmental friendly feature, such breakwaters that permit the water to flow through its structure openings of their bottom have been suggested. Ohmatsu (2005) and Maeda et al. (2001) have suggested numerous types of breakwaters like the Oscillating Water Column (OWC) system and structure fixed by OWC system breakwater. Some researchers have suggested a method involving a floating breakwater via an underwater plate while others have focussed on the vertical barriers floating or goes by fixed types in general and have researched the hydroelastic responses of the VLFS by changing the gap sandwiched between the bottommost of a breakwater and the seabed surface (Suzuki et al., 2006). They have determined that the hydro-elastic response of VLFS could be decreased by more than $70 \%$ via sole surface piercing vertical wave barrier with $50 \%$ below the water opening proportion and for the double layer wave barriers, the further consequence is only probable where a similar size wave barrier is to be installed. The behaviour of the multi-layered wave barriers is principally related to the wave barrier with the biggest blockage ratio as well as that the further underwater barriers have slight consequence too (Wang et al., 2008). 


\subsection{Configurations}

As stated earlier, the most important type formations of the VLFS are the pontoon or barge and the semi-submersible construction types. Several superior characteristics could be envisioned for the VLFS pontoon type. For example, it could be linked to an underwater plate and skirt like structures that decreases the motions (Maeda et al., 2001), or it could as well be connected to the floating breakwater to decrease the wave forces on the floating structure itself. Another characteristic that might give an upper hand when implementing the pontoon type VLFS is the design of the edges. When selecting the suitable outline, the propagation by the wave occurrence to the primary area of the floating structure is decreases by either an effective scattering or reflecting such wave occurrence on the windy side (Wang et al., 2008). Lastly, the probable usage of aircushion to decrease the excitation of perpendicular motions (vertical loads) must be approached (Maeda et al., 2001). Some of such innovative design characteristics are promising, but usually they also come with their own disadvantages too, therefore addressing such challenges should be addressed.

\subsubsection{Design Loads}

When designing VLFSs, it is required to consider the subsequent loads: dead load, hydrostatic pressure (counting the buoyancy as well), live load, abnormal loads (for instance, the impact of the loads which are caused by collisions made from the vessels and the ships with the mega-floating structure), also the pressure of earth on the mooring system like dolphins, the wind loads, the forces from the waves (counting the swell as well), the effects accompanied by possible earthquakes (as well as the dynamic water pressure), the climate change effects, the effects of water currents, effects of nonstop tidal variations, the effects of seabed motion, the forces of motion actions of bearings, as well as the possible snow loads, 
effects of tsunamis, the effects of storm flows, also the vessels and ship waves, the seaquakes, the brake load, the erection load, the effects of the drifts ice and ice pressure, the effects of probable drifting bodies, and finally the possible effects of possible marine developments and expansions for instance, the corrosion and friction effects (Wang et al., 2008).

\subsubsection{Load Effect and Design Checks}

When creating the floating body (when modeled as a plate) dimensions, the depth of the water, the wave rate (or period), the waves' heights, and amplitude of the waves occurrence, also hydro-elastic investigations provide the speed possibilities and vertical deflections (tensions and compressions) in the floating structure. Usually, the perpendicular (vertical) deflections could then be used when calculating the stress effects as well as the stresses. Such deflections are to be checked compared to the serviceability requirements whereas the stresses are checked compared to the strength requirements (Wang et al., 2008).

\subsubsection{Local Structural Analysis}

In order to achieve the structural design of the load effects in the several components which form the floating structure, like the hardened panels of the deck, the bottom part and the bulkheads, girders, stiffeners and plates are essential to obtain (Wang et al., 2008). A certain encounter is related when defining the load effects for the fatigue design checks, whereas the local hot spot stresses are essential. Principally, a hierarchy pyramid of such fixed section models should be used for such purpose (Suzuki et al., 2006).

\subsection{Hydro-elastic response}

Pontoon-type VLFS are like enormous plates which appears to be resting on the water. Since such structures occupy a great surface area, in contrast, they have small depth, they 
perform elastically with wave motions. Such sort of fluid-structure contact has been defined as hydroelasticity. Hydro-elastic analysis is therefore essential to be done for the VLFS project to measure the dynamic motions and tensions cause by the wave movements. There are two methods measure the hydro-elastic activity for the VLFS, which are the frequency domain method and the time domain method (Wang \& Tay, 2011).

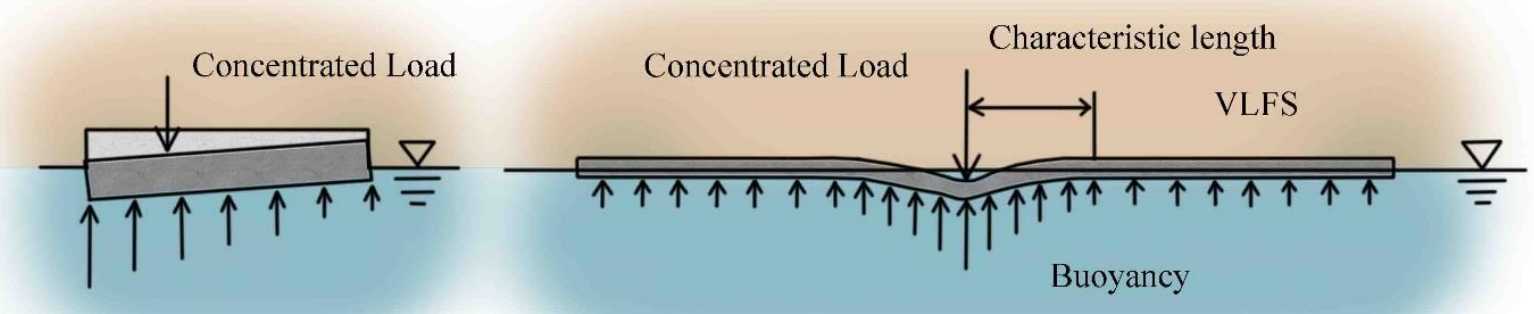

(a) Conventional ships

(b) VLFS

23 Figure 5.4: Worldwide response under a static load (own illustration). Created with data from Suzuki et al. (2006).

\subsubsection{Frequency Domain Method}

Generally, the frequency domain method is implemented as an alternative to the time domain method while establishing the hydro-elastic response amplitude operator of the VLFS which is modeled as a plate-like shape due of its simplicity and capability to capture the appropriate response parameters in a stable state condition (Suzuki et al., 2006).

In the frequency domain method, the Laplace equation for possible velocity is transformed into a limit value issue when calculating for the motion of the floating platform (Suzuki et al., 2006). The limit situations are the Neumann state at the ocean-floor or the seabed, and the submerged areas of the floating platform, the linearized clear surface state and the 
radiation situations are limitless. Nevertheless, former studies on the wave-structure relation problems and solutions has only considered where the floating structure is an inflexible rigid body. While the growing attention for VLFS as an answer for making land from the sea, therefore hydro-elastic analysis on VFLS has developed as a new study field in the 1990s (Suzuki et al., 2006).

VLFS has a rather small draft when in relation to its length span. The general method is to plan the whole floating structure by only a sole plate as founded on the standard thin plate theory whereas the water wave is shaped via the linear wave theory. Furthermore, in the VLFS fuel storage modules, the floating production storage and offloading (FPSO or FPS), have a greater draft to length span proportions contrasting the mat-like VLFS (Wang et al., 2008). Such model requires the planning of the floating modules as a thick plate as stated by the Mindlin plate theory where such method not only leads into a more precise assumption of the possible deflections, but also it delivers an improved estimate for the stress-resultants. Researches on the hydro-elastic relations of two big box-shaped FPSO units done by Tay and his research group (Tay, Wang, \& Utsunomiya, 2009). These modules have an impact on each other caused by diffracted waves, emitted waves and waves that has been squeezed in a channel shaped by the floating structure modules when being positioned adjacently (Tay et al., 2009).

\subsubsection{Time Domain Method}

Time domain method is essential when its required to obtain the temporary response of VLFS. The frequently used methods for time-domain analysis of VLFS are the direct time implementation method in which uses the Fourier transform (Ohmatsu, 2005). In this direct time implementation method, the calculations of motion are discretized for the floating 
structure as well as the fluid domain. In the Fourier transform method, initially one should acquire the frequency domain solutions as for the fluid domain and at that moment Fourier transforms the outcomes for substitution into some differential equations for the elastic motions. The equations are then answered instantly in the time domain analysis via the finite element process or any further appropriate computational methods.

The computational fluid dynamic (CFD) method, that includes answering the Navier Stokes equation, has also developed as a general study area caused by its capability to handle vortex formations while the wave is deflected by sharp edges or its extensions on the VLFS. For Instance, some researchers used the composite grid method to examine the hydrodynamic interaction possibilities that the behavior between the underwater anti-motion device and VLFS (Wang \& Tay, 2011). They have found that the vortex produced by the underwater plate as waves interrupt on the structure increases the additional masses as well as the damping forces of VLFS, thus, extremely reducing structural responses (Wang \& Tay, 2011).

\subsubsection{Mitigation of Hydro-elastic Response}

Several approaches have been planned by engineers to decrease the hydro-elastic response of the mega-floating structures. One of the initial approaches is by building the bottom-founded offshore barrier nearby the VLFS as was made for the Mega-Floating Structures Studies was by (Ohmatsu, 2005; Wang et al., 2009). where they displayed the bottom-founded system pier is extremely efficient in decreasing both the hydro-elastic response and the drift forces. Nevertheless, this method of breakwater keeps possessing some disadvantages which consist of huge construction material necessities, complication in construction, situating in large valuable sea area, complication in decreasing the breakwater 
if VLFS is to be resituated to another place, not eco-friendly, and as a consequence of such reflected waves from breakwaters could outcome in shore destruction. (Wang \& Tay, 2011).

The floating box-like breakwater moored with mooring lines plan was suggested as an substitute to the conservative bottom-founded method breakwater when shielding VLFS from the harmful sea (Suzuki et al., 2006). While the floating breakwaters don't disturb the sea current flow but on the other hand, they rather harm to the seabed slightly. Moreover, the floating box-like breakwater is the furthermost common way used, it is built nearby the floating fuel storage facility (FFSF) and it can possibly also work as in impacts and oil spill barriers. Also, in the solitary box-like floating breakwater strategy, the floating breakwaters of diverse formations and cross-sections have been previously planned to improve the effectiveness of the breakwater in decreasing the wave forces impacts (Wang \& Tay, 2011).

As the practice of breakwaters for decreasing wave forces affecting on the VLFS comes with a high cost and needs even more time for building, therefore, engineers are encouraged to create an anti-motion device that could be connected to the VLFS. The underwater plate parts are capable to deplete the constant wave energy and decrease the incident wavelength by producing breaking wave, wave fission, and vortices (Wang \& Tay, 2011). According to some research groups like Maeda et al. (2001) have studied the usage of the "Oscillating Water Column" (OWC) anti-motion method in decreasing the hydro-elastic response of the VLFS. This method is comparable to the underwater anti-motion method but might possibly reach more decreases in the hydro-elastic responses caused by the ability of the OWC air chamber in collecting the wave energy. Nevertheless, the connection of the OWC anti-motion system could outcome in a rise in the drift forces. To decrease the hydro-elastic response caused by either the strong waves or air-craft take-off/landing load (Wang \& Tay, 2011). 
The hybrid type anti-motion method that includes a blend of floating breakwater, underwater plate anti-motion method and the OWC chamber is suggested for better decrease in the hydro-elastic response of the VLFS. A suggested a hybrid wave load decreasing system, that involves of a floating breakwater positioned in front of the Eco-float, which is a blend of seaport and airport with its own sustainable power plant (Wang \& Tay, 2011). However, the Corporation for Advanced Transport and Technology in Japan has also planned the sub-plate VLFS, that involves of an underwater plate anti-motion method which is connected to the front and secured by the underwater plate floating breakwaters (Wang \& Tay, 2011).

\subsection{Structural integrity (Functionality and Safety Criteria)}

The functionality and safety measures and standards are crucial matters that control and lead the structural plan of the VLFS project. In the VLFS for instance, the criteria in terms of functionality which leads the VLFS project is the impact of the hydro-elastic responses on the delicate equipment landing system, as well as the accuracy method pass indicator, and system of air navigation (Wang \& Tay, 2011). Henceforward, the VLFS ought to have the appropriate stiffness to decrease the hydro-elastic response caused by the wave activity. The safety measurements are to guarantee that the VLFS is adequately durable to endure the structural elements stresses due to the manmade live loads as well as the environmental loads. Suzuki has stated that in a case of a floating airport or a runway, stresses in the structural elements the vertical motion of airplanes on the floating runway expressively rely on the structural wave distribution, which is the hydro-elastic response (Suzuki et al., 2006).

In 2005, Suzuki stated that the extreme malformation, movements, and the vibration impact on the VLFS might disturb the practicality of the VLFS as a floating runway when the cyclical loading caused by the waves motion could outcome in an exhaustion of the 
structural elements (Seto, Ohta, Ochi, \& Kawakado, 2005). The extreme structural response may possibly also lead into sinking of the VLFS caused by the continuous and no stop flooding as well as drifting of the VLFS caused by a failure in the dolphin-fender system. More advanced hydro-elastic analysis has been done for a whole 3D VLFS, where it aimed to acquire the sufficient data needed about the deflections and stresses as to the secondary structural elements in the VLFS (Seto et al., 2005).

\subsection{Drift Forces for Mooring System Design}

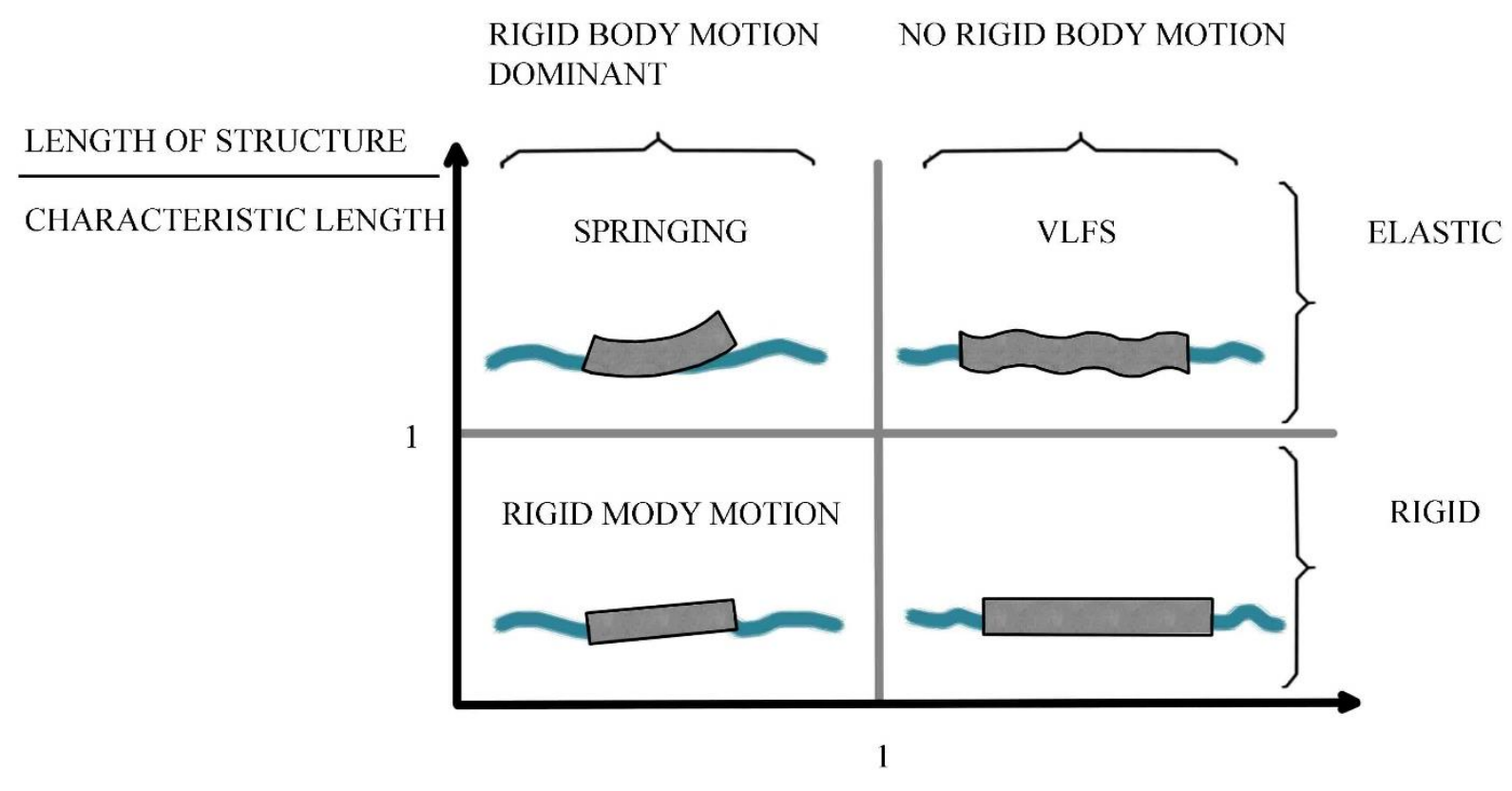

LENGTH OF STRUCTURE

WAVE LENGTH

24 Figure 5.5: Plotting of the worldwide response of floating structures (own illustration). Created with data from Suzuki et al. (2006).

The design proposal of a mooring system needs to study and resolve of wave drift forces activity on the VLFS. Usually, here are two general methods for measuring the wave drift forces. Specifically, the near-field method it was founded on the direct pressure integration 
method and the far-field method founded on the momentum-conservation standards (Seto et al., 2005). Although both of there approaches can estimate the drift forces to be fairly good for a sole VLFS, on the other hand the far field method holds somehow a few boundaries in a scenario where two or more VLFS modules are designed to be positioned neighboring each other like in the situation of the FFSF. It is due to the far-field method which gives just the overall forces activity on every floating module, therefore the forces activities on separate modules might not be possibly achieved (Seto et al., 2005). However, the near-field method gives the separate force to every VLFS while the calculations are somewhat difficult due to the several elements that require to be assessed, like the current velocity on the wet surface as well as the relative wave altitude lengthwise the waterline of a boat or a vessel (Wang \& Tay, 2011).

\subsection{Development of VLFS Technology}

The VLFS technologies as well as their developments are demonstrated next. Concentrating on the design methods of the VLFS in terms of the mooring systems, also the mitigation approaches of the hydro-elastic responses and connector strategies.

\subsubsection{Mooring Systems}

The mooring system guarantees that the VLFS is stay in location in order that the facilities mounted on the VLFS could be constantly working, also to avoid any drifting of the floating structure caused by the dangerous sea situations and storms. In a case where the very large floating structure drift away then such VLFS could possibly lead to not only to harm to the adjacent facilities, but it also could lead to a possible loss of human lives, for example if a collision with boats or ships occurs (Suzuki et al., 2006). 


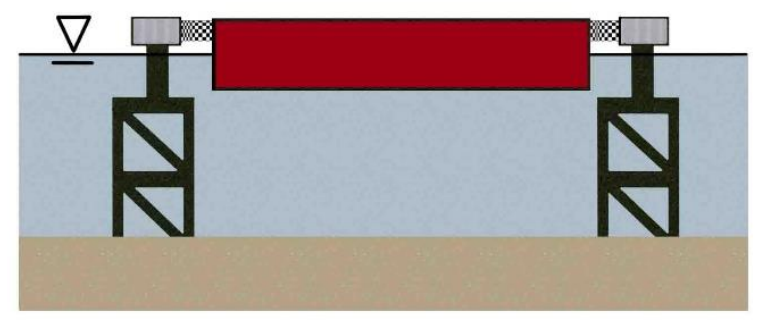

DOLPHIN-FRAMGUIDE METHOD

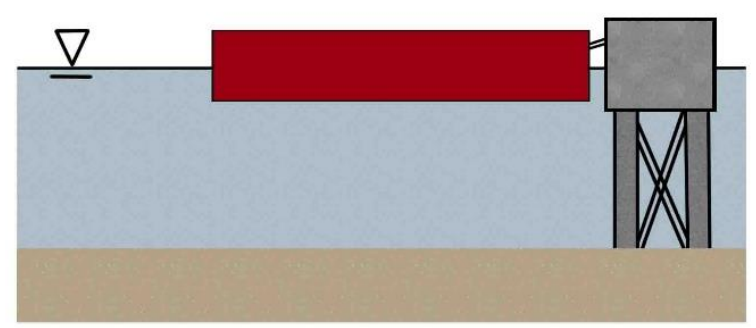

PIER/QUAY WALL METHOD

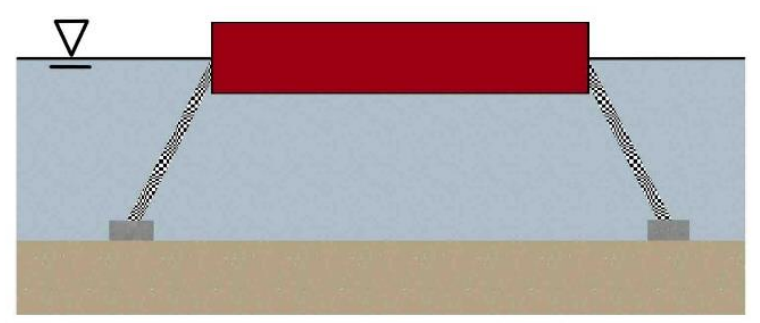

CHAIN/CABLE METHOD

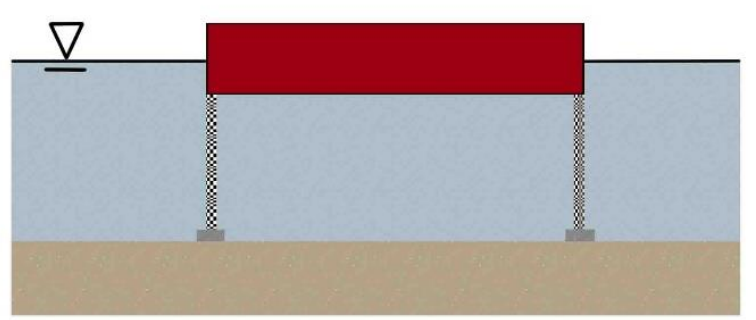

TENSION LEG METHOD

25 Figure 5.6: Several methods of Mooring Systems (own illustration). Created with data from Wang \& Tay (2011).

The station system of the mega-floating structure could be categorized into two main approaches:

I. The chain/cable and the tension leg methods.

II. The pier/quay wall and pile-type dolphins-foreguide with rubber fender system.

The previous methods practices with all of chains, wire ropes, synthetic ropes, chemical fiber ropes, steel pipe piles, and hollow pillar links (Wang \& Tay, 2011). Such mooring systems are practiced in the VLFS which operates in deep seas like the tension leg floating wind farm or in the floating salmon farm in Vancouver, Canada. Nevertheless, the movements of the Mega-floating structures turn out to be big where the dimension of mooring 
line is relatively elongated. Particularly in the case of deep seas, the tension leg system is implemented where the pretension is enforced to the mooring line in pursuance of preventing any motion occurrence. In a similar station keeping system, it is very hard to control the horizontal movements well and frequently the mooring lines encounter some substantial tension forces (Wang \& Tay, 2011).

The initial rubber fender-dolphin mooring system was implemented in two floating oil storage project bases at Kamigoto and the Shirashima islands in Japan. The mooring system has subsequently been implemented for further facilities like floating piers, floating terminals, floating exhibition halls, floating emergency bases, and floating bridges (Wang \& Tay, 2011). The rubber fender-dolphin method is extremely efficient in controlling the horizontal dislocation that may occur in the mega-floating structure. As the big size rubber fenders can endure a very great dislocation, to be exact up to about roughly one-third of their spans, whereas a substantial quantity of the kinetic energy of the mega-floating structure could be absorbed (Suzuki et al., 2006).

\subsection{Strength and Failure Behavior}

\subsubsection{Components}

For the objective of ensuring the structural integrity as well as the constancy of the VLFS, failure levels and related design border conditions are to be effectively acknowledged from the module as well as the system stages. The next Tables briefly demonstrate the boundary conditions which are established by the safety standards by both the MOB and of Mega-Float. While the small difference in the terminology of border conditions of the MOB and the Mega- 
Float, nevertheless the fundamental philosophy and descriptions are nearly one (Suzuki et al., 2006).

\begin{tabular}{|c|c|c|c|}
\hline \multicolumn{3}{|l|}{ Limit State } & \\
\hline MOB & \multicolumn{2}{|c|}{ Mega-Float Definition } & Description \\
\hline $\begin{array}{l}\text { Serviceability and } \\
\text { operability }\end{array}$ & \multicolumn{2}{|c|}{ Serviceability } & $\begin{array}{l}\text { Disruption of usual usage caused } \\
\text { by extreme distortion, movements } \\
\text { or vibration. }\end{array}$ \\
\hline Fatigue & \multicolumn{2}{|l|}{ Fatigue } & $\begin{array}{l}\text { Critical level of increasing fatigue } \\
\text { problems or critical crack scale. }\end{array}$ \\
\hline Strength & \multicolumn{2}{|c|}{ Strength Allowable } & $\begin{array}{l}\text { Failure of structural component } \\
\text { (for example a panel or stiffener), } \\
\text { assembly (like stiffened panel or } \\
\text { bulkhead) as well as the } \\
\text { subsystem } \\
\text { (like the decks or columns) } \\
\text { counting the inter-module } \\
\text { connector. }\end{array}$ \\
\hline \multirow[t]{2}{*}{$\begin{array}{l}\text { Global failure and } \\
\text { Survivability }\end{array}$} & $\begin{array}{l}\text { Progressive } \\
\text { collapse }\end{array}$ & $\begin{array}{l}\text { Ultimate } \\
\text { Strength }\end{array}$ & \multirow{2}{*}{$\begin{array}{l}\text { Loss or failure of the whole } \\
\text { structure (for example capsizing, } \\
\text { sinking, drifting, global } \\
\text { collapse). Because of either: } \\
\text { The progressive collapse. } \\
\text { In damaged condition. }\end{array}$} \\
\hline & $\begin{array}{l}\text { Damaged } \\
\text { condition } \\
\text { Damage }\end{array}$ & $\begin{array}{l}\text { State after } \\
\text { Partial }\end{array}$ & \\
\hline
\end{tabular}

21 Table 5.4: Limit states for both MOB and Mega-Floats. Reproduced from Suzuki et al. (2006).

In the MOB descriptions, the fatigue and strength border states, they are basically unit stage limit states are element/assembly or subsystem stage, whereas the latter relates to the whole system. This component-level border situations are those usually analyzed and confirmed when designing the huge steel-plated structures, and therefore the current 
standards for yielding, fastening and fatigue strengths could be usually done (Suzuki et al., 2006).

\begin{tabular}{|c|c|c|}
\hline Limit State & $\begin{array}{l}\text { Scale of Structural } \\
\text { Participation }\end{array}$ & Definition of Limit State \\
\hline $\begin{array}{l}\text { Serviceability/ } \\
\text { Operability }\end{array}$ & $\begin{array}{l}\text { Elements and assemblies, } \\
\text { occasionally subsystem } \\
\text { and system. }\end{array}$ & $\begin{array}{l}\text { Disturbance of the regular } \\
\text { use (as well as military } \\
\text { activities) caused by the } \\
\text { extreme deflection, possible } \\
\text { distortion, movements or } \\
\text { vibrations. }\end{array}$ \\
\hline Fatigue & $\begin{array}{l}\text { Element/assemblies. } \\
\text { As well as the inner-module } \\
\text { connectors. }\end{array}$ & $\begin{array}{l}\text { Critical level of increasing } \\
\text { fatigue damage or critical } \\
\text { crack size defined by the } \\
\text { functional reflections, } \\
\text { fracture durability, or static } \\
\text { strength. }\end{array}$ \\
\hline Strength & $\begin{array}{l}\text { Element and assemblies. } \\
\text { As well as inter-module } \\
\text { Connectors. }\end{array}$ & $\begin{array}{l}\text { Local failure like the } \\
\text { rupture, unsteadiness, as } \\
\text { well as plastic mechanism, } \\
\text { and buckling. }\end{array}$ \\
\hline $\begin{array}{l}\text { Survivability/ } \\
\text { Global Failure }\end{array}$ & $\begin{array}{l}\text { The whole system (entirely } \\
\text { connected MOB, or } \\
\text { some sole modules when } \\
\text { disconnected). }\end{array}$ & $\begin{array}{l}\text { Damage of the whole } \\
\text { structure (for instance the } \\
\text { instability leads to } \\
\text { capsizing, sinking, damage } \\
\text { of station keeping). } \\
\text { As an outcome of the } \\
\text { progressive collapse, or } \\
\text { In damaged condition after } \\
\text { sustaining severe damage in } \\
\text { a sub-system. }\end{array}$ \\
\hline
\end{tabular}

22 Table 5.5: The structure limit states of the VLFS. Created with data from Suzuki et al. (2006).

The inner unit connectors are a vital factor when designing a MOB. A possible increase in the conducted forces past those of the FPSO connectors could be expected for the MOB inner unit connectors (Suzuki et al., 2006). The crack of the inner unit connectors could 
directly lead to a disastrous failure for the whole system, and therefore an accurate estimate of the fatigue life expectancy is one of the crucial subjects to understand in the MOB (Suzuki et al., 2006). It is thought that the fatigue strategy for the MOB unit connectors is achievable based on the break mechanic method, nevertheless the consistency level is essential for arrangement could be fulfilled except if the hot spot stress stages are decreased to $135 \mathrm{MPa}$, at least when designing the inflexible connectors (Suzuki et al., 2006). Additionally, the corrosion fatigue impacts could not be involved with the assurance in the lack of experimentally authorized matching fatigue crack proportion development model Fujikubo (2005).. The articulated connector units rely on the special way of the cyclic loading which includes extremely great forces distributed over a comparatively insignificant contact and effect bearing surfaces. The selection of specifically planned sleeve bearings lined along with large strength polymers were suggested for articulated connector units by Seto et al. (2005).

On the other hand, the Mega-Float VLFS is considered by its slim mat-like outline shape. Different from the ships and vessels which could be viewed as a beam, on the other hand in the Mega-floats, the deck as well as the lowermost panels are usually controlled by the joint biaxial and shear loads relatively same. In a case of a longitudinal framing system is done, the loading situations on the deck and lowermost panels are usually plainer in the diagonal side than that of the longitudinal one as reported by Fujikubo (2005). Due to the comparatively slim and small depth of the floating structure, shear strength of bulkheads should be cautiously inspected, mainly where a big opening for the interior space usage of the floating structure exists in the bulkheads. In such scenario, shear bending impacts on the deck as well as the bottom girders could be possibly substantial (Fujikubo, 2005). 


\subsubsection{Load Types and Combinations}

Every limit state which is appropriate to a specified structural component and for assembly, as well as systems and subsystems, all the load categories plus the load blends must be measured. The subsequent load types must be involved in the loop plan wherever related as stated by the Suzuki et al. (2006) in the International Ship and Offshore Structures Congress (ISSC) committee VI.2: VLFS":

- "Permanent or dead loads. Permanent loads include self-weight, weight of connectors, fixed equipment, permanent ballast, etc.

- Variable or live loads. Variable loads include weight of temporary/movable equipment, people, cargo (dry and liquid), variable ballast (dry and liquid), etc.

- Frequent and Rare Environmental loads. Environmental loads can arise from wind, current, waves and earthquakes. Frequent environmental load represents annual maximum load, which is a random variable. Its nominal value is its one-year return period value. Rare environmental load represents lifetime maximum load, which is a random variable; it is nominally its 100 -year return period value.

- Operation loads. Operational loads include aircraft landing loads, crane loads, berthing/docking loads, connection/ disconnection loads, etc.

- Cyclic loads. Cyclic loads include repetitive components of environmental and operational loads.

- Accidental loads. Accidental loads include on-board explosions, fires, and abrupt changes in buoyancy, inter-module collision, crash of aircraft, grounding etc. 
- In addition, any load associated with construction, fabrication and installation shall also be considered."

(Suzuki et al., 2006).

\begin{tabular}{|c|c|c|c|c|c|c|c|c|}
\hline \multirow[t]{3}{*}{ Limit States } & \multicolumn{8}{|l|}{ Load Types } \\
\hline & \multirow[b]{2}{*}{ Permeant } & \multirow[b]{2}{*}{ Variable } & \multicolumn{2}{|c|}{ Environment } & \multirow[b]{2}{*}{ Operational } & \multirow[b]{2}{*}{ Cyclic } & \multirow[b]{2}{*}{ Accidental } & \multirow[b]{2}{*}{ Installation } \\
\hline & & & Frequent & Rare & & & & \\
\hline Serviceability & $\mathrm{X}$ & $\mathrm{X}$ & $\mathrm{X}$ & & $\mathrm{X}$ & & & \\
\hline Fatigue & & & & & & $\mathrm{X}$ & & \\
\hline \multirow[t]{5}{*}{ Strength } & $\mathrm{X}$ & $\mathrm{X}$ & & $\mathrm{X}$ & & & & \\
\hline & $\mathrm{X}$ & $\mathrm{X}$ & $\mathrm{X}$ & & $\mathrm{X}$ & & & \\
\hline & $\mathrm{X}$ & $\mathrm{X}$ & $\mathrm{X}$ & & & & $\mathrm{X}$ & \\
\hline & $\mathrm{X}$ & $\mathrm{X}$ & $\mathrm{X}$ & & & & & \\
\hline & $\mathrm{X}$ & & & & & & & $\mathrm{X}$ \\
\hline $\begin{array}{l}\text { Global Failure: } \\
\text { (a) Progressive } \\
\text { Collapse }\end{array}$ & $\mathrm{X}$ & $\mathrm{X}$ & & $\mathrm{X}$ & & & & \\
\hline $\begin{array}{l}\text { (b) Damaged } \\
\text { Condition }\end{array}$ & $\mathrm{X}$ & $\mathrm{X}$ & $\mathrm{X}$ & & & & & \\
\hline
\end{tabular}

23 Table 5.6: Load combinations outline. Reproduced from Suzuki et al. (2006).

\subsubsection{System}

Two categories of the system border condition checks are done for the VLFS. The first one is a continuous failure investigation of a whole structural system going through some irregular load effects and the second one is an enduring strength investigation of the entire structural system which is in a bad situation. Usually in VLFS, such system checks are crucial in order to identify the failure circumstances and an assessment of related dangers, that could give a calculable degree of the safety (Suzuki et al., 2006).

The Mega-Float structures should be protected from disastrous failures, for instance like sinking, drifting, and tragic collapsing failures of the VLFS. The model implemented in the researches had a surface area of 500 hectares where it was moored by over than 30 dolphins 
Fujikubo (2005) has studied the liberal collapse behavior of the VLFS with dangerous waves environments and explained some possibility of such progressive collapse in the crested unusual waves. Time domain mathematical simulations of the dolphin method in small crested unusual waves are done with changing winds and currents while considering the nonlinear features of the fenders and dolphins (Wang \& Tay, 2011). The outcome has showed the possibility of drifting of the VLFS which is moored, for example by 50 dolphin parts was $10^{-6}$ (Suzuki et al., 2006). The ideal quantity of dolphins was discoursed founded on the anticipated overall life-span budget by Suzuki et al. (2006).

British Columbia Float Home Standard (2015) involves an global safety assessment of the entire Mega-Floating structure system which involves of the floating structure, the topside facility, the mooring facility, as well as the passageway from the coastline and the wave control facility if needed Fujikubo (2005) Its purpose that anticipate the worst probable failure situation and to inspect if the VLFS satisfies the consistent satisfactory risk stages for the entire system. Fujikubo (2005) has done a structural safety valuation of the pontoontype in risky waves with respect to the harm to the breakwater and demonstrated that the possibility of failure fulfilled the targeted safety measures (Suzuki et al., 2006).

\section{Conclusion concerning the strength and failure:}

Distinctive threats which could lead to a significant harm to the MOB consist of weapons impacts, detonations, violence, etc. Concerning the damaged situation, damages which are caused by the vessels and ship collisions should be evaluated. Impacts of the section size on the damage degree as well as the lasting strength after a challenge or a flooding should also be studied. 


\subsection{Difference Between Conventional Ship, Offshore}

\section{Structures, and VLFS}

Unlike ships and the floating offshore structures, the elastic response is a main issue in VLFS. An evaluation of the static response with load concentration is demonstrated schematically in Figure 5.5. As a balanced way to differentiate the VLFS from a conventional ship or the offshore floating structures in relations to the global response has been done by Suzuki et al. (2009).

If the span of the structure is less than its characteristic length, the response is subjugated to the rigid-body motions, however if it is more than its characteristic length, as characteristically in the most of the VLFS projects, therefore the response is subjugated to the elastic bends.

The ratio of the wavelength to the characteristic length is also has a vital influence on the global response of the VLFS. In a case where the wavelength is less than the characteristic length, therefore the wave forces substitutes in the series of the floating structure length and the load effect cancels each other out, the outcome is a reduced global response, however in a case where it is superior than the characteristic length, therefore the outcome is substantial global response becomes (Suzuki et al., 2006). In general, the VLFS could be categorized by its enormous structural scale related to the characteristic length as well and not only to the wave length. 


\subsection{Design of VLFS}

Floating cities is a proposed worldwide approach by architects, engineers, investigators and even organizations to tackle the global warming and land scarcity problems, or to produce a cultural and political modification possibilities. Even though the number of ideas and concepts for the floating communities is currently notable, yet the real execution is still restricted to such small-scale projects.

This section initially conducts comparative analysis for different approaches, methods, and strategies to for architectural design guidelines for building on water: such analysis is concerned with approaches and methods followed when designing floating structures in respect to Egypt's criteria and characteristics of the Nile Delta to offer guidelines for building on water to cope with future situations. Such evaluation analyses: movability, dynamic geography, seakeeping, water experience, growth development, and mooring system.

\subsubsection{Design Methodology for Any Floating City Project}

As stated by Czapiewska et al. (2013) at the Seasteading Institute, a method of five essential features should be met:

I. The residents' needs and requirements.

II. Site appropriateness.

III. Future expansion and development progress.

IV. Design of the proposed project.

V. Financial evaluation of the proposed project. 
The initial feature could work as the project goals. Whereas in order to achieve such feature, the project design as well as the development plan are required to be both financially achievable and capable of repositioning in case of incidents if the original site doesn't fit the requirements anymore. For the Nile Delta situation here, the attention for the initial feature would be positioning the project in protected waters (Suzuki et al., 2006). Due to such former approaches, the proportions of such floating platform should be reduced from when designing for open waters. The perfect scenario is that if the platforms wouldn't require a breakwater. If moved to open waters, the platforms ought to be capable of surviving, nevertheless it may be rather uncomfortable to live on. In general, repositioning the project to open waters may serve as a temporary solution throughout heavy storms, while afterword's the platform should be repositioned back into protected waters. The perfect scenario is that the floating community may be surrounded by a breakwater, so they could fit in open waters (Czapiewska et al., 2013).

\subsubsection{Comparative Analysis for Different Approaches and}

\section{Methods for Floating Cities}

The six most significant design strategies concluded from the previous chapter are: portability, dynamic geography, development, survival/durability, security, and water life. Every objective has its own the pros and cons, plus how every objective will affect such project. After the comparative analysis on each of the six approaches, arranging them in order of the priorities for the Nile Delta's situation and the options which are not practicable will be excluded. 


\subsubsection{Portability}

The most significant strategic goals in relation to portability are the easiness, speed, safety, and suitability of transportation. Different ways to relocate any floating structure are related to the modules' sizes. VLFS have a rather simple mooring system and therefore, could be relocated faster, while small floating structures usually contain more connectors linking the community components with the seabed (Czapiewska et al., 2013).. The anticipated frequency of relocating is unusual, if ever. Nevertheless, in the case of the Nile delta, moving won't not be frequent, but it may be very useful for some areas around the world where relocating is available in scenarios like in unsettling environments or natural disasters.

If a floating structure is to be only infrequently relocated once in ten years for instance, therefore the idea of self-propelled may not be expensive. To avoid storms, the idea of disassembly would not be very practical as it most probably will take so much time to disassemble (Wang \& Tay, 2011). The two most appropriate ideas are dragging the floating modules or moving the floating modules via semi-submersible vessels. Such approach could be done to move both large and small floating structures, only the semi-submersible vessel is able to drag small floating structures over the open waters' high seas. The Blue Marlin for instance has a surface dimensions of $63 \times 178.2$ meters and a surface area of 11,227 meters squared while the biggest semi-submersible vessel is the Dock-wise Vanguard (Boskalis) which is 70x275 meters and it's a very appropriate for extreme loads (Suzuki et al., 2006). 


\begin{tabular}{|c|c|c|c|c|}
\hline Option & Archetype & Characteristics & Advantages & Disadvantages \\
\hline $\begin{array}{l}\text { Self- } \\
\text { propelled }\end{array}$ & & $\begin{array}{l}\text { Ultimate movability } \\
\text { is achieved by } \\
\text { incorporating a } \\
\text { seastead or } \\
\text { constructing it on a } \\
\text { vessel which the } \\
\text { optimum solution if } \\
\text { city is frequently } \\
\text { repositioned. }\end{array}$ & $\begin{array}{l}\text { Easily } \\
\text { repositioned. } \\
\text { Rapidly } \\
\text { repositioned. } \\
\text { Basic mooring } \\
\text { system for big } \\
\text { constructions. }\end{array}$ & $\begin{array}{l}\text { Large external } \\
\text { propulsion system } \\
\text { is required for } \\
\text { relocation. } \\
\text { High maintenance } \\
\text { expenses. }\end{array}$ \\
\hline Towed & & $\begin{array}{l}\text { Floating platforms } \\
\text { are planned to be } \\
\text { easily repositioned } \\
\text { using tugboats or } \\
\text { further exterior } \\
\text { propulsion system. }\end{array}$ & $\begin{array}{l}\text { Easily } \\
\text { repositioned. } \\
\text { Rapidly } \\
\text { repositioned. }\end{array}$ & 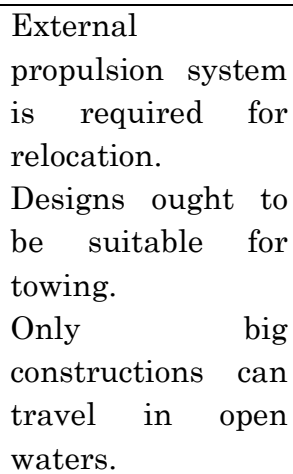 \\
\hline $\begin{array}{l}\text { Semi- } \\
\text { submersib } \\
\text { le ship }\end{array}$ & & $\begin{array}{l}\text { Moved by semi- } \\
\text { submersible vessels. }\end{array}$ & $\begin{array}{l}\text { Rapidly } \\
\text { repositioned. } \\
\text { Minimum design } \\
\text { limitations. } \\
\text { Freeboard could be } \\
\text { lower to give the } \\
\text { optimum water } \\
\text { experience. } \\
\text { Diverse platform } \\
\text { dimensions could } \\
\text { be repositioned. } \\
\text { Permits smaller } \\
\text { structures to be } \\
\text { moved to open } \\
\text { waters. } \\
\text { Whole structure is } \\
\text { intact. }\end{array}$ & $\begin{array}{l}\text { External } \\
\text { propulsion system } \\
\text { is required for } \\
\text { relocation. } \\
\text { Great number of } \\
\text { vessels are } \\
\text { required for high } \\
\text { number of small } \\
\text { platforms. } \\
\text { Mostly appropriate } \\
\text { for big structures. } \\
\text { Floating platform } \\
\text { dimensions are } \\
\text { controlled to vessel } \\
\text { size. } \\
\text { Structure have to } \\
\text { be sufficiently } \\
\text { durable to be } \\
\text { elevated out from } \\
\text { water. }\end{array}$ \\
\hline $\begin{array}{l}\text { Disassem } \\
\text { bled }\end{array}$ & A险彾 & $\begin{array}{l}\text { Should be planned } \\
\text { to be } \\
\text { assembled/disassem } \\
\text { bled and moved in } \\
\text { containers. }\end{array}$ & $\begin{array}{l}\text { Rapidly } \\
\text { repositioned. } \\
\text { Transported to any } \\
\text { site. }\end{array}$ & $\begin{array}{l}\text { Preparing for } \\
\text { transportation is } \\
\text { time-consuming. } \\
\text { Residents can't } \\
\text { move together. }\end{array}$ \\
\hline
\end{tabular}

24 Table 5.7: Analyzed possibilities for movability (own illustrations). 


\subsubsection{Dynamic Geography}

\begin{tabular}{|c|c|c|c|c|}
\hline Option & Archetype & Characteristics & Advantages & Disadvantages \\
\hline Islands & 1 & $\begin{array}{l}\text { Each structure is } \\
\text { repositioned on its } \\
\text { own platform or } \\
\text { its hull which } \\
\text { facilitates the best } \\
\text { movement } \\
\text { flexibility. } \\
\text { Buildings are } \\
\text { linked with } \\
\text { hinged joints. }\end{array}$ & $\begin{array}{l}\text { - Best dynamic } \\
\text { layout. }\end{array}$ & $\begin{array}{l}\text { Great quantity of } \\
\text { connections. } \\
\text { Great quantity of } \\
\text { mooring systems } \\
\text { is required. } \\
\text { Great swell. }\end{array}$ \\
\hline Branch & & $\begin{array}{l}\text { Floating } \\
\text { structures contain } \\
\text { of various homes } \\
\text { or further } \\
\text { buildings. } \\
\text { On platform } \\
\text { structures could } \\
\text { be connected with } \\
\text { either hinged or } \\
\text { rigid joints. }\end{array}$ & $\begin{array}{l}\text { Easily } \\
\text { repositioned. } \\
\text { Not as much of } \\
\text { swell like in } \\
\text { islands. }\end{array}$ & \begin{tabular}{|lr}
\multicolumn{2}{|l}{ No option to } \\
relocate single \\
houses. \\
Structures \\
require being \\
identical ro \\
connect. \\
Great quantity of \\
mooring systems \\
is required. \\
\end{tabular} \\
\hline $\begin{array}{l}\text { Compos } \\
\text { ite } \\
\text { structur } \\
\text { e }\end{array}$ & & $\begin{array}{l}\text { Semi-large } \\
\text { platforms are } \\
\text { linked together to } \\
\text { form a greater } \\
\text { one. } \\
\text { Rigid joints. }\end{array}$ & $\begin{array}{l}\text { Less quantity of } \\
\text { mooring systems } \\
\text { is required. } \\
\text { Small amount of } \\
\text { swell. }\end{array}$ & $\begin{array}{l}\text { Disassembly is } \\
\text { complex. } \\
\text { In repositioning, } \\
\text { adjoining } \\
\text { structures } \\
\text { require moving. }\end{array}$ \\
\hline $\begin{array}{l}\text { Single } \\
\text { large } \\
\text { structur } \\
\text { e }\end{array}$ & & $\begin{array}{l}\text { Huge structure } \\
\text { like a ship or oil } \\
\text { platform as a } \\
\text { single unit. }\end{array}$ & $\begin{array}{l}\text { Less quantity of } \\
\text { mooring systems } \\
\text { is required. } \\
\text { Small amount of } \\
\text { swell. }\end{array}$ & $\begin{array}{l}\text { Relocation is not } \\
\text { an option. }\end{array}$ \\
\hline
\end{tabular}

25 Table 5.8: Analyzed possibilities for dynamic geography (own illustrations).

Floating communities allows more flexibility on the community and individual levels. Such idea could be accomplished with potential adding a unit which hosts some houses or facilities. Also, relocating the community's platforms to another location. If possible, a finegrained scale as possible could allow better portability for even each housing unit. The 
foremost appropriate possibilities are the islands and branch platform modules, where such modules could connect to form whole units to form a community. The platforms are linked by connections or piers, the branches-like platforms are connected via hinged joints, consequently both platforms could be simply attached and detached. The branches connect the community together on foot allowing people to go from one place to another.

\subsubsection{Survivability and Durability}

Seakeeping is both the capability to endure the difficult sea situations in protected waters and capable of surviving in the harsh open waters' environments. The main matters in the open waters are water depth, high waves and hurricanes. Such features create challenges for the mooring system and the breakwaters (Tsaltas et al., 2010). Tugboat vessels or the submerged-type alternatives are not appropriate for accomplishing the needed comfort level for the inhabitants. Vessels practices a lot of swell, while the submerged-type neither gets the required sunlight nor fresh air (Suzuki et al., 2006). Thus, the best appropriate solutions are the oilrigs and breakwaters (Czapiewska et al., 2013). 


\begin{tabular}{|c|c|c|c|c|}
\hline Option & Archetype & Characteristics & Advantages & Disadvantages \\
\hline Ship & & $\begin{array}{l}\text { Vessels is a } \\
\text { recognized } \\
\text { approach, while big } \\
\text { ones are specifically } \\
\text { appropriate for open } \\
\text { waters for their } \\
\text { form and } \\
\text { dimensions. } \\
\text { Wave attenuators } \\
\text { are incorporated in } \\
\text { the vessel. } \\
\text { Buildings are very } \\
\text { reactive to wave } \\
\text { activities and may } \\
\text { result a great } \\
\text { quantity of swell. }\end{array}$ & $\begin{array}{l}\text { Incorporated wave } \\
\text { protection system. }\end{array}$ & $\begin{array}{l}\text { Wave attenuators } \\
\text { just work when } \\
\text { vessels are moving. } \\
\text { Not the best form } \\
\text { to build a city with } \\
\text { public spaces, } \\
\text { connections, etc. }\end{array}$ \\
\hline $\begin{array}{l}\text { Raised } \\
\text { platform }\end{array}$ & 会会 & $\begin{array}{l}\text { Elevated platforms } \\
\text { like in oilrigs or an } \\
\text { air container sort of } \\
\text { structure reduces } \\
\text { the surface which is } \\
\text { in contact with } \\
\text { water, hence } \\
\text { diminishes wave } \\
\text { activities. }\end{array}$ & $\begin{array}{l}\text { Breakwater } \\
\text { incorporated. } \\
\text { Least contact with } \\
\text { water decreases } \\
\text { wave activities and } \\
\text { its effects. }\end{array}$ & $\begin{array}{l}\text { Suitable just for } \\
\text { huge structures. }\end{array}$ \\
\hline $\begin{array}{l}\text { Breakwa } \\
\text { ter }\end{array}$ & & $\begin{array}{l}\text { External structure } \\
\text { is built to function } \\
\text { as a breakwater } \\
\text { barrier, and the city } \\
\text { could take any form } \\
\text { behind such barrier. }\end{array}$ & 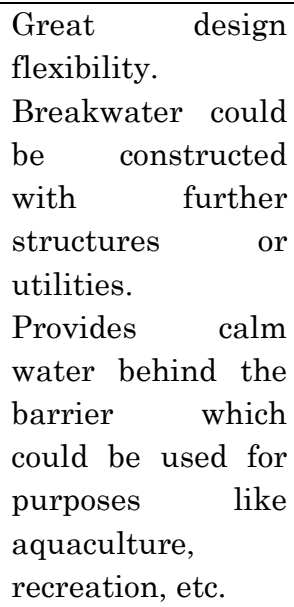 & $\begin{array}{l}\text { External structure } \\
\text { requires further } \\
\text { mooring systems. } \\
\text { Not being able to } \\
\text { endure all wave } \\
\text { impacts, which } \\
\text { could result in } \\
\text { swell behind the } \\
\text { barrier in some } \\
\text { conditions. }\end{array}$ \\
\hline $\begin{array}{l}\text { Submerg } \\
\text { ed }\end{array}$ & 令令令 & $\begin{array}{l}\text { When submerged, } \\
\text { wave impacts are } \\
\text { decreased. } \\
\text { Wave activities } \\
\text { reduces relatively } \\
\text { with water depth. }\end{array}$ & $\begin{array}{l}\text { Applicable in } \\
\text { nearly each site. }\end{array}$ & $\begin{array}{l}\text { Offering sufficient } \\
\text { sunlight will be a } \\
\text { challenge. } \\
\text { Residents need O2. } \\
\text { No interaction } \\
\text { with external } \\
\text { climate may result } \\
\text { in mental } \\
\text { discomfort. }\end{array}$ \\
\hline
\end{tabular}

26 Table 5.9: Analyzed possibilities for survivability (own illustrations). 


\subsubsection{Water Life}

It could be sectioned in physical and visual experiences. Physical experience consists of aquaculture as well as water sports such as swimming, diving, surfing, and sailing. Living in a community nearby water is more desirable than oilrigs or vessels, which has only visual relations with the water as well as being far. Visual experience is mainly intended for the inhabitants' water scenery.

\begin{tabular}{|c|c|c|c|c|}
\hline Option & Archetype & Characteristics & Advantages & Disadvantages \\
\hline Islands & 트를 & $\begin{array}{l}\text { Each structure is } \\
\text { repositioned on its } \\
\text { own platform or its } \\
\text { hull which } \\
\text { facilitates the best } \\
\text { movement } \\
\text { flexibility. } \\
\text { Buildings are linked } \\
\text { with hinged joints. }\end{array}$ & $\begin{array}{l}\text { - Optimum water } \\
\text { experience. }\end{array}$ & $\begin{array}{l}\text { Low stability. } \\
\text { Require } \\
\text { breakwater } \\
\text { protection which } \\
\text { could block water } \\
\text { view. }\end{array}$ \\
\hline Branch & & $\begin{array}{l}\text { Floating structures } \\
\text { contain of various } \\
\text { homes or further } \\
\text { buildings. } \\
\text { On platform } \\
\text { structures could be } \\
\begin{array}{l}\text { connected } \\
\text { hinged or rigid } \\
\text { joints. }\end{array}\end{array}$ & $\begin{array}{l}\text { High water } \\
\text { experience. } \\
\text { Moderate stability. }\end{array}$ & $\begin{array}{ll}\text { Require } & \\
\text { breakwater } & \\
\text { protection which } \\
\text { could block water } \\
\text { view. }\end{array}$ \\
\hline Bay & & $\begin{array}{l}\text { Semi-large } \\
\text { platforms are linked } \\
\text { together to form a } \\
\text { greater one. } \\
\text { Rigid joints. }\end{array}$ & $\begin{array}{l}\text { Good bay-like } \\
\text { experience. } \\
\text { High stability. }\end{array}$ & $\begin{array}{lr}\text { Various } & \text { platform } \\
\text { shapes. } & \\
\text { Several } & \text { rigid } \\
\text { connections } & \text { are } \\
\text { required. } & \end{array}$ \\
\hline Platform & & $\begin{array}{l}\text { Huge structure like } \\
\text { a ship or oil } \\
\text { platform as a single } \\
\text { unit. }\end{array}$ & $\begin{array}{l}\text { Good bay-like } \\
\text { experience. } \\
\text { High stability. }\end{array}$ & $\begin{array}{l}\text { Low water } \\
\text { experience, apart } \\
\text { from the edges. } \\
\text { Edges have less } \\
\text { ideal water } \\
\text { experience, since } \\
\text { they are exposed to } \\
\text { waves. }\end{array}$ \\
\hline
\end{tabular}

27 Table 5.10: Analyzed possibilities for water life (own illustrations). 
Only large platforms are not appropriate fit. Generally, the smaller the platform modules are the better the water experience will be. The platform and branch possibilities offer the best water experience where the distance to water is not far as well as offering all houses to have straight contact with water (Czapiewska et al., 2013).

\subsubsection{Development and Expansion}

The two ways to build a floating structure is by a large floating structure constructed as a whole at once or small flexible platform modules that can expand when connected to form a whole unit. The disadvantage of the submersible-type or vessel-like floating structures are that they require both funding and building at once as well as being difficult for future expanding (Wang et al., 2008). Small floating structures might have breakwaters for protection or united to form a large floating structure as they provide gradual expansion. In an expansion approach, modular small platforms are better than large floating structures which are complicated and require a lot of time (Czapiewska et al., 2013).

\begin{tabular}{|c|c|c|c|}
\hline Option & Single model unit & Connected units & $\begin{array}{l}\text { City-like grouped } \\
\text { units }\end{array}$ \\
\hline Ship & & & \\
\hline Raised platform & & & \\
\hline Breakwater & & & \\
\hline Composite structure & & & \\
\hline
\end{tabular}

28 Table 5.11: Analyzed possibilities for growth development (own illustrations). 


\subsubsection{Safety and Mooring Systems}

\begin{tabular}{|c|c|c|c|}
\hline Option & Archetype & Advantages & Disadvantages \\
\hline The chain/cable. & $\nabla$ & $\begin{array}{l}\text { Operates in open } \\
\text { waters. }\end{array}$ & $\begin{array}{l}\text { VLFS motions } \\
\text { become high } \\
\text { especially in open } \\
\text { waters where } \\
\text { mooring length is } \\
\text { long. }\end{array}$ \\
\hline $\begin{array}{l}\text { The tension leg } \\
\text { methods. }\end{array}$ & $\nabla$ & $\begin{array}{l}\text { Implemented } \\
\text { where pretension } \\
\text { is enforced on } \\
\text { mooring to } \\
\text { prevent any } \\
\text { motions. } \\
\text { Operates in open } \\
\text { waters. }\end{array}$ & $\begin{array}{l}\text { Very hard to } \\
\text { control horizontal } \\
\text { movements well } \\
\text { and frequently the } \\
\text { mooring lines } \\
\text { encounter some } \\
\text { substantial } \\
\text { tension forces }\end{array}$ \\
\hline $\begin{array}{l}\text { The pier/quay } \\
\text { wall. }\end{array}$ & $\nabla$ & $\begin{array}{l}\text { Very stable in } \\
\text { modular } \\
\text { platforms. }\end{array}$ & $\begin{array}{l}\text { May experience } \\
\text { some vibrations. } \\
\text { Should only be } \\
\text { used in small } \\
\text { platforms. } \\
\text { Not ideal to } \\
\text { operate in open } \\
\text { waters. }\end{array}$ \\
\hline $\begin{array}{l}\text { The pile-type } \\
\text { dolphins- } \\
\text { foreguide with } \\
\text { rubber fender } \\
\text { system. }\end{array}$ & $\underline{\nabla}$ & $\begin{array}{l}\text { Extremely } \\
\text { efficient to } \\
\text { control } \\
\text { horizontal } \\
\text { dislocation that } \\
\text { may occur in } \\
\text { VLFS. } \\
\text { Endure large } \\
\text { dislocations (1/3 } \\
\text { of their spans) as } \\
\text { great quantity of } \\
\text { platform's kinetic } \\
\text { energy could be } \\
\text { absorbed. }\end{array}$ & $\begin{array}{l}\text { Not ideal to } \\
\text { operate in open } \\
\text { waters. }\end{array}$ \\
\hline
\end{tabular}

29 Table 5.12: Analyzed possibilities for mooring systems (own illustrations).

The residents' safety is a main issue, where such feature has a huge effect on design choices. Safety is offering a dependable structure as well as a living atmosphere that allow 
people to live their lives securely (Wang et al., 2008). It's vital to protect the floating community from natural disasters such as high waves and storms. Thus, it's significant to be quick enough in avoiding storms. Therefore, the mooring system must be assembled to the platform correctly to offer the foremost capability of safety from storms and wave activities that creates movements and vibrations to the floating community and may create dizziness or seasickness.

\subsubsection{Concluding the main objectives and influence on the design}

The utmost significant design strategies were recognized as the portability and survival/durability, specifically for safety. The dynamic geography, water experience and development were recognized as less significant. Dynamic geography is a subject to the platforms sizes as they should be assessed to design and calculate their practicability, therefore if the objective is to achieve movable modules (not a vital approach in the case of the Nile Delta), then it should not be a priority. Usually, any size could be moved in regular situations, where moving to high seas could be accomplished only via large platforms. The semi-submersible vessels or tugboats could transport very large-scale oilrigs, but the scale of each semi-submersible is a subject to the scale of each platform (Suzuki et al., 2006; Wang \& Tay, 2011)

Mostly, the dynamic geography is subjected to the number of citizens of the platform wanting to relocate. Small platform modules could be easily relocated in the community than big ones. Survival/durability is highly subjected to the wave features of each area. The Nile delta case does not suffer from high waves most of the year. Where the smaller the platform dimensions, the more swell. However, large platform dimensions may lead to hogging and sagging occurrence, which as a result leads to more costs to reinforce the structure. The 
smaller the platforms and the lower in height are, the better the water experience will be. Small platforms units are preferable for expanding, as well as requiring lesser costs than the bigger ones. Portability is a subject to the next destination. Although the herein proposal is planned to survive the high seas, the floating community proposal for the Nile Delta is intended to take place in protected waters of the Nile Delta while implementing a breakwater. For infrequent relocating, using semi-submersibles and pulling platforms are still some ideas to consider. Where the large floating structures such as vessels or oilrigs are found to be unexciting for water experience, dynamic geography and expansions, therefore, such approaches are excluded. Consequently, only breakwaters are still considered for safety. Small islands are not appropriate as well in terms of safety, where breakwaters comfort may be highly compromised. The branch-like layout which could interconnect to form one major community or could be positioned behind the breakwater. Flexible modular elements as a branch-like community can be pulled depending on its size with a semisubmersible vessel or tug boats to a new location. 


\begin{tabular}{|c|c|c|c|c|c|c|c|c|}
\hline & Objective & Approach & $\begin{array}{l}\text { Practicali } \\
\text { ty }\end{array}$ & $\begin{array}{l}\text { Feasibilit } \\
\mathrm{y}\end{array}$ & $\begin{array}{l}\text { Repositioni } \\
\text { ng }\end{array}$ & $\begin{array}{l}\text { Low } \\
\text { Maintenan } \\
\text { ce costs }\end{array}$ & $\begin{array}{l}\text { Minimu } \\
\mathrm{m} \text { design } \\
\text { limitatio } \\
\mathrm{ns}\end{array}$ & $\begin{array}{l}\text { Overall } \\
\text { Evaluatio } \\
\mathrm{n}\end{array}$ \\
\hline 1 & \multirow[t]{4}{*}{ Movability } & $\begin{array}{l}\text { Self- } \\
\text { propelled }\end{array}$ & ++ & ++ & ++++ & + & +++ & $60 \%$ \\
\hline & & Towed & ++++ & ++++ & +++++ & +++ & ++ & 90 \\
\hline & & $\begin{array}{l}\text { Semi- } \\
\text { submersible } \\
\text { ship }\end{array}$ & ++ & + & ++++ & + & ++++ & $60 \%$ \\
\hline & & $\begin{array}{l}\text { Disassembl } \\
\text { ed }\end{array}$ & +++ & ++ & +++ & + & ++ & $55 \%$ \\
\hline \multirow[t]{4}{*}{2} & \multirow{4}{*}{$\begin{array}{l}\text { Dynamic } \\
\text { geography }\end{array}$} & Islands & ++++ & +++ & +++ & ++ & ++ & $70 \%$ \\
\hline & & Branch & +++ & +++ & ++++ & ++ & ++ & $70 \%$ \\
\hline & & $\begin{array}{l}\text { Composite } \\
\text { structure }\end{array}$ & ++ & ++ & ++ & +++ & ++ & $55 \%$ \\
\hline & & $\begin{array}{l}\text { Single large } \\
\text { structure }\end{array}$ & ++ & ++ & + & +++ & + & $45 \%$ \\
\hline \multirow[t]{4}{*}{3} & \multirow{4}{*}{$\begin{array}{l}\text { Seakeepin } \\
\mathrm{g}\end{array}$} & Ship & ++ & + & ++ & + & ++ & $40 \%$ \\
\hline & & $\begin{array}{l}\text { Raised } \\
\text { platform }\end{array}$ & ++ & + & + & +++ & ++ & $45 \%$ \\
\hline & & Breakwater & ++++ & ++ & +++ & ++ & +++ & $70 \%$ \\
\hline & & Submerged & + & + & +++ & ++ & + & $40 \%$ \\
\hline \multirow[t]{4}{*}{4} & \multirow{4}{*}{$\begin{array}{l}\text { Water } \\
\text { experience }\end{array}$} & Islands & ++ & ++ & +++ & + & ++ & $50 \%$ \\
\hline & & Branch & +++ & ++ & ++++ & ++ & ++ & $65 \%$ \\
\hline & & Bay & ++ & + & ++ & ++ & +++ & $50 \%$ \\
\hline & & Platform & ++ & ++ & + & +++ & + & $45 \%$ \\
\hline \multirow[t]{4}{*}{5} & \multirow{4}{*}{$\begin{array}{l}\text { Growth } \\
\text { developme } \\
\text { nt }\end{array}$} & Ship & ++ & ++ & ++++ & + & +++ & $60 \%$ \\
\hline & & $\begin{array}{l}\text { Raised } \\
\text { platform }\end{array}$ & ++ & + & + & +++ & ++ & $45 \%$ \\
\hline & & Breakwater & ++++ & ++ & +++ & ++ & +++ & $70 \%$ \\
\hline & & $\begin{array}{l}\text { Composite } \\
\text { structure }\end{array}$ & ++ & ++ & ++ & +++ & ++ & $55 \%$ \\
\hline \multirow[t]{4}{*}{6} & \multirow{4}{*}{$\begin{array}{l}\text { Mooring } \\
\text { system }\end{array}$} & Chain/cable & +++ & +++ & ++ & +++ & + & $60 \%$ \\
\hline & & $\begin{array}{l}\text { Tension } \\
\text { methods. }\end{array}$ & +++ & +++ & ++ & +++ & + & $60 \%$ \\
\hline & & $\begin{array}{l}\text { Pier/quay } \\
\text { wall. }\end{array}$ & ++ & ++ & + & + & ++++ & $50 \%$ \\
\hline & & $\begin{array}{l}\text { Dolphins- } \\
\text { foreguide }\end{array}$ & ++++ & ++ & + & ++ & ++++ & $65 \%$ \\
\hline
\end{tabular}

30 Table 5.13: Analyzed design methods and criteria for central Abu-Qir Bay. ${ }^{2}$

2 Very High (+++++) High (++++) Moderate (+++) Low (++) Very low (+) Not addressed (-). Method adopted from (IDSC, 2011). where each “+” accounts for $4 \%$ out of $20 \%$ stress of each parameter. Method adopted from: IDSC (2011) and Frihy \& El-Sayed (2013).

Main References: British Columbia Float Home Standard (2015), Czapiewska et al. (2013), Dal Bo Zanon et al. (2017), Frihy \& El-Sayed (2013), IPCC (2007; 2014), Suzuki et al. (2006), (Tennessee Valley Authority, 2016), Tsaltas et al. (2010), UNFCCC (2007, 2016), Wang (2017), Wang \& Tay (2011), Watanabe et at. (2008). 


\begin{tabular}{|c|c|c|c|c|c|c|c|c|}
\hline & Objective & Approach & $\begin{array}{l}\text { Practical } \\
\text { ity }\end{array}$ & $\begin{array}{l}\text { Feasibil } \\
\text { ity }\end{array}$ & $\begin{array}{l}\text { Reposition } \\
\text { ing }\end{array}$ & $\begin{array}{l}\text { Low } \\
\text { Maintena } \\
\text { nce costs }\end{array}$ & $\begin{array}{l}\text { Minimu } \\
\mathrm{m} \text { design } \\
\text { limitatio } \\
\mathrm{ns}\end{array}$ & $\begin{array}{l}\text { Overall } \\
\text { Evaluati } \\
\text { on }\end{array}$ \\
\hline & \multirow[t]{4}{*}{$\begin{array}{l}\text { Movabilit } \\
\mathrm{y}\end{array}$} & $\begin{array}{l}\text { Self- } \\
\text { propelled }\end{array}$ & +++ & +++ & ++++ & + & +++ & $70 \%$ \\
\hline \multirow{2}{*}{1} & & Towed & ++++ & ++++ & ++++ & +++ & ++ & $85 \%$ \\
\hline & & $\begin{array}{l}\text { Semi- } \\
\text { submersibl } \\
\text { e ship }\end{array}$ & ++ & + & ++++ & + & ++++ & $60 \%$ \\
\hline & & $\begin{array}{l}\text { Disassemb } \\
\text { led }\end{array}$ & +++ & +++ & +++ & + & +++ & $65 \%$ \\
\hline \multirow[t]{3}{*}{2} & \multirow{4}{*}{\begin{tabular}{|l} 
Dynamic \\
geograph \\
$\mathrm{y}$
\end{tabular}} & Islands & +++ & ++ & +++ & +++ & ++ & $65 \%$ \\
\hline & & Branch & ++++ & +++ & ++++ & ++ & ++ & $75 \%$ \\
\hline & & $\begin{array}{l}\text { Composite } \\
\text { structure }\end{array}$ & ++ & ++ & ++ & +++ & +++ & $60 \%$ \\
\hline & & $\begin{array}{l}\text { Single } \\
\text { large } \\
\text { structure }\end{array}$ & ++ & ++ & + & +++ & ++ & $50 \%$ \\
\hline 3 & \multirow{4}{*}{$\begin{array}{l}\text { Seakeepi } \\
\text { ng }\end{array}$} & Ship & +++ & + & +++ & ++ & ++ & $55 \%$ \\
\hline & & $\begin{array}{l}\text { Raised } \\
\text { platform }\end{array}$ & +++ & + & + & +++ & ++ & $50 \%$ \\
\hline & & $\begin{array}{l}\text { Breakwate } \\
\mathrm{r}\end{array}$ & ++++ & ++ & +++ & ++ & ++++ & $60 \%$ \\
\hline & & $\begin{array}{l}\text { Submerge } \\
\text { d }\end{array}$ & + & + & ++ & ++ & + & $35 \%$ \\
\hline \multirow[t]{4}{*}{4} & \multirow{4}{*}{$\begin{array}{l}\text { Water } \\
\text { experienc } \\
\text { e }\end{array}$} & Islands & ++ & +++ & ++++ & + & ++ & $60 \%$ \\
\hline & & Branch & ++++ & ++ & ++++ & ++ & ++ & $70 \%$ \\
\hline & & Bay & +++ & + & + & ++ & ++++ & $55 \%$ \\
\hline & & Platform & ++ & ++ & + & +++ & + & $45 \%$ \\
\hline \multirow[t]{4}{*}{5} & \multirow{4}{*}{$\begin{array}{l}\text { Growth } \\
\text { developm } \\
\text { ent }\end{array}$} & Ship & ++ & + & +++ & ++ & ++ & $55 \%$ \\
\hline & & $\begin{array}{l}\text { Raised } \\
\text { platform }\end{array}$ & +++ & + & + & +++ & ++ & $50 \%$ \\
\hline & & $\begin{array}{l}\text { Breakwate } \\
\mathrm{r}\end{array}$ & ++++ & ++ & +++ & ++ & ++++ & $75 \%$ \\
\hline & & $\begin{array}{l}\text { Composite } \\
\text { structure }\end{array}$ & ++ & ++ & ++ & +++ & +++ & $60 \%$ \\
\hline \multirow[t]{4}{*}{6} & \multirow[t]{4}{*}{$\begin{array}{l}\text { Mooring } \\
\text { system }\end{array}$} & $\begin{array}{l}\text { Chain/cabl } \\
\mathrm{e}\end{array}$ & +++ & +++ & +++ & +++ & + & $65 \%$ \\
\hline & & $\begin{array}{l}\text { Tension } \\
\text { methods. }\end{array}$ & ++++ & +++ & ++ & +++ & + & $65 \%$ \\
\hline & & $\begin{array}{l}\text { Pier/quay } \\
\text { wall. }\end{array}$ & ++ & ++ & + & + & ++++ & $50 \%$ \\
\hline & & $\begin{array}{l}\text { Dolphins- } \\
\text { foreguide }\end{array}$ & ++++ & ++ & + & ++ & ++++ & $65 \%$ \\
\hline
\end{tabular}

31 Table 5.14: Analyzed design methods and criteria for East Alexandria. ${ }^{3}$

${ }^{3}$ Very High (+++++) High (++++) Moderate (+++) Low (++) Very low (+) Not addressed (-). Method adopted from (IDSC, 2011). where each "+" accounts for $4 \%$ out of $20 \%$ stress of each parameter. Method adopted from: IDSC (2011) and Frihy \& El-Sayed (2013). 


\begin{tabular}{|c|c|c|c|c|c|c|}
\hline & Objective & Approach & $\begin{array}{l}\text { Suitability for } \\
\text { Central Abu- } \\
\text { Qir Bay }\end{array}$ & $\begin{array}{l}\text { Suitability for } \\
\text { East } \\
\text { Alexandria's } \\
\text { coastline }\end{array}$ & Ideal methods & $\begin{array}{l}\text { Design } \\
\text { methods } \\
\text { selected }\end{array}$ \\
\hline \multirow[t]{4}{*}{1} & \multirow[t]{4}{*}{ Movability } & Self-propelled & $60 \%$ & $70 \%$ & $65 \%$ & $65 \%$ \\
\hline & & Towed & 90 & $85 \%$ & $82.5 \%$ & $82.5 \%$ \\
\hline & & $\begin{array}{l}\text { Semi- } \\
\text { submersible } \\
\text { ship }\end{array}$ & $60 \%$ & $60 \%$ & $60 \%$ & $60 \%$ \\
\hline & & Disassembled & $55 \%$ & $65 \%$ & $60 \%$ & $60 \%$ \\
\hline \multirow[t]{4}{*}{2} & \multirow{4}{*}{$\begin{array}{l}\text { Dynamic } \\
\text { geography }\end{array}$} & Islands & $70 \%$ & $65 \%$ & $67.5 \%$ & $67.5 \%$ \\
\hline & & Branch & $70 \%$ & $75 \%$ & $72.5 \%$ & $72.5 \%$ \\
\hline & & $\begin{array}{l}\text { Composite } \\
\text { structure }\end{array}$ & $55 \%$ & $60 \%$ & $60 \%$ & $60 \%$ \\
\hline & & $\begin{array}{l}\text { Single large } \\
\text { structure }\end{array}$ & $45 \%$ & $50 \%$ & $47.5 \%$ & $47.5 \%$ \\
\hline \multirow[t]{4}{*}{3} & \multirow[t]{4}{*}{ Seakeeping } & Ship & $40 \%$ & $55 \%$ & $47.5 \%$ & $47.5 \%$ \\
\hline & & Raised platform & $45 \%$ & $50 \%$ & $47.5 \%$ & $47.5 \%$ \\
\hline & & Breakwater & $70 \%$ & $60 \%$ & $65 \%$ & $65 \%$ \\
\hline & & Submerged & $40 \%$ & $35 \%$ & $37.5 \%$ & $37.5 \%$ \\
\hline \multirow[t]{4}{*}{4} & \multirow{4}{*}{$\begin{array}{l}\text { Water } \\
\text { experience }\end{array}$} & Islands & $50 \%$ & $60 \%$ & $57.5 \%$ & $57.5 \%$ \\
\hline & & Branch & $65 \%$ & $70 \%$ & $67.5 \%$ & $67.5 \%$ \\
\hline & & Bay & $50 \%$ & $55 \%$ & $52.5 \%$ & $52.5 \%$ \\
\hline & & Platform & $45 \%$ & $45 \%$ & $45 \%$ & $45 \%$ \\
\hline \multirow[t]{4}{*}{5} & \multirow{4}{*}{$\begin{array}{l}\text { Growth } \\
\text { development }\end{array}$} & Ship & $60 \%$ & $55 \%$ & $57.5 \%$ & $57.5 \%$ \\
\hline & & Raised platform & $45 \%$ & $50 \%$ & $47.5 \%$ & $47.5 \%$ \\
\hline & & Breakwater & $70 \%$ & $75 \%$ & $72.5 \%$ & $72.5 \%$ \\
\hline & & $\begin{array}{l}\text { Composite } \\
\text { structure }\end{array}$ & $55 \%$ & $60 \%$ & $57.5 \%$ & $57.5 \%$ \\
\hline \multirow[t]{4}{*}{6} & \multirow{4}{*}{$\begin{array}{l}\text { Mooring } \\
\text { system }\end{array}$} & Chain/cable. & $60 \%$ & $65 \%$ & $62.5 \%$ & $62.5 \%$ \\
\hline & & $\begin{array}{l}\text { Tension } \\
\text { methods. }\end{array}$ & $60 \%$ & $65 \%$ & $62.5 \%$ & $62.5 \%$ \\
\hline & & Pier/quay wall. & $50 \%$ & $50 \%$ & $50 \%$ & $50 \%$ \\
\hline & & $\begin{array}{l}\text { Dolphins- } \\
\text { foreguide }\end{array}$ & $65 \%$ & $65 \%$ & $65 \%$ & $65 \%$ \\
\hline
\end{tabular}

32 Table 5.15: Analyzed design methods and criteria for central Abu-Qir Bay and East Alexandria's coastline.

Main References: British Columbia Float Home Standard (2015), Czapiewska et al. (2013), Dal Bo Zanon et al. (2017), Frihy \& El-Sayed (2013), IPCC (2007; 2014), Suzuki et al. (2006), (Tennessee Valley Authority, 2016), Tsaltas et al. (2010), UNFCCC (2007, 2016), Wang (2017), Wang \& Tay (2011), Watanabe et at. (2008). 


\subsubsection{Local Conditions Criteria that Should be Considered}

Local conditions are an inevitable issue when planning floating structures. For instance, waves should define the measurements of both floating structures and breakwaters (Tsaltas et al., 2010). The seabed or the ocean floor (bathymetry) depth defines the measurements, mooring systems' expenses and whether these systems are more economical station than keeping facilities (Czapiewska et al., 2013). Local features must not have fixed standards, as floating structures must be able to move and deal with several imaginable situations. Being able to relocate to an alternative location with similar situations is a must. It must be able to endure harsh sea conditions such as waves throughout storms and relocating. In general, floating structures must be able to survive the open waters high seas with or without any further safety measures, but Mediterranean conditions are different for the case of the Nile Delta as it's situated in protected waters. To effectively develop an expansion vision, the local conditions and their impacts on the floating structure must be studied. The conditions will form the impacts on the structure and design in matters of energy and resources.
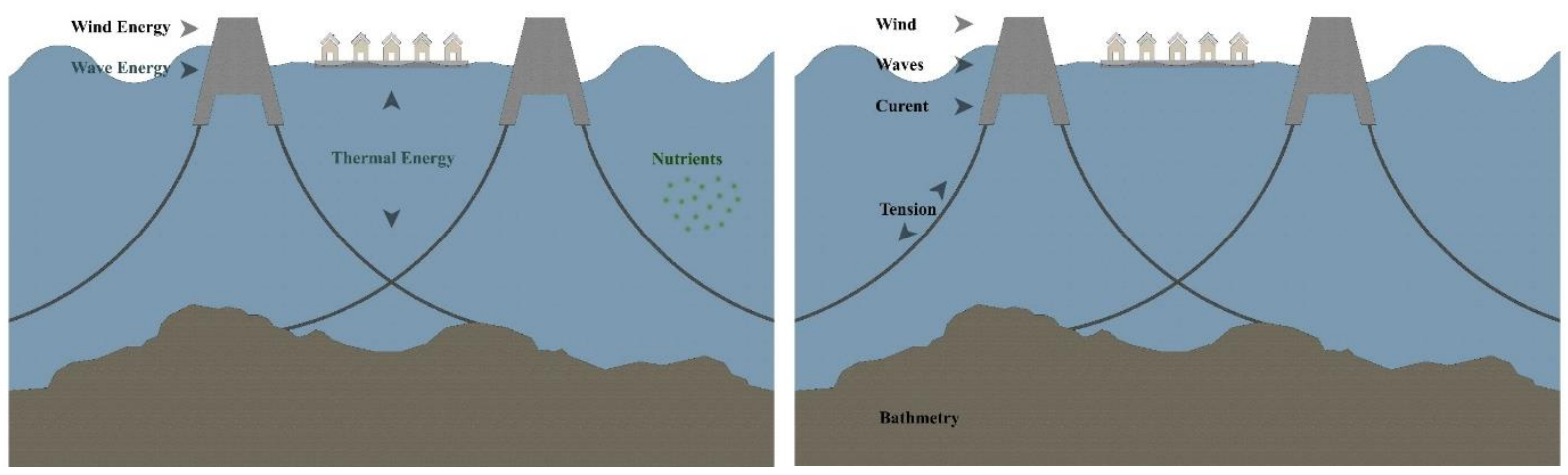

26 Figure 5.7: (Left) Bathymetry Energy and Resources (own illustration).

27 Figure 5.8: (Right) Bathymetry Structural Aspects (own illustration). 


\begin{tabular}{|l|l|l|}
\hline Factors & Properties & Impact on floating structures Design \\
\hline $\begin{array}{l}\text { Local } \\
\text { bathymetry }\end{array}$ & $\begin{array}{l}\text { 0 to } 10 \mathrm{~m} \text { depth within } 10 \mathrm{~km} \\
\text { from the shoreline. }\end{array}$ & $\begin{array}{l}\text { Mooring system dimensioning will } \\
\text { be considered an average depth } 20 \\
\mathrm{~m} .\end{array}$ \\
\hline $\begin{array}{l}\text { Tides and } \\
\text { currents }\end{array}$ & $\begin{array}{l}\text { Cycle of tides is on average } \\
2.5 \mathrm{~m} / \text { day }(2 \text { cycles per day). } \\
\text { Current speed from } 6.0-6.3 \\
\text { seconds. }\end{array}$ & $\begin{array}{l}\text { The difference in height considered } \\
\text { a mean tide of } 1 \mathrm{~m} \text { as highest wave is } \\
\text { around } 2 \mathrm{~m} \text {. Total }=2 \mathrm{~m} \text { circa }\end{array}$ \\
\hline
\end{tabular}

33 Table 5.16: Local conditions impacts on the floating structures design. Adapted from Czapiewska et al. (2013).

\subsubsection{Bathymetry}

Ocean floor depth defines VLFS measurements, materials and the mooring system expenses. In shallow waters up to 100 meters, cables attached to anchors is usually the best solution. Selecting materials and their compositions rely on soil characteristics, strength required for the currents, tides variances, occasional relocating and so on. In open waters, seamounts and ridges offer attractive sites as they offer better depth for the anchoring or mooring systems. Bathymetry has an impact on waves as well in shallow waters (Tsaltas et al., 2010). Naturally, waves heights are equivalent to half the wavelength, therefore a 200 meters long wave is relatively smaller than a 100 meters long wave. Usually, when waves of higher than 80 percent of the water depth advance towards shorelines, more energy is generated, and waves gets steeper and unsteady till they break (Tsaltas et al., 2010).

\subsubsection{Tides and Currents}

Local currents and tides define the water forces on the underwater part of the floating structure. To preserve the structure in location, a counterforce activity such as a mooring system should be added. In locations where ocean currents could be very high like in the Gulf Stream where currents may reach a velocity of 2.5 meters per second (Czapiewska et al., 
2013). With a current velocity of $2.0 \mathrm{~m} / \mathrm{s}$, then the pressure on the floating structure is 2.0 $\mathrm{kPa}\left(\mathrm{kN} / \mathrm{m}^{2}\right)^{3}$ (Czapiewska et al., 2013). This pressure equates with a category 3 hurricane with wind velocity of about $60 \mathrm{~m} / \mathrm{s}$ (Czapiewska et al., 2013). A velocity of $1.0 \mathrm{~m} / \mathrm{s}$ is compared to wind velocity of $30 \mathrm{~m} / \mathrm{s}$ by a wind force of 11 (according to Beaufort scale). Such velocities could even be found nearby continents not only in open waters. Usually, floating structures deal with a matching direction in both currents and winds in the case of storms where highwater pressure and strong wind pressure could happen at the same time (Suzuki et al., 2006).

\subsubsection{Waves}

Important waves properties are the period, height, and wavelength. The wave period is the time taken for consecutive waves to cross the very same point in seconds. The long period waves (over 14 seconds) have more energy, plainer outline in deep waters and create higher waves once they enter shallower waters, nevertheless their lengths reduce (see figure 5.4). Wavelengths could be categorized as short when it's smaller that a hundred meters, average when it's between one to two hundred, and long when it's longer than two hundred second (Czapiewska et al., 2013). Wave heights are categorized low when the height is less that two meters, average when the height is between two to four meters and high when above than four meters. Wave periods define both wavelength and height. Hunt's method measures a wavelength of period waves in water depth at a precision of $0.1 \%$ second (Czapiewska et al., 2013). Wave properties data are essential to get, as they influence the platform dimensions, which is clarified in chapter 7 . Wave properties for a certain site is always preferable in bays or inlets than of open waters situations. 


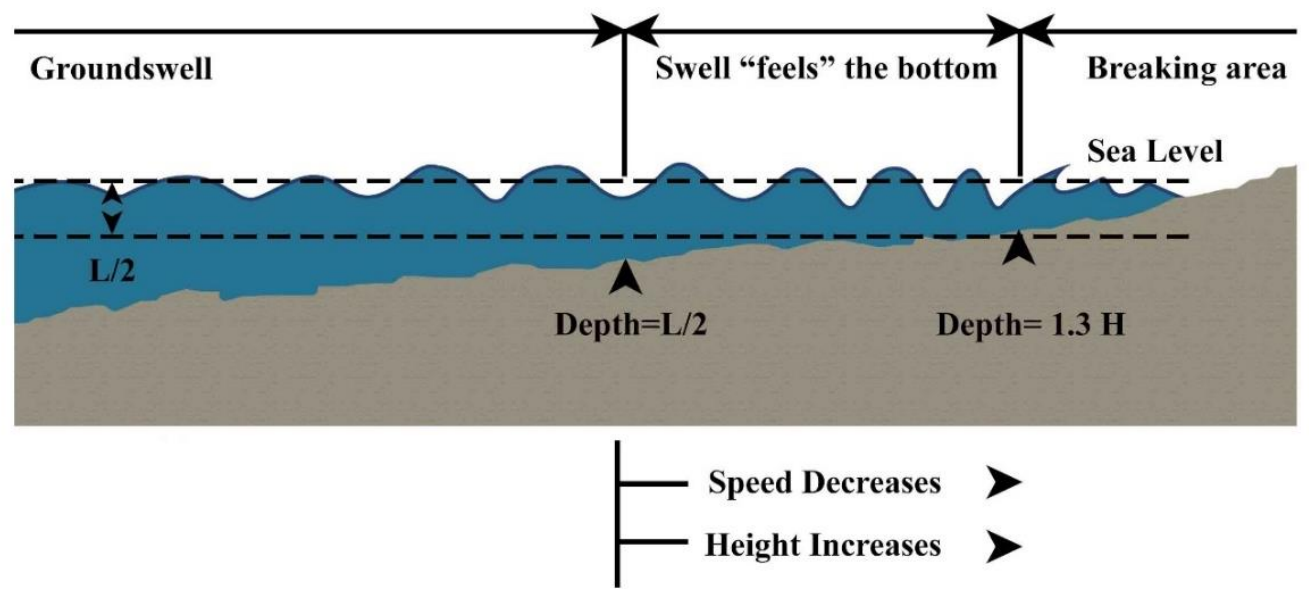

28 Figure 5.9: Wave Behaviour (own illustration).

\subsubsection{Wind}

As winds create waves, a wave size is a subject to both strength and duration of winds, in relation to water depth (Wang \& Tay, 2011). High waves in open seas travel long distances even when winds stop. As they travel, such waves get affected by tides, winds coming from other directions, and the coastlines forms. Therefore, data on wind velocity and their directions for every site is essential when designing floating communities. In case of bays for instance, wind waves which happen on water surface due to winds over a long water surfaces, and they can be assumed from fetch length and wind velocity (Seto et al., 2005). Therefore, letting wave protection to be implemented precisely where they're required the most.

\subsubsection{Climate}

Climate settings, like rain, humidity, sunlight and wind are related to the design and structure of the floating community. High humidity is in any water surface, meaning that moisture is something to build in respect to. Moreover, some areas could have strong storms like cyclones or hurricanes. Cyclones are relatively less powerful than that of hurricanes, thus its easier to deal with (Czapiewska et al., 2013). 
Worldwide, there are around 80 tropical cyclones that happen per year, one-third of them attain the hurricane level. Mainly, it is the western Pacific Ocean region that is the most vulnerable zone for such occurrence, where such area has warm ocean water(Center for International Earth Science Information Network (CIESIN)/Columbia University, 2013). On the contrary, the Atlantic Ocean ranges around ten storms per year, six of them attain the hurricane level (Blake \& Zelinsky, 2018). The strength of hurricanes could be measured by the Saffir-Simpson hurricane scale. Strong winds and rains of a hurricane could spread from $40 \mathrm{~km}$ and can reach more than $240 \mathrm{~km}$, where tropical storm could spread to $500 \mathrm{~km}$ (Blake \& Zelinsky, 2018). Hurricanes could be predicted before forming by 3 to 5 days (Blake \& Zelinsky, 2018). In worst-case scenarios such as level five hurricane should be measured in order to be able to plan 24 hours ahead of occurrence. In such scenario, each platform should be detached. Depending on each platforms' scale, one or some tugboats should arrive immediately where they should find the platforms positioned in the correct formation to be smoothly tugged away. Tugboats could reach a velocity of $22 \mathrm{~km} /$ hour, but in heavy currents situations, tugboats go by $11 \mathrm{~km} /$ hour. Meaning that relocating to avoid hurricane's damaging winds could probably last 22 hours, keeping two hours for other measures (Blake \& Zelinsky, 2018). While in case of tropical storms, another 24 hours may be needed for relocating. Although hurricanes are rare to happen in the Mediterranean, Mediterranean hurricanes are referred as Mediterranean tropical-like cyclones, or "medicanes" (a word combination of the Mediterranean and hurricane). The Nile Delta floating community project still focused on such aspect. 


\subsubsection{Design Procedure}

In the structural strategy for the typical ships and floating offshore structures, the exterior load and foremost load effects, like the cross-sectional forces, are driven from the rigid-body motions (Wang \& Tay, 2011). Measurements of the structural components and their plan are then defined that the structure has the appropriate durability and rigidity to handle the provided loads and load effects. However, in the VLFS, the global responses with the possible deflections, as well as the load and load effects, are defined through the elastic responses. The structural rigidity is consequently a leading parameter when designing the VLFS. The relationship of the structural rigidity and the global elastic responses is usually difficult because of the fluid-structure interaction effects (Suzuki et al., 2006).

In a case of an increasement in the structural rigidity, that could possibly lead to an upsurge in the cross-sectional forces as well as the stresses, also the hydro-elastic response will be affected by such change. Consequently, the hydro-elastic response analysis ought to be completed at each structural design phase to consider the effects of the design variations on structural rigidity and responses. Figure 5.10 demonstrates the archetypal design chart planned for the VLFS that reflects the features of VLFS and adopted from the design projects of the Mega-Float which is based on the framework established by Suzuki et al. (2006). As demonstrated, the design chart could be shown through three fundamentally phases.

Throughout the first phase, a comparatively simple way of the hydro-elastic response study is done, on the other hand the global stiffness and the consistent essential design variables, like the structural depth, the main components plan, and the scale are defined. The typical length and frequency as stated by Suzuki et al. (2009) are referenced throughout such development. The hydro-elastic response studies which adopts the regular rectangular 
plate model (Ohmatsu, 2005) are usually done. A blend of the plate FE model and a modal method is correspondingly functional for a more advanced structural modeling in required for example like with the adjustable flexural stiffness Suzuki et al. (2006). These issues are, while not restricted to, the difference of water depth, structural and the wave irregularities (Wang et al., 2008).

Throughout the second phase, comprehensive design for real structural formations that have the flexible structural depth, the adjustable planar form, opening in bulkheads for the interior space, and so on is done. The 3D part process of hydro-elastic response study, which progressed by Seto et al. (2005) is usually done in this phase. The modeling of the fluid domain executed in this process could undertake the uneven body limit, the adjustable sea depth, and the existence of breakwaters and coastlines (Wang et al., 2008). From such outcomes of global response study, the local stress response under the joint load effects is assessed via a zooming procedure. By such calculation of the strength and serviceability perimeter conditions, the scale as well as the planning of the structural components can be then resolved (Suzuki et al., 2006). As shown in the outline, both the primary and secondary (detailed) design phases have a loop strategy which contains the hydro-elastic global response investigation. This is a characteristic aspect of the structural design process when designing floating structures.

Throughout the third phase, the structural safety calculations are done for the system levels. One of the safety evaluations inspects partly the damaged situations as the other inspects the system failure behavior under unanticipated irregular load effects. The safety evaluation throughout this phase usually requires a nonlinear progressive collapse investigation (Suzuki et al., 2006). 


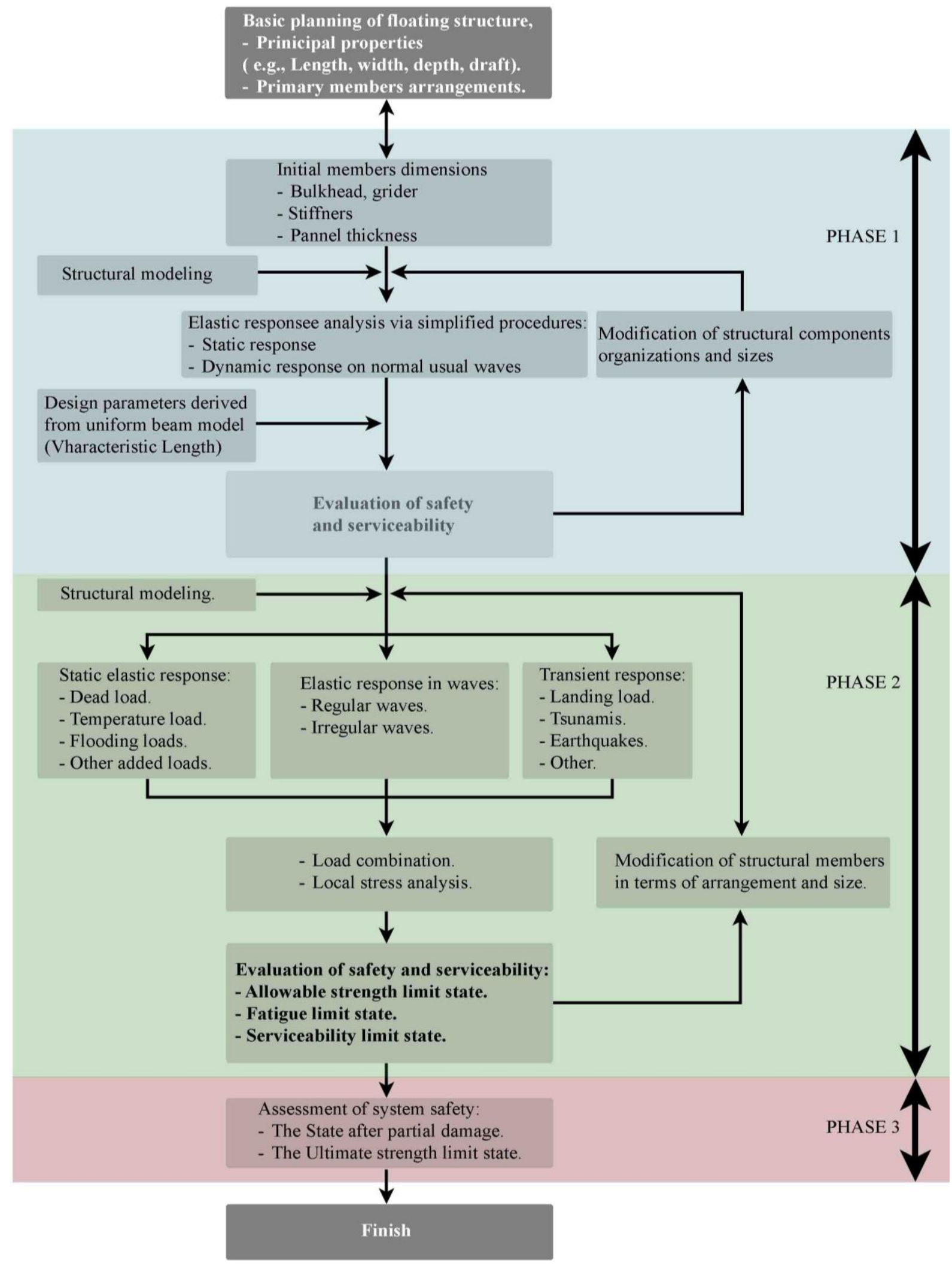

29 Figure 5.10: Archetypal structural design outline as for the Mega-floats (own illustration). Created from Suzuki et al. (2006). 


\subsection{Conclusions}

Megastructure's definition, applications, analysis, investigation, advancement and design after featuring the current VLFSs were demonstrated with some possible applications of VLFS as an agricultural city as well as for a future human residence. The study developments of the VLFS are as well offered with foremost importance on the hydro-elastic response, structural integrity and steady drift forces. The conventional technique in the execution of the hydro-elastic analysis is via the frequency and time domain methods and a more recent method based on CFD were briefly discoursed. Studies on the practicality as well as the safety criteria which affect the structural integrity of the VLFS and the near-field and far field ways which are implemented in order to acquire the stable drift forces of the VLFS were addressed as well.

For further specifics and details concerning the analysis and design on pontoon-type VLFS, one could possibly refer to the long list of references that was presented by Tsaltas et al. (2010); Suzuki et al. (2006); Wang \& Tay (2011); Wang et al. (2008). As for the semisubmersible type, which is archetypal for the MOB components, was advanced for the offshore usage activities. Nevertheless, the strength of the semi-submersible type in contrast to the early stated hazards will not be discussed in this thesis as the pontoon type was selected as the ideal solution for the Nile Delta's coastlines.

The technological advances as per the mooring system, anti-motion devices and connector designs of VLFS throughout the previous decades were featured as well. Two different categories of mooring system are implemented for the VLFS, which are either the mooring lines system or the caisson/dolphin system. The mooring lines system is frequently done in case of the VLFS positioned in deep seas while the caisson/dolphin system for VLFS in 
shallow seas. Approaches which are implemented in the mitigation of the hydro-elastic responses consist of both the bottom-founded and floating breakwaters, underwater and OWC anti-motion equipment's, air cushion, and the hybrid type anti-motion equipment's. Connectors which are used in connecting the units together when creating VLFS have also witnessed a technological development from the fixed type to semi-rigid and hinge systems. Both semi-rigid and hinged system connectors are rather very practical when decreasing the hydro-elastic response of the VLFS.

The dolphin system is found to be the most suitable solution for the Nile Delta's coastlines. The pathways are frequently attached to the floating building to the coastline and especially that in urbanized areas are generally very well attached to the neighbouring traffic system. The pathways have also a floatation ability as well due to that the space gap from coast to the floating building as it requires mooring to the seabed. Global common safety procedures since the floating buildings and the emergency vehicles need some routes to the location and close to the building (British Columbia Building Code Interpretation Committee, 2015).

Furthermore, the "Dolphin-Frameguide" is moderately global stationary providing and securing the system of the mega floating structure to hold in place from tides as well as any further dynamic occurrences like drifting Suzuki et al. (2006); Wang \& Tay (2011); Wang et al. (2008). Such system is frequently implemented where there are no docks, or any coastline attached structure to make the floating structure stay in position (Wang \& Tay, 2011).

The pathways afterwards frequently serve as a mediator where it attaches the floating building to the coastline. In coastline cities, they are frequently well attached to the adjacent traffic system. The pathways also have a floating ability due to the long distance from floating building to the coast and they as well have to be attached to the seabed. Some general safety necessities and procedures since the floating structures and emergency vehicles need a route 
to the location and close to the building (British Columbia Building Code Interpretation Committee, 2015).

The findings support the argument that traditional land reclamation methods are not a practical long-term solution apart from its various disadvantages on the ecosystem. The findings provide support for the key arguments that VLFS are more sustainable as it offers a cost-effective solution where there is a big water depth in terms of space creation and preserving the marine ecosystem. They are planned to be ecologically friendly as they don't disturb sea currents or silt-up the deep harbours of the Nile Delta. Also, they could easily be detached or expanded as well as not getting affected by seismic shockwaves as they are characteristically remotely based. However, such solution may does not seem to be practical in every case, nevertheless, VLFS may offer a practical solution for further areas when the SLRs even more.

Findings on the evaluation of six design approaches in terms of: movability, dynamic geography, seakeeping, water experience, growth development, and mooring system in terms of: practicality, feasibility, repositioning, low maintenance costs, and minimum design limitations conclude that the optimum options for the Nile Delta Vulnerable regions are: towed, branch, breakwater, branch, breakwater, dolphins-foreguide respectively. Where the local conditions criteria that should be considered are bathymetry, tides and currents, waves, wind, climate.

This chapter develops an archetypal structural and architectural design outline that is set for designing VLFS which forms the methodology for designing VLFS not only for Egypt but in any site where its characteristics would identify such solution as the optimum solution for it. Accordingly, the next chapter identifies site analysis and conditions of the most vulnerable site in the Nile Delta for a possible floating community. 


\section{Chapter 6}

\section{CASE STUDY ANALYSIS: THE}

\section{NILE DELTA, EGYPT}

\subsection{Introduction}

Upon analyzing VLFS and their characteristics in respect to the Nile Delta's site, setting design strategies and principles, and local conditions of the Nile Delta. This chapter conducts site analysis to conclude the most vulnerable sites in the Nile Delta as their properties will provide the required knowledge for selecting the best adaptation approach and mitigation solution for such areas and test the hypothesis that VLFS may offer the optimum solution for such vulnerable sites in the Nile Delta. This chapter sought to answer this research question: What are the most vulnerable sites to SLR impacts in the Nile Delta's coastline?

Initially, this chapter conducts time series analysis and ranking for the Nile Delta, where such analysis is a compilation of examinations of precise data items acquired through frequent measurements over periods of time to improve the capability to coping with future 
situations. Secondly, this chapter conducts qualitative assessment on SLR impacts for ten case studies, where such analysis is concerned with the probabilities of decreasing the negative impacts and of refining the capability to coping with future situations. Thirdly, this chapter conducts site analysis and time series analysis and ranking of impacted sectors in the most Vulnerable area is identified.

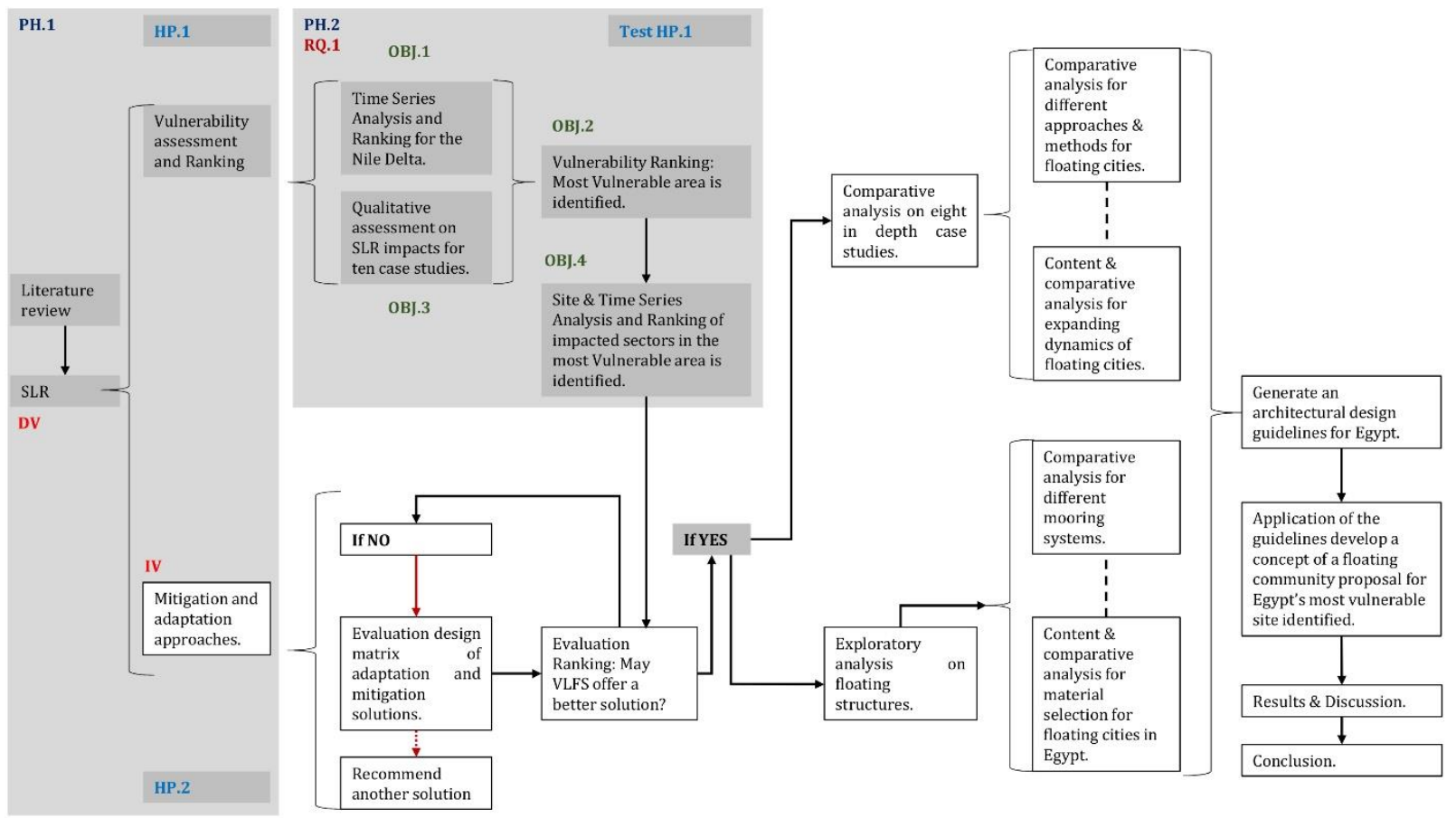

30 Figure 6.1: Analytical framework for site and time series analysis, and assessment on adaptation approaches practiced in the Nile Delta's most vulnerable sites.

\subsection{History "Then and Now"}

History shows that human civilizations always seem to settle nearby water surfaces whether oceans, seas, lakes or rivers. In the $10^{\text {th }}$ millennium BC, Egypt just like any other civilization, people have settled where water is found. Apart from the Nile Valley, most of Egypt's landscape is desert (Tolba \& Saab, 2009). Because of the country's dry weather, 
therefore most people centre themselves around the Nile Valley and the Delta. This means that about $99 \%$ of the country's population are using about only $5.5 \%$ of the country's area (Tolba \& Saab, 2009).

The nearby Abu-Qir bay has witnessed the sinking of both cities of Canopus and Heracleion into the Mediterranean. It was also the site of three naval battles which left several shipwrecks that remain until now on the sea floor (Fabre \& Goddio, 2013).

Heracleion (also known as Thonis in ancient Greece), like Atlantis, an ancient Egyptian city that has disappeared 1,200 years ago under the Mediterranean Sea (Fabre \& Goddio, 2013). A city that was founded as early as in the $8^{\text {th }}$ century BC, not long ago before the foundation of Alexandria in 331 BC (Fabre \& Goddio, 2013). Heracleion had several harbors and ports, it is thought that it has served as the main port of entry to Egypt for all Greek world ships. Heracleion was initially built on number or adjacent islands in the Nile Delta as well being intersected by canals.

Before discovering the sunken city in 2000 by the archaeologist Franck Goddio, the president of the European Institute for Underwater Archeology (IEASM) no trace was found of Heracleion. A name that almost disappeared from mankind's memory, preserved only by history's ancient texts as well as some rare inscriptions which are found on walls by archaeologists (Fabre \& Goddio, 2013). Franck Goddio and his IEASM team have located, mapped and excavated parts of the sunken city Heracleion. The city lies 6.5 kilometres off the current shoreline and around 150 feet underwater. The city is situated in an exploration area of 11 by 15 kilometres in the west of Abu-Qir Bay. The study suggests that what caused the city submergence was both a geological and cataclysmic phenomenon. The measured movement of soil subsidence has affected this area in the south-eastern Mediterranean. Also, the SLR had extremely contributed to the submergence of the area. The IEASM have made 
some geological observations that led to conclusions of why such phenomenon has occurred when discovering seismic effects in the underlying geology (Fabre \& Goddio, 2013).

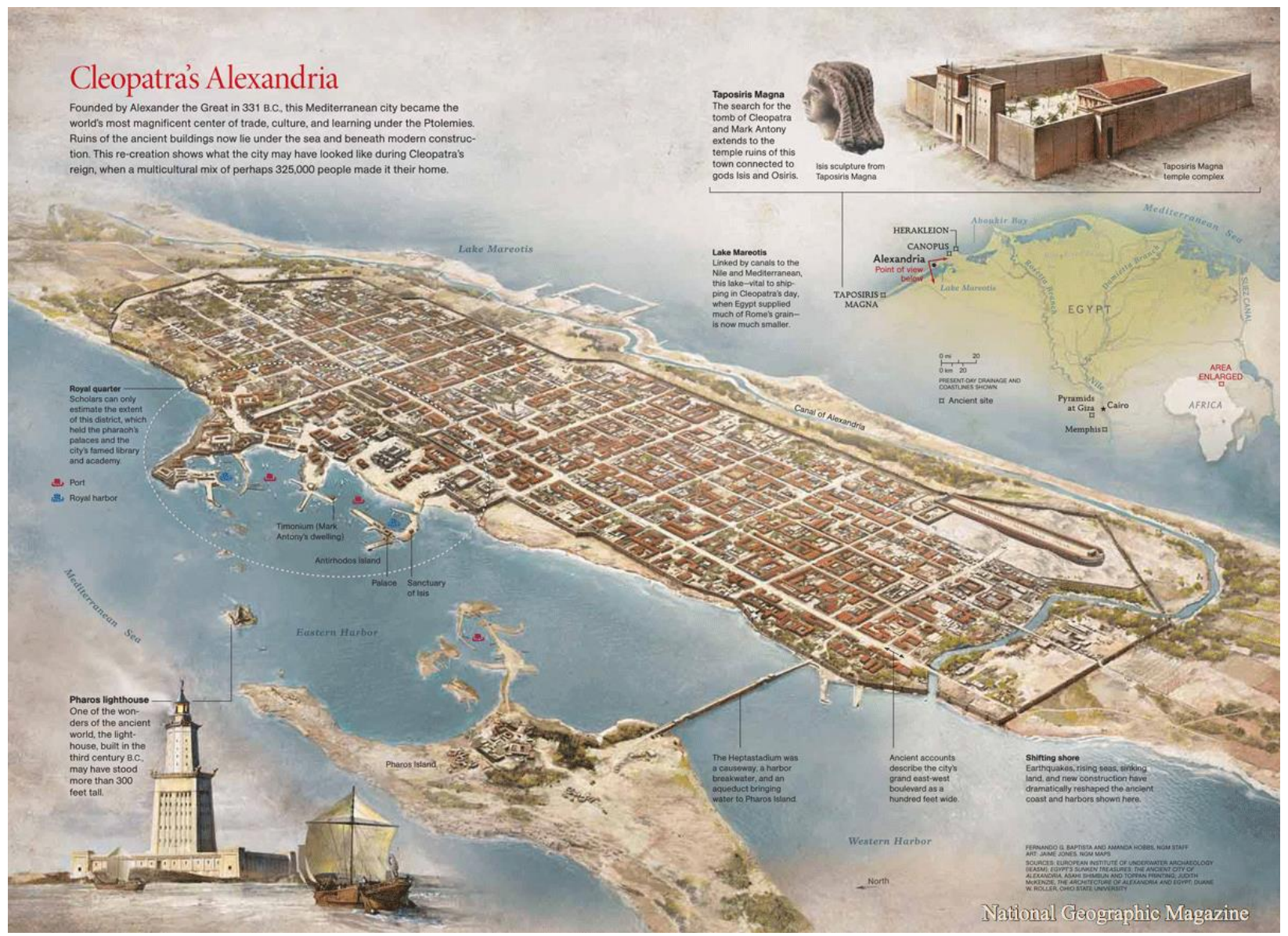

31 Figure 6.2: Heracleion-Thonis, Ancient Alexandria (National Geographic Magazine, 2011).

Site analysis as well suggests that soil liquefaction has occurred. Such a local phenomenon could be caused due to the act of excessive pressure on soil which has a high clay and water content. The weight pressure put on the ground from the buildings, plus the overload of weight caused by the high floods or tidal waves could have compressed the soil as well as to force the expulsion of water contained inside the clay's structure. Clay is a material which loses volume rapidly, where that makes an unexpected disturbance of subsidence activity. 
Also, an earthquake could be the reason for such a phenomenon. All these factors, whether having occurred together or independently, may possibly cause a substantial demolition and explain why the submergence has occurred (Fabre \& Goddio, 2013).

\subsubsection{The Situation in the $20^{\text {th }}$ Century}

The Nile delta is one of the lowest lying coastal areas in the world. Due to the ascending terrain from Ethiopia until the Nile delta, the Nile river carries the fertile water of freshwater and silt which benefits agricultural soil, descending from their sources according to the terrain of the earth. Over time, the delta has formed from the continuous flow of silt, which is deposited in large quantities in the delta and inside the Mediterranean waters, therefore adding land to the Nile delta from the sea. Unfortunately, after the construction of the High Dam in 1970 the balance between Nile and the sea have changed. According to the results of studies in 1975, when the silt was cut of in the Nile River after the obstacle of the High Dam, the sea overtook the Nile Delta over time, parts of which were strongly eroded by the impact of continuous waves, leading to a decline in the level of the Delta corresponding to sea level.

\subsubsection{Dangers Facing the Nile Delta}

In the Nile delta, citizens still build near seashores, therefore forming big problems as people risk a lot when extending the shorelines into the sea. There are four main driving reasons in this thesis for protecting coastal cities against SLR. The first is historical where the city of Thonis-Heracleion as well as other unknown underwater areas hold more submerged world heritage historical monuments, properties and sites of Pharaonic, Greek, Roman, and Christian as listed by the UNESCO can not be replaced. The second is to safeguard Egypt's marine borderlines sovereignty. The third is ecological where it endangers 
the marine and coral life habitat. The fourth is people risking their own lives building in such sites risking the scenario of Thonis-Heracleion to reoccur again.

\subsection{Site Analysis}

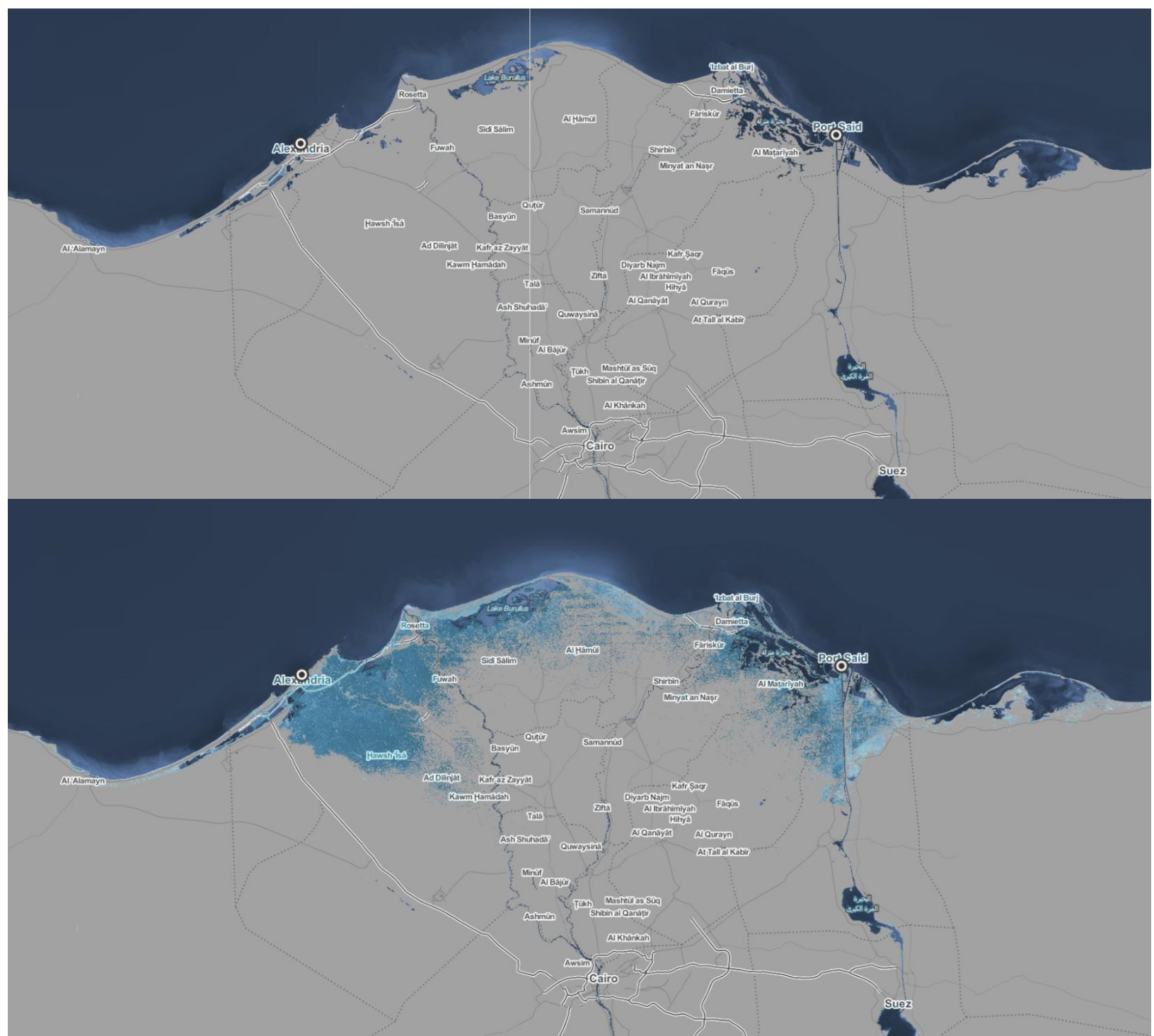

32 Figure 6.3: Before and After submergence $2 \mathrm{~m}$ due to the rising seas on the Egyptian Nile Delta (“Climate Central's Surging Seas: Risk Zone Map,” n.d.).

Since the beginning of civilization, floating societies have occurred even from pre-Incan periods. Throughout history, humankind's habitat has developed always coast by and in cases 
it has developed into floating communities, which shows how water plays an essential role in the living environment. According to NASA's estimations, around 40\% of Earth's population live within 100 kilometres from water surfaces (Socioeconomic Data and Applications Center (World Bank, 2010).

Urban growth in increasing already populated seaside cities as well as the increasing land prices and condensed infrastructure. In addition to the raising sea level, circumstances may increase the demand for floating community developments. In some situations, around the world it could be disastrous and can be clearly noticed in Egypt since the Nile Delta is already subsiding at a 3 to $5 \mathrm{~mm}$ rate yearly Tolba \& Saab (2009). Where a 100-mm rise could submerge $1 / 4$ of the Nile Delta, meaning that 10.5\% of Egypt's whole population will be forced to move out from the Nile Delta (IPCC, 2007) and future countermeasures should take place.

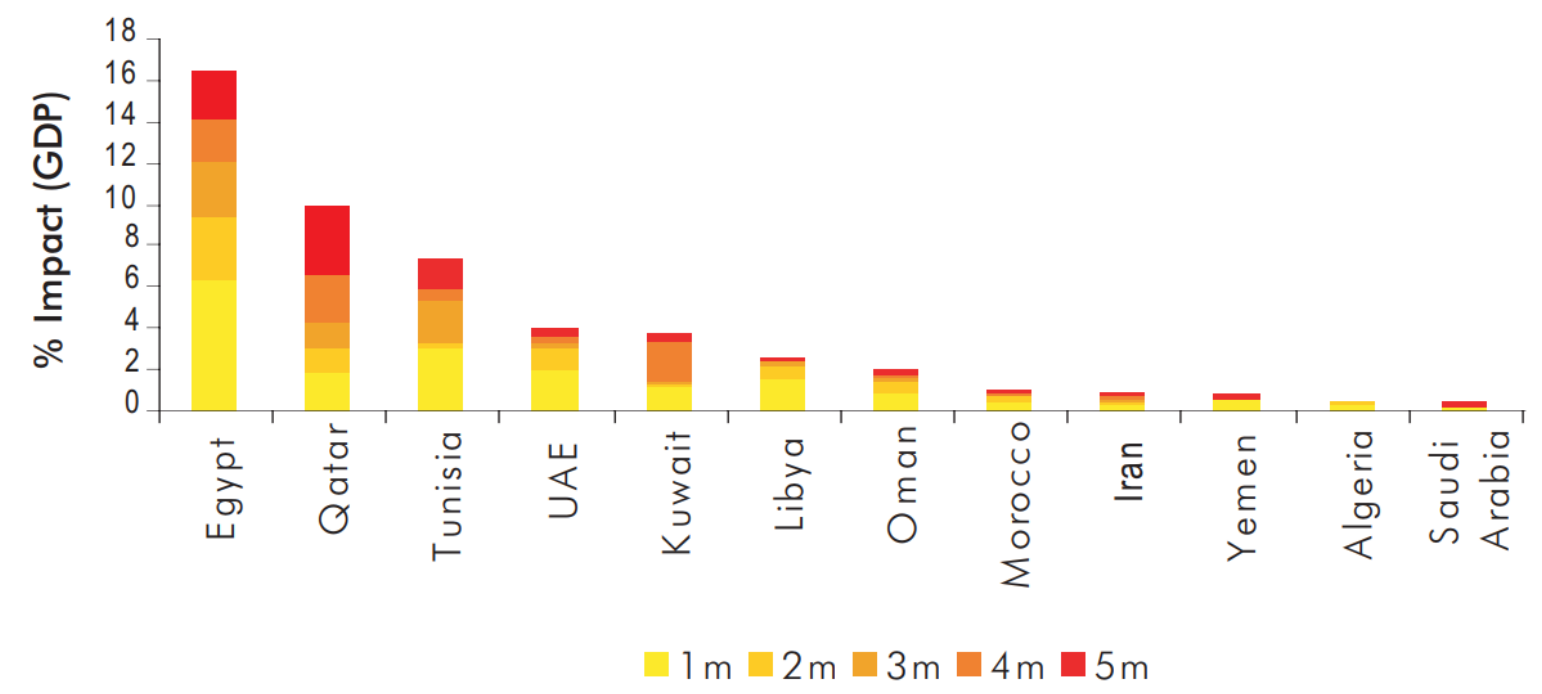

Source: Dasgupta et al., 2007

Note: Countries not mentioned did not provide data

33 Figure 6.4: A comparison of percentage impacts of SLR on the GDP of Arab countries. Reproduced from the Arab Environment Climate Change Report by Tolba \& Saab (2009). 


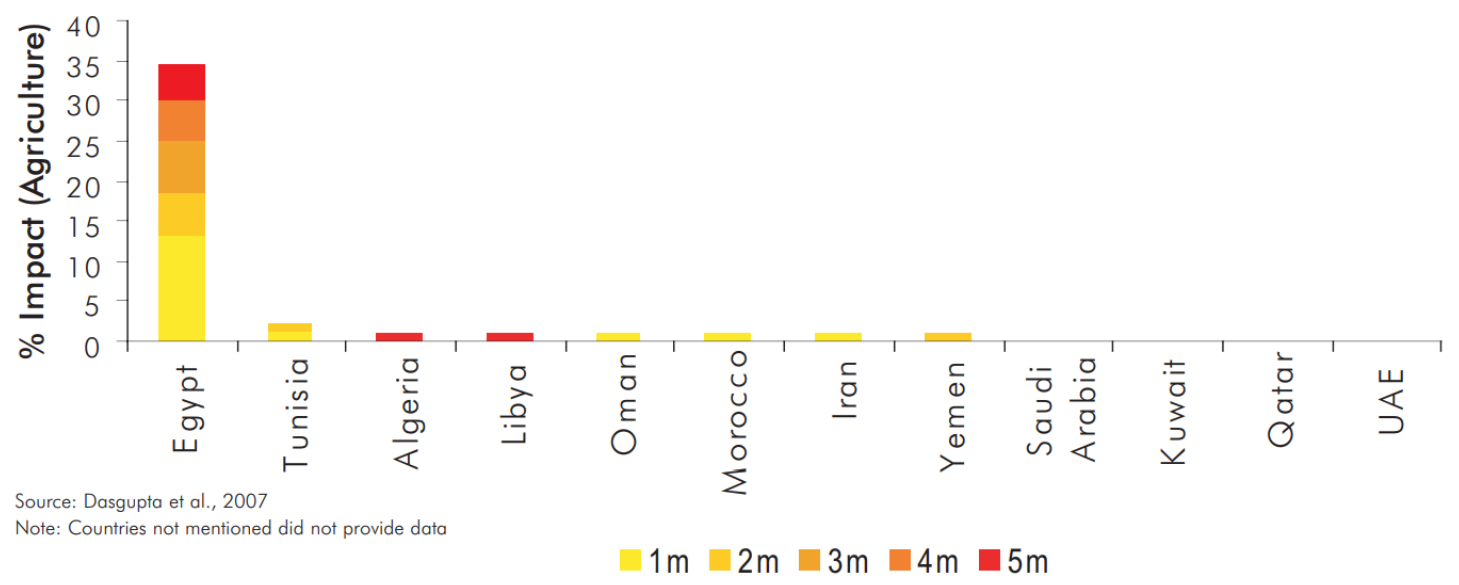

34 Figure 6.5: Comparison of SLR impacts on the agricultural production of Arab countries. Reproduced from the Arab Environment Climate Change Report by Tolba \& Saab (2009).

The Egyptian authorities have already prepared for the rise of sea level by integrating flood blockades and beach embankment height necessities in coastlines for future challenges (Meehl et al., 2012). In addition to that Egypt has also challenged new weather phenomena in stronger rainfalls which caused major flooding in Cairo.

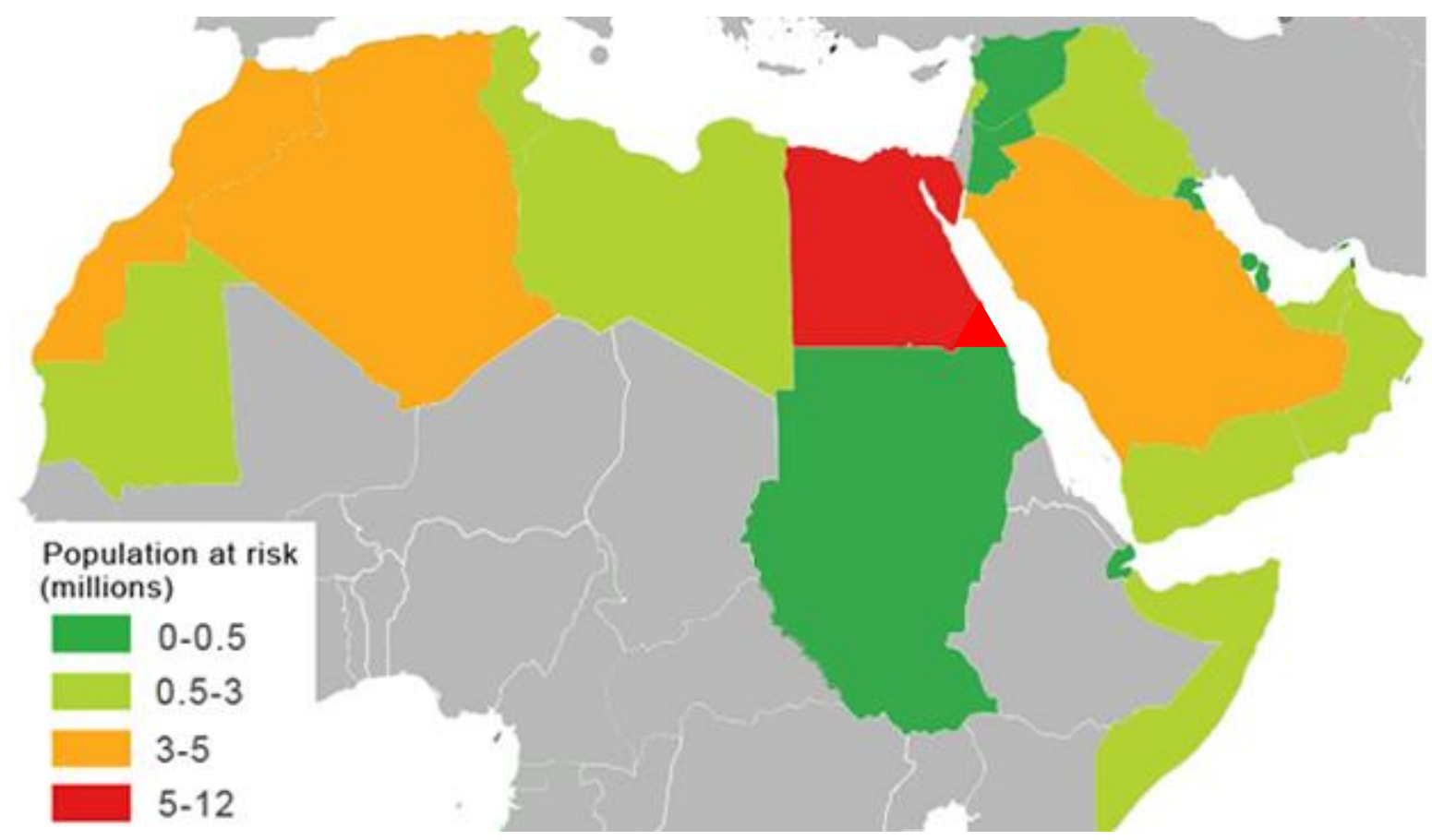

35 Figure 6.6: Extreme scenario (5m SLR) on the Arab world, by total population affected. Reproduced from the Arab Environment Climate Change Report by Tolba \& Saab (2009). 
Egypt is ranked as the $14^{\text {th }}$ most populated country in the world Tolba \& Saab (2009). The Egyptian officials are keen to go clean in terms of energy to keep the limited natural resources for future generations. Egypt has banned using diesel as a fossil fuel for all types of vehicles. Also, Egypt started using solar energy like using powered lightening columns in whole cities in some cases like in Sharm El-Sheikh city. Egypt also started building two nuclear power plant reactors in "El-Dabaa", North Coast (World Nuclear Association, 2018). Egypt has also implemented some reclamation projects although they may be expensive as well as having an environmental impact on adjacent shoreline areas where various maritime ecosystems are (The International Tanker Owners Pollution Federation [ITOPF], 2016). Sustainable floating developments specifically for housing purposes would help dramatically when planning for solving the rise in population and demands near coastline areas.

\subsubsection{Concluded Climate Change Impacts on Egypt}

The officials in Egypt are already showing commitment towards sustainability in some levels on some city activities. Such commitment could be shown in the Blueprint from the Egyptian Government until 2030 and beyond when a lot of goals are ahead for achieving sustainability in Egypt in 2030 and beyond (United Nations Development Programme, 2014). The impact of rising temperature as well as the raising sea level has already encouraged the necessity for future strategies for the Egyptian officials and real measures. The Egyptian officials has already planned and has already started implementing some countermeasures (United Nations Development Programme, 2014).

Although Egypt is a North African country and its landscape is mostly deserted, but Egyptians rely mostly on its own agriculture as agriculture from the Nile Delta as one of its main elements of the economy, where it contributes up to $14.5 \%$ of the country's GDP and 
$28 \%$ of all jobs (World Bank, 2018). In the future, the danger of the rising seas will rise due to the global warming threats the food security of Egypt. Such consequence makes the Nile Delta at risk, which is where the agriculture of Egypt takes place. As a result, Egyptians will be defenceless to instabilities in their own land and will head to importing where people will face the unstable universal food supply and prices. Such aspect has been one of the driving forces in this thesis.

\subsection{Time Series Analysis and Ranking for the Nile Delta}

The Nile Delta's most vulnerable locations to SLR would be some of the possible locations to implement floating structures community. Unsurprisingly, such locations have experienced land reclamation solutions by the Egyptian government. The new land areas that could be used as reserve location sites for 2030 and beyond are in the lowest lying Egyptian coastline areas which lie on the Nile Delta's coastline and especially Lake Burullus and Abu-Qir bay.

The Nile Delta stretches for around $240 \mathrm{~km}$ from Alexandria on the west to Port Said on the east. The Nile Delta coastline is bordered by two modern distributaries which are Rosetta and Damietta and Burullus Lake in the centre. Such promontories are separated by embayment which have undergone accretion (Frihy \& El-Sayed, 2013). The wide seashores of the Nile Delta are supported by ridges, cultivated land, urban settlements and littoral swamplands creating natural inlets and pisciculture. Such saline littoral lakes like Idku, Burullus and Manzala are separated from the Mediterranean by sandy barricades by manmade inlets. Such lowland blockades are rather small and are currently exposed to erosion and collapsing. Sea levels have been assessed from tide gauges mounted in Alexandria, AbuQir, Rosetta, Burullus, Damietta, and Port Said (Frihy \& El-Sayed, 2013). Measurements 
have shown that sea level is consistently increasing from $1.8-4.9 \mathrm{~mm} /$ year with a mean of $3 \mathrm{~mm} /$ year. Sea levels demonstrate increment as an outcome from land subsidence and eustatic sea-level (Frihy \& El-Sayed, 2013). Lately (December 2003, December 2010 and January 2011), the Nile Deltas' coastline has experienced strong storm events. Such storms have occurred throughout a relatively short interval of time surging up to $1 \mathrm{~m}$ over the mean sea level (Frihy \& El-Sayed, 2013).

\subsubsection{SLR Impacts on the Nile Delta's Coastline Area}

Vulnerability valuation is created on social vulnerabilities as well as the exposed population and the effectiveness of the coastal management approaches practiced for managing such challenges, and the biophysical vulnerabilities counting both geological and geomorphologic responses to SLR.

\subsubsection{Impacts on Infrastructure}

Six Mediterranean governorates (Table 6.1) lie in the Nile Delta region. They demonstrate different socio-economic features and resources.

\begin{tabular}{|c|c|c|c|c|c|}
\hline Governorate & $\begin{array}{l}\text { Tourism \& } \\
\text { recreation }\end{array}$ & $\begin{array}{l}\text { Business \& } \\
\text { energy }\end{array}$ & $\begin{array}{l}\text { Ports \& } \\
\text { transport }\end{array}$ & Pisciculture & $\begin{array}{l}\text { Agricultural } \\
\text { areas }\end{array}$ \\
\hline Alexandria & $\mathrm{H}$ & $\mathrm{H}$ & $\mathrm{H}$ & $\mathrm{A}$ & $\mathrm{A}$ \\
\hline Beheira & $\mathrm{L}$ & $\mathrm{L}$ & $\mathrm{L}$ & $\mathrm{H}$ & $\mathrm{H}$ \\
\hline $\begin{array}{ll}\text { Kafr } & \text { El- } \\
\text { Sheikh } & \\
\end{array}$ & $\mathrm{L}$ & $\mathrm{L}$ & $\mathrm{L}$ & $\mathrm{H}$ & $\mathrm{H}$ \\
\hline Dakahleya & $\mathrm{A}$ & $\mathrm{L}$ & $\mathrm{A}$ & $\mathrm{H}$ & $\mathrm{H}$ \\
\hline Damietta & $\mathrm{L}$ & $\mathrm{A}$ & $\mathrm{H}$ & $\mathrm{H}$ & A \\
\hline Port-Said & $\mathrm{A}$ & $\mathrm{A}$ & $\mathrm{A}$ & $\mathrm{A}$ & $\mathrm{L}$ \\
\hline
\end{tabular}

34 Table 6.1: Classification of socio-economic features and resources the Nile Deltas' coastal governorates.

H: High; A: Average; L: Low 


\subsubsection{Population}

In 2019, the Egyptian population have reached 98.57 million according to the Central Authority for Mobilization and Statistics (CAPMAS). The residents of the Nile Delta's littoral are assessed to be around 13.30 million, which accounts for 13.5\% of Egypt's population (Table 6.2). The Nile Delta accounts for the highest population density when compared to the neighboring vast areas of Sinai, the western and eastern deserts. The most densely populated are the governorates of Alexandria, Kafr El Sheikh, and Dakahleya (500-2,000 persons/km2) when related to the governorates of Beheira and Port Said (300-500 persons/km2).

\begin{tabular}{|l|l|l|l|l|}
\hline Governorate & Area $\mathrm{km}^{2}$ & Population & $\begin{array}{l}\text { Population } \\
\text { density } \\
\left(\text { persons } / \mathrm{km}^{2}\right)\end{array}$ & $\begin{array}{l}\text { Annual } \\
\text { growth }\end{array}$ \\
\hline Alexandria & 2,879 & $5,316,094$ & 1498.971 & $2.3 \%$ \\
\hline Beheira & 10,130 & $6,456,004$ & 494.185 & $2.7 \%$ \\
\hline Kafr El-Sheikh & 3,748 & $3,507,962$ & 737.96 & $2.4 \%$ \\
\hline Dakahleya & 4,370 & $6,732,733$ & 1207.564 & $2.5 \%$ \\
\hline Damietta & 13,307 & $1,548,557$ & 87.567 & $3.0 \%$ \\
\hline Port-Said & 1,351 & 766,738 & 442.914 & $2.7 \%$ \\
\hline
\end{tabular}

35 Table 6.2: Data on population and areas from Alexandria to Port-Said.

While there is an obvious negative impact on the Nile Delta's coastlines due to SLR, however, it's rather hard to measure such impacts with the available data on the accurate demographics based on the SLR scenarios, social and biophysical vulnerabilities. Nevertheless, densely populated areas like Alexandria would be highly impacted when related to lower densely populated regions. 


\subsubsection{Tourism and Recreation Activities}

Throughout the last decades, the Mediterranean shores in the Nile delta's and neighboring regions, predominantly Alexandria, was the main destination for many Egyptians during summer holidays. Nevertheless, throughout the last two decades, Egypt has experienced an unparalleled level of tourism in the western regions of Rosetta's distributary, especially in Alexandria and Matruh. Ras El-Bar is a central resort city in Damietta's distributary of the Nile. Other resorts that are already founded are Baltim and Gamasa. Rosetta and Port-Said comparatively attract a small amount of tourism annually. Tourism activities are being established at the Mediterranean region of Sinai Peninsula and mostly in El-Arish. SLR would probably reduce tourism in several the littoral attractions lengthways the Nile Delta's coastlines because of the erosion and flooding of sandy beaches.

\subsubsection{Businesses and Energy}

Large number of the Egypt's industries are situated around the region of Alexandria. Such in industries consist of textile, chemical, paper, food, metal factories as well as oil plants and petrochemicals (Tolba \& Saab, 2009).

Mining and generating oil and gas is increasing in Egypt's Mediterranean littoral region, mainly in the Nile Delta. Producing and transporting liquefied natural gas (LNG) has developed to a significant activity in Egypt's Mediterranean littoral region. Alexandria's region hosts large electric power producing industries.

\subsubsection{Ports and Transport}

Large ports are situated lengthways the Nile Delta's coastlines. Ports in Alexandria like El-Dekhiela harbor, the eastern and western harbors and Abu-Qir Bay are the biggest and 
most jammed ports in Egypt. Such ports are sheltered by breakwaters and levees (Frihy \& El-Sayed, 2013). Further important harbours are Damietta and Port-Said. Furthermore, there are oil and natural gas docks. Some fishing docks are situated nearby several fish landing facilities like Abu-Qir Bay and Burullus lagoon.

The design of harbours, barriers and harbour facilities must consider high waves, floods, and storm activities, for the purpose of safeguarding people, buildings, and infrastructures from SLR impacts. Nevertheless, such protection approaches must to be strengthened to sustain such ports in the future.

\subsubsection{Pisciculture}

Pisciculture of Egypt's northern coastlines are about 240,000t/year (United Nations Development Programme, 2014). Three major areas account for such number which are the Mediterranean Sea, Northern Delta lagoons and aquaculture activities. The negative SLR impacts on fishing in Egypt's northern coastlines is unknown. This is due to the capability of such aquatic organisms to progressively adapt to temperature changes, salinity, or high waves and tides by altering their environment or relocation routes. Nevertheless, SLR could impact breeding areas of various fish and other marine organisms, mainly in wetlands, also disturb the natural food-chain of these aquatic organisms.

There is a probability where the water quality of the inlets of Egypt's Mediterranean coastlines vary as a result of the SLR and climate change. This could destroy the thin sand barricade which separates the Mediterranean Sea from such inlets. Accordingly, a probable change in both aquatic biodiversity and fish are expected. 


\subsubsection{Littoral Ecosystems and Wetlands}

Littoral ecosystems are characterized by the seaside societies as sea grass, algae, and other related species. Wetlands and lakes on Egypt's Mediterranean coastlines are Maryut, Idku, Burullus, Manzala and Bardawil.

At a global scale, SLR will extremely endanger sensitive littoral ecosystems like coastal wetlands, particularly when lands are being controlled for anthropogenic activities (IPCC, 2007). The damage of coastal wetlands will have several negative impacts like food production, clarification of water, nutrient cycles, and the wildlife (IPCC, 2007).

\subsubsection{Agricultural Areas}

The rise of sea level in parallel with the Egyptian Nile Delta's rise in population and coastal cities developments, the need for a solution was a must due to the low-lying lands of the Egyptian Nile Delta. Egypt is possibly the most vulnerable African nation to SLR. The water in 2000 was assessed around $70 \mathrm{~km} 3$ where that is already exceeds the existing resources (Organización de las Naciones Unidas, 2005). A main challenge is closing the growing gap between the available water with growing demand for water for numerous economical areas. Water use percentage has already reached its maximum 100\% in Egypt, and climate change impacts would only worsen the situation.

Agriculture already use around 85\% of Egypt's water supply yearly and has a crucial part in the country's economy, which forms around 20\% of Egypt's GDP. Over 70\% of the cultivated area rely on low-efficiency water systems, where that outcomes in a lot of water losses, less land production, waterlogging as well as salinity challenges (Conway, 2005). Furthermore, such unsustainable farming techniques and inappropriate water management 
impact the quality of water supply. The decrease in such irrigation water quality impacts negatively on the agricultural soils and harvests.

The Egyptian government are working to accomplish the next goals via the National Improvement Plan (IPCC, 2007; Organización de las Naciones Unidas, 2005):

- Enhancing water sanitation network in both cities and countryside regions.

- Managing wastewater

- Enhancing the usage of water resources by refining irrigation proficiency and recycling drainage-water for agricultural purposes.

Nevertheless, with such global warming impacts, several significant threats are obvious.

- Sea-level rise may have a great effect the Nile Delta and its inhabitants and other seaside regions (Conway, 2005).

- Higher temperature would probably decrease main crops production and increase their water necessities which consequently outcomes in less crop water-use productivity (UNFCCC, 2007).

- There might be an overall increase in the irrigation demand (Attaher et al., 2010).

- A large degree of ambiguity of the Nile stream is probable.

- According to SRES scenarios, Egypt would probably experience higher water stress, with an anticipated decrease in rainfall with an expected population of 151 million by 2050. Therefore, increasing water stress in every aspect.

- The constant development of irrigated zones would decrease the Egypt's ability in dealing with the future flow instability (Conway, 2005). 


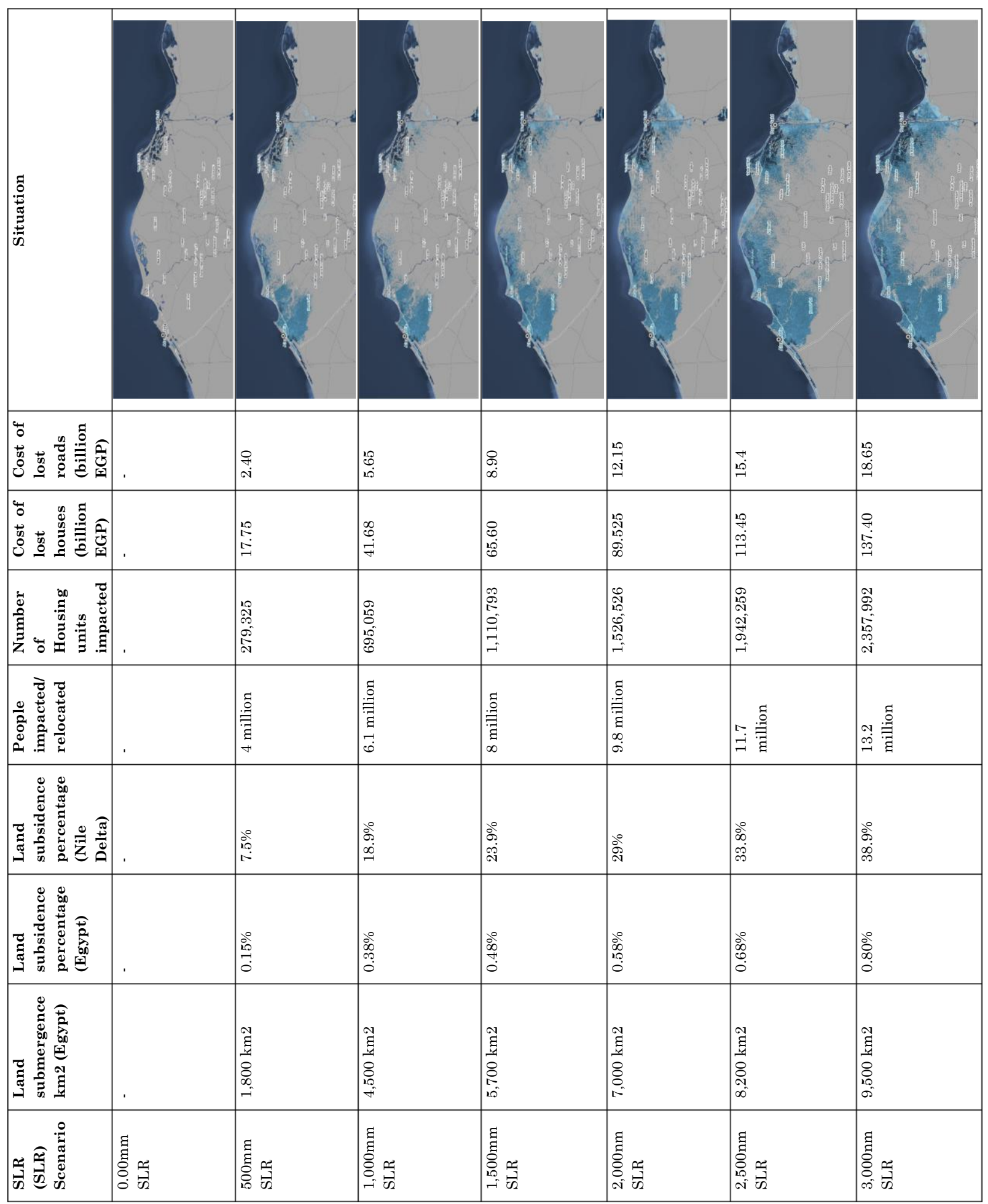

36 Table 6.3: SLR scenarios and impacts on the Nile delta's coastline.

Main observatories used to create such scenarios: AFED reposts: Saab (2017), Tolba \& Saab (2009), Saab \&Sadik (2018); IDSC (2011, 2013), IPCC (2007; 2014), NOAA, (2010, 2017), 
UNEP (2017). Monitoring data from the Ministry of State for Local Development, and Ministry of Environment.

\subsection{Risk Assessment on the Nile Delta's Coastline Against SLR Impacts}

\subsubsection{Coastal Management Approaches}

Coastal adaptation approaches are natural high topographies like sand dunes or artificial barriers like seawalls, levees, and breakwaters.

\subsubsection{Natural Protection}

A stone ridge of around $+4 \mathrm{~m}$ over the mean sea level is one of eight coastal ridges which expand from Abu-Qir Bay to the Arab's Bay, around 100km west of Abu-Qir Bay (Frihy \& ElSayed, 2013). Therefore, the majority of Alexandria's shoreline, a section of such ridge, is rather safeguarded from the anticipated SLR, excluding the lowland zones of Lake Maryut, Mandara (Table 6.4 \& Figure 6.7) as well as the southeastern depression. Nevertheless, areas exposed to disruption or any gaps in the ridge are defenceless to SLR.

Additional ridges support the northwestern shoreline and act like a natural protection system against floods and storm surges. Correspondingly, several littoral dune belts run parallel to the shorelines of various parts of such accretion coastlines.

\subsubsection{Artificial Protection}

Artificial structures such as (revetments, jetties, groins, detached breakwaters and seawalls) are constructed by the Egyptian Shore Protection Authority (ESPA) lengthways 
the Nile Delta's coastlines have multifunctional purposes, which involve either erosion management, or controlling shore variations and sediment accumulation at the harbor's entries, river distributaries, bays, and inlets. The materials practiced for constructing such structures are sandstones, basalt mounds, and concrete either for creating dolos or blocks (Frihy \& El-Sayed, 2013; IDSC, 2011).

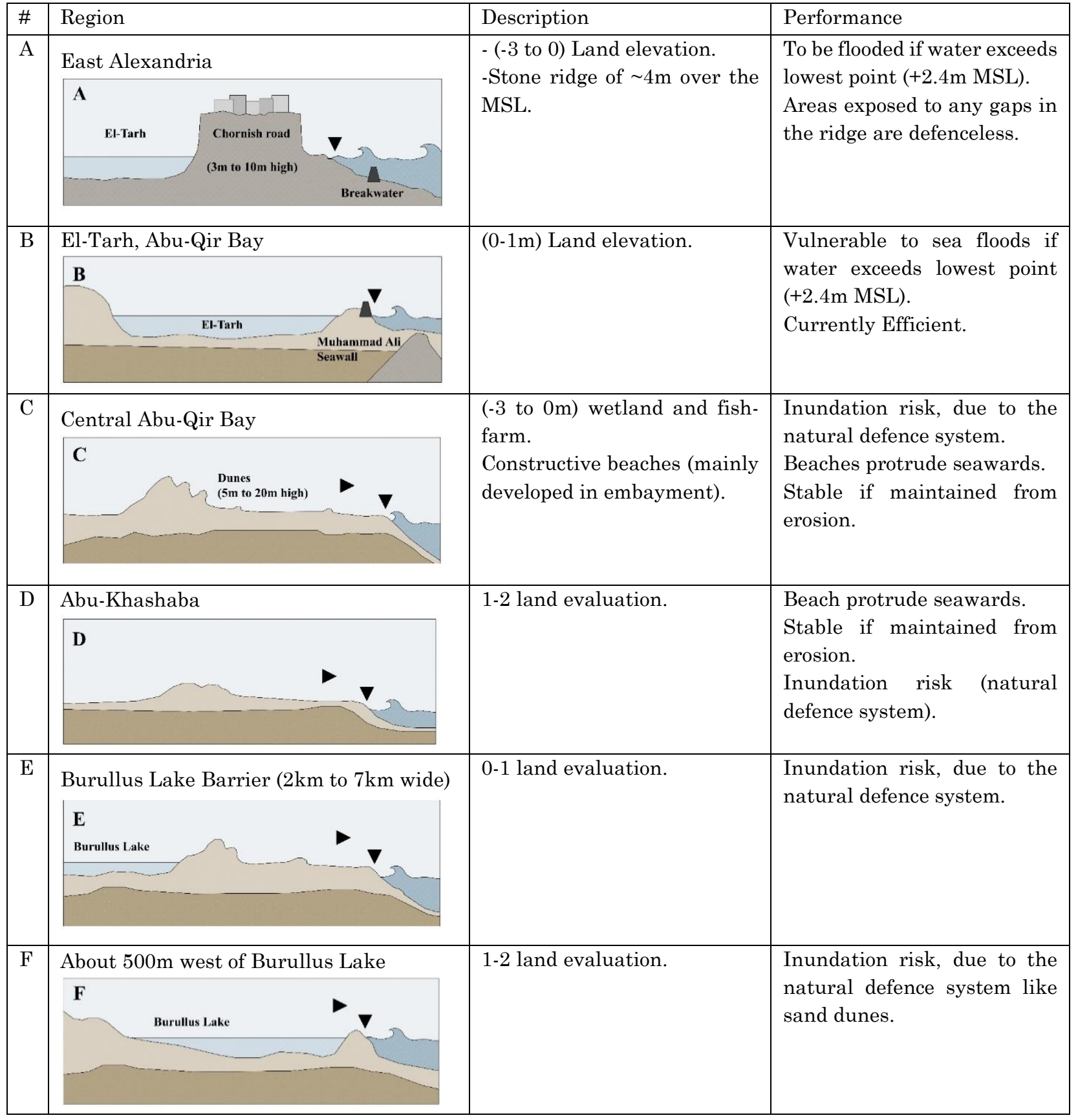




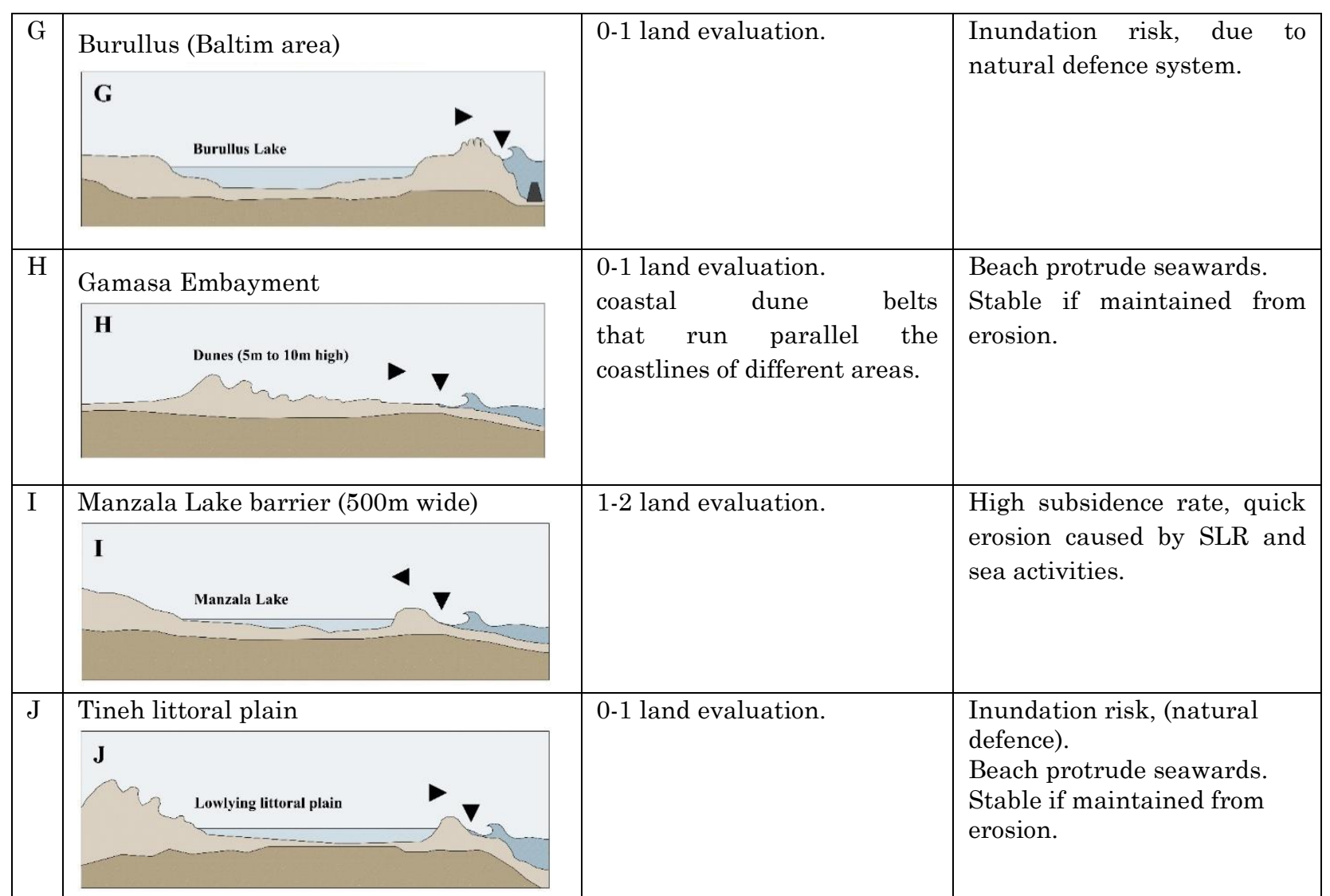

37 Table 6.4: Cross sections for vulnerable coastal areas analyzed along the study from Alexandria to Port-Said showing adaptation approaches practiced and main topographic characteristics that influence flood levels of and permanent inundation of lowlands which are caused by SLR impacts and strong storm events (own illustrations).

Separate breakwaters and a set of barriers and piers were built at the northwestern coastline as the shore is very dynamics, like in the resorts of Alamein and Marbella. From 2005 and 2007, submerged rubble mound breakwaters were mounted to lessen the erosion and high waves at Asafra and Mandara seashores in Alexandria. Such breakwater involves two overlying sectors of around 3,000m at an offshore distance amid 150-300m (Frihy \& ElSayed, 2013). Abu-Qir bay has a 1.2km stretched seawall which was constructed in 1830 and recognized as Mohamed Aly's Seawall (Table 6.4). Such seawall is 3.5m over the mean sea level to prevent the probable SLR and high wave (Frihy \& El-Sayed, 2013). 
Presently, the external boundaries of the Rosetta and Damietta distributaries are safeguarded by seawalls of $5.0 \mathrm{~km}$ and $6.2 \mathrm{~km}$ respectively. A set of 17 coast-parallel breakwaters were installed in phases lengthways the Burullus to Baltim area. A set of eight coast-parallel breakwaters were installed lengthways Ras El-Bar resort. A set of four coastparallel breakwaters were installed lengthways Gamil to Port-Said road. A stone basalt riprap of around $1.0 \mathrm{~km}$ was constructed lengthways the Burullus village. Nonetheless, such approaches have disturbed the coastal sediments which outcomes in down-drift shore erosion s well as up-drift accretion.

\subsubsection{Vulnerability Ranking}

\begin{tabular}{|l|l|l|l|l|l|l|}
\hline$\#$ & Area & $\begin{array}{l}\text { High risk } \\
(++++)\end{array}$ & $\begin{array}{l}\text { Moderate risk } \\
(+++)\end{array}$ & $\begin{array}{l}\text { Low risk } \\
(++)\end{array}$ & $\begin{array}{l}\text { Under extreme } \\
\text { events (+) }\end{array}$ & No risk \\
\hline & Western coastal plain & & & & & \\
\hline A & Alexandria & & & & & \\
\hline B & El-Tarh, Abu-Qir Bay & & & & & \\
\hline C & Central Abu-Qir Bay & & & & & \\
\hline D & Abu-Khashaba & & & & & \\
\hline E & $\begin{array}{l}\text { Burullus Lake Barrier } \\
(2 \mathrm{~km} \text { to 7km wide) }\end{array}$ & & & & & \\
\hline G & Eastern coastal plain & & & & & \\
\hline About 500m west of & & & & & \\
\hline F & Burullus Lake & & & & \\
\hline G & Gamasa Embayment & & & & & \\
\hline H & $\begin{array}{l}\text { Manzala Lake barrier } \\
\text { (500m wide) }\end{array}$ & & & & & \\
\hline I & Tineh littoral plain & & & & & \\
\hline
\end{tabular}

38 Table 6.5: Vulnerability ranking of coastal regions to SLR ${ }^{4}$

${ }^{4}$ Method adopted from: IDSC (2011).

Main sources for this evaluation: Main observatories used to create such scenarios: AFED reposts: Saab (2017), Tolba \& Saab (2009), Saab \&Sadik (2018); IDSC (2011, 2013), IPCC (2007; 2014), Frihy \& El-Sayed (2013).

Reports and geological plans from the Ministry of State for Local Development, and Ministry of Environment. 
The vulnerability of the Nile Delta's coastlines to SLR impacts are shown in Table 6.4 which is founded on the zoning map of the Nile Delta in Table 6.4 \& Figure 6.7.

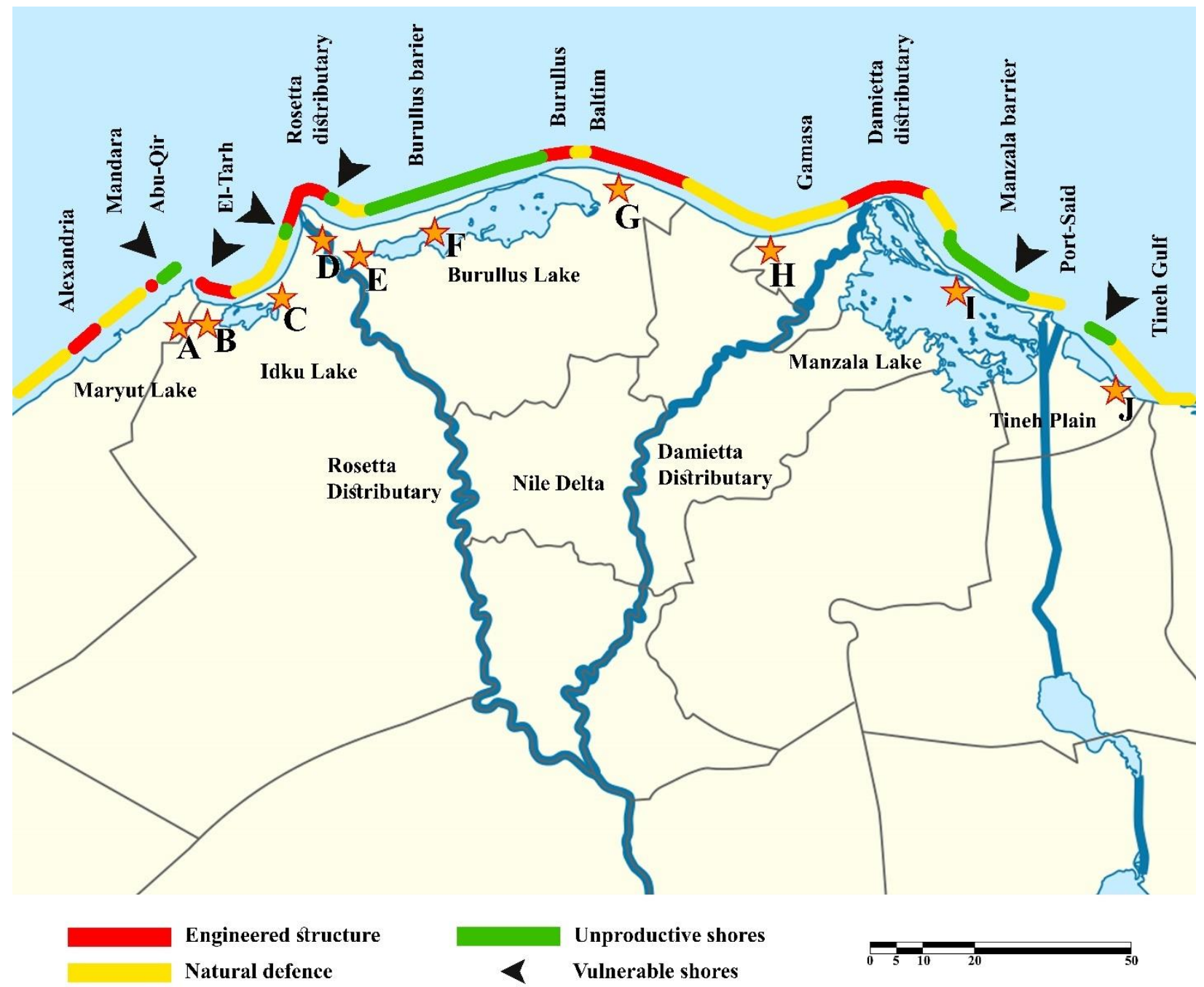

36 Figure 6.7: Coastal areas from Alexandria to Port-Said demonstrating the impacts of $2 \mathrm{~m}$ of SLR, and coastal management methods practiced protective state (own illustration). 


\subsubsection{The Nile Delta}

Around $60 \%$ of the Nile Delta's shoreline is somewhat supported by natural sand dunes and artificial structures of $17.5 \%$ and $42.5 \%$ respectively, whereas the other $40 \%$ of the coastline is not safeguarded (Saab, 2017; Saab \& Sadik, 2018). The valuation of the littoral exposure to SLR in such area demonstrates asymmetrical outcomes due to the status of the following different zones.

\subsubsection{Risk Assessment}

Alexandria's coastline has a natural semi-consolidated carbonate ridge in $67 \%$ of the its shorelines is significantly more than artificial structures which accounts for around 20\%, while the rest $13 \%$ are defenceless. Apart from for the low-lying zones which are regularly vulnerable to high waves and storm surges, like Mandara city, almost all of Alexandria's littoral areas are safeguarded from 0.5-1.0m SLR. The artificial structures and accretion tombolo formations have provided some accretion efficient coastal barriers. Such structures have decreased the threats caused by the storm surges which have occurred in the winter between 2010 to 2011.

\subsubsection{Time Series Analysis and Ranking for Alexandria}

According to previous results which consists of: classification of the problem, the vulnerability assessment and ranking, qualitative risk assessment is used to recognize probable risks, and to display the coastal management approaches which have already been practiced by the Egyptian Shore Protection Authority (ESPA). Therefore, the Nile Delta and Alexandria achieve more risks to the SLR when related to the other coastal areas in Egypt. About 10 million people live in littoral areas of both the Nile Delta and Alexandria will 
probably be exposed to SLR impacts, mostly the ones who inhabit the vulnerable areas mentioned. Economy will face threats as various activities depend on such low-lying regions for purposes as agriculture, fisheries, business, tourism and other activities specially at Alexandria and the Nile Delta. SLR impacts on the biophysical structure in the Nile Delta would be more than any other area on Egypt's coastlines.

\begin{tabular}{|l|l|l|l|l|l|l|l|l|l|}
\hline $\begin{array}{l}\text { SLR } \\
\text { (SLR) } \\
\begin{array}{l}\text { Scenari } \\
\text { o }\end{array}\end{array}$ & $\begin{array}{l}\text { Land } \\
\text { subsiden } \\
\text { percenta } \\
\text { ge }\end{array}$ & $\begin{array}{l}\text { People } \\
\text { impacte } \\
\text { d/ } \\
\text { relocate } \\
\text { d }\end{array}$ & $\begin{array}{l}\text { Agricult } \\
\text { ure }\end{array}$ & $\begin{array}{l}\text { Indust } \\
\text { ry }\end{array}$ & $\begin{array}{l}\text { Resident } \\
\text { ial }\end{array}$ & $\begin{array}{l}\text { Munici } \\
\text { pal } \\
\text { Service } \\
\text { s }\end{array}$ & $\begin{array}{l}\text { Commerc } \\
\text { ial Areas }\end{array}$ & $\begin{array}{l}\text { Commun } \\
\text { ity } \\
\text { Facility }\end{array}$ & $\begin{array}{l}\text { Archeologi } \\
\text { cal Sites }\end{array}$ \\
\hline $\begin{array}{l}0.0 \mathrm{~m} \\
\text { SLR }\end{array}$ & - & - & - & - & - & - & - & - & - \\
\hline $\begin{array}{l}500 \mathrm{~mm} \\
\text { SLR }\end{array}$ & $51 \%$ & $50 \%$ & $93 \%$ & $65 \%$ & $45 \%$ & $30 \%$ & $20 \%$ & $15 \%$ & $48 \%$ \\
\hline $\begin{array}{l}1,000 \mathrm{~m} \\
\mathrm{~m} \text { SLR }\end{array}$ & $62 \%$ & $64 \%$ & $95 \%$ & $70 \%$ & $50 \%$ & $50 \%$ & $25 \%$ & $20 \%$ & $55 \%$ \\
\hline $\begin{array}{l}1,500 \mathrm{~m} \\
\mathrm{~m} \text { SLR }\end{array}$ & $76 \%$ & $79 \%$ & $98 \%$ & $80 \%$ & $63 \%$ & $60 \%$ & $30 \%$ & $25 \%$ & $62 \%$ \\
\hline $\begin{array}{l}2,000 \mathrm{n} \\
\mathrm{m} \text { SLR }\end{array}$ & $95 \%$ & $93 \%$ & $100 \%$ & $90 \%$ & $75 \%$ & $70 \%$ & $35 \%$ & $30 \%$ & $70 \%$ \\
\hline
\end{tabular}

39 Table 6.6: SLR scenarios and impacts on the Alexandria. ${ }^{5}$

Vulnerable regions in the Alexandria Governorate are Mandara and El-Tarh, while in the Nile Delta area are the littoral inlets barrier, eastern and western areas of the Rosetta's distributary at Gamil, and the Tineh plain. Such vulnerability valuation exposed that

${ }^{5}$ Main observatories used to create such scenarios: AFED reposts: Saab (2017), Tolba \& Saab (2009), Saab \&Sadik (2018); IDSC (2011, 2013), IPCC (2007; 2014), NOAA, (2010, 2017), UNEP (2017).

Tidal gauges data from Alexandria governorate (2017) and Ministry of Environment (2018). 
physical coastal management systems involving natural and artificial structures are the most efficient as for the present situation. Coastal management systems must be maintained and reinforced to manage such accelerated SLR.

\subsubsection{Possible Location in the Nile Delta's Coastline for a Floating Community Project}

Egypt is a very high populated country with current population of 98.57 million (CAPMAS). Its population growth by the year 2030 will reach its highest population estimates of 120.00 million.

Egypt is a transcontinental country spanning the northeast corner of Africa and the southwest corner of Asia. The Suez Canal sets the border between the two continents. The Suez Canal crosses through four governates, Damietta, Port-Said, Ismailia and Suez. Where Port-Said serves as the Entrance from the Mediterranean and the northern outlet of the canal while Suez serves as the Entrance from the Red Sea and the southern outlet of the canal. A joint population of 4.4 million who live in an area with a surface elevation similar to sea level and just $0.5 \mathrm{~m}$ would completely flood the region.

Abu-Qir Bay lies on the western side of Rosetta distributary between Maryut lake and Burulus lake. It lies between two governorates, Beheira and Alexandria. A joint population of 11.772 million who live in an area with a surface elevation similar to sea level and just 0.5m would completely flood the region. Such analysis indicates that the region of Abu-Qir Bay appears to be the lowest lying region in Egypt and one of the lowest-lying regions in the world (see Tables $6.7 \& 6.8$ ). 


\begin{tabular}{|c|c|c|c|c|c|c|}
\hline \multicolumn{2}{|l|}{ Area } & $\begin{array}{l}\text { SLR impacts on } \\
\text { current } \\
\text { adaptation } \\
\text { approaches }\end{array}$ & $\begin{array}{l}\text { Adaptation } \\
\text { solutions used }\end{array}$ & $\begin{array}{l}\text { Performance of } \\
\text { adaptation } \\
\text { solution }\end{array}$ & $\begin{array}{l}\text { Overall } \\
\text { evaluation }\end{array}$ & $\begin{array}{l}\text { State and } \\
\text { Recommendation }\end{array}$ \\
\hline \multirow{12}{*}{$\begin{array}{l}\text { Western } \\
\text { coastal } \\
\text { plain }\end{array}$} & \multirow{2}{*}{$\begin{array}{l}\text { East } \\
\text { Alexandria }\end{array}$} & \multirow[t]{2}{*}{++++} & Breakwaters. & ++ & \multirow{2}{*}{$\begin{array}{l}\text { Very Low } \\
\text { High Risk }\end{array}$} & \multirow{2}{*}{$\begin{array}{l}\text { Critical } \\
\text { In need for a } \\
\text { better solution }\end{array}$} \\
\hline & & & Raising roads. & ++ & & \\
\hline & \multirow{2}{*}{$\begin{array}{l}\text { El-Tarh, } \\
\text { Abu-Qir } \\
\text { Bay }\end{array}$} & \multirow[t]{2}{*}{+++} & $\begin{array}{l}\text { Mohamed Aly } \\
\text { seawall. }\end{array}$ & +++ & \multirow[t]{2}{*}{$\begin{array}{l}\text { Low } \\
\text { Risk }\end{array}$} & \multirow{2}{*}{$\begin{array}{l}\text { Risk exists } \\
\text { Solutions appear } \\
\text { to work, but are } \\
\text { short term }\end{array}$} \\
\hline & & & $\begin{array}{l}\text { Creating natural } \\
\text { infrastructure. }\end{array}$ & +++ & & \\
\hline & \multirow{3}{*}{$\begin{array}{l}\text { Central } \\
\text { Abu-Qir } \\
\text { Bay }\end{array}$} & \multirow[t]{3}{*}{++++} & Sand dunes. & ++ & \multirow{3}{*}{$\begin{array}{l}\text { Very Low } \\
\text { High Risk }\end{array}$} & \multirow{3}{*}{$\begin{array}{l}\text { Critical } \\
\text { In need for a } \\
\text { better solution }\end{array}$} \\
\hline & & & $\begin{array}{l}\text { Using beaches } \\
\text { as barriers. }\end{array}$ & ++ & & \\
\hline & & & $\begin{array}{l}\text { Creating natural } \\
\text { infrastructure. }\end{array}$ & +++ & & \\
\hline & \multirow[t]{3}{*}{$\begin{array}{l}\text { Abu- } \\
\text { Khashaba }\end{array}$} & \multirow[t]{3}{*}{++} & $\begin{array}{l}\text { Using beaches } \\
\text { as barriers. }\end{array}$ & ++++ & \multirow[t]{3}{*}{$\begin{array}{l}\text { Moderate } \\
\text { Low Risk }\end{array}$} & \multirow{3}{*}{$\begin{array}{l}\text { Low risk } \\
\text { Solutions appear } \\
\text { to work (for } \\
\text { now) }\end{array}$} \\
\hline & & & Sand dunes. & ++ & & \\
\hline & & & $\begin{array}{l}\text { Creating natural } \\
\text { infrastructure. }\end{array}$ & ++++ & & \\
\hline & \multirow{2}{*}{$\begin{array}{l}\text { Burullus } \\
\text { Lake } \\
\text { Barrier } \\
\text { ( } 2 \mathrm{~km} \text { to } \\
7 \mathrm{~km} \text { wide) }\end{array}$} & \multirow[t]{2}{*}{+++} & $\begin{array}{l}\text { Using beaches } \\
\text { as barriers. }\end{array}$ & ++ & \multirow[t]{2}{*}{$\begin{array}{l}\text { Low } \\
\text { Risk }\end{array}$} & \multirow{2}{*}{$\begin{array}{l}\text { Risk exists } \\
\text { Solutions appear } \\
\text { to work, but are } \\
\text { short term }\end{array}$} \\
\hline & & & $\begin{array}{l}\text { Creating natural } \\
\text { infrastructure. }\end{array}$ & +++ & & \\
\hline \multirow{10}{*}{$\begin{array}{l}\text { Eastern } \\
\text { coastal } \\
\text { plain }\end{array}$} & \multirow{2}{*}{$\begin{array}{l}\text { About } \\
500 \mathrm{~m} \text { west } \\
\text { of Burullus } \\
\text { Lake }\end{array}$} & \multirow[t]{2}{*}{++} & Sand dunes. & +++ & \multirow{2}{*}{$\begin{array}{l}\text { Moderate } \\
\text { Low Risk }\end{array}$} & \multirow{2}{*}{$\begin{array}{l}\text { Low risk } \\
\text { Solutions appear } \\
\text { to work (for } \\
\text { now) }\end{array}$} \\
\hline & & & $\begin{array}{l}\text { Creating natural } \\
\text { infrastructure. }\end{array}$ & ++++ & & \\
\hline & \multirow{3}{*}{$\begin{array}{l}\text { Burullus } \\
\text { (Baltim } \\
\text { area) }\end{array}$} & \multirow[t]{3}{*}{+++} & Breakwater. & +++ & \multirow{3}{*}{$\begin{array}{l}\text { Low } \\
\text { Risk }\end{array}$} & \multirow{3}{*}{$\begin{array}{l}\text { Risk exists } \\
\text { Solutions appear } \\
\text { to work, but are } \\
\text { short term }\end{array}$} \\
\hline & & & Sand dunes. & ++ & & \\
\hline & & & $\begin{array}{l}\text { Creating natural } \\
\text { infrastructure. }\end{array}$ & +++ & & \\
\hline & \multirow[t]{2}{*}{$\begin{array}{l}\text { Gamasa } \\
\text { Embayment }\end{array}$} & \multirow[t]{2}{*}{+++} & $\begin{array}{l}\text { Using beaches } \\
\text { as barriers. }\end{array}$ & ++ & \multirow[t]{2}{*}{$\begin{array}{l}\text { Low } \\
\text { Risk }\end{array}$} & $\begin{array}{l}\text { Risk exists } \\
\text { Solutions appear }\end{array}$ \\
\hline & & & $\begin{array}{l}\text { Creating natural } \\
\text { infrastructure. }\end{array}$ & +++ & & $\begin{array}{l}\text { to work, but are } \\
\text { short term }\end{array}$ \\
\hline & $\begin{array}{l}\text { Manzala } \\
\text { Lake } \\
\text { barrier } \\
\text { (500m } \\
\text { wide) } \\
\end{array}$ & ++ & $\begin{array}{l}\text { Creating natural } \\
\text { infrastructure. }\end{array}$ & +++ & $\begin{array}{l}\text { Moderate } \\
\text { Low Risk }\end{array}$ & $\begin{array}{l}\text { Low risk } \\
\text { Solutions appear } \\
\text { to work (for } \\
\text { now) }\end{array}$ \\
\hline & $\begin{array}{l}\text { Tineh } \\
\text { littoral }\end{array}$ & ++ & $\begin{array}{l}\text { Creating natural } \\
\text { infrastructure. }\end{array}$ & +++ & $\begin{array}{l}\text { Low } \\
\text { Risk }\end{array}$ & $\begin{array}{l}\text { Risk exists } \\
\text { Solutions appear }\end{array}$ \\
\hline & plain & & $\begin{array}{l}\text { Using beaches } \\
\text { as barriers. }\end{array}$ & ++ & & $\begin{array}{l}\text { to work, but are } \\
\text { short term }\end{array}$ \\
\hline
\end{tabular}

40 Table 6.7: Evaluation of vulnerable areas and adaptation solutions practiced. ${ }^{6}$

${ }_{6}^{6}$ Very High (+++++) High (++++) Moderate (+++) Low (++) Very low (+).

Method adopted from: IDSC (2011) and Frihy \& El-Sayed (2013). 


\begin{tabular}{|c|c|c|c|c|c|}
\hline \multicolumn{2}{|c|}{ 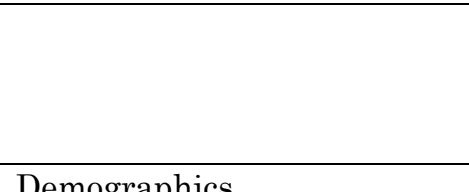 } & \multirow{3}{*}{ Population } & & \multirow{2}{*}{$\begin{array}{ll}\begin{array}{l}\text { Abu-Qir } \\
\text { Eastern }\end{array} & \text { Bay: } \\
\text { (EP) } & \\
\text { Beheira: } & \\
6,337,373 & \end{array}$} & \multirow{2}{*}{$\begin{array}{l}\text { Damietta } \\
\text { Harbor: } \\
\text { Western Plain } \\
\text { (WP) } \\
\text { Damietta: } \\
1,527,189 \\
\end{array}$} \\
\hline \multirow{7}{*}{\multicolumn{2}{|c|}{ Demographics }} & & $\begin{array}{l}\text { Main } \\
\text { governorate }\end{array}$ & & \\
\hline & & & $\begin{array}{l}\text { Bordering } \\
\text { governorate }\end{array}$ & $\begin{array}{l}\text { Alexandria: } \\
5,259,818\end{array}$ & $\begin{array}{l}\text { Port-Said: } \\
760,152\end{array}$ \\
\hline & & \multicolumn{2}{|l|}{ Total } & $11,597,109$ & $2,287,341$ \\
\hline & & \multirow[t]{2}{*}{ Area } & \multirow[t]{2}{*}{$\begin{array}{l}\text { Per Square } \\
\text { kilometre }\end{array}$} & $\begin{array}{l}\text { Beheira: } 9,826 \\
\mathrm{~km}^{2}\end{array}$ & $\begin{array}{l}\text { Damietta: } 910 \\
\mathrm{~km}^{2}\end{array}$ \\
\hline & & & & $\begin{array}{l}\text { Alexandria: } \\
2,300 \mathrm{~km}^{2} \\
\end{array}$ & $\begin{array}{l}\text { Port-Said: } \\
1,345 \mathrm{~km}^{2} \\
\end{array}$ \\
\hline & & \multirow[t]{2}{*}{ Density } & \multirow[t]{2}{*}{$\begin{array}{l}\text { Per Square } \\
\text { kilometre }\end{array}$} & $\begin{array}{l}\text { Beheira: } \\
645.0 / \mathrm{km}^{2}\end{array}$ & $\begin{array}{l}\text { Damietta: } \\
1,678 / \mathrm{km}^{2}\end{array}$ \\
\hline & & & & $\begin{array}{l}\text { Alexandria: } \\
2,287 / \mathrm{km}^{2}\end{array}$ & $\begin{array}{l}\text { Port-Said: } \\
565.2 / \mathrm{km}^{2}\end{array}$ \\
\hline \multirow[t]{19}{*}{$\begin{array}{l}\text { Local } \\
\text { conditions }\end{array}$} & \multirow[t]{9}{*}{ Climate } & \multirow[t]{3}{*}{ Weather } & $\begin{array}{l}\text { Average annual } \\
\text { temperature }\end{array}$ & $20.5^{\circ} \mathrm{C}$. & $20.2^{\circ} \mathrm{C}$ \\
\hline & & & Highest & $30.6^{\circ} \mathrm{C}$. & $30.4^{\circ} \mathrm{C}$. \\
\hline & & & Lowest & $9.7^{\circ} \mathrm{C}$. & $9^{\circ} \mathrm{C}$. \\
\hline & & \multirow[t]{3}{*}{ Precipitation } & $\begin{array}{l}\text { Average annual } \\
\text { rainfall }\end{array}$ & $260 \mathrm{~mm}$. & $117.6 \mathrm{~mm}$. \\
\hline & & & Highest & $52 \mathrm{~mm}$. & $28.6 \mathrm{~mm}$. \\
\hline & & & Lowest & $0 \mathrm{~mm}$. & $0 \mathrm{~mm}$. \\
\hline & & \multirow[t]{3}{*}{ Humidity } & $\begin{array}{l}\text { Average annual } \\
\text { humidity }\end{array}$ & $71.3 \%$. & $71.2 \%$ \\
\hline & & & Highest & $75 \%$. & $73.4 \%$. \\
\hline & & & Lowest & $65 \%$. & $67.5 \%$. \\
\hline & \multirow{10}{*}{$\begin{array}{l}\text { Local } \\
\text { bathymetry } \\
\text { and wave } \\
\text { properties }\end{array}$} & \multirow[t]{6}{*}{ Total period } & Measured Depth & $18.5 \mathrm{~m}$. & $12.0 \mathrm{~m}$. \\
\hline & & & $\begin{array}{l}\text { Significant Wave } \\
\text { Height }(\mathrm{Hs})\end{array}$ & $1.91 \mathrm{~m}$ & $1.02 \mathrm{~m}$. \\
\hline & & & $\begin{array}{l}\text { Average Wave } \\
\text { Height (Hav) }\end{array}$ & $1.12 \mathrm{~m}$. & $0.56 \mathrm{~m}$. \\
\hline & & & $\begin{array}{l}\text { Average peak } \\
\text { wave period (Tp } \\
\text { av.) }\end{array}$ & 6.0 seconds. & 6.3 seconds. \\
\hline & & & Direction & North West. & North West. \\
\hline & & & $\begin{array}{l}\text { Maximum wave } \\
\text { condition }\end{array}$ & $\begin{array}{l}\mathrm{Hs}=5.44, \mathrm{Tpc}= \\
12.8 \text { sec., WNW. }\end{array}$ & $\begin{array}{l}\mathrm{Hs}=4.47, \mathrm{Tsc}= \\
5.6 \text { sec., NW. }\end{array}$ \\
\hline & & \multirow[t]{2}{*}{ Winter Period } & Monthly Hs & $1.24-3.18 \mathrm{~m}$ & $0.5-2.16 \mathrm{~m}$ \\
\hline & & & Monthly Tp av & $4.5-7.8$ sec. & $4.4-8.3 \mathrm{sec}$. \\
\hline & & \multirow{2}{*}{$\begin{array}{l}\text { Summer } \\
\text { Period }\end{array}$} & Monthly Hs & $1.15-2.12 \mathrm{~m}$. & $0.43-1.12 \mathrm{~m}$ \\
\hline & & & Monthly Tp av & $4.9-6.8 \mathrm{sec}$. & $4.5-7.3 \mathrm{sec}$. \\
\hline
\end{tabular}

41 Table 6.8: Data gathered on demographics, climate, and wave properties of Abu-Qir Bay and Damietta Harbor for selecting the most vulnerable site for its properties. ${ }^{7}$

${ }^{7}$ Data gathered on demographics, climate, and wave properties of Abu-Qir Bay and Damietta Harbor are created from data from (CAPMAS), ("Climate-Data," n.d.), and (Iskander, 2013). respectively. 
Findings from site analysis shows that the best location for the floating community is Abu-Qir Bay (Table 6.7 \& Figure 6.7) preferring it to Damietta harbor for its protected water, population, water depth (as seen in Figure 6.8), and wave properties (as seen in Table 6.8). Abu-Qir Bay didn't only seem as the most vulnerable areas when addressing SLR, but also the ideal location for floating structures regarding its depth (18.5-22) and being in protected waters (however, as sea levels rise, such depth numbers will change).

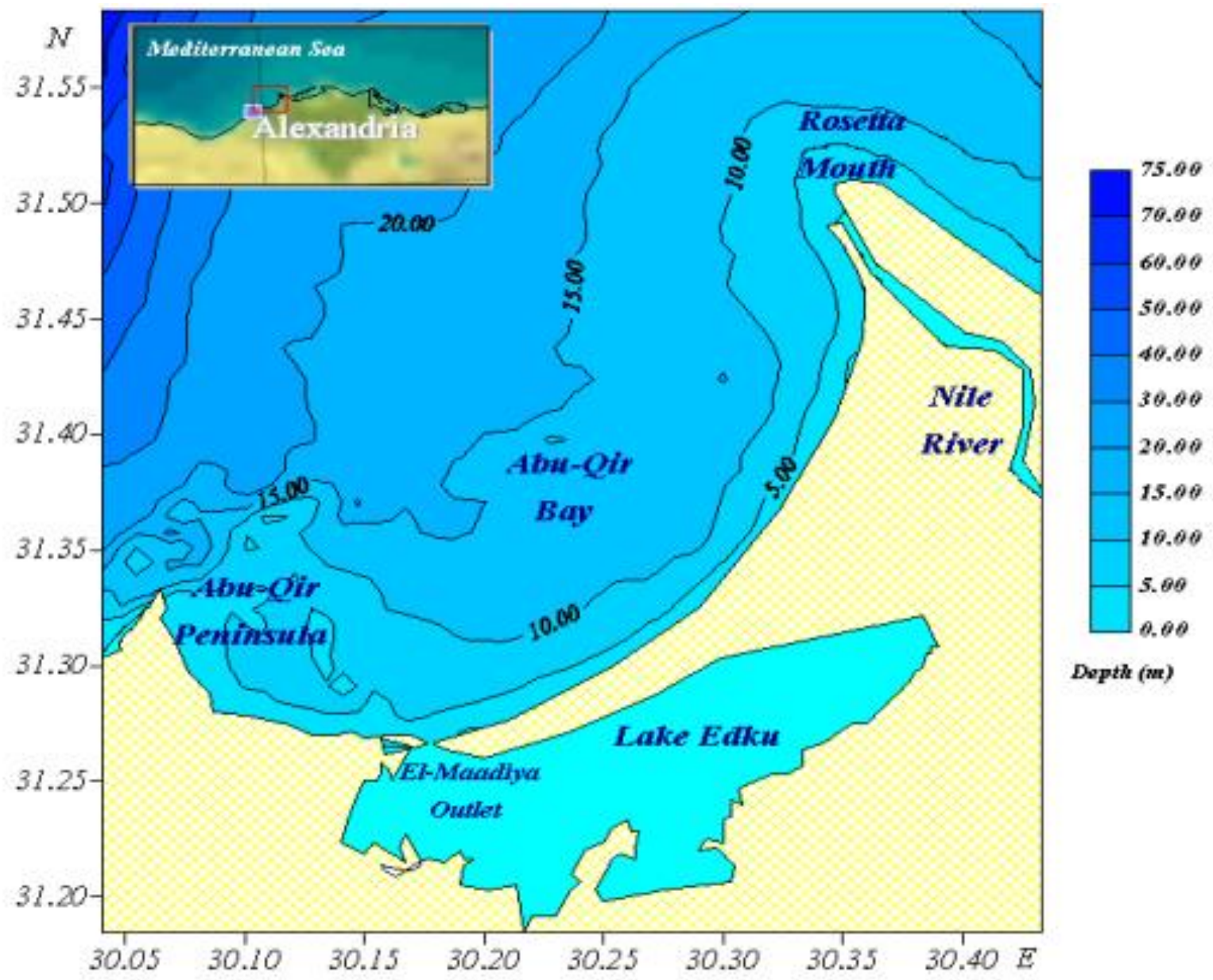

37 Figure 6.8: Bathymetric map of Abu-Qir Bay (Khedr, Abdelrahman, \& Alam ElDin, 2018). 
Being in protected waters means shielding from high waves as well as being able to expand. Therefore, modular platforms would be the way to expand and being nearby the coasts helps in emergency cases and transporting goods and people in and out. Although the Manzala Lake which lies on the eastern side of Damietta's distributary is in high risk to SLR, however its situation is not as critical as the situation in Abu-Qir Bay as well as its shallow water makes floating structures appear not to be cost effective solution for such site.

\subsubsection{Settings the Timescale for a Floating Community Project in}

\section{Abu-Qir Bay}

The time-span has been set between 2030 to 2050 in order to envision a practical proposal to create a time-span for the project design as that 10 to 30 years to provide time for new and more advances to develop while not being very far from the present situation (Sääskilahti et al., 2005). Another influential issue was the study of future renewable materials as stated by McDonough \& Braungart (2010) and United Nations Sustainable Development Knowledge Platform (2017). It had useful and practicable approach regarding the goals for Egypt in 2030 and further.

\subsubsection{The Probable Client}

The probable client for the floating community proposal is opened in this feature. The purpose herein is to generate a design with open options in order to consider all kinds of real users, services and operators. The unquestionable feature in the design that it has been planned for a town sized environment as well as small business activities. However, the classification whether if it will be either owned, rental or housing resort is still not clear yet. 
The most important issue is to offer an innovative and an opened platform of data of floating community well-defined for the future environment of Abu-Qir Bay. Some comparisons for the apartment characteristics and selecting locations have been investigated. The freedom of choice of diverse unit sizes is a feature which could be implemented here to attract more classes, so the project may catch more attention (Wang et al., 2008).

\subsubsection{Environmental Aspects for Building on Water in Abu-Qir Bay}

Egypt has an active and busy coastline activities. Egypt's location on the map makes it one of the most important country ports in the world as that the sea trading routes makes it a very favoured port. This huge sea traffic as well as the huge amount of sea vessels anchored in the western part of the Nile Delta at Abu-Qir Bay as that the there is special demand for probable floating community in such area. Where the demand of international companies for setting there their quarter offices and docks to serve their trade is high. The potential occurrence of collisions with such possible floating community if nearby the anchoring areas and docks for the crossing vessels would be one feature to handle and to be considered as a design concern in such floating community project. As that such collisions by vessels might be present causing damaging accidents and spills.

Since it is planned to propose a design in a modular form, as well as being moored to the expandable seabed and linking aisles to the coast, therefore the concept proposal is suitable to fit in many locations. Each floating building also has its position set according to the wind as well as the sunrays direction. The sea depth level in an essential feature for locating the site which is a vital subject as that the project has been planned to be located either in deeper 
levels below the sea level across seashores in order not to affect the maritime ecology or where the land is predicted to disappear below sea level.

\subsubsection{Sustainability Approaches when planning a Floating Community in Abu-Qir Bay}

The ecological features on building on the shorelines of the Nile Delta cities require basic investigation to understand them more. The possible coastal locations for the floating community project can be situated in water body near the shoreline in an area which is called nearshore environment.

Coastlines is a vital zone of the water where it's situated between the land and the deep waters and it is referred as nearshore environment (Meehl et al., 2012). The nearshore environment hosts some special types of floras, algae and fish which the basis of the aquatic life is. Sadly, such sensitive zone is the one which nearly all human activities takes place (Meehl et al., 2012) and make land reclamation projects.

The enormous deviations to Abu-Qir Bay affects the seaside areas ecosystems by shattering the unique habitats. Therefore, the design for floating structures in such shoreline must respect the ecological features of the nearshore environment and the current aquatic habitat.

The suitable matters concerning the floating community project according to Lefebvre \& Collu (2012):

- Floating community projects should be built in deeper water as that they may obstruct the sunlight which outcomes in decreasing the shade on the aquatic vegetation need or having the suitable design characteristics which permit the suitable sunlight to 
pass through in order to permit the photosynthesis process to take its natural cycle in underwater vegetation.

- The system of sanitation should prevent the human waste from being discharged into water.

- Preventing the floating structures and underwater elements from either destroying or dragging the seabed.

- The location and design form of the floating structure should be in such way in which the water could flow freely and therefore, preventing stagnation and the buildup waste and sediment.

- Placing floating structures into deeper water in distance from the important sea vegetation and vital nesting zones.

- The loud noise that will be caused by the floating community may disturb fish, birds and other creatures and as a result, pushing them to move and leave their nests.

- Limiting the vehicular or foot traffic in shallow water zones or using the areas that have less aquatic vegetation and environment to avoid harming their ecology.

(Lefebvre \& Collu, 2012).

C2C Building Charter stresses on the amount of variety in species like Flora and Fauna and in this situation, it cold be as well be the underwater vegetation and environment (McDonough \& Braungart, 2010).

VLFS are well-defined by their different sizes like if the floating structure is longer than 60meters in any dimension lengthways the waterline then they are called VLFS (Wang et al., 2008). VLFS has environmental friendly advantages over the old traditional land 
reclamation as stated by a research group which was led by Professor Wang about the advantages of VLFS over the old school traditional land reclamation longer than 60meters in any dimension lengthways the waterline then they are called VLFS (Wang et al., 2008). As stated in a report by a basic approximation that the land reclamation is not really any profitable where the water depth is anymore than 20meter in (Wang et al., 2008). The benefits of VLFS as explained by Watanabe and his research group:

- "They are cost effective when the water depth is large.

- Environmentally friendly as they do not damage the marine ecosystem, or silt-up deep harbors or disrupt the tidal/ocean currents.

- They are easy and fast to construct (components may be made at different shipyards and then brought to the site for assembling).

- They can be easily removed (if the sea space is needed in future) or expanded (since they are of a modular form).

- The facilities and structures on VLFSs are protected from seismic shocks since they are inherently base isolated.

- Their positions with respect to the water surface are constant and thus facilitate small boats and ship to come alongside when used as piers and berths.

- Their location in coastal waters provide scenic body of water all around, making them suitable for developments associated with leisure and water sport activities

- They are not affected by global warming.

(Wang et al., 2008). 
Such features might be all met if a floating community could have system to take a part in seawater cleansing as well as offering new prospects as for the subsurface habitat like for fishes.

\subsubsection{Rosetta's Distributary and Abu-Qir Bay Climate Conditions}

The usual northwestern wind comes from the Mediterranean Sea constantly. Consequently, blowing over the Egyptian northern coastline, also without the interposition of an subsequent mountain series and consequently, that significantly controls the temperatures during the year (United Nations Development Programme, 2014). As a result, the temperature in the Nile Delta is much better than the rest of the country as the dry sandy deserts dominates the rest of the country.

\begin{tabular}{|c|c|c|c|c|c|c|c|c|c|c|c|c|c|}
\hline Area & Unit & Jan & Feb & Mar & Apr & May & June & July & Aug & Sep & Oct & Nov & Dec \\
\hline \multirow[t]{4}{*}{ Rosetta } & $\begin{array}{l}\text { Avg. } \\
\text { Temperature } \\
\left({ }^{\circ} \mathrm{C}\right)\end{array}$ & 14.5 & 14.4 & 16 & 18.6 & 21.8 & 24.4 & 26.2 & 26.9 & 25.9 & 23.9 & 20.3 & 16.4 \\
\hline & $\begin{array}{l}\text { Min. } \\
\text { Temperature } \\
\left({ }^{\circ} \mathrm{C}\right)\end{array}$ & 10.2 & 10 & 11.2 & 13.2 & 16.4 & 19.5 & 21.7 & 22.4 & 21.3 & 19 & 15.7 & 12 \\
\hline & $\begin{array}{l}\text { Max. } \\
\text { Temperature } \\
\left({ }^{\circ} \mathrm{C}\right)\end{array}$ & 18.8 & 18.9 & 20.9 & 24 & 27.2 & 29.3 & 30.7 & 31.5 & 30.5 & 28.8 & 25 & 20.8 \\
\hline & $\begin{array}{l}\text { Precipitation / } \\
\text { Rainfall (mm) }\end{array}$ & 50 & 26 & 13 & 4 & 3 & 0 & 0 & 0 & 0 & 9 & 25 & 51 \\
\hline \multirow[t]{4}{*}{$\begin{array}{l}\text { Abu-Qir } \\
\text { Bay }\end{array}$} & $\begin{array}{l}\text { Avg. } \\
\text { Temperature } \\
\left({ }^{\circ} \mathrm{C}\right)\end{array}$ & 13.7 & 14.3 & 16 & 18.5 & 21.6 & 24.6 & 25.9 & 26.5 & 25.5 & 23.5 & 20 & 15.9 \\
\hline & $\begin{array}{l}\text { Min. } \\
\text { Temperature } \\
\left({ }^{\circ} \mathrm{C}\right)\end{array}$ & 9.7 & 10.2 & 11.4 & 13.6 & 16.7 & 20.3 & 22.1 & 22.5 & 21.4 & 18.9 & 15.6 & 11.7 \\
\hline & $\begin{array}{l}\text { Max. } \\
\text { Temperature } \\
\left({ }^{\circ} \mathrm{C}\right)\end{array}$ & 17.8 & 18.4 & 20.6 & 23.5 & 26.6 & 29 & 29.7 & 30.6 & 29.7 & 28.2 & 24.5 & 20.1 \\
\hline & $\begin{array}{l}\text { Precipitation / } \\
\text { Rainfall (mm) }\end{array}$ & 52 & 31 & 9 & 2 & 2 & 0 & 0 & 0 & 0 & 7 & 28 & 52 \\
\hline
\end{tabular}

42 Table 6.9: The Annual climate in Rosetta and Abu-Qir Bay, Egypt ("Climate-Data," n.d.). 
The climate in Abu-Qir Bay is like in the desert. There is almost no precipitation throughout the year in Abu-Qir Bay. The mean temperature in Abu-Qir Bay is about $20.5{ }^{\circ} \mathrm{C}$ yearly. This means that in Abu-Qir Bay, the use of natural ventilation is desirable and could be achieved by integrating natural ventilation in the building design. The mean rainfall is around $183 \mathrm{~mm}$ yearly. This means that a precipitation collection system could be implemented in the building design, however a floating community project in Abu-Qir Bay should not only rely on such solution for. The driest period is in June, with $0 \mathrm{~mm}$ of precipitation, while the precipitation is at its peak in January, with a mean of about $52 \mathrm{~mm}$. Furthermore, August is the hottest time where the temperature is about $26.5^{\circ} \mathrm{C}$. At $13.7^{\circ} \mathrm{C}$ on average, whereas January is the coolest (see Table 6.9). There is a variance of $52 \mathrm{~mm}$ of rainfall amid both the driest and wettest months, as such variation is about $12.8^{\circ} \mathrm{C}$ of the temperature annually ("Climate-Data," n.d.).

\subsection{Egypt's Energy Consumption and Production}

In 2015, the total electricity production of Egypt reached about 16,504 ktoe, where 90.7\% are generated from fossil fuels. The total consumption of electricity of the same year reached about 13,385 ktoe. Consumption by industry was about $2.4 \%$ (UNEP, 2017). Key consumption and production statistics are demonstrated in the Figure 6.9.

\subsubsection{Natural Gas}

Confirmed natural gas reserves by December 2011 reached about 2,186 bcm while the production was 61.3 bcm (The World Bank and International Energy Agency, 2017). 


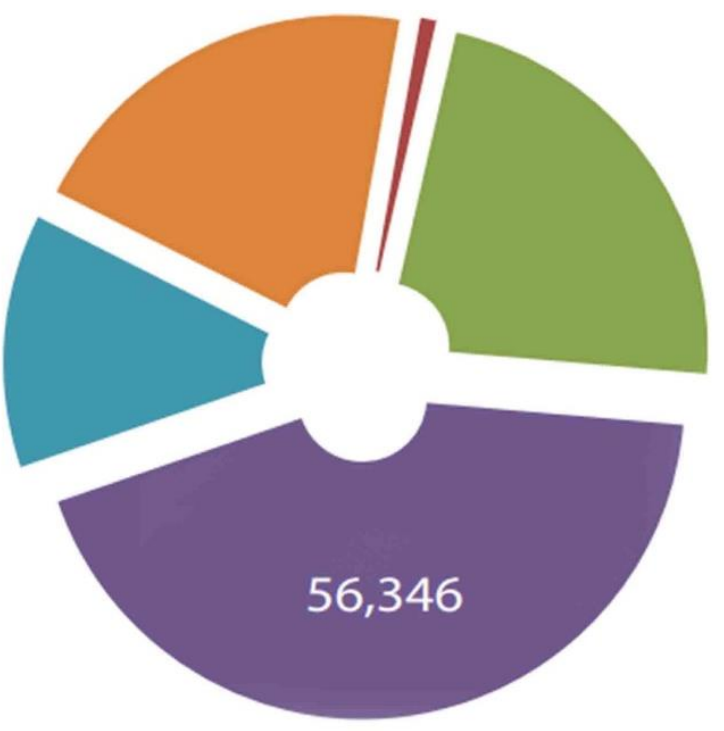

Production of coking coal

Production of charcoal

Production of crude oil, NLG and additives

- Production of natural gas

Total production of electricity

Refinery output of oil products

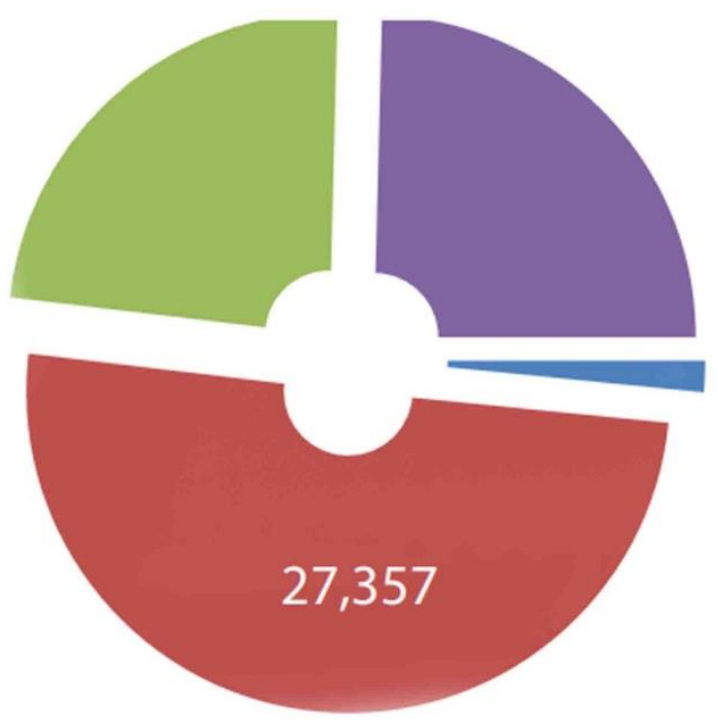

Consumption of coking coal

Consumption of oil

Consumption of natural gas

Consumption of electricity

38 Figure 6.9: (Left) Total Energy Production in Egypt (ktoe), (Right) Total Energy Consumption in Egypt (ktoe) (UNEP, 2017).

\subsubsection{Coal}

By the end of 2011, Egypt had confirmed reserves that is up to 16 million tonnes of bituminous coal, together with anthracite (International Energy Agency, 2013).

\subsubsection{Wind}

The Eastern seaside part of Egypt, there is a high potential wind energy generation by the Red Sea, where the recording wind speeds are of $7-10 \mathrm{~m} / \mathrm{s}$ (The World Bank and International Energy Agency, 2017). As by the end of 2013, 550 MW of wind power was installed, where that was increased to $610 \mathrm{MW}$ in 2014. The objective is to reach 7,200 MW 
by 2020 (giving $12 \%$ of the national electric capacity installed as well as contributing to the country's $20 \%$ of the renewable electricity target by 2020) (World Energy Council, 2016).

\begin{tabular}{|l|l|l|l|l|l|l|l|l|}
\hline Region & End & End & End & End & End & End & End & End \\
& 2007 & 2008 & 2009 & 2010 & 2011 & 2012 & 2013 & 2014 \\
\hline Egypt & 365 & 430 & 550 & 550 & 550 & 550 & 610 & Egypt \\
\hline Africa & 539 & 635 & 866 & 1,065 & 1,033 & 1,165 & 1,602 & 2,535 \\
\hline
\end{tabular}

43 Table 6.10: Installed wind power capacity in Egypt, (MW) (International Energy Agency, 2013).

\subsubsection{Nuclear}

In 1976, Egypt has established a Nuclear Power Plants Authority (NPPA). El-Dabaa location which is on the Mediterranean coast was chosen to expand in nuclear power in Egypt in 1983. Nevertheless, such proposed plans were frozen after the Chernobyl incident in 1986. In 2006, some signs showed the restoration of the Egyptian civilian nuclear power programme, where a commitment was to build a 1,000 MW nuclear power station at ElDabaa site, where the assessed cost of US\$1.5 billion. In March 2008, Egypt has signed an agreement with Russia for developing a programme for peaceful practices of nuclear energy (UNEP, 2017).

\subsubsection{Solar}

Egypt has many solar energy opportunities, where there is already $140 \mathrm{MW}$ currently in operation (UNEP, 2017). Several of the already installed photovoltaic systems are being used and especially in inaccessible parts of the country for water pumping, desalination, rural clinics, and telecommunications, etc. (World Energy Council, 2016). 
The fact in the statistics is the total number of public waste and bio-mass energy manufacture which is rather low, nevertheless they demonstrate signs for a steady raising production. The usage of biomass for a probable energy source has been carefully taken into consideration from the early start as this encouraged by the C2C Principle for using possible waste for food and a maybe as an energy production source.

\subsubsection{The Use of Renewable Energy Sources in Egypt}

There is a pressure of finding sustainable energy production solutions in Egypt. Egypt is one of the top 10 nations globally that has achieved the highest development levels in providing electricity to its people. As stated by the World Bank and International Energy Agency (2017) around 1.3 million of the Egyptians have acquired access to electricity in the last two decades (1990-2010). In 2010, 100\% of the Egyptian population (both urban and rural citizens) had access to electricity, while 99.99\% of them had access to non-solid fuels (The World Bank and International Energy Agency, 2017). Egypt's energy power ha improved at a multiple compound annual growth rate (CAGR) of $-0.41 \%$ throughout the 20 years from 1990 to 2010 and at $1.62 \%$ throughout the tracking period from 2010 to 2012 (World Bank, 2015a).

The Egyptian economy energy power (the proportion of the amount of energy consumption per unit of economic productivity) from 2010 to 2012 has enlarged from 3.7 to $3.8 \mathrm{MJ}$ per US dollar (2005 dollars at PPP (UNEP, 2017). A National Energy Conservation proposal is being executed; such activities consist of expanding the usage of compact fluorescent lamps, as well as improving the energy efficiency of street lighting and public buildings, also scaling up solar energy in water heating. The Credit Guarantee Company (CGC) is developing a programme for energy efficiency for small and medium initiatives. As for the supply side, the focal effort 
is to improve the practice of using fossil fuels by the improved practice of joint cycle gas turbine power plants and supercritical technology for the steam power plants. Egypt has adopted a National Energy Efficiency Action Plan (NEEAP) (2012-2015) with progressive energy efficiency which targets 5\% (UNEP, 2017). An Energy Efficiency (EE) unit exists at the Council of Ministers secretariat, where it is the authorized unit for developing and executing this strategy plan. Nevertheless, there is neither an elected energy efficiency organization nor an overall legal framework for EE actions. The percentage of the renewable energy in the overall energy consumption in Egypt has decreased from 8.5\% in 1990 to 5.5\% in 2012 (The World Bank and International Energy Agency, 2017). In 2008, the New National Renewable Energy Strategy was implemented where it aimed to reach a generation of $20 \%$ of the Egypt's electricity just from renewable resources by the year 2020 .

According to such results, then the usage of solar energy source as a based energy system as well as the possible biogas-based energy solutions are the furthermost required methods for the such concepts for energy production. Such idea helps improving the quantity of topsoil, biomass, resource recycle on the site location as stated by the $\mathrm{C} 2 \mathrm{C}$ Building Charter principles (McDonough \& Braungart, 2010). 


\subsubsection{Intended Nationally Determined Contributions (INDC) within}

\section{the Framework of the Paris Climate Agreement}

\begin{tabular}{|c|c|c|c|c|}
\hline Category & 2000 & 2005 & 2010 & $2015 \mathrm{P}$ \\
\hline Production of coking coal & 20 & 14 & 12 & 0 \\
\hline Production of charcoal & 0 & 0 & 1,000 & 1,030 \\
\hline $\begin{array}{l}\text { Production of crude oil, NLG and } \\
\text { additives }\end{array}$ & 35,293 & 29,226 & 26,410 & 29,608 \\
\hline Production of natural gas & 18,555 & 35,901 & 57,629 & 56,346 \\
\hline $\begin{array}{l}\text { Production of electricity from biofuels } \\
\text { and waste }\end{array}$ & 0 & 0 & 0 & 0 \\
\hline $\begin{array}{l}\text { Production of electricity from fossil } \\
\text { fuels }\end{array}$ & 5,302 & 8,211 & 11,354 & 14,970 \\
\hline Production of nuclear electricity & - & - & - & - \\
\hline Production of hydro electricity & 1,260 & 1,087 & 1,122 & 1,097 \\
\hline Production of geothermal electricity & - & - & - & - \\
\hline $\begin{array}{l}\text { Production of electricity from solar, } \\
\text { wind, Etc. }\end{array}$ & 12 & 47 & 147 & 438 \\
\hline Total production of electricity & 6,575 & 9,346 & 12,622 & 16,504 \\
\hline Refinery output of oil products & 26,105 & 34,318 & 28,082 & 26,404 \\
\hline Final Consumption of coking coal & 453 & 755 & 511 & 855 \\
\hline Final consumption of oil & 20,285 & 23,562 & 28,323 & 27,357 \\
\hline Final consumption of natural gas & 7,015 & 8,829 & 12,171 & 12,795 \\
\hline Final consumption of electricity & 5,627 & 7,801 & 11,215 & 13,385 \\
\hline Consumption of oil in industry & 5,461 & 5,548 & 5,231 & 3,697 \\
\hline $\begin{array}{l}\text { Consumption of natural gas in } \\
\text { industry }\end{array}$ & 2,072 & 5,567 & 5,970 & 6,958 \\
\hline Consumption of electricity in industry & 2,111 & 2,812 & 3,500 & 3,314 \\
\hline $\begin{array}{l}\text { Consumption of coking coal in } \\
\text { industry }\end{array}$ & 453 & 203 & 203 & 189 \\
\hline Consumption of oil in transport & 9,060 & 9,374 & 13,758 & 15,060 \\
\hline Consumption of electricity in transport & 0 & 0 & 0 & 29 \\
\hline Net imports of coking coal & 720 & 945 & 504 & 496 \\
\hline Net imports of crude oil, NGL, Etc. & $-7,379$ & 2,892 & $-3,969$ & $-6,110$ \\
\hline Net imports of oil product & -692 & $-6,737$ & 4,567 & 7,546 \\
\hline Net imports of natural gas & 0 & $-14,049$ & $-11,776$ & $-5,874$ \\
\hline Net imports of electricity & 14 & -67 & -137 & -34 \\
\hline
\end{tabular}

44 Table 6.11: Total energy statistics (ktoe). Reproduced from (UNEP, 2017). 
Egypt is determined to contribute with the international efforts in addressing the climate change problem, and as increasing temperatures are probably will affect the energy and other productive divisions in a negative way like on agriculture and tourism. The energy related Intended Nationally Determined Contributions (INDC) are shown in the Table 6.11.

\subsubsection{Institutional and Legal Framework}

The national owned Egyptian Electricity Holding Company (EEHC) leads the electricity sector in Egypt, as it has 16 joined corporations (six productions, nine suppliers, and the Egyptian Electricity Transmission Company). As for the regional level, Egypt has been member of the East African Power Pool, before pulling out in 2016. The legal agenda has been provided by the new Egyptian Electricity Law, which was issued by law no. 87 in 2015 (UNEP, 2017). The primary objectives of the Energy Policy Strategy embrace energy security, as well as meeting the national demand as well as developing the country's existing energy resources (The World Bank and International Energy Agency, 2017)

\subsubsection{Ocean Energy Production}

Local settings define the renewable energy sources. At present, numerous small-sized floating wind farms are executed. Generally, such projects apply offshore platform technologies, for instance the Hywind system which presents a turbine on a floating pole with a draft such as spars with 100 meters of depth (Union of Concerned Scientists, 2015). Costs of offshore wind facilities are noticeably more than the land-based ones as well as relying on both water depth and wave conditions. Nevertheless, wind turbines could be joint with breakwaters. Such joint could reduce the prices to match of those of land-based wind energy which may possibly be one of the most economical and sustainable energy sources. Ocean 
Thermal Energy Conversion (OTEC) is the change of temperature of the cold deep waters and hot shallow waters to harvest electricity. Temperature difference is the issue in thermal energy, where high temperature regions such as Egypt or tropical regions could be a valuable source. Some other possible renewable energy resources are solar cells, algae biofuel and osmotic power (World Energy Council, 2016).

The Authorities in Egypt are backing up and raising the amount of green areas which is linked to the built environment. The $\mathrm{C} 2 \mathrm{C}$ building Charter points two strategies and motives that identify the route for progressing to more renewable energy and the smart usage of native resources that could be used for energy production. The $\mathrm{C} 2 \mathrm{C}$ states that the renewable energy ought to be implemented into buildings as well as area plans and consequently the buildings would make more energy than they consume. $\mathrm{C} 2 \mathrm{C}$ also tend to think about different material opportunities rather than energy resources problems (McDonough \& Braungart, 2010).

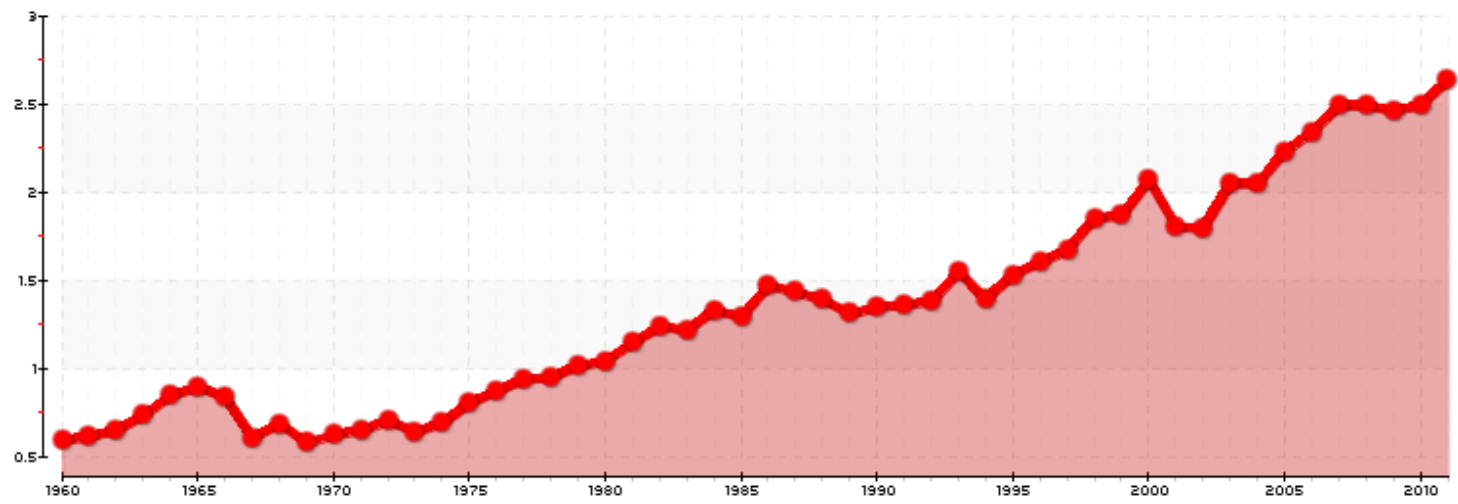

39 Figure 6.10: Egypt's CO2 Emissions (metric tons per capita) (World Energy Council, 2016). 
The implementation a large amount of green areas that made biomass originated from some blend design motivations. An eco-friendly method that used the locally made bio waste for a sustainable energy making is the anaerobic digestion (AD). Such the anaerobic digestion procedure as plants and animals' wastes are transformed to beneficial energy resource by micro-organisms. Such biomass could be undesirable form of waste, like slurry and food leftovers (World Energy Council, 2016).

The practicality and advantages of the anaerobic co-digestion of the sewer sludge and other solid organic wastes should decrease the possible toxic compounds, better nutrients balance, synergetic impacts on micro-organisms, more load of the biodegradable organic substances and an enhanced biogas yield (Van Timmeren \& Tawil, 2006). Keeping it simple, the making biogas rely on several parameters that influences the yields of gas from several substrates. The vital features are the $\mathrm{pH}$, temperature and essentially, the Carbon to Nitrogen $(\mathrm{C} / \mathrm{N})$ ratio as that the lesser values are generally preferred for a faster composting rates and biogas making (Van Timmeren \& Tawil, 2006).

An example of implementing the $\mathrm{AD}$ digester with the Living Machine in the EVA Centre Lanxmeer in Culemborg (Van Timmeren \& Tawil, 2006). Such case has alike purposes when it is linked to the floating building and the important was the actual procedure which is defined below from their case.

The founded method which was used to define the proses in the design is as follows:

- "Gathering blackwater on the one hand and green waste on the other and leading them into the system.

- The fermentation process, with biogas, effluent and sludge as its output.

- Purifying and improving the gas into natural fossil gas equivalent. 
- Purifying the effluent until it has surface water quality.

- Composting sludge into usable garden compost.

(Van Timmeren \& Tawil, 2006).”

\subsubsection{Multi-fuel Cell Technology}

The gathered information shows that the most advanced fuel cell systems have the property to use multiple fuel sources for instance like the case of "Bloom Energy Servers" that transforms natural gas or renewable biogas into energy through an electrochemical reaction process without any combustion processes. Such very effective procedure isn't limited by any similar thermodynamic limitations to generate power which allows very high conversion effectiveness (Bloomenergy, 2017). The Bloom energy presents higher efficiency, as well as multi-fuel potentials and constancy to energy making and can be implemented in the design.

The data demonstrates that about 30\% lower CO2 emission when linked to even average natural gas power plants could achieve with the Bloom Energy solution. The matter is the obtainability of this Bloombox Energy server where being made currently only in the USA, nevertheless they plan to go and reach all around the world which could occur until 2030. Natural gas that is generally being used in Egypt could come as a backup system and such idea of such sort of a flexible power source is the probability for using the rising quantity of biogas that is being produced on location when the biodegradable waste quantity starts to increase on location. Such usage of the increased biogas would lead to achieving Zero $\mathrm{CO} 2$ emission, nonetheless the additional fuel for the Bloom Box is possibly required. This is a theoretical report for a very probable solution. As the situation in the EVA Centre Lanxmeer 
in Culemborg had addressed such matter (Van Timmeren \& Tawil, 2006). Still, it is worth the effort to try to all the available biowaste on location. This biogas system aims to transform the waste to fuel which is a C2C Building Charter approach (McDonough \& Braungart, 2010).

Another fuel option for the fuel cell technology is using hydrogen as that several new advancements in such field of solar hydrogen have been achieved. The practice of using hydrogen in energy making also as an additional fuel source could happen.

\subsection{Floating Building System Design Background}

The general strategy of the floating building concept proposal has been split into separate parts (systems) due to that more comprehensive design forces, research and findings effect the focal features of any floating community project. Such strategy has been a basic systemic method to the project as well. It was extremely important that the floating community proposal is planned that the sub-systems would be designed in relation with the $\mathrm{C} 2 \mathrm{C}$ Building Charter goals and principles.

\subsubsection{Floating Building Design, Layout, Superstructure and}

\section{Orientation}

There is no guideline developed for floating structures in Egypt, nonetheless, it's not recommended to build high buildings in floating structures as the foundations and the structure can become very complicated. Singapore is a country of small area and have been developing floating structures for quite some time, so taking it a reference as their local authorities have already outlined the limitations for the floating building heights there where that helped to define the floating community proposal. The outline had set the height limitations to six floors above water based on the stability and safety causes. (Yiting, 2012, 
p. 3). Such limitation has affected the volumes, layout and structure of the floating community project.

The adaptation sustainability variation of different uses throughout time has been taken into consideration in the outline design of the building as well as the modularity. Such idea is highly stressed out by the C2C Building Charter by McDonough \& Braungart (2010).

In the case of the residential area, the plan aims to place elderly people into near areas to connect to access points and to lower levels of the building. The access to the floating building must be easy as well as the pedestrian paths, stairways, and elevators. Such feature must demonstrate in the basic level in the plan of the building.

To maximize the daylight potentials, the usage of small floor level depth is to be implemented all over the building like in the Ijburg Floating Community which was designed by Marlies Rohmer in way to find a flexible modular form for apartment units for the project which permits the creation of different variations in the design (Witsen, 2012).

\subsubsection{The Structure Envelope}

The structure envelope is the layer that separates the interior and the exterior of the structure. It functions as a shield which guards the interior area and regulates the climate. The structure envelope design is a specific field of architectural and engineering which draws all fields of building construction and internal climate regulator. Assad, Hosny, Elhakeem, \& El Haggar (2015) state that there are five performance issues that impact that forms the objectives of the envelope in the floating community project. Such characteristics are the structural ethics, the moisture control, the temperature regulator, air pressure control restrictions and the solar control radiation which as well embraces daylight. Such issues have 
been taken into consideration when designing the floating building and are demonstrated in the project design proposal in chapter 7 .

\subsubsection{The Flotation System}

The situation in Abu-Qir Bay for implementing a floating community project may have some issues like a potential collision of vessels to occur due to the high ship traffic (like if the floating platforms are to be repositioned near important ports in Alexandria or the entrances of the Suez Canal). Therefore, it is essential to put some further measures to improve the occurrence of a collision and add more safety measures around the floating building.

The C2C Building Charter points out to predict the evolution and any future alterations by improving the floating buildings capability to adapt into the diversity of usages that may occur through time (McDonough \& Braungart, 2010). Correspondingly, when designing the floatation components, they should adapt to the surrounding environment variations in the future. For instance, probable accidents or breaching in the floatation components could cause some circumstances that in return may make an unavoidable change.

A couple of the design criterions of the floating building since the floatation devices as well as the floating structure were adopted from the British Columbia Float Home Standard. It provided the desirable straightforward vision for the concept design for the floating device (British Columbia Building Code Interpretation Committee, 2015).

Due to the busy marine traffic which is close by the probable sites for the floating community building. Therefore, the flotation system is preferable to have a modular structure in order to facilitate the on-site assembly, as well as for maintenance and dismantling throughout it's floating building's lifespan. 


\subsubsection{Natural Ventilation and Controlling Air Quality Internally}

C2C Building Charter mentions that implementing healthy air production in the floating buildings and area plans and as a result of that, they recreate healthier air than the air being used (McDonough \& Braungart, 2010).

The habit of relying on natural ventilation in the floating building is indispensable for decreasing the required energy for conserving the equipment, as well as enhancing the human relief throughout the building, also refining the air quality and self-regulate the thermal comfort (Assad et al., 2015).

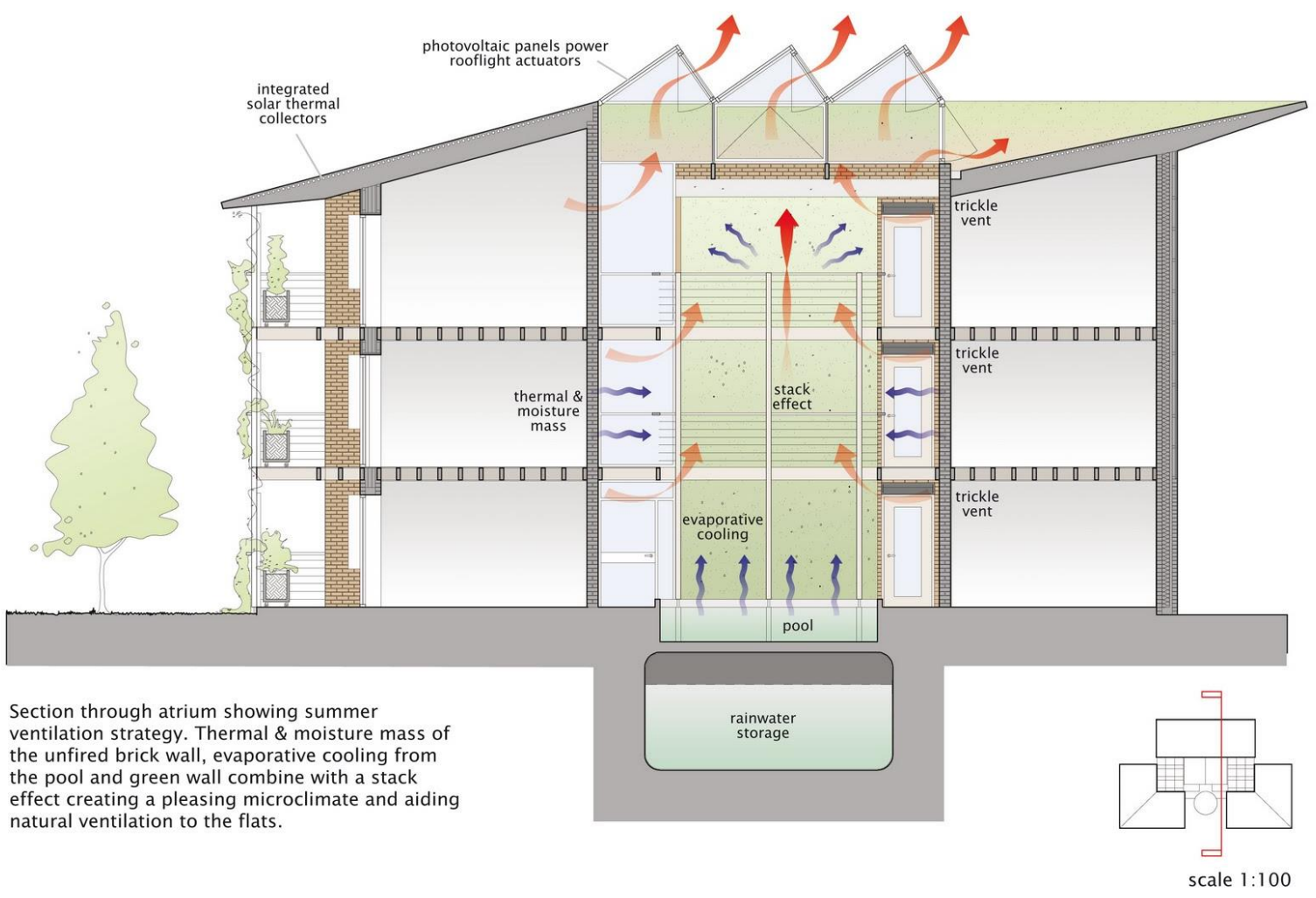

40 Figure 6.11: Stack effect principle with an atrium design. (Sidell Gibson Architects, 2010). 
Natural ventilation is when air flows through the buildings without being driven by any mechanical movement like air conditioners or even fans (Assad et al., 2015). The habit of using the stack ventilation for the floating building has been achievable due to the nature of the building modular structure. Stack ventilation drives air via temperature variances. As hot air rises due to its low pressure; therefore, it's referred occasionally as buoyancy ventilation (Assad et al., 2015).

The implementation of natural ventilation in the floating building isn't easy especially in humid and high temperature areas. The outdoor air could transfer a great quantity of moisture into the building through the building's envelope by undesirable pressure in the building's interior and as a result causing unwanted mold problems to the building where that leads to damages in the structures and bad air (British Columbia Building Code Interpretation Committee, 2015). Such feature required a solution that could decrease this moisture coming from the sea from the exterior earlier before it could reach the interior of the building. For such matter, the fog harvesting solution was implemented.

Fog harvesting technology involves some sort of nets which traps the moisture found in humid climates and then guides the collected droplets into containers, so it could be used as an additional water supply (Klemm et al., 2012). "Such invention answers to the problems of the interior air quality as well as an additional water reserve simultaneously. It is stated that this fog layer solution more effective than any existing fog harvesting solution at least five times. There is a possibility to collect $10 \%$ of the air transitory moisture and create 1 liter of water each day from each square meter of the fog nest (Klemm et al., 2012). Such system may be sufficient to achieve some better moistness comfort levels in the interior of the building and simultaneously make filtered water into the building units. 
Relying on natural ventilation in the floating building has been crucial for decreasing the required energy for conserving the equipment, enhancing the human relief in the interior spaces provided, enhancing the air quality inside and to regulate of the thermal comfort for the maximum comfort of the inhabitants (Assad et al., 2015). Therefore, the practice of such a fog nest system is implemented in the building façade as characteristic.

\subsection{Air Purification System Based on Hydroponic Plants}

The hydroponic vegetations presents a natural method to preserve the air fresh, therefore such feature has been taken into consideration for the project. Active Modular Phytoremediation system's (AMP) focal point is to assist the microorganisms which exist on the vegetations' roots. Microorganism's take Volatile Organic Compounds (VOC)s and other toxins and breaks them down where that leads to achieving non-toxic material. Once the air is filtered, the air returns by the AMP system and circulates the rooms (Bittsánszky et al., 2016). Such a pioneering solution supports the idea of development the biological systems which are implemented into the building structure as well as to both the coals for a better air quality and a larger quantity of biomass in the project (McDonough \& Braungart, 2010).

\subsection{Natural Lighting}

In Egypt, the sun is nearly perpendicular throughout daytime since Egypt is situated $26^{\text {th }}$ North of the equator. The feature of achieving natural light in the floating building by natural sunlight has been measured, but not in the expenditure of gaining an additional heat. The hot sunlight and the climate of Egypt backs up ideas such as natural light and solar energy.

Decreasing the solar heat gains is vital, as well as benefiting from natural light and harnessing it to reach every apartment. Such approach decreases relying on artificial illumination that consume substantial amount of energy (Assad et al., 2015). 
In Egypt's situation, it is better to place the floating building so that the Western and the Eastern parts of the building would have less sun during daytime as that should heat less surfaces due to the strong sunlight. The areas in the building that are contain more windows ought to have an improved shading system for them. In the Harvest City, the windows integrate some smart reflecting abilities.

The natural lighting and shading elements in the floating building have highly influenced the form and massing of the structure. The Western or the Eastern parts of the floating building are exposed to a higher quantity of sunlight during daytime. On the other hand, the Northern and Southern parts would be more resilient to the sun where they have more shading competences during daytime.

A further matter regarding in the entire area of the floating building with the structures around is the accessibility of the natural light to the underwater environment. Such feature is vital in any similar project for the whole building area. When designing the floating building, the entire area should have access to the sunlight. The underwater structure should not prevent the sunlight from reaching the subsurface as much as possible. In general, floating structures tend to put less shade than needed on the aquatic vegetation and especially in deeper water. Allowing sunlight to reach the aquatic vegetation is a must to make photosynthesis happen.

The floating building lighting technology matters have not been integrated in the design proposal where it will require plenty of time and work project with such scale. Nevertheless, it is vital to mention that until 2030, the lighting technologies would most probably have some improved energy efficiency systems. A matter that is worth reviewing is the extensive usage of night lighting and the its impact on the subaquatic habitat and ecosystems. 


\subsection{Water Collection, Purification and Recycling}

Pure water is an essential element for mankind's existence and therefore it should be always accessible. Relying only on imports sources is risky. Dependency is inevitable when designing floating communities, where producing pure water when the floating community expands to a specific extent is important. The two possible solutions for purifying water are water desalination and harvesting rainwater, both solutions are possible for achieving adequate and enough water source. However, rainwater would probably be insufficient water resource in the case of Abu-Qir Bay and Nile Delta in general, where the raining season doesn't last too long.

Egypt's plans for 2025 has a determined plan that displays an additional supply node which is the desalination solution. Such plan for 2025 is expected to execute of some diverse other procedures to develop the water resources system performance and decrease the water necessities in all divisions. The verified measures in such scenario have been gathered from different plans, approaches and reports (Omar \& Moussa, 2016).

For a better self-sufficiency and efficiency, the C2C Building Charter stresses on recycling water in the floating building and using some biological nutrients in such floating developments (McDonough \& Braungart, 2010).

The usage of natural means for filtering the waste water in the floating building was measured as one of the most significant matters in the design. There is a high necessity for using recycled water for watering green areas. The aim is to work not only with an effective system, but also a low maintenance with a big scale natural water filtering system to be both used and maintained together by the inhabitants. Such idea is considered as one of the goals for achieving the required sustainable development. 


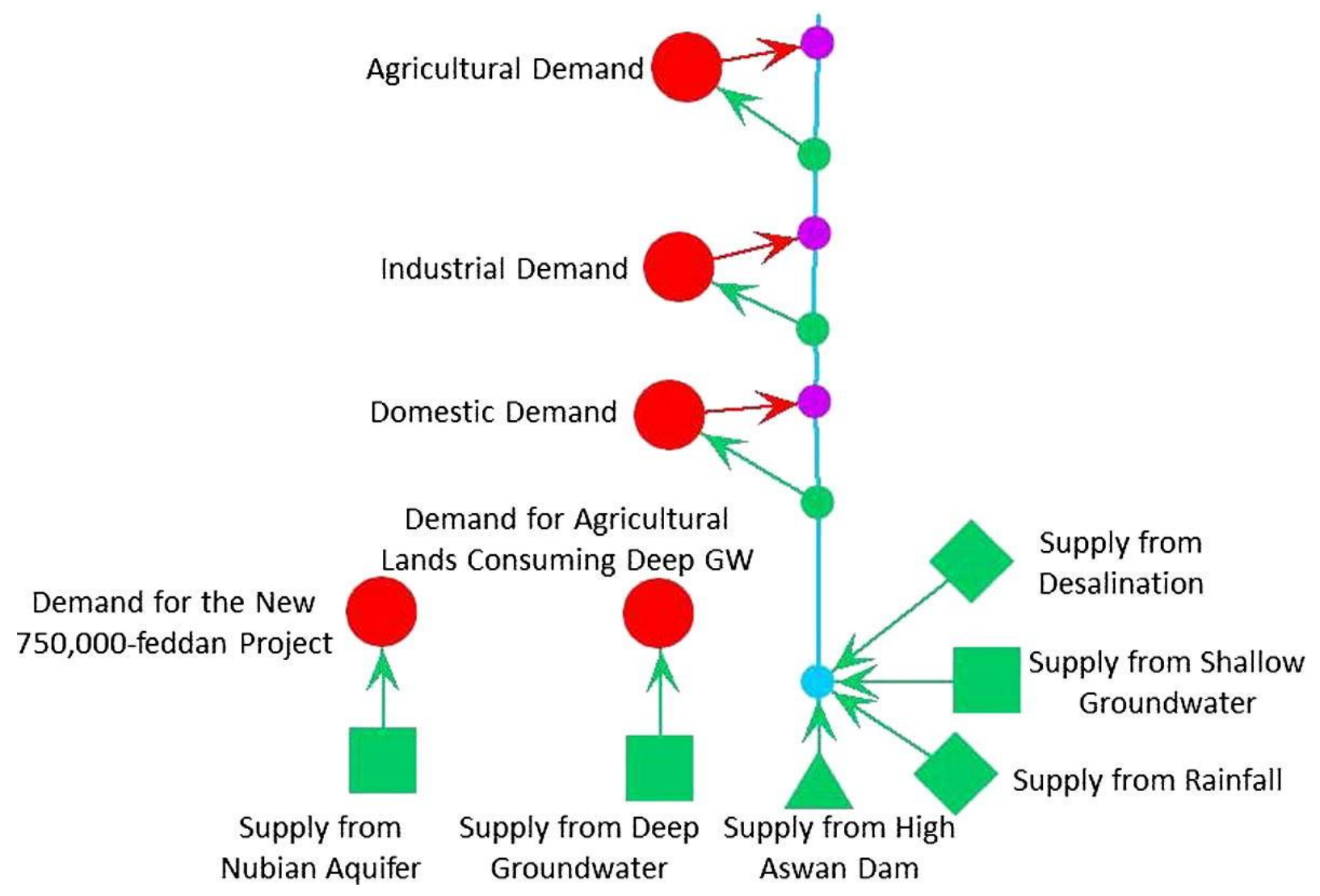

41 Figure 6.12: Egypt's water ambitious plan for 2025 (Omar \& Moussa, 2016).

An innovative system which is called the Living Machine might have the right biomimicry solution. Such system offers an encouraged biological natural seaside wetlands solution to the waste water recycling and filtration. As stated by the Living Machine Systems, the process mimics the methods of natural seaside wetlands with some defined biological units. (Van Timmeren \& Tawil, 2006). The motive in selecting such system was grounded on the remarkably small physical as well as the carbon footprint and its extreme effectiveness for filtering the local black and grey water, and most importantly that is very flexible in its scale abilities adaptability. Relatively, the Living Machine has very low maintenance and price which are important aspects when selecting such water cleaning system for floating community projects. 
Although, Living Machine has already demonstrated positive outcomes in a lot of projects and has never stopped upgrading. Such technology could stay enhancing until 2030. The system could simply expand in a city scale level as well as the ability to be integrated as a part of the radial wave attenuator as a joint element together with the AD system (Van Timmeren \& Tawil, 2006).

The core elements of the Living Machine System are:

I. "Primary Tank: here solids settle and begin to degrade

II. Equalization Tank: the tank buffers periods of high and low flow.

III. Phase 1 Tidal Flow Wetland Cells: these aggregate media-filled planters are alternately drained and filled up to 18 times per day.

IV. Phase 2 Tidal Flow Wetland Cells: a portion of water moves to Stage 2 and undergoes the same process, where smaller treatment media provides faster treatment.

V. Polishing System: water undergoes final polishing and treatment.

VI. Reuse Tank: treated water enters the reuse tank before moving on to different reuse applications."

(Van Timmeren \& Tawil, 2006).

The pioneering method to preserve the important tap water tank cleaner for the usage of the inhabitants of the floating platforms has been the PAX Water Mixer. Such mixer thrusts water at the bottommost to the uppermost part of the tank as well as mixing water in the whole tank to avoid any undesirable outcomes. An efficient mixing of great volumes is realized by a Lily impeller mixer, as it's capable to creating a strong flow in the tank size 
(PAX Water Technologies, 2011). Such detail has been significant for preserving the big water tank as clean as possible for the usage of the tap water source. Although, the real calculation for water usage in the building was not done, but the enhanced water collection zone for the floating building roofs was examined for its impotency.

\begin{tabular}{|l|l|l|}
\hline & Living Machine Systems & Conventional technology \\
\hline Size/Footprint & $14 \mathrm{~m}^{2}$ per $3,785 \mathrm{lt} / \mathrm{d}$ & $7 \mathrm{~m}^{2}$ per $3,785 \mathrm{lt} / \mathrm{d}$ \\
\hline Aesthetics/Land use & Pleasing / Dual use space. & $\begin{array}{l}\text { - Unpleasant \& dangerous. } \\
- \text { No other use. }\end{array}$ \\
\hline Energy use & Very little. & High. \\
\hline Effluent quality & Tertiary + & Tertiary + \\
\hline Installed cost & $\begin{array}{l}\text { Substantial probable } \\
\text { savings. }\end{array}$ & $\begin{array}{l}\text { - Expensive. } \\
\text { - Extensive piping systems. }\end{array}$ \\
\hline Operating cost & - Very low. & High. \\
\hline Scalability & Very easy. & Must be built all at once. \\
\hline GHG Emissions & Very low. & High. \\
\hline
\end{tabular}

45 Table 6.12: The living machine in comparison with the conventional technology. Reproduced from (Van Timmeren \& Tawil, 2006).

\subsection{Floating Building Vegetation and Marine Ecosystem}

Globally, numerous nutrients are released into open waters for food or algae production. Human waste may possibly be recycled, that would reduce pollution. High nutrient concentration levels happen at continental boundaries with the water where currents create upwelling.

The floating building vegetation as well as the aquatic ecosystem have the potentials to attain the regenerative aims and goals in floating communities. The selected approaches which are presented in this chapter have been selected due to their capability to offer some regenerative, social and environmental potentials required. 
The usage of vegetation and recreational areas in building requirements is a highly focused matter by the Egyptian officials for 2030 (United Nations Development Programme, 2014). The idea to increase vegetation that leads to the regenerative project goals in all the floating building green areas. Throughout the investigation, numerous potential pioneering solutions have been reviewed.

In the regenerative plan, the goal is to go beyond than just a sustainable and a strong floating structures proposal. The regenerative design tends to sustain the environment as well as creating new resources. The collaboration of both natural and human resources to enhance the ecological situations throughout time which improves the lifestyle of both. Closed loop processes are usually implemented to maintain and redevelop the resources and environments (Seto et al., 2005; Suzuki et al., 2009). For instance, the water harvest filtering treatments in wetlands which also helps life to take place, and then recycle the filtered water to houses or industry.

The C2C Building Charter leads to a similar path. The products are constantly recycled to create other new materials to be reused, also waste is measured as a valued material for reprocess (McDonough \& Braungart, 2010).

The Aquaponics Cycle grows fish and vegetables together. The simplest description is when combining aquaculture and hydroponics which raises fish and vegetations in one united process. Fish waste offers a food source for vegetations and deliver a natural water filter for the fish. The Also, the microorganisms and red worms which flourish in such environment could transform the ammonia produced in the waste of the fish to nitrites, then to nitrates and the solids into vermicomposting which could be consumed by vegetations as food (Lund \& Vollenweider, 2006). 
An additional pioneering solution for making such a floating vegetation by the water filtering quality to the floating building area, is the Bio-haven Floating Breakwaters system which is established by the Martins Ecosystem (Lund \& Vollenweider, 2006).

The Bio-haven Floating Breakwaters (BFB) system is essentially is an entirely recyclable flexible floating web meaning that the matt permitting several varieties of aquatic growing vegetation to grow in such netlike mesh. In the BFB the plants roots grow through such net beneath the water level where the roots grant shelter for fish and marine life whereas it also functions as a filter to filter the undesirable nutrients from water. Another effective aspect is the wave absorbing competence of the BFB system as well as that the system could be joint to the floating building structure. An additional encouraging feature of the BFB system is the greenery that could be implemented over the floating net, whereas it functions as a stage for the green vegetation which permits the nature to exist with such floating platforms for flora and greenery (Lund \& Vollenweider, 2006). The process is more described in the design. For instance, it is implemented in a project in Sengkang Floating Wetlands project in Singapore where they have implemented the same system type similar to the offered BFB system is demonstrated in the floating community proposal for Abu-Qir Bay.

The improved practice of both herbal and medicine flora is very important since there is an influence from the Uros people who rely on the Totora reed as herbal elements for the welfare resolutions. Such feature is demonstrated in agricultural zone in the project outline of the floating community project.

\subsection{Wave Attenuators and Walkways}

The research led to discover that the wave attenuators implemented to the pathway could be the initial shield versus the high and strong tides earlier before they could reach the 
floating building itself. Wave attenuators are intended to take in open sea wave motion and to prevent the floating building which it shields from any of the harmful and destructive or even any critical wave movements (Cox \& Czlapinski, 2016).

Such sort of projects with a radial wave attenuator plan was made in the Harvest City project for Haiti avoiding the probable damaging tide movements and undesirable wave interrupting motions which leads to the interior areas of the floating building. Such characteristic has functioned as an influence and motivation in the project. Herein the concept proposal, some detailed structural system design for such plans were involved to some level, as well as the architectural design outline and interpretations which demonstrates the scale of such constructions as well as their presence in the project.

\subsection{Conclusions}

Local conditions and their impacts on floating structures design are concluded in Table 6.13 and 6.14. It has been determined that bathymetry, waves, tides and winds are the essential features for critical issues in floating structures. Therefore, the floating platform and its mooring system are the main two components when designing floating structures.

Qualitative analysis executed on ten areas in the Nile Delta conclude that the Eastern coastal plain is more vulnerable to SLR impacts that the Western Coastal Plain, where the most vulnerable areas are Central Abu-Qir Bay and East Alexandria respectively. In order on vulnerability: Central Abu-Qir Bay, East Alexandria, El-Tarh, Abu-Qir Bay, Tineh littoral plain, Burullus Lake Barrier, Baltim area (Burullus), Gamasa Embayment, Manzala Lake barrier, Burullus Lake, Abu-Khashaba.

Adaptation approaches practiced analysed regarding their cost, durability, construction time, lifespan, and environmental impact, in order are: breakwaters, raising roads, creating 
natural infrastructure, sand dunes, and using beaches as barriers. Egypt still practice unsustainable land reclamation methods not only for the abundance and cost of sand in Egypt, but also for being rapid, easy, and doesn't requiring high technology.

SLR scenarios created for East Alexandria and central Abu-Qir area of .5m, 1m, 1.5m, and $2.0 \mathrm{~m}$ SLR, conclude that the most vulnerable sectors in order are: agriculture, people, land subsidence, industry, residential, archeological sites, commercial areas, community facilities. However, agricultural, industry, and residential areas could be recreated elsewhere, but world heritage properties and sites of Pharaonic, Greek, Roman, and Christian as listed by the UNESCO can not be replaced.

Every location has its own political condition, piracy issues, climate situations, protected waters conditions, and so on. Findings from site analysis show that the best location for the floating community is Abu-Qir Bay preferring it to Damietta harbor not only because of its vulnerability but also for its characteristics in terms of its protected water, population, water depth, and wave properties (see Table 6.8). Being in protected waters means shielding from high waves as well as being able to expand since such solution may not be bounded by a breakwater. Therefore, modular platforms would be the way to expand and being nearby coasts helps in emergency cases and transporting goods and people in and out. Although Lake Manzalah in Damietta is in protected water and have better wave properties in comparison to Abu-Qir Bay, however water depth is extremely shallow (1.2-1.5 meters) and its population makes floating structures solution appear not to be cost effective approach for such site. Nevertheless, dykes and land reclamation methods may appear as an attractive despite being short-term solution for Damietta despite being unsustainable. To sum up, Abu-Qir Bay didn’t only seem as the most vulnerable areas when addressing SLR, but also the ideal location for floating structures regarding its depth (18.5-22) and being in protected waters. 
To deliver a real genuine proposal, as location properties explained earlier, Abu-Qir Bay in Alexandria has been taken as a case study to focus on a precise location as several other seaside regions have swamplands and mangroves. In this thesis, proposing the Abu-Qir Bay coastal site has been an important decision due to the protected waters opportunities available in the bay's zone. The existence of fish farming projects may deliver nutrients for algae farming. Therefore, local conditions have been gathered and connected to the floating community proposal.

\begin{tabular}{|l|l|l|}
\hline Factors & Local conditions & Impact on floating structures design \\
\hline Structure & Local bathymetry & mooring system measurements \\
\cline { 2 - 3 } & Tides and currents & structure and mooring system measurements \\
\cline { 2 - 3 } & Waves & $\begin{array}{l}\text { platform measurements } \\
\text { breakwater measurements } \\
\text { mooring system measurements }\end{array}$ \\
\cline { 2 - 3 } & Wind and tropical & $\begin{array}{l}\text { structures and mooring system measurements } \\
\text { time needed to escape, 240 km max from } \\
\text { storms }\end{array}$ \\
& $\begin{array}{l}\text { destructive } \\
\text { hurricane force, 500 km maximum from tropical } \\
\text { storm force }\end{array}$ \\
\cline { 2 - 3 } & building design and construction (sun/rain control) \\
\cline { 2 - 3 } & Climate & and their effects on designing floating structures.
\end{tabular}

46 Table 6.13: Structural conditions and their effects on designing floating structures. Reproduced from Czapiewska et al. (2013).

\begin{tabular}{|l|l|l|}
\hline Factors & Local conditions & Impact on floating structures design \\
\hline Energy \& & Precipitation & water treatment \& storage facilities \\
\cline { 2 - 3 } Resources & Nutrient upwelling & food production possibilities \\
\cline { 2 - 3 } & Solar radiance & energy production possibilities \\
\cline { 2 - 3 } & Wave energy & energy production possibilities \\
\cline { 2 - 3 } & $\begin{array}{l}\text { Ocean thermal } \\
\text { energy }\end{array}$ & energy production possibilities \\
\cline { 2 - 3 } & Wind energy & energy production possibilities \\
\hline
\end{tabular}

47 Table 6.14: Energy and resources conditions and their effects on designing floating structures. Reproduced from Czapiewska et al. (2013). 
Upon analyzing Egypt's land submergence history, site analysis, and concluding Abu-Qir Bay as the most vulnerable site in the Nile Delta in this chapter as well as analyzing VLFS and their characteristics in respect to the Nile Delta's site and conditions of the Nile Delta in the previous chapter. Accordingly, the next chapter defines the floating community concept development, guidelines, and project characteristics on floating structures for Abu-Qir Bay. 


\section{Chapter 7}

\section{CASE STUDY DESIGN: FLOATING}

\section{COMMUNITY CONCEPT PROPOSAL}

\section{FOR THE NILE DELTA}

\subsection{Introduction}

This chapter applies the findings and conclusions of the previous three chapters of site analysis, adaptation approach, and mitigation solutions, and floating structures to define a floating community proposal and guidelines on floating structures for Abu-Qir Bay. This chapter sought to answer this research question: How to implement floating structures in the Nile Delta's most vulnerable coastline sites to SLR impacts?

Initially, this chapter addresses the approaches and methods followed when designing floating structures in respect to the criteria and characteristics of the Nile Delta to offer guidelines for building on water to cope with future situations. 


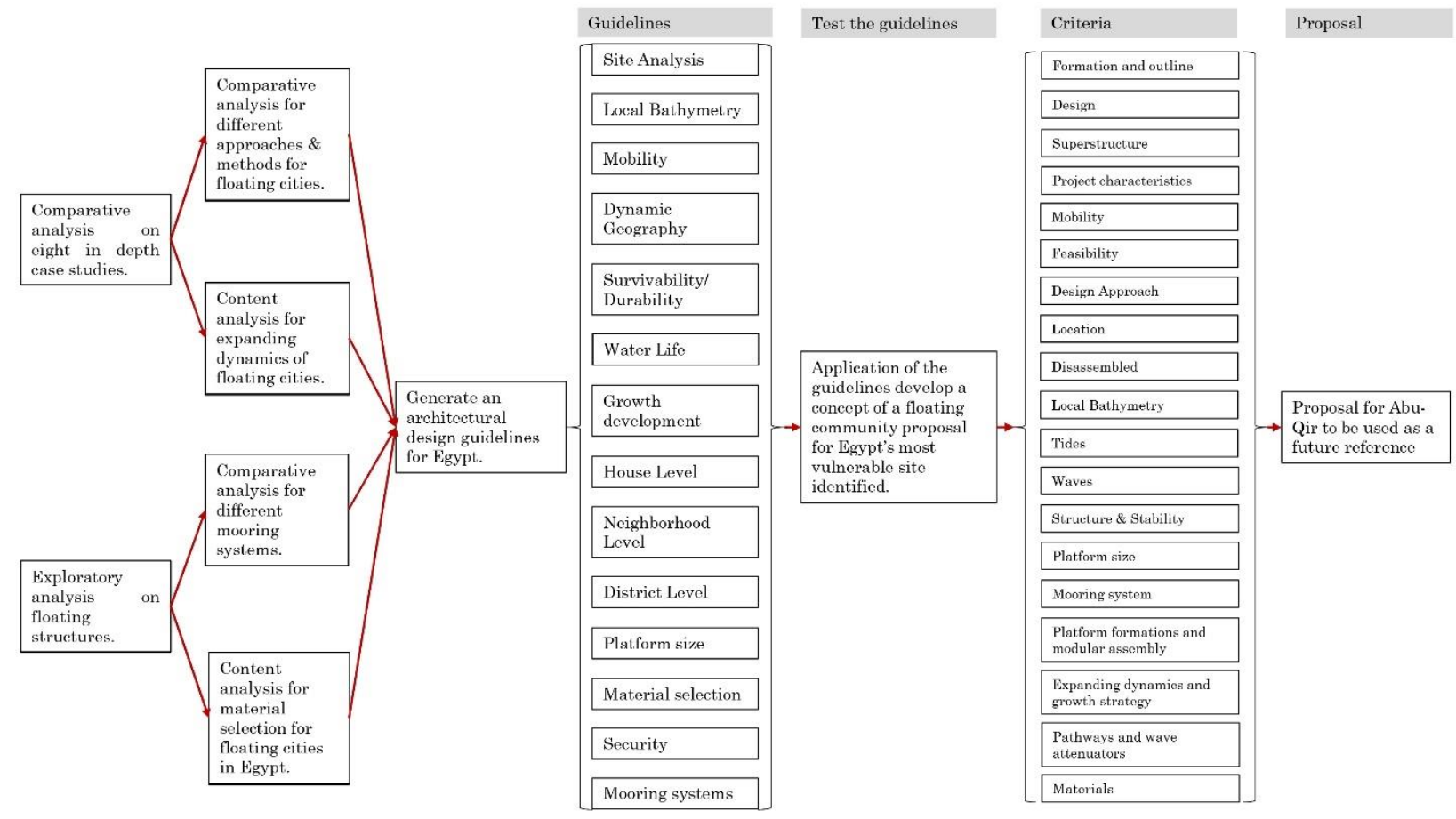

42 Figure 7.1: Analytical framework for concept proposal.

Secondly, this chapter conducts content analysis for expanding dynamics of floating cities: such analysis is concerned with the expanding dynamics on various stages when designing floating structures in respect to Egypt's criteria and characteristics to add to the guidelines for building on water to cope with future situations.

Upon analyzing adaptation approaches, mitigation solutions, and floating community cases in chapter 4; floating structures and setting design strategies and principles, and local conditions of the Nile Delta in chapter 5; and site characteristics and selecting Abu-Qir Bay as the most vulnerable site in the Nile Delta and Egypt in chapter 6; this chapter applies the conclusions of the previous three chapters to apply floating structures research and site analysis to define floating community proposal model for Abu-Qir Bay. This chapter generates the floating community project's outline, design, project characteristics, superstructure, mooring system, circulation, preliminary members formation, sustainability 
approach, reuse of nutrients, waste and recycling, water system, mobility, feasibility, growth strategy, and expanding dynamics.

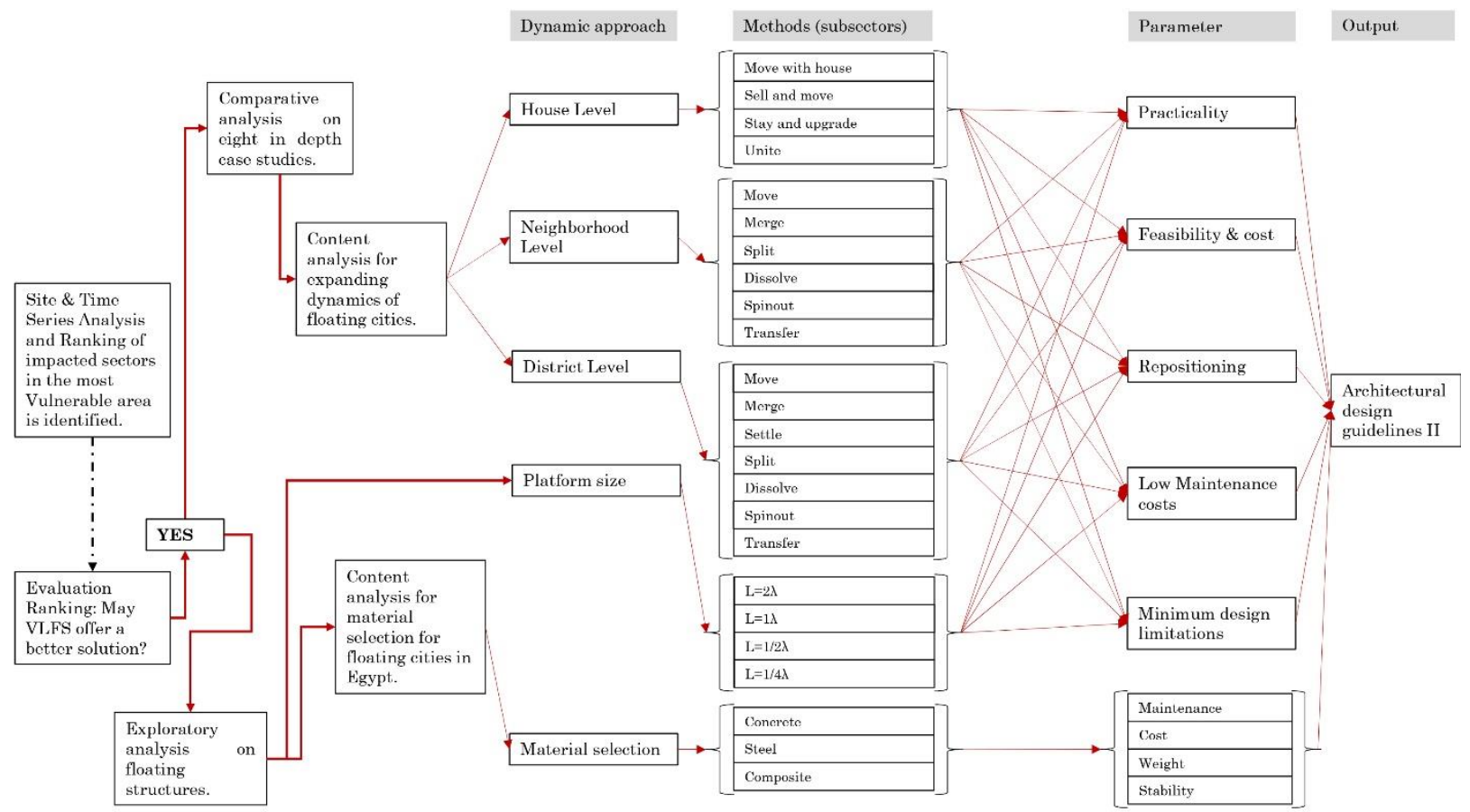

43 Figure 7.2: Analytical framework for expanding dynamics, platform size, and material selection.

The floating community proposal is proposed to be a flexible floating community at a small city-scale in Abu-Qir Bay and promoting for further advancements to be done to raise awareness from the local authorities and investors. Design philosophies and purposes for the floating community have been constructed throughout the investigation on floating structures and naval architecture. The ultimate general architectural form and extent of the entire floating building design have been a mixture of aesthetical, practical and sustainability driven forces blended together to shape and floating modules and units. The proposal for Abu-Qir Bay was aimed to collect the required components for the social welfare via the physical environment and to a better quality of life. 


\subsection{Project Outline}

It is vital to a provide a new approach on how to sustain the pressure of the rising seas on the coastal settlements. There are four main driving reasons in this thesis for protecting coastal cities against SLR. The first is historical where the city of Thonis-Heracleion as well as other unknown underwater areas hold more submerged world heritage historical monuments, properties and sites of Pharaonic, Greek, Roman, and Christian as listed by the UNESCO can not be replaced. The second is to safeguard Egypt's marine borderlines sovereignty. The third is ecological where it endangers the marine and coral life habitat. The fourth is people risking their own lives building in such sites risking the scenario of ThonisHeracleion to reoccur again.

The project form, outline, plan, and scale are formed upon wide variety of diverse modular outlines and forms of angular profiles to established modules that can interconnect to create bigger diverse group forms. At that moment, it was taken to consideration the result of the most used forms and the advantages of diverse geometrical forms for the sea environment. A research has been done to assess such modular forms which some possible forms might be leading into shaping the floatation components as well as the building superstructure.

According to the researches done, several floating structures technology requirements could be easily picked off the shelf. For instance, at present innovation in areas like water purification or sanitation facilities, whereas solutions have been already extensively executed in the shipping and cruise areas.

When designing floating structures, the main attention should be on the elementary structure plan. Floating buildings must be safe, economical, comfortable, and modular. Safe as being adaptable as well as being able to survive natural disasters or other problems 
regarding their loads, form or the life expectancy of the materials used. The herein proposal is planned to be affordable for various income classes in such a developing area in Egypt. The project is proposed to also to be comfortable and secure to attract and accommodate a middleclass family in the sea environments and under unsettling situations. Modular design approach is the strategy for flexibility and expandability objectives as the inhabitants' number starts increasing, permitting modular platforms to get attached and detached easily.

Subsequently, the building codes and height limitations with sizes and masses, the project started to appear to form some improved proportions giving a better image of the project. Then, researches on the modular design systems and superstructure that can be a unit by itself and to connect to other floating structures of the same platform and superstructure design to form even bigger floating superstructure that can be united with other modular modules if positioned in a circular form or parallel to the coastline. Such modular form offers a lot of advantages in terms of the sustainability, future developments and adaptation advancements where the design shape starts to make sense for the project design. The results on the earlier study cases such as the Lily-pad design has inspired the introduction of the inner courtyard-like green area and the spreading superstructure from two sides providing shade as well as natural light competences with a route in the ground floor. The design of the agricultural area in the centre and the top floors came where the idea was to provide a source for vegetations since the proposal is aimed to be self-sufficient as well as the SLR scenarios have shown the huge negative impact on agriculture areas. Such approach has provided a respected amount of recreational spaces and some farming activities.

Throughout such development, measurements are calculated such as the dimensions and masses suitable for the floating platforms. It is hard to create a rotating building, therefore in this case, it could turn around 360 degrees of its circular center axis of the floating building 
with a spinning center like the Harvest City. The Harvest City design inspired for both geometrical and radial form of the floating building that integrates openings as well as implementing greeneries and business places for such areas. At that moment, it was when the scale and form of the floating building is set, and the project begins to focus on the real layout and advanced details in the floating building as a module with all the technical and biological system conclusions.

The idea of the floating building area is the creation of movement system and adjust the circulation on the light water traffic around the floating building such as trade, recreational, and tourism. Since Egyptians would rather building on agricultural land or near water, therefore, the idea of lively floating building with a market as well as a transportation system lengthways the shorelines of Egypt might create a new sort of interest in Egypt.

\subsection{Initial Structural Design Proposal}

The initial design phase has been constructed upon the Suzuki et al. (2006) archetypal structural design outline proposed for Mega-floats structures. The principal properties in terms of units' dimensions were geometrical modular forms consisting limited numbers of basic components that create many variations which as a result creates high dimensional stability as well as using round variations in order to achieve the optimal circumference. Many variations have been considered concluding into the two best variations solutions for the project, either in squared and pentagonal forms or squared and hexagonal forms, where the latter was chosen for the following explanations. 


\subsubsection{Pentagonal and Squared Modules}

The pentagonal and squared platforms design offers some more organic freedom of design as well as being a reliable idea too. On the other hand, it only offered circular circulation paths where that would decrease its practicality and result in more power used to be consumed to go from one place to another. Also, creating a lot of unsolved bizarre shaped areas which would be unused spaces of water gaps.

\subsubsection{Hexagonal and Squared Modules}

The hexagonal and squared platforms design appears to be the overall perfect combination solution, where it offered a straight-roads achievement, a reliable and more durable solution, as well as being able to continue growing while only using the hexagonal modules, while the squared modules can only expand in linear way.

Since the most important idea is its flexibility and the ability to assemble to each other while it does not need to rely on the squared modules makes it more sustainable and more practical solution. Also, since the best module would be circular, therefore the hexagonal module offers the closest geometrical form to a circle while in the same time it could achieve a complete combination in terms of assembly with one another, providing both practicality as the project will not have any space gaps of water as well as a better centre of gravity distribution and value.

Many variations have been considered to conclude that only three, four, and six sided modules were the best where they could form perfectly without leaving any unused space gaps in between. While the hexagonal is more practical design it may not provide the same 
organic design that the pentagonal module offers. Finally, the honey comb has been chosen as it checks in all the criteria needed.

\subsection{Project Characteristics}

This chapter is where the objectives earlier explained (chapter 4 and 5) are set and the properties of a precise region (chapter 6) are integrated to build the floating community proposal for Abu-Qir Bay. Initially, an assessment of the ideal platform measurements is set. Afterwards, the most appropriate materials, then structural and building design will be shaped.

\subsubsection{Estimation of Platform Size}

The ideal platform measurements are a subject to on several aspects, some could be accurately defined whereas some could be just speculated. Related influences which have been involved are demonstrated in figure 7.3. 


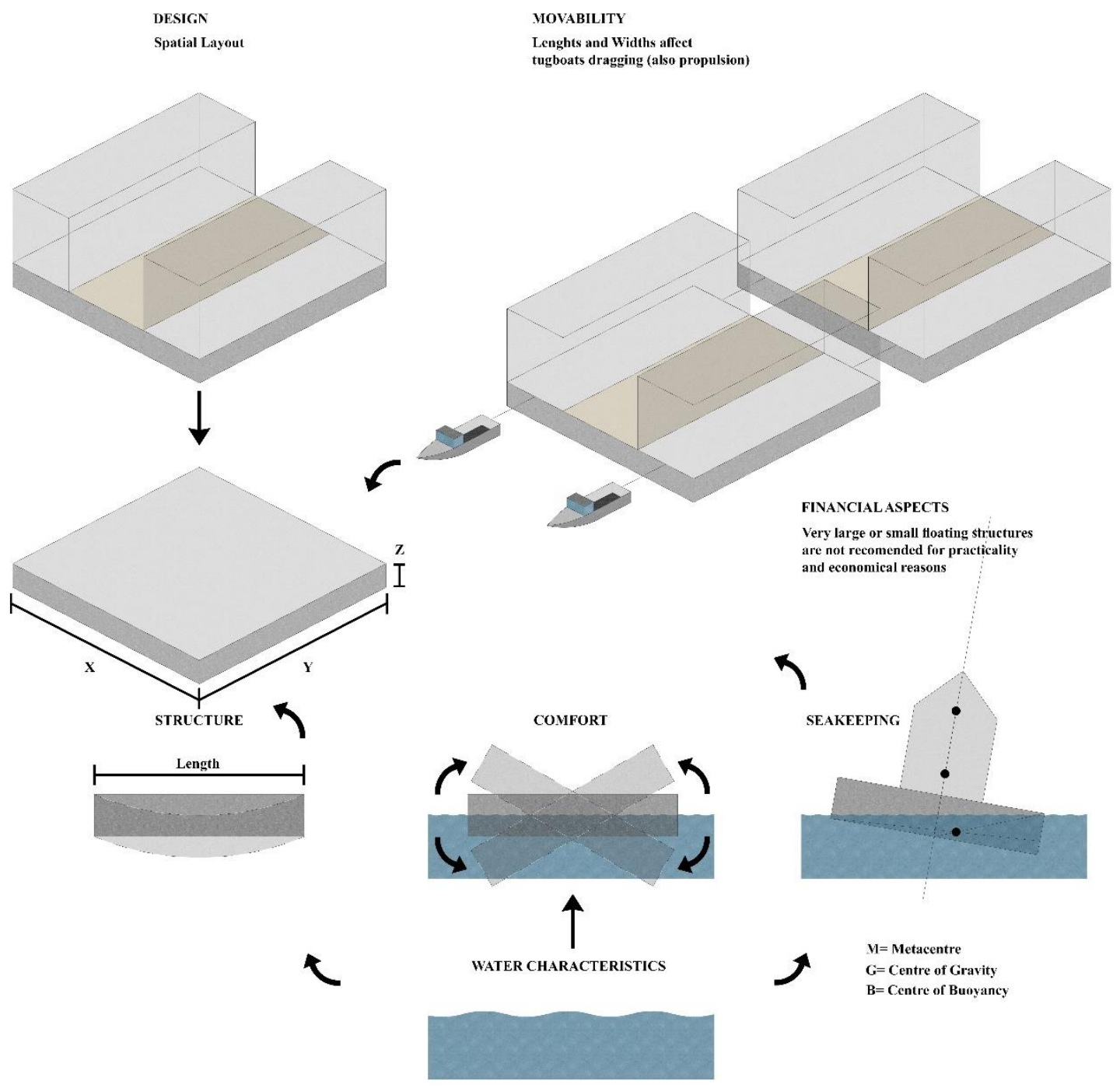

44 Figure 7.3: Factors influence size of VLFS (own illustration).

\subsubsection{Transportation}

It is significant to have the ability to move the floating community, in emergencies or if another site was found as a better replacement. Numerous influences affect if relocating would be beneficial or not. The first influence would be the connectors, based on the type and amount of mooring system connectors and interconnectors between each platform and the other. Secondly, comes the resistance, based on the body to water resistance throughout the relocating process. Thirdly, comes to transportation, for instance if via semi-submersible, 
tugboats, or other means. The connectors whether to seabed or between platforms, they are essential to a practical and efficient community. Mooring systems restrain the floating structures from drifting off which may cause accidents and collisions. Between each platform and the other, there are numerous types of connectors, such as structural connectors, utilities and bridges. To allow the emergency repositioning process, such connectors should not only be sturdy and flexible, but also to be simply detached. Such criteria influence the expenses to form a more realistic budget. Choosing small platforms means more platforms to fill the space needed, that as a result increases the connectors number. Six to twelve platforms will be needed for platforms of 50 meters for each side. Supposing where they are attached side by side, therefore twelve connectors will be needed to attach all twelve platforms together, on the other hand supplementary connections could strengthen and add more stability to the floating structures group.

The irony is that if a platform has less dimensions than $25 \times 25$ meters, then the connectors number will increase not decrease. Connectors between platforms are frequently complex, smaller in dimensions and could be of a significant role of the total expenses. Furthermore, many connectors could unfavourably disturb the capability to moving the floating community in emergency situations.

Body to water resistance determines if the relocating is beneficial or not. When transporting the platforms to their water site, the hull's form defines the resistance and therefore the propulsion power needed for transporting the platforms. Bigger platforms require more structural height and a bigger share of such height would be underwater, outcoming in an increased draft (Suzuki et al., 2006). Meaning that the bigger the size of the platform, the more the resistance and the propulsion power needed will be. Propulsion is a major difficulty for bigger vessels. 
Although platform's dimensions greatly affect movability's velocity, but generally platforms would probably be moved at a low velocity in order not to disturb the life above. A full calculation is needed to establish the platform's maximum measurements to realize the needed tugboat engine capabilities and possible towing velocity.

The last issue which effects movability is the needed type of movability. The capability to relocate during strong storms is one of the challenges that must be measured. For such purpose, floating structure must have the ability to move fast enough to avoid such environmental challenges as well as having the means of transport accessible constantly. The possibility of semi-submersible vessels is not advantageous where the fact that won't always be able to arrive on time is highly risky. Integrating a propulsion system such as azipods could be rather pricy, particularly when only used for emergencies, although they could be used for also generating tidal energy where tides are much more predictable than either the sun or the wind. Such boats may be used also for moving people and goods. This probably restricts the possibilities of transportability to towing by tugboats.

\subsubsection{Seakeeping, Well-being and Structural Characteristics}

The meaning of 'seakeeping' is rather vague. It may signify a ship's dynamic response to wind or wave situations, or it may signify the scale of a vessel's behaviour in various sea situations where it runs. The difference is made amid both:

- Safety: It consists of the suitable strength, constancy and buoyancy for local environments.

- Comfort: It concentrates on malformations, movements, and acceleration which derive from floating structures reactions to forces of waves and wind. 
Such aims are subjected to the platform's size. Usually, bigger and heavier floating structures would have lower movements than the smaller and lighter ones, as the applicable size and energy made by waves will be less.

Stability is the platform's resistance degree of leaning. Where forces such as waves tilting a platform, the angle of the center of buoyancy changes, and as one side transfers more water than the other then vice versa. As the buoyant force will restrain such tilting and movements, with such gravitational downward weight of the floating platform, it returns to balance. The space between the buoyancy and gravity forces is called the righting arm. Big platforms have greater resistance to tilting, as more water is required to be transferred to tilt the floating platform. A small platform which has a high center of gravity are risky due to their negative stability behaviour. Nevertheless, big platform which has a low center of gravity comes with its own difficulties as well. In such scenario, the righting arm would be great and as a result the platform would quickly return to balance (such scenario is called a stiff vessel). Even though such condition decreases the danger of possible deck immersion, this outcomes in more forces on the structure as well as higher accelerations which could lead to seasickness.

In a scenario where the platform dimensions are smaller than half the wavelength in dimensions, platforms behaviour would generally trail such waves (Suzuki et al., 2006). Where the platform's dimensions are larger than twice the wavelength, platforms behaviour would generally lean to none. This is demonstrated in Table 7.1. In more than 100 meters waves, massive platforms might be required for decreasing the wave-generated movements in each wave form. Moreover, these massive platforms would be vulnerable to great forces caused by sagging and hogging. For such forces, the structure height might require being higher, where that should highly affect any floating city project both financially as well as practically. 
Where the platform to wavelength ratio is the major reason for seasickness. Whether or not the platform's size to half the wavelength outcomes in the adequate levels is a subject to various issues:

I. Wave time behaviour of the floating structure is a subject to the overall load and load distribution on the platform (Suzuki et al., 2006).

II. Changing the outline form of a floating platform could substantially decrease acceleration (Wang et al., 2008).

III. Numerous floating platforms would require connecting.

Such approaches could decrease the negative impacts on the structure from waves. When designing floating structures, each water site requires its own environmental studies as well as comprehensive simulations for the ideal dimensions, outline, and connectors. 


\begin{tabular}{|c|c|c|c|c|}
\hline $\begin{array}{l}\text { Wave } \\
\text { length }\end{array}$ & $\begin{array}{l}\text { Wave motion on structure stress of various platform } \\
\text { sizes }\end{array}$ & Advantages & Disadvantages & $\begin{array}{l}\text { Suitability } \\
\text { for AbuQir }\end{array}$ \\
\hline $\mathrm{L}=2 \lambda$ & 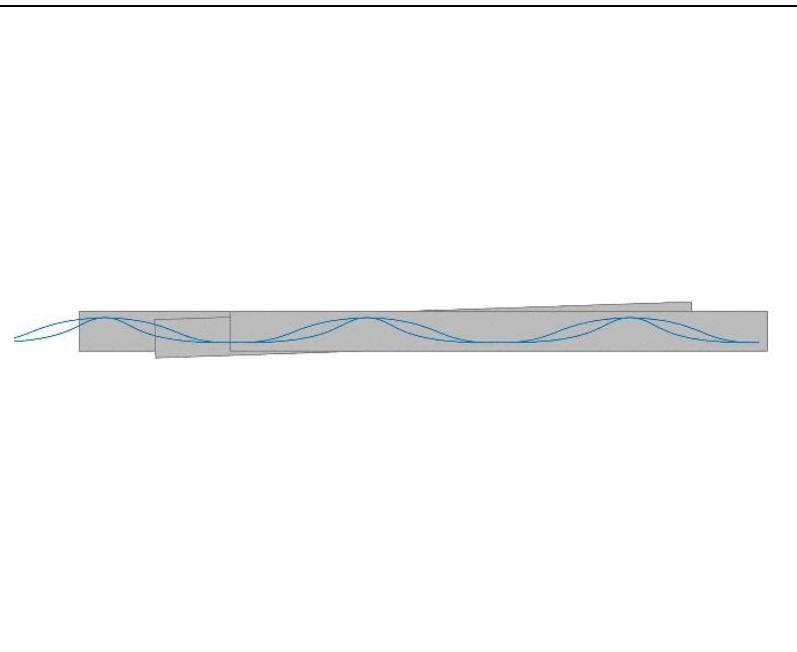 & $\begin{array}{l}\text { Platforms } \\
\text { behaviour } \\
\text { would } \\
\text { generally lean } \\
\text { to none. } \\
\text { Function in } \\
\text { protected and } \\
\text { open waters. } \\
\text { Required for } \\
\text { decreasing the } \\
\text { wave- } \\
\text { generated } \\
\text { movements in } \\
\text { each wave } \\
\text { form }\end{array}$ & $\begin{array}{l}\text { Very hard to } \\
\text { reposition. } \\
\text { Massive platforms } \\
\text { are vulnerable to } \\
\text { great forces caused } \\
\text { by sagging and } \\
\text { hogging. } \\
\text { Structure height } \\
\text { might require being } \\
\text { higher, that should } \\
\text { highly affect } \\
\text { financially and } \\
\text { practicability. }\end{array}$ & $\begin{array}{l}\text { High } \\
\text { suitability }\end{array}$ \\
\hline $\mathrm{L}=1 \lambda$ & $3 x$ & $\begin{array}{l}\text { Platforms } \\
\text { behaviour } \\
\text { would may } \\
\text { outcome in sea } \\
\text { sickness. } \\
\text { May function } \\
\text { in open waters. }\end{array}$ & $\begin{array}{l}\text { Hard to relocate. } \\
\text { Massive platforms } \\
\text { are vulnerable to } \\
\text { great forces caused } \\
\text { by sagging \& } \\
\text { hogging. } \\
\text { Structure height } \\
\text { might require being } \\
\text { higher which affects } \\
\text { financially \& } \\
\text { practicability. }\end{array}$ & $\begin{array}{l}\text { Very High } \\
\text { suitability }\end{array}$ \\
\hline $\mathrm{L}=1 / 2 \lambda$ & нос & $\begin{array}{l}\text { Ideal for single } \\
\text { platform } \\
\text { houses. } \\
\text { Function well } \\
\text { in protected } \\
\text { waters. } \\
\text { Easy } \\
\text { repositioning. }\end{array}$ & $\begin{array}{l}\text { High seasickness } \\
\text { levels. } \\
\text { Not preferred in } \\
\text { open waters. } \\
\text { A lot of platforms to } \\
\text { connect. } \\
\text { Subject to overall } \\
\text { load \& load } \\
\text { distribution on the } \\
\text { platform. Changing } \\
\text { the outline form of a } \\
\text { floating platform } \\
\text { could decrease } \\
\text { acceleration. }\end{array}$ & $\begin{array}{l}\text { Moderate } \\
\text { suitability }\end{array}$ \\
\hline $\mathrm{L}=1 / 4 \lambda$ & 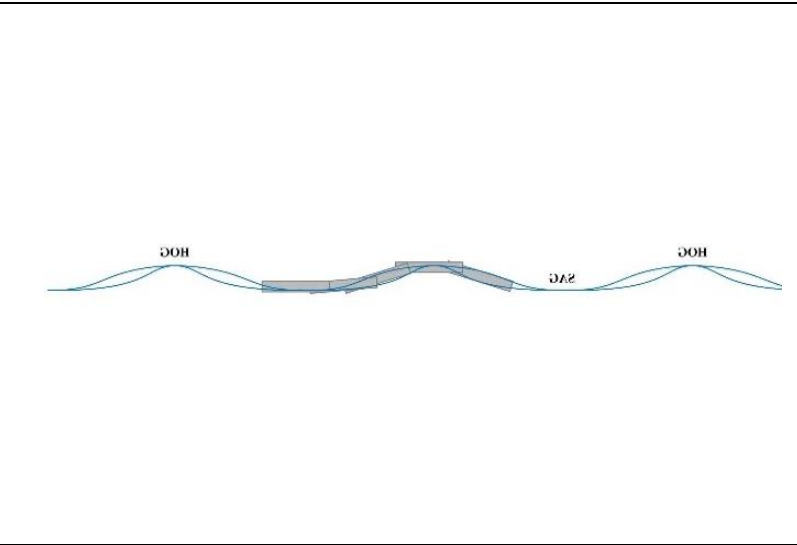 & $\begin{array}{ll}\text { Function in } \\
\text { protected } \\
\text { waters. } \\
\text { Very easy to } \\
\text { reposition. }\end{array}$ & $\begin{array}{l}\text { Very high } \\
\text { seasickness levels. } \\
\text { Not recommended in } \\
\text { open waters. } \\
\text { Numerous platforms } \\
\text { to connect. } \\
\text { Subject to overall } \\
\text { load and load } \\
\text { distribution on the } \\
\text { platform. } \\
\text { Changing the } \\
\text { outline platform } \\
\text { could substantially } \\
\text { decrease } \\
\text { acceleration. }\end{array}$ & $\begin{array}{l}\text { Very Low } \\
\text { suitability }\end{array}$ \\
\hline
\end{tabular}

48 Table 7.1: Wave motion on structure stress of various platform sizes (own illustrations). 


\subsubsection{Ideal Size from a Design Perspective}

The floating platform is usually the most expensive component in floating structures. To be economical, the total floor space should be used. If the dimensions of a floating platform should be between 40 to 60 meters, then the best solution would be creating two housing rows which leaves the adequate space required for streets or access/escape paths. On the other hand, platforms smaller than 40 meters having just one housing row might still require a street to allow access or offer emergency escape paths (see figure 7.3) Whereas such approach could create a less effective design regarding the used floor space.

\subsubsection{Conclusion}

It is better to reach a most achievable substitute to big scale floating structures like cruise ships and semi-submersibles. A design perspective of dimensions between 40 to 60 meters platform, meaning that dimensions of 50x50 meters appears to be the best possible solution. Such size would be decent to certify tugboats transportability. Greater wavelengths could create difficulties regarding comfort, nevertheless it would not be structurally beneficial to deal with such challenges by constructing enormous platforms. As for comfort, more comprehensive studies on interconnected structures with semi-flexible connectors react with diverse wave situations. Even though the sufficient findings on the optimal platform measurements isn't definite yet, herein the proposal, the measurements of 50x50 meters have been selected as the preferred measurements. Nevertheless, more information on each location's wave properties and additional studies on the structural strategy are required to be assessed. 


\subsubsection{Platform Materials and Structure}

The project features have defined the innovative structural materials. The materials used in current floating structures mainly have similar requirements to land-based buildings (British Columbia Building Code Interpretation Committee, 2015).

The three dominant material possibilities for the structure of the floating platform are steel, concrete, and other composites. Usually, steel is utilized in a lot of the ship building industries, due to its high-flexibility in moulding and bending, as well as their stretchable strength and their uncomplicated restoration or altering processes. The disadvantages of using steel are that they are expensive as well as requiring high-maintenance costs like that they require repainting frequently to avoid corrosion.

The corrosion and erosion from salty water and humid sea climate environments need sturdy and anti-corrosion material. The usage of maritime appropriate materials anywhere in contact with saltwater is required. For instance, the floating system and over waterline areas such as the ground level are the most impacted areas to saltwater and humid air.

The mooring system and its linkage to the seabed are mostly observed mechanically and ecologically challenging as both marine steel and concrete require a life span of 50 to 100 years. The focal idea regarding the weight and strength of the project is to implement sturdier materials in the underwater areas of the structure. The upper areas should have lighter yet durable weight materials as the structure should have stronger materials in the lower areas of the structure keeping the weight centre point to stay low.

Composite materials combine two categories. The first would be fibers such as carbon, glass, cellulose, Kevlar, and so on. The second would be hardened resin such as epoxy, 
polyester, vinyl ester, and so on. Regardless of being frequently expensive, they are usually applied more in high-performance areas, like aircrafts and vehicles. It's frequently used in yachts, boats and surfboards, and presently growing in several other industries. It's durable and doesn't rust, also it barely needs maintenance. It could be sturdier than steel while simultaneously being much lighter. The major disadvantage is its cost where it varies between high to extremely high as it's subjected to what sort of resin or fibers being is used.

Concrete is regularly practiced in marine developments as well, like in underwater tunnels, offshore and subsea facilities. Some marine projects have practiced underwater concrete which have since existed over than 50 years. Although regarding durability and stability concrete has high-pressure strength, nevertheless it has low-tensile one. The biggest disadvantage in using concrete is the steel reinforced which is implanted inside the concrete structure to offer a better tensile strength, although such material could rust. Thus, the appropriate concrete coating thickness is required to preserve the steel is unaffected. Such process has great impact on the weight of the concrete structure. Lately, further supporting layers should be implemented like fibers, for instance like the Engineered Cementitious Composite (ECC) and the Fiber-reinforced concrete (FRC). In platforms, implementing noncorrosive materials may offer huge progresses regarding resilience, mass, and usage.

The fundamental materials explained are practical in marine developments. In Table 7.2 the advantages and disadvantages of every material is mentioned. Concrete is favoured, as it barely requires maintenance as well as being the cheapest material in the market, specifically in big projects when a lot of material are needed. Weighty concrete platforms are steady as well, as they have a low center of gravity. In contrast, Light concrete platforms have a rather high center of gravity and thus less steady, specifically when adding further structures like superstructures. Apart from the cost, composites should be the optimum 
material especially for properties like being lighter and requiring low maintenance. Where the adequate research on such innovative technology doesn't exist yet as well as not founding the adequate references for it in Egypt, therefore normal concrete is preferred herein the proposal especially for costs evaluation.

\begin{tabular}{|l|l|l|l|l|}
\hline Material & Maintenance & Cost & Weight & Stability \\
\hline Concrete & 20 to 50 years & + & $600 \mathrm{~kg} / \mathrm{m} 2$ & $\begin{array}{l}\text { Extremely } \\
\text { stable }\end{array}$ \\
\hline Steel & 2 to 5 years & ++ & $200 \mathrm{~kg} / \mathrm{m} 2$ & Stable \\
\hline Composite & 20 to 50 years & +++ to ++++ & $70 \mathrm{~kg} / \mathrm{m} 2$ & Less stable \\
\hline
\end{tabular}

49 Table 7.2: Floating structures platforms materials and properties. ${ }^{8}$

The structure of the floating platform herein is designed like a void chamber using caisson engineering. Generally, big concrete caissons are divided by walls to strengthen the platform. A rib-like structure could be positioned on the caisson's bottom then placing walls all over. Such rib-like structure would transfer the water pressure loads into the pillars like how the beams do to the floor's loads. The cavities between such rib-like structure, is useful for chains, cables coated by insulation materials. The major components of such concrete structure platform are demonstrated in Table 7.3. The exterior layer of the concrete body works as a concrete protection layer that shelters the platform's steel reinforcement from harmful seawaters. Local conditions in each site should determine the detailed dimensions of the platform's void chamber.

8 Very High (+++++) High (++++) Moderate (+++) Low (++) Very low (+) Not addressed (-). Method adopted from: IDSC (2011) and Frihy \& El-Sayed (2013).

Main sources: Suzuki et al. (2006), Tsaltas et al. (2010), Wang \& Tay (2011), Watanabe et at. (2008). 


\begin{tabular}{|c|c|c|}
\hline Item & Structural illustration of platform & Characteristics \\
\hline Platform roof & $\begin{array}{l}\text { Floor } \mathrm{Tl} \\
30 \mathrm{~cm}\end{array}$ & $\begin{array}{l}\text { Platform's roof. } \\
\text { Herein the platform size of } \\
50 \mathrm{~m} \text { a side has been set for } \\
\text { interconnecting } \\
\text { characteristics. }\end{array}$ \\
\hline $\begin{array}{l}\text { Reinforcement } \\
\text { walls }\end{array}$ & $\begin{array}{l}\text { Wall Thickness } \\
30 \mathrm{~cm}\end{array}$ & $\begin{array}{l}\text { Rib-like structure could be } \\
\text { positioned on the caisson's } \\
\text { bottom than placing walls } \\
\text { all over. } \\
\text { Such rib-like structure } \\
\text { would transfer the water } \\
\text { pressure loads into the } \\
\text { pillars like how the beams } \\
\text { do to the floor's loads. } \\
\text { The cavities between such } \\
\text { rib-like structure, is useful } \\
\text { for chains, cables coated by } \\
\text { insulation materials. }\end{array}$ \\
\hline $\begin{array}{l}\text { Floor and } \\
\text { perimeter walls }\end{array}$ & $\frac{}{\substack{\text { Wall Thickness } \\
50 \mathrm{~cm}}}$ & $\begin{array}{l}\text { The platform of the floating } \\
\text { structure is designed like a } \\
\text { void chamber using caisson } \\
\text { engineering. Generally, big } \\
\text { concrete caissons are } \\
\text { divided by walls to } \\
\text { strengthen the platform. } \\
\text { The exterior layer of the } \\
\text { concrete body works as a } \\
\text { concrete protection layer } \\
\text { that shelters the platform's } \\
\text { steel reinforcement from } \\
\text { the harmful seawater. } \\
\text { Local conditions in each } \\
\text { site determines the } \\
\text { detailed dimensions of the } \\
\text { platform's void chamber. }\end{array}$ \\
\hline
\end{tabular}

50 Table 7.3: Foundation structure of the floating platform (own illustrations). 


\subsubsection{Building Structure}

The real form and size of each platform is a mixture of several practical characteristics supporting ecological, architectural and modular standards. Using interconnected platforms that allowed future expansions is inspired by the Seasteading Institute projects.

The architectural characteristics regarding the urban shoreline of Abu-Qir Bay are the appropriate scale, shape, and outline for the floating building which allows future expansions. As the height limitation discussed earlier, and in this case where there is a noticeable rise in population, more buildings could be further added by manufacturing them and shipping them to the water site to be assembled with the other module. The idea of having two main large floatation components in the squared module and three in the hexagonal module were selected at the primary phase to outline the structure of the floating platform proposal.

If the water traffic routes option should be implemented over the vehicles option, the building structure on top will connect the two or three floating structures together at the first floor. The idea of having apartment buildings above two main floating structures are designed simultaneously and the design of two buildings between the floating structures are for design and practical motives such as shading. The first floor connects the two buildings structure which improves the solidity of the entire floating structures together.

The roof level is a main feature in the proposal is used for light weight probable activities and green roof purposes. Such idea is primarily for generating solar energy but could also be used for running and bicycles tracks too. The design inspirations relative for the concept and architecture in the Nile Delta has been covered in chapter 4. The idea is to plan a floating city that can be suitable for the needs of the residents of the Nile Delta. 


\subsubsection{The Mooring System}

The loads and strengths in the structure were investigated in chapter 5 . The basic structural components and standards regarding strength and structure in the floating city concept proposal have been investigated. The challenging subject is in the water traffic option in the ground level where the floating structures are connected by the mooring system. The load and bending forces in the core are moved to the main focal flotation structures. See the mooring systems in figure $7.4 \& 7.5$.
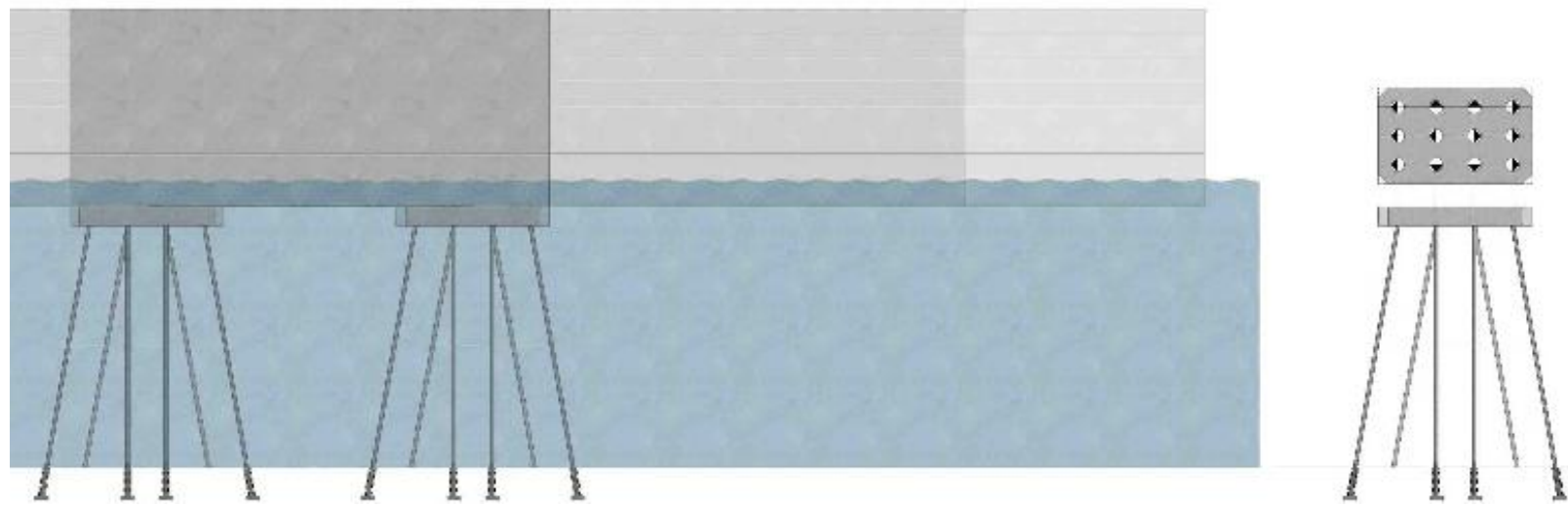

45 Figure 7.4: Longitudinal section of the mooring system (own illustration).

The main strength area in the proposal is the first floor which works as a bridge-like zone connecting the buildings together. Then the façade tube-like layer and other layers which are mainly for shading, apartment units' columns and beams, and finally central area pillars (which could also be used as windmill columns). In general, the building integrates light yet durable materials. 

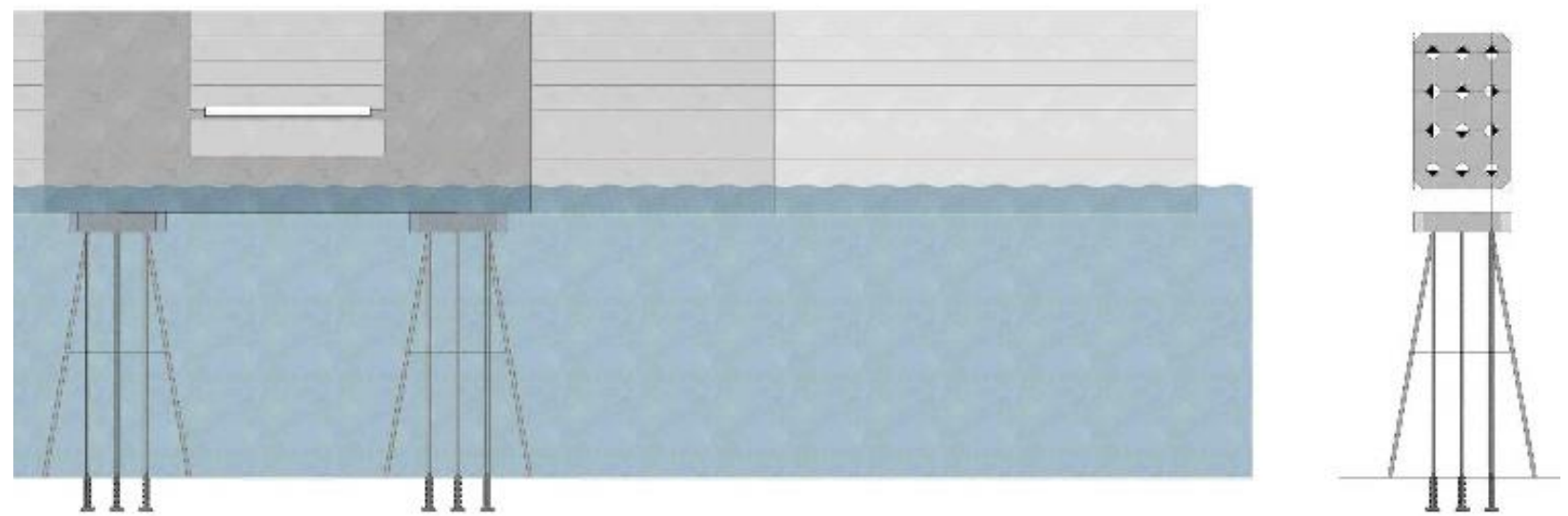

46 Figure 7.5: Cross section of the mooring system (own illustration).

Herein the proposal, the dolphin mooring system was concluded to be the most suitable system for Abu-Qir Bay as discussed upon the investigation done in chapter 5. The results regarding the coastal environment concluded that the floating community must not be too close to the nearshore zone in order to be ecologically friendly (unless if it will be built on a submerged land). Such plan would certainly elongate the distance of the pathway from the coastline to the floating community. Although designing and employing the dolphin mooring system and pathways have been studied, yet such matter is another subject isn't my area of expertise. The dolphin system connects the foundation structure to the seabed by using a group of relatively smaller dolphin systems linking the foundation structure to the seabed (two or four sets for the squared module and three or six sets mooring systems for the hexagonal one).

\subsubsection{Orientation of the Floating Project}

The outline and design of the project should be developed for a precise location for to reach both the optimum natural lighting and natural ventilation. The annual wind conditions in Abu-Qir Bay demonstrates wind directions mostly from the northwestern side and the 
Khamasin (south sandy winds) (Tolba \& Saab, 2009). Such data has defined the positioning for the optimum natural ventilation in the floating community.

Such positioning for the wind provides the best natural ventilation the community over the central agricultural corridor in the first floor to the roof creating a stack effect. The probable additional humidity on location will be decreased by fog layer system in the facades and air inlets.

The access of sunlight should reach all corridors and all apartments from both sides (see figure 7.7). The exterior part of the building requires more shading elements than the corridor one which is shaded by the corridor and the columns.

The Nile Delta cities have heavy vessel traffic and marinas with anchored ships, therefore, probable ship collisions on the floating community and the environment must be considered. The circular form when the modules interconnect was found as the most appropriate for the project. Platforms of 50 by 50 meters lengths then uniting them with the building found as the best option.

The 50 by 50 meters lengths are found to be appropriate for absorbing the wave movement for a better stability for the platforms in Abu-Qir Bay coastline. Once the modules assemble to one full circle as shown in figure 7.12 and 7.13, having wave attenuator around the floating platforms should protect and provide it with more safety measures from collisions or larger wave movements.

The weight calculation of the floatation building and platform in the ground and first levels are and should be calculated as marine steel shaped structure. The deadweight (structure plus furniture weights) was founded on a cruise ship cabin which is comparable to the housing apartments. 
The probable vegetation and furniture in the roof should put load on the floor below. The load should be calculated in cubic meters for each level. The balance in damage situations will be adjusted by the mooing system. The buoyancy modifications are required once the platforms are assembled on site. The buoyancy requires adjusting according to the building weight variations.

\subsubsection{Façade}

The façade layer should be separated into two major parts, the roof, and the interior and exterior façades. Several features counting sustainability were considered in the roof design. The primary feature was having a light weight approach on the roof which can used efficiently for collecting solar energy, wind power, and rainwater as well as being an adaptable shading system (see figure 7.6).

Using bamboo as a shading element as influenced by the Harvest City project could be implemented as a shading element. Bamboo could be implemented in roof beams as its strong and enduring abilities as well as being $20 \%$ to $40 \%$ steadier in climate changes and humidity (Lomholt, 2010). Bamboo sticks for columns or beams have are very flexible. The roof level should have an advanced water gathering abilities where the inclination guides the water to the columns that transfers the through pipes to the ground floor for the water filtration process. The ground floor façade could be more open to the sea to be used for fishing activities and for the fresh fish market. Also, to be used in water in water activities and transportation. 

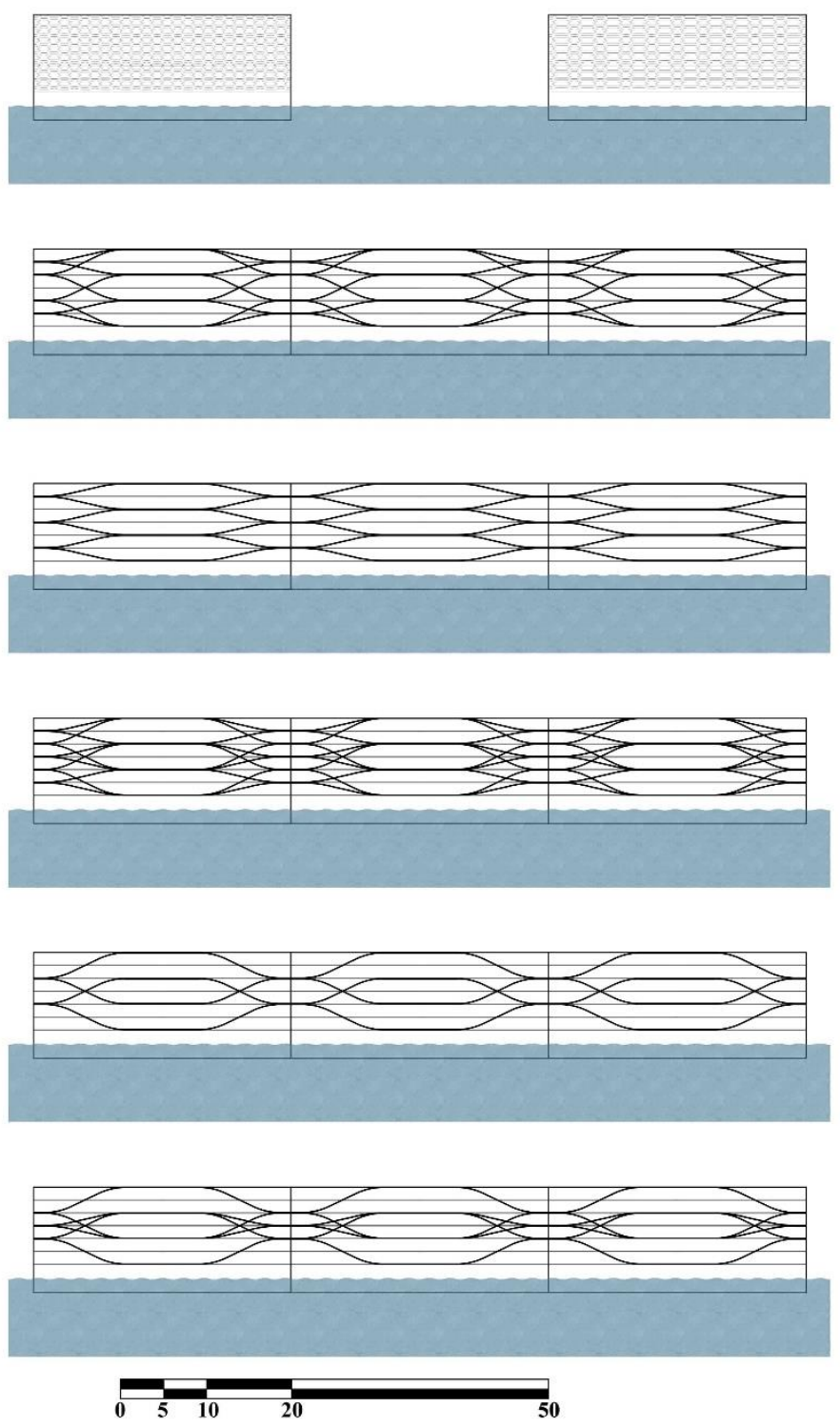

47 Figure 7.6: Elevations Facades (own illustration).

Building facades should be designed in consideration to shading and energy generation but without measured simulations. The aim is to reach a probable approach that could be advanced further if required.

Figure 7.6 demonstrates the façade details in the building structure in the apartments. The cross wave-like beam in the façade supports the structural integrity and the load stress vertically and horizontally of the structure. 
The exterior of the window, a fog layer is useful to filter the constant humidity and guide it to the water purification system. Such fog nests could as well filter the wind and act as shading elements. Such columns and beams which integrates pipes to collect water can have a programmed watering system for watering the vegetation in the balconies or having green façade. Such details stated concerning the building façade support the structural integrity, humidity control, temperature regulator, air pressure control and solar radiation (Assad et al., 2015).

\subsubsection{Natural Ventilation}

Natural ventilation potentials of the floating building are a matter of the project's location. Herein the ground floor centre is under a bridge-like structure at the first floor, thus, it can be cooler than other areas regarding the amount of sunlight reaching it. The upper levels get more sunlight radiation and heat. The outcome is a temperature variance amid the lower and upper levels in the building creating the stack effect discussed earlier. Another subject is the high humidity which crosses $90 \%$. A fog nest façade can offer a be humble and low-tech answer to decrease the humidity to improve comfort in the building.

The usage of modifiable air flow channels throughout the building and the atrium in the first-floor centre in the hexagonal building module would allow the sea winds in to ventilate the ground floor roads area. The stack effect would guide the air flow in the apartments and the uppermost roof which could have a distinct air duct permitting the hot air to outflow, nevertheless not permitting the rain to enter. Such characteristics were the core approach for natural ventilation in the project (see figure 7.7 ). 


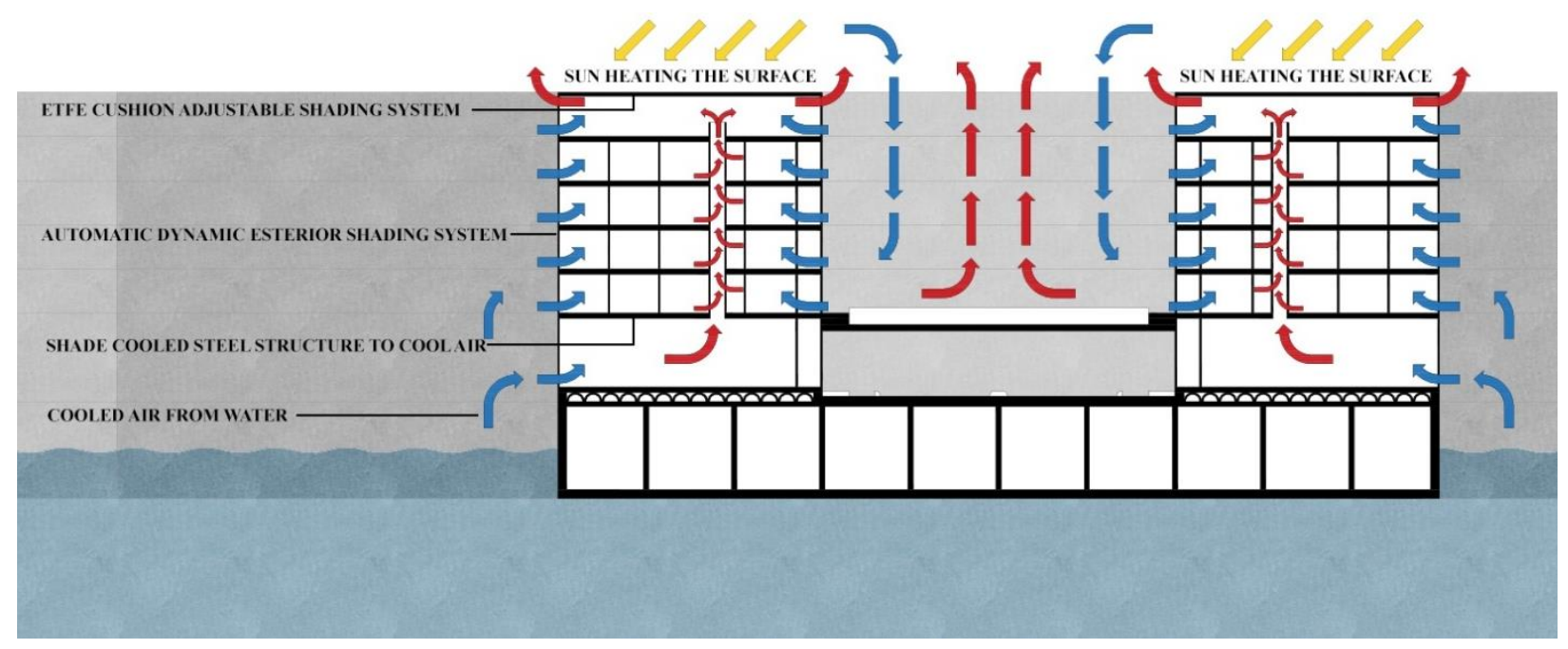

48 Figure 7.7: Detail Section Natural Ventilation (own illustration).

For improving the air quality inside, the natural airflow and air filtration led to the AMP system as it can improve air quality by $80 \%$ so the rely on HVAC systems in the building would be decreased. HVAC was not implemented herein the project. Such system can significantly improve the internal air quality. Further humidity of external air may as well be handled in such procedure.

\subsubsection{Circulation and Functions}

Platforms dimensions should be designed from a real estate standpoint to comprehend the diverse services, activities and building typologies which should be integrated in the project. The services may consist of: building for housing, offices, stores and hotel; and must consist of: roads, agriculture, public and private spaces. All functions whether buildings or open space must be executed on the 50 by 50 meters platforms. Several functions would be implemented on each platform demonstrating the project's possibilities. The roads width herein ranges amid 7 to 10 meters each direction to preserve an adequate space between the 
houses from each side. The building depth herein won't exceed 12 meters to enable having natural ventilation, which is essential in hot and humid weathers.

\subsubsection{Housing}

The initial typology herein consists of three-level housing blocks which have spacious porches positioned in the direction of the sea. The platform contains two buildings where each is 15 meters wide and between each other there is about seven to 20 meters as access roads (ground floor) and greenery (first floor). The platform boundaries would have private areas which will be owned the ground level inhabitants. Road view building facades could contain walkways which may offer shades from sunlight and rain. Ground level should contain businesses, offices and shops. These squared platforms could host about 256 to 320 residents, where the hexagonal platforms could host about 480 to 600 residents.

Another housing typology would be merging some apartments together, in order to have a low density. In case of having just a couple of houses on a sole platform, thus an access to a road is required. In such case, the best possible solution which permits realizing low housing density would be by constructing two sides with three leveled apartments or two levels apartments above shops or offices. Where both platform typologies contain a road inbetween and buildings would have greenery and sea façade making around 30 residents for each platform.

\subsubsection{Businesses. Offices, and Stores}

The whole ground floor and possibly the first floor too are to be used for stores, businesses and offices. Fishing and agricultural businesses and stores can use the nearby sea and the agricultural area in the centre and in the uppermost floor to not to pay high transportation coasts and to export their productions. 


\subsubsection{Hotel}

The same structure and design which got a gross floor area of around $2000 \mathrm{~m} 2$. A hotel could be implemented to use the same apartments as suites hotel rooms or divide them for smaller and more economical ones. If the hotel takes a full platform then the platform could offer a swimming pools and other services. If the hotel took the whole platform then the platform could host whatever they the hotel wants, but if the hotel shared the platform then balancing both needs should be respected.

\subsubsection{Ground Floor Structure}

In a situation where buildings, infrastructures and vegetation are implemented on a platform, it is vital to make the interior of the ground level higher than the exterior to avoid any rainwater and dirt from the vegetation and infrastructure and gardens from entering. Platform's roof vegetation for instance, could be 30 to $40 \mathrm{~cm}$ high counting the soil, drainage, and floor finishes.
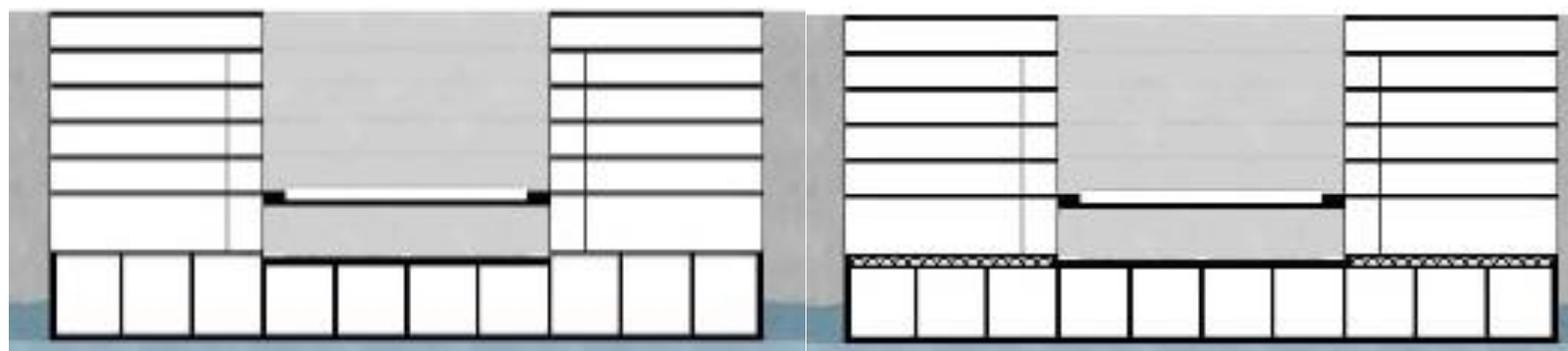

49 Figure 7.8: (Left) Section Option A of ground floor which has different foundation heights (own illustration).

50 Figure 7.9: (Right) Section Option B of ground floor which integrates plastic formwork for ventilated floors to create one universal height throughout all modules (own illustration). 
There are two possibilities when designing the platform. The major advantages and disadvantages of every possibility are vital to decide the best possible solution. The initial one is to increase the height of the platform's roof where construction will occur resulting in different platform levels. (See figure $7.8 \& 7.9$ ).

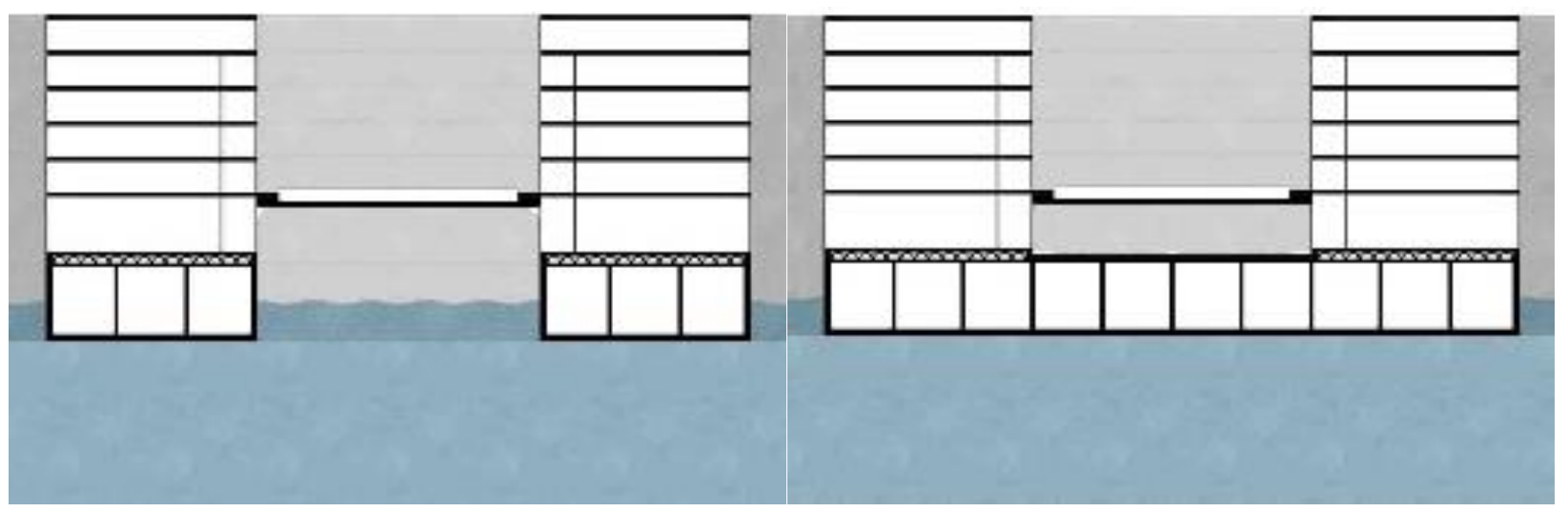

51 Figure 7.10: (Left) Section Option B of ground floor where the waterway will allow boats to be the only means of transportation (own illustration).

52 Figure 7.11: (Right) Section Option B of ground floor which has paths for pedestrians, bicycles, and vehicles as the only means of transportation (own illustration).

The first possibility seems to be the best solution for Egypt's Abu-Qir Bay regarding its high flexibility, waterproofing, as well as standardizing the platform. Nevertheless, it needs an extra level mounted on the ground level. Using plastic formwork when constructing the foundations is a practical possibility. Such flexible components offer a self-load platform when pouring the concrete. It's uncomplicated to build, as well as being both flexible and costeffective as it ranges from 30 to 40 euro/ $\mathrm{m}^{2}$. The positives are being fast to build, permitting the convenient space to implement tubing below the floor, maintaining ventilation for humidity, and overall most cost-effective. The second one would be to construct a plane platform roof to increase the height of the ground level sufficiently to avoid dirt and water 
from entering resulting in a usual platform which wouldn't require planning on a specific place on the platform. (See figure $7.10 \& 7.11$ ).

\subsection{Preliminary Members Formation}

The conclusions of earlier chapters led to this design for Abu-Qir Bay floating community. Intermediate interconnected platforms would be the most favourable solution. Such possibility would permit moving with normal tugboats. Breakwaters would deliver safety shield from waves. As discussed earlier, local conditions have concluded that average-sized platforms of 50 meters in envisioned to offer the ideal equilibrium between all protection, comfort and practicability. A development plan that lets the floating community to begin small and progressively expand have been considered and explained later in details. Apart from earlier mentioned objectives, further various considerations are required for the project development:

- The platform ought to involve small number of standard components to stay economical and have uniform connectors. As a result, facilitating the components organizations s well as any future reorganizations in the project's outline.

- The outline ought to allow numerous diversities for the community's future potentials.

- The outline ought to allow modular plans to be capable of suiting breakwaters with the lowest perimeter measurement where circular shapes provide.

- The platforms ought to attach where they form a group. Meaning that numerous platforms require attaching where they form circular outline which means not one or two platforms but more. 
According to such criteria, two forms have been established, the square and hexagonal forms. The outcomes and reflections are demonstrated. The hexagonal form enables making circular designs when assembled, having 120 degrees enables six hexagonal modules to be joined together to form one circular unit as demonstrated in figure 7.13. The squared modules could only expand in a modular form on their own. While if one squared platform is positioned in between the hexagonal modules are assembled with six squared modules the arc increases to form a bigger circular unit as demonstrated in figure 7.12.

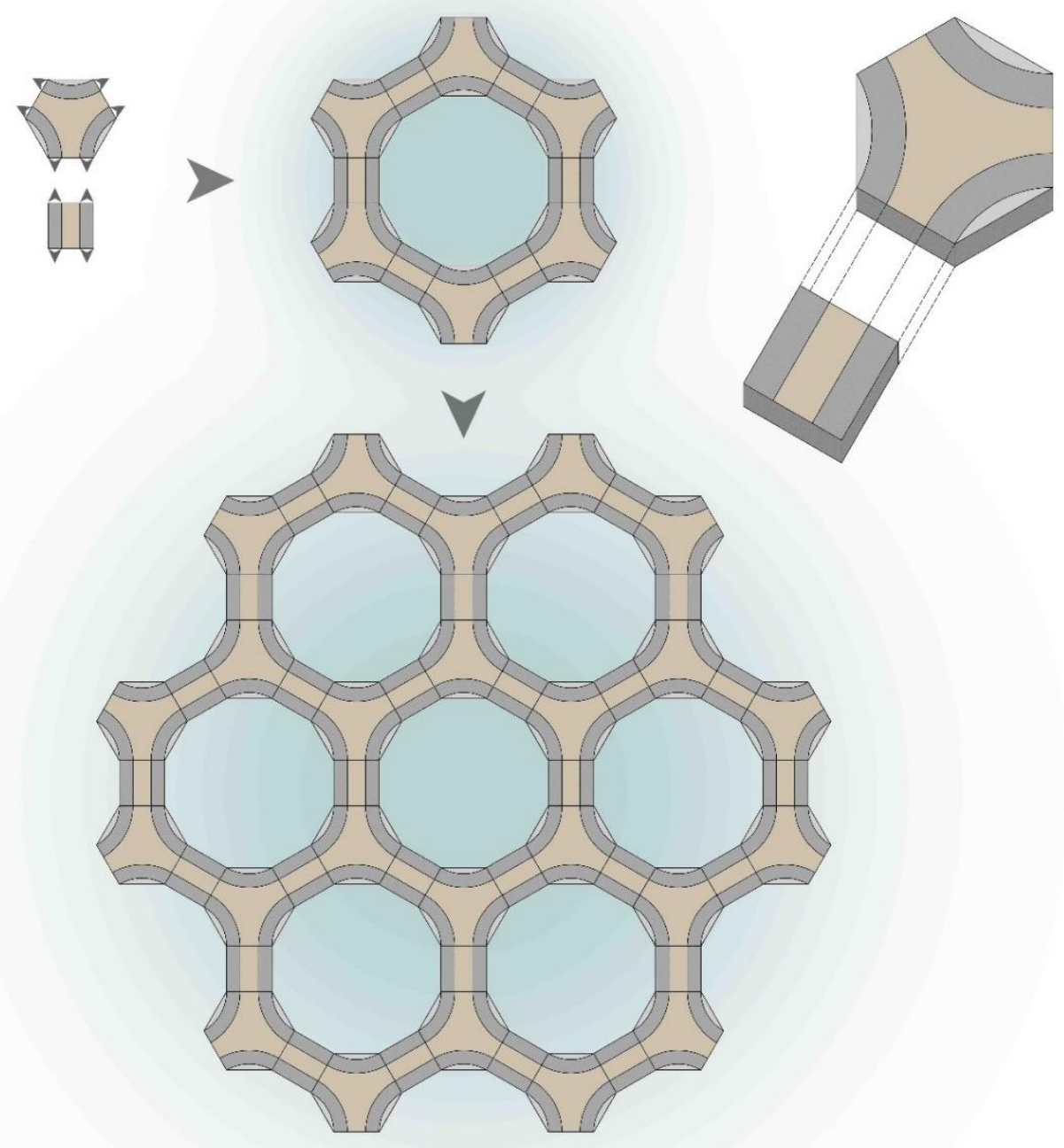

53 Figure 7.12: Master-Plan 'A' where hexagonal and square platforms are assembled together (own illustration). 


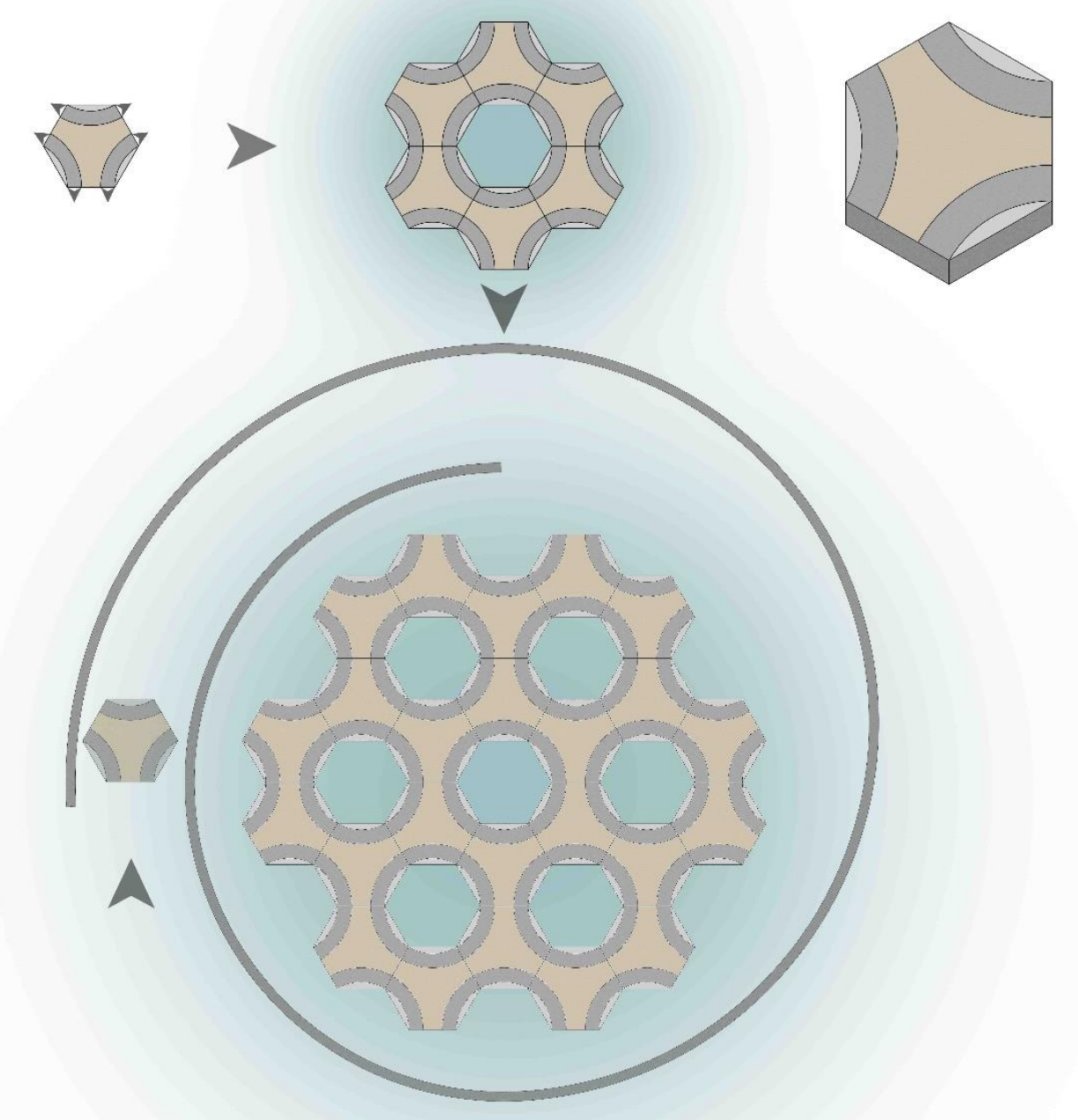

54 Figure 7.13: Master-Plan 'B' showing the independency of the hexagonal platform from the square one, also showing the breakwater around the united platforms (own illustration).

\subsubsection{Floating Modules Layout and Space Distribution}

Both the outline and the masses of the floating structures should be designed simultaneously. The outline of the design sustains the modular structure with modular constructability. The restrictions to five floors s well as the roof floor with light roofing has 
outlined the general form and spaces of the floating building proposal. The outline herein is set to position each apartment to be similarly spread round the floating building in directions to have water view from either the windows or balconies. In the proposal here, the hexagonal building module consist of three buildings, where the square building module consist of two buildings to spread the tension in the entire floating building from inside out.

The idea of the hexagonal and square building modules was found to be very functional for the proposal for Abu-Qir Bay. Such form provides the expansion option, where the two modules are designed to interconnect and expand into various forms. Such outline eases the pressure of the buildings on the foundations.
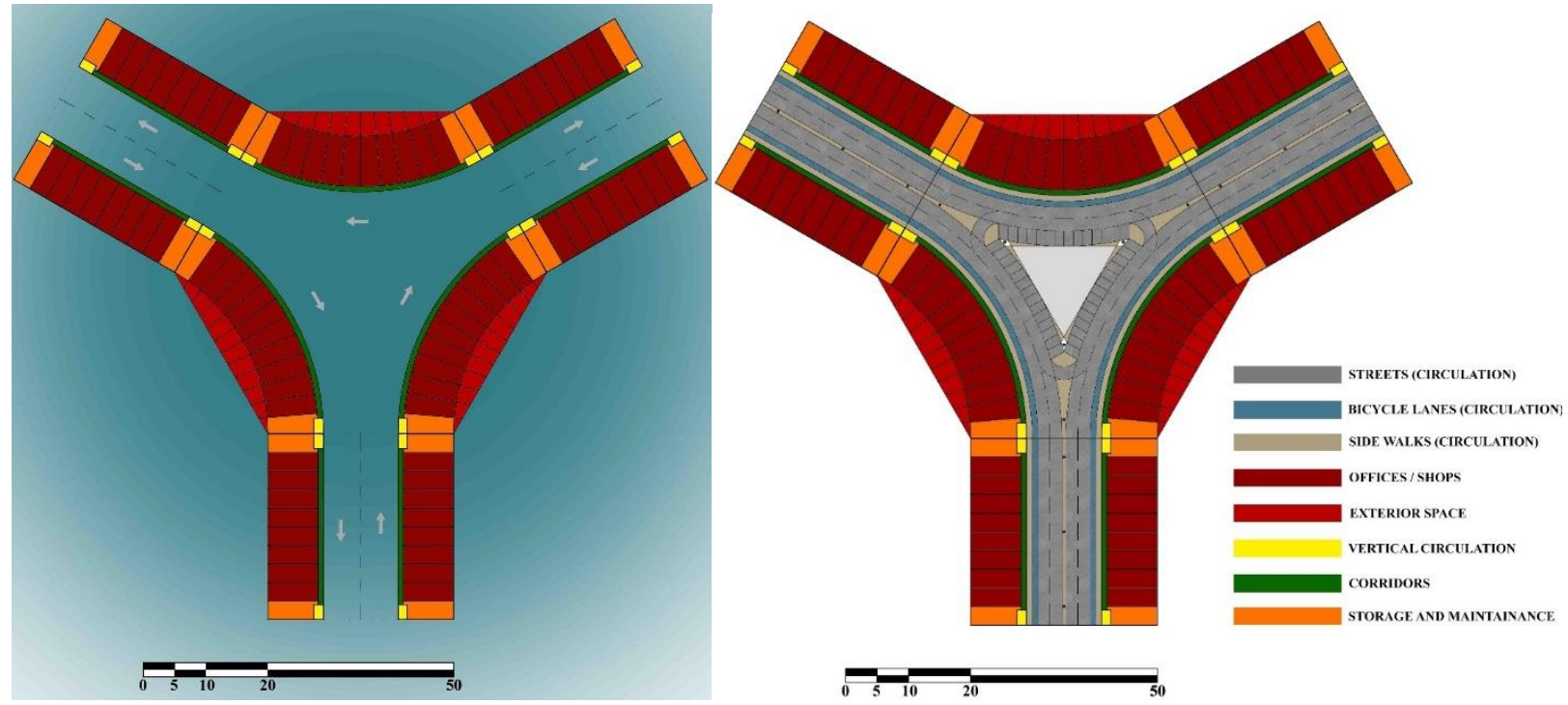

55 Figure 7.14: (Left) Ground floor plan of one hexagonal module connected to three squared modules. Water circulation option (own illustration).

56 Figure 7.15: (Right) Ground floor plan of one hexagonal module connected to three squared modules. Street circulation option (own illustration).

The ground floor on the floatation device herein is about 1.5 to 2 meters above sea-level. The ground floor herein may contain offices, service and storage, as well as roads for cars, 
parking, pedestrians and bicycles under the first floor of housing, shops, service and storage, agriculture and the open spaces (as shown in Figure 7.15).
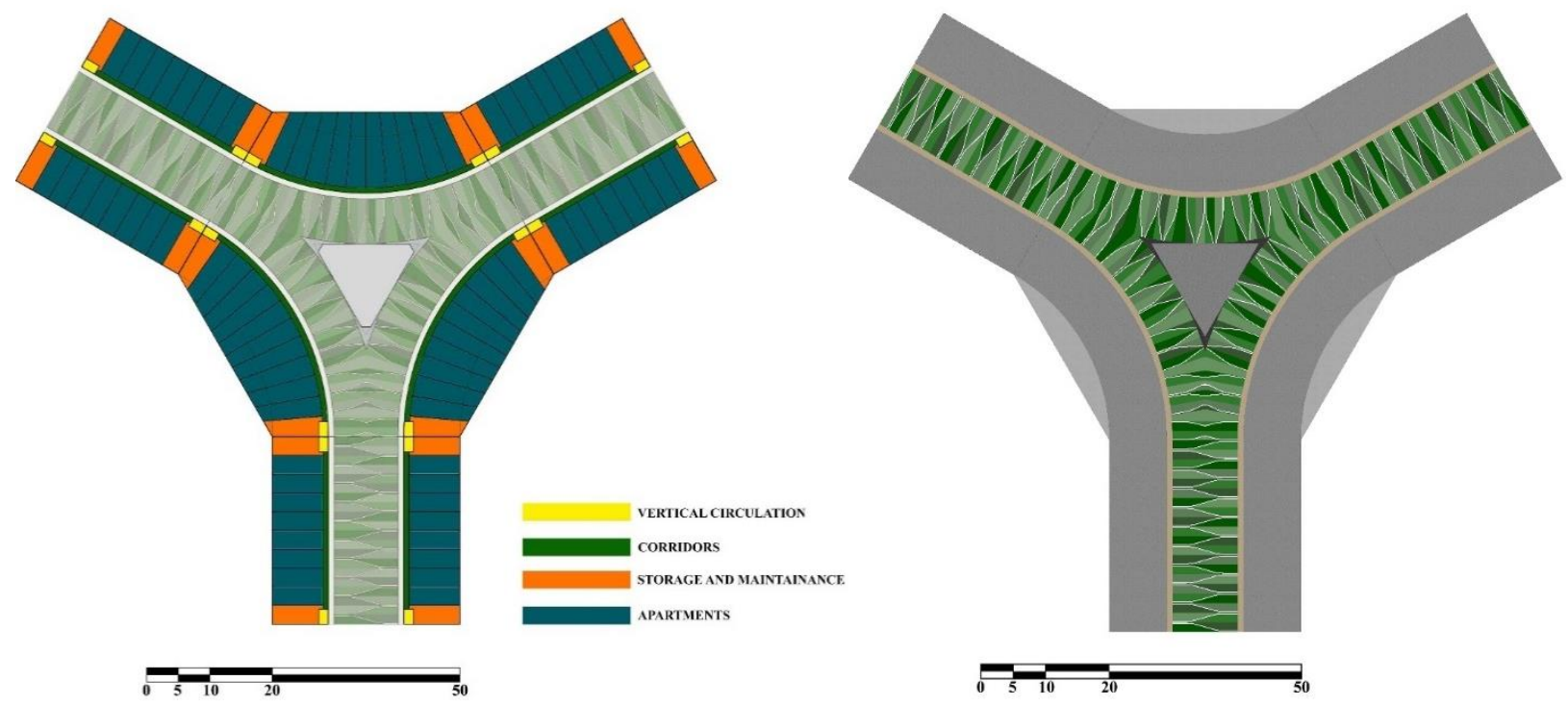

57 Figure 7.16: (Left) First floor plan of one hexagonal module connected to three squared modules. (own illustration).

58 Figure 7.17: (Right) The agricultural plan (own illustration).

Herein the proposal, the ground floor two building areas contains offices, businesses and stores, as well as having storage, maintenance spaces for water, electricity, and AC. While the centre is traffic route which contains roads, bicycle lanes, sidewalks and parking. Another option is to replace the centre area in the ground floor into a water route to eliminate all vehicles, however, the pedestrian paths in both the ground and first floors should be kept as shown in Figure 7.14.

The outline modular structure idea allows the hexagonal building to adjust apartments' dimensions by basically increasing or decreasing the lengths of the manufactured apartment blocks. The modification of the apartments should not alter either the character or structure of the building's exterior. The linear modular outline approach makes it achievable. The 
smaller apartments are favourable to be in the lower floors as the elderly would most probably require lower apartments.

Ship cabin design has proven in several situations to give the cabins more value. The proposal here concentrates on natural lighting. The light reaches each apartment as the renders demonstrate. The two parallel longitudinal buildings in the squared module have been a significant aspect to shape the project's outline. These illustrations are envisioned as initial valuations regarding the main outline and masses.

\subsubsection{Roof Floor Possible Usages}

Herein the proposal, the roof top main idea is to generate solar energy, however other ideas such as pedestrian and bicycles paths should be considered as attractive solutions. Nevertheless, the roof floor area is an attractive idea to integrate services such as sports areas, creating water views, meeting points, and for welfare.

\section{Services and Sustainable Life}

As the project proposal here has no real client, the project's outline should be designed for expansion concerning the facilities and spaces. These proposed services for the project are primary and in their framework. Such aspects together with the C2C Building Charter guidelines have guided the proposal.

\section{Sports Area}

The roof areas could be planned for leisure and gymnasiums, but the top floor is intended for sports activities. If the roof floor is not to be used for generating photovoltaic solar energy, then the approach is using it for running and bicycles tracks (once the modules assemble to a produce a full formation). As the modules assemble to unit to one full circular outline, the 
water option as a traffic route instead of cars in the ground floor could be an attractive option, the central water area could be used for fishing, boating, leisure and sporting activities.

\section{Water View}

The roof areas could be used for leisure for weekends and after work relaxation. It could also be a common space for socializing and sporting area too. (Such aspect is encouraged by the Lily-Pad and the Marina Bay Sands projects).

\section{Herbal and Health}

The herbal and medical vegetation for medical florae for public wellbeing which could fulfill the residents' requirements. Such aspect was influenced by the Urus culture where they used Totora as herb where researches showed that medical plants have various usages.

\section{Gathering Places}

The top floor level may contain public facilities with restaurants and bars potentials. When the modules herein unit to assemble one complete formation, the common inner water area could be used for fishing which provide a fresh food market. Such idea is highly important sustainable and practical objectives.

\subsection{Sustainability}

Herein in this proposal, the goal is to find sustainable energy resources with the current technology to reach zero pollution in 2030 . The challenging aspect in this phase is converting waste into energy system which could be assessed by relating to other similar existing projects with similar conditions. 
Based on earlier conclusions, the most possible renewable energy source in Egypt is solar power. The plan should be to use natural gas as a backup source of energy where the target is zero pollution. Implemented systems should have fuel energy generators to be used as a security measure in case on emergences.

Using biomass such as recyclable public waste, black and gray water to generate energy should be considered as probable power source for the project. This is because of the slow rising approach to use waste and bio-mass to generate energy where greenery and vegetation in buildings and can be probable sources for more biomass.

Using of anaerobic co-digestion (AD) has demonstrated to function with different input such as probable sewage, vegetation and domestic recyclable waste. The AD system size related to the floating buildings has been evaluated by projects closer in size. Building technology including probable business areas are herein set in a radial wave attenuator, as the ship traffic require loading facilities for energy consumption.

The following step is to find the best biogas to energy generation process. The gas turbine is found as the best fuel cell technology for energy generation. A power production as flexible fuel regarding future probable changes in demands and supply in Abu-Qir Bay could be the advanced fuel cell technology of the Bloom Energy. The domestic appliances could decrease energy consumption in the future meaning that each module could require about one Bloom Box Energy Servers at present rate that can be improved in the future. Using energy efficient appliances of a Bloom Energy server of $200 \mathrm{~kW}$ energy output (80 apartments) should be adequate for each module in its ultimate use. In maintenance of the server, up to $1 / 2$ of the energy available should be available. The future improved productivity in the energy generation could alter positively the project. Still as a backup plan like in case of emergencies, such servers may rely on local natural gas source although it's not environmentally friendly. 


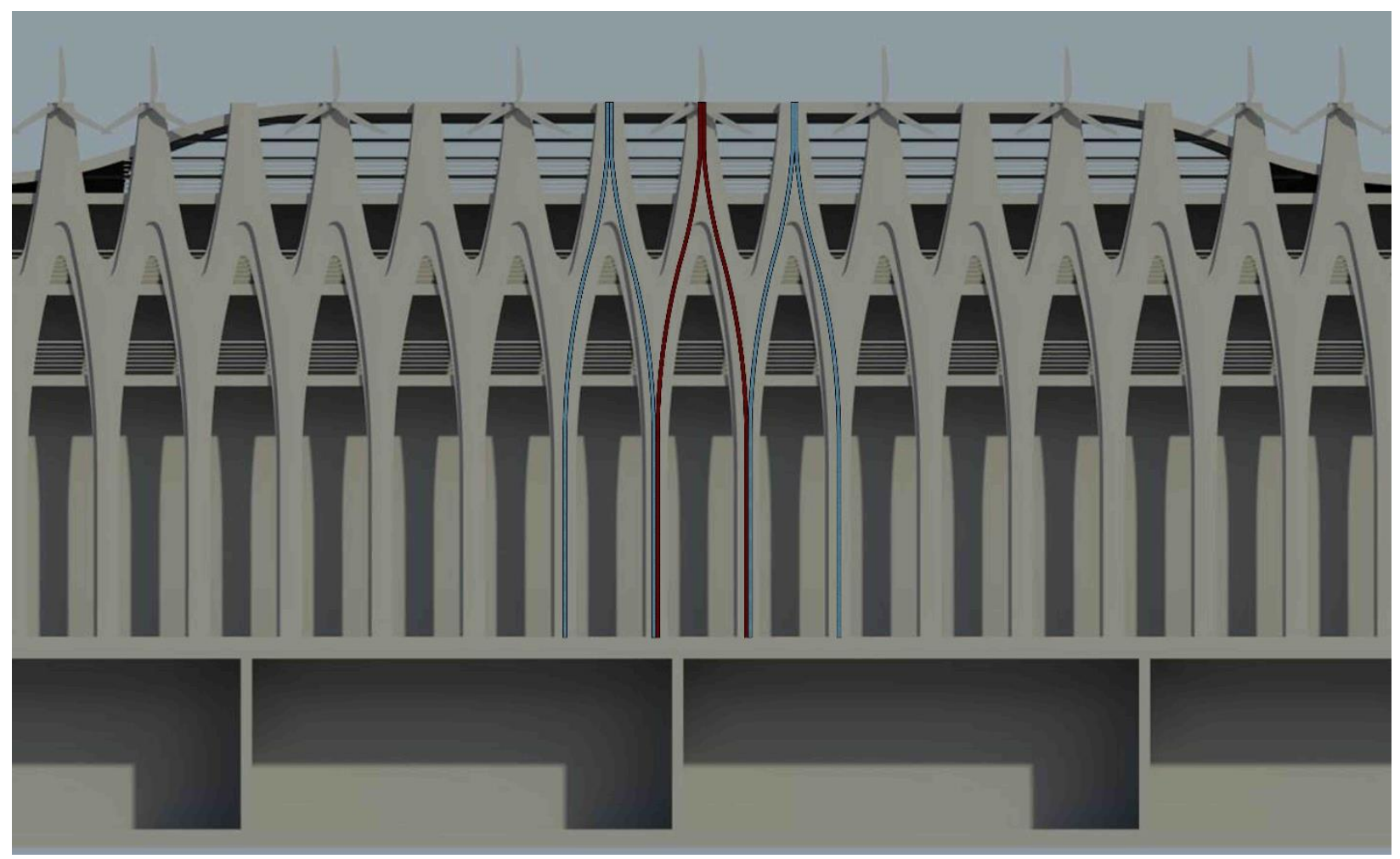

59 Figure 7.18: The façade columns transfer collected water for the factorization process and integrating windmills to generate clean wind energy (own illustration).

Although in the biogas generating process has its own disadvantages like that there are only few technological advancements, it has impurities, being affected by cold require more heat energy, and being less suitable for dense metropolitan areas. Thus, a more reliable approach should be used in the top floor for integrating a photovoltaic system as well as the windmills integrated in the columns have been considered as a great possible solution too as shown in figure 7.18 .

The plan should be to generate a secure and habitable environment on water, decreasing the effect on maritime ecosystems, and producing the required needs from obtainable resources. The Blue Revolution concept helps supplying the floating community with the three basic requirements which are water, food, and energy. 


\subsubsection{Blue Revolution Concept}

Throughout time, settlements have relied on the nearby regions for water, food, and energy, and other materials. In the last fifty years, we've established that the natural resources existing are of limited quantities especially with the continuously rising population indicates the obligation in altering the means cities use such resources to attain their requirements. As cities development, Metropolises uses most raw materials, fuel, and water that could be found and then convert them into structures, biomass and wastes (Czapiewska et al., 2013).

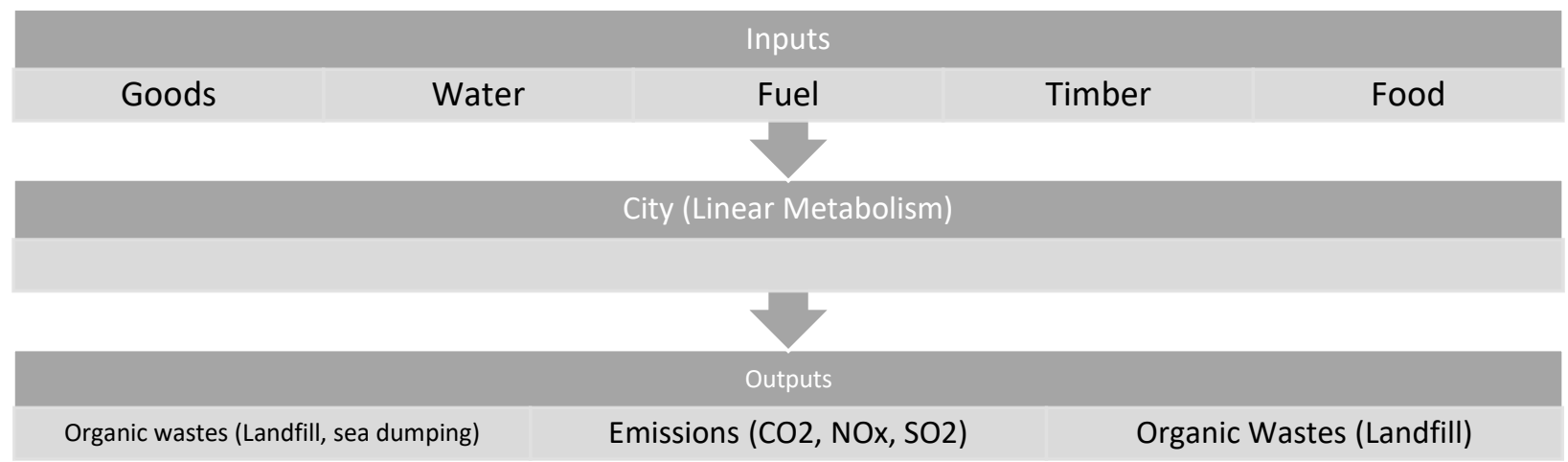

60 Figure 7.19: Linear metabolism cities consume resources and create waste and pollution on a high rate. Created with data from Girardet (2014).

Cities witnessing an abundance in both materials and resources is identified as Urban Metabolism (Girardet, 2014). As cities expand, more energy and resources consumption, outcoming in more waste to be often discharged in the environment. Such linear metabolism causes fast reduction in resources at the start in such resource's abundance and build-up in waste later. For using Earth's limited resources effectively, therefore sustainability requires having a circular metabolism process as a must to avoid any unused waste. 


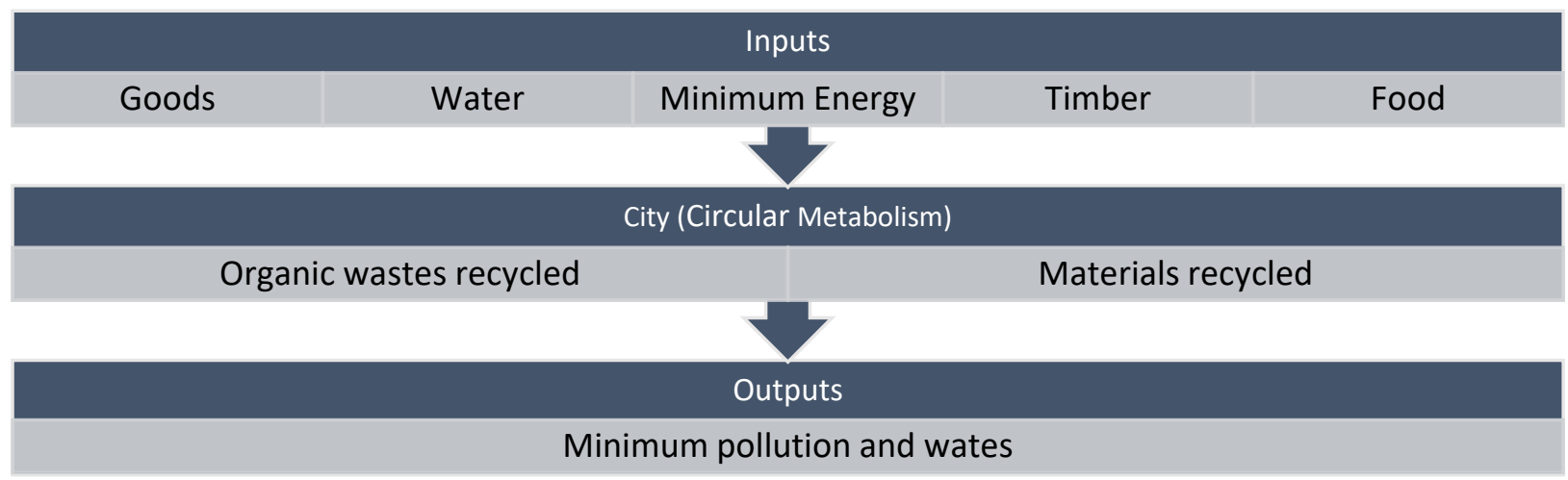

61 Figure 7.20: Circulative metabolism cities reduce consumption pollution, recyclable and maximize renewables. Created with data from Girardet (2014).

Cities metabolism raises productivity, where the result of one system is the input for the other. Changing from direct resources usage to a cycle is essential for sustainability. Such values are the foundations of the Blue Revolution, that suggests that floating communities should recycle the nutrients and carbon dioxide wastes from current delta cities, making food and energy effectively on water.

\subsubsection{Clean Energy}

Where the situation herein is to position the floating community in a hot sunny climate. The advantage of such climate is the abundance in solar energy production possibilities. Solar panels create energy by turning the solar radiation to electric currents via semiconductors. The electricity solar panels could create is a subject to the homegrown solar radiation that occur. In Honduras for instance, about $6 \mathrm{kWh} / \mathrm{m}^{2} /$ day or about $2190 \mathrm{kWh} / \mathrm{m}^{2}$ per year. (Fosnight et al., 2010).

The effectiveness of these solar panels is just about $15 \%$ at present, nevertheless the technology is developing quickly due to the high demand as that it's anticipated that solar panels in the next decades would be contending with the normal electricity bills. 
The only disadvantage to the solar panels is storing at night. Such approach could be achieved by linking the system to an electrical grid, nevertheless where the floating community is disconnected from land, such possibility isn't very practical. On the other hand, it is preferred to implement a micro-grid system as the solar panels are joint with batteries.

\subsection{The Reuse of Nutrients}

A lot of energy is needed for industrial ammonia synthesis even if just to support the inhabitants. Nevertheless, nutrients in agro-environmental areas are frequently lost, infecting the water and killing the marine ecosystems in contaminated zones. Nutrients reduction is a real danger for cities food availability.

\subsubsection{Algae Production}

Such nutrients which are wasted may be practiced in floating communities for algae, food and energy. Biofuels created on water, ten to twenty times more effective than crops without the shortage challenge in agricultural land. Biofuel via microalgae contains about $40 \%$ of lipid material, providing biodiesel from 40 to 50 t/year (Schlagermann, Gerold, Dillschneider, Rosello-sastre, \& Posten, 2012). 


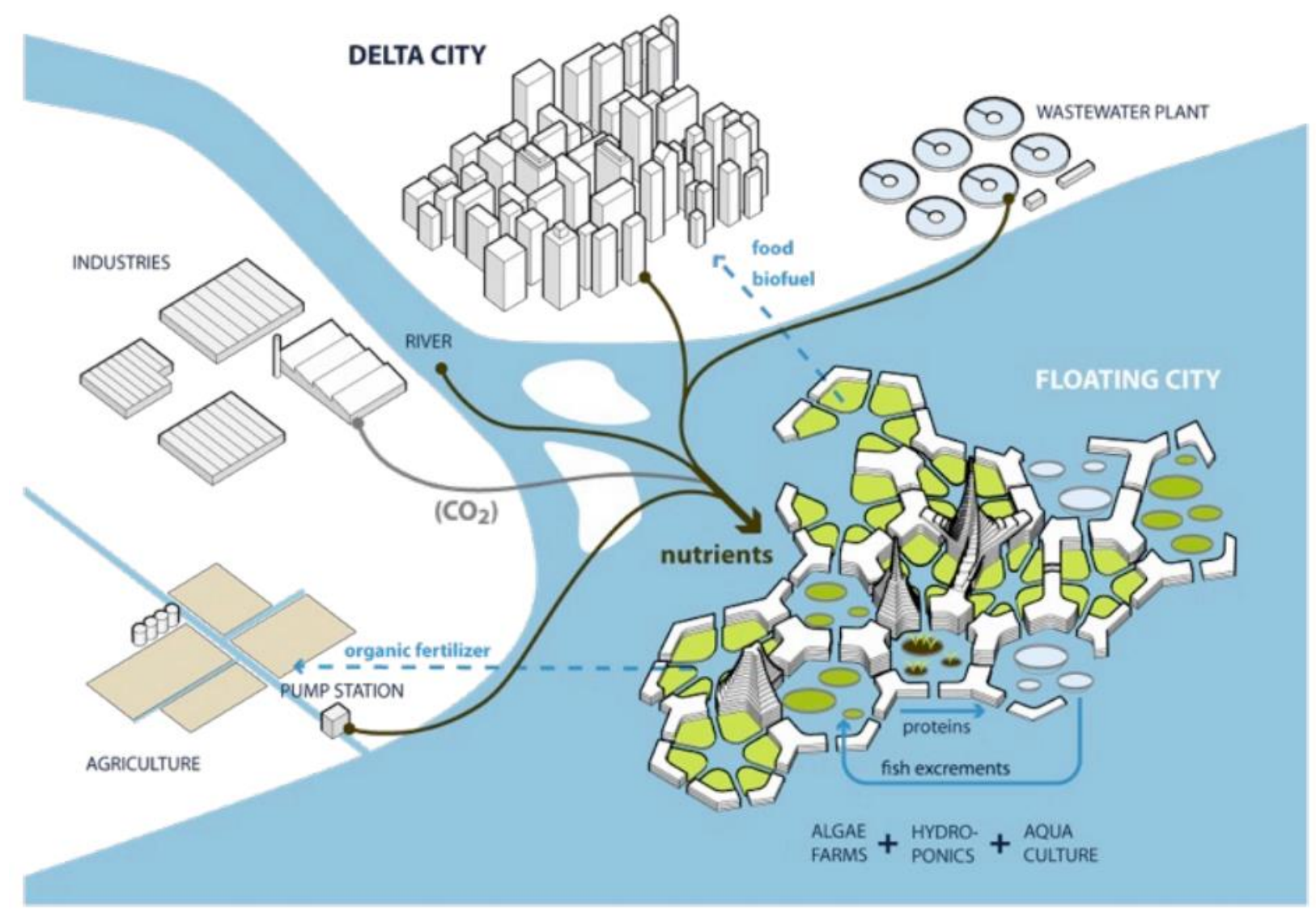

62 Figure 7.21: Nutrients System and CO2 of the delta streaming through the floating community. The waste generated from the delta can be recycled for food and energy generation, which forms a synergetic relation amid the land-based settlements and the floating community (Czapiewska et al., 2013).

Concluding that such floating community could create energy via wastewater and carbon dioxide. When withdrawing such nutrients and carbon dioxide, floating communities would have a good effect on the marine ecosystems where water quality would remarkably increase.

Seaweed farming and floating algae could take place on the floating community. The advanced way for growing floating algae is the Offshore Membrane Enclosure for Growing Algae (OMEGA), which was excelled by Jonathan Trent in NASA. OMEGA is a group of closed photo-bioreactors made from flexible plastic which could be by filling treated human or agricultural wastewater and releasing them after into the water. Since they float on the 
water, they provide the algae with the adequate daylight. Osmosis layers enable fresh water to spread out of the bioreactors, keeping the rest of the adhesive algae inside, that could simply be collected and treated to create biofuels, animal food, fertilizers, and other products (Schlagermann et al., 2012).

\subsubsection{Vegetation and Aquatic Ecosystem}

In respect to the surrounding environment as the Urus people do by using the Totora reeds and other natural materials to construct their floating community is a strong example of living and working with the environment. On the other hand, the Ha-Long people demonstrated unhealthy lifestyle by over-fishing and polluting the water environment which is risky to their own environment.

Such examples presented both respecting and disrespecting the environment in using the local living systems. The full potential of such systems to meet ecological and social goals was regarded to be most significant share herein in the proposal. While the current local state on Egypt's Nile Delta with the marine environment and nearby shoreline helped understanding the local conditions.

Agriculture and the number of species on location of the floating community should be a significant objective in any floating community project. The regenerative design approach embraces the philosophy of Lund \& Vollenweider (2006) which supports the sustainability approach of the C2C Building Charter philosophy (McDonough \& Braungart, 2010). The clean city approach implemented for recycling water and organic nutrients, as well as the spatial plans, landscape, and the probable incensement in the number of species supports the cradle to cradle building charter. 
Egypt's approach for 2030 and beyond is the clean energy and as the Nile Delta region is mainly agricultural areas, the main idea of the community is using clean energy and to be for agriculture which defined the project. The objective of the proposal herein is to address the necessity for more recycling rates of water usage and rainwater filtering for irrigation and waste water for flushing. As a backup plan, linking the land-based water network or seawater desalination to drinkable water could be advantageous in cases of emergencies.

\subsubsection{Local Food Production}

Food production could be implemented in floating communities. The objective of producing food locally in the specified agricultural lands of the floating city is influenced by the various encouraging reasons. Principally, it is influenced by the Haiti's Harvest City project with the Charter City project as the pre-designed business and facility potentials for producing food locally. Such model can be applied in the floating community for Abu-Qir Bay or other similar areas in the Nile Delta if created in real life scale.

The probable usage of both roof and first floor centre areas helps such objective of probable food production (see figure 7.17). Another efficient way for producing food by Hydroponics and fish farming. The motivation of food source and merging agriculture with habitat in Egypt led to the floating farming city proposal, where green roof is already a feature in the world. The internal courtyard sea area could also be used food production by coating a fishing area while the market place stores can sell or export them if the local fish needs were met. Apart from fishing, such area could be used for leisure and sports activities too.

Such approach supported the C2C Building Charter philosophy of recreating designs. The idea is not only envisioned to supply its residents and decreasing the necessity to import it 
from the outside, but also to export to other regions in the country and possibly to other countries as well.

\subsubsection{Aquaponic Farming}

The relationship between fish and vegetation nearly creates a loop in aquaponics agricultural system as fish and vegetation rely on each other, nevertheless, their maintenance requires some effort. Such activity could be implemented in the top level as a shared activity, in the wave attenuator, and in the central common area once the modules assemble to a complete united formation. Such activity could be used as food for daily use, fish markets, and in restaurants.

Technologies such as aquaponics and various hydroponics might be employed in the floating community, making food for the community for consumption and/or exporting. Some products are essential for production, especially vegetables, where it's hard to preserve it fresh when shipped from outside the community.

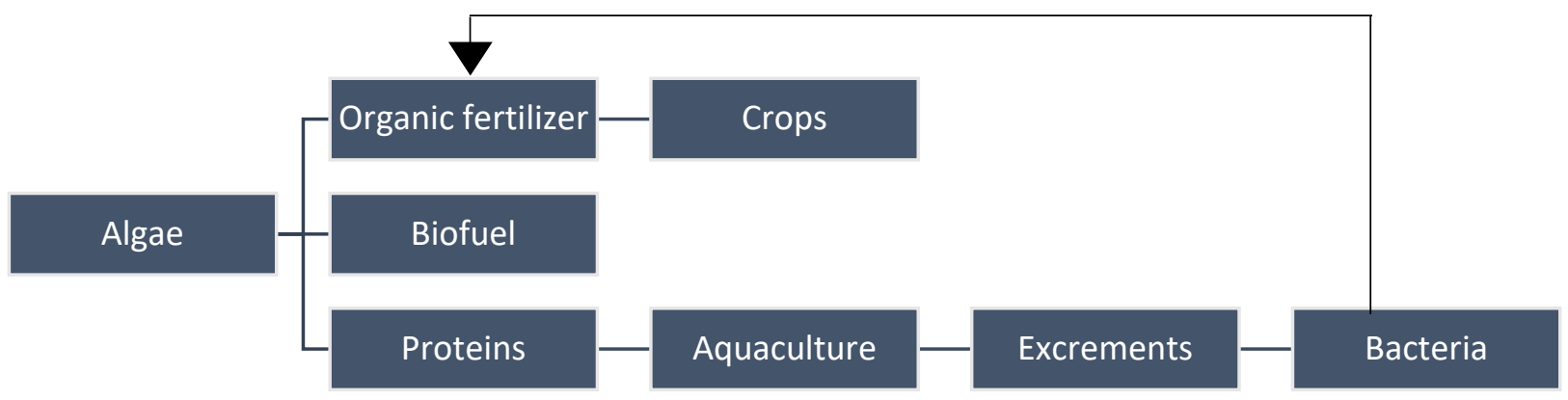

63 Figure 7.22: The process of algae culture, aquaculture and crops production which could be achieved in the floating community project. Created with data from Czapiewska et al. (2013). 
Via aquaponics, such vegetables can be grown on the floating community, a process which merges both aquaculture with hydroponics in a self-sufficient environment. Hydroponics is a process to plant plants in a liquid solution through water and the essential nutrients each plant (Bittsánszky et al., 2016). Floras and microorganisms sanitize water via the nutrients which fish produce. The water for yields could be possibly decreased to $1 / 10^{\text {th }}$ of the usual planting and decreases the water which is required for the fish farming to $95 \%$ or even more. The process could be employed in fresh water for all of tomatoes, bell peppers, cucumbers, herbs, lettuce, spinach, chives, watercress and further plants in joint with tilapia, trout, perch, arctic char and bass (Bittsánszky et al., 2016).

Saline fish could be categorized in the circular metabolism concept which integrates multi-trophic aquaculture (IMTA). In such process, the surplus of waste, nutrients and byproducts to a kind of fish are recollected and transformed to fertilizers, food and energy for other kinds of fish. IMTA mix sea creatures, with other similar sea creatures which feed on both organic and inorganic food which could be obtained from the ecosystem. Shellfish, an organic extractor which lives on small particulate substance like fish leftovers and waste. Seaweed, an inorganic extractor which lives on inorganic nutrients dissolved in the water, like nitrogen and phosphorus which are made by the other farmed fish. The God-given capability of such creatures to reprocess the nutrients, delivers a food production process which haven't any harmful effects on the environment. The IMTA process is extremely elastic enables adding diverse sorts of fish/shrimp with vegetables, microalgae, seaweed, and shellfish like bivalves or abalone (Neori et al., 2004). 


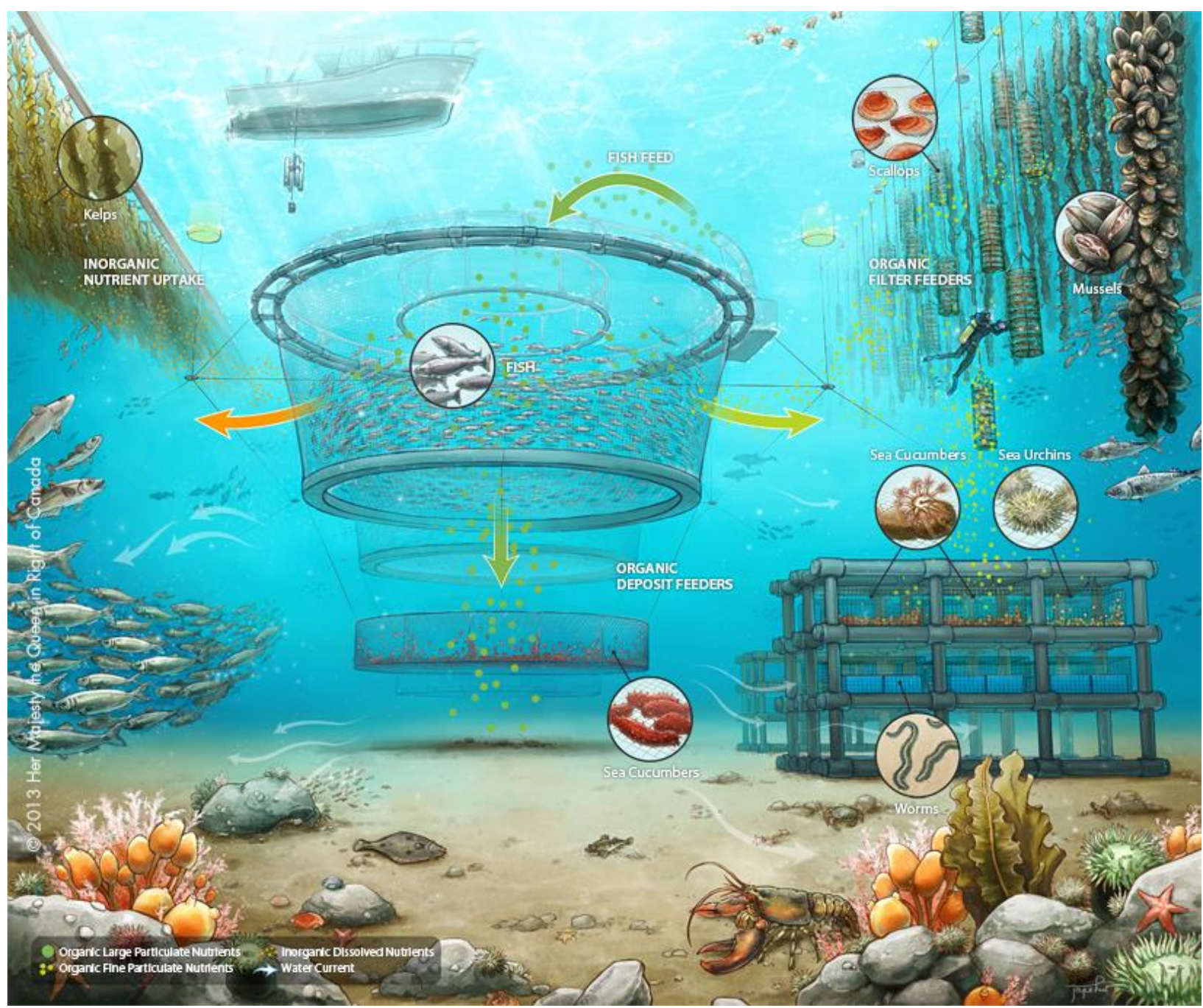

64 Figure 7.23: Integrated multi-trophic aquaculture (IMTA) process system viewing how a grouping of variable levels of the food chain in the similar setting take benefit of organic and inorganic nutrients done via the several organisms ("Government of Canada," 2018).

\begin{tabular}{|l|l|l|l|}
\hline Conventional & Meat & $\begin{array}{l}\text { Vegetables } \\
\text { (Tomatoes for } \\
\text { example) }\end{array}$ & $\begin{array}{l}\text { Fresh water } \\
\text { consumption }\end{array}$ \\
\hline $\begin{array}{l}\text { Farming and } \\
\text { agriculture }\end{array}$ & $\begin{array}{l}\text { Beef needs 15,500 } \\
\text { litres of water. }\end{array}$ & $\begin{array}{l}\text { Needs 1,260 litres of } \\
\text { water. }\end{array}$ & 16,760 litres of water. \\
\cline { 2 - 4 } & $\begin{array}{l}\text { Chicken needs 3,900 } \\
\text { litres of water. }\end{array}$ & $\begin{array}{l}\text { Needs 1,260 litres of } \\
\text { water. }\end{array}$ & 5,160 litres of water. \\
\hline Cyclicity & Fish. & Vegetables & $\begin{array}{l}\text { 22 litres of water as } \\
\text { they grow together in } \\
\text { a closed system. }\end{array}$ \\
\hline
\end{tabular}

51 Table 7.4: Water consumption of food production. Regular farming vs agriculture and aquaponics schemes. Reproduced from Czapiewska et al. (2013). 
Aquaponics and IMTA processes (see figure 7.23) may be employed for food in an effective and ecologically friendly means. In relation to normal farming and agriculture methods, aquaponics enables plants and fish enclosed together, where it recycles clean water and decreasing water losses. As shown in Table 7.2, a kilo of fish as well as seven kilos of vegetables could be farmed for each 22 liters of water (Neori et al., 2004).

\subsection{Waste and Recycling}

Any decomposable and blackwater waste from the floating community should be managed by uniting the Biogas and Living machine systems (Van Timmeren \& Tawil, 2006). The section below displays the biological and technical materials flow out of the building. See figure 7.24.

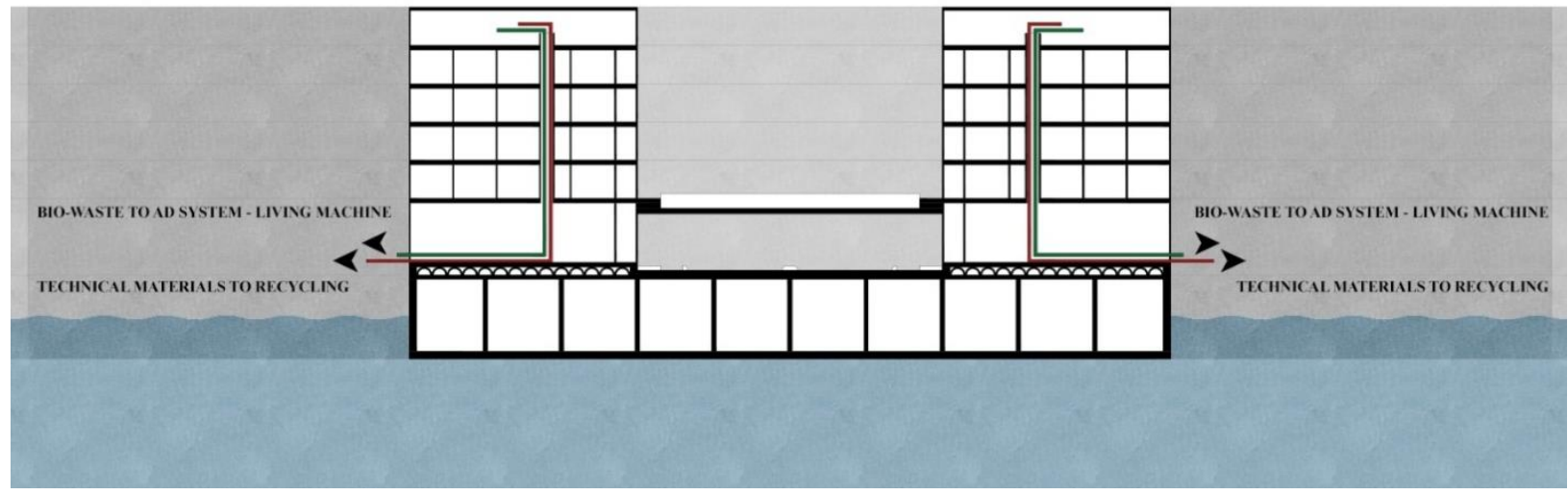

65 Figure 7.24: Detail Section Waste Flow (own illustration).

The bio-waste to the AD and living machine systems method could be executed by:

- Blending both blackwater and green waste of the building and agricultural areas into the system for improved results.

- The fermentation and anaerobic digestion procedure outcoming in biogas, effluent, and sludge. 
- Purifying processes enhance gas into biogas, then stored into gas tanks for the Bloom Energy Servers.

- The effluent left is then taken to the Living machine system for purification by natural wetland technology for irrigation water usages.

- The composting sludge functions as a fertilizer.

(Van Timmeren \& Tawil, 2006).

System maintenance could be a public effort to a more sustainable approach and may contain basic education to teach the residents comprehend the processes in the system. Integrating the Living Machine and Biogas system is proposed in the project regarding the fermentation and biogas.

\subsection{Sustainable Water System}

The effective management plan for water could develop water usage by the floating community's residents themselves. Like any other community, they input clean water and output sewage water. Although, globally rainwater isn't frequently used where it's mostly transformed into wastewater once it unites with sewage systems. Nevertheless, rainwater could be practical in numerous cases. On floating communities, rainwater can be a significant supply of water. In case where rainwater won't be used, pure water must be local water desalinated or brought from outside.

For such situations, gathering and storing rainwater is a valuable solution in regions which express a lot of rain. On the other hand, hot-humid climates like in Egypt, such solution is to be very reliable due to the dry weather and the lack of rain. To guarantee the total usage of the raining season, the suitable rainwater storage space must be offered. The 
buildings on the floating community could collected rainwater through their roofs and platforms, and they could be stored in elastic containers. Filtered rainwater could be for drinking, cooking, and bathing. Subsequently, wastewater can be possibly recollected in other containers for greywater. It will be treated but won't be for drinking but planting inedible planting. Where water for washing machines may return to greywater containers, wastewater from toilets may serve as a source for algae. Where the wastewater is collected in the OMEGA bioreactors, algae absorbs nutrients and clear water gradually.

As the climate in Abu-Qir Bay is humid, sunny, and rainy (only in winter), therefore harvesting rainwater for the project could be a source during winter. Herein the proposal, the objective is to harvest rainwater from the roof to offer a water source. Also, the fog nest system in the facades. Implementing large water tanks to store the adequate tap water for the floating building. Using water tanks which could move vertically is reliant on its fullness which could separate it from influencing the buoyancy of the floating platforms. Another approach could be placing such water tanks at each end of the floating building and possibly underwater for cooling approach by seawater and shade to improve the water quality.

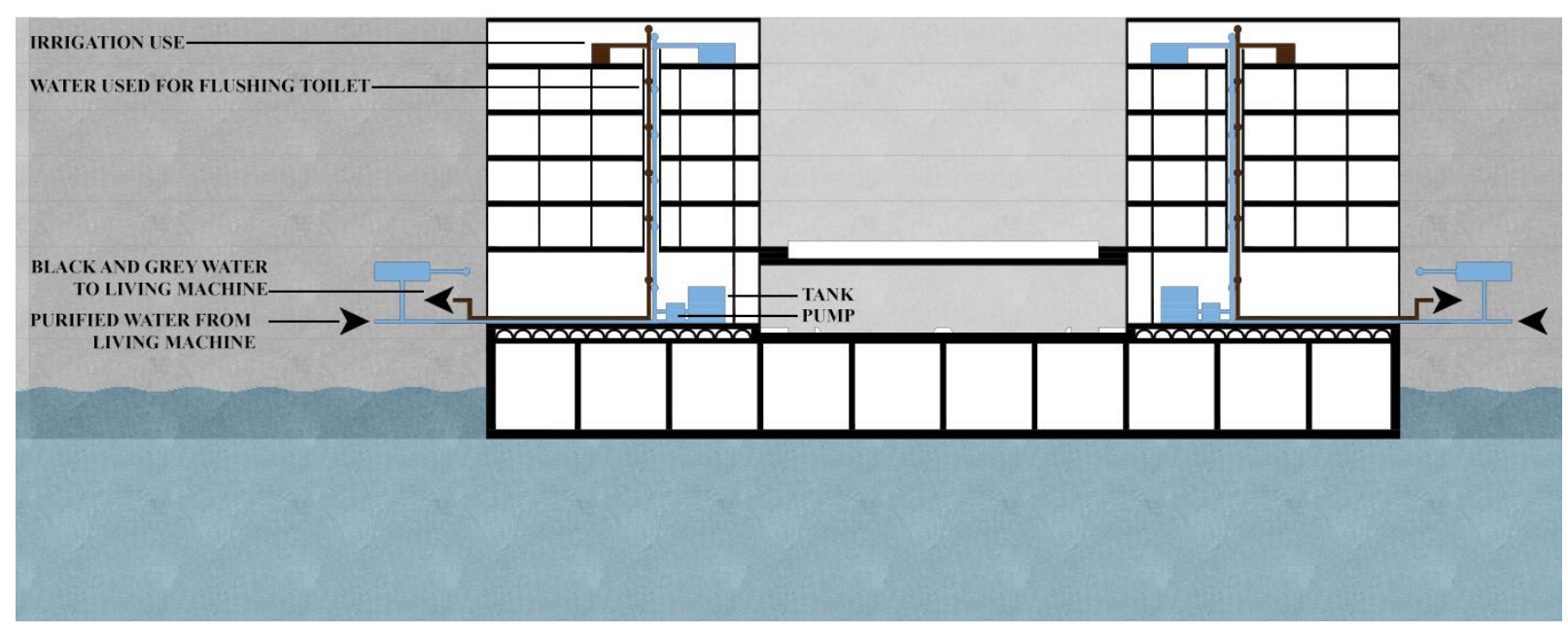

66 Figure 7.25: Detail Section Living Machine (own illustration). 
The main way in water harvesting and usage in the roof are presented in figure 7.25. The water quality is improved by the Pax Water impeller keeping water tanks in good quality for a longer time. As an emergency backup plan, local land-based water network should be connected in emergencies or maintenance.

\subsection{Mobility}

\subsubsection{Marina, Wave Attenuating Paths, Floating Wetlands, Building Forms and Patios}

The aim in floating wetlands started in the wave attenuator pathway design, vegetation and docks once the modules assemble. Implementing Bio-haven Floating Breakwaters (BFB) would be advantageous for their various characteristics such as their recreational features, seawater cleansing and adding vegetation abilities (C2C Building Charter Goals).

Should the BFB be created in the wave attenuator to absorb the wave impacts as such Floating treatment wetlands can endure high storm situations up to $145 \mathrm{~km} / \mathrm{hr}$ (Lund \& Vollenweider, 2006). The BFB function as recyclable floating material that provides a platform for growing salt-water flora. 


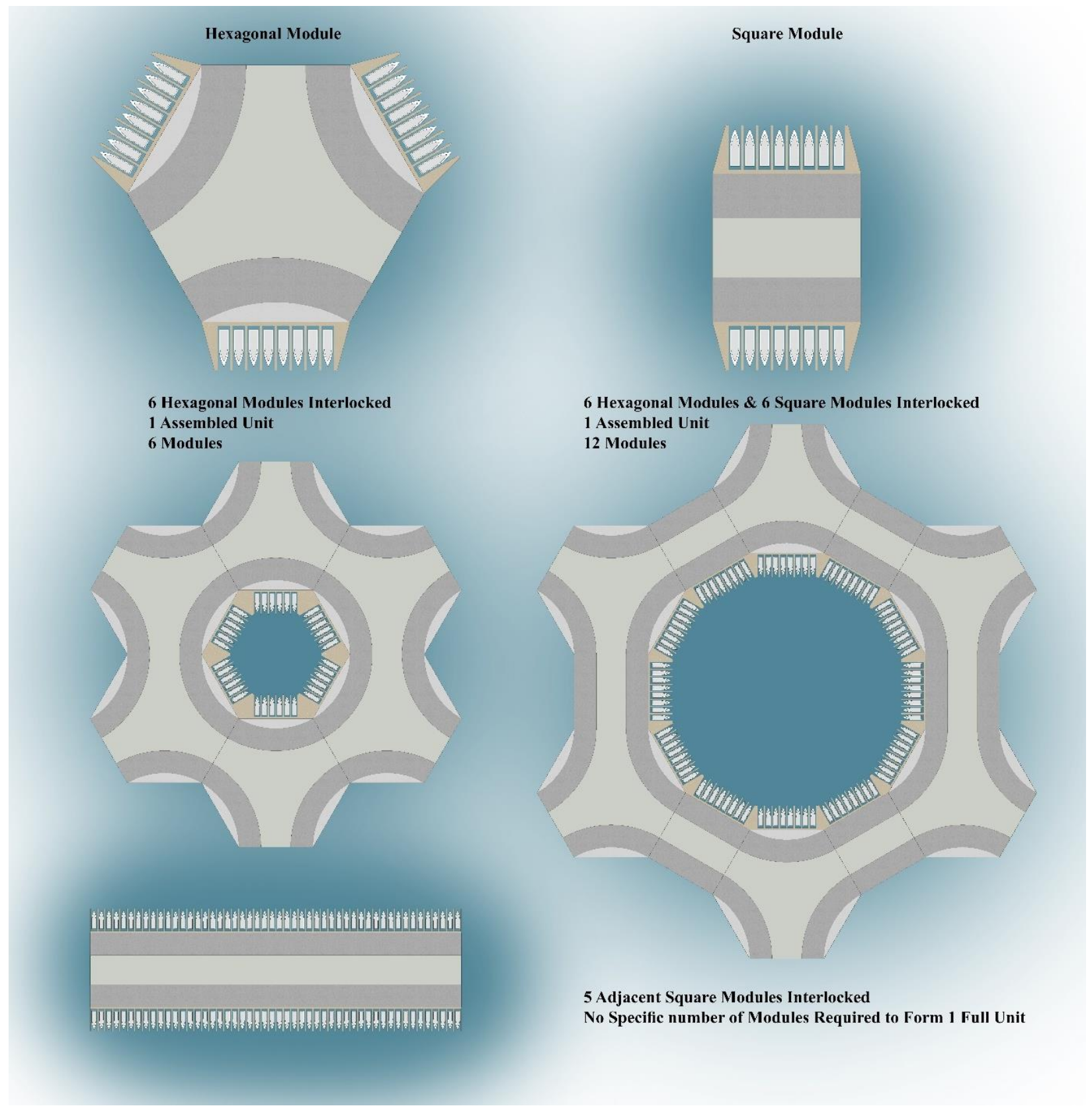

67 Figure 7.26: Units Assembly Proposals of both Modules showing the harbour and wave attenuators (own illustration). 
Herein the proposal for Abu-Qir Bay, the objective of wave attenuators was not only for architectural aspects, but for safety against collisions and stability reasons as well as making docks, pedestrian circulation paths and recreational spaces. Such goal could better be executed once the modules connect to one full formation. The proposal herein is to create a central building patio-like area for the residents for agriculture, view, and passageway. The central water patio herein has several impacts like water circulation paths, floating vegetation, hydroponics and fishing. Such features created recreational spaces inside and outside each full assembled cycle unit for various activities.

The goal of the docks and the wave attenuator is to facilitate assembly, dismantle, and maintenance for the flotation units under the ground floor. The coastal areas of the Nile Delta had a busy ship traffic and anchoring where the probable sites new land reclamation areas. The attenuator protects the floating community from probable marine collisions like ships or high waves in case a breakwater isn't implemented.

The wave attenuator advantage over breakwater is that it does not interrupt underwater streams as that are not as deep as breakwaters which makes them better in sustaining the underwater ecosystem as nutrients travel underwater to the shore (Cox \& Czlapinski, 2016).

Artificial islands and wetland technologies are executed globally for water purification reasons with positive outcomes. Floating wetland demonstrated significant wave absorbing capabilities in seawater wherever implemented. Such capabilities led to using wave attenuators which supports the $\mathrm{C} 2 \mathrm{C}$. 


\subsubsection{Traffic Routes and Security}

The principal traffic path herein the proposal is the roof floor, first floor, and ground floor (implements two options). The roof floor should implement pedestrian and bicycles paths at the top, although it wont function until the modules assemble to a full formation. The firstfloor herein integrates pedestrian and bicycles on both sides of the agricultural area. The ground floor first option is using roads for vehicles, as well as bicycles and pedestrian paths (see figure 7.28), while the second one is using boats as water traffic (see figure 7.27). Floating pathways are an essential safety and comfort requirement (British Columbia Building Code Interpretation Committee, 2015).
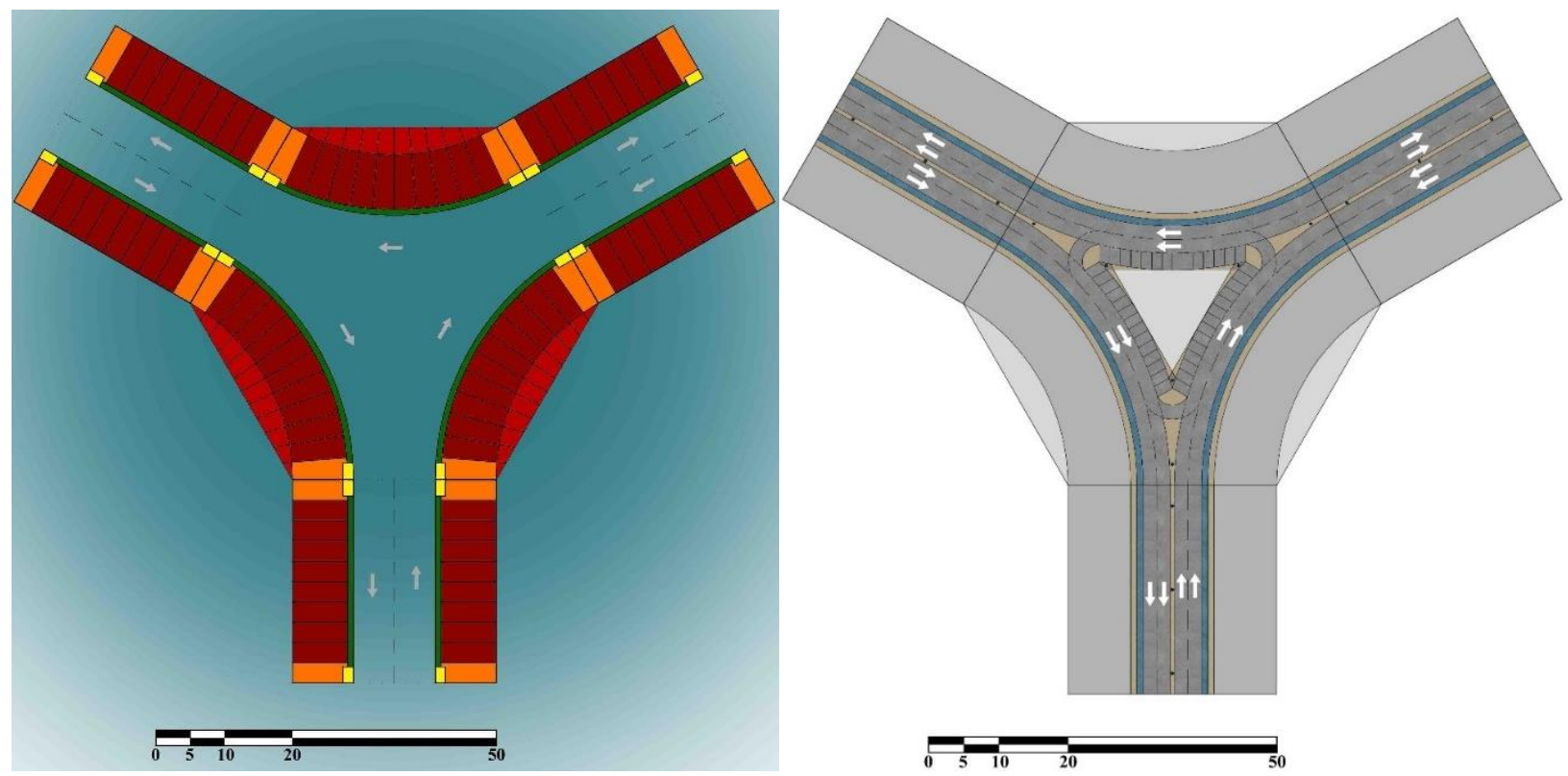

68 Figure 7.27: (Left) Ground floor plan of one hexagonal module connected to three squared modules. Water circulation option (own illustration).

69 Figure 7.28: (Right) Plan traffic routes (own illustration). 
Emergency situations require implementing two lanes road in each direction whether for water and vehicle traffic routes (maximum of five meters high) for either small tugboats or firefighter trucks to reach the site and return to coast. Such characteristic is required for any floating module where units are planned for several formations. Tugboats and firefighting units should be near shore and ready for any emergency. They should be improved by seawater pump employed into the breakwater structure or wave attenuators. The pathways should be stable and avoid the wave action by integrating breakwater structure around the assembled united modules.

\subsubsection{Transportation System}

The local taxi-boat could provide a light mobile network of water traffic solution was influenced by Thailand's floating markets and Harvest City for connecting and transporting the residents of the floating community, employees in the small offices and businesses, and for friends and family visitors. Taxi boat and quay areas can be located around the united modules of the floating community. They could use clean energy by using local powered energy source in the taxi docks. They are more desirable as they're less noisy and more environmentally friendly. As mentioned earlier, tugboats could be integrated for transporting platforms to the site and for relocating in case of any emergency cases.

\subsection{Cost Evaluation and Practicability}

The budget, site conditions and the residents have a significant effect on the practicability. Predominantly, in any floating community it's vital to have practical access to dryland for a constant economic development, and for the public and transporting goods (see Table 7.7). 


\subsubsection{Linkage to Seaside Cities}

Assembling the primary small-scale platforms to form the community and the economic development might be a lot better when the floating community is neighbouring a big seaside city. Throughout time, urbanizations which advanced on coasts were frequently for trade or to defend strategic areas. For such purpose, main cities are usually situated near rivers, bays or ports, or at the intersection of central land trade courses. A floating community for AbuQir Bay should take such aspect in consideration. The overall conclusion from cities development throughout history where there are three main impacts which are the economic progress, natural development, and countryside to city relocation. The main substantial purpose to relocate to cities is economical. Vital pull features are anticipated for work and comfort, whereas the push features are the contrary situations of the rural areas.

The economical effects must be respected, meaning that the floating community must comply with the rules of the government where it lies. The community must attract various businesses and industries. Therefore, companies and entrepreneurs would bring possibilities for leisure businesses such as hotels, cafeterias, shops, and restaurants. Encouragements must take place like in containing plain and direct legislation, low taxes, cheaper rents for businesses than in city centres, trained labor-force, accessibility to information and data, technology and upgrading, efficient public transportation networks to the city, particularly when the community is still small. One more significant feature would be their access to worldwide markets via sea and/or air. 


\subsubsection{Cost Estimate}

To evaluate costs, a lot of aspects should be calculated such as: housing, agriculture, offices and stores, water sources, and energy sources. Other factors which would affect the graphics such as: harbours, hospitals, and schools.

\subsubsection{Model}

For each platform evaluation costs, in Egypt in terms of per cubic meter of concrete is about 400 EGP (20 USD), of steel would be around 1,200 EGP (67 USD), and overall the structure value would be approximately 4,300 EGP (240 USD). The following stage, the structure will be planned on some more detailed wave information, inter platforms connectors and the mooring system, that requires the complete design first for comprehensive cost statistics. The concrete platform structure with chains and sewage system would cost around 5,000,000 EGP (139,800 USD) or 4,640 EGP (260 USD) per meter squared.

\begin{tabular}{|l|l|l|}
\hline $\begin{array}{l}\text { First-Level Space classification (Squared } \\
\text { Module) }\end{array}$ & Percentage & Area \\
\hline Platform & $100 \%$ & $2500 \mathrm{~m}^{2}$ \\
\hline Walkways (Including in building area) & $6 \%(11 \%)$ & $150 \mathrm{~m}^{2}\left(270 \mathrm{~m}^{2}\right)$ \\
\hline Vegetation & $34 \%$ & $850 \mathrm{~m}^{2}$ \\
\hline Built up area & $60 \%$ & $1500 \mathrm{~m}^{2}$ \\
\hline
\end{tabular}

52 Table 7.5: Spaces and Functions.

\begin{tabular}{|l|l|l|}
\hline $\begin{array}{l}\text { First-Level Space classification } \\
\text { (Hexagonal Module) }\end{array}$ & Percentage & Area \\
\hline Platform & $100 \%$ & $6500 \mathrm{~m} 2$ \\
\hline Walkways (Including in building area) & $4.8 \%(8.5 \%)$ & $315 \mathrm{~m} 2(555 \mathrm{~m} 2)$ \\
\hline Courtyard & $5.2 \%$ & $341 \mathrm{~m} 2$ \\
\hline Vegetation (Including possible added courtyard) & $37.8 \%(43 \%)$ & $2460 \mathrm{~m} 2(2800 \mathrm{~m} 2)$ \\
\hline Built up area & $52.2 \%$ & $3400 \mathrm{~m} 2$ \\
\hline
\end{tabular}

53 Table 7.6: Spaces and Functions. 


\begin{tabular}{|c|c|c|c|c|c|}
\hline & Item & & Unit & Square & Hexagonal \\
\hline \multirow[t]{11}{*}{ Materials } & \multirow[t]{4}{*}{ Concrete } & \multirow[t]{2}{*}{$\begin{array}{l}\text { Cost per cubic } \\
\text { meter }\end{array}$} & $\begin{array}{l}\text { Cost per cubic } \\
\text { meter (EGP) }\end{array}$ & 400 (EGP) & 400 (EGP) \\
\hline & & & $\begin{array}{l}\text { Cost per cubic } \\
\text { meter (USD) }\end{array}$ & 20 (USD) & 20 (USD) \\
\hline & & \multirow[t]{2}{*}{$\begin{array}{l}\text { Cost per } \\
\text { square meter }\end{array}$} & $\begin{array}{l}\text { Cost per } \\
\text { meter squared } \\
(\mathrm{EGP})\end{array}$ & 4,640 (EGP) & 4,640 (EGP) \\
\hline & & & $\begin{array}{l}\text { Cost per } \\
\text { meter squared } \\
(\mathrm{EGP})\end{array}$ & 260 (USD) & 260 (USD) \\
\hline & \multirow[t]{4}{*}{ Steel } & \multirow[t]{2}{*}{$\begin{array}{l}\text { Cost per cubic } \\
\text { meter }\end{array}$} & $\begin{array}{l}\text { Cost per cubic } \\
\text { meter (EGP) }\end{array}$ & 1,200 (EGP) & 1,200 (EGP) \\
\hline & & & $\begin{array}{l}\text { Cost per cubic } \\
\text { meter (USD) }\end{array}$ & 67 (USD) & 67 (USD) \\
\hline & & \multirow[t]{2}{*}{$\begin{array}{l}\text { Cost per } \\
\text { square meter }\end{array}$} & $\begin{array}{l}\text { Cost per } \\
\text { meter squared } \\
(\mathrm{EGP})\end{array}$ & 4,640 (EGP) & 4,640 (EGP) \\
\hline & & & $\begin{array}{l}\text { Cost per } \\
\text { meter squared } \\
(\mathrm{EGP}) \\
\end{array}$ & 260 (USD) & 260 (USD) \\
\hline & \multirow[t]{3}{*}{ Platform } & \multicolumn{2}{|l|}{ Area } & $6,500 \mathrm{~m}^{2}$ & $2,500 \mathrm{~m}^{2}$ \\
\hline & & \multirow[t]{2}{*}{ Platform } & $\begin{array}{l}\text { Per Platform } \\
\text { (EGP) }\end{array}$ & $\begin{array}{l}5,000,000 \\
(\mathrm{EGP})\end{array}$ & $\begin{array}{l}20,000,000 \\
\text { (EGP) }\end{array}$ \\
\hline & & & $\begin{array}{l}\text { Per Platform } \\
\text { (USD) }\end{array}$ & 139,800 (USD) & $\begin{array}{l}1,183,000 \\
\text { (USD) }\end{array}$ \\
\hline \multirow[t]{4}{*}{ Unit } & \multirow[t]{2}{*}{6 Units } & \multirow[t]{2}{*}{$\begin{array}{l}\text { Six hexagonal } \\
\text { platforms }\end{array}$} & $\begin{array}{l}6 \mathrm{x} \text { platforms } \\
\text { (EGP) }\end{array}$ & $\begin{array}{l}30,000,000 \\
(\mathrm{EGP})\end{array}$ & $\begin{array}{l}120,000,000 \\
\text { (EGP) }\end{array}$ \\
\hline & & & $\begin{array}{l}6 \mathrm{x} \text { platforms } \\
\text { (USD) }\end{array}$ & 838,800 (USD) & $\begin{array}{l}7,098,00 \\
\text { (USD) }\end{array}$ \\
\hline & \multirow[t]{2}{*}{12 Units } & \multirow{2}{*}{$\begin{array}{l}\text { Six hexagonal } \\
\text { platforms and } \\
\text { six squared } \\
\text { platforms }\end{array}$} & $\begin{array}{l}1 \text { Unit (12x } \\
\text { platforms) } \\
(\mathrm{EGP})\end{array}$ & \multicolumn{2}{|c|}{$150,000,000$ (EGP) } \\
\hline & & & $\begin{array}{l}1 \text { Unit (12x } \\
\text { platforms) } \\
\text { (USD) }\end{array}$ & \multicolumn{2}{|l|}{$7,936,800$ (USD) } \\
\hline
\end{tabular}

54 Table 7.7: Cost for building the hexagonal and squared floating platforms.

Throughout the concept development, it has been concluded that maximizing the flexibility for the floating community could highly be effective when uniting squared and hexagonal formed platforms. The $6,500 \mathrm{~m}^{2}$ hexagonal platform will cost around 20,000,000 EGP $(1,183,000$ USD) if all the platform characteristics remain the same. For each 
neighborhood in the floating community project, six hexagonal units can unit to form one neighborhood or they can unite with six square platforms to create a larger formation.

Apart from the cost evaluation, any similar project should measure the practicability of a clean water and power sources. Either ways, each platform should be completely provided by desalination system, wind and solar power.

\subsubsection{Water Supply}

To measure the practicability of the self-sufficient water scheme, the amount of rain per year should be measured first. Afterwards, such number should be related to:

- Domestic water usage per inhabitant per day.

- Offices or stores water usage per square meter per day.

- Hotel water usage per room per day.

- Agriculture usage per square meter per day.

For the previous purposes mentioned, the low and high-water usage such as in the Netherlands and USA for either low or high usage situations, not enough rainwater could possibly be collected for all requirements in the case of the Nile Delta.

Water should be divided to each platform depending on each platform's purpose(s), which means that each platform contains its own water collection and factorization systems. In a high usage situation such as in a hotel platform is one of the main reasons that rain water won't be satisfactory. In a situation where the platform hosts offices, such platform wont use nearly what it collects. Rainwater and water purification systems would cost about 2,100,000 EGP (117,460 USD) for the first year in the one formation (six hexagonal platforms and six 
squared platforms), but each further year would be more economical as the systems are already implemented, although it would involve extra costs such as new filters, running, preservation.

\subsubsection{Energy}

As for the solar energy, generally the strong sunlight in Egypt makes it a powerful source of energy. Solar radiation information is transferred to kilowatt per hour for comparing it with the demand. Low and high usage situations depend on the purpose whether housing, businesses or hotels. The demand statistics is then likened to the power generated by the panels, created upon the rooftop area. Both situations are seen practicable, where the supply minimum is higher than the demand.

Afterwards, the expenses of micro-grid method were related to diesel generators methods and as a result the micro-grid seems to be a more feasible solution. Although the price of the solar system is higher than that of price diesel generators, on the other hand the solar system has significantly lower costs throughout its lifespan.

\subsection{Growth Strategy}

As discussed earlier, biomimicry is a great reference for sustainability and development approaches. Numerous creatures, such as salmon, they pass their early stages in protected waters, and once they are strong enough, they move to the open waters. Correspondingly, a floating community should act similarly in protected waters until they have the suitable scale, they should gradually move into deeper zones until they reach the open waters. Breakwater should be considered in any floating community plan where it can expand with the community's expansion. If such community is to be relocated to open waters, it must be 
secure from the waves of high seas. Such community needs to imitate fish and adapt to the aquatic environment.

Throughout the beginning of any floating community, just a few urban approaches could be done. Nevertheless, as it expands, further functions could be added, like a hospital, a school and possibly a runway. Such development could as well assist the community into becoming self-sufficient from the outside. Finally, only when the floating community become independent regarding water, energy, and economical, it could relocate to the open waters.

Level 1: Bay (inland and protected water):

- Calm waters conditions.

- Suburban.

- Dependent (airports, gas, other services).

Level 2: Seacoast (inland sea) which is in outside territorial sea borders:

- Moderate waters conditions.

- Satellite district.

- Semi-independent (some energy or water production or not sufficient for the required demand).

Level 3: Sea (open water) which is in outside economical zones:

- Harsh water conditions.

- Isolated city.

- Independent (own water, waste, and energy resources). 


\subsection{Expanding Dynamics}

Such floating community concept proposal delivers of diverse dynamic expansions for the floating community, where various stages take place:

- House, from four to five residents.

- Building, from 256 to 320 residents in 64 apartments (Square module).

Building, from 480 to 600 residents in 120 apartments (Hexagonal module).

- Town, from 4416 to 5,520 residents.

- City, from 19,200 to 24,000 houses.

Such dynamic expansion could generate the essential settings for the complete community. The community should be worth their money for all levels, or inhabitants might move out. Profitable procedures should be rewarded, as such act would interest more new residents and industries. City governments applying high taxes and/or would not offer the adequate services would not be able to either attract or hold on to their residents and businesses. An incompetent municipality with the government interfering in each subject would result in such floating communities to dissolve. Nevertheless, a qualified municipality may generate unlimited opportunities for the inhabitants, investors and business as shown in Table 7.8, 7.9, \& 7.10 and for possibility analysis Table 7.11, 7.12, \& 13. (Fore more information about the residential possibilities regarding expanding dynamics consequences, refer to Annex B). 


\begin{tabular}{|c|c|c|c|}
\hline Option & Expansion method & Characteristics & $\begin{array}{l}\text { Probable } \\
\text { drivers }\end{array}$ \\
\hline $\begin{array}{l}\text { Move } \\
\text { with } \\
\text { house }\end{array}$ & & $\begin{array}{l}\text { Relocating the } \\
\text { floating house } \\
\text { within the city. }\end{array}$ & $\begin{array}{l}\text { Unsatisfied } \\
\text { with } \\
\text { neighborhood. } \\
\text { Being nearby } \\
\text { work, family or } \\
\text { friends. }\end{array}$ \\
\hline $\begin{array}{l}\text { Sell and } \\
\text { move }\end{array}$ & & $\begin{array}{l}\text { Like in land- } \\
\text { based areas. } \\
\text { Sell your home } \\
\text { and relocate in } \\
\text { or outside the } \\
\text { city. }\end{array}$ & \begin{tabular}{ll}
\multicolumn{2}{l}{ Unsatisfied } \\
with your \\
home. \\
Craving a \\
more \\
appealing \\
area.
\end{tabular} \\
\hline $\begin{array}{l}\text { Stay and } \\
\text { upgrade }\end{array}$ & & $\begin{array}{l}\text { Remain at the } \\
\text { same site. } \\
\text { Sell the home } \\
\text { on web-based } \\
\text { platform. } \\
\text { Buy a bigger } \\
\text { home for the } \\
\text { same site. }\end{array}$ & $\begin{array}{l}\text { Satisfied with } \\
\text { neighborhood } \\
\text { but unsatisfied } \\
\text { with home. }\end{array}$ \\
\hline Unite & & $\begin{array}{l}\text { Encounter new } \\
\text { people with } \\
\text { same desires, } \\
\text { values and } \\
\text { vision to form a } \\
\text { new } \\
\text { neighborhood in } \\
\text { or outside the } \\
\text { city. }\end{array}$ & $\begin{array}{l}\text { The crave to } \\
\text { form a } \\
\text { distinguished } \\
\text { society. }\end{array}$ \\
\hline
\end{tabular}

55 Table 7.8: Analyzed possibilities for growth development on a house level (own illustrations). 


\begin{tabular}{|c|c|c|c|}
\hline Option & Expansion method & Characteristics & $\begin{array}{l}\text { Probable } \\
\text { drivers }\end{array}$ \\
\hline Move & & $\begin{array}{l}\text { Neighborhood } \\
\text { relocation } \\
\text { within the city. }\end{array}$ & $\begin{array}{l}\text { More } \\
\text { possibilities for } \\
\text { economic } \\
\text { growth. } \\
\text { Relocation } \\
\text { required for } \\
\text { general growth } \\
\text { approach of } \\
\text { city. }\end{array}$ \\
\hline Merge & & $\begin{array}{l}\text { Unite } \\
\text { neighborhoods } \\
\text { to form a } \\
\text { bigger one. }\end{array}$ & $\begin{array}{l}\text { To be appealing } \\
\text { for inhabitants } \\
\text { and residents. } \\
\text { More lobby } \\
\text { power with the } \\
\text { municipality. } \\
\text { Enhance } \\
\text { capability to } \\
\text { form better } \\
\text { services. }\end{array}$ \\
\hline Split & & $\begin{array}{l}\text { Divide } \\
\text { neighborhood } \\
\text { to form to } \\
\text { smaller one. }\end{array}$ & $\begin{array}{l}\text { Enhance } \\
\text { human scale. } \\
\text { Unsatisfied } \\
\text { with } \\
\text { neighborhood } \\
\text { council. }\end{array}$ \\
\hline Dissolve & & $\begin{array}{l}\text { Divide } \\
\text { neighborhood } \\
\text { into separate } \\
\text { houses to be } \\
\text { free to go } \\
\text { anywhere in } \\
\text { the city. }\end{array}$ & $\begin{array}{l}\text { Absence of } \\
\text { social unity. } \\
\text { Disagreements. } \\
\text { Incompetent } \\
\text { neighborhood } \\
\text { council. }\end{array}$ \\
\hline Spinout & & $\begin{array}{l}\text { Leave city to } \\
\text { form new } \\
\text { floating } \\
\text { community in } \\
\text { a shoreside } \\
\text { protected bay. }\end{array}$ & $\begin{array}{l}\text { Unsatisfied } \\
\text { with city } \\
\text { administration. } \\
\text { More } \\
\text { possibilities to } \\
\text { relocate nearby } \\
\text { other littoral } \\
\text { city. }\end{array}$ \\
\hline Transfer & & $\begin{array}{l}\text { Relocate } \\
\text { neighborhood } \\
\text { to another city. }\end{array}$ & $\begin{array}{l}\text { Unsatisfied } \\
\text { with city } \\
\text { administration. } \\
\text { More } \\
\text { possibilities in } \\
\text { other cities. }\end{array}$ \\
\hline
\end{tabular}

56 Table 7.9: Analyzed possibilities for growth development on a neighborhood level (own illustrations). 


\begin{tabular}{|c|c|c|c|}
\hline Option & Expansion method & Characteristics & $\begin{array}{l}\text { Probable } \\
\text { drivers }\end{array}$ \\
\hline Move & & $\begin{array}{l}\text { District } \\
\text { relocation } \\
\text { within the city. }\end{array}$ & $\begin{array}{l}\text { More } \\
\text { possibilities for } \\
\text { economic } \\
\text { growth. } \\
\text { Required for } \\
\text { general growth } \\
\text { approach of } \\
\text { city. }\end{array}$ \\
\hline Merge & & $\begin{array}{l}\text { Unite districts } \\
\text { to form a } \\
\text { bigger one. }\end{array}$ & $\begin{array}{l}\text { To be appealing } \\
\text { for inhabitants. } \\
\text { More lobby } \\
\text { power with the } \\
\text { municipality. } \\
\text { Enhance } \\
\text { capability to } \\
\text { form better } \\
\text { services. }\end{array}$ \\
\hline Settle & & $\begin{array}{l}\text { Unite with } \\
\text { other districts } \\
\text { from same or } \\
\text { further cities } \\
\text { to form a } \\
\text { bigger one. }\end{array}$ & $\begin{array}{l}\text { More } \\
\text { possibilities } \\
\text { elsewhere. } \\
\text { Economic } \\
\text { collaboration of } \\
\text { districts. }\end{array}$ \\
\hline Split & & $\begin{array}{l}\text { Divide district } \\
\text { to form to } \\
\text { smaller one. }\end{array}$ & $\begin{array}{l}\text { Enhance } \\
\text { human scale. } \\
\text { Unsatisfied } \\
\text { with district } \\
\text { council. }\end{array}$ \\
\hline Dissolve & & $\begin{array}{l}\text { Divide districts } \\
\text { into separate } \\
\text { neighborhoods } \\
\text { to be free to go } \\
\text { anywhere in } \\
\text { the city. }\end{array}$ & $\begin{array}{l}\text { Absence of } \\
\text { social unity. } \\
\text { Disagreements. } \\
\text { Incompetent } \\
\text { district council. }\end{array}$ \\
\hline Spinout & & $\begin{array}{l}\text { Leave city to } \\
\text { form new } \\
\text { floating city in } \\
\text { open waters. }\end{array}$ & $\begin{array}{l}\text { Unsatisfied } \\
\text { with city } \\
\text { administration. } \\
\text { More } \\
\text { possibilities } \\
\text { elsewhere. }\end{array}$ \\
\hline Transfer & & $\begin{array}{l}\text { Relocate } \\
\text { district to } \\
\text { another city. }\end{array}$ & $\begin{array}{l}\text { Unsatisfied } \\
\text { with city } \\
\text { administration. } \\
\text { More } \\
\text { possibilities in } \\
\text { other cities. }\end{array}$ \\
\hline
\end{tabular}

57 Table 7.10: Analyzed possibilities for growth development on a district level (own illustrations). 


\begin{tabular}{|c|c|c|c|c|c|c|c|c|}
\hline Objective & Level & Approach & $\begin{array}{l}\text { Practicali } \\
\text { ty }\end{array}$ & $\begin{array}{l}\text { Feasibilit } \\
\mathrm{y}\end{array}$ & $\begin{array}{l}\text { Repositio } \\
\text { ning }\end{array}$ & $\begin{array}{l}\text { Low } \\
\text { Maintena } \\
\text { nce costs }\end{array}$ & $\begin{array}{l}\text { Minimu } \\
\mathrm{m} \text { design } \\
\text { limitatio } \\
\mathrm{ns}\end{array}$ & $\begin{array}{l}\text { Overall } \\
\text { Evaluatio } \\
\mathrm{n} \text { for } \\
\text { Alexandr } \\
\text { ia coast }\end{array}$ \\
\hline \multirow{17}{*}{$\begin{array}{l}\text { Expandi } \\
\text { ng } \\
\text { dynamic } \\
\text { s }\end{array}$} & \multirow[t]{4}{*}{$\begin{array}{l}\text { House } \\
\text { Level }\end{array}$} & $\begin{array}{l}\text { Move } \\
\text { with } \\
\text { house }\end{array}$ & +++ & ++++ & ++++ & ++ & ++ & $75 \%$ \\
\hline & & $\begin{array}{l}\text { Sell and } \\
\text { move }\end{array}$ & +++ & +++ & ++ & +++ & ++ & $65 \%$ \\
\hline & & $\begin{array}{l}\text { Stay and } \\
\text { upgrade }\end{array}$ & ++ & +++ & +++ & ++ & ++ & $60 \%$ \\
\hline & & Unite & +++++ & ++++ & +++++ & ++++ & + & $95 \%$ \\
\hline & \multirow{6}{*}{$\begin{array}{l}\text { Neighbo } \\
\text { rhood } \\
\text { level }\end{array}$} & Move & +++ & +++ & +++ & ++ & + & $60 \%$ \\
\hline & & Merge & ++++ & +++++ & +++++ & +++ & + & $90 \%$ \\
\hline & & Split & +++ & +++ & ++ & ++ & ++ & $60 \%$ \\
\hline & & Dissolve & + & + & + & ++ & + & $30 \%$ \\
\hline & & Spinout & ++++ & ++ & +++ & ++ & ++ & $65 \%$ \\
\hline & & Transfer & ++ & + & ++ & ++ & ++ & $45 \%$ \\
\hline & \multirow{7}{*}{$\begin{array}{l}\text { District } \\
\text { level }\end{array}$} & Move & ++ & ++ & ++ & + & ++ & $45 \%$ \\
\hline & & Merge & +++++ & ++++ & +++++ & ++++ & + & $95 \%$ \\
\hline & & Settle & ++++ & +++++ & +++++ & ++++ & + & $95 \%$ \\
\hline & & Split & ++ & +++ & ++ & ++ & ++ & $55 \%$ \\
\hline & & Dissolve & + & ++ & ++ & ++ & ++ & $45 \%$ \\
\hline & & Spinout & + & + & + & + & + & $25 \%$ \\
\hline & & Transfer & ++ & ++ & ++ & ++ & ++ & $50 \%$ \\
\hline \multirow[b]{4}{*}{$\begin{array}{l}\text { Platform } \\
\text { dimensi } \\
\text { ons }\end{array}$} & \multirow{4}{*}{$\begin{array}{l}\text { Wave } \\
\text { motion } \\
\text { on } \\
\text { structur } \\
\text { e stress } \\
\text { of } \\
\text { various } \\
\text { platform } \\
\text { sizes }\end{array}$} & $\mathrm{L}=2 \lambda$ & +++++ & ++++ & + & +++ & +++ & $80 \%$ \\
\hline & & $\mathrm{L}=1 \lambda$ & ++++ & ++++ & ++ & ++ & +++ & $75 \%$ \\
\hline & & $\mathrm{L}=1 / 2 \lambda$ & ++ & ++ & +++ & + & ++ & $50 \%$ \\
\hline & & $\mathrm{L}=1 / 4 \lambda$ & + & ++ & ++++ & + & + & $45 \%$ \\
\hline
\end{tabular}

58 Table 7.11: Analyzed design methods and criteria for central Abu-Qir Bay. ${ }^{9}$

9 Very High (+++++) High (++++) Moderate (+++) Low (++) Very low (+) Not addressed (-). Method adopted from (IDSC, 2011). where each “+” accounts for $4 \%$ out of $20 \%$ stress of each parameter. Method adopted from: IDSC (2011) and Frihy \& El-Sayed (2013). Main References: British Columbia Float Home Standard (2015), Czapiewska et al. (2013), Dal Bo Zanon et al. (2017), IPCC (2007; 2014), Suzuki et al. (2006), (Tennessee Valley Authority, 2016), Tsaltas et al. (2010), UNFCCC (2007, 2016), Wang (2017), Wang \& Tay (2011), Watanabe et at. (2008). 


\begin{tabular}{|c|c|c|c|c|c|c|c|c|}
\hline Objective & Level & Approach & $\begin{array}{l}\text { Practicali } \\
\text { ty }\end{array}$ & $\begin{array}{l}\text { Feasibilit } \\
\mathrm{y}\end{array}$ & $\begin{array}{l}\text { Repositio } \\
\text { ning }\end{array}$ & $\begin{array}{l}\text { Low } \\
\text { Maintena } \\
\text { nce costs }\end{array}$ & $\begin{array}{l}\text { Minimu } \\
\text { m design } \\
\text { limitatio } \\
\text { ns }\end{array}$ & $\begin{array}{l}\text { Overall } \\
\text { Evaluatio } \\
\mathrm{n} \text { for } \\
\text { Alexandr } \\
\text { ia coast }\end{array}$ \\
\hline \multirow{17}{*}{$\begin{array}{l}\text { Expandi } \\
\text { ng } \\
\text { dynamic } \\
\text { s }\end{array}$} & \multirow[t]{4}{*}{$\begin{array}{l}\text { House } \\
\text { Level }\end{array}$} & $\begin{array}{l}\text { Move } \\
\text { with } \\
\text { house }\end{array}$ & ++ & ++++ & ++++ & ++ & ++ & $70 \%$ \\
\hline & & $\begin{array}{l}\text { Sell and } \\
\text { move }\end{array}$ & ++ & ++ & ++ & +++ & ++ & $60 \%$ \\
\hline & & $\begin{array}{l}\text { Stay and } \\
\text { upgrade }\end{array}$ & ++ & +++ & +++ & ++ & ++ & $60 \%$ \\
\hline & & Unite & +++++ & ++++ & +++++ & ++++ & + & $95 \%$ \\
\hline & \multirow{6}{*}{$\begin{array}{l}\text { Neighbo } \\
\text { rhood } \\
\text { level }\end{array}$} & Move & ++ & + & +++ & ++ & + & $45 \%$ \\
\hline & & Merge & +++++ & ++++ & +++++ & +++ & + & $90 \%$ \\
\hline & & Split & +++ & +++ & ++ & ++ & ++ & $60 \%$ \\
\hline & & Dissolve & + & + & ++ & ++ & + & $35 \%$ \\
\hline & & Spinout & +++ & + & +++ & +++ & ++ & $60 \%$ \\
\hline & & Transfer & ++ & + & ++ & ++ & + & $40 \%$ \\
\hline & \multirow{7}{*}{$\begin{array}{l}\text { District } \\
\text { level }\end{array}$} & Move & +++ & ++ & ++ & ++ & + & $50 \%$ \\
\hline & & Merge & +++++ & ++++ & +++++ & ++++ & + & $95 \%$ \\
\hline & & Settle & +++++ & ++++ & +++++ & +++ & + & $90 \%$ \\
\hline & & Split & +++ & +++ & ++ & ++ & ++ & $65 \%$ \\
\hline & & Dissolve & ++ & ++ & ++ & ++ & ++ & $50 \%$ \\
\hline & & Spinout & + & + & ++ & + & + & $30 \%$ \\
\hline & & Transfer & ++ & ++ & +++ & ++ & ++ & $55 \%$ \\
\hline \multirow[b]{4}{*}{$\begin{array}{l}\text { Platform } \\
\text { dimensi } \\
\text { ons }\end{array}$} & \multirow{4}{*}{$\begin{array}{l}\text { Wave } \\
\text { motion } \\
\text { on } \\
\text { structur } \\
\text { e stress } \\
\text { of } \\
\text { various } \\
\text { platform } \\
\text { sizes }\end{array}$} & $\mathrm{L}=2 \lambda$ & ++++ & ++++ & ++ & +++ & +++ & $85 \%$ \\
\hline & & $\mathrm{L}=1 \lambda$ & +++++ & ++++ & +++ & ++ & +++ & $85 \%$ \\
\hline & & $\mathrm{L}=1 / 2 \lambda$ & ++ & +++ & ++++ & ++ & ++ & $65 \%$ \\
\hline & & $\mathrm{L}=1 / 4 \lambda$ & + & +++ & +++++ & ++ & ++ & $60 \%$ \\
\hline
\end{tabular}

59 Table 7.12: Analyzed design methods and criteria for East Alexandria's coastline. ${ }^{10}$

10 Very High (+++++) High (++++) Moderate (+++) Low (++) Very low (+) Not addressed (-). Method adopted from (IDSC, 2011). where each “+” accounts for $4 \%$ out of $20 \%$ stress of each parameter. Method adopted from: IDSC (2011) and Frihy \& El-Sayed (2013). Main References: British Columbia Float Home Standard (2015), Czapiewska et al. (2013), Dal Bo Zanon et al. (2017), IPCC (2007; 2014), Suzuki et al. (2006), (Tennessee Valley Authority, 2016), Tsaltas et al. (2010), UNFCCC (2007, 2016), Wang (2017), Wang \& Tay (2011), Watanabe et at. (2008). 


\begin{tabular}{|c|c|c|c|c|c|c|}
\hline Objective & Level & Approach & $\begin{array}{l}\text { Suitability } \\
\text { for East } \\
\text { Alexandria's } \\
\text { coastline }\end{array}$ & $\begin{array}{l}\text { Suitability } \\
\text { for } \\
\text { Central } \\
\text { Abu-Qir } \\
\text { Bay }\end{array}$ & $\begin{array}{l}\text { Ideal } \\
\text { methods }\end{array}$ & $\begin{array}{l}\text { Design } \\
\text { methods } \\
\text { selected }\end{array}$ \\
\hline \multirow[t]{17}{*}{$\begin{array}{l}\text { Expanding } \\
\text { dynamics }\end{array}$} & \multirow[t]{4}{*}{ House Level } & $\begin{array}{l}\text { Move } \\
\text { with } \\
\text { house }\end{array}$ & $75 \%$ & $70 \%$ & $72.5 \%$ & $72.5 \%$ \\
\hline & & $\begin{array}{l}\text { Sell and } \\
\text { move }\end{array}$ & $65 \%$ & $60 \%$ & $62.5 \%$ & $62.5 \%$ \\
\hline & & $\begin{array}{l}\text { Stay and } \\
\text { upgrade }\end{array}$ & $60 \%$ & $60 \%$ & $60 \%$ & $60 \%$ \\
\hline & & Unite & $95 \%$ & $95 \%$ & $95 \%$ & $95 \%$ \\
\hline & \multirow{6}{*}{$\begin{array}{l}\text { Neighborhood } \\
\text { level }\end{array}$} & Move & $60 \%$ & $45 \%$ & $52.5 \%$ & $52.5 \%$ \\
\hline & & Merge & $90 \%$ & $90 \%$ & $90 \%$ & $90 \%$ \\
\hline & & Split & $60 \%$ & $60 \%$ & $60 \%$ & $60 \%$ \\
\hline & & Dissolve & $30 \%$ & $35 \%$ & $32.5 \%$ & $32.5 \%$ \\
\hline & & Spinout & $65 \%$ & $60 \%$ & $62.5 \%$ & $62.5 \%$ \\
\hline & & Transfer & $45 \%$ & $40 \%$ & $42.5 \%$ & $42.5 \%$ \\
\hline & \multirow[t]{7}{*}{ District level } & Move & $45 \%$ & $50 \%$ & $47.5 \%$ & $47.5 \%$ \\
\hline & & Merge & $95 \%$ & $95 \%$ & $95 \%$ & $95 \%$ \\
\hline & & Settle & $95 \%$ & $90 \%$ & $92.5 \%$ & $92.5 \%$ \\
\hline & & Split & $55 \%$ & $65 \%$ & $60 \%$ & $60 \%$ \\
\hline & & Dissolve & $45 \%$ & $50 \%$ & $47.5 \%$ & $47.5 \%$ \\
\hline & & Spinout & $25 \%$ & $30 \%$ & $27.5 \%$ & $27.5 \%$ \\
\hline & & Transfer & $50 \%$ & $55 \%$ & $52.5 \%$ & $52.5 \%$ \\
\hline \multirow{4}{*}{$\begin{array}{l}\text { Platform } \\
\text { dimensions }\end{array}$} & \multirow{4}{*}{$\begin{array}{l}\text { Wave motion } \\
\text { on structure } \\
\text { stress of } \\
\text { various } \\
\text { platform sizes }\end{array}$} & $\mathrm{L}=2 \lambda$ & $80 \%$ & $85 \%$ & $82.5 \%$ & $82.5 \%$ \\
\hline & & $\mathrm{L}=1 \lambda$ & $75 \%$ & $85 \%$ & $80 \%$ & $80 \%$ \\
\hline & & $\mathrm{L}=1 / 2 \lambda$ & $50 \%$ & $65 \%$ & $57.5 \%$ & $57.5 \%$ \\
\hline & & $\mathrm{L}=1 / 4 \lambda$ & $45 \%$ & $60 \%$ & $52.5 \%$ & $52.5 \%$ \\
\hline
\end{tabular}

60 Table 7.13: Analyzed design methods and criteria for growth development for central Abu-Qir Bay and East Alexandria's coastline. 


\subsection{Conclusions}

This chapter has applied previous conclusions of site analysis, adaptation solutions, and floating structures to define a floating community concept model for Abu-Qir Bay to analyze each feature. This chapter has conducted a floating community model of floating interconnecting platforms for an expandable floating community to establish architectural design guidelines for developing floating houses for Egypt. Abu-Qir Bay didn't only seem as the most vulnerable areas when addressing SLR, but also the ideal location for floating structures regarding its depth (18.5-22). And being in protected waters. Although the Manzala Lake which lies on the eastern side of Damietta's distributary is in high risk to SLR, however its situation is not as critical as the situation in Abu-Qir Bay as well as its shallow water makes floating structures appear not to be cost effective solution for such site.

The entire research on discovering the issues that influence floating community designs has been an extremely challenging mission. Initially, there are a various matters and criterion to create a realistic proposal, as the project is an architectural one, some engineering variables remain unresolved. The other subject was multidisciplinary material required for such project and material quantity which is not as familiar for architects as industrial engineers who's mostly specialized in on external ship design.

The biomimetic approach has shown significant conclusions whereas the road to sustainability began where the nature solved challenges of the build environment. The subjects regarding the housing, circulation, aquatic environment, floating wetlands and agriculture have shaped the proposal. The implementation of bio-waste to energy, fuel cells and the other innovative technologies as solar and wind energy have affected the building 
design proposal. More developed future concepts dealing with more detailed various ecological matters are required, that could demonstrate more precise data.

The modular structural interconnected modules have a blend of several positive matters. The approach was to integrate agricultural and water patios once the modules assemble. Integrating breakwater which surrounds the community is required if the project has expanded and extended in the deep seas. Evaluation on expanding dynamics in terms of house, neighborhood, district/city levels conclude that the optimum options for East Alexandria and central Abu-Qir area are: unite, merge, settle respectively.

\subsubsection{Floating Structures Design Approach}

The most significant objectives concluded for any site are portability, dynamic geography, development, survival/durability, security, and water life. If such features are to be integrated with energy and food production in any design, the result will be a fully selfindependent community from the outside. The main objective here has been to sustain Egypt's coastal sovereignty while offering a self-sufficient platform to compensate for the submerged areas instead of retrieving it by traditional land reclamation solutions.

\subsubsection{Location}

Although the surrounding environment. The public demands, and the government officials. Define the project development and boundaries regarding building on water, nevertheless, VLFS also plays a role in choosing the most suitable site as it may not offer the optimum solution in any site. Therefore, site analysis is crucial for any site to create genuine, practical, and suitable conclusions regarding such area. 

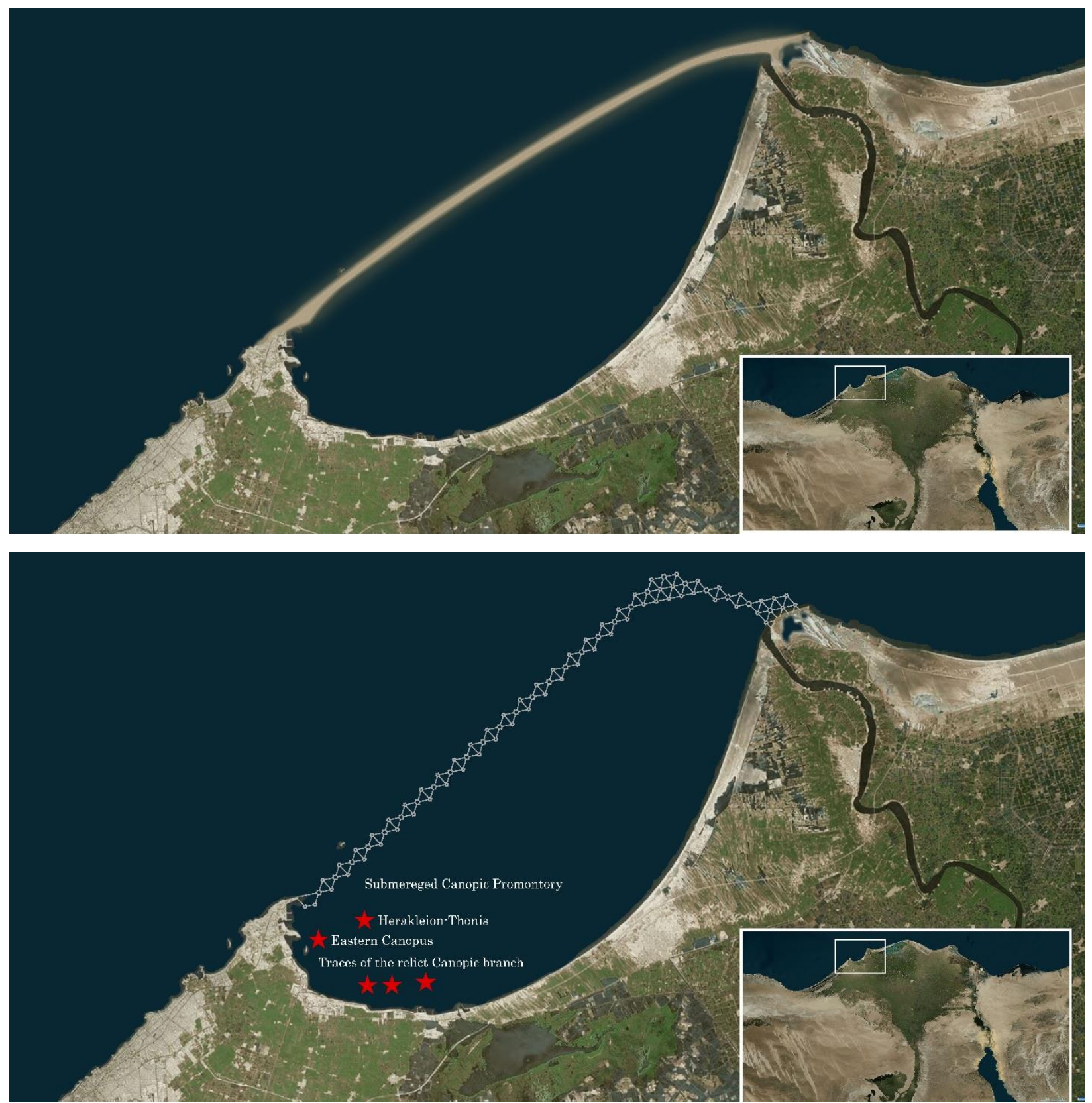

70 Figure 7.29: (Top) If land reclamation, sand dunes, \& breakwater unsustainable solutions are to be executed by the ESPA (own illustration); (Bottom) proposed floating community for Abu-Qir Bay (own illustration).

Floating structures must be designed to be able to survive not only in protected waters, but also in open waters if relocating is needed, however that would be unusual like in shortterm situations such as in natural disasters. Modular platforms could help in expansion 
strategies, movability in case of emergencies, and creating ordered formations, especially since findings demonstrate that harbors appear to create traffic chaos. Findings demonstrate the practicality and uncomplexity of VLFS as it could be assembled/disassembled easily or totally withdrawn if their location is required in the future as well as being able of expanding where they acquire modular forms. They demonstrate to offer different elements and components could be manufactured at different dockyards and then transported to the location to be assembled and thus sea-area could be exploited quickly.

The simulation should show the platforms' behaviour with the anticipated wave properties. If there is more than a possible site for the floating structure, the properties of permeant and relocation sites should be studied. The required data includes waves, bathymetry, and local conditions (nature and pollution should not be disregarded). Where the data required was insufficient for a specific site, a buoy might be positioned to calculate wave properties. Such method may be applied presently in any probable future settings. This thesis proposes Abu-Qir Bay as the ideal location after analyzing such site in detail, mainly for the findings on its water depth, wave properties, being in protected waters, and its connectivity to an existing infrastructure.

\subsubsection{Local bathymetry, Tides, and Waves}

VLFS are ecological friendly for the conservation of fragile ecosystems where they neither harm the maritime eco-system, nor do they silt-up deep ports or disturb the tides and sea waves, however, some criteria should be taken into consideration for bathymetry, tides and currents, and wave properties (see Table 7.14) where their properties and impacts on designing floating structures are set. 


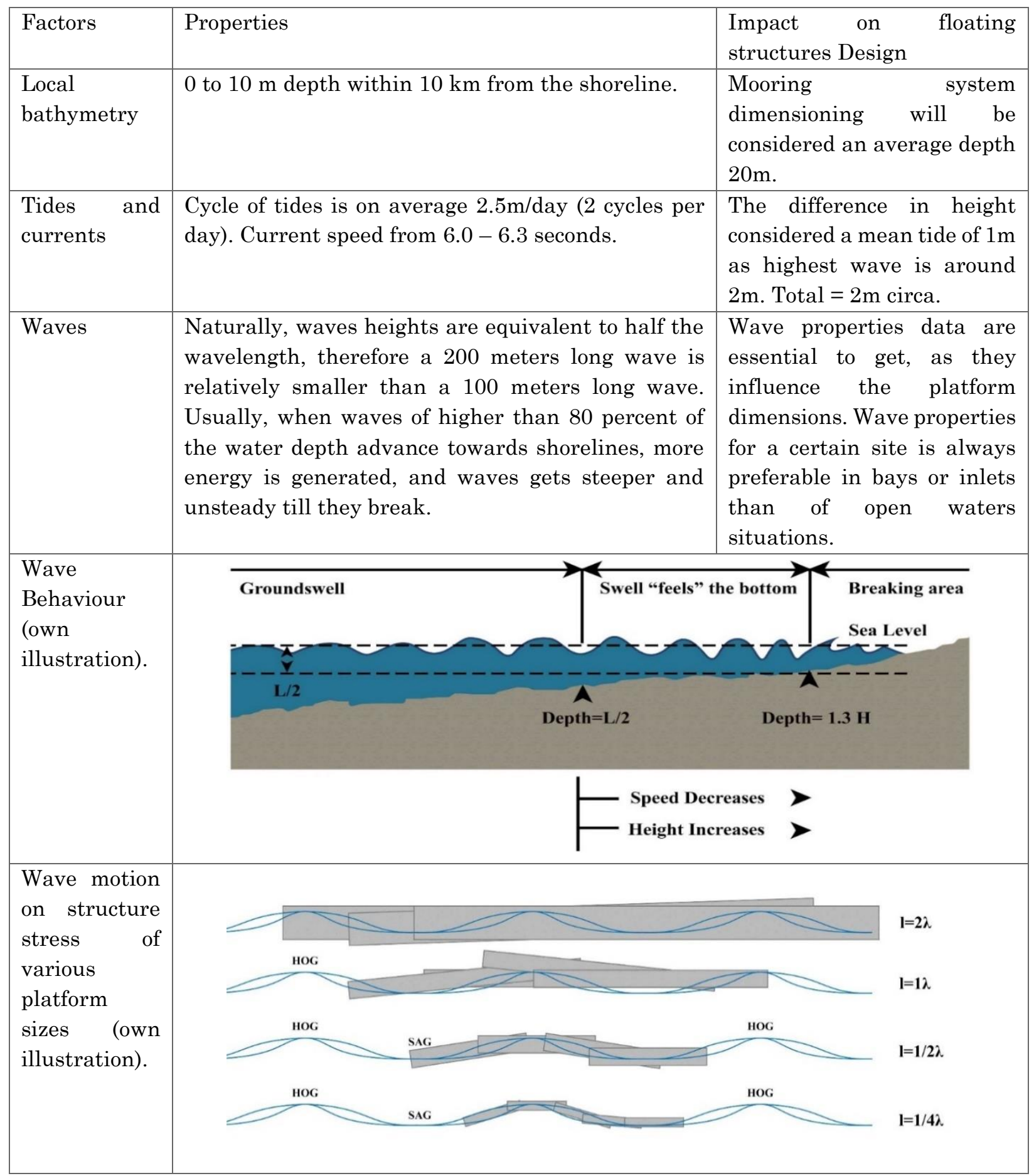

61 Table 7.14: Properties and impacts of bathymetry, tides and currents, and waves on the floating structures design (own illustrations).

Findings support the argument that traditional land reclamation methods are not a practical long-term solution apart from its various disadvantages on the ecosystem. The 
findings provide support for the key arguments that VLFS are more sustainable as it offers a cost-effective solution where there is a big water depth in terms of space creation and preserving the marine ecosystem. They are planned to be ecologically friendly as they don't disturb sea currents or silt-up the deep harbours of Abu-Qir and the Nile Delta in general. Also, they could easily be detached or expanded as well as not getting affected by seismic shockwaves as they are characteristically remotely based. However, such solution may does not seem to be practical in every case, nevertheless, VLFS may offer a practical solution for further areas when the SLRs even more.

\subsubsection{Water and Energy Supply}

The solar energy and further climate aspects offered such as rain water determine the practicability of a floating community to be self-sustainable. This is contingent to the climate properties of a precise site. Therefore, studies are required for any other sites for energy generation purposes. Water should be divided to each platform depending on each platform's purpose(s), which means that each platform contains its own water collection and factorization systems. In a high usage situation such as in a hotel platform is one of the main reasons that rain water won't be satisfactory. In a situation where the platform hosts offices, such platform wont use nearly what it collects.

\subsubsection{Structure and Stability}

Long-term structural stability is one of the greatest challenging objectives. Predominantly, the floating structure must be appropriate for the sea-site. Ultimately, the floating city herein is proposed to be able to survive not only in protected waters, but also in open waters where that would be infrequently and only short-term in natural disasters 
situations. Facilities and the structure of the VLFS should be protected to avoid harmful seismic shocks where their bases are fundamentally isolated. They do not suffer from a settlement gap because of the reclaimed soil consolidation. They have constant situations regarding water surface, hence, this enable small ships and vessels to come along to be used as docks and ports. VLFS also demonstrate to protect strategic economic in and offshore actions as well as safeguarding borders and habitats like in the situations in which the submerged area was highly important and unacceptable.

\subsubsection{Platform Size}

The platform size might be the best fit for the floating community regarding the objectives, site properties and further aspects such as financial and structure boundaries. The optimal size of the platforms is subjected to a lot of matters, where some could be accurately measured where some others could stay hypothetical. Findings show that optimum platform size varies between 45 to 75 meters for structural stability and safety purposes. Herein the platform size of $50 \mathrm{~m}$ a side has been set for interconnecting characteristics. Platform to wave-induced motion at various platform sizes and stress outcome on structure (see Table 7.14). However, more comprehensive information on the structure regarding the local wave properties are required for better estimations.

The platform must be designed to be appropriate for sea settings. The danger of whether the platforms' size is too big or too small is highlighted herein the proposal. Moreover, the conventional concrete structure is applied herein for its overall more effective features. More advanced systems constructed from composites could perhaps be a lot more suitable for such environment. Such technology is now in progress and have various advantages over other 
materials especially in weight and maintenance. Therefore, such material may substitute concrete if it wasn't for their current high value.

Afterwards, the rules and guidelines for buildings and platforms on fire and collision impacts must be considered. Moreover, maximizing the area usage of the platform must be defined, for instance for agriculture and for storing food and water.

\subsubsection{Mooring System}

Findings from site analysis and mooring system research conclude that the dolphin system to be the most suitable for Egypt's Nile Delta coasts since such mooring system is best implemented where there are no docks, or any coastline attached structure so that the floating structure could stay in position.

\subsubsection{Connections}

A feature which is related to transporting platforms is the interconnections between them, that it must not be complicated in dissembling. Such connections would be connected differently when towed disjointedly or in a row.

It is preferred where the mooring systems simply detached, and the precise engineering should be more developed, and cost considered. Afterward the temporary site when avoiding natural disasters, and how to stay placed in the temporary site. Reliant on the platforms interconnections and the anticipated forces of the site, the system could be improved, that may favor less connections and bigger anchors. 


\subsubsection{Platform Formations and Modular Assembly}

Modular structural interconnected modules have a blend of several positive matters. Since the project is aimed for the protected water of Abu-Qir Bay, so integrating breakwater which surrounds the community was not required for expansions. However, a proposal of how to implement breakwater has been offered in case of relocating to deep seas is required as the floating community must be designed to be able to survive not only in protected waters, but also in open waters where that would be infrequently and only short-term in natural disasters situations.

Herein the proposal, two platform forms are established, the squared and the hexagonal. The hexagonal and square design platform designs have offered the overall perfect combination solution, where it offered a straight-roads achievement, a reliable and more durable solution, as well as being able to continue growing while only using the hexagonal modules while the squared modules can only expand in linear way. The hexagonal shape could be interconnected to the square one and they could group into forming bigger geometric formations, like either six hexagonal and six squared platforms or only six hexagons could form full circular formations when grouped modularly. The hexagonal shape for platforms was found the optimum fit in terms of circulation and modular interconnecting.

\subsubsection{Movability}

Throughout this thesis, it has been concluded that the floating community should be capable of relocating in natural disasters. Simulations must be directed of such scenarios to predict the time and possible destinations of relocating. One of the important study questions 
is what kind of tugboat and the platforms outline where the best fit if relocating is required.

Relocating numerous joint platforms simultaneously in a train-like method could be useful.

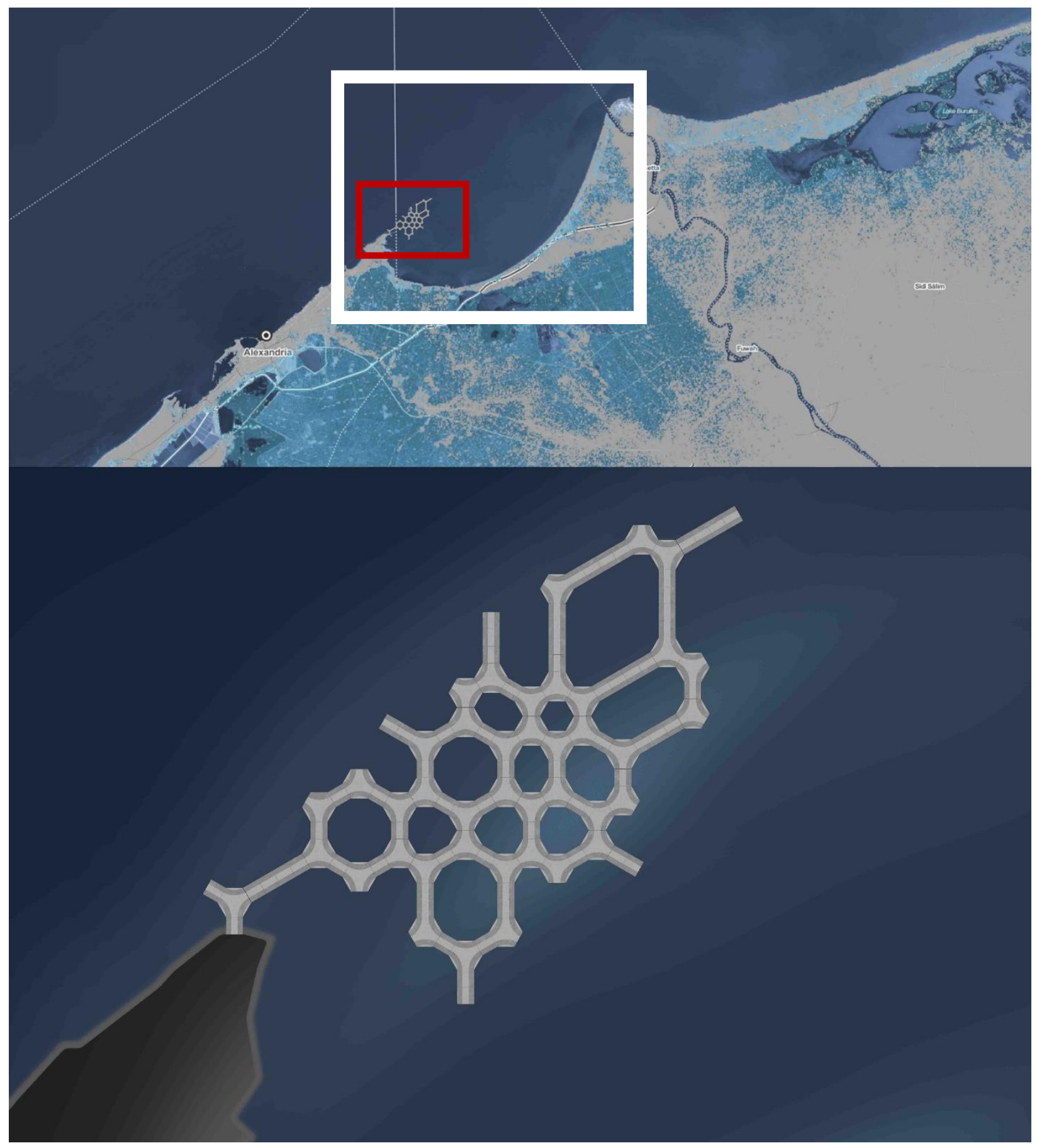

71 Figure 7.30: Demonstrating possible assembly formations when modules connect in AbuQir Bay (own illustration). 
Such merge offers an elongated formation, where its better regarding water resistance. Thus, it is vital to study which hull shape is the best fit regarding costs and construction, and whether its required just on the front platform or all of them. Moreover, such platforms must be tested for calculating the buildings' behaviour on the platforms when relocating.

\subsubsection{Pathways and Wave Attenuators}

Pathways are frequently attached to the floating building to the coastline and especially that in urbanized areas are generally very well attached to the neighbouring traffic system. Pathways of floatation ability are required for the gap space from coast to the floating community as it requires mooring to the seabed. Global common safety procedures require floating buildings to have emergency vehicles routes to the location and close to the building.

\subsubsection{Materials}

Materials selection analyzed in terms of maintenance, cost, weight, and stability show demonstrate of concrete, steel, composite materials show that concrete is the optimum selection in terms of maintenance, cost, and stability. However, steel is better only in terms of weight, while showing superiority over composites regarding its cost. Nevertheless, composites have emerged a great material in terms of maintenance and weight, however, it could be only implemented in high budget projects (possibly by the private sector). Concrete is regularly practiced in marine developments, like in underwater tunnels, offshore and subsea facilities. Some marine projects have practiced underwater concrete which have since existed over than 50 years. Although regarding durability and stability concrete has highpressure strength, nevertheless it has low-tensile one. The biggest disadvantage in using concrete is the steel reinforced which is implanted inside the concrete structure to offer a 
better tensile strength, although such material could rust. Thus, the appropriate concrete coating thickness is required to preserve the steel is unaffected. Such process has great impact on concrete structures weights. Lately, further supporting elements are implemented like fibers, for instance the Engineered Cementitious Composite (ECC) and the Fiberreinforced concrete (FRC). In platforms, implementing non-corrosive materials may offer huge progresses regarding resilience, mass and usage. On the other hand, composites have emerged a great material in terms of maintenance and weight, however, it could be implemented in high budget projects which will be mainly by the private sector.

\subsubsection{Expanding Dynamics and Growth Strategy}

Characteristics of Abu-Qir Bay in terms of its protected water, population, water depth (18.5-22), and wave properties makes VLFS as the optimum solution for such area. Being in protected waters means shielding from high waves as well as being able to expand since it won't be bounded by the breakwater. Therefore, modular platforms would be the way to expand and being nearby the coasts helps in emergency cases and transporting goods and people in and out. Although Lake Manzala in Damietta is in protected water and have better wave properties in comparison to Abu-Qir Bay, however water depth is extremely shallow (1.2-1.5 meters) and its population makes floating structures solution appear not to be cost effective approach for such site.

Upon defining the floating community proposal herein in terms of the outline, design, project characteristics, superstructure, mooring system, circulation, preliminary members formation, sustainability, reuse of nutrients, waste and recycling, water system, mobility, feasibility, growth strategy, and expanding dynamics for Abu-Qir Bay. Accordingly, the next chapter discusses results and findings of this thesis. 


\section{Chapter 8}

\section{RESULTS AND DISCUSSION}

\subsection{Introduction}

SLR challenges will disturb a lot of coastal areas around the world, either urban or agricultural, would possibly be flooded. Whereas the Nile Delta in Egypt is one of the lowest lying coastal areas in the world, therefore, the rise of sea level in parallel with the Nile Delta's rise in population and coastal cities developments urges the need for a long-term solution such in low-lying lands. Initial findings on Egypt's adaptation approaches demonstrate that Egypt rely heavily on lagoon drainage, dredging, and land reclamation solutions which have several high negative impacts such as land abandonment, high maintenance costs, soil erosion, disturb sea currents, silt-up deep harbours, and destroying coral reefs. Upon studying various solutions executed for SLR challenges around the world, a matrix has been set in order to evaluate the attitude of each solution. The findings demonstrate how floating structures are the most effective solution in terms of cost, durability, lifespan, and environmentally friendly. In this Chapter, the methods and materials used to produce the results to the four empirical and analytical chapters are discussed where the main findings 
to the objectives, research questions, and the hypotheses are discussed as well as the relation to similar studies and alternative explanations.

\subsection{Methods and Materials}

This thesis has composed theoretical contributions and reliable secondary data regarding the impacts of SLR on low-lying coastal areas in the world like the Nile Delta. Using local, national, and international data to explore the impacts of SLR on Egypt's coasts and to propose floating structures to tackle them. Nowadays, several studies have focussed on floating structures when addressing land subsidence problems, specifically in small islands and low-lying areas around the world like the Nile Delta. To provide a valuable long-term sustainable solution for tackling SLR impacts on the Nile Delta, therefore state-of-the-art solutions should be practically considered. Such system should be sustainable, cost-effective, movable, adaptable, and feasible.

The general theoretical literature on this subject and specifically in the context of Egypt is inconclusive on several vital questions. Therefore, this study sought to answer these three questions:

1. What are the most vulnerable sites to SLR impacts in the Nile Delta's coastline?

2. What are the adaptation approaches and mitigation solutions practiced in theses sites and can floating structures offer a better solution against SLR for these sites?

3. How to implement floating structures in the Nile Delta's most vulnerable coastline sites to SLR impacts?

To answer the research questions, the study conducts eight researches using up-to-date data. The first study conducts time series analysis and ranking of impacted areas from SLR 
on the Nile Delta. The second study conducts a qualitative assessment on SLR impacts for ten case studies and evaluates adaptation solutions practiced in each case. The third study conducts site analysis on the most impacted area identified. The fourth study conducts evaluation design matrix of adaptation approaches and mitigation solutions. The fifth study conducts comparative analysis on eight in depth floating community case studies. The sixth study conducts comparative analysis of different approaches and methods to set guidelines for building on water. The seventh study conducts content analysis to set expanding dynamics guidelines of floating cities. Finally, the eighth study sets architectural design guidelines and floating community concept proposal model for the Nile Delta.

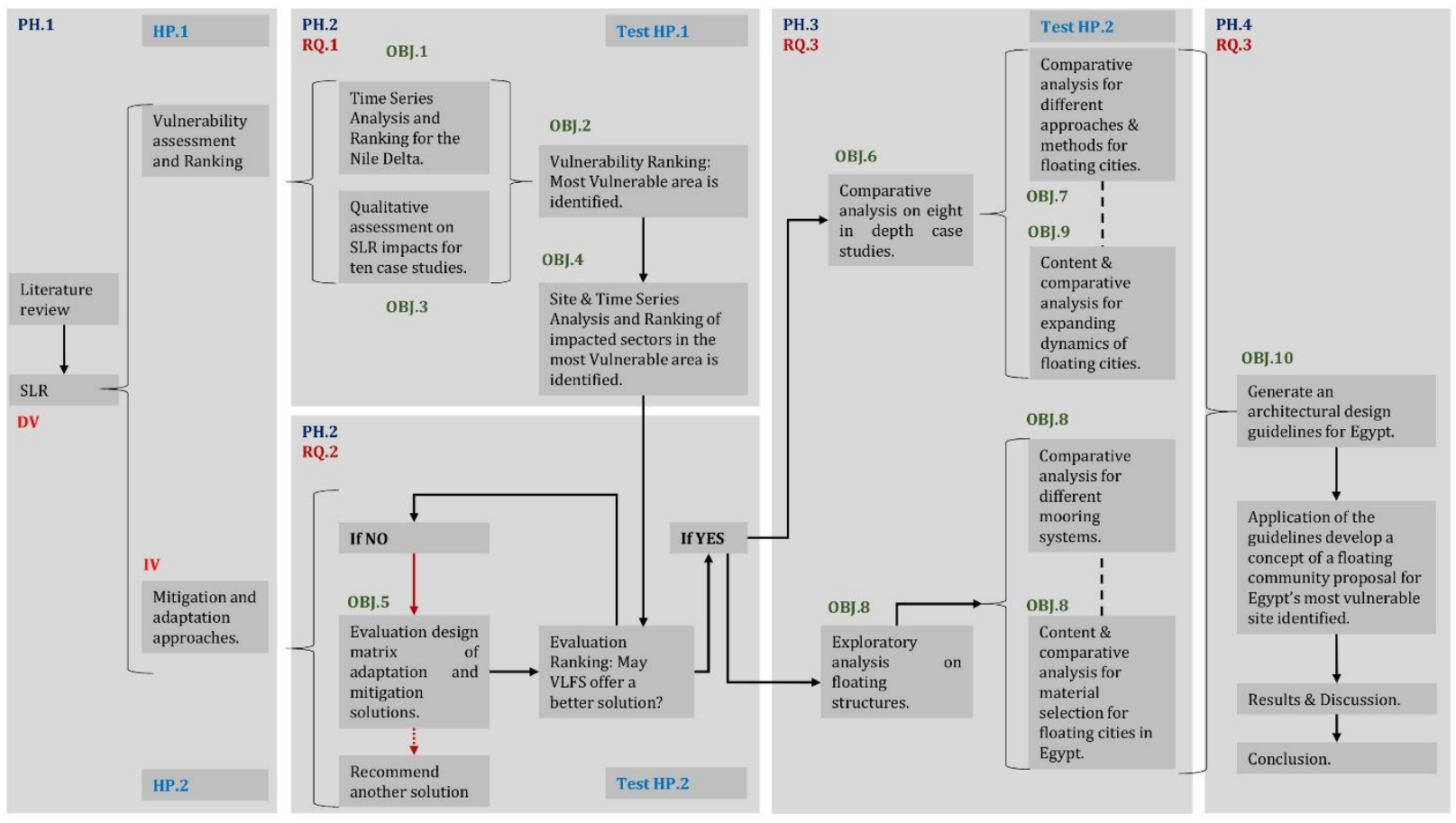

72 Figure 8.1: Analytical framework of the research methodology.

The empirical part of this thesis was conducted in the summer of 2018 . This thesis was conducted in Egypt at Abu-Qir Bay as such SLR challenges could not be solved without site 
analysis because not every solution could be applied in any site. Therefore, the first step is to define the most vulnerable areas in Egypt. The data gathered from but not limited to the Intergovernmental Panel on Climate Change (ICPP, 2014; Ipcc, 2007), Tolba \& Saab (2009), and UNFCCC (2007) have provided the necessary data on Egypt as a whole about SLR challenges like land subsidence to create scenarios for land submergence areas, number of people affected, different coastal management solutions implemented. The information gathered from but not limited to Tolba \& Saab (2009) and ICPP (2014) have provided the necessary information about the adaptation approaches and mitigation solutions practiced in the Nile Delta's coastline.

Once the most vulnerable areas in the Nile Delta and approaches practiced against SLR have been identified and analyzed in each aspect, floating structures is analyzed as the optimum solution for such site. Wang \& Tay (2011), and (Wang et al., 2008) have stated their preference of floating structures over old land reclamation solutions. The thesis reviews findings of various types of floating structures projects where it analyzes their features. The data gathered from but not limited to Suzuki et al. (2006), Wang et al. (2008), Clauss, Lehmann, \& Östergaard (1992), Moan (2004), Wang \& Tay (2011) were vital for defining the best location in the Nile Delta for creating a realistic VLFS concept as much as possible.

Having analyzed floating structures and site analysis, an attempt will be made to create a concept floating community model for the Nile Delta. Suzuki et al. (2006) have provided the adequate of information regarding load displacements, design, and the optimum size for floating structures. The guidelines and principles for achieving a sustainable floating community concept for Egypt is based on McDonough \& Braungart (2010). However, the criteria selected for the concept proposal were influenced by Dal Bo Zanon, Roeffen, Czapiewska, de Graaf-Van Dinther, \& Mooij (2017). Andrisano et al. (2018) have contributed 
in achieving the sustainable objectives for the floating community concept via their strategy for multidisciplinary methods and technological tools for the sustainable development and their employment for smart and sustainable cities.

\subsection{Results and Impacts}

There are four main driving reasons in this thesis for protecting coastal cities against SLR. The first is historical where the city of Thonis-Heracleion as well as other unknown underwater areas hold more submerged world heritage historical monuments, properties and sites of Pharaonic, Greek, Roman, and Christian as listed by the UNESCO can not be replaced. The second is to safeguard Egypt's marine borderlines sovereignty. The third is ecological where it endangers the marine and coral life habitat. The fourth is people risking their own lives building in such sites risking the scenario of Thonis-Heracleion to reoccur again.

This thesis well deserves careful analysis on SLR impacts, adaptation approaches, and sustaining the coastal developments of the Nile Delta as it highlights the most vulnerable locations, adaptation approaches and mitigation solutions practiced. The findings of this thesis introduce floating community model and architectural design guidelines for floating structures to demonstrate the benefits of VLFS as the optimum adaptation approach or mitigation solution for tackling SLR impacts in some of the most vulnerable areas in the Nile Delta coastline and to offer a future floating structures design reference for Egypt. The more the SLR, the greater the risk on vulnerable and low-lying coastal areas around the world. Therefore, old fashioned and traditional land reclamation solutions practiced by the Egyptian Shore Protection Authority (ESPA) should be abolished and replaced by floating structures wherever possible. The distinct sustainable and flexibility features of floating buildings in 
settings and environments makes them preferred for their various applications and advantages. If the government applies the recommended method derived from the outcomes of this thesis, it will safeguard Egypt's coastal sovereignty for the long-term wherever implementation is possible. Herein this thesis, authorities are guided on what should be done to efficiently design and sustain costal urbanizations in the Nile Delta's most vulnerable locations. The study uncovers critical impacts of SLR on costal urbanizations of the Nile Delta and offers VLFS as a sustainable long-term adaptation solution that Egyptian researches seem to disregard. Therefore, a new approach on adapting to SLR concerning Egypt's Nile Delta is explored.

\begin{tabular}{|l|c|c|c|c|}
\hline & Chapter 4 & Chapter 5 & Chapter 6 & Chapter 7 \\
\hline SLR Impacts & $\mathrm{X}$ & $\mathrm{X}$ & $\mathrm{X}$ & $\mathrm{X}$ \\
\hline Climate Change & $\mathrm{X}$ & & $\mathrm{X}$ & \\
\hline $\begin{array}{l}\text { Adaptation } \\
\text { Approaches }\end{array}$ & $\mathrm{X}$ & & $\mathrm{X}$ & $\mathrm{X}$ \\
\hline $\begin{array}{l}\text { Mitigation } \\
\text { Solutions }\end{array}$ & $\mathrm{X}$ & $\mathrm{X}$ & $\mathrm{X}$ & $\mathrm{X}$ \\
\hline VLFS & $\mathrm{X}$ & $\mathrm{X}$ & $\mathrm{X}$ & \\
\hline $\begin{array}{l}\text { Artificial } \\
\text { Islands }\end{array}$ & $\mathrm{X}$ & $\mathrm{X}$ & $\mathrm{X}$ & \\
\hline $\begin{array}{l}\text { Local \& Site } \\
\text { Analysis }\end{array}$ & & $\mathrm{X}$ & & \\
\hline $\begin{array}{l}\text { Local } \\
\text { Bathymetry }\end{array}$ & & & & \\
\hline
\end{tabular}

62 Table 8.1: A recap summary of the main analyzed items in the empirical and analytical chapters.

In what follows, the results of the four empirical and analytical chapters. 


\subsubsection{Chapter 4: Analysis on Solutions to SLR Impacts and Floating Community Cases}

This chapter conducts analysis on artificial islands and floating structures to test the hypothesis if it may offer the optimum solution regarding the Nile Delta's most vulnerable coastal regions to SLR.

Key Variables and Methods

This chapter initially conducts an evaluation design matrix of adaptation approaches and mitigation solutions: Such evaluation is concerned with the evaluation performance of each adaptation approach and mitigation solution against SLR impacts to choose the optimum solution for the most vulnerable site in the Nile Delta's coastline to adapt to future situations.

Secondly, this chapter conducts a comparative analysis on eight in depth case studies: Such analysis is concerned with the problems addressed and methods followed of each floating community case to conclude the design objectives and strategies when designing floating cities against SLR impacts to adapt to future situations.

\section{Main Results}

\section{Adaptation solutions:}

- Adaptation approaches analysed in terms of cost, durability, construction time, lifespan, environmental impact suggest VLFS as the most efficient solution.

- In order of efficiency: VLFS, creating natural infrastructure, upgrading sewage systems, elevating houses, raising roads, building storm-water pumps, slowing land 
sink-age, building seawalls, using beaches as barriers, and managed retreat (see Table 8.2, 8.3 and Figure 8.2).

- Despite of what has been stated about the advantages of VLFS for tackling SLR problems like land subsidence, specifically in small islands and low-lying areas in the world like in Egypt's Nile Delta, the Egyptian government is yet to consider such solution. 


\begin{tabular}{|c|c|c|c|c|}
\hline Approach & Archetype & Characteristics & Advantages & Disadvantages \\
\hline $\begin{array}{l}\text { Building } \\
\text { seawalls }\end{array}$ & & $\begin{array}{l}\text { They are built } \\
\text { on the coast. } \\
\text { They decrease } \\
\text { flooding from } \\
\text { both tides and } \\
\text { storms. }\end{array}$ & $\begin{array}{l}\text { Tolerable } \\
\text { construction } \\
\text { time. } \\
\text { Tolerable } \\
\text { durability. } \\
\text { Walls could be } \\
\text { raised. }\end{array}$ & $\begin{array}{l}\text { Expensive. } \\
\text { Short lifespan. } \\
\text { Negative } \\
\text { environmental } \\
\text { impact on } \\
\text { marine } \\
\text { environment. }\end{array}$ \\
\hline Raising roads & . & $\begin{array}{l}\text { Elevating roads } \\
\text { above sea level } \\
\text { may help drain } \\
\text { water and } \\
\text { decrease tidal } \\
\text { floods. }\end{array}$ & $\begin{array}{l}\text { High } \\
\text { durability. } \\
\text { Tolerable } \\
\text { lifespan. } \\
\text { Tolerable } \\
\text { environmental } \\
\text { impact. }\end{array}$ & $\begin{array}{l}\text { Expensive. } \\
\text { Construction } \\
\text { time might } \\
\text { vary. }\end{array}$ \\
\hline $\begin{array}{l}\text { Building } \\
\text { storm-water } \\
\text { pumps }\end{array}$ & 百 & $\begin{array}{l}\text { Pumps could } \\
\text { speed up the } \\
\text { course of } \\
\text { removing water } \\
\text { from the roads } \\
\text { by vacuuming } \\
\text { up flood waters } \\
\text { and discharging } \\
\text { it back into the } \\
\text { sea/ocean. }\end{array}$ & $\begin{array}{l}\text { High } \\
\text { durability. } \\
\text { Long lifespan } \\
\text { if maintained. } \\
\text { Tolerable } \\
\text { environmental } \\
\text { impact. }\end{array}$ & $\begin{array}{l}\text { Very } \\
\text { expensive. } \\
\text { Long } \\
\text { construction } \\
\text { time. }\end{array}$ \\
\hline $\begin{array}{l}\text { Upgrading } \\
\text { sewage } \\
\text { systems }\end{array}$ & & $\begin{array}{l}\text { Whereas } \\
\text { saltwater is } \\
\text { corrosive, it } \\
\text { could disturb } \\
\text { tanks and push } \\
\text { sewage to spew } \\
\text { out, which } \\
\text { outcomes in a } \\
\text { smelly problem } \\
\text { and other } \\
\text { possible health } \\
\text { hazards. }\end{array}$ & $\begin{array}{l}\text { Tolerable } \\
\text { durability. } \\
\text { Long lifespan. } \\
\text { Tolerable } \\
\text { environmental } \\
\text { impact. }\end{array}$ & $\begin{array}{l}\text { Expensive. } \\
\text { Long } \\
\text { construction } \\
\text { time. } \\
\text { Needs regular } \\
\text { maintenance. }\end{array}$ \\
\hline $\begin{array}{l}\text { Using beaches } \\
\text { as barriers }\end{array}$ & & $\begin{array}{l}\text { Beaches and } \\
\text { dunes could } \\
\text { function as a } \\
\text { natural wall } \\
\text { that decreases } \\
\text { the effect of } \\
\text { storm surges } \\
\text { plus shielding } \\
\text { them from } \\
\text { erosion. }\end{array}$ & $\begin{array}{l}\text { Tolerable } \\
\text { durability. } \\
\text { Fast } \\
\text { construction } \\
\text { time. } \\
\text { If maintained, } \\
\text { could live long. }\end{array}$ & $\begin{array}{l}\text { Expensive. } \\
\text { Short lifespan } \\
\text { (but could be } \\
\text { maintained by } \\
\text { adding sand } \\
\text { frequently). } \\
\text { Negative } \\
\text { environmental } \\
\text { impact on } \\
\text { marine } \\
\text { environment. }\end{array}$ \\
\hline
\end{tabular}




\begin{tabular}{|c|c|c|c|c|}
\hline $\begin{array}{l}\text { Creating } \\
\text { natural } \\
\text { infrastructure }\end{array}$ & thet & $\begin{array}{l}\text { Natural } \\
\text { structures like } \\
\text { barrier islands, } \\
\text { oyster, coral } \\
\text { reefs, } \\
\text { mangroves, } \\
\text { seagrass, and } \\
\text { salt marshes } \\
\text { could be united } \\
\text { with built } \\
\text { infrastructure, } \\
\text { to function as } \\
\text { seawalls, to } \\
\text { shield from } \\
\text { storm surges. }\end{array}$ & $\begin{array}{l}\text { High } \\
\text { durability. } \\
\text { Good } \\
\text { environmental } \\
\text { impact. } \\
\text { If maintained, } \\
\text { could live long. }\end{array}$ & $\begin{array}{l}\text { Average to } \\
\text { high costs. } \\
\text { Average to } \\
\text { long } \\
\text { construction } \\
\text { time. } \\
\text { Moderate } \\
\text { lifespan if not } \\
\text { maintained. }\end{array}$ \\
\hline $\begin{array}{l}\text { Slowing land } \\
\text { sink-age }\end{array}$ & & $\begin{array}{l}\text { Towns could } \\
\text { decrease land } \\
\text { sink-age by } \\
\text { preventing } \\
\text { additional } \\
\text { groundwater } \\
\text { pumping plus } \\
\text { introducing } \\
\text { pilot schemes to } \\
\text { reverse such } \\
\text { land sink-age. }\end{array}$ & $\begin{array}{l}\text { Good lifespan. } \\
\text { Good } \\
\text { environmental } \\
\text { impact. }\end{array}$ & $\begin{array}{l}\text { Expensive. } \\
\text { Long } \\
\text { construction } \\
\text { time. } \\
\text { Needs regular } \\
\text { maintenance. }\end{array}$ \\
\hline $\begin{array}{l}\text { Managed } \\
\text { retreat }\end{array}$ & & Relocation. & Safety. & $\begin{array}{l}\text { Expensive. } \\
\text { Hard work. }\end{array}$ \\
\hline $\begin{array}{l}\text { Elevating } \\
\text { houses }\end{array}$ & & $\begin{array}{l}\text { Elevating } \\
\text { houses over } \\
\text { flood levels by } \\
\text { using two } \\
\text { meters high } \\
\text { wooden stands } \\
\text { or concrete } \\
\text { blocks. }\end{array}$ & $\begin{array}{l}\text { Tolerable } \\
\text { lifespan. } \\
\text { Tolerable } \\
\text { durability. }\end{array}$ & $\begin{array}{l}\text { Moderate } \\
\text { environmental } \\
\text { impact. } \\
\text { Could be } \\
\text { expensive. } \\
\text { Could take } \\
\text { long. }\end{array}$ \\
\hline VLFS & $\Delta$ & $\begin{array}{l}\text { Artificial } \\
\text { floating islands. }\end{array}$ & $\begin{array}{l}\text { Moderate cost. } \\
\text { High } \\
\text { durability. } \\
\text { Moderate } \\
\text { construction } \\
\text { time. } \\
\text { Moderate } \\
\text { lifespan. } \\
\text { Good } \\
\text { environmental } \\
\text { impact. }\end{array}$ & $\begin{array}{l}\text { Poor } \\
\text { maintenance } \\
\text { expertise. }\end{array}$ \\
\hline
\end{tabular}

63 Table 8.2: Analyzed adaptation approaches practiced against SLR around the world. 


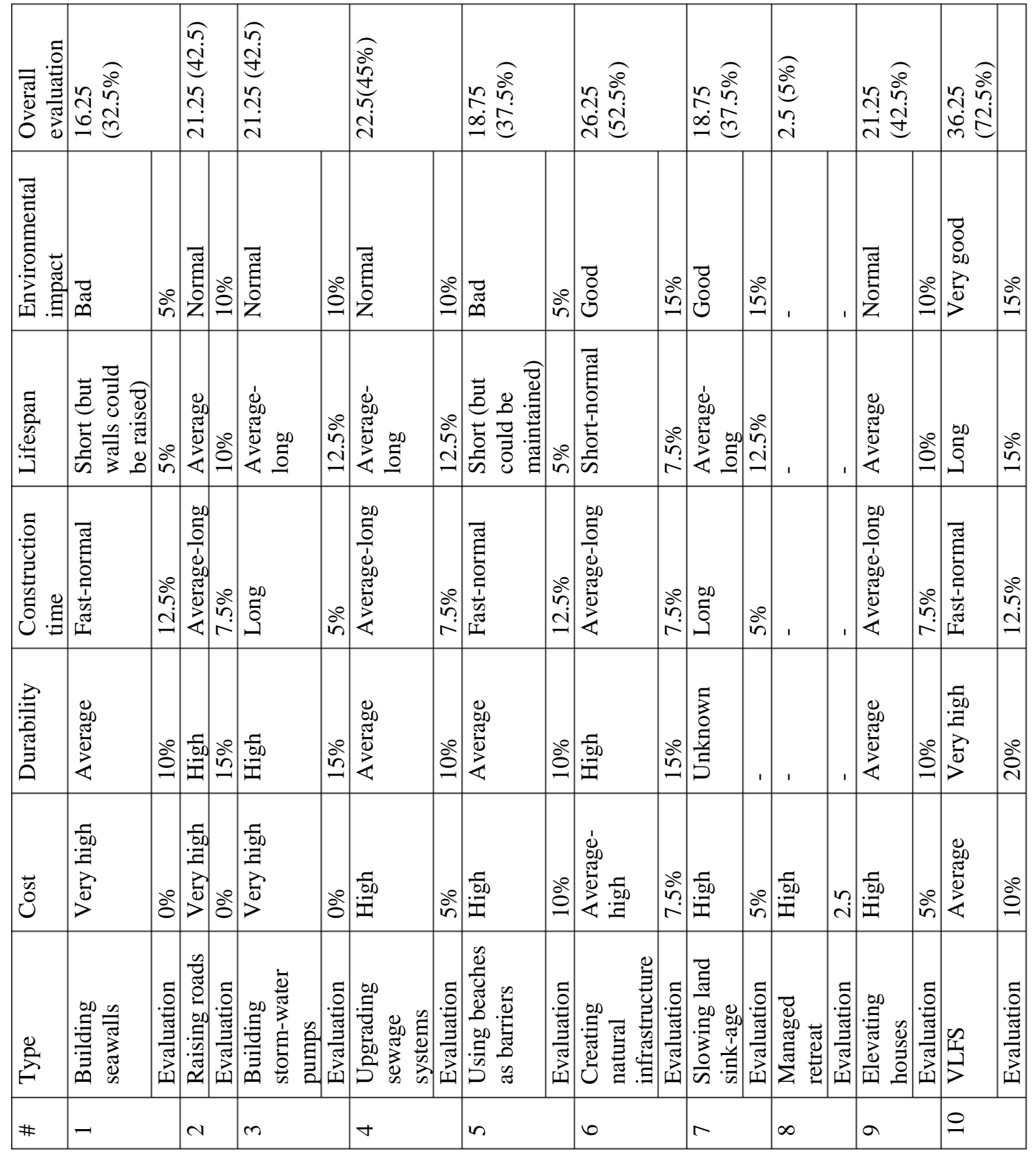

64 Table 8.3: Evaluation design matrix for different types and characteristics of adaptation approaches and mitigation solutions to SLR impacts.

Cost: Very High (0) High (5) Moderate (10) Low (15) Very low (20). Durability, Construction time, lifespan, Environmental impact: Very High (20) High (15) Moderate (10) Low (5) Very low (0). Main references: AFED reposts: Saab (2017), Tolba \& Saab (2009), Saab \&Sadik (2018); EEA (2013), Eldeberky (2011, 2015), Frihy \& El-Sayed (2013), IDSC (2011, 2013), IPCC (2007; 2014), NOAA (2010, 20,12, 2015), Tam (2009), UCS (2014, 2015). 


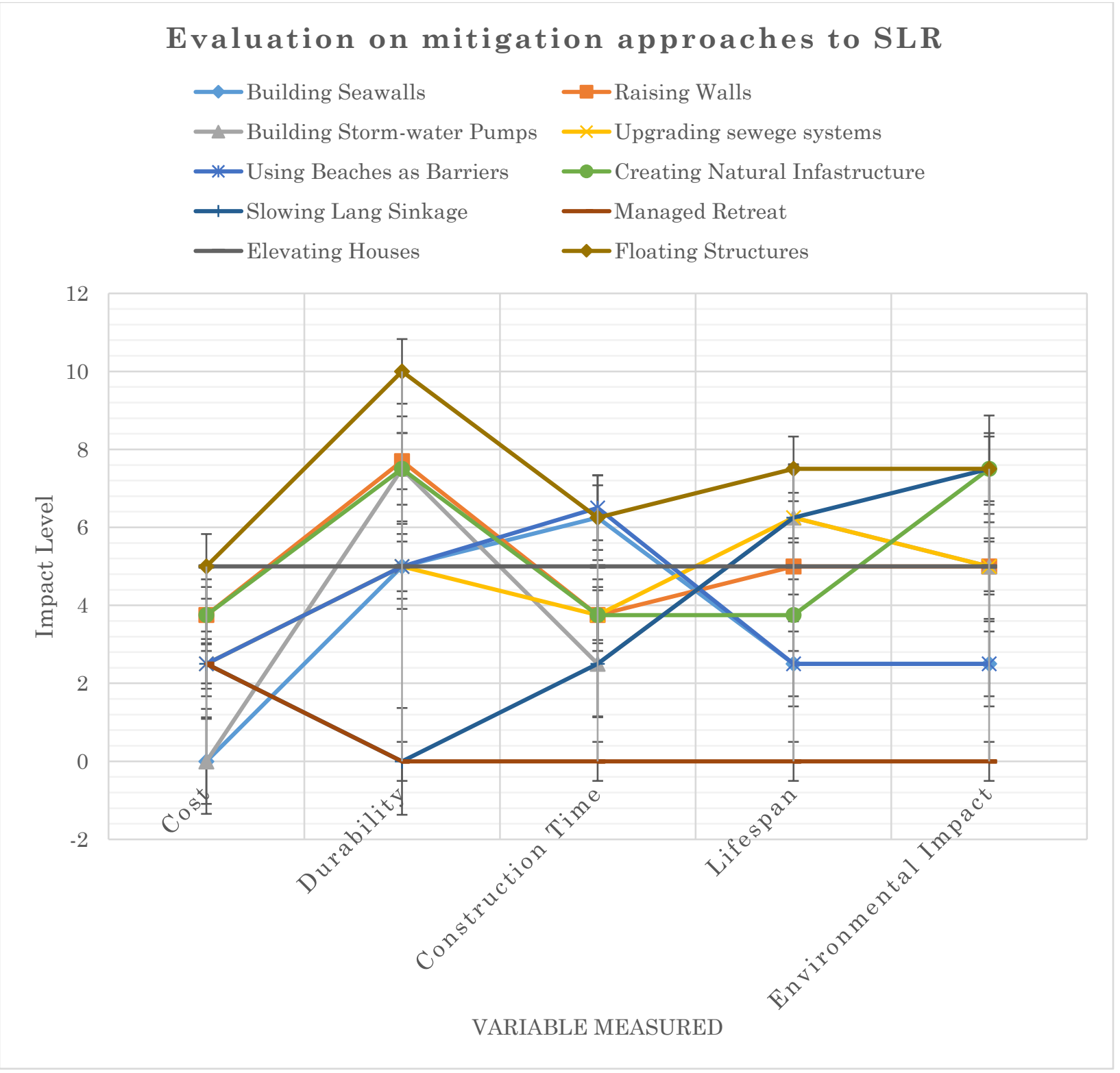

73 Figure 8.2: Evaluation Findings on different adaptation approaches and mitigation solutions to SLR impacts.

\section{Floating community study cases:}

- Eight floating community cases evaluated which are: Uros people, Ha-long community, Bangkok fishing markets, Harvest city, Ijburg, Lily-pad, Humanitarian Harbour of the Ocean, Seasteading institute. They have been analyzed in terms of: facilities, natural materials, growth development, local food production, 
mobility, markets, wave attenuator/ water life, agriculture, business, dynamic geography, modular design, and self-sufficient/ survivability. Such evaluation concludes that the most significant design approaches for floating communities in order are: movability, dynamic geography, seakeeping, water experience, growth development, and mooring system (see Table 8.4 and Figure 8.3).

\begin{tabular}{|c|c|c|c|c|c|c|c|c|c|c|c|c|c|}
\hline Project & $\begin{array}{l}\text { Facilitie } \\
\text { s } \\
\text { (school/ } \\
\text { hospital } \\
\text { ) }\end{array}$ & $\begin{array}{l}\text { Natu } \\
\text { ral } \\
\text { Mate } \\
\text { rials }\end{array}$ & $\begin{array}{l}\text { Growt } \\
\mathrm{h} \\
\text { develo } \\
\text { pment }\end{array}$ & $\begin{array}{l}\text { Local } \\
\text { food } \\
\text { prod } \\
\text { uctio } \\
\mathrm{n}\end{array}$ & $\begin{array}{l}\text { Mob } \\
\text { ility }\end{array}$ & $\begin{array}{l}\text { Mar } \\
\text { kets }\end{array}$ & $\begin{array}{l}\text { Wave } \\
\text { atten } \\
\text { uator/ } \\
\text { Wate } \\
\text { r life }\end{array}$ & $\begin{array}{l}\text { Agric } \\
\text { ultur } \\
\text { e }\end{array}$ & $\begin{array}{l}\text { Busi } \\
\text { ness/ } \\
\text { Indu } \\
\text { stry }\end{array}$ & $\begin{array}{l}\text { Dyna } \\
\text { mic } \\
\text { geogr } \\
\text { aphy }\end{array}$ & $\begin{array}{l}\text { Mod } \\
\text { ular } \\
\text { desi } \\
\text { gn }\end{array}$ & $\begin{array}{l}\text { Self- } \\
\text { suffici } \\
\text { ent/ } \\
\text { Surviv } \\
\text { ability }\end{array}$ & $\begin{array}{l}\text { To } \\
\text { tal }\end{array}$ \\
\hline Uros people & ++ & $\begin{array}{l}\text { +++ } \\
+\end{array}$ & ++++ & ++ & +++ & + & + & + & - & +++ & - & ++++ & 10 \\
\hline $\begin{array}{l}\text { Ha-long } \\
\text { community }\end{array}$ & - & +++ & ++ & ++++ & $\begin{array}{l}+++ \\
+\end{array}$ & ++ & + & - & - & +++ & + & ++++ & 9 \\
\hline $\begin{array}{l}\text { Bangkok } \\
\text { fishing } \\
\text { markets }\end{array}$ & - & - & - & ++++ & ++ & $\begin{array}{l}+++ \\
+\end{array}$ & - & - & - & - & - & ++ & 4 \\
\hline Harvest city & + & + & +++ & - & - & - & ++ & + & ++ & + & +++ & +++ & 9 \\
\hline Ijburg & - & - & ++++ & + & $\begin{array}{l}\text { +++ } \\
+\end{array}$ & - & + & - & - & ++++ & $\begin{array}{l}+++ \\
+\end{array}$ & - & 6 \\
\hline Lily-pad & - & - & ++ & - & $\begin{array}{l}+++ \\
+\end{array}$ & - & - & + & - & - & ++ & +++ & 5 \\
\hline $\begin{array}{l}\text { Humanitari } \\
\text { an Harbour } \\
\text { of the Ocean }\end{array}$ & + & - & ++++ & ++++ & $\begin{array}{l}+++ \\
+\end{array}$ & +++ & + & ++++ & + & +++ & +++ & ++++ & 11 \\
\hline $\begin{array}{l}\text { Seasteading } \\
\text { institute }\end{array}$ & ++++ & - & ++++ & ++ & $\begin{array}{l}+++ \\
+\end{array}$ & ++ & ++ & ++ & ++ & +++ & $\begin{array}{l}+++ \\
+\end{array}$ & +++ & 11 \\
\hline Total & 4 & 3 & 7 & 6 & 7 & 5 & 6 & 5 & 3 & 6 & 6 & 7 & \\
\hline
\end{tabular}

65 Table 8.4: Evaluation of features of the selected floating community case studies. ${ }^{11}$

Very High (++++) High (+++) Moderate (++) Low (+) Not addressed (-) where each "+" accounts for 25\% stress of each feature. Method adopted from Frihy \& El-Sayed (2013) and (IDSC, 2011).

${ }^{11}$ Very High (++++) High (+++) Moderate (++) Low (+) Not addressed (-) where each “+” accounts for $25 \%$ stress of each feature.

Method adopted from (IDSC, 2011) and Frihy \& El-Sayed (2013). 


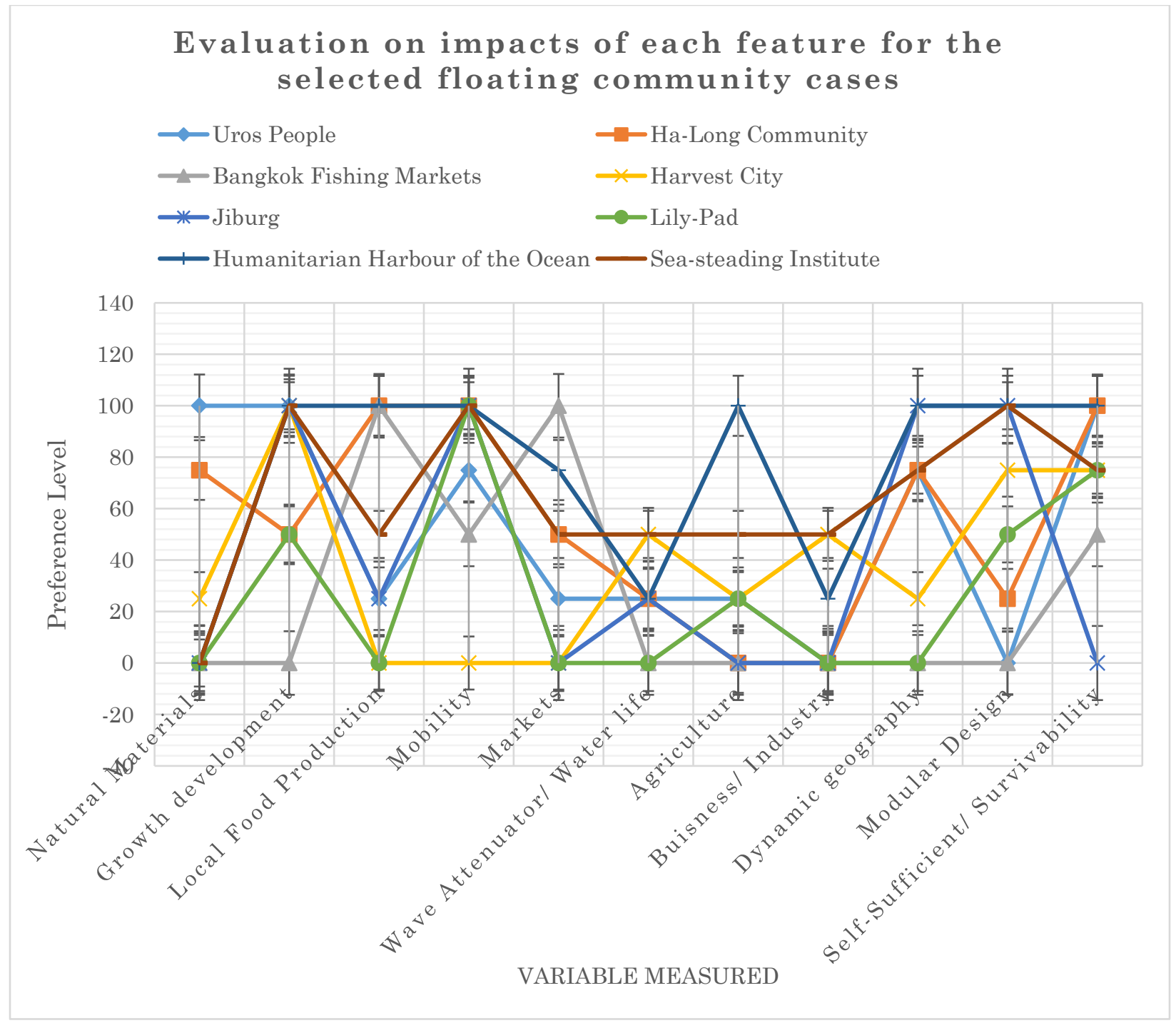

74 Figure 8.3: Evaluation of the impacts of each feature of the selected floating community case studies.

VLFS do not look like working every time, where such solution is functional only water depth is shallow with a maximum of $15-20$ meters. In a situation that the water depth is less than that, the seabed would be very soft and as a result, land reclamation solutions are no longer cost effective or even reasonable. It presents a cost-effective possibility where the water depth is deep as well as not affecting the nearshore marine ecosystem. 


\subsubsection{Chapter 5: Applications, Analysis, Development, and Design}

\section{Approaches for VLFS}

This chapter conducts analysis on artificial islands and floating structures to test the hypothesis if it may offer the optimum solution regarding the Nile Delta's most vulnerable coastal regions to SLR.

\section{Research Question}

What are the adaptation approaches and mitigation solutions practiced in theses sites and can floating structures offer a better solution against SLR for these sites?

\section{Key Variables and Methods}

This chapter initially conducts an exploratory analysis to investigate floating structures and artificial islands as a more sustainable and long-term solution and analyzes adaptation approaches and mitigation solutions practiced in Egypt. Therefore, it analyzes floating structures by investigating their applications, advantages, analysis, technological advancement, environment, and design considerations for floating body, mooring systems, and breakwaters, structural integrity, drift forces, strength and failure, and design. These analyses would provide the required information on VLFS for Egypt's Nile Delta's coastline.

Secondly, this chapter conducts a comparative analysis for different approaches and methods for floating cities: Such analysis is concerned with approaches and methods followed when designing floating structures in respect to Egypt's criteria and characteristics of the Nile Delta to offer guidelines for building on water to cope with future situations. 


\section{Main Results}

\section{Mooring Systems}

- Exploratory analysis on floating structures and the mooring systems regarding the chain/cable, the tension leg methods, the pier/quay wall, and the pile-type dolphinsforeguide with rubber fender system. The chain/cable: Operates in open waters. However, VLFS motions become high especially in open waters where mooring length is long. The tension leg methods: Implemented where pretension is enforced on mooring to prevent any motions as well as operating in open waters. Nevertheless: Very hard to control horizontal movements well and frequently the mooring lines encounter some substantial tension forces. The pier/quay wall: Very stable in modular platforms. Nonetheless, may experience some vibrations. It should only be used in small platforms. Also, it's not ideal to operate in open waters. The pile-type dolphinsforeguide with rubber fender system: Extremely efficient to control horizontal dislocation that may occur in VLFS. It endures large dislocations (1/3 of their spans) as great quantity of platform's kinetic energy could be absorbed. However, they are not ideal to operate in open waters. Analysis regarding of cost, durability, construction time, lifespan, environmental impact, suggest that the dolphins-foreguide mooring system appear to be the optimum mooring system regarding Alexandria's Abu-Qir Bay site (see Figure $8.4 \&$ Table 8.5). 


\section{Design Approaches and Strategies}

- Comparative analysis on the first design approach "movability" regarding selfpropelled, towed, semi-submersible ship, and disassembled. Self-propelled: Ultimate movability is achieved by incorporating a seastead or constructing it on a vessel which the optimum solution if city is frequently repositioned. Towed: Floating platforms are planned to be easily repositioned using tugboats or further exterior propulsion system. Semi-submersible ship: Moved by semi-submersible vessels. Disassembled: Should be planned to be assembled/disassembled and moved in containers. According to the conclusions of movability approach, self-propelled: easily repositioned; rapidly repositioned; basic mooring system for big constructions. However, a large external propulsion system is required for relocation; high maintenance expenses. Towed: easily repositioned; rapidly repositioned. Nevertheless, external propulsion system is required for relocation; designs ought to be suitable for towing; only big constructions can travel in open waters. Semi-submersible ship: rapidly repositioned; minimum design limitations; freeboard could be lower to give the optimum water experience; diverse platform dimensions could be repositioned; permits smaller structures to be moved to open waters; whole structure is intact. Nevertheless, external propulsion system is required for relocation; great number of vessels are required for high number of small platforms; mostly appropriate for big structures; floating platform dimensions are controlled to vessel size; structure have to be sufficiently durable to be elevated out from water. Disassembled: rapidly repositioned; transported to any site. However, preparing for transportation is time-consuming; residents can't move together. Analysis in terms of cost, durability, construction time, lifespan, environmental impact, suggests that the "towed" strategy appear to be the optimum 
method for movability regarding Alexandria's Abu-Qir Bay site (see Figure 8.4 \& Table 8.5).

- Comparative analysis on the second design approach "dynamic geography" regarding islands, branch, composite structure, and single large structure. Islands: Each structure is repositioned on its own platform or its hull which facilitates the best movement flexibility. Also, buildings are linked with hinged joints. Branch: Floating structures contain of various homes or further buildings. Also, on platform structures could be connected with either hinged or rigid joints. Composite structure: Semi-large platforms are linked together to form a greater one. It has rigid joints. According to the conclusions of movability approach, islands: best dynamic layout. However, great quantity of connections; great quantity of mooring systems is required; great swell. Branch: easily repositioned; not as much of swell like in islands. Nevertheless, no option to relocate single houses; structures require being identical to connect; great quantity of mooring systems is required. Composite structure: less quantity of mooring systems is required; small amount of swell. Nonetheless, disassembly is complex; in repositioning, adjoining structures require moving. Single large structure: less quantity of mooring systems is required; small amount of swell. However, relocation is not an option. Single large structure: Huge structure like a ship or oil platform as a single unit. Analysis in terms of cost, durability, construction time, lifespan, environmental impact, suggests that the "branch" strategy appear to be the optimum method for dynamic geography regarding Alexandria's Abu-Qir Bay site (see Figure 8.4 \& Table 8.5).

- Comparative analysis on the third design approach "seakeeping and survivability" regarding ship, raised platform, breakwater, and submerged. Ship: Vessels is a 
recognized approach, while big ones are specifically appropriate for open waters for their form and dimensions; Wave attenuators are incorporated in the vessel; Buildings are very reactive to wave activities and may result a great quantity of swell. Raised platform: Elevated platforms like in oilrigs or an air container sort of structure reduces the surface which is in contact with water, hence diminishes wave activities. Breakwater: External structure is built to function as a breakwater barrier, and the city could take any form behind such barrier. Submerged: When submerged, wave impacts are decreased; Wave activities reduces relatively with water depth. According to the conclusions of movability approach, ship: Incorporated wave protection system. However, wave attenuators just work when vessels are moving not the best form to build a city with public spaces, connections, etc. Raised platform: breakwater incorporated; least contact with water decreases wave activities and its effects. Nevertheless, it's Suitable just for huge structures. Breakwater: great design flexibility; breakwater could be constructed with further structures or utilities; provides calm water behind the barrier which could be used for purposes like aquaculture, recreation, etc. Nonetheless, External structure requires further mooring systems; not being able to endure all wave impacts, which could result in swell behind the barrier in some conditions. Submerged: applicable in nearly each site. However, offering adequate sunlight will be a challenge; residents need O2; no interaction with external climate may result in mental discomfort. Analysis in terms of cost, durability, construction time, lifespan, environmental impact, suggests that the "breakwater" strategy appear to be the optimum method for seakeeping regarding Alexandria's Abu-Qir Bay site (see Figure 8.4 \& Table 8.5). 
- Comparative analysis on the fourth design approach "water experience" regarding platform, branch, bay, and islands. Islands: Each structure is repositioned on its own platform or its hull which facilitates the best movement flexibility; Buildings are linked with hinged joints. Branch: Floating structures contain of various homes or further buildings; On platform structures could be connected via hinged or rigid joints. Bay: Semi-large platforms are linked together to form a greater one as well as having rigid joints. Platform: Huge structure like a ship or oil platform as a single unit. According to the conclusions of movability approach, islands: optimum water experience. However, low stability; require breakwater protection which could block water view. Branch: high water experience; moderate stability. Nevertheless, require breakwater protection which could block water view. Bay: good bay-like experience; high stability. Nonetheless, various platform shapes; several rigid connections are required. Platform: good bay-like experience; high stability. However, low water experience; apart from the edges; edges have less ideal water experience, since they are exposed to waves. Analysis in terms of cost, durability, construction time, lifespan, environmental impact, suggests that the "branch" strategy appear to be the optimum method for water experience regarding Alexandria's Abu-Qir Bay site (see Figure 8.4 \& Table 8.5).

- Comparative analysis on the fifth design approach "growth development" regarding ship, raised platform, breakwater, and composite structure, in terms of cost, durability, construction time, lifespan, environmental impact, suggests that the "breakwater" strategy appear to be the optimum method for growth development regarding Alexandria's Abu-Qir Bay site (see Figure 8.4 \& Table 8.5). 


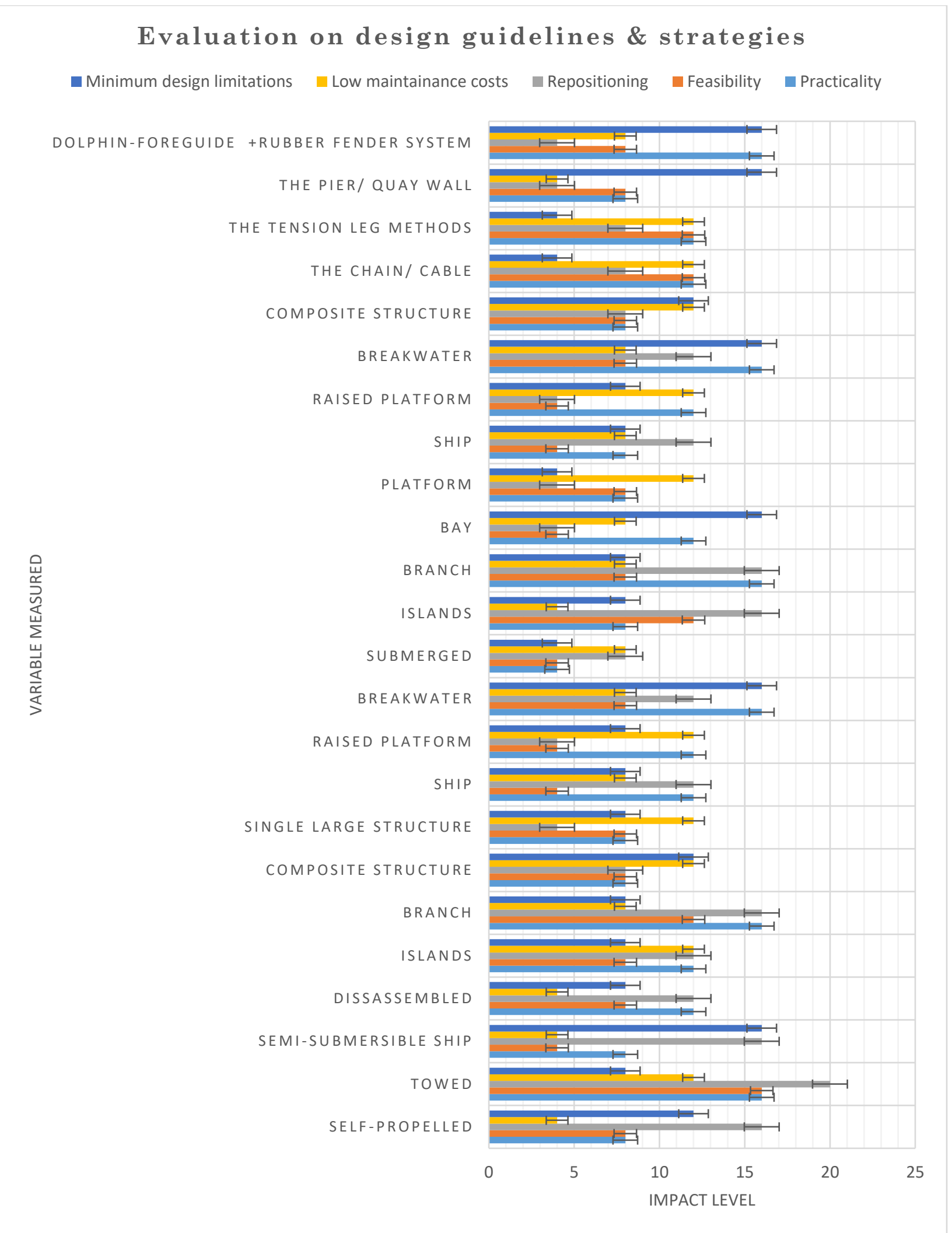

75 Figure 8.4: Evaluation of design guidelines and strategies for VLFS. 


\begin{tabular}{|c|c|c|c|c|c|c|}
\hline & Objective & Approach & $\begin{array}{l}\text { Suitability for } \\
\text { Central Abu- } \\
\text { Qir Bay }\end{array}$ & $\begin{array}{l}\text { Suitability for } \\
\text { East } \\
\text { Alexandria's } \\
\text { coastline }\end{array}$ & Ideal methods & $\begin{array}{l}\text { Design } \\
\text { methods } \\
\text { selected }\end{array}$ \\
\hline \multirow[t]{4}{*}{1} & \multirow[t]{4}{*}{ Movability } & Self-propelled & $60 \%$ & $70 \%$ & $65 \%$ & $65 \%$ \\
\hline & & Towed & 90 & $85 \%$ & $82.5 \%$ & $82.5 \%$ \\
\hline & & $\begin{array}{l}\text { Semi- } \\
\text { submersible } \\
\text { ship }\end{array}$ & $60 \%$ & $60 \%$ & $60 \%$ & $60 \%$ \\
\hline & & Disassembled & $55 \%$ & $65 \%$ & $60 \%$ & $60 \%$ \\
\hline \multirow[t]{4}{*}{2} & \multirow{4}{*}{$\begin{array}{l}\text { Dynamic } \\
\text { geography }\end{array}$} & Islands & $70 \%$ & $65 \%$ & $67.5 \%$ & $67.5 \%$ \\
\hline & & Branch & $70 \%$ & $75 \%$ & $72.5 \%$ & $72.5 \%$ \\
\hline & & $\begin{array}{l}\text { Composite } \\
\text { structure }\end{array}$ & $55 \%$ & $60 \%$ & $60 \%$ & $60 \%$ \\
\hline & & $\begin{array}{l}\text { Single large } \\
\text { structure }\end{array}$ & $45 \%$ & $50 \%$ & $47.5 \%$ & $47.5 \%$ \\
\hline \multirow[t]{4}{*}{3} & \multirow[t]{4}{*}{ Seakeeping } & Ship & $40 \%$ & $55 \%$ & $47.5 \%$ & $47.5 \%$ \\
\hline & & Raised platform & $45 \%$ & $50 \%$ & $47.5 \%$ & $47.5 \%$ \\
\hline & & Breakwater & $70 \%$ & $60 \%$ & $65 \%$ & $65 \%$ \\
\hline & & Submerged & $40 \%$ & $35 \%$ & $37.5 \%$ & $37.5 \%$ \\
\hline \multirow[t]{4}{*}{4} & \multirow{4}{*}{$\begin{array}{l}\text { Water } \\
\text { experience }\end{array}$} & Islands & $50 \%$ & $60 \%$ & $57.5 \%$ & $57.5 \%$ \\
\hline & & Branch & $65 \%$ & $70 \%$ & $67.5 \%$ & $67.5 \%$ \\
\hline & & Bay & $50 \%$ & $55 \%$ & $52.5 \%$ & $52.5 \%$ \\
\hline & & Platform & $45 \%$ & $45 \%$ & $45 \%$ & $45 \%$ \\
\hline \multirow[t]{4}{*}{5} & \multirow{4}{*}{$\begin{array}{l}\text { Growth } \\
\text { development }\end{array}$} & Ship & $60 \%$ & $55 \%$ & $57.5 \%$ & $57.5 \%$ \\
\hline & & Raised platform & $45 \%$ & $50 \%$ & $47.5 \%$ & $47.5 \%$ \\
\hline & & Breakwater & $70 \%$ & $75 \%$ & $72.5 \%$ & $72.5 \%$ \\
\hline & & $\begin{array}{l}\text { Composite } \\
\text { structure }\end{array}$ & $55 \%$ & $60 \%$ & $57.5 \%$ & $57.5 \%$ \\
\hline \multirow[t]{4}{*}{6} & \multirow{4}{*}{$\begin{array}{l}\text { Mooring } \\
\text { system }\end{array}$} & Chain/cable. & $60 \%$ & $65 \%$ & $62.5 \%$ & $62.5 \%$ \\
\hline & & $\begin{array}{l}\text { Tension } \\
\text { methods. }\end{array}$ & $60 \%$ & $65 \%$ & $62.5 \%$ & $62.5 \%$ \\
\hline & & Pier/quay wall. & $50 \%$ & $50 \%$ & $50 \%$ & $50 \%$ \\
\hline & & $\begin{array}{l}\text { Dolphins- } \\
\text { foreguide }\end{array}$ & $65 \%$ & $65 \%$ & $65 \%$ & $65 \%$ \\
\hline
\end{tabular}

66 Table 8.5: Analyzed design methods and criteria for central Abu-Qir Bay and East Alexandria's coastline.

- Evaluation of six design approaches in terms of: movability, dynamic geography, seakeeping, water experience, growth development, and mooring system. The two ways to build a floating structure is either large floating structure to be constructed as a whole at once or small platform modules that can would be flexible and expand when connected to form a whole unit. The disadvantage of the submersible-type or vessel-like floating structures are that they require both funding and building at once as well as being difficult for future expanding. Small floating structures might have 
breakwaters for protection or united to form a large floating structure as they provide gradual expansion. In an expansion approach, modular small platforms are better than large floating structures which are complicated and require a lot of time. Analysis conclude that the optimum options for East Alexandria and central Abu-Qir area in terms of cost, durability, construction time, lifespan, environmental impact are: towed, branch, breakwater, branch, breakwater, dolphins-foreguide respectively (see Figure $8.4 \&$ Table 8.5). 


\subsubsection{Chapter 6: Case Study Analysis: The Nile Delta, Egypt}

This chapter conducts site analysis to explore the most vulnerable sites in the Nile Delta and investigates coastal management approaches practiced as their properties provide the required knowledge for selecting the best adaptation approach and mitigation solution for the most vulnerable area.

\section{Research Question}

What are the most vulnerable sites to SLR impacts in the Nile Delta's coastline?

\section{Key Variables and Methods}

This chapter initially conducts a time series analysis and ranking for the Nile Delta: Such analysis is a compilation of examinations of precise data items acquired through frequent measurements over periods of time to improve the capability to coping with future situations.

Secondly, this chapter conducts a qualitative assessment on SLR impacts for ten case studies: Such analysis is concerned with the probabilities of decreasing the negative impacts and of refining the capability to coping with future situations.

Finally, this chapter conducts site and time series analysis and ranking of the impacted sectors in Alexandria.

\section{Main Results}

- Initial time series analysis through $0.5 \mathrm{~m}, 1 \mathrm{~m}, 1.5 \mathrm{~m}, 2.0 \mathrm{~m}, 2,5 \mathrm{~m}$, and $3.0 \mathrm{~m}$ SLR demonstrate the amount of submerged areas and the amount of people impacted as well as the infrastructure loss in terms of the amount of losses in buildings and roads (see Table 8.6). 


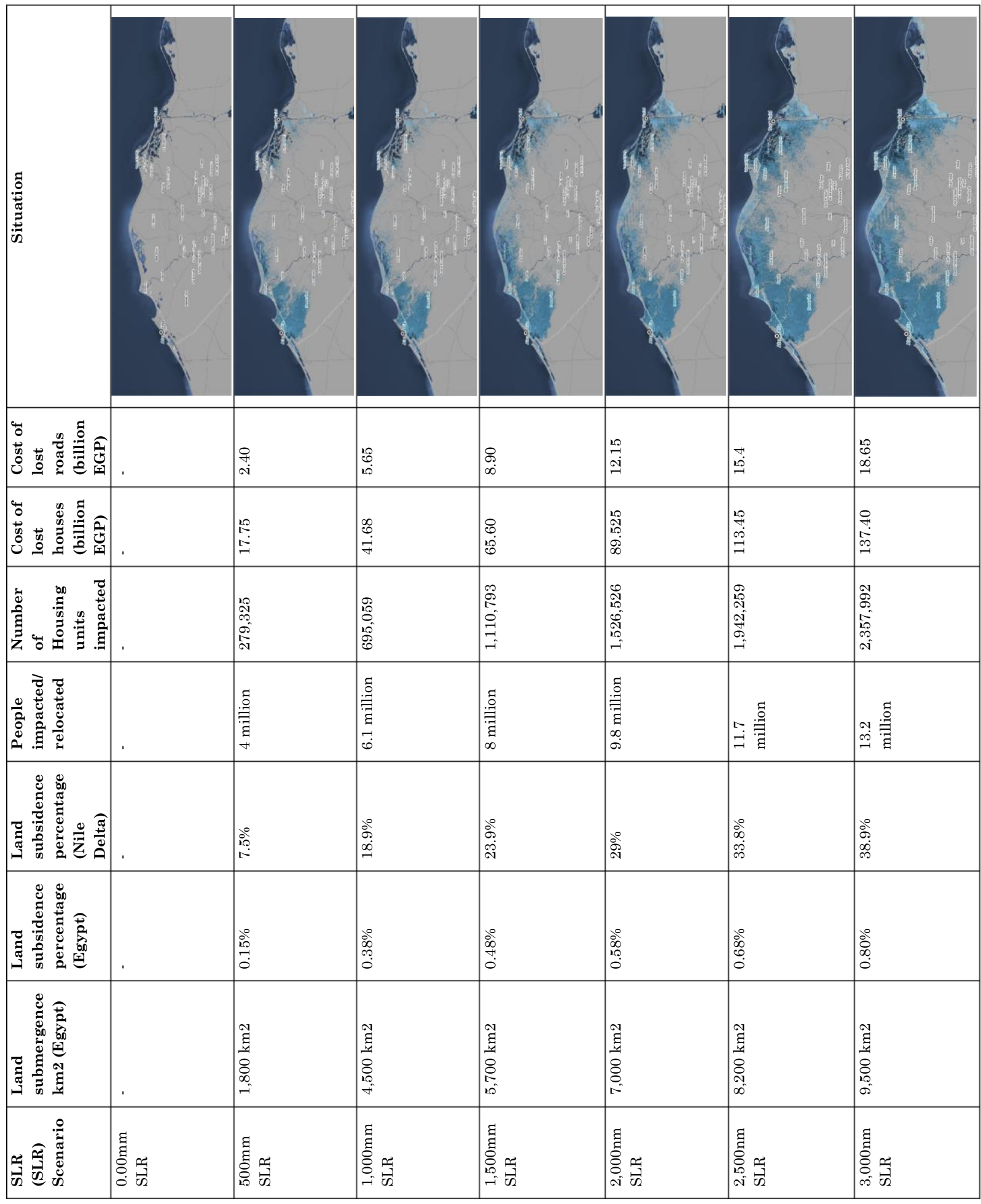

67 Table 8.6: SLR scenarios and impacts on the Nile delta's coastlines.

Main observatories used to create such scenarios: AFED reposts: Saab (2017), Tolba \& Saab (2009), Saab \&Sadik (2018); IDSC (2011, 2013), IPCC (2007; 2014), NOAA, (2010, 2017), 
UNEP (2017). Monitoring data from the Ministry of State for Local Development, and Ministry of Environment.

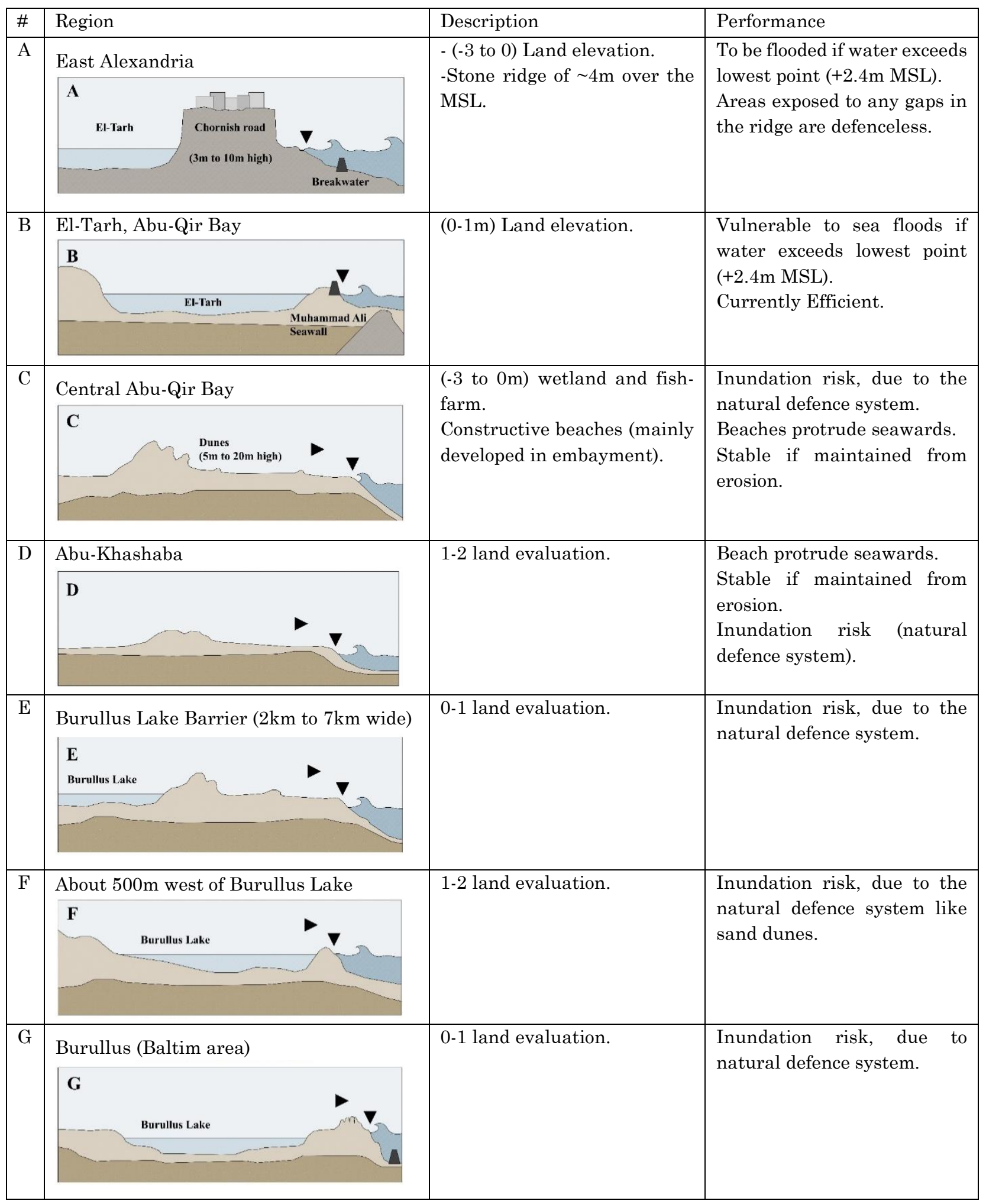




\begin{tabular}{|c|c|c|c|}
\hline $\mathrm{H}$ & $\begin{array}{l}\text { Gamasa Embayment } \\
\begin{array}{|l}\text { H } \\
\text { Dunes (5m to } 10 \mathrm{~m} \text { high) }\end{array}\end{array}$ & $\begin{array}{l}\text { 0-1 land evaluation. } \\
\text { coastal dune belts } \\
\text { that run parallel the } \\
\text { coastlines of different areas. }\end{array}$ & $\begin{array}{l}\text { Beach protrude seawards. } \\
\text { Stable if maintained from } \\
\text { erosion. }\end{array}$ \\
\hline $\mathrm{I}$ & $\begin{array}{l}\text { Manzala Lake barrier }(500 \mathrm{~m} \text { wide) } \\
\text { I }\end{array}$ & 1-2 land evaluation. & $\begin{array}{l}\text { High subsidence rate, quick } \\
\text { erosion caused by SLR and } \\
\text { sea activities. }\end{array}$ \\
\hline $\mathrm{J}$ & $\begin{array}{l}\text { Tineh littoral plain } \\
\mathbf{J}\end{array}$ & 0-1 land evaluation. & $\begin{array}{l}\text { Inundation risk, (natural } \\
\text { defence). } \\
\text { Beach protrude seawards. } \\
\text { Stable if maintained from } \\
\text { erosion. }\end{array}$ \\
\hline
\end{tabular}

68 Table 8.7: Cross sections for vulnerable coastal areas analyzed along the study from Alexandria to Port-Said showing adaptation approaches practiced and main topographic characteristics that influence flood levels of and permanent inundation of lowlands which are caused by SLR impacts and strong storm events (own illustrations).

- Adaptation approaches practiced analysed regarding their cost, durability, construction time, lifespan, and environmental impact, in order are: breakwaters, raising roads, creating natural infrastructure, sand dunes, and using beaches as barriers. Egypt still practice unsustainable land reclamation methods not only for the abundance and cost of sand in Egypt, but also for being rapid, easy, and doesn't requiring high technology (see Table 8.7).

- Qualitative analysis executed on ten areas in the Nile Delta conclude that the Eastern coastal plain is more vulnerable to SLR impacts that the Western Coastal Plain, where the most vulnerable areas are Central Abu-Qir Bay and East Alexandria respectively. 
- In order on vulnerability: Central Abu-Qir Bay, East Alexandria, El-Tarh, Abu-Qir Bay, Tineh littoral plain, Burullus Lake Barrier, Baltim area (Burullus), Gamasa Embayment, Manzala Lake barrier, Burullus Lake, Abu-Khashaba (see Table 8.8).

\begin{tabular}{|l|l|l|l|l|l|}
\hline$\#$ & Area & High risk & $\begin{array}{l}\text { Moderate } \\
\text { risk }\end{array}$ & Low risk & $\begin{array}{l}\text { Under } \\
\text { extreme } \\
\text { events }\end{array}$ \\
\hline & Western coastal plain & & & \\
\hline A & Alexandria & & & & \\
\hline B & El-Tarh, Abu-Qir Bay & & & & \\
\hline C & Central Abu-Qir Bay & & & & \\
\hline D & Abu-Khashaba & & & \\
\hline E & $\begin{array}{l}\text { Burullus Lake Barrier } \\
\text { (2km to 7km wide) }\end{array}$ & & & & \\
\hline & Eastern coastal plain & & & \\
\hline G & $\begin{array}{l}\text { About 500m west of } \\
\text { Burullus Lake }\end{array}$ & & & & \\
\hline F & Burullus (Baltim area) & & & & \\
\hline G & Gamasa Embayment & & & & \\
\hline H & $\begin{array}{l}\text { Manzala Lake barrier } \\
\text { (500m wide) }\end{array}$ & & & & \\
\hline I & Tineh littoral plain & & & & \\
\hline
\end{tabular}

69 Table 8.8: Vulnerability ranking of coastal regions to SLR. ${ }^{12}$

- SLR scenarios created for East Alexandria and central Abu-Qir area of $0.5 \mathrm{~m}, 1 \mathrm{~m}$, $1.5 \mathrm{~m}$, and $2.0 \mathrm{~m}$ SLR, conclude that the most vulnerable sectors in order are: agriculture, people, land subsidence, industry, residential, archeological sites, commercial areas, community facilities. However, agricultural, industry, and

12 Method adopted from: IDSC (2011). Main sources for this evaluation: $\quad$ AFED (2009, 2017, 2018), IDSC (2011, 2013), IPCC (2007; 2014), Frihy \& El-Sayed (2013). Reports and geological plans from the Ministry of State for Local Development, and Ministry of Environment. 
residential areas could be recreated elsewhere, but world heritage properties and sites of Pharaonic, Greek, Roman, and Christian as listed by the UNESCO can not be replaced (see Figure 8.5).

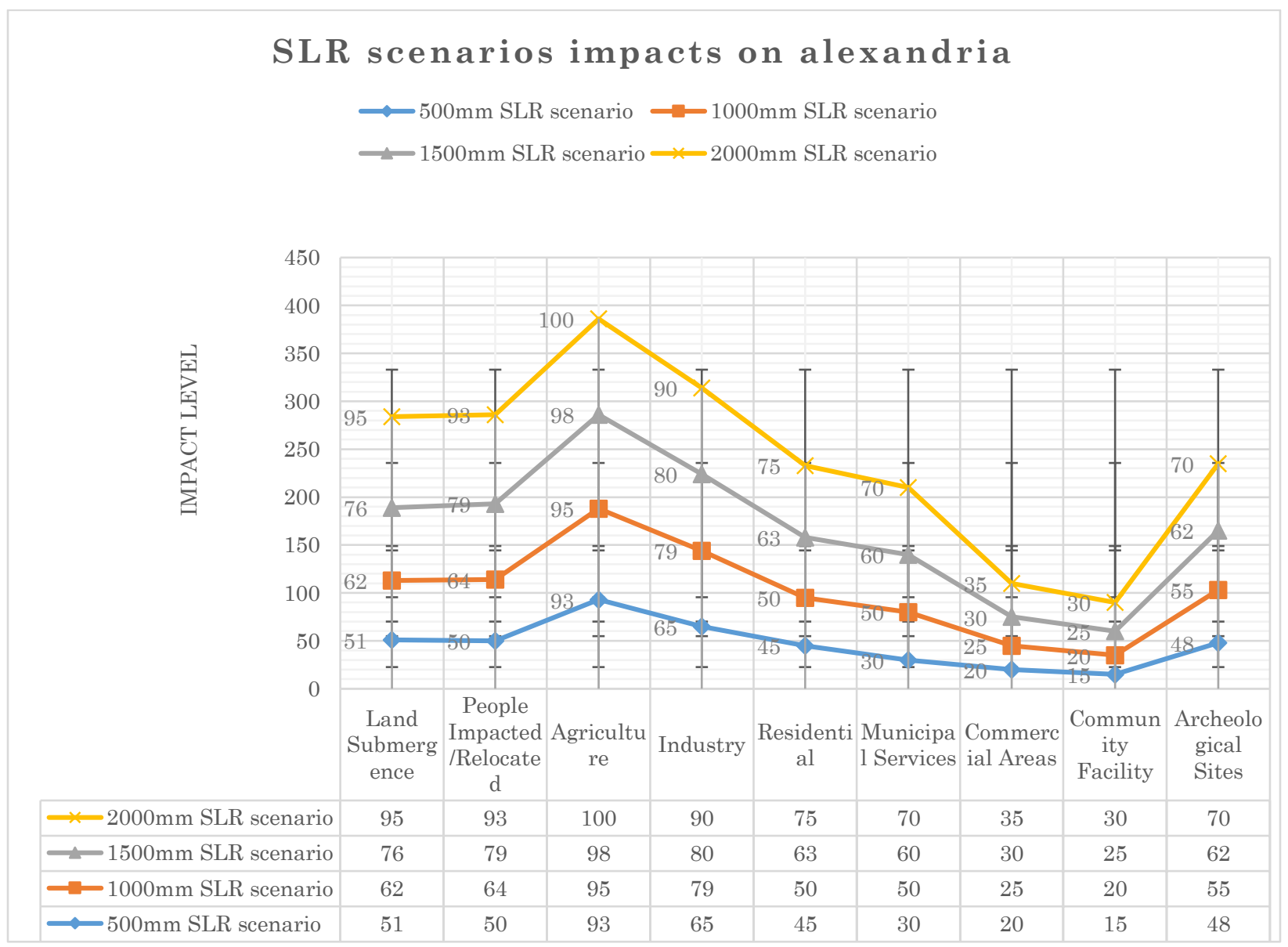

76 Figure 8.5: Findings on impacts of SLR scenarios on the Nile delta's coastlines. ${ }^{13}$

${ }^{13}$ Main observatories used to create such scenarios: AFED reposts: Saab (2017), Tolba \& Saab (2009), Saab \&Sadik (2018); IDSC (2011, 2013), IPCC (2007; 2014), NOAA, (2010, 2017), UNEP (2017).

Tidal gauges data from Alexandria governorate (2017) and Ministry of Environment (2018). 


\subsubsection{Chapter 7: Case Study Design: Floating Community Concept Proposal for the Nile Delta}

This chapter applies the conclusions of the previous three empirical and analytical chapters of site analysis, adaptation approaches, mitigation solutions, and floating structures to define a floating community model for Abu-Qir Bay and architectural design guidelines for Egypt.

\section{Research Question}

How to implement floating structures in the Nile Delta's most vulnerable coastline sites to SLR impacts?

\section{Key Variables and Methods}

This chapter initially conducts a content analysis for expanding dynamics of floating cities: Such analysis is concerned with the expanding dynamics that are various stages when designing floating structures in respect to Egypt's criteria and characteristics of the Nile Delta to add to the guidelines for building on water to cope with future situations.

Secondly, this chapter sets a concept development and guidelines on floating structures: Such study is concerned with approaches and methods followed when designing floating structures in respect to Egypt's criteria and characteristics of the Nile Delta to offer guidelines for building on water to cope with future situations. 


\section{Main Results}

\section{Possible Site:}

- Although the qualitative risk analysis executed on ten areas in the Nile Delta conclude that the most vulnerable areas lie in Abu-Qir bay, but upon site analysis, this thesis also proposes Abu-Qir bay as the perfect site for such solution as it appears to be the ideal site to implement floating community for many reasons but most importantly for its depth (18.5-22), wave properties, being in protected waters, population, and its connectivity to main land (existing infrastructure).

- Also, such solution is proposed on Abu-Qir Bay to protect the risks on world heritage properties and sites, where floating structures protection capabilities and its positive environmental impact made it appear to be a perfect match.

- To answer this research question, a floating community proposal for Egypt has been established to analyze every single detail. Findings demonstrates that modular structural interconnected modules have a blend of several positive matters.

- Findings support that long-term structural stability is one of the greatest challenging objectives (see Figure 8.6). Initially, the floating structure must be appropriate for the sea-site.

- Findings show that the platform size is subjected to peoples' needs, functionality, site properties and further aspects such as financial and structural boundaries. Main criteria that influence platform design: design, movability, water characteristics, comfort, seakeeping, structure, financial aspects. Main criteria for site: properties and 
impacts on designing floating structures are local bathymetry, tides and currents, and wave properties.

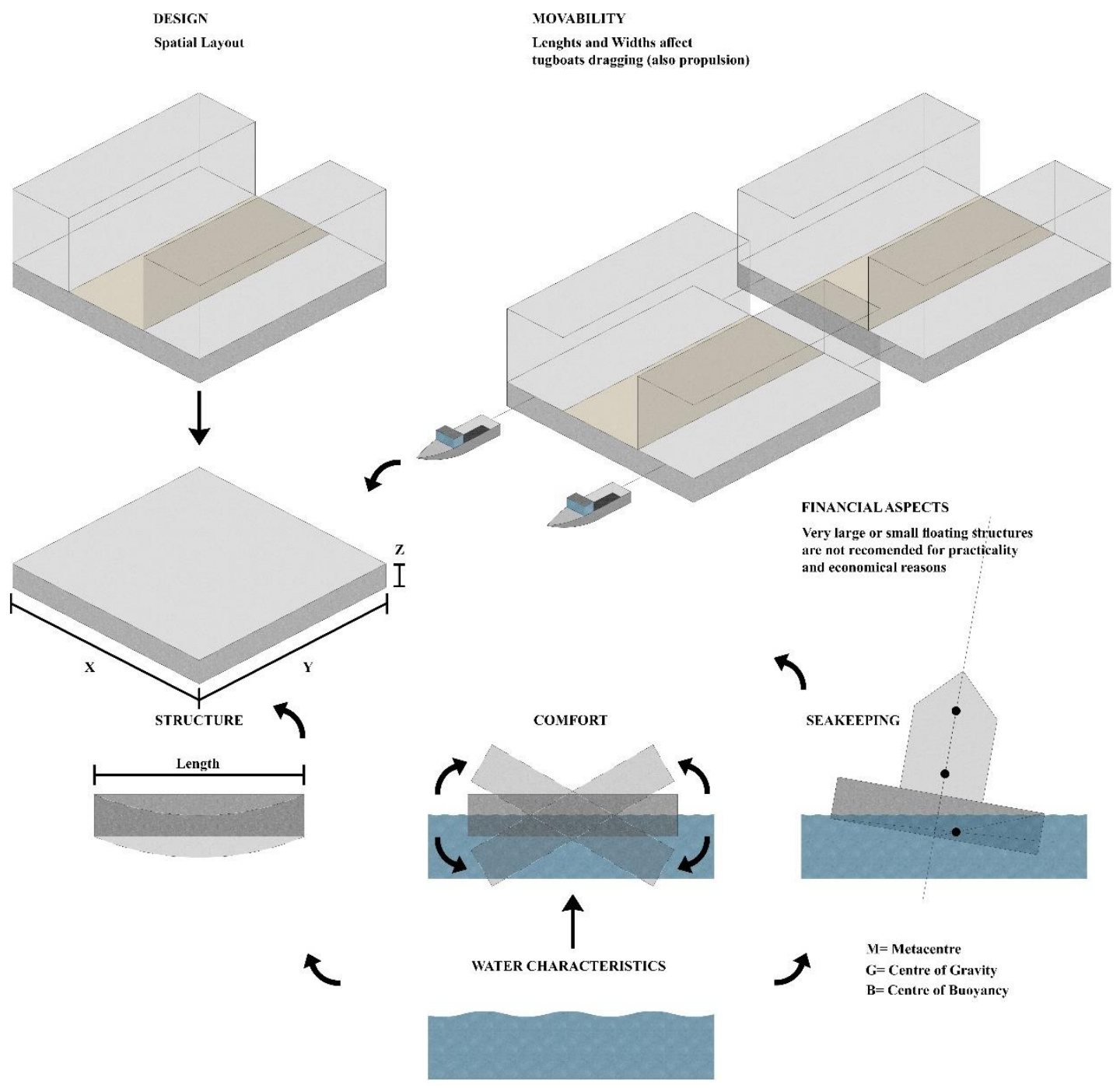

77 Figure 8.6: Factors influence size of VLFS (own illustration).

- The optimal size of the platforms is subjected to a lot of matters, where some could be accurately measured where some others could stay hypothetical. However, the ideal platform size appears to vary between $45-75 \mathrm{~m}$ for structural stability and safety purposes where the proposed design of platform size here is $50 \mathrm{~m}$ a side has been set for interconnecting characteristics and the wave length in Abu-Qir Bay. 
- Content analysis on the evaluation on wave motion on structure stress of various platform sizes regarding $\mathrm{L}=2 \lambda, \mathrm{L}=1 \lambda, \mathrm{L}=1 / 2 \lambda$, and $\mathrm{L}=1 / 4 \lambda$, in terms of cost, durability, construction time, lifespan, environmental impact, suggests that the " $\mathrm{L}=1 \lambda$ " approach appear to be the optimum method for platform size regarding Alexandria's Abu-Qir Bay site (see Figure 8.7).

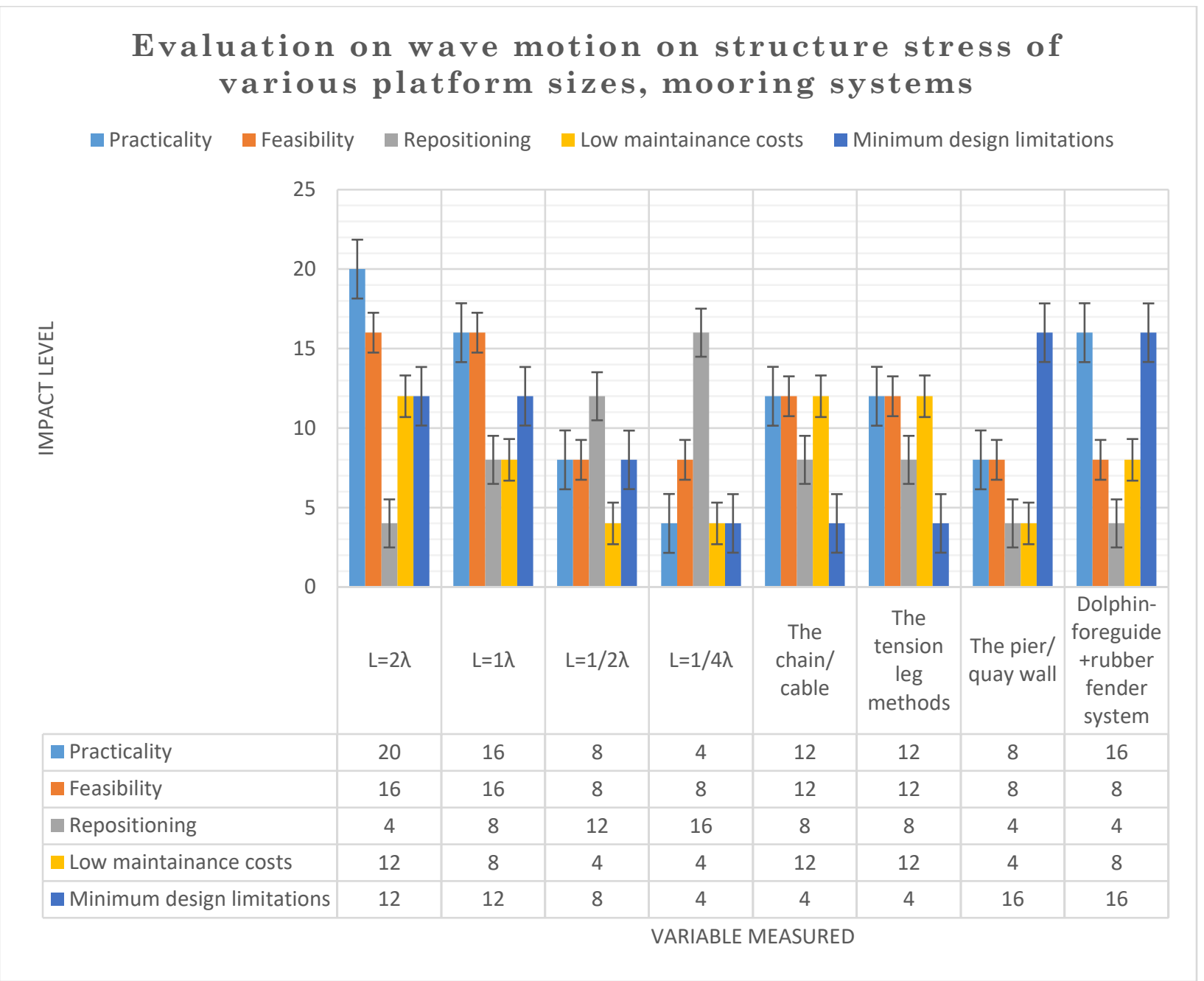

78 Figure 8.7: Evaluation on wave motion on structure stress of various platform sizes and mooring systems. ${ }^{14}$

${ }^{14}$ Main References: British Columbia Float Home Standard (2015), Suzuki et al. (2006), (Tennessee Valley Authority, 2016), Tsaltas et al. (2010), UNFCCC (2007, 2016), Wang (2017), Wang \& Tay (2011), Watanabe et at. (2008). 


\begin{tabular}{|c|c|c|}
\hline Item & Structural illustration of platform & Characteristics \\
\hline Platform roof & $\begin{array}{l}\text { Floor } \mathrm{Tl} \\
30 \mathrm{~cm}\end{array}$ & $\begin{array}{l}\text { Platform's roof. } \\
\text { Herein the platform size of } \\
50 \mathrm{~m} \text { a side was set for } \\
\text { interconnecting } \\
\text { characteristics. }\end{array}$ \\
\hline $\begin{array}{l}\text { Reinforcement } \\
\text { walls }\end{array}$ & $\begin{array}{l}\text { Wall Thickness } \\
30 \mathrm{~cm}\end{array}$ & $\begin{array}{l}\text { Rib-like structure could be } \\
\text { positioned on the caisson's } \\
\text { bottom than placing walls } \\
\text { all over. } \\
\text { Such rib-like structure } \\
\text { would transfer the water } \\
\text { pressure loads into the } \\
\text { pillars like how the beams } \\
\text { do to the floor's loads. } \\
\text { The cavities between such } \\
\text { rib-like structure, is useful } \\
\text { for chains, cables coated by } \\
\text { insulation materials. }\end{array}$ \\
\hline $\begin{array}{l}\text { Floor and } \\
\text { perimeter walls }\end{array}$ & $\frac{}{\substack{\text { Wall Thickness } \\
50 \mathrm{~cm}}}$ & $\begin{array}{l}\text { The platform of the floating } \\
\text { structure is designed like a } \\
\text { void chamber using caisson } \\
\text { engineering. Generally, big } \\
\text { concrete caissons are } \\
\text { divided by walls to } \\
\text { strengthen the platform. } \\
\text { The exterior layer of the } \\
\text { concrete body works as a } \\
\text { concrete protection layer } \\
\text { that shelters the platform's } \\
\text { steel reinforcement from } \\
\text { the harmful seawater. } \\
\text { Local conditions in each } \\
\text { site determines the } \\
\text { detailed dimensions of the } \\
\text { platform's void chamber. }\end{array}$ \\
\hline
\end{tabular}

70 Table 8.9: Foundation structure of the floating platform (own illustrations). 


\begin{tabular}{|c|c|c|}
\hline Platform model & $\begin{array}{l}\text { Platforms assembled to one unit } \\
\text { (district/neighborhood) }\end{array}$ & $\begin{array}{l}\text { Unites united assembled to one great } \\
\text { unit (city-scale) }\end{array}$ \\
\hline VIVIV & 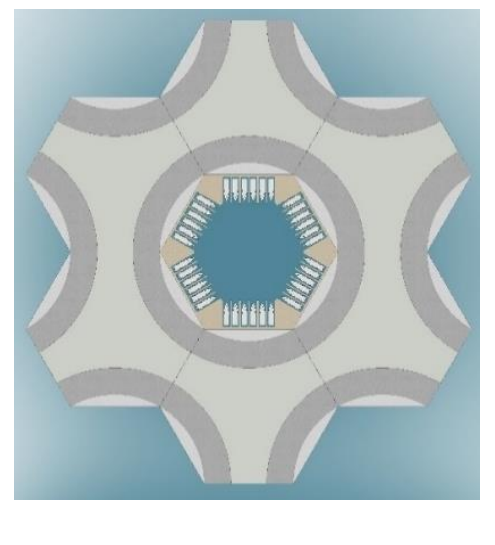 & 4 \\
\hline One hexagonal floating platform & $\begin{array}{l}\text { Six hexagonal models assembled to } \\
\text { create a district/neighborhood. }\end{array}$ & $\begin{array}{l}\text { Master-Plan 'B' showing the } \\
\text { independency of the hexagonal platform } \\
\text { from the square one, also showing the } \\
\text { breakwater around the united } \\
\text { platforms. }\end{array}$ \\
\hline 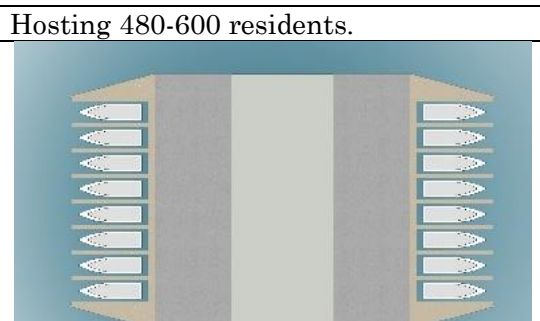 & Hosting $2880-3,600$ residents. & | \\
\hline One squared floating platform & $\begin{array}{l}\text { Five squared models assembled to } \\
\text { create a district/neighborhood. }\end{array}$ & $\begin{array}{l}\text { Squared model doesn't need a specific } \\
\text { platform number to create a city-scale. }\end{array}$ \\
\hline Hosting 256-320 residents. & Dependable. & Dependable. \\
\hline & $\begin{array}{l}6 \text { Hexagonal Modulues \& } 6 \text { Square Modules Interlocked } \\
\text { 1Assembled Unit } \\
12 \text { Modules }\end{array}$ & + \\
\hline $\begin{array}{l}\text { Hexagonal and squared platforms } \\
\text { interlocking together for further } \\
\text { expansion as a dynamic growth strategy. }\end{array}$ & $\begin{array}{l}\text { Six hexagonal models and Five } \\
\text { squared models assembled to create } \\
\text { a district/neighborhood. }\end{array}$ & $\begin{array}{l}\text { Master-Plan 'A' where hexagonal and } \\
\text { square platforms are assembled } \\
\text { together. }\end{array}$ \\
\hline & Hosting 4,416-5,520 residents. & Hosting $19,200-24,000$ residents. \\
\hline
\end{tabular}

71 Table 8.10: Units Assembly Proposals of both Modules showing the harbour, wave attenuators, and master-plan options proposed (own illustrations). 
- Since the project is aimed for the protected water of Abu-Qir Bay, so integrating breakwater which surrounds the community was not required for expansions. However, a proposal of a breakwater has been offered in case of relocating to deep seas is required as the floating community must be designed to be able to survive not only in protected waters, but also in open waters where that would be infrequently and only short-term in natural disasters situations. Regarding the design, two platform forms have been set, the squared and the hexagonal. The hexagonal shape could be interconnected to the square one and they could group into forming big circular formations, since either six hexagons and six squares or only six hexagons could form circular formations when grouped properly. The hexagon shape for platforms has been found to be the optimum fit in terms of circulation and interconnecting (see Table 8.9 \& 8.10). Pathways are frequently attached to the floating building to the coastline and especially that in urbanized areas are generally very well attached to the neighbouring traffic system. Pathways of floatation ability are required for the gap space from coast to the floating community as it requires mooring to the seabed. Global common safety procedures require floating buildings to have emergency vehicles routes to the location and close to the building.

- Comparative analysis on the first expanding dynamic approach "house level" move with house, sell and move, stay and upgrade, and unite, in terms of practicality, feasibility, repositioning, low maintenance costs, and minimum design limitations, suggests that the "unite" strategy appear to be the optimum method on house level regarding Alexandria's Abu-Qir Bay site (see Table 8.11 \& Figure 8.8). 


\begin{tabular}{|c|c|c|c|}
\hline Option & Expansion method & Characteristics & $\begin{array}{l}\text { Probable } \\
\text { drivers }\end{array}$ \\
\hline $\begin{array}{l}\text { Move } \\
\text { with } \\
\text { house }\end{array}$ & & $\begin{array}{l}\text { Relocating the } \\
\text { floating house } \\
\text { within the city. }\end{array}$ & $\begin{array}{l}\text { Unsatisfied } \\
\text { with } \\
\text { neighborhood. } \\
\text { Being nearby } \\
\text { work, family or } \\
\text { friends. }\end{array}$ \\
\hline $\begin{array}{l}\text { Sell and } \\
\text { move }\end{array}$ & & $\begin{array}{l}\text { Like in land- } \\
\text { based areas. } \\
\text { Sell your home } \\
\text { and relocate in } \\
\text { or outside the } \\
\text { city. }\end{array}$ & $\begin{array}{l}\text { Unsatisfied } \\
\text { with your } \\
\text { home. } \\
\text { Craving a } \\
\text { more } \\
\text { appealing } \\
\text { area. }\end{array}$ \\
\hline $\begin{array}{l}\text { Stay and } \\
\text { upgrade }\end{array}$ & & $\begin{array}{l}\text { Remain at the } \\
\text { same site. } \\
\text { Sell the home } \\
\text { on web-based } \\
\text { platform. } \\
\text { Buy a bigger } \\
\text { home for the } \\
\text { same site. }\end{array}$ & $\begin{array}{l}\text { Satisfied with } \\
\text { neighborhood } \\
\text { but unsatisfied } \\
\text { with home. }\end{array}$ \\
\hline Unite & & $\begin{array}{l}\text { Encounter new } \\
\text { people with } \\
\text { same desires, } \\
\text { values and } \\
\text { vision to form a } \\
\text { new } \\
\text { neighborhood in } \\
\text { or outside the } \\
\text { city. }\end{array}$ & $\begin{array}{l}\text { The crave to } \\
\text { form a } \\
\text { distinguished } \\
\text { society. }\end{array}$ \\
\hline
\end{tabular}

72 Table 8.11: Analyzed possibilities for growth development on a house level

- Comparative analysis on the first expanding dynamic approach "neighborhood level" move, merge, split, dissolve, spinout, and transfer, in terms of practicality, feasibility, repositioning, low maintenance costs, and minimum design limitations, suggests that the "merge" strategy appear to be the optimum method on neighborhood level regarding Alexandria's Abu-Qir Bay site (see Table 8.12 \& Figure 8.8. 


\begin{tabular}{|c|c|c|c|}
\hline Option & Expansion method & Characteristics & $\begin{array}{l}\text { Probable } \\
\text { drivers }\end{array}$ \\
\hline Move & & $\begin{array}{l}\text { Neighborhood } \\
\text { relocation } \\
\text { within the city. }\end{array}$ & $\begin{array}{l}\text { More } \\
\text { possibilities for } \\
\text { economic } \\
\text { growth. } \\
\text { Relocation } \\
\text { required for } \\
\text { general growth } \\
\text { approach of } \\
\text { city. }\end{array}$ \\
\hline Merge & & $\begin{array}{l}\text { Unite } \\
\text { neighborhoods } \\
\text { to form a } \\
\text { bigger one. }\end{array}$ & $\begin{array}{l}\text { To be appealing } \\
\text { for inhabitants } \\
\text { and residents. } \\
\text { More lobby } \\
\text { power with the } \\
\text { municipality. } \\
\text { Enhance } \\
\text { capability to } \\
\text { form better } \\
\text { services. }\end{array}$ \\
\hline Split & & $\begin{array}{l}\text { Divide } \\
\text { neighborhood } \\
\text { to form to } \\
\text { smaller one. }\end{array}$ & $\begin{array}{l}\text { Enhance } \\
\text { human scale. } \\
\text { Unsatisfied } \\
\text { with } \\
\text { neighborhood } \\
\text { council. }\end{array}$ \\
\hline Dissolve & & $\begin{array}{l}\text { Divide } \\
\text { neighborhood } \\
\text { into separate } \\
\text { houses to be } \\
\text { free to go } \\
\text { anywhere in } \\
\text { the city. }\end{array}$ & $\begin{array}{l}\text { Absence of } \\
\text { social unity. } \\
\text { Disagreements. } \\
\text { Incompetent } \\
\text { neighborhood } \\
\text { council. }\end{array}$ \\
\hline Spinout & & $\begin{array}{l}\text { Leave city to } \\
\text { form new } \\
\text { floating } \\
\text { community in } \\
\text { a shoreside } \\
\text { protected bay. }\end{array}$ & $\begin{array}{l}\text { Unsatisfied } \\
\text { with city } \\
\text { administration. } \\
\text { More } \\
\text { possibilities to } \\
\text { relocate nearby } \\
\text { other littoral } \\
\text { city. }\end{array}$ \\
\hline Transfer & & $\begin{array}{l}\text { Relocate } \\
\text { neighborhood } \\
\text { to another city. }\end{array}$ & $\begin{array}{l}\text { Unsatisfied } \\
\text { with city } \\
\text { administration. } \\
\text { More } \\
\text { possibilities in } \\
\text { other cities. }\end{array}$ \\
\hline
\end{tabular}

73 Table 8.12: Analyzed possibilities for growth development on a neighborhood level (own illustrations). 


\begin{tabular}{|c|c|c|c|}
\hline Option & Expansion method & Characteristics & $\begin{array}{l}\text { Probable } \\
\text { drivers }\end{array}$ \\
\hline Move & & $\begin{array}{l}\text { District } \\
\text { relocation } \\
\text { within the city. }\end{array}$ & $\begin{array}{l}\text { More } \\
\text { possibilities for } \\
\text { economic } \\
\text { growth. } \\
\text { Required for } \\
\text { general growth } \\
\text { approach of } \\
\text { city. }\end{array}$ \\
\hline Merge & & $\begin{array}{l}\text { Unite districts } \\
\text { to form a } \\
\text { bigger one. }\end{array}$ & $\begin{array}{l}\text { To be appealing } \\
\text { for inhabitants. } \\
\text { More lobby } \\
\text { power with the } \\
\text { municipality. } \\
\text { Enhance } \\
\text { capability to } \\
\text { form better } \\
\text { services. }\end{array}$ \\
\hline Settle & & $\begin{array}{l}\text { Unite with } \\
\text { other districts } \\
\text { from same or } \\
\text { further cities } \\
\text { to form a } \\
\text { bigger one. }\end{array}$ & $\begin{array}{l}\text { More } \\
\text { possibilities } \\
\text { elsewhere. } \\
\text { Economic } \\
\text { collaboration of } \\
\text { districts. }\end{array}$ \\
\hline Split & & $\begin{array}{l}\text { Divide district } \\
\text { to form to } \\
\text { smaller one. }\end{array}$ & $\begin{array}{l}\text { Enhance } \\
\text { human scale. } \\
\text { Unsatisfied } \\
\text { with district } \\
\text { council. }\end{array}$ \\
\hline Dissolve & & $\begin{array}{l}\text { Divide districts } \\
\text { into separate } \\
\text { neighborhoods } \\
\text { to be free to go } \\
\text { anywhere in } \\
\text { the city. }\end{array}$ & $\begin{array}{l}\text { Absence of } \\
\text { social unity. } \\
\text { Disagreements. } \\
\text { Incompetent } \\
\text { district council. }\end{array}$ \\
\hline Spinout & & $\begin{array}{l}\text { Leave city to } \\
\text { form new } \\
\text { floating city in } \\
\text { open waters. }\end{array}$ & $\begin{array}{l}\text { Unsatisfied } \\
\text { with city } \\
\text { administration. } \\
\text { More } \\
\text { possibilities } \\
\text { elsewhere. }\end{array}$ \\
\hline Transfer & & $\begin{array}{l}\text { Relocate } \\
\text { district to } \\
\text { another city. }\end{array}$ & $\begin{array}{l}\text { Unsatisfied } \\
\text { with city } \\
\text { administration. } \\
\text { More } \\
\text { possibilities in } \\
\text { other cities. }\end{array}$ \\
\hline
\end{tabular}

74 Table 8.13: Analyzed possibilities for growth development on a district level (own illustrations). 
- Comparative analysis on the first expanding dynamic approach "district level" move, merge, settle, split, dissolve, spinout, and transfer, in terms of practicality, feasibility, repositioning, low maintenance costs, and minimum design limitations, suggests that the "settle and merge" strategies appear to be the optimum method on district level regarding Alexandria's Abu-Qir Bay site (see Table 8.13 \& Figure 8.8.

- Evaluation on expanding dynamics in terms of house, neighborhood, district/city levels conclude that the optimum options for East Alexandria and central Abu-Qir area are: unite, merge, settle respectively (see Table 8.14).

\begin{tabular}{|c|c|c|c|c|c|c|}
\hline - $\quad$ Objective & Level & Approach & $\begin{array}{l}\text { Suitability } \\
\text { for East } \\
\text { Alexandria's } \\
\text { coastline }\end{array}$ & $\begin{array}{l}\text { Suitability } \\
\text { for } \\
\text { Central } \\
\text { Abu-Qir Bay }\end{array}$ & $\begin{array}{l}\text { Ideal } \\
\text { methods }\end{array}$ & $\begin{array}{l}\text { Design } \\
\text { methods } \\
\text { selected }\end{array}$ \\
\hline \multirow[t]{17}{*}{$\begin{array}{l}\text { Expanding } \\
\text { dynamics }\end{array}$} & \multirow[t]{4}{*}{ House Level } & $\begin{array}{l}\text { Move with } \\
\text { house }\end{array}$ & $75 \%$ & $70 \%$ & $72.5 \%$ & $72.5 \%$ \\
\hline & & $\begin{array}{l}\text { Sell and } \\
\text { move }\end{array}$ & $65 \%$ & $60 \%$ & $62.5 \%$ & $62.5 \%$ \\
\hline & & $\begin{array}{l}\text { Stay and } \\
\text { upgrade }\end{array}$ & $60 \%$ & $60 \%$ & $60 \%$ & $60 \%$ \\
\hline & & Unite & $95 \%$ & $95 \%$ & $95 \%$ & $95 \%$ \\
\hline & \multirow{6}{*}{$\begin{array}{l}\text { Neighborhood } \\
\text { level }\end{array}$} & Move & $60 \%$ & $45 \%$ & $52.5 \%$ & $52.5 \%$ \\
\hline & & Merge & $90 \%$ & $90 \%$ & $90 \%$ & $90 \%$ \\
\hline & & Split & $60 \%$ & $60 \%$ & $60 \%$ & $60 \%$ \\
\hline & & Dissolve & $30 \%$ & $35 \%$ & $32.5 \%$ & $32.5 \%$ \\
\hline & & Spinout & $65 \%$ & $60 \%$ & $62.5 \%$ & $62.5 \%$ \\
\hline & & Transfer & $45 \%$ & $40 \%$ & $42.5 \%$ & $42.5 \%$ \\
\hline & \multirow[t]{7}{*}{ District level } & Move & $45 \%$ & $50 \%$ & $47.5 \%$ & $47.5 \%$ \\
\hline & & Merge & $95 \%$ & $95 \%$ & $95 \%$ & $95 \%$ \\
\hline & & Settle & $95 \%$ & $90 \%$ & $92.5 \%$ & $92.5 \%$ \\
\hline & & Split & $55 \%$ & $65 \%$ & $60 \%$ & $60 \%$ \\
\hline & & Dissolve & $45 \%$ & $50 \%$ & $47.5 \%$ & $47.5 \%$ \\
\hline & & Spinout & $25 \%$ & $30 \%$ & $27.5 \%$ & $27.5 \%$ \\
\hline & & Transfer & $50 \%$ & $55 \%$ & $52.5 \%$ & $52.5 \%$ \\
\hline \multirow{4}{*}{$\begin{array}{l}\text { Platform } \\
\text { dimensions }\end{array}$} & \multirow{4}{*}{$\begin{array}{l}\text { Wave motion } \\
\text { on structure } \\
\text { stress of } \\
\text { various } \\
\text { platform sizes }\end{array}$} & $\mathrm{L}=2 \lambda$ & $80 \%$ & $85 \%$ & $82.5 \%$ & $82.5 \%$ \\
\hline & & $\mathrm{L}=1 \lambda$ & $75 \%$ & $85 \%$ & $80 \%$ & $80 \%$ \\
\hline & & $\mathrm{L}=1 / 2 \lambda$ & $50 \%$ & $65 \%$ & $57.5 \%$ & $57.5 \%$ \\
\hline & & $\mathrm{L}=1 / 4 \lambda$ & $45 \%$ & $60 \%$ & $52.5 \%$ & $52.5 \%$ \\
\hline
\end{tabular}

75 Table 8.14: Analyzed design methods and criteria for growth development and platform sizes for central Abu-Qir Bay and East Alexandria's coastline. 


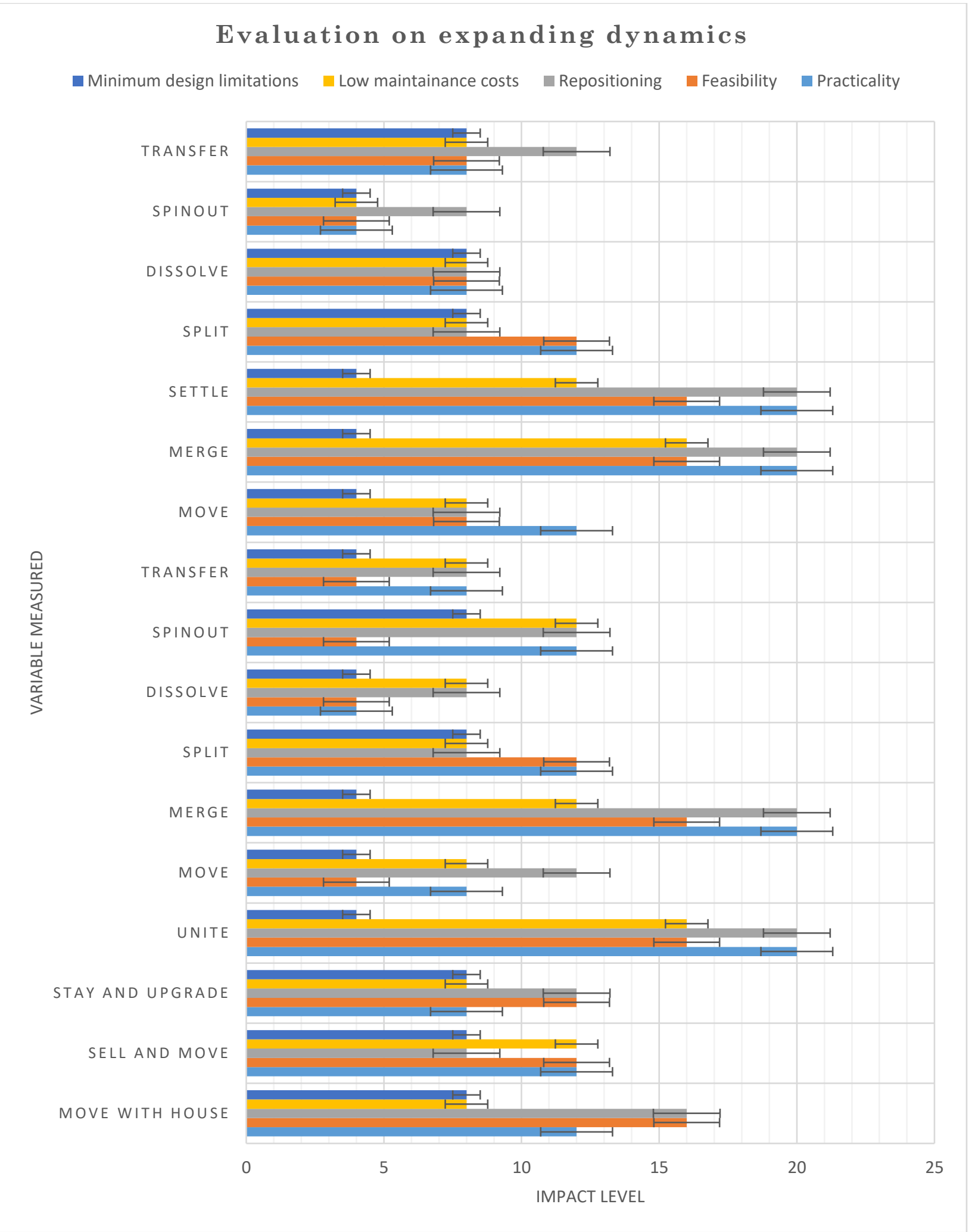

79 Figure 8.8: Evaluation of expanding dynamic strategies for VLFS. 


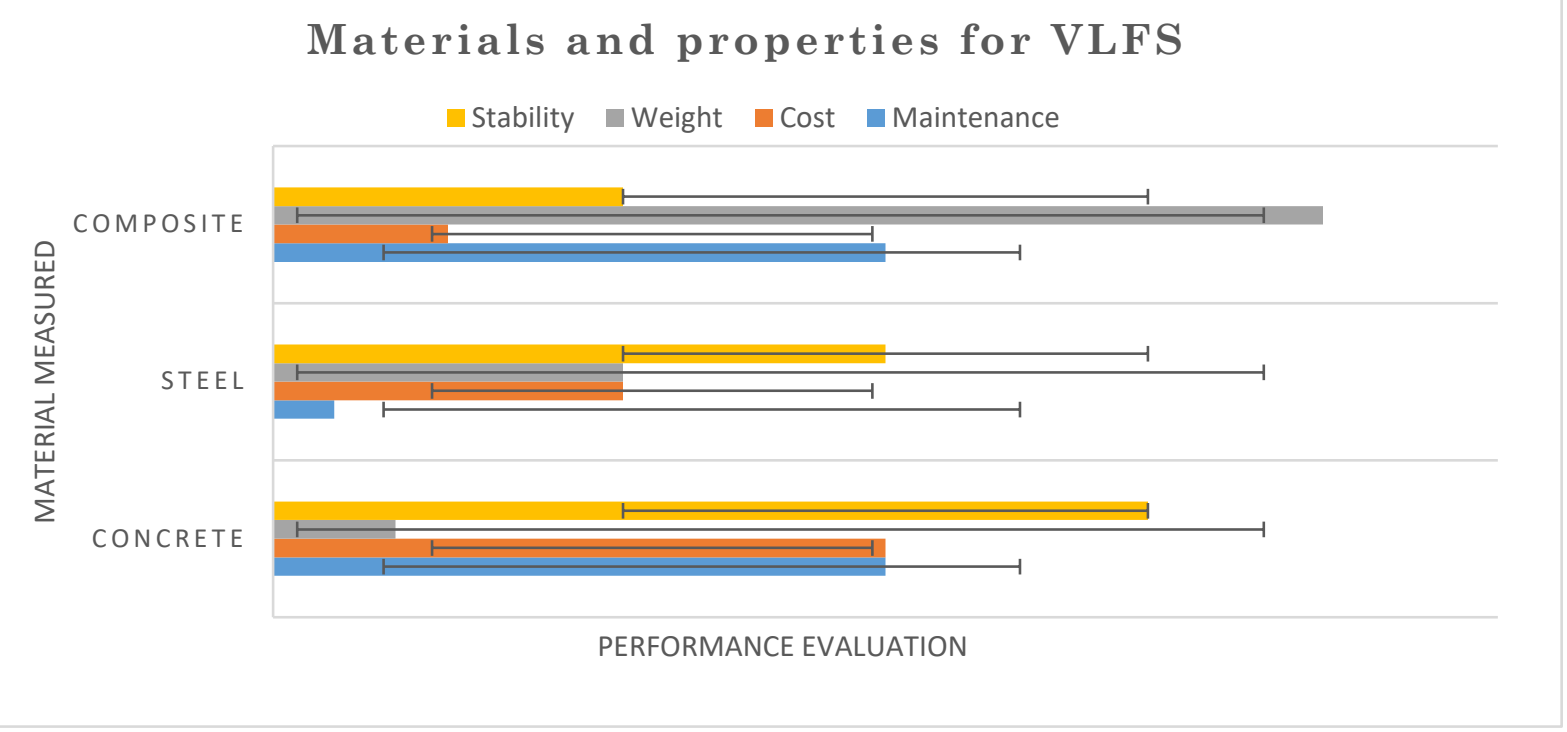

80 Figure 8.9: Findings on floating structures platforms' materials and properties.

- Materials selection analyzed in terms of maintenance, cost, weight, and stability show demonstrate of concrete, steel, composite materials show that concrete is the optimum selection in terms of maintenance, cost, and stability. However, steel is better only in terms of weight (see Figure 8.9) while showing superiority over composites regarding its cost. Nevertheless, composites have emerged a great material in terms of maintenance and weight, however, it could be only implemented in high budget projects (possibly by the private sector). Concrete is regularly practiced in marine developments as well, like in underwater tunnels, offshore and subsea facilities. Some marine projects have practiced underwater concrete which have since existed over than 50 years. Although regarding durability and stability concrete has high-pressure strength, nevertheless it has low-tensile one. The biggest disadvantage in using concrete is the steel reinforced which is implanted inside the concrete structure to offer a better tensile strength, although such material could rust. Thus, the appropriate concrete coating thickness is required to preserve the steel is unaffected. 
Such process has great impact on concrete structures weights. Lately, further supporting sorts have been implemented like fibers, for instance the Engineered Cementitious Composite (ECC) and the Fiber-reinforced concrete (FRC). In platforms, implementing non-corrosive materials may offer huge progresses regarding resilience, mass and usage. On the other hand, composites have emerged a great material in terms of maintenance and weight, however, it could be implemented in high budget projects.

To sum up, this thesis proposes Abu-Qir Bay didn't only seem as the most vulnerable areas when addressing SLR impacts, but also as an ideal location for floating community regarding its depth (18.5-22), wave properties, and being in protected waters. It is proposed for its underwater areas which hold more submerged world heritage historical monuments, properties and sites of Pharaonic, Greek, Roman, and Christian as listed by the UNESCO can not be replaced. Also, VLFS can parallelly safeguard Egypt's marine borderlines sovereignty and not endanger the marine and coral life habitat. Being in protected waters means shielding from high waves as well as being able to expand. Therefore, modular platforms would be the way to expand and being nearby the coasts helps in emergency cases and transporting goods and people in and out. Although Lake Manzalah in Damietta is in protected water and have better wave properties in comparison to Abu-Qir Bay, however water depth is extremely shallow (1.2-1.5 meters) and its population makes floating structures solution appear not to be cost effective approach for such site. 


\subsection{Architectural Design Guidelines for Building on Water in the Nile Delta's Coastline}

Architectural design of floating structures against SLR impacts rely on various aspects, such as the existing infrastructure, capitals, expertise, data and the level of reasonable distribution of resources. The results of this thesis suggest the following architectural design guidelines when designing floating structures in the Nile Delta:

- Main criteria for site: properties and impacts on designing floating structures are local bathymetry, tides and currents, and wave properties.

- Main criteria that influence platform design: design, movability, water characteristics, comfort, seakeeping, structure, financial aspects.

- Evaluation of six design approaches in terms of: movability, dynamic geography, seakeeping, water experience, growth development, and mooring system conclude that the optimum options for East Alexandria and central Abu-Qir area are: towed, branch, breakwater, branch, breakwater, dolphins-foreguide respectively. If such features are to be integrated with energy and food production in any design, the result will be a fully self-independent community from the outside.

- Floating structures must be designed to be able to survive not only in protected waters, but also in open waters if relocating is needed, however that would be unusual like in short-term situations such as in natural disasters.

- Expanding dynamics: Evaluation on expanding dynamics in terms of house, neighborhood, district/city levels conclude that the optimum options for Abu-Qir Bay area are: unite, merge, settle respectively. Findings show that modular platforms 
could help in expansion strategies, movability in case of emergencies, and creating ordered formations, especially since findings demonstrate that harbours appear to create traffic chaos.

- Design strategy could help achieving self-sufficiency if the design considers integrating sustainable approaches for achieving natural lightening, ventilation system, waste flow system, and water recycling system in the superstructure design.

- Platform size is subjected to peoples' needs, functionality, site properties and further aspects such as financial and structural boundaries. However, the optimum platform size recommended varies between 45 to 75 meters for structural stability and safety purposes where the proposed design of platform size here is $50 \mathrm{~m}$ a side has been set for interconnecting characteristics and the wave length in Abu-Qir Bay.

- The dolphin system to be the most suitable for Egypt's Nile Delta coasts since such mooring system is best implemented where there are no docks, or any coastline attached structure so that the floating structure could stay in position.

- Mooring system dimensioning will be considered an average depth $20 \mathrm{~m}$. The difference in height considered a mean tide of $1 \mathrm{~m}$ as highest wave is around $2 \mathrm{~m}$. Total $=2 \mathrm{~m}$ circa. Wave properties data are essential to get, as they influence the platform dimensions. Wave properties for a certain site is always preferable in bays or inlets than of open waters situations.

- Pathways of floatation ability are required for the gap space from coast to the floating community as it requires mooring to the seabed. Global common safety procedures require floating buildings to have emergency vehicles routes to the location and close to the building. 
- Material selection: The selected materials (concrete, steel, and composite materials) are analyzed in terms of maintenance, cost, weight, and stability. The analysis shows that concrete is the optimum selection in terms of maintenance, cost, and stability in respect to Egypt's economy. However, composites have emerged a great material in terms of maintenance and weight that should be highly considered for future floating community proposals. In platforms, implementing non-corrosive materials may offer huge progresses regarding resilience, mass and usage.

- Establishing rules and guidelines for coastal management and integrating the adaptation approaches like floating structures against SLR impacts. Including SLR impacts in the framework of the Environmental Impact Assessment (EIA) as well as the Strategic Impact Assessment (SEA). Establishing restrictions and binding regulations when providing licences for drilling wells for extracting groundwater in littoral areas.

- Involving floating structure approaches and policies to both climate change and SLR in national development strategies.

- Improving the public awareness, and scientific research, and building regulations on floating structures for vulnerable areas.

- Improving official capability and capacity for monitoring, creating strategies, and developing early stage cautionary systems. 


\subsection{Relation to Similar Studies}

The results on Egypt's Nile Delta relates to the Intergovernmental Panel on Climate Change (IPCC, 2014; IPCC, 2007) regarding the SLR impacts on the Nile Delta. Such reports have also helped advancing the understandings on SLR impacts on Egypt by motivating this thesis. The Arab Environment Climate Change Report by Tolba \& Saab (2009) where it supports the finding that land reclamation solutions are not environmental friendly. On the other hand, Atlas of Africa Energy Resources (UNEP, 2017) have supported land reclamation solutions, however only of degraded lands. The results on VLFS were similar to those of Suzuki et al. (2006) regarding load displacements, design, and the optimum size for floating structures. The advantages of VLFS were related to those of Wang et al. (2008), except that sand cost in Egypt regarding land reclamation is not an issue and that's why land reclamation solutions haven't stopped in Egypt as it offers a very cheap solution. The results on the floating community concept proposal have been similar to the Seasteading Institute concept by DeltaSync by Czapiewska et al. (2013) regarding the platform dimensions and the expanding dynamics. Comparison on research findings in terms of addressing climate challenges, their impacts, and different solutions are shown in Table 8.15.

To sum up, the contribution to the papers in this thesis are: redefining the means of SLR, analysing practices of various adaptation approaches and mitigation solutions, and updating data concerning SLR impacts on the Nile Delta; developing a new prospective for tackling SLR impacts on the Nile Delta; advancing in the architectural design methodology framework of self-sustaining and expanding floating communities; establishing architectural design guidelines for constructing floating structures for Egypt; and presenting two architectural models of floating interconnecting platforms for an expandable floating community for the Nile Delta. 


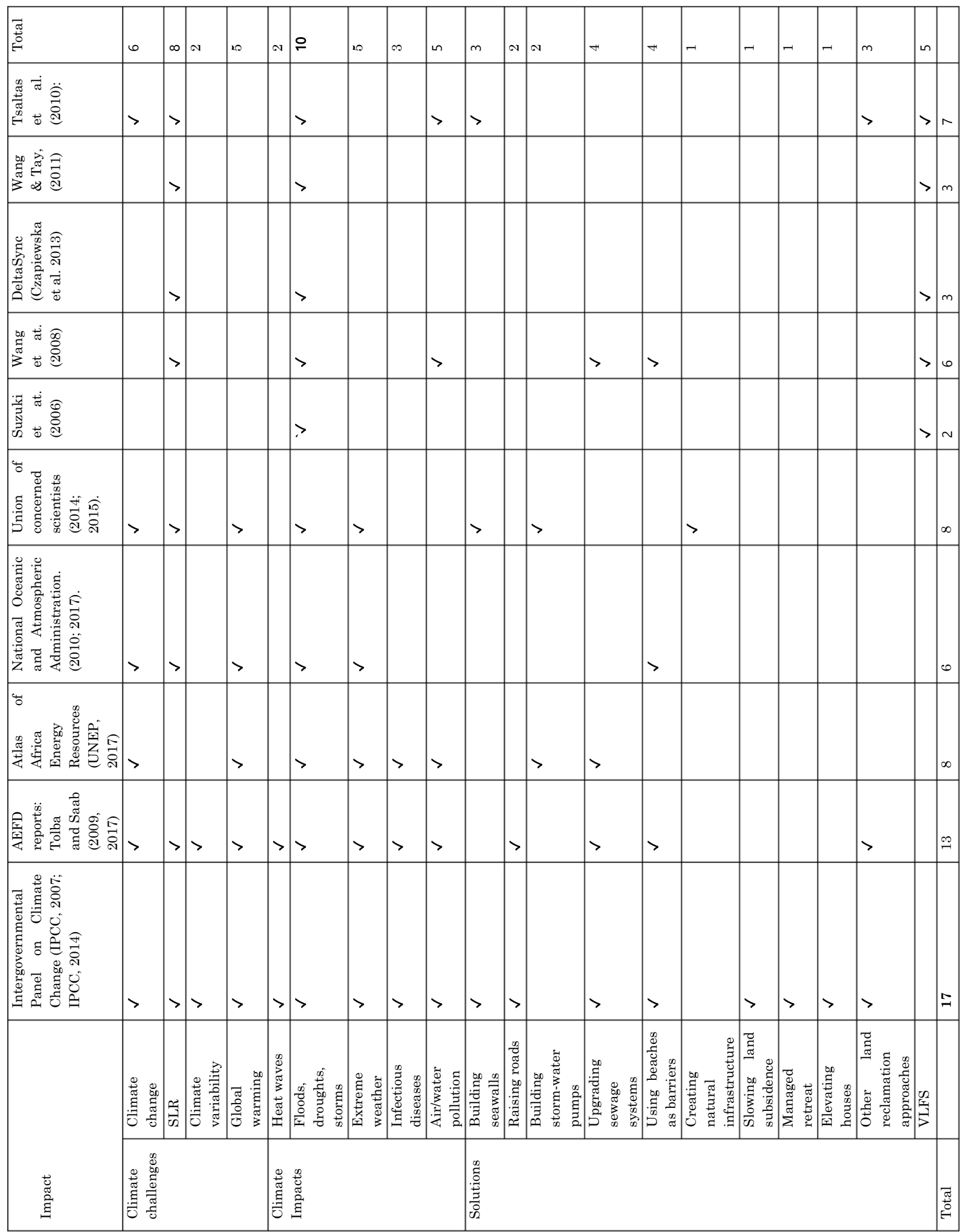

76 Table 8.15: Comparison on research findings with similarities with this dissertation. 


\subsection{Alternative Explanations}

In this dissertation, the initial approach has been to study the Nile delta's most vulnerable sites to SLR, then addressing the most suitable adaptation approach and mitigation solution to adapt and mitigate the Nile Delta from the rising seas impacts. Although the initial approach herein was going in the direction of land reclamation methods, nevertheless its negative impact of the environment made it seem to be very unsustainable approach. The unexpected price of land reclamation makes it understandable why such solution may look very attractive for the Egyptian government. Egypt's vast landscape consist of desert, therefore the price of sand for land reclamation makes it such an easy decision. Not only its cost that makes it practiced in Egypt, but also being rapid, easy, and doesn't requiring high technology. However, the approach has been altered since the initial comparisons and analysis on solutions regarding SLR. Whereas the VLFS do not look like working every time, especially for the depth requirements, however such solution may look more attractive in other spots in the Nile Delta when the sea level rises even more. 


\section{Chapter 9}

\section{CONCLUSIONS, IMPLICATIONS,}

\section{AND FUTURE RESEARCH}

\subsection{Introduction}

The initial aim of this dissertation was set out to explore SLR impacts on the Nile Delta's coastlines, furthermore, this dissertation highlights the probable uses of VLFS for tackling the SLR challenges, to emphasize the absence of global an authorised context regarding their implementation and usage. This study was designed to assess two hypotheses: The Nile Delta's coastlines will eventually be submerged where land reclamation approaches practiced only offer short-term solutions; and that floating structures offer the optimum solution for safeguarding Egypt's coastal sovereignty when addressing land subsidence problems. The initial aim of this dissertation is set out to explore SLR impacts on the Nile Delta's coastlines, furthermore, this dissertation highlights the probable uses of VLFS for tackling the SLR challenges, to emphasize the absence of global an authorised context regarding their implementation and usage. The objectives of this thesis research have been: 
- To identify the impacts of SLR on the Nile delta region in terms of people affected, land subsidence on the infrastructure, and land submergence area.

- To identify the most vulnerable sites to SLR in the Nile Delta.

- To identify adaptation approaches practiced and main topographic characteristics that influence flood levels and permanent inundation of lowlands by SLR impacts in most vulnerable sites to SLR and their evaluation in respect to Egypt's most vulnerable regions identified.

- To assess the most vulnerable area identified to evaluate SLR impacts on people, buildings, and infrastructure in the most vulnerable site.

- To identify the most sustainable and cost-effective solution against SLR impacts.

- To analyze and study different floating community cases in respect to Egypt's most vulnerable regions to set design approaches and strategies.

- To develop an architectural systematic design guidelines approach for developing floating communities for Egypt and the Nile Delta coastline to function as a future reference for architects and urban planners in Egypt when designing and planning coastal developments.

- To identify the optimum materials and sustainability approaches, mooring system, and project feasibility.

- To set an expanding dynamics design guidelines approach for developing floating communities for Egypt's coastlines to function as a future reference for architects and urban planners to be considered in Egypt when designing and planning coastal developments. 
- To offer a floating community concept proposal for the Nile Delta's most vulnerable area identified to function as a future reference for architects and urban planners in Egypt when designing and planning coastal developments.

The general theoretical literature on this subject and specifically in the context of Egypt is inconclusive on several vital questions. Therefore, this study sought to answer these three questions:

1. What are the most vulnerable sites to SLR impacts in the Nile Delta's coastline?

2. What are the adaptation approaches and mitigation solutions practiced in theses sites and can floating structures offer a better solution against SLR for these sites?

3. How to implement floating structures in the Nile Delta's most vulnerable coastline sites to SLR impacts?

To answer the research questions, the study conducts eight researches using up-to-date data. The first study conducts time series analysis and ranking of impacted areas from SLR on the Nile Delta. The second study conducts a qualitative assessment on SLR impacts for ten case studies and evaluates adaptation solutions practiced in each case. The third study conducts site analysis on the most impacted area identified. The fourth study conducts evaluation design matrix of adaptation approaches and mitigation solutions. The fifth study conducts comparative analysis on eight in depth floating community case studies. The sixth study conducts comparative analysis of different approaches and methods to set guidelines for building on water. The seventh study conducts content analysis to set expanding dynamics guidelines of floating cities. Finally, the eighth study sets architectural design guidelines and floating community concept proposal model for the Nile Delta. 
In this Chapter, the empirical and analytical findings, theoretical implications, policy implications, recommendation for future research, study limitations, research gaps, significance for the study, and the conclusion to the objectives, research questions, and the hypotheses are discussed.

\subsection{Empirical and Analytical Findings}

The foremost empirical and analytical findings are collected and summarized in detail within the empirical chapter 8 (8. Results and Discussion). This section will synthesize the empirical and analytical findings in order to answer the study's three research questions and to test the two hypotheses made to achieve the objectives mentioned in the introduction section.

\section{What are the most vulnerable sites to SLR impacts in the Nile Delta's coastline?}

This research question is set to achieve these objectives:

- To identify the impacts of SLR on the Nile delta region in terms of people affected, land subsidence on the infrastructure, and land submergence area.

- To identify the most vulnerable sites to SLR in the Nile Delta.

- To identify adaptation approaches practiced and main topographic characteristics that influence flood levels and permanent inundation of lowlands by SLR impacts in most vulnerable sites to SLR and their evaluation in respect to Egypt's most vulnerable regions identified.

- To assess the most vulnerable area identified to evaluate SLR impacts on people, buildings, and infrastructure in the most vulnerable site. 


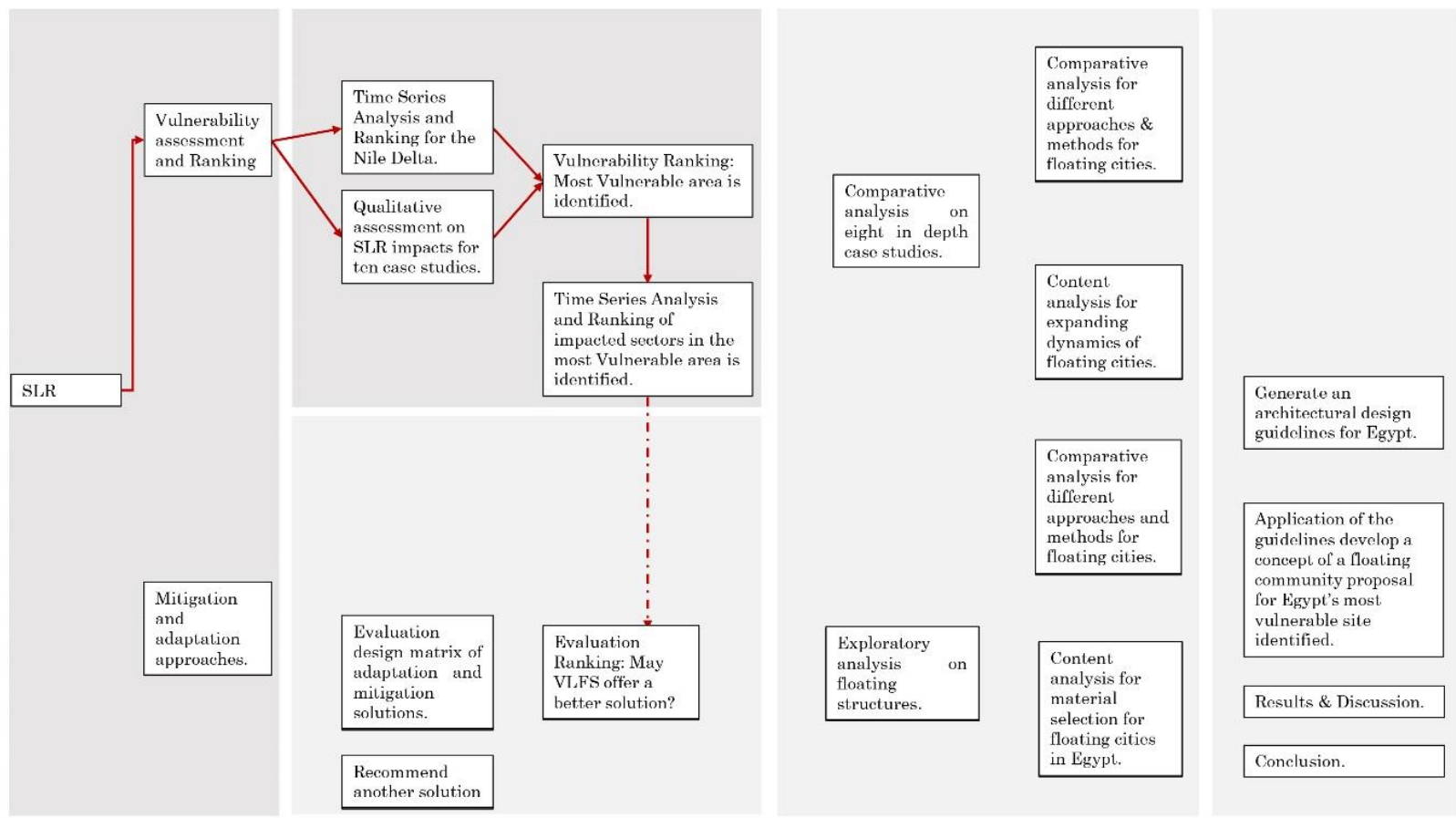

81 Figure 9.1: Analytical framework of the research methodology for the first research question and to test the first hypothesis.

\section{Study Cases:}

- Qualitative analysis executed on ten areas in the Nile Delta conclude that the Eastern coastal plain is more vulnerable to SLR impacts that the Western Coastal Plain, where the most vulnerable areas are Central Abu-Qir Bay and East Alexandria respectively.

- In order on vulnerability: Central Abu-Qir Bay, East Alexandria, El-Tarh, Abu-Qir Bay, Tineh littoral plain, Burullus Lake Barrier, Baltim area (Burullus), Gamasa Embayment, Manzala Lake barrier, Burullus Lake, Abu-Khashaba. 


\section{Adaptation Solutions Practiced:}

- Adaptation approaches practiced analysed regarding their cost, durability, construction time, lifespan, and environmental impact, in order are: breakwaters, raising roads, creating natural infrastructure, sand dunes, and using beaches as barriers. Egypt still practice unsustainable land reclamation methods not only for the abundance and cost of sand in Egypt, but also for being rapid, easy, and doesn't requiring high technology.

\section{SLR Scenarios:}

- SLR scenarios created for East Alexandria and central Abu-Qir area of .5m, 1m, 1.5m, and $2.0 \mathrm{~m}$ SLR, conclude that the most vulnerable sectors in order are: agriculture, people, land subsidence, industry, residential, archeological sites, commercial areas, community facilities. However, agricultural, industry, and residential areas could be recreated elsewhere, but world heritage properties and sites of Pharaonic, Greek, Roman, and Christian as listed by the UNESCO can not be replaced.

What are the adaptation approaches and mitigation solutions practiced in theses sites and can floating structures offer a better solution against SLR for these sites?

This research question is set to achieve these objectives:

- To identify the most sustainable and cost-effective solution against SLR impacts.

- To analyze and study different floating community cases in respect to Egypt's most vulnerable regions to set design approaches and strategies. 


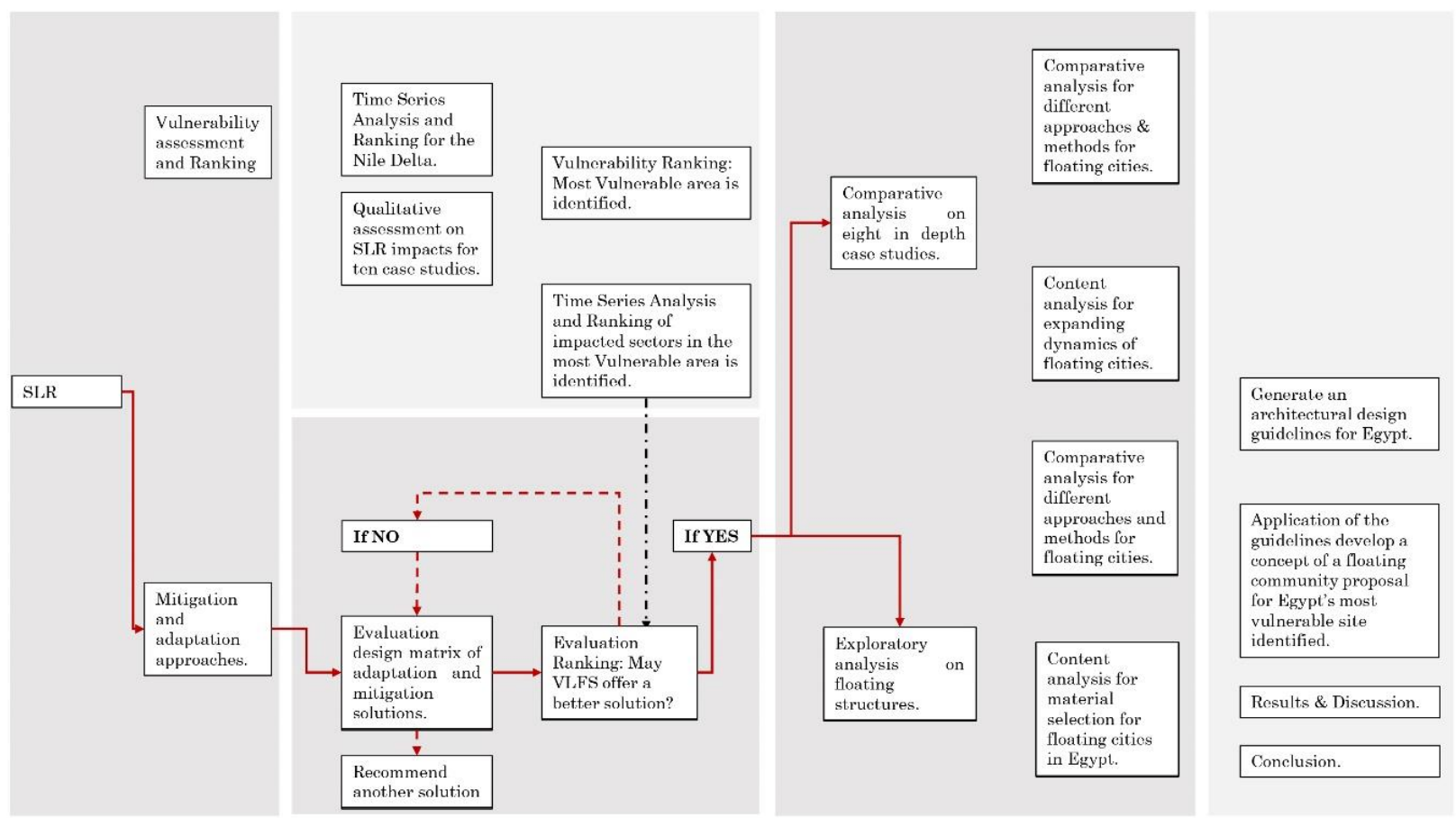

82 Figure 9.2: Analytical framework of the research methodology for the second research question and to test the second hypothesis.

\section{A. Adaptation Solutions:}

- Adaptation approaches analysed in terms of cost, durability, construction time, lifespan, environmental impact suggest VLFS as the most efficient solution.

- In order of efficiency: VLFS, creating natural infrastructure, upgrading sewage systems, elevating houses, raising roads, building storm-water pumps, slowing land sink-age, building seawalls, using beaches as barriers, and managed retreat.

- Adaptation approaches analysed practiced in the Nile Delta analyzed in terms of cost, durability, construction time, lifespan, environmental show that both natural and artificial coastal management protection methods used by ESPA like creating natural infrastructure, sand dunes, using beaches as barriers, and breakwaters are not delivering the required results. Despite of what has been stated about the advantages 
of VLFS for tackling SLR problems like land subsidence, specifically in small islands and low-lying areas in the world like in Egypt's Nile Delta, the Egyptian government is yet to consider such solution.

\section{B. Floating Community Study Cases:}

- Eight floating community cases evaluated which are: Uros people, Ha-long community, Bangkok fishing markets, Harvest city, Ijburg, Lily-pad, Humanitarian Harbour of the Ocean, Seasteading institute, they have been analyzed in terms of: facilities, natural materials, growth development, local food production, mobility, markets, wave attenuator/ water life, agriculture, business, dynamic geography, modular design, and self-sufficient/ survivability. Such evaluation concludes that the most significant design approaches for floating communities in order are: movability, dynamic geography, seakeeping, water experience, growth development, and mooring system.

- VLFS do not look like working every time, where such solution is functional only water depth is shallow with a maximum of $15-20$ meters. In a situation that the water depth is less than that, the seabed would be very soft and as a result, land reclamation solutions are no longer cost effective or even reasonable. It presents a cost-effective possibility where the water depth is deep as well as not affecting the nearshore marine ecosystem. 


\section{How to implement floating structures in the Nile Delta's most vulnerable coastline sites to SLR impacts?}

This research question is set to achieve these objectives:

- To develop an architectural systematic design guidelines approach for developing floating communities for Egypt and the Nile Delta coastline to function as a future reference for architects and urban planners in Egypt when designing and planning coastal developments.

- To set an expanding dynamics design guidelines approach for developing floating communities for Egypt's coastlines to function as a future reference for architects and urban planners to be considered in Egypt when designing and planning coastal developments.

- To identify the optimum materials and sustainability approaches, mooring system, and project feasibility.

- To offer a floating community concept proposal for the Nile Delta's most vulnerable area identified to function as a future reference for architects and urban planners in Egypt when designing and planning coastal developments. 


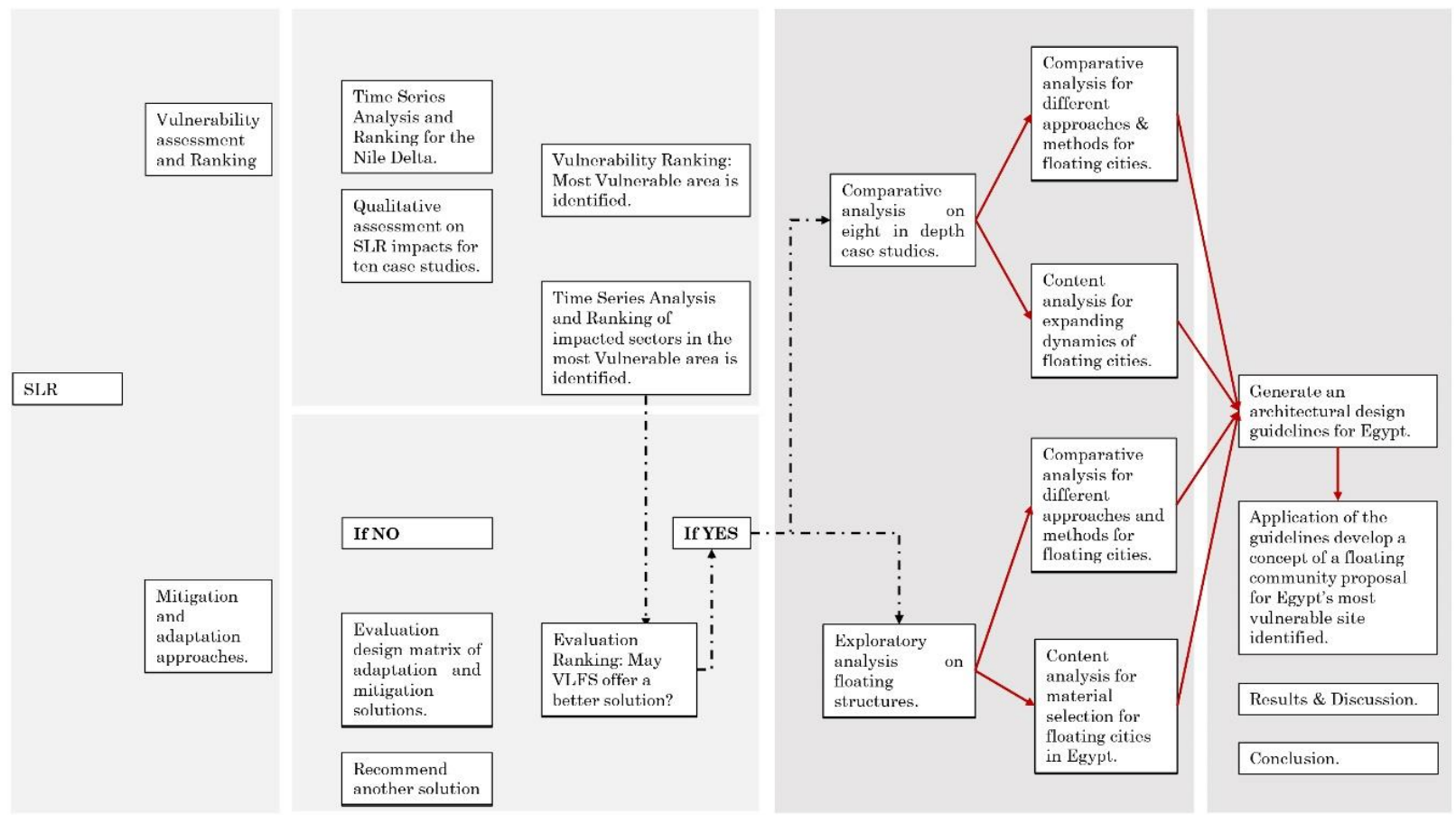

83 Figure 9.3: Analytical framework of the research methodology for the third research question and to test both hypotheses.

\section{A. Possible Site:}

- Although the qualitative risk analysis executed on ten areas in the Nile Delta conclude that the most vulnerable areas lie in Abu-Qir bay, but upon site analysis, this thesis also proposes Abu-Qir bay as the perfect site for such solution as it appears to be the ideal site to implement floating community for many reasons but most importantly for its depth (18.5-22), wave properties, being in protected waters, population, and its connectivity to main land (existing infrastructure).

- Also, such solution is proposed on Abu-Qir Bay to protect the risks on world heritage properties and sites, where floating structures protection capabilities and its positive environmental impact made it appear to be a perfect match. 


\section{B. Design Guidelines:}

- Evaluation of six design approaches in terms of: movability, dynamic geography, seakeeping, water experience, growth development, and mooring system conclude that the optimum options for East Alexandria and central Abu-Qir area are: towed, branch, breakwater, branch, breakwater, dolphins-foreguide respectively.

- Main Criteria that Influence Platform Design: Design, movability, water characteristics, comfort, seakeeping, structure, financial aspects.

- Platform Size: The ideal platform size appears to vary between $45-75 \mathrm{~m}$ for structural stability and safety purposes where the proposed design of platform size here has been set as 50m a side for interconnecting characteristics and the wave length in Abu-Qir Bay.

- Main criteria for site: properties and impacts on designing floating structures are local bathymetry, tides and currents, and wave properties.

- Expanding Dynamics: Evaluation on expanding dynamics in terms of house, neighborhood, district/city levels conclude that the optimum options for Abu-Qir Bay area are: unite, merge, settle respectively.

- Material Selection: The selected materials (concrete, steel, and composite materials) are analyzed in terms of maintenance, cost, weight, and stability. The analysis shows that concrete is the optimum selection in terms of maintenance, cost, and stability in respect to Egypt's economy. However, composites have emerged a great material in terms of maintenance and weight that should be highly considered for future floating community proposals. 


\subsection{Theoretical Implications}

The theoretical concepts on adaptation approaches and mitigation solutions in the Nile Delta require to be readdressed for further understandings on how they could be implemented in the Nile Delta regions and how it can be more sustainable.

- This study is considered one of the first researches to analytically test and demonstrate VLFS approaches on the Nile Delta's coastline.

- It redefines the means against SLR and develops a new prospective for tackling SLR impacts on the Nile Delta.

- It provided a broad understanding on the status of various adaptation approaches and mitigation solutions practiced on the long term and updating data concerning SLR impacts on Abu-Qir.

- It advances the architectural design methodology framework of self-sustaining and expanding floating communities and establishes architectural design guidelines for constructing floating structures for Egypt.

- This thesis addresses the neglected subject of underwater UNESCO listed world heritage properties and sites and provides a sustainable long-term solution with the research methodology and architectural guidelines are offered.

- Wang (2017) suggests that land reclamation solutions are expensive due to the price of sand globally, however, this thesis notes that sand cost in Egypt regarding land reclamation is not an issue and that's why land reclamation solutions haven't stopped in Egypt as it offers a very cheap solution. 
- NOAA (2017) suggests seawalls and elevating houses as practical solutions. However, this thesis notes that such solutions are neither long lasting nor sustainable.

- This thesis supports the (Union of Concerned Scientists, 2015) that barriers are false hope. It supports the AEFD report by Saab (2017) that land reclamation solutions have a negative impact on the environment.

- This thesis supports Wang (2017) and Suzuki et al. (2006) that concrete offers a great material in sea sites, however composites appear to be a great material for future VLFS research. This study supports Tsaltas et al. (2010) and Wang \& Tay (2011) that VLFS offer a cost effective and sustainable approach against SLR.

\subsection{Practical Implications}

This thesis functions as a link between such previous research and possible future research on adaptation approaches and mitigation solutions in coastal cities against SLR impacts in the Nile Delta.

- A specific report with long theoretical foundations which was the IPCC report (IPCC, 2014) has contributed significantly in collecting and updating the data on SLR research, it suggests several adaptation approaches like building seawalls and artificial barriers. Nevertheless, evidence from various papers, including but not limited to Saab (2017), Tsaltas et al. (2010), Wang (2017), and Wang \& Tay (2011), and this thesis, point out that such solutions are short term and not environmental friendly, thus the Ministry of State for Local Development and the Ministry of Environment should work together for more sustainable approaches. 
- This thesis has used analytical findings to demonstrate that the current adaptation approaches and mitigation solutions to SLR impacts on ten several areas in the Nile Delta coastline are not making the anticipated measures. The theoretical arguments for this justification suggest that there is a need for an authorised context of codes and regulations regarding floating structures and their implementation and usage against SLR impacts which would enable enhanced countermeasures on Egyptian coastal cities.

- The society would highly benefit from an actual implementation of floating community project in Abu-Qir Bay, not only for protection and environmental purposes from the anticipated SLR impacts, but also for leisure activities.

- The Ministry of Antiquities, Ministry of Tourism, Ministry of Culture, and the public interest would highly profit from a real implementation of the proposed project in AbuQir Bay where it will protect world heritage properties and sites in risk and protect the marine borders. Therefore, an underwater Museum for the sunken treasures should be practically considered.

- If the government applies the recommended method derived from the outcomes of this research, it may help safeguarding Egypt's coastal sovereignty for the long-term wherever implementation is possible. Therefore, traditional land reclamation solutions practiced by ESPA should be abolished and replaced by VLFS wherever possible. This research offers design approaches and architectural guidelines regarding VLFS against SLR impacts for Egypt and proposes Abu-Qir Bay as a possible site to test the findings practically. Authorities are guided on what should be done to efficiently design and sustain costal urbanizations. 


\subsection{Study Limitations}

The thesis has demonstrated an evaluative perspective on SLR impacts on Egypt and proposed floating structures upon site analysis for the Nile delta and adaptation approaches research. As a result of such methodology, this thesis has encountered some limitations which require considering:

- Lack of some local data on long-term SLR scenarios, uncertainties and assumptions regarding SLR impacts to measure potential loss and probability of occurrence. Therefore, several observatories were utilized and compared to provide a more precise assessment on SLR scenarios on SLR impacts on the Nile Delta, however, specialists in SLR scenarios would offer a more detailed and accurate measurements.

- Advanced proposals focussing on environmental concerns with more details would show actual capabilities of the floating community since this proposal was done solely on current findings. Also, results conclude that composites offer superiority regarding maintenance and weight. However, it was not implemented in the proposal since it's not a cost-effective approach along with the Egyptian economy since it's much more expensive to concrete and local guides have not been sufficient.

- There is an absence of global authorised context regarding VLFS implementation and usage. Therefore, this thesis offers design approaches and guidelines for VLFS against SLR impacts on Egypt where authorities are guided on what should be done. However, any actual VLFS project in Egypt would show any hidden absences.

The driving reason for attempting to generate architectural design guidelines for floating structures against SLR impacts for the Nile Delta was the limitations that were faced. Furthermore, the practical features of the floating community concept proposal have been 
debated and approved in each level by specialists who had more knowledge in certain technical features of the design.

\subsection{Generalization}

This evaluation concludes that there is a lack of consistency on the information level with the possible challenges caused by climate change and coastal zones. The Intergovernmental Panel on Climate Change provides a significant amount of knowledge and data through its reports which are published every seven years. Whereas information is not sufficient in any issue, therefore doubt regarding the relation between the natural sub-system to the human sub-system increases. Such relation is vital to understand the human challenges in seaside and low-lying regions and must involve the officials and public roles.

- The results of this research regarding VLFS should not be generalized in any lowlying coastal area impacted by SLR in the Nile Delta or anywhere. However, in an area with similar site and climate characteristics, wave properties, and the appropriate water depth, VLFS would present itself as an attractive solution especially regarding cost effectiveness, lifespan, and sustainability like in the case of Abu-Qir Bay.

- The results of this research regarding architectural design guidelines and concept proposal per say should not be observed as a precise demonstration for a future floating community anywhere, but somewhat a blend of probable future factors to guide the future seaside area developments in which floating community projects could be well-thought-out rather than the costly land recuperation solution. 


\subsection{Significance of the Study}

This dissertation well deserves careful analysis on SLR impacts on the coastlines of the Nile Delta in Egypt and highlights the most vulnerable locations, and adaptation approaches and mitigation solutions practiced. The findings of this research demonstrate the benefits of VLFS as the optimum solution for tackling SLR impacts in some of the most vulnerable areas in the coastlines of the Nile Delta. The more the SLR, the greater the risk on vulnerable and low-lying coastal areas around the world. Therefore, old fashioned and traditional land reclamation solutions practiced by the Egyptian government should be abolished and replaced by floating structures wherever possible. Their distinct features in settings and environments makes them preferred for their various applications and advantages. If the government applies the recommended method derived from the outcomes of this thesis, it will safeguard Egypt's coastal sovereignty for the long-term. Herein this thesis, authorities are guided on what should be done to efficiently sustain costal urbanizations in the Nile Delta's most vulnerable locations. The study uncovers critical impacts of SLR on costal urbanizations and offers VLFS as a sustainable long-term adaptation solution that Egyptian researches seem to disregard. Therefore, a new approach on adapting to SLR impacts concerning Egypt's Nile Delta's coastline was explored.

To sum up, the contribution to the papers in this thesis are: redefining the means of SLR, analysing practices of various adaptation approaches and mitigation solutions, and updating data concerning SLR impacts on Egypt through creating scenarios; presenting a new prospective for tackling SLR impacts on the Nile Delta; advancing in the methodology of selfsustaining and expanding floating communities; establishing a design framework for constructing floating structures; and presenting two models of floating interconnecting platforms for an expandable floating community for the Nile Delta. 


\subsection{Conclusion}

SLR problems impact Egypt's' heritage sites and properties, safeguarding borders, economical situation and resources, and affect the architectural strategies of structures. This study advances our understandings on VLFS against SLR challenges in Egypt as the most vulnerable locations have been high-lightened as well as presenting the required architectural design guidelines and proposals for future references.

Whereas the initial objective has been to explore SLR impacts on Egypt's northern coastlines, this thesis concludes that Abu-Qir bay is the most impacted area in the Nile Delta and in Egypt. It proposes Abu-Qir Bay as an ideal location to host VLFS projects to protect the bay from the anticipated SLR risks on world heritage properties and sites, where VLFS protection capabilities and its positive environmental impact made it appear to be a perfect match.

Hypothesis 1: The Nile Delta's coastlines will eventually be submerged where land reclamation approaches practiced only offer short-term solutions.

- Site analysis and SLR scenarios created support the initial hypothesis made on the Nile Delta's coastlines that it will eventually be submerged where the analyzed traditional mitigation solutions and adaptation approaches practiced may offer an effective yet unsustainable and short-term solutions.

Hypothesis 2: Floating structures offer the optimum solution for safeguarding Egypt's coastal sovereignty when addressing land subsidence problems.

- Findings do not fully support the $2^{\text {nd }}$ hypothesis made on VLFS as results reveal that it does not offer the optimum solution in each case in the Nile Delta in terms of cost 
effectiveness and site suitability, however upon site analysis, it has presented itself to be the ideal solution for Abu-Qir bay for many reasons, most importantly for its water depth, wave properties, being in protected waters, and its connectivity to an existing infrastructure.

\section{Generalization}

- The results of this thesis regarding floating structures should not be generalized in any low-lying coastal area impacted by SLR in the Nile Delta or anywhere. However, in an area with similar site and climate characteristics, wave properties, and the appropriate water depth, VLFS would present itself as an attractive solution especially in terms of cost effectiveness and sustainability like in the case of Abu-Qir Bay.

- The results of this thesis regarding architectural design guidelines and concept per say should not be observed as a precise demonstration for a future floating community anywhere, but somewhat a blend of probable future factors to guide the future seaside area developments in which floating community projects could be well-thought-out rather than the costly land recuperation solution.

\subsection{Recommendation for Future Research}

The scale of this issue is thus wide-ranging and multi-layered even at several local levels. To produce attainable strategies and development objectives regarding floating structures, further studies are vital at local level for further assessment of local dimensions of the issue. Exploring the following research approaches could enable realizing such goals: 
- Architectural research against SLR must consider also other non-climate factors to understand other possible effects and behaviours, particularly regarding human impacts, integrated assessment approaches, and adaptation objectives.

- Whereas future studies at all scales are needed like from a local to regional scale assessments, however, complications beyond the $21^{\text {st }}$ century must not be disregarded.

- There is a need for researches to generate an authorised context of codes and regulations regarding floating structures and their implementation and usage against SLR impacts in Egypt which would enable enhanced countermeasures on Egyptian coastal cities.

- Developing sustainable coastal management and architectural design strategies against SLR impacts are required in Egypt. However, any VLFS design approach in Egypt should consider Egyptian and Mediterranean architecture since it's one of Egypt's facades and links to Europe which facilitates in bridging civilizations.

- Practical research for implementing VLFS would test the findings. Therefore, any practical research regarding implementing VLFS against SLR impacts in Egypt should consider Abu-Qir Bay as a possible site to use this paper as a reference and built upon it to protect the priceless world heritage properties and sites in risk.

- This thesis recommends concrete over composites to offer a feasible approach along with the Egyptian economy since local guides regarding composite have not been sufficient. However, any future research regarding material selection for VLFS projects should highly consider composite materials.

- For future research regarding floating communities, it should address the impact of inconstant water depth as well as wave short-crestedness anti-motion measures. Also, 
further site analysis to verify the efficiency of such anti-motion measures on floating structures in actual environmental situations and the consequence of the gradual changeable drift forces on anti-motion measures in order to design sustainable floating communities accordingly.

- It's recommended to investigate VLFS against SLR impacts in Ganges-Brahmaputra Delta in Bangladesh/India and the Mekong Delta in Vietnam. Different architectural and construction characteristics to should be considered in each region's climate, culture, and ecology. 


\section{BIBLIOGRAPHY}

\subsection{List of References}

Abdrabo, M. A., Hassaan, M. A., \& Selmy, A. R. N. (2014). Economic Valuation of Sea Level Rise Impacts on Agricultural Sector in Northern Governorates of the Nile Delta. Journal of Environmental Protection, 5(June), 87-95. https://doi.org/http://dx.doi.org/10.4236/jep.2014.52012

Ambica, A., \& Venkatraman, K. (2016). Floating Architecture: A Design on Hydrophilic Floating House for Fluctuating Water Level. Indian Journal of Science and Technology. https://doi.org/10.17485/ijst/2015/v8i1/84304

Andrisano, O., Bartolini, I., Bellavista, P., Boeri, A., Bononi, L., Borghetti, A., ... Vigo, D. (2018). The Need of Multidisciplinary Approaches and Engineering Tools for the Development and Implementation of the Smart City Paradigm. Proceedings of the IEEE, 106(4), 738-760. https://doi.org/10.1109/JPROC.2018.2812836

Anthoff, D., Nicholls, R. J., Tol, R. S. J., \& Vafeidis, A. T. (2006). Global and regional exposure to large rises in sea-level : a sensitivity analysis Global and regional exposure to large rises in sea-level : a sensitivity analysis. Tyndall Centre for Climate Change Research.

Assad, M., Hosny, O., Elhakeem, A., \& El Haggar, S. (2015). Green building design in Egypt from cost and energy perspectives. Architectural Engineering and Design Management. https://doi.org/10.1080/17452007.2013.775100

Attaher, S. M., Medany, M. A., \& El-Gindy, A. (2010). Feasibility of some adaptation measures of on- farm irrigation in Egypt under water scarcity conditions. Options Méditerranéennes. Séries A. Mediterranean Seminars.

Bittsánszky, A., Uzinger, N., Gyulai, G., Mathis, A., Junge, R., Villarroel, M., ... Kômíves, T. (2016). Nutrient supply of plants in aquaponic systems. Ecocycles. https://doi.org/10.19040/ecocycles.v2i2.57

Blake, E. S., \& Zelinsky, D. A. (2018). National Hurricane Center Tropical Cyclone Report: Hurricane Harvey, (2005), 1-77. 
Bloomenergy. (2017). Energy Server 5. Retrieved from https:/www.bloomenergy.com/sites/default/files/es5-200kw-datasheet.pdf

British Columbia Building Code Interpretation Committee. British Columbia Float Home Standard (2015). Canada: Ministry of Municipal Affairs and Housing, Province of British Columbia. Retrieved from https://www2.gov.bc.ca/assets/gov/...standards/.../2003_float_home_standard.pdf

Caron, D. D. (2009). Climate Change, Sea Level Rise And The Coming Uncertainty In Oceanic Boundaries: A Proposal To Avoid Conflict. In Maritime Boundary Disputes, Settlement Processes, and the Law of the Sea. https://doi.org/10.1163/ej.9789004173439.i-308.7

Caron, D. D. (2014). When Law Makes Climate Change Worse: Rethinking the Law of Baselines in Light of a Rising Sea Level. Ecology Law Quarterly.

Center for International Earth Science Information Network (CIESIN)/Columbia University. (2013). Low elevation coastal zone: urban-rural population and land area estimates Version 2. Palisades, NY: NASA Socioeconomic Data and Applications Center (SEDAC), (December), 1-17. https://doi.org/10.1017/CBO9781107415324.004

Clauss, G., Lehmann, E., \& Östergaard, C. (1992). Offshore Structures Volume I: Conceptual Design and Hydromechanics. Meerestechnische Konstruktionen. https://doi.org/10.1007/978-1-4471-3193-9

Climate-Data. (n.d.). Climate ABu Qir. Retrieved from https://en.climatedata.org/africa/egypt/alexandria-governorate/abu-qir-32439/

Cohen, E. A., \& Vogel, S. (2010). Cat's Paws and Catapults: Mechanical Worlds of Nature and People. Foreign Affairs. https://doi.org/10.2307/20049153

Conway, D. (2005). From headwater tributaries to international river: Observing and adapting to climate variability and change in the Nile basin. Global Environmental Change. https://doi.org/10.1016/j.gloenvcha.2005.01.003

Cox, J. C., \& Czlapinski, R. E. (2016). Engineering of an island-style breakwater system for the Fort Pierce marina. Proceedings of the Institution of Civil Engineers - Maritime Engineering, 169(1), 37-43. https://doi.org/10.1680/jmaen.15.00014

Czapiewska, K., Roeffen, B., Dal Bo Zanon, B., \& De Graaf, R. (2013). Seasteading Implementation Plan Final Concept Report, 85.

Dal Bo Zanon, B., Roeffen, B., Czapiewska, K. M., de Graaf-Van Dinther, R. E., \& Mooij, P. R. (2017). Potential of floating production for delta and coastal cities. Journal of Cleaner Production. https://doi.org/10.1016/j.jclepro.2017.03.048

de Graaf, R., Roeffen, B., Czapiewska, K., Dal Bo Zanon, B., Lindemans, W., Escarameia, M., ... Zevenbergen, C. (2013). The effectiveness of flood proofing vulnerable hotspots to improve urban flood resilience. In Comprehensive Flood Risk Management. https://doi.org/10.1201/b13715-199

Eldeberky, Y. (2011). Coastal adaptation to sea level rise along the Nile delta, Egypt. WIT Transactions on Ecology and the Environment, 149(February), 41-52. https://doi.org/10.2495/CP110041 
Ericson, J. P., Vörösmarty, C. J., Dingman, S. L., Ward, L. G., \& Meybeck, M. (2006).

Effective sea-level rise and deltas: Causes of change and human dimension implications. Global and Planetary Change, 63-82.

https://doi.org/10.1016/j.gloplacha.2005.07.004

Fabre, D., \& Goddio, F. (2013). Thonis-Heracleion, emporion of Egypt, recent discoveries and research perspectives: the shipwrecks. Journal of Ancient Egyptian Interconnections.

FDN Group. (2013). Functional Design NL: Reference projects. Amsterdam. Retrieved from https://docs.wixstatic.com/ugd/709f31_2c4f08c64dbf46b4963abde4856d1a4a.pdf

Feyen, J., Shannon, K., \& Neville, M. (2008). Water \& Urban Development Paradigms: Towards an integration of engineering, design and management approaches. Retrieved from http://books.google.com/books?id=9hBZUdlT8MQC\&pgis=1

FitzGerald, D. M., Fenster, M. S., Argow, B. A., \& Buynevich, I. V. (2008). Coastal Impacts Due to Sea-Level Rise. Annual Review of Earth and Planetary Sciences. https://doi.org/10.1146/annurev.earth.35.031306.140139

Fondation Jacques Rougerie. (n.d.). Ambitions. Retrieved from http://www.fondationjacques-rougerie.com/ambitions

Frihy, O. E., \& El-Sayed, M. K. (2013). Vulnerability risk assessment and adaptation to climate change induced sea level rise along the Mediterranean coast of Egypt. Mitigation and Adaptation Strategies for Global Change. https://doi.org/10.1007/s11027-012-9418-y

Fujikubo, M. (2005). Structural analysis for the design of VLFS. Marine Structures. https://doi.org/10.1016/j.marstruc.2005.07.005

Gebremichael, E., Sultan, M., Becker, R., El Bastawesy, M., Cherif, O., \& Emil, M. (2018). Assessing Land Deformation and Sea Encroachment in the Nile Delta: A Radar Interferometric and Inundation Modeling Approach. Journal of Geophysical Research: Solid Earth. https://doi.org/10.1002/2017JB015084

Girardet, H. (2014). Creating Regenerative Cities. Creating Regenerative Cities. https://doi.org/10.4324/9781315764375

Hereher, M. E. (2010). Vulnerability of the Nile Delta to sea level rise: An assessment using remote sensing. Geomatics, Natural Hazards and Risk, 1(4), 315-321. https://doi.org/10.1080/19475705.2010.516912

IDSC. (2011). Egypt's National Strategy for Adaptation to Climate Change and Disaster Risk Reduction. Retrieved from http://faolex.fao.org/docs/pdf/egy141200.pdf

International Energy Agency. (2013). Key World Energy Statistics. International Energy Agency. https://doi.org/10.1201/b15566-3

IPCC. (2007). Climate Change 2007: Impacts, Adaptation and Vulnerability. Contribution of Working Group II to the fourth assessment report of the Intergovernmental Panel. Genebra, Suiça. https://doi.org/10.1256/004316502320517344

IPCC. (2014). Climate Change 2014 Impacts, Adaptation, and Vulnerability Part B: 
Regional Aspects. Contribution of Working Group II to the fifth assessment report of the Intergovernmental Panel. Igarss 2014. https://doi.org/10.1007/s13398-014-0173-7.2

Iskander, M. M. (2013). Wave Climate and Coastal Structures in the Nile Delta Coast of Egypt. Emirates Journal for Engineering Research.

Kent, M. (2008). The Making of Customary Territories: Social Change at the Intersection of State and Indigenous Territorial Politics on Lake Titicaca, Peru. The Journal of Latin American and Caribbean Anthropology. https://doi.org/10.1111/j.19354940.2008.00039.x

Klemm, O., Schemenauer, R. S., Lummerich, A., Cereceda, P., Marzol, V., Corell, D., ... Fessehaye, G. M. (2012). Fog as a fresh-water resource: Overview and perspectives. Ambio. https://doi.org/10.1007/s13280-012-0247-8

Kwiatkowska, B., \& Soons, A. H. A. (1990). Entitlement to maritime areas of rocks which cannot sustain human habitation or economic life of their own. Netherlands Yearbook of International Law. https://doi.org/10.1017/S0167676800002087

Lamas-Pardo, M., Iglesias, G., \& Carral, L. (2015). A review of Very Large Floating Structures (VLFS) for coastal and offshore uses. Ocean Engineering. https://doi.org/10.1016/j.oceaneng.2015.09.012

Lefebvre, S., \& Collu, M. (2012). Preliminary design of a floating support structure for a 5 MW offshore wind turbine. Ocean Engineering. https://doi.org/10.1016/j.oceaneng.2011.12.009

Levieil, D. P., \& Orlove, B. (2004). Local Control of Aquatic Resources: Community and Ecology in Lake Titicaca, Peru. American Anthropologist. https://doi.org/10.1525/aa.1990.92.2.02a00070

Lomholt, I. (2010). Harvest City Republic of Haiti - design by Schopfer Associates LLC. Retrieved from https://www.e-architect.co.uk/haiti/harvest-city-haiti

Lund, J. W. G., \& Vollenweider, R. A. (2006). A Manual on Methods for Measuring Primary Production in Aquatic Environments. The Journal of Ecology. https://doi.org/10.2307/2258304

Maeda, H., Rheem, C.-K., Washio, Y., Osawa, H., Nagata, Y., Ikoma, T., ... Arita, M. (2001). Reduction Effects of Hydroelastic Responses on a Very Large Floating Structure with Wave Energy Absorption Devices Using OWC System. In Proceedings of the International Conference on Offshore Mechanics and Arctic Engineering - OMAE.

McDonough, W., \& Braungart, M. (2010). Cradle to Cradle ${ }^{\circledR}$ Certification Program. McDonough Braungart Disign Chemistry (MBDC).

Meehl, G.A., Stocker, T. F., Collins, W. D., Friedlingstein, P., Gaye, A. T., Gregory, J. M., ... Zhao, Z.-C. (2007). 2007: Global Climate Projections. Climate Change 2007: Contribution of Working Group I to the Fourth Assessment Report of the Intergovernmental Panel on Climate Change. https://doi.org/10.1080/07341510601092191

Meehl, Gerald A., Hu, A., Tebaldi, C., Arblaster, J. M., Washington, W. M., Teng, H., ... White, J. B. (2012). Relative outcomes of climate change mitigation related to global 
temperature versus sea-level rise. Nature Climate Change. https://doi.org/10.1038/nclimate1529

Meehl, Gerald A., Washington, W. M., Collins, W. D., Arblaster, J. M., Hu, A., Buja, L. E., ... Teng, H. (2005). How much more global warming and sea level rise? Science. https://doi.org/10.1126/science.1106663

Moan, T. (2004). Safety of offshore structures. Second Keppel Offshore and Marine Lecture, CORE ....

National Oceanic and Atmospheric Administration (NOAA). (2010). Adapting to Climate Change: A Planning Guide for State Coastal Managers. Management.

National Oceanic and Atmospheric Administration (NOAA). (2017). State of the Climate: Global Climate Report for Annual 2016. Bulletin of the American Meteorological Society, 98(8), 1-298. Retrieved from https://www.ncdc.noaa.gov/sotc/global/201613

Neori, A., Chopin, T., Troell, M., Buschmann, A. H., Kraemer, G. P., Halling, C., ... Yarish, C. (2004). Integrated aquaculture: Rationale, evolution and state of the art emphasizing seaweed biofiltration in modern mariculture. Aquaculture. https://doi.org/10.1016/j.aquaculture.2003.11.015

Nicholls, R J, Hanson, S. E., Lowe, J. A., Vaughan, D. A., Lenton, T., Ganopolski, A., ... Vafeidis, A. T. (2006). Metrics for Assessing the Economic Benefits of Climate Change Policies: Sea Level Rise. Report to the OECD. ENV/EPOC/GSP(2006)3/FINAL.

Nicholls, Robert J, \& Tol, R. S. J. (2006). Impacts and responses to sea-level rise: a global analysis of the SRES scenarios over the twenty-first century. Philosophical Transactions. Series A, Mathematical, Physical, and Engineering Sciences. https://doi.org/10.1098/rsta.2006.1754

Ohmatsu, S. (2005). Overview: Research on wave loading and responses of VLFS. Marine Structures. https://doi.org/10.1016/j.marstruc.2005.07.004

Omar, M. E. D. M., \& Moussa, A. M. A. (2016). Water management in Egypt for facing the future challenges. Journal of Advanced Research, 7(3), 403-412. https://doi.org/10.1016/j.jare.2016.02.005

Organización de las Naciones Unidas. (2005). Coping with water scarcity: Challenge of the twenty-first century. UN WATER. https://doi.org/10.3362/0262-8104.2005.038

Parris, A., Bromirski, P., Burkett, V., Cayan, D., Culver, M., Hall, J., ... Weiss, J. (2012). Global Sea Level Rise Scenarios for the US National Climate Assessment. NOAA Tech Memo OAR CPO. Retrieved from http://cpo.noaa.gov/sites/cpo/Reports/2012/NOAA_SLR_r3.pdf

PAX Water Technologies. Experimental Data Confirms CFD Models of Mixer Performance (2011). Retrieved from http://www.paxwater.com/hs-fs/hub/79614/file-15758143pdf/docs/case_study_cfd_012011.pdf

Radding, C., \& Orlove, B. (2008). Lines in the Water: Nature and Culture at Lake Titicaca. Environmental History. https://doi.org/10.2307/3985776

Romer, P. (2015). Interview on Urbanization, Charter Cities and Growth Theory. Retrieved 
from https://paulromer.net/interview-on-urbanization-charter-cities-and-growththreory/index.html

Saab, N. (2017). Arab Environment in 10 Years. Beirut, Lebanon, Technical Publications. Retrieved from http://www.afedonline.org/webreport2017/FINAL/L/AFEDreport2017L.pdf

Saab, N., \& Sadik, A.-K. (2018). Financing Sustainable Development in Arab Countries Financing Sustainable Development. Beirut, Lebanon, Technical Publications. Retrieved from http://www.afedonline.org/webreport2018/AFEDReportfinancingSDinArabCountries2018-.pdf

Sääskilahti, M. T. ., Kuuva, M. H. ., \& Leppimäki, S. M. . (2005). A Method for Systematic Future Product Concept Generation. In International Conference on Engineering Design (pp. 1-15).

Sánchez-Arcilla, A., Jiménez, J. A., \& Valdemoro, H. I. (1998). The Ebro delta: Morphodynamics and vulnerability. Journal of Coastal Research, 50.

Sato, C., \& Inoue, K. (2003). Results of 6 Years Research Project of Mega-Float. Ocean Space Utilization Technology, 436-442. Retrieved from https://www.nmri.go.jp/main/cooperation/ujnr/24ujnr_paper_jpn/sato.PDF

Schlagermann, P., Gerold, G., Dillschneider, R., Rosello-sastre, R., \& Posten, C. (2012). Composition of Algal Oil and Its Potential as Biofuel, 2012. https://doi.org/10.1155/2012/285185

Seto, H., Ohta, M., Ochi, M., \& Kawakado, S. (2005). Integrated hydrodynamic-structural analysis of very large floating structures (VLFS). Marine Structures. https://doi.org/10.1016/j.marstruc.2005.07.008

Shimizu Corporation. (2010). The Botanical Future City Concept of a Plant-like City. Retrieved from https://www.shimz.co.jp/en/topics/dream/content03/pdf/greenfloat_e.pdf

Smith, C. (2013). Living Histories Engaging Paolo Soleri's Arcosanti Project through the Notion of "History/Becoming. Proceedings of the Society of Architectural Historians, Australia and New Zealand: 30, Open.

Soons, A. H. A. (1990). The Effects of a Rising Sea Level on Maritime Limits and Boundaries. Netherlands International Law Review. https://doi.org/10.1017/S0165070X00006513

Stopp, H., \& Strangfeld, P. (2010). Floating houses - Chances and problems. WIT Transactions on Ecology and the Environment. https://doi.org/10.2495/ARC100191

Suzuki, H, Bhattacharya, B., Fujikubo, M., Hudson, D. A., Riggs, H. R., Seto, H., ... Zong, Z. (2006). ISSC committee VI.2: very large floating structures. 16th International Ship and Offshore Structures Congress, 2(August), 391-442. https://doi.org/10.1115/OMAE2007-29758

Suzuki, Hideyuki, Yoshida, K., Iijima, K., \& Kobayashi, K. (2009). Response Characteristics of Semisubmersible-Type-Megafloat in Waves and Accuracy of Hydroelastic Response Analysis Program VODAC (pp. 773-781). ASME International. https://doi.org/10.1115/omae2002-28215 
Tam, L. (2009, November). Strategies for Managing Sea Level Rise: SPUR weighs the advantages and disadvantages of seven strategies to manage sea level rise. The Urbanist, (487). Retrieved from https://www.spur.org/publications/urbanistarticle/2009-11-01/strategies-managing-sea-level-rise

Tavsan, C., Tavsan, F., \& Sonmez, E. (2015). Biomimicry in Architectural Design Education. Procedia - Social and Behavioral Sciences. https://doi.org/10.1016/j.sbspro.2015.04.832

Tay, Z. Y., Wang, C. M., \& Utsunomiya, T. (2009). Hydroelastic responses and interactions of floating fuel storage modules placed side-by-side with floating breakwaters. Marine Structures. https://doi.org/10.1016/j.marstruc.2008.11.002

Tennessee Valley Authority. (2016). Floating Houses Policy Review: Final Environmental Impact Statement. Knoxville, Tennessee, USA.

The International Tanker Owners Pollution Federation. (2016). Oil tanker spill statistics 2016. The International Tanker Owners Pollution Federation Limited.

The World Bank and International Energy Agency. (2017). Global Tracking Framework 2017. Global Tracking Framework: Progress toward Sustainable Energy. https://doi.org/10.1787/dcr-2013-20-en

Tol, R. S. J. (2002). Estimates of the damage costs of climate change: Part II. Dynamic estimates. Environmental and Resource Economics, 135-160. https://doi.org/10.1023/A:1014539414591

Tolba, M. K., \& Saab, N. W. (2009). Arab Environment: Climate Change Impact of Climate Change on Arab Countries. Arab Environment: Climate Change Impact of Climate Change on Arab Countries. Beirut, Lebanon, Technical Publications. Retrieved from http://www.droughtmanagement.info/literature/AFED_climate_change_arab_countries _2009.pdf

Tsaltas, G., Bourtzis, T., \& Rodotheatos, G. (2010). Artificial Islands and Structures As a Means of Safeguarding State Sovereignty Against Level Rise. A Law of the Sea Perspective. 6th IHO-IAG ABLOS Conference, (October 2010), 17. Retrieved from http://www.iho.int/mtg_docs/com_wg/ABLOS/ABLOS_Conf6/S2P3-P.pdf

UNEP. (2017). Atlas of Africa Energy Resources. (C) 2017, United Nations Environment Programme.

UNFCCC. (2007). Climate Change: Impacts, Vulnerabilities and Adaptation in Developing Countries. United Nations Framework Convention on Climate Change. https://doi.org/10.1029/2005JD006289

Union of Concerned Scientists. (2015). Fact Sheet: Causes of Sea Level Rise. Retrieved from https://www.ucsusa.org/sites/default/files/legacy/assets/documents/global_warming/Cau ses-of-Sea-Level-Rise.pdf

United Nations Development Programme. (2014). Human Development Report: Sustaining Human Progress: Reducing Vulnerabilities and Building Resilience. Human Development Report 2014. https://doi.org/ISBN: 978-92-1-126340-4

United Nations Division for Sustainable Development Goals (DSDG). (2017). Sustainable 
Development Knowledge Platform, The Division for Sustainable Development Goals (DSDG) in the United Nations Department of Economic and Social Affairs (UNDESA). https://doi.org/DOI: 10.1016/j.fusengdes.2010.02.021

United Nations Framework Convention Change Climate. (2016). Egypt Third National Communication Under the United Nations Framework Convention on Climate Change. Egypt. Retrieved from https://unfccc.int/sites/default/files/resource/TNC report.pdf

Van Timmeren, A., \& Tawil, M. (2006). Integration of living machine and biogas plant case EVA centre lanxmeer, culemborg. In PLEA 2006 - 23rd International Conference on Passive and Low Energy Architecture, Conference Proceedings.

Vincent Callebaut Architectures. (2017). LILYPAD: Floating ecopolis for climate refugees. Retrieved from http://vincent.callebaut.org/object/080523_lilypad/lilypad/projects/user

Visser, W., \& Benyus, J. M. (2013). Biomimicry. In The Top 50 Sustainability Books. https://doi.org/10.9774/gleaf.978-1-907643-44-6_23

Wang, C. M., \& Tay, Z. Y. (2011). Very large floating structures: Applications, research and development. Procedia Engineering, 14, 62-72.

https://doi.org/10.1016/j.proeng.2011.07.007

Wang, C.M. (2017). VLFS technology for land creation on the sea. In Mechanics of Structures and Materials: Advancements and Challenges - Proceedings of the 24th Australasian Conference on the Mechanics of Structures and Materials, ACMSM24 2016.

Wang, C M, Watanabe, E., \& Utsunomiya, T. (2008). Very Large Floating Structures: applications, analysis and design. Tailor \& Fransis, 1-30.

Wang, Chien Ming, Riyansyah, M., \& Choo, Y. S. (2009). Reducing hydroelastic response of interconnected floating beams using semi-rigid connections. In ASME 2009 28th International Conference on Ocean, Offshore and Arctic Engineering. https://doi.org/10.1115/OMAE2009-79692

Wattanacharoensil, W., \& Sakdiyakorn, M. (2016). The Potential of Floating Markets for Creative Tourism: A Study in Nakhon Pathom Province, Thailand. Asia Pacific Journal of Tourism Research. https://doi.org/10.1080/10941665.2014.998250

Wilkinson, C. (2008). Status of Coral Reefs of the World: 2008. Global Coral Reef Monitoring Network (GCRMN). https://doi.org/10.1111/j.1528-1167.2006.00475.x

Witsen, P. P. Floating Amsterdam (2012). The Netherlands. Retrieved from https://www.ansa.it/documents/1334931625986_AmsterdamFloating.pdf

Woodroffe, C. D., Nicholls, R. J., Saito, Y., Chen, Z., \& Goodbred, S. L. (2006). Landscape variability and the response of Asian megadeltas to environmental change. Global Change and Integradted Coastal Management, 277-314. https://doi.org/10.1007/1-40203628-0

World Bank. (2010). Cities and Climate Change: An aurgent agenda. Urban Development and Local Government. https://doi.org/10.1787/9789264091375-en 
World Bank. (2018). DataBank - World Development Indicators.

World Energy Council. (2016). E-storage: Shifting from cost to value. Wind and solar applications. Report. World Future Energy Summit. https://doi.org/http://www.worldenergy.org/wpcontent/uploads/2013/09/Complete_WER_2013_Survey.pdf

World Nuclear Association. (2018). World Nuclear Performance Report. World Nuclear Association. https://doi.org/10.1109/PVSC.2009.5411432

Wu, Y.-S., Zhou, G.-J., \& Cui, W.-C. (2016). Practical Design of Ships and Other Floating Structures. Practical Design of Ships and Other Floating Structures. https://doi.org/10.1016/b978-0-08-043950-1.x5000-5

Zicheng, C. (2016). H2O - Humanitarian Harbour of the Ocean. Retrieved from http://www.jacquesrougeriedatabase.com/Projects/project/412/data\%3D 


\subsection{List of Figures}

1 Figure 2.1: Relative vulnerability of shore deltas in 2050 as the anticipated population distribution and sea-level rates by present percentages (extreme is one million or over, high is from 50,000 up to one million, and medium if from 5,000 to 50,000)

Parry, M. L., Canziani, O. F., Palutikof, J. P., van der Linden, P. J., and Hanson, C. E. (Authors) (2007). Climate Change 2007: Working Group II: Impacts, Adaptation and Vulnerability, [Digital image] Retrieved from: Intergovernmental Panel on Climate Change [IPCC] website: https://www.ipcc.ch/publications_and_data/ar4/wg2/en/xccsc3.html

2 Figure 3.1: Analytical framework of the research methodology.

3 Figure 4.1: Analytical framework for evaluating adaptation approaches and mitigation solutions against SLR.

4 Figure 4.2: Coastal population and shoreline degradation.

Rekacewicz, P., Ahlenius, H., \& UNEP/GRID-Arendal. (Graphic designers) (2006). Coastal population and altered land cover in coastal zones (100 km of coastline), Global Environment Outlook 4 (GEO-4) [Digital image]. Retrieved from: http://old.grida.no/graphicslib/detail/coastal-population-and-altered-land-cover-incoastal-zones-100-km-of-coastline_7706

5 Figure 4.3: Analytical framework for floating community case studies.

6 Figure 4.4: The extensive rely on totora reed.

The extensive rely on totora reed [Photograph]. (n.d.). Retrieved from: http://www.contiki.com/six-two/13-fascinating-facts-people-uros/

7 Figure 4.5: The Ha Long fishing society.

Stroud, L. (Photographer). (2013). No More Bikes \& Sleeper Bus to Sapa [Photograph]. Retrieved from: twistedfootsteps.com/category/twisted-treks/vietnam/on-the-road-hcmhanoi/

8 Figure 4.6: Floating markets in Bangkok, Thailand.

Floating markets in Bangkok, Thailand [Photograph]. (n.d.). Retrieved from: www.theakyra.com/blog/explore-bangkoks-floating-markets/

9 Figure 4.7: Harvest City.

Tangram 3DS. (Graphic Designer). (2010). Harvest City / Tangram 3DS [Digital Image]. Retrieved from: https://www.archdaily.com/98488/harvest-city-tangram-3ds

10 Figure 4.8: A floating module house being transported to site location.

Architectenbureau Marlies Rohmer (Graphic Designer). (2011). Floating Houses in IJburg / Architectenbureau Marlies Rohmer. [Digital Image]. Retrieved from: www.archdaily.com/120238/floating-houses-in-ijburg-architectenbureau-marlies-rohmer 
11 Figure 4.9: Varieties of apartment sizes from similar modular units.

Architectenbureau Marlies Rohmer. (Graphic Designer). (2011). Floating Houses in IJburg / Architectenbureau Marlies Rohmer. [Digital Image]. Retrieved from: www.archdaily.com/120238/floating-houses-in-ijburg-architectenbureau-marlies-rohmer

12 Figure 4.10: The design of the Lily-pad concept showing the concept influences.

Vincent Callebaut Architectures. (Graphic Designer). (2017). Lilypad. Floating eco-polis for climate refugees, Oceans 2008-2017. [Digital Image]. Retrieved from: http://vincent.callebaut.org/object/080523_lilypad/lilypad/projects/user

13 Figure 4.11: Different layers forming the Lily-pad project.

Vincent Callebaut Architectures. (Graphic Designer). (2017). Lilypad. Floating eco-polis for climate refugees, Oceans 2008-2017. [Digital Image]. Retrieved from: http://vincent.callebaut.org/object/080523_lilypad/lilypad/projects/user

14 Figure 4.12: The Humanitarian Harbour of the Ocean concept "H2O”.

Zicheng, C. (Graphic Designer). (2016). H2O - Humanitarian Harbour of the Ocean. [Digital Image]. Retrieved from: http://www.jacquesrougeriedatabase.com/Projects/project/412/data\%3D

15 Figure 4.13: Section Elevation of the $\mathrm{H} 2 \mathrm{O}$ concept.

Zicheng, C. (Graphic Designer). (2016). H2O - Humanitarian Harbour of the Ocean. [Digital Image]. Retrieved from:

http://www.jacquesrougeriedatabase.com/Projects/project/412/data\%3D

16 Figure 4.14: The Botanical City system demonstrating its sustainable features.

Shimizu Corporation. (Graphic Designer). (2010). The Botanical Future City Concept of a Plant-like City. [Digital Image]. Retrieved from:

https://www.shimz.co.jp/en/topics/dream/content03/pdf/greenfloat_e.pdf

17 Figure 4.15: The Botanical City Modules.

Shimizu Corporation. (Graphic Designer). (2010). The Botanical Future City Concept of a Plant-like City. [Digital Image]. Retrieved from:

https://www.shimz.co.jp/en/topics/dream/content03/pdf/greenfloat_e.pdf

18 Figure 4.16: The outline system of project.

Czapiewska, K., Roeffen, B., Zanon, B., de Graaf, R. (Graphic Designer). (2013). Seasteading Implementation Plan: Final Report. The Seasteading Institute. [Digital Image]. Retrieved from: https://www.seasteading.org/floating-city-project/

19 Figure 4.17: The initial plan for the long-term Seasteading community.

Czapiewska, K., Roeffen, B., Zanon, B., de Graaf, R. (Graphic Designer). (2013). Seasteading Implementation Plan: Final Report. The Seasteading Institute. [Digital Image]. Retrieved from: https://www.seasteading.org/floating-city-project/

20 Figure 5.1: Analytical framework for different approaches \& methods for floating cities, and mooring systems. 
21 Figure 5.2: Components of Mega Floating Structure System (own illustration).

Watanabe, E., Wang, C.M., Utsunomiya, T and Moan, T. (Graphic designers) (2008). VLFS: Applications, Analysis and Design. [Digital image]. CORE Report No. 2004-02. National University of Singapore. Retrieved from:

https://www.eng.nus.edu.sg/core/Report\%20200402.pdf

22 Figure 5.3: Corrosion rate distribution rate of steel in the air, water and seabed (own illustration).

Watanabe, E., Wang, C.M., Utsunomiya, T and Moan, T. (Graphic designers) (2008). VLFS: Applications, Analysis and Design. [Digital image]. CORE Report No. 2004-02. National University of Singapore. Retrieved from:

https://www.eng.nus.edu.sg/core/Report\%20200402.pdf

23 Figure 5.4: Worldwide response under a static load (own illustration).

Suzuki, H., Bhattacharaya, B., Fujikubo, M., Hudson, D.A., Riggs, H.R., Seto, H., Shin, H., Shugar, T.A., Yasuzawa, Y., and Zong, Z. (Graphic designers) (2006). ISSC Committee Vi.2: VLFS. [Digital image]. 394-442, 16th ISSC; 2006. Southampton, UK. Retrieved from:

https://www.researchgate.net/publication/236168675_Very_Large_Floating_Structures

24 Figure 5.5: Plotting of the worldwide response of floating structures (own illustration).

Suzuki, H., Bhattacharaya, B., Fujikubo, M., Hudson, D.A., Riggs, H.R., Seto, H., Shin, H., Shugar, T.A., Yasuzawa, Y., and Zong, Z. (Graphic designers) (2006). ISSC Committee Vi.2: VLFS. [Digital image]. 394-442, 16th ISSC; 2006. Southampton, UK. Retrieved from: https://www.researchgate.net/publication/236168675_Very_Large_Floating_Structures

25 Figure 5.6: Several methods of Mooring Systems (own illustration).

Wang, C. M., and Tay, Z.Y. (Graphic designers) (2011). VLFS: Applications, Research and Development. [Digital image]. Procedia Engineering 14; 62-72, 2011. Retrieved from: https://www.researchgate.net/publication/251716800_Very_Large_Floating_Structures_ Applications_Research_and_Development

26 Figure 5.7: (Left) Bathymetry Energy and Resources (own illustration).

Czapiewska, K., Roeffen, B., Zanon, B., de Graaf, R. (Graphic Designer). (2013). Seasteading Implementation Plan: Final Report. The Seasteading Institute. [Digital Image]. Retrieved from: https://www.seasteading.org/floating-city-project/

27 Figure 5.8: (Right) Bathymetry Structural Aspects (own illustration).

Czapiewska, K., Roeffen, B., Zanon, B., de Graaf, R. (Graphic Designer). (2013). Seasteading Implementation Plan: Final Report. The Seasteading Institute. [Digital Image]. Retrieved from: https://www.seasteading.org/floating-city-project/

28 Figure 5.9: Wave Behaviour (own illustration).

29 Figure 5.10: Archetypal structural design outline as for the Mega-floats (own illustration). 
Suzuki, H., Bhattacharaya, B., Fujikubo, M., Hudson, D.A., Riggs, H.R., Seto, H., Shin, H., Shugar, T.A., Yasuzawa, Y., and Zong, Z. (Graphic designers) (2006). ISSC Committee Vi.2: VLFS. [Digital image]. 394-442, 16th ISSC; 2006. Southampton, UK. Retrieved from: https://www.researchgate.net/publication/236168675_Very_Large_Floating_Structures

30 Figure 6.1: Analytical framework for site and time series analysis, and assessment on adaptation approaches practiced in the Nile Delta's most vulnerable sites.

31 Figure 6.2: Heracleion-Thonis, Anciant Alexandria.

National Geographic Magazine. (2011, July). Egypt's Sunken Treasures: The Ancient City of Alexandria [Digital image]. Retrieved from: http://www.athcreative.com/cleopatrasalexandria/

32 Figure 6.3: Before and After submergence $2 \mathrm{~m}$ due to the rising seas on the Egyptian Nile Delta.

Before and After submergence $2 \mathrm{~m}$ due to the rising seas on the Egyptian Nile Delta, Climate Central's Surging Seas: Risk Zone Map. [Digital image]. (n.d.). Retrieved from: https://ss2.climatecentral.org/\#9/30.8114/30.9828? show $=$ satellite\&projections $=0$ K14_RCP85-SLR\&level=2\&unit=meters\&pois=hide

33 Figure 6.4: A comparison of percentage impacts of SLR on the GDP of Arab countries.

Tolba, M. K., \& Saab, M. W. (Editors) (2009). Arab Environment: Climate Change Report Impact of Climate Change on Arab countries. Arab Forum for Environment and Development [Digital image] Retrieved from: Intergovernmental Panel on Climate Change [IPCC] website: http://www.afedonline.org/afedreport09/Full\%20English\%20Report.pdf

34 Figure 6.5: A comparison of percentage impacts of SLR on the agricultural production of Arab countries.

Tolba, M. K., \& Saab, M. W. (Editors) (2009). Arab Environment: Climate Change Report Impact of Climate Change on Arab countries. Arab Forum for Environment and Development [Digital image] Retrieved from: Intergovernmental Panel on Climate Change [IPCC] website: http://www.afedonline.org/afedreport09/Full\%20English\%20Report.pdf

35 Figure 6.6: The extreme scenario (5 meters SLR) impacts on the Arab world, by total population affected.

Tolba, M. K., \& Saab, M. W. (Editors) (2009). Arab Environment: Climate Change Report Impact of Climate Change on Arab countries. Arab Forum for Environment and Development [Digital image] Retrieved from: Intergovernmental Panel on Climate Change [IPCC] website: http://www.afedonline.org/afedreport09/Full\%20English\%20Report.pdf

36 Figure 6.7: Coastal areas from Alexandria to Port-Said demonstrating the impacts of $2 \mathrm{~m}$ of SLR, and coastal management methods practiced protective state (own illustration).

37 Figure 6.8: Bathymetric map of Abu-Qir Bay (Khedr, Abdelrahman, \& Alam El-Din, 2018). 
Khedr, A. M., Abdelrahman, S. M., Alam El-Din, K. A. (Graphic design) (2018). Currents and Sea Level Variability off Alexandria Coast in Association with Wind Forcing. [Digital image]. Retrieved from: https://www.researchgate.net/publication/322277272_Currents_and_Sea_Level_Variabili ty_off_Alexandria_Coast_in_Association_with_Wind_Forcing

38 Figure 6.9: (Left) Total Energy Production in Egypt (ktoe), (Right) Total Energy Consumption in Egypt (ktoe).

African Energy Commission. (Graphic designer) (2015). Africa Energy Commission, Algiers: African Energy Commission (AFREC) [Digital image].

39 Figure 6.10: Egypt's CO2 Emissions (metric tons per capita).

World Bank. (2015). Egypt's CO2 Emissions (metric tons per capita) [Digital image]. Retrieved from: Global Tracking Framework, World Bank.

40 Figure 6.11: Stack effect principle with an atrium design.

Sidell Gibson Architects. (Graphic design) (2010). The villa [Digital image]. Retrieved from: sidellgibson.blogspot.com/2010/04/

41 Figure 6.12: Egypt's water ambitious plan for 2025.

Omar, M. M., Moussa, A. M. (Graphic designers) (2016). Water management in Egypt for facing the future challenges. [Digital image]. Retrieved from: https://www.sciencedirect.com/science/article/pii/S0078323415000895\#

42 Figure 7.1: Analytical framework for concept proposal.

43 Figure 7.2: Analytical framework for expanding dynamics, platform size, and material selection.

44 Figure 7.3: Factors influence size of VLFS (own illustration).

45 Figure 7.4: Longitudinal section of the mooring system (own illustration).

46 Figure 7.5: Cross section of the mooring system (own illustration).

47 Figure 7.6: Elevations Facades (own illustration).

48 Figure 7.7: Detail Section Natural Ventilation (own illustration).

49 Figure 7.8: (Left) Section Option A of ground floor which has different foundation heights (own illustration).

50 Figure 7.9: (Right) Section Option B of ground floor which integrates plastic form-work for ventilated floors to create one universal height throughout all modules (own illustration).

51 Figure 7.10: (Left) Section Option B of ground floor where the waterway will allow boats to be the only means of transportation (own illustration).

52 Figure 7.11: (Right) Section Option B of ground floor which has paths for pedestrians, bicycles, and vehicles as the only means of transportation (own illustration). 
53 Figure 7.12: Master-Plan ' $A$ ' where hexagonal and square platforms are assembled together (own illustration).

54 Figure 7.13: Master-Plan 'B' showing the independency of the hexagonal platform from the square one, also showing the breakwater around the united platforms (own illustration).

55 Figure 7.14: (Left) Ground floor plan of one hexagonal module connected to three squared modules. Water circulation option (own illustration).

56 Figure 7.15: (Right) Ground floor plan of one hexagonal module connected to three squared modules. Street circulation option (own illustration).

57 Figure 7.16: (Left) First floor plan of one hexagonal module connected to three squared modules. (own illustration).

58 Figure 7.17: (Right) The agricultural plan (own illustration).

59 Figure 7.18: The façade columns transfer collected water for the factorization process and integrating windmills to generate clean wind energy (own illustration).

60 Figure 7.19: Linear metabolism cities consume resources and create waste and pollution on a high rate. Created with data from Girardet (2014).

Girardet, H., (2010), Regenerative Cities. The Cities and Climate Commission of the World Future Council and HafenCity University Hamburg (HCU).

61 Figure 7.20: Circulative metabolism cities reduce consumption pollution, recyclable and maximize renewables. Created with data from Girardet (2014).

Girardet, H., (2010), Regenerative Cities. The Cities and Climate Commission of the World Future Council and HafenCity University Hamburg (HCU).

62 Figure 7.21: Nutrients System and CO2 of the delta streaming through the floating community. The waste generated from the delta can be recycled for food and energy generation, which forms a synergetic relation amid the land-based settlements and the floating community (Czapiewska et al., 2013).

Czapiewska, K., Roeffen, B., Zanon, B., de Graaf, R. (Graphic Designer). (2013). Seasteading Implementation Plan: Final Report. The Seasteading Institute. [Digital Image]. Retrieved from: https://www.seasteading.org/floating-city-project/

63 Figure 7.22: The process of algae culture, aquaculture and crops production which could be achieved in the floating community project. Created with data from Czapiewska et al. (2013).

Czapiewska, K., Roeffen, B., Zanon, B., de Graaf, R. (Graphic Designer). (2013). Seasteading Implementation Plan: Final Report. The Seasteading Institute. [Digital Image]. Retrieved from: https://www.seasteading.org/floating-city-project/

64 Figure 7.23: Integrated multi-trophic aquaculture (IMTA) process system viewing how a grouping of variable levels of the food chain in the similar setting take benefit of organic and inorganic nutrients done via the several organisms ("Government of Canada," 2018). 
Government of Canada (Graphic design) (2018). Integrated Multi-Trophic Aquaculture. Fisheries and Oceans Canada. [Digital image]. Retrieved from: www.dfompo.gc.ca/aquaculture/sci-res/imta-amti/index-eng.htm

65 Figure 7.24: Detail Section Waste Flow (own illustration).

66 Figure 7.25: Detail Section Living Machine (own illustration).

67 Figure 7.26: Units Assembly Proposals of both Modules showing the harbour and wave attenuators (own illustration).

68 Figure 7.27: (Left) Ground floor plan of one hexagonal module connected to three squared modules. Water circulation option (own illustration).

69 Figure 7.28: (Right) Plan traffic routes (own illustration).

70 Figure 7.29: (Top) If land reclamation, sand dunes, \& breakwater unsustainable solutions are to be executed by the ESPA (own illustration); (Bottom) proposed floating community for Abu-Qir Bay (own illustration).

71 Figure 7.30: Demonstrating possible assembly formations when modules connect in AbuQir Bay (own illustration).

72 Figure 8.1: Analytical framework of the research methodology.

73 Figure 8.2: Evaluation findings on different adaptation approaches and mitigation solutions to SLR impacts.

74 Figure 8.3: Evaluation of the impacts of each feature of the selected floating community case studies.

75 Figure 8.4: Evaluation of design guidelines and strategies for VLFS.

76 Figure 8.5: Findings on impacts of SLR scenarios on the Nile delta's coastlines.

77 Figure 8.6: Factors influence size of VLFS (own illustration).

78 Figure 8.7: Evaluation on wave motion on structure stress of various platform sizes and mooring systems.

79 Figure 8.8: Evaluation of expanding dynamic strategies for VLFS.

80 Figure 8.9: Findings on floating structures platforms' materials and properties.

81 Figure 9.1: Analytical framework of the research methodology for the first research question and to test the first hypothesis.

82 Figure 9.2: Analytical framework of the research methodology for the second research question and to test the second hypothesis.

83 Figure 9.3: Analytical framework of the research methodology for the third research question and to test both hypotheses.

84 Figure B.1: Demonstrating the assembled floating community project proposed for the Abu-Qir Bay. Also, showing the submerged areas of Abu-Qir Bay by the Mediterranean Sea caused by the SLR (own illustration). 
85 Figure B.2: Rendered section shows the pedestrian, bicycle, and traffic routes, as well as the central agricultural area for the squared module (own illustration).

86 Figure B.3: Render showing how the sum reaches the interior facades too as well as showing the shading elements for the hexagonal module (own illustration).

87 Figure B.4: Tugboats transporting the platforms (own illustration). 


\subsection{List of Tables}

1 Table 2.1: Associated climate change effects on the socio-economic areas in coastal regions (Meehl et al., 2007). 18 2 Table 2.2: Revealing approximations of continents' vulnerabilities to SLR and baseline socio-economics. Market Exchange Rates (MER) (Anthoff, Nicholls, Tol, \& Vafeidis, 2006). 19

3 Table 2.3: Predicted land loss and people affected in the Nile delta Caused by SLR (SLR) scenarios (Eldeberky, 2011).

4 Table 2.4: The best coastal management costs and number of people to be displaced

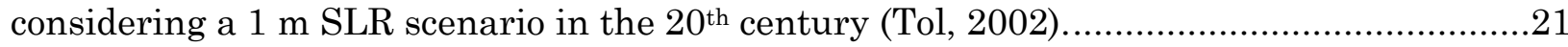

5 Table 2.5: Urban percentages considering different SLR scenarios (IPCC, 2007). ..........23

6 Table 2.6: Coral reefs conditions in important areas of Asia in 2004 (Wilkinson, 2008). .24

7 Table 3.1: The framework for the first study in the research methodology process..........40

8 Table 3.2: The framework for the second study in the research methodology process......41

9 Table 3.3: The framework for the third study in the research methodology process. .......41

10 Table 3.4: The framework for the fourth study in the research methodology process. ...42

11 Table 3.5: The framework for the fifth study in the research methodology process. ......42

12 Table 3.6: The framework for the sixth study in the research methodology process. .....43

13 Table 3.7: The framework for the seventh study in the research methodology process..44

14 Table 3.8: The framework for the eighth study in the research methodology process....44

15 Table 4.1: Analyzed adaptation approaches practiced against SLR around the world...82

16 Table 4.2:Evaluation design matrix for different types and characteristics of adaptation approaches and mitigation solutions to SLR impacts.

17 Table 4.3:Evaluation of features of the selected floating community case studies. 124

18 Table 5.1: Milestones VLFS projects. Reproduced from Suzuki et al. (2006).

19 Table 5.2: Safety Criteria (e.g. ISO 19900 1994, Moan 2004). Reproduced from Wang et al. (2008). $\quad 154$

20 Table 5.3: Levels of Corrosion. Reproduced from Wang et al. (2008). 156

21 Table 5.4: Limit states for both MOB and Mega-Floats. Reproduced from Suzuki et al. (2006). 171

22 Table 5.5: The structure limit states of the VLFS. Created with data from Suzuki et al. (2006). 172

23 Table 5.6: Load combinations outline. Reproduced from Suzuki et al. (2006).............175

24 Table 5.7: Analyzed possibilities for movability (own illustrations)...........................181

25 Table 5.8: Analyzed possibilities for dynamic geography (own illustrations). .............182

26 Table 5.9: Analyzed possibilities for survivability (own illustrations). .......................184

27 Table 5.10: Analyzed possibilities for water life (own illustrations)...........................185

28 Table 5.11: Analyzed possibilities for growth development (own illustrations)...........186

29 Table 5.12: Analyzed possibilities for mooring systems (own illustrations)................187

30 Table 5.13: Analyzed design methods and criteria for central Abu-Qir Bay................190 
31 Table 5.14: Analyzed design methods and criteria for East Alexandria. 191

32 Table 5.15: Analyzed design methods and criteria for central Abu-Qir Bay and East Alexandria's coastline.

33 Table 5.16: Local conditions impacts on the floating structures design. Adapted from Czapiewska et al. (2013).

34 Table 6.1: Classification of socio-economic features and resources the Nile Deltas' coastal governorates.

35 Table 6.2: Data on population and areas from Alexandria to Port-Said.....................216

36 Table 6.3: SLR scenarios and impacts on the Nile delta's coastline.

37 Table 6.4: Cross sections for vulnerable coastal areas analyzed along the study from Alexandria to Port-Said showing adaptation approaches practiced and main topographic characteristics that influence flood levels of and permanent inundation of lowlands which are caused by SLR impacts and strong storm events (own illustrations). ...........................2224

38 Table 6.5: Vulnerability ranking of coastal regions to SLR .....................................225

39 Table 6.6: SLR scenarios and impacts on the Alexandria......................................228

40 Table 6.7: Evaluation of vulnerable areas and adaptation solutions practiced............230

41 Table 6.8: Data gathered on demographics, climate, and wave properties of Abu-Qir Bay and Damietta Harbor for selecting the most vulnerable site for its properties.................231

42 Table 6.9: The Annual climate in Rosetta and Abu-Qir Bay, Egypt ("Climate-Data," n.d.). 238

43 Table 6.10: Installed wind power capacity in Egypt, (MW) (International Energy Agency, 2013). 241

44 Table 6.11: Total energy statistics (ktoe). Reproduced from (UNEP, 2017). .244

45 Table 6.12: The living machine in comparison with the conventional technology. Reproduced from (Van Timmeren \& Tawil, 2006). .259

46 Table 6.13: Structural conditions and their effects on designing floating structures. Reproduced from Czapiewska et al. (2013). .264

47 Table 6.14: Energy and resources conditions and their effects on designing floating structures. Reproduced from Czapiewska et al. (2013). 264

48 Table 7.1: Wave motion on structure stress of various platform sizes (own illustrations). 280

49 Table 7.2: Floating structures platforms materials and properties. .284

50 Table 7.3: Foundation structure of the floating platform (own illustrations). .285

51 Table 7.4: Water consumption of food production. Regular farming vs agriculture and aquaponics schemes. Reproduced from Czapiewska et al. (2013)...................................314

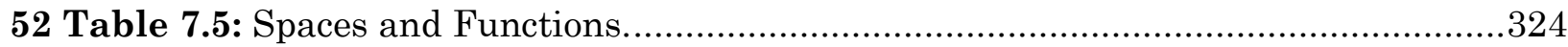

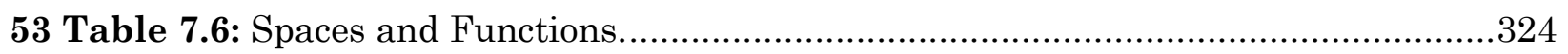

54 Table 7.7: Cost for building the hexagonal and squared floating platforms.................325

55 Table 7.8: Analyzed possibilities for growth development on a house level (own illustrations).

56 Table 7.9: Analyzed possibilities for growth development on a neighborhood level (own illustrations). .331 
57 Table 7.10: Analyzed possibilities for growth development on a district level (own illustrations) .332

58 Table 7.11: Analyzed design methods and criteria for central Abu-Qir Bay.

59 Table 7.12: Analyzed design methods and criteria for East Alexandria's coastline......334

60 Table 7.13: Analyzed design methods and criteria for growth development for central Abu-Qir Bay and East Alexandria's coastline.

61 Table 7.14: Properties and impacts of bathymetry, tides and currents, and waves on the floating structures design (own illustrations)....

62 Table 8.1: A recap summary of the main analyzed items in the empirical and analytical chapters. $\quad 354$

63 Table 8.2: Analyzed adaptation approaches practiced against SLR around the world. 358

64 Table 8.3: Evaluation design matrix for different types and characteristics of adaptation approaches and mitigation solutions to SLR impacts. .359

65 Table 8.4: Evaluation of features of the selected floating community case studies. .....361

66 Table 8.5: Analyzed design methods and criteria for central Abu-Qir Bay and East Alexandria's coastline.

67 Table 8.6: SLR scenarios and impacts on the Nile delta's coastlines.

68 Table 8.7: Cross sections for vulnerable coastal areas analyzed along the study from Alexandria to Port-Said showing adaptation approaches practiced and main topographic characteristics that influence flood levels of and permanent inundation of lowlands which are caused by SLR impacts and strong storm events (own illustrations). ..............................375

69 Table 8.8: Vulnerability ranking of coastal regions to SLR....................................376

70 Table 8.9: Foundation structure of the floating platform (own illustrations). ..............382

71 Table 8.10: Units Assembly Proposals of both Modules showing the harbour, wave attenuators, and master-plan options proposed (own illustrations). ...............................383

72 Table 8.11: Analyzed possibilities for growth development on a house level ...............385

73 Table 8.12: Analyzed possibilities for growth development on a neighborhood level (own illustrations). .386

74 Table 8.13: Analyzed possibilities for growth development on a district level (own illustrations).

75 Table 8.14: Analyzed design methods and criteria for growth development and platform sizes for central Abu-Qir Bay and East Alexandria's coastline. .388

76 Table 8.15: Comparison on research findings with similarities with this dissertation.396

77 Table B.1: Number of people, apartments, platforms, units and other calculations.....459

78 Table B.2: Prices of Functional Design Netherlands (FDN) (FDN Group, 2013).........460

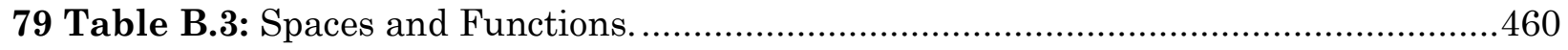

80 Table B.4: Spaces and Functions........................................................................460

81 Table B.5: Douglas scale to estimate sea state.................................................461 


\subsection{List of Abbreviations}

\begin{tabular}{|c|c|}
\hline $\mathrm{ABS}$ & American Bureau of Shipping \\
\hline $\mathrm{AC}$ & Air Conditioning \\
\hline $\mathrm{AD}$ & Anaerobic Digestion \\
\hline AFREC & African Energy Commission \\
\hline AIS & Artificial Islands and Structures \\
\hline ALS & Accidental Limit State \\
\hline AMP & Active Modular Phytoremediation system \\
\hline $\mathrm{BC}$ & Before Christ \\
\hline $\mathrm{BCDC}$ & San Francisco Bay Conservation and Development Commission \\
\hline bcm & Billion cubic metres of natural gas \\
\hline $\mathrm{BFB}$ & Bio-haven Floating Breakwaters \\
\hline $\mathrm{C} 2 \mathrm{C}$ & Cradle to Cradle \\
\hline CAGR & Compound Annual Growth Rate \\
\hline CAPMAS & Central Authority for Mobilization and Statistics \\
\hline $\mathrm{CCC}$ & California Coastal Commission \\
\hline CFD & Computational Fluid Dynamic \\
\hline CGC & Credit Guarantee Company \\
\hline CIA & Central Intelligence Agency \\
\hline $\mathrm{CO} 2$ & Carbon Dioxide \\
\hline $\mathrm{COP}$ & Conference of Parties \\
\hline DARPA & Defense Advanced Research Projects Agency \\
\hline DPS & Dynamic Positioning System \\
\hline DSDG & United Nations Division for Sustainable Development Goals \\
\hline ECC & Engineered Cementitious Composite \\
\hline $\mathrm{EE}$ & Energy Efficiency \\
\hline EEHC & Egyptian Electricity Holding Company \\
\hline
\end{tabular}


EGYPT ERA Egyptian Electric Utilities and Consumer Protection Regulatory Agency

EIA United States Energy Information Administration

ESPA Egyptian Shore Protection Authority

EVA Centre Education, Vision and Advocacy Centre

FDN Functional Design Netherlands

FFSF Floating Fuel Storage Facility

FLS Fatigue Limit State

FPSO/FPS Floating Production Storage and Offloading

FRC Fiber-Reinforced Concrete

GDP Gross Domestic Product

GHG Green-House Gas emissions

GWEC Global Wind Energy Council

HCU HafenCity University Hamburg

HVAC Heating, Ventilation, and Air Conditioning

HWL High Water Level

IDSC Information and Decision Support Center

IEA International Energy Agency

IEASM Institut Européen d'Archéologie Sous-Marine (European Institute for Underwater Archeology, in English)

IMTA Integrated Multi-Trophic Aquaculture

INDC Intended Nationally Determined Contributions

IPCC Intergovernmental Panel on Climate Change

ISO International Organization for Standardization

ISSC International Ship and Offshore Structures Congress

ITOPF International Tanker Owners Pollution Federation

ktoe Kilo tonne of oil equivalent

kWh Kilowatt per Hour

LID Low-Impact Development 
LNG Liquefied Natural Gas Carriers

LWL Low Water Level

MFS Mega Floating Structures

MJ Mega-Joules

MLWL Mean Low Water Level

MOB Mobile Offshore Bases

MOEE The Ministry of Electricity and Energy

MPa Megapascal Pressure Unit

MW Mega-Watt

NASA National Aeronautics and Space Administration

NEEAP National Energy Efficiency Action Plan

NOAA National Oceanic and Atmospheric administration

NPPA Nuclear Power Plants Authority

NRC National Research Council

NW Northwest

OAPEC Organization of Arab Petroleum Exporting Countries

OECD Organisation for Economic Co-operation and Development

OMEGA Offshore Membrane Enclosure for Growing Algae

ONR Office for Nuclear Regulation

OTEC Ocean Thermal Energy Conversion

OWC Oscillating Water Column

PESTE Political, Economic, Socio-cultural, Technological and Environmental

PPP purchasing power parity

RH Relative Humidity

SBF Sea-Based Facility

SEDAC Socioeconomic Data and Applications Center

SLR SLR

SNAJ Structure Division of Offshore Engineering Committee 
SRA Scanning Radar Altimeter

TRAM Technological Research Association of Mega-Float

TVA Tennessee Valley Authority

UCS Union od Concerned Scientists

UK United Kingdom

ULS Ultimate Limit State

UNCLOS United Nations Convention on the Law of the Sea

UNEP United Nations Environment Programme

UNESCO United Nations Educational, Scientific and Cultural Organization

UNFCCC United Nations Framework Convention on Climate Change

US\$ United States Dollars

US/USA United States of America

VLFS VLFS

VOC Volatile Organic Compounds

WBDG Whole Building Design Guide

WEC World Energy Council

WNA World Nuclear Association

WNW West-Northwest 


\section{Annex A}

\section{A. BIOMIMETIC ARCHITECTURE}

\section{A.1 Biomimetics Introduction}

\section{A.1.1 Nature as Model}

Biomimicry is a science which works with nature's models, imitates and gets inspired from their designs and methods to find solutions to our problems.

\section{A.1.2 Nature as Measure}

Biomimicry uses some environmental principles to evaluate the efficiency of our inventions. Evolution taught nature throughout 3.8 billion years: what functions, what is suitable, and what is long-lasting. 


\section{A.1.3 Nature as Mentor}

Biomimicry is a complete method of observing and respecting nature. It presents an time which is not founded on what to we should and should not take from nature, but on what we should learn from it (Visser \& Benyus, 2013).

\section{A.2 Biomimetic Approach}

A subsidiary approach of study searches for answers by determine the universal process of natural design and using them as guiding principles for developing. Where it is hard to efficiently classify the whole group of natural designs into separate items there are some frequent principles. Some methods are perceived to make a comprehensible approach for a research are described in " 12 Methods by Which Nature Can Inform the Development of Technology”: (Visser \& Benyus, 2013).

\section{A.2.1 Self Assembly}

The organism's capability to independently own its course of development.

\section{A.2.2 Chemistry in Water}

Nature produces its chemicals in ordinary ecological surroundings without the requirement of special temperatures or chemicals.

\section{A.2.3 Solar Transformations}

Numerous creatures highly rely on the sun to expand their energy absorption. 


\section{A.2.4 The Power of Shape}

Nature tend to rely on a lot of structurally effective non-orthogonal shapes to make their structures.

\section{A.2.5 Materials as Systems}

Nature forms from small scale to large scale with an equivalent size of function in relation to the materials and chemicals required for their specific functions.

\section{A.2.6 Natural Selection as an Innovative Engine}

Ecological forces which performs on the organisms and influence their fitness will lead the future organisms' development.

\section{A.2.7 Material Recycling}

Make structures via nontoxic materials that could be recycled.

\section{A.2.8 Ecosystems that Grow Food}

Systems used should have a net surplus of production without requiring any additional natural resources. 


\section{A.2.9 Energy Savvy Movement and Transport}

Movement and internal flow systems have adapted to use only the energy needed for each purpose.

\section{A.2.10 Resilience and Healing}

Organisms can heal themselves from any impacts by absorbing and overcoming them.

\section{A.2.11 Sensing and Responding}

A sequence of response systems helps the organism to sense several ecological factors and to react to each them in the proper manner.

\section{A.2.12 Life Creates Conditions Conducive to Life}

Waste and other numerous by-products of sustenance and development produce materials which are advantageous for the other organisms.

\section{A.3 Biomimetic Solutions Concerning Designing Disciplines}

History shows that designs made by all civilizations were done through observing and researching the environment, although there is a difference between imitation and influence. From Leonardo DaVinci flying wings, to todays nanotechnology, several disciplines have comprehended the unlimited source of design inspiration which the environment offers. The 
subsequent examples deliver a list of features that biomimetic inspirations could be seen (Cohen \& Vogel, 2010).

\section{A.3.1 Streamlined Bodies}

Marine creatures' researches led into developing efficient forms in technology. Such as a dolphin's body which travels through the air or water to minimise resistance where its front is rounded, and its back is tapered.

\section{A.3.2 Airfoils}

Bird wings are curved at the top but rather plane at the bottom. Such aerodynamic figure is crucial to sustain the aircraft wings.

\section{A.3.3 Maneuverability of Aircraft}

Upon spotting how buzzards fly, the Wright Brothers were driven to recover the lateral balance when moderately inverted by a wind draft by turning the wings' tips. Such understanding has helped developing the ailerons which control the flying movement of an aircraft by making it turn.

\section{A.3.4 Extruded Fibers}

Manmade fibers like carbon fiber are based on principles developed through studying spiders and silkworms. Although the manufacturing method is not the same, but the system behind such technology is based on studying them. 


\section{A.3.5 Telephone Transducers}

Simulating the mechanisms of an eardrum.

\section{A.3.6 Velcro}

Investigation of the darts on burdock burrs.

\section{A.3.7 Drag Reduction}

Fish slime usage for stretched, linear, and synthetic water-soluble polymers.

\section{A.3.8 Peristaltic Pumps}

Many creatures' intestines transfer their fluids via a peristaltic action. Some machines have peristaltic pumps which have revolving rollers pressured against a flexible tubing to generate a pressurized current. The pipe is pressured at a series of points connected with either the rollers or shoes.

\section{A.4 Further Biomimetic Solutions}

\section{A.4.1Nature Inspired Shape Shifter Shelters}

Emergency shelters have become significantly important especially after the worldwide refugee problem, as well as designing these shelters. Haresh Lalvani, cofounder of the Pratt Institute Centre for Experimental Structures, is working on a system based on biomimicrybased system which should allow the shelter to form itself, the way that trees and plants 
grow and shape themselves. He tests materials encoded with genomic directives to allow substances erected from such materials the capability to form themselves by adding an external just like gravity or wind. That allows the deploying them in a case of a disaster like earthquakes, floods or worsened political conflicts (Visser \& Benyus, 2013).

Nevertheless, creating 'temporary structures' involves a series of levels of forward and out-of-the-box thinking accompanied with innovative technology levels. Lalvani, in association with a metal manufacturer Milgo/Bufkin, succeeded in making some rigid 3D models with flat metal sheets, pierced with openings in detailed outlines. These structures develop by growing upon the encoded commands implanted in the material, just like how a tree grows based on its genetic information which is embedded within its' cells. These adjustable openings can also stretch or compress by gravity, allowing the structure the capability to change into different forms. The structures do not need any tools to assemble as well as being made from just one light sheet of metal. They can bend into form in less than a minute, also they can be covered externally with a layer of fabric-like material to form a tentlike shelter. They are easy to transport as they are very light weighted structures. Lalvani's strategies are fit for numerous kinds and sorts of emergency circumstances and are a possible positive push in shelter design (Visser \& Benyus, 2013).

\section{A.4.2Termites and Air Conditioning}

Mother natures principles can be strongly found as an inspiration in the East gate Centre in Harare by architect Mick Pearce and Arup engineers, which is the biggest shopping and office compound in Zimbabwe. Even though the building has no straight heating or cooling networks; yet, the building succeeds in keeping its temperature controlled all year long, as well as using much less energy than buildings alike with conservative air conditioning 
systems. The building uses temperature regulation approaches stimulated from self-cooling mounds of African termites. Termites produce fungus in their mounds which they feed upon. The fungus flourishes at 30 degrees Celsius. Termites succeed superbly to normalise this temperature, even if it's freezing zero degrees night or 50 degrees sunny day. Termites accomplished this by a nonstop process opening and closing the cooling and heating outlets through the mound. They adjust a system where currents suck air at the bottom of the mound, then goes up top by several canals in the mud., they close old outlets and create new ones regularly all gay to regulate temperature (Visser \& Benyus, 2013).

The buildings ventilation system functions relatively the same. Whether the outside air or the buildings concrete is hotter, the outside air gets drawn in by fans on the ground floor which then streams it into the structure where it cools or warms to regulate the building's temperature. Then, the air gets guided through the rest of the buildings' floors. After such process, the air gets flushed out through a special chimneys network. The whole building consumes less than ten percent of an alike sized building with full air conditioning systems. Other than being extremely efficient and eco-friendly, the energy consumption and saving reduces the rental prices up to twenty percent lower in comparison with other similar buildings in the area (Visser \& Benyus, 2013).

\section{A.4.3Coral Reefs and Carbon Neutral Cement}

Brent Constanz, a scientist who's an expert in biomineralization at Stanford University, has studied how sea creatures like coral reefs form. Inspired by how they absorb minerals, $\mathrm{CO} 2$ and a special calcium carbonate to form their strong exterior layers, Constanz has discovered new means of forming carbon-neutral cement. He found a method to dissolve $\mathrm{CO} 2$ in seawater in order to form carbonate. This material's properties fit perfectly to create strong 
materials for construction usage and might eventually substitute cement, dropping down the construction harm effects on the environment. The method of dissolving CO2 into seawater to produce calcium carbonate is one perfect illustration of how biomimicry in reducing our environmental footprint. Constanz has created the Calera Corporation in order to market this technology. In his plant in California, the $\mathrm{CO} 2$ released by the nearby factories is taken to be transformed into calcium carbonate, where its produced into white powder to be used either as an enhancement to traditional cement or as a substitute for it. One ton of calcium carbonate prevents a ton of $\mathrm{CO} 2$ emission by traditional cement production (Cohen \& Vogel, 2010).

\section{A.4.4Floating Jellyfish Lodge and Polluted Rivers}

Janine Hung, a Filipino architect, who created a Jellyfish Lodge, a solar powered structure that filters polluted water and air, whereas at the same time making healthy food in its aquaponic garden. The trash-gathering limbs beneath the structure cautiously gather floating garbage without damaging the environment. The water purification system filters the water and purifies polluted water by special bacterial absorption cavities. Then the filtered water gets directed to the river or stored in container tanks. The sophisticated electrostatic process cleans the air making the aquaponic gardens produce (Visser \& Benyus, 2013).

The aim is to motivate inhabitants in the zone to sustain them though gaining from its benefits like the vegetables and fish that grow. The Jellyfish Lodge offers to clean one of the most polluted river areas by eliminating the waste, filtering water, produce food, as well as cleansing air all done by clean solar energy. Hung's aim was the desire to connect mankind and Mother Nature (Visser \& Benyus, 2013). 


\section{Annex B}

\section{B. EXTENSION TO THE FLOATING}

\section{PROPOSAL FOR ABU-QIR}

\section{B.1 Floating Modules Layout and Space Distribution}

To provide diverse platform outlines, the squared and hexagonal platforms have been herein selected. The initial typology herein consists of three-level housing blocks which have spacious porches positioned in the direction of the sea. The platform contains two buildings where each is 15 meters wide (see Figure B.2) and between each other there is about seven to 20 meters as access roads (ground floor) and greenery (first floor). The platform boundaries would have private areas which will be owned the ground level inhabitants. Road view building facades could contain walkways which may offer shades from sunlight and rain. Ground level should contain businesses, offices and shops. These squared platforms could host about 256 to 320 residents, where the hexagonal platforms could host about 480 to 600 residents. 


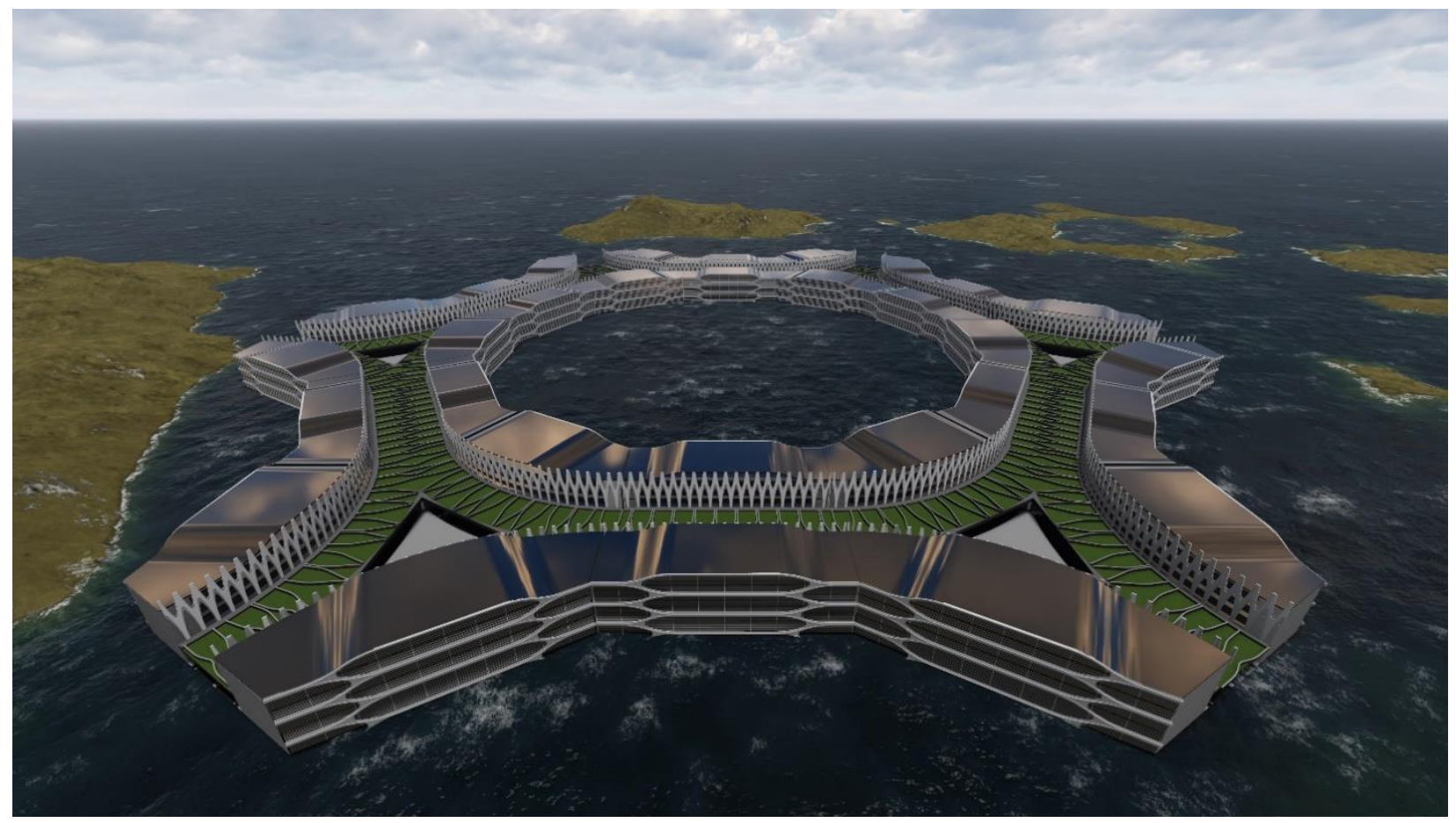

84 Figure B.1: Demonstrating the assembled floating community project proposed for the Abu-Qir Bay. Also, showing the submerged areas of Abu-Qir Bay by the Mediterranean Sea caused by the SLR (own illustration).

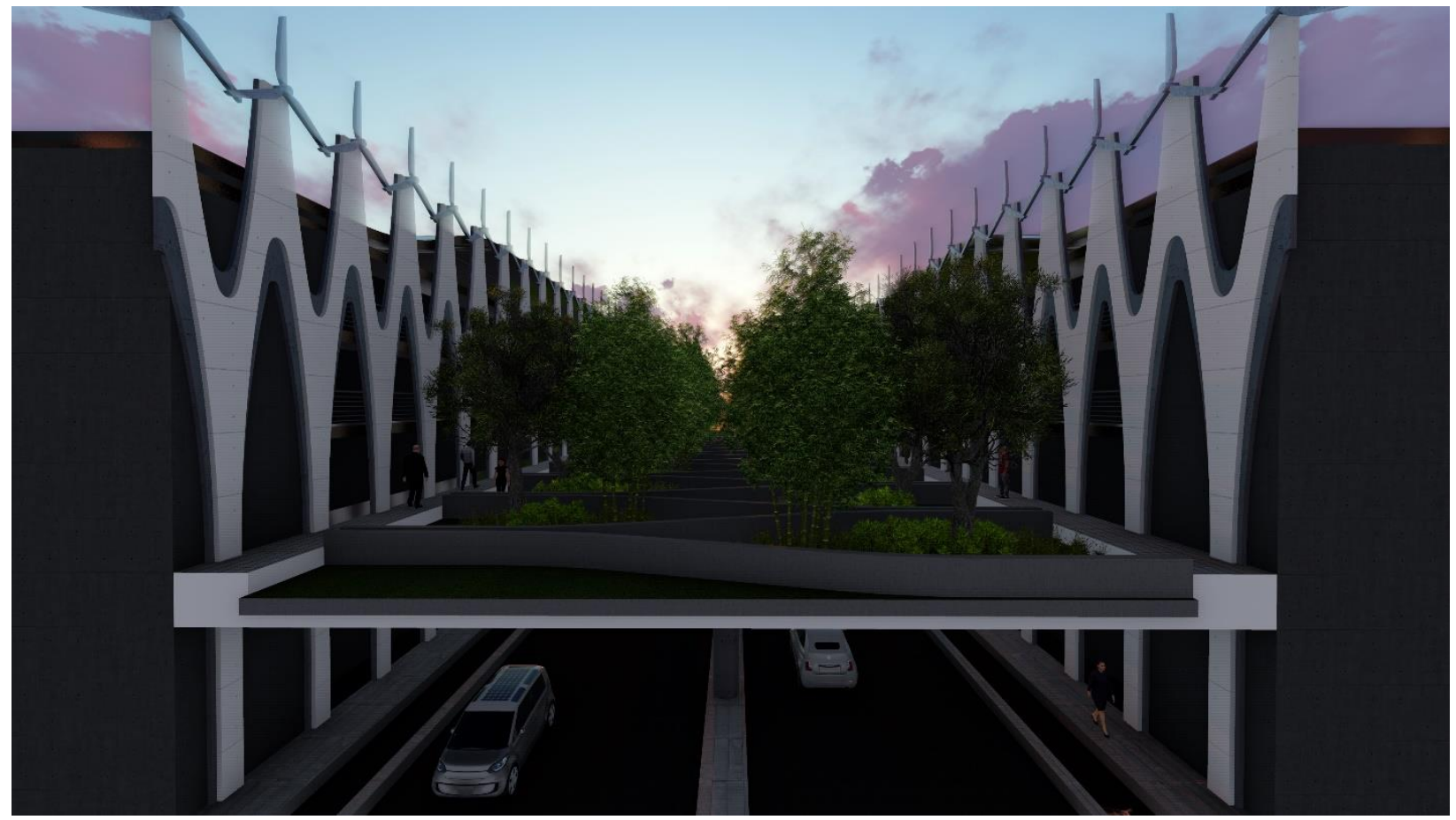

85 Figure B.2: Rendered section shows the pedestrian, bicycle, and traffic routes, as well as the central agricultural area for the squared module (own illustration). 
Another housing typology would be merging some apartments together to have a low density. In case of having just a couple of houses on a sole platform, thus an access to a road is required. In such case, the best possible solution would be low housing density would be by constructing two sides with three leveled apartments or two levels apartments above shops or offices. Where both platform typologies contain a road in-between and buildings would have greenery and sea façade making around 30 residents for each platform.

The ground floor on the floatation device herein is about 1.5 to 2 meters above sea-level. The ground floor herein may contain offices, service and storage, as well as roads for cars, parking, pedestrians and bicycles under the first floor of housing, shops, service and storage, agriculture and the open spaces. Herein the proposal, the ground floor two building areas contains offices, businesses and stores, as well as having storage, maintenance spaces for water, electricity, and AC. While the centre is traffic route which contains roads, bicycle lanes, sidewalks and parking. Another option is to replace the centre area in the ground floor into a water route to eliminate all vehicles, however, the pedestrian paths in both the ground and first floors should be kept.

Herein the proposal, the first floor two building areas should be a blend of residential, small stores (mainly essential goods), and maintenance. While the centre should be a mix of agriculture, pedestrian routes, and public spaces. From the second to the fifth floor, a typical floor plan in set for apartments, emergency staircases, and maintenance. The roof floor may have leisure, sports, well-being activities. Such floor will probably empty at night. The first and second floor ought to be for living areas for old residents. The second to the fourth floors can be for younger residents who may need more space, therefore, the option of uniting two adjacent apartments is probable as well providing larger apartment sizes if required. 
Herein the proposal, design for both modules of the hexagonal or the squared floating buildings have been fully proposed. There are six vertical accesses in the hexagonal module while four in the squared module which facilitates the access and connects the buildings through all floors. Such shape links all the levels and provide an easy circulation. The stairs and elevators lie in each end of each building, which means two in each building. The squared module has two buildings, thus four stairs and elevators whereas the hexagonal building has six as the module has three buildings. As the building goes up, the façade has a shading system for the windows and balconies as the renders demonstrate.

\section{B.2 Housing and Expanding Dynamics}

The water view has been a standard feature for enhancing the quality of life for all apartments. The arrangement of the apartments is developed to provide the maximum natural lighting and ventilation features. The two buildings (squared module) or three buildings (hexagonal module) on each ends of the floating platform makes an active outline of increasing apartments up to the roof.

In the typical floors, two adjacent apartments can be adjusted by interconnecting them together to offer more space and leisure regarding the client needs and capabilities. The courtyard with shading yet light transmitting gives sunlight to the upmost level creating an internal pedestrian area in the green roof level. The green roof could be used as well for recreational, well-being and community agricultural usages. 


\begin{tabular}{|c|c|c|c|c|}
\hline Module & Square & Hexagonal & Square & Hexagonal \\
\hline Number of buildings per platform & 2 & 3 & 2 & 3 \\
\hline Number of people per apartment & \multicolumn{2}{|l|}{4} & \multicolumn{2}{|l|}{5} \\
\hline Number of floors & \multicolumn{2}{|l|}{4} & \multicolumn{2}{|l|}{4} \\
\hline Number of apartments per floor & 8 & 10 & 8 & 10 \\
\hline Number of apartments per building & 32 & 40 & 32 & 40 \\
\hline Number of apartments per platform & 64 & 120 & 64 & 120 \\
\hline Number of people per building & 128 & 160 & 128 & 160 \\
\hline Number of people per platform & 256 & 480 & 320 & 600 \\
\hline $\begin{array}{l}\text { Number of platforms per unit } \\
\text { (neighborhood-scale) }\end{array}$ & \multicolumn{2}{|l|}{6} & \multicolumn{2}{|l|}{6} \\
\hline Number of people per united platforms & 1,536 & 2,880 & 1,920 & 3,600 \\
\hline $\begin{array}{l}\text { Number of people per united unit } \\
\text { (neighborhood-scale) }\end{array}$ & \multicolumn{2}{|l|}{4,416} & \multicolumn{2}{|l|}{5,520} \\
\hline $\begin{array}{l}\text { Number of units per six united formations } \\
\text { (city-scale) }\end{array}$ & 30 & 24 & 30 & 24 \\
\hline $\begin{array}{l}\text { Number of people per six united formations } \\
\text { (city-scale) }\end{array}$ & 7,680 & 11,520 & 9,600 & 14,400 \\
\hline $\begin{array}{l}\text { Number of platforms per six united } \\
\text { formations (city-scale) }\end{array}$ & \multicolumn{2}{|l|}{54} & \multicolumn{2}{|l|}{54} \\
\hline $\begin{array}{l}\text { Number of people per six united formations } \\
\text { (city-scale) }\end{array}$ & \multicolumn{2}{|l|}{19,200} & \multicolumn{2}{|l|}{24,000} \\
\hline
\end{tabular}

77 Table B.1: Number of people, apartments, platforms, units and other calculations.

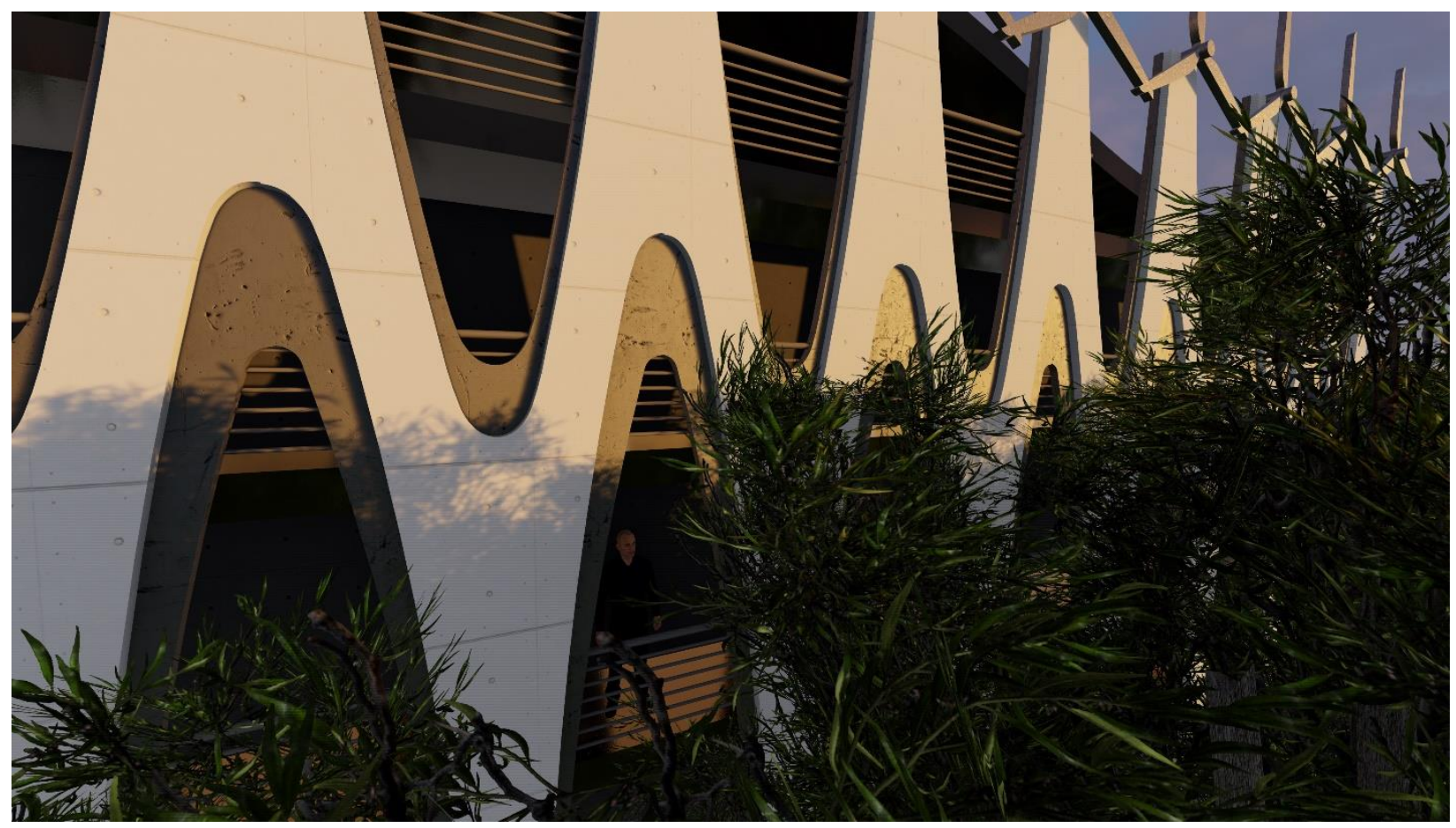

86 Figure B.3: Render showing how the sum reaches the interior facades too as well as showing the shading elements for the hexagonal module (own illustration). 


\section{B.3 Model and Mobility}

In 50x50m platforms, each platform would host 64 apartments in the squared module while the hexagonal one would host 120 apartments (see Table B.3 \& B.4). Wave attenuators and breakwaters herein this proposal were not only for architectural aspects, but also for safety against collisions and stability reasons. It could be better executed once the modules connect to one full formation. The central building patio-like area for the residents for agriculture, view, passageway, circulation, floating vegetation, hydroponics and fishing.

\begin{tabular}{|l|l|l|l|l|}
\hline & T-Block & U-Block & Heavy Duty U-Block & Monaco \\
\hline Length & $>20 \mathrm{~m}$ & $>30 \mathrm{~m}$ & $+50 \mathrm{~m}$ & $352 \mathrm{~m}$ \\
\hline Width & $3-4 \mathrm{~m}$ & $4-7 \mathrm{~m}$ & $7-18 \mathrm{~m}$ & $30 \mathrm{~m}$ \\
\hline Height (total) & $3-4 \mathrm{~m}$ & $4-7 \mathrm{~m}$ & $7-18 \mathrm{~m}$ & $30 \mathrm{~m}$ \\
\hline $\begin{array}{l}\text { Section area } \\
\text { (approx.) }\end{array}$ & $10 \mathrm{~m} 2$ & $20 \mathrm{~m} 2$ & $80 \mathrm{~m} 2$ & $900 \mathrm{~m} 2$ \\
\hline Water depths & $>6 \mathrm{~m}$ & $6-12 \mathrm{~m}$ & $>12 \mathrm{~m}$ & 175,000 tons \\
\hline Wave heights & $>1.1 \mathrm{~m}$ & $1.1-2.5 \mathrm{~m}$ & $>2.5 \mathrm{~m}$ & \\
\hline Cost estimate & $€ 3,000 \mathrm{p} / \mathrm{m}$ & $€ 5,000 \mathrm{p} / \mathrm{m}$ & $€ 10,000 \mathrm{p} / \mathrm{m}$ & $€ 150$ million \\
\hline Cost/m3 & $€ 300$ & $€ 250$ & $€ 125$ & $€ 320$ \\
\hline
\end{tabular}

78 Table B.2: Prices of Functional Design Netherlands (FDN) (FDN Group, 2013).

\begin{tabular}{|l|l|l|}
\hline $\begin{array}{l}\text { First-Level Space classification (Squared } \\
\text { Module) }\end{array}$ & Percentage & Area \\
\hline Platform & $100 \%$ & $2500 \mathrm{~m}^{2}$ \\
\hline Walkways (Including in building area) & $6 \%(11 \%)$ & $150 \mathrm{~m}^{2}\left(270 \mathrm{~m}^{2}\right)$ \\
\hline Vegetation & $34 \%$ & $850 \mathrm{~m}^{2}$ \\
\hline Built up area & $60 \%$ & $1500 \mathrm{~m}^{2}$ \\
\hline
\end{tabular}

79 Table B.3: Spaces and Functions.

\begin{tabular}{|l|l|l|}
\hline $\begin{array}{l}\text { First-Level Space classification } \\
\text { (Hexagonal Module) }\end{array}$ & Percentage & Area \\
\hline Platform & $100 \%$ & $6500 \mathrm{~m} 2$ \\
\hline Walkways (Including in building area) & $4.8 \%(8.5 \%)$ & $315 \mathrm{~m} 2(555 \mathrm{~m} 2)$ \\
\hline Courtyard & $5.2 \%$ & $341 \mathrm{~m} 2$ \\
\hline Vegetation (Including possible added courtyard) & $37.8 \%(43 \%)$ & $2460 \mathrm{~m} 2(2800 \mathrm{~m} 2)$ \\
\hline Built up area & $52.2 \%$ & $3400 \mathrm{~m} 2$ \\
\hline
\end{tabular}

80 Table B.4: Spaces and Functions. 


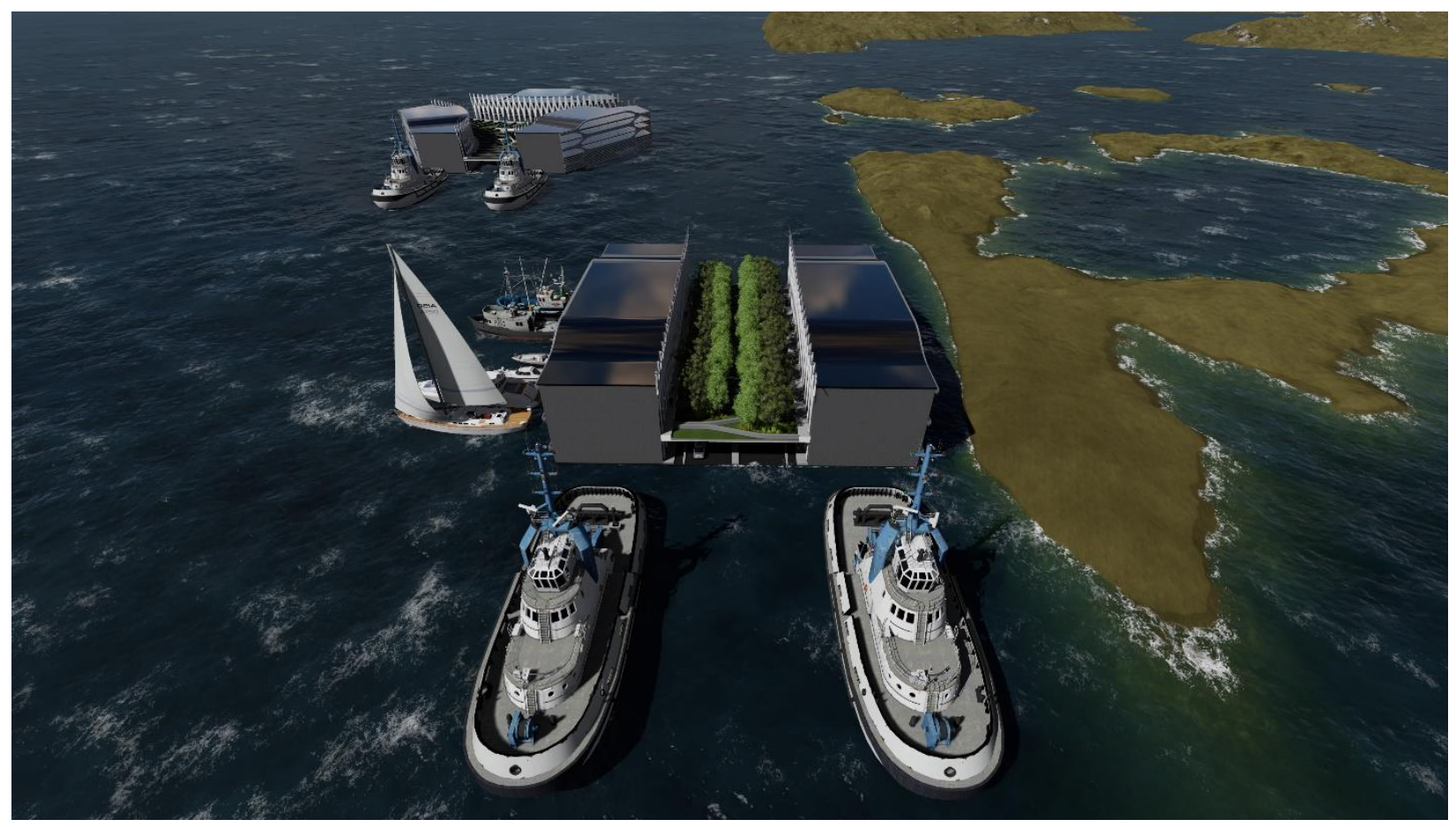

87 Figure B.4: Tugboats transporting the platforms (own illustration).

Swell waves are produced when winds blow on a distant sea area that travel fast over water surface of a constant time and flat crests. Swell assessments as well must include wave directions regarding the 8 foremost directions of wind rose (N, NE, E, SE, S, SW, W, NW).

\begin{tabular}{|l|l|l|l|}
\hline \multicolumn{2}{|l|}{ Wind sea } & Swell \\
\hline \multicolumn{2}{|l|}{ Sea state } & Average wave height & Wave length and height \\
\hline 0 & Calm (glassy) & - & None \\
\hline 1 & Calm (ripped) & $0-0.1 \mathrm{~m}$ & VL (short/low wave) \\
\hline 2 & Smooth & $0.1-0.5 \mathrm{~m}$ & L (long/low wave) \\
\hline 3 & Slight & $0.5-1.25 \mathrm{~m}$ & Lt (short/moderate wave) \\
\hline 4 & M & $1.25-2.5 \mathrm{~m}$ & M (average/moderate wave) \\
\hline 5 & R & $2.5-4 \mathrm{~m}$ & MR (long/moderate wave) \\
\hline 6 & VR & $4-6 \mathrm{~m}$ & R (short/heavy wave) \\
\hline 7 & H & $6-9 \mathrm{~m}$ & H (average/heavy wave) \\
\hline 8 & VH & $9-14 \mathrm{~m}$ & VH (long/heavy wave) \\
\hline 9 & Ph & $+14 \mathrm{~m}$ & Cn (WL and height indefinite) \\
\hline
\end{tabular}

81 Table B.5: Douglas scale to estimate sea state. ${ }^{15}$

15 VL: Very low; L: Low; M: Moderate; MR: Moderate rough; R: Rough; H: High; Very: Very high; Cn: Confused; Lt: light; Ph: Phenomenal. 